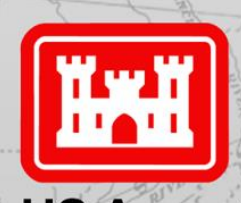

US Army Corps of Engineers ${ }_{\circledast}$

\title{
Numerical Sedimentation Investigation Mississippi River Cairo to Pilots Station
} MRG\&P Report No.30 • February 2020

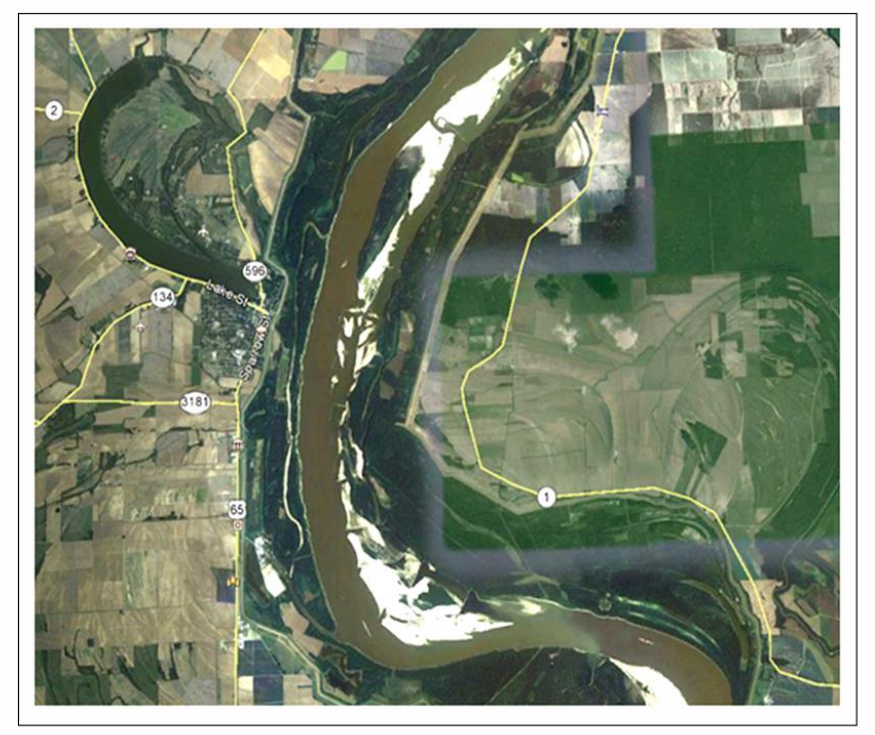

\section{MRG\&P}

Mississippi River Geomorphology \& Potamology Program 



\title{
Numerical Sedimentation Investigation Mississippi River Cairo to Pilots Station
}

\author{
Ronald R. Copeland
}

U.S. Army Corps of Engineers

Vicksburg District

4155 Clay Street

Vicksburg, Mississippi 39183

Leslie Lombard

U.S. Army Corps of Engineers

New Orleans District

7400 Leake Avenue

New Orleans, Louisiana 70118

Roger A. Gaines

U.S. Army Corps of Engineers

Memphis District

167 N. Main St., Rm B-202

Memphis, Tennessee 38103-1894

Final report

Approved for public release; distribution is unlimited.

Prepared for U.S. Army Corps of Engineers

Washington, DC 20314-1000

Under Project No. 127672, “Mississippi River Geomorphology and Potamology Program" 


\section{Abstract}

A HEC-6T numerical model of the entire Lower Mississippi River between the end of Southwest Pass and the confluence of the Ohio River was developed. The model, which included over 1000 river miles, was calibrated to 1991-2002 measured data. The purpose of the numerical sedimentation model was to provide a tool to evaluate the long-term and system-wide effects of specific Mississippi River and Tributaries Project features. Model applications related to the effects of sediment diversions and the effects of dredging in the New Orleans District were demonstrated. The model demonstrated the effects of new constrictive works on the longterm and short-term river morphology. The model was used to test the effects of changes in upstream sediment inflow. The model's ability to assess the effects of natural geomorphic changes, such as erosion of hard points, was demonstrated. Future application of this model to specific project sites should include the addition of more detailed geometry in the area of interest.

DISCLAIMER: The contents of this report are not to be used for advertising, publication, or promotional purposes. Citation of trade names does not constitute an official endorsement or approval of the use of such commercial products. All product names and trademarks cited are the property of their respective owners. The findings of this report are not to be construed as an official Department of the Army position unless so designated by other authorized documents.

DESTROY THIS REPORT WHEN NO LONGER NEEDED. DO NOT RETURN IT TO THE ORIGINATOR. 


\section{Contents}

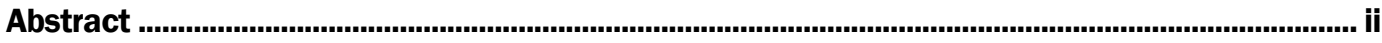

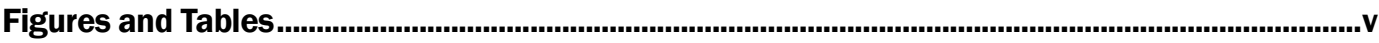

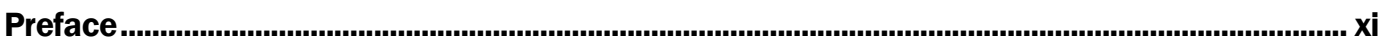

1 Introduction ............................................................................................................................... 1

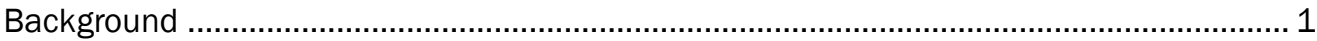

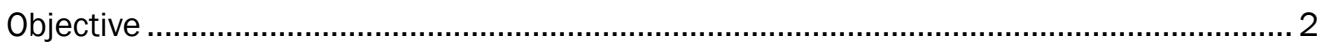

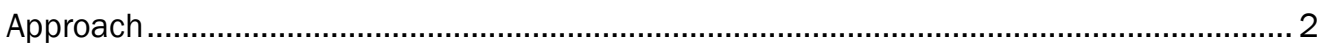

Questions and metrics .................................................................................. 3

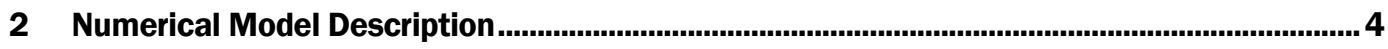

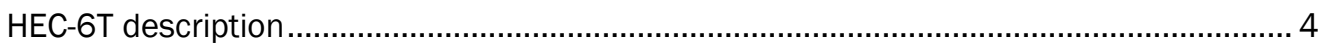

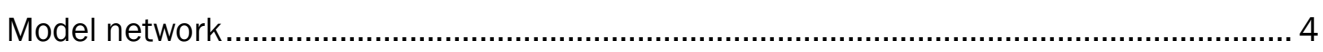

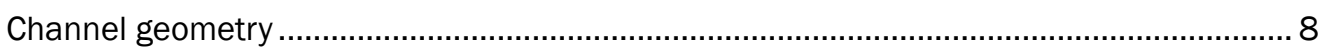

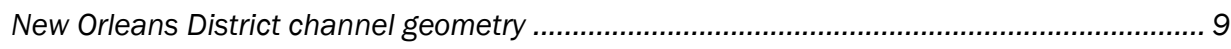

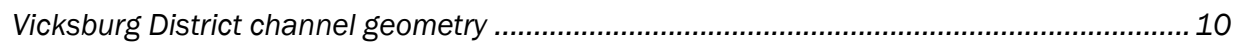

Memphis District channel geometry ............................................................................ 11

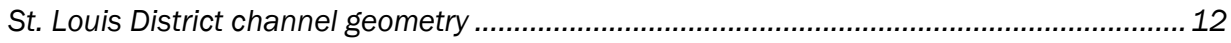

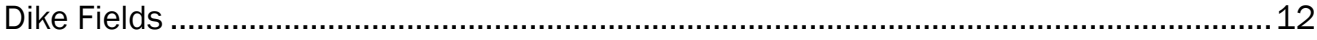

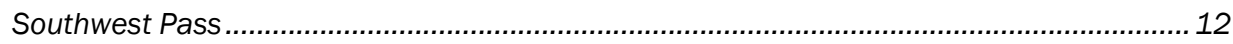

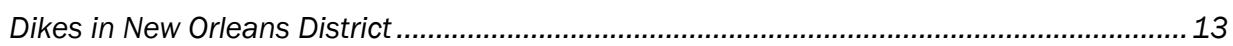

Dikes in Vicksburg and Memphis Districts ................................................................ 15

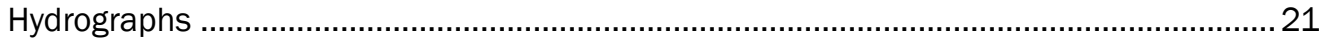

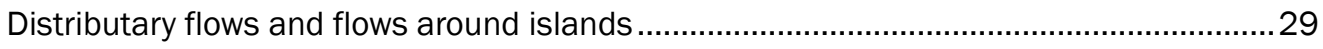

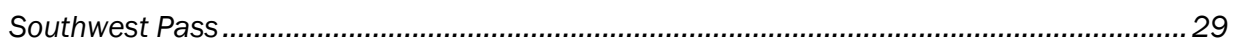

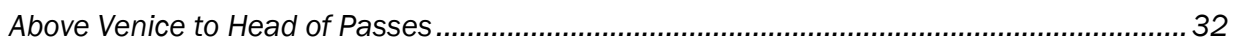

Tarbert Landing to Above Venice discharge range ........................................................... 38

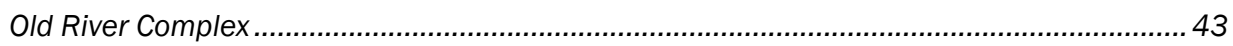

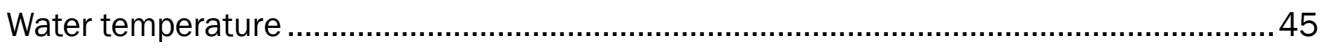

Downstream water-surface elevations ...................................................................... 46

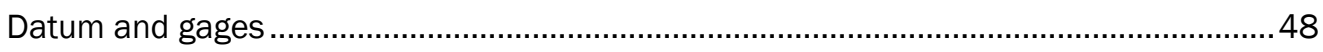

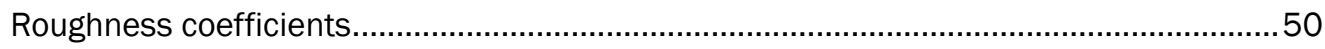

Roughness coefficients for Ohio and Arkansas Rivers ..............................................64

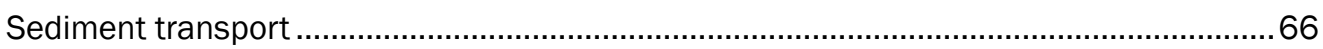

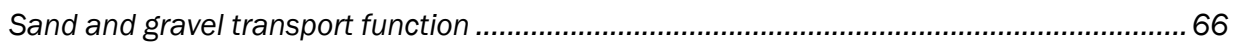

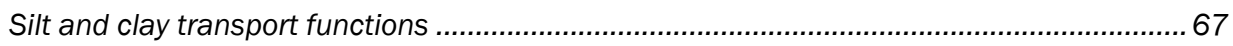

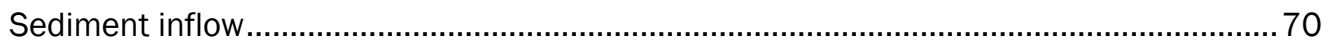

Sediment inflow Middle Mississippi River at Thebes and Chester...................................... 73

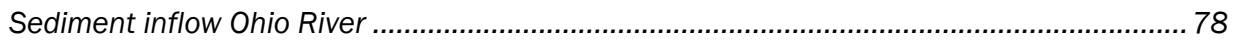

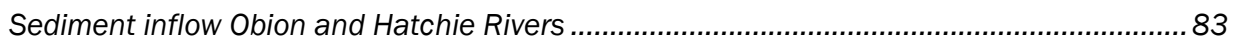

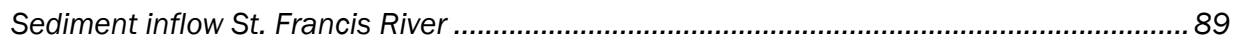




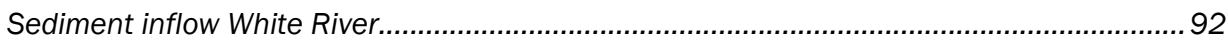

Sediment inflow Arkansas River.................................................................................... 96

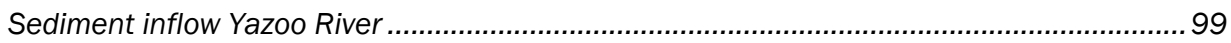

Sediment inflow sources................................................................................................ 102

Depth of bed sediment reservoir................................................................................ 103

Mississippi River bed material gradations.............................................................104

Tributary bed gradations .....................................................................................109

Middle Mississippi River bed gradations ........................................................................... 109

Ohio River bed gradations ...................................................................................... 109

Obion and Hatchie River bed gradations.......................................................................111

St. Francis River bed gradations .............................................................................111

White River bed gradations ................................................................................... 112

Arkansas River bed gradations ...............................................................................113

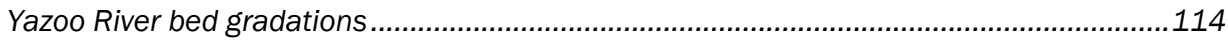

Sediment concentrations in distributary flows ......................................................... 114

Sediment distribution around islands ................................................................... 124

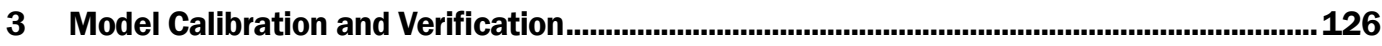

Selection of model parameters ...................................................................................126

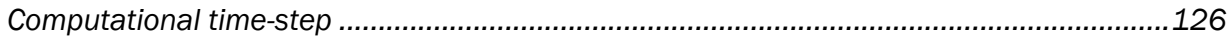

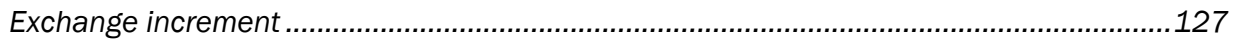

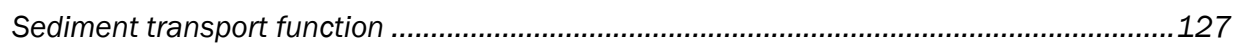

Calibration tests ................................................................................................ 131

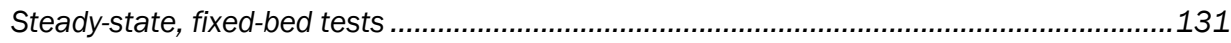

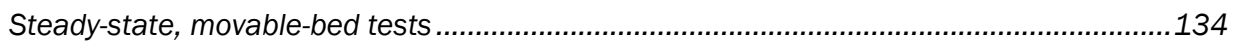

Quasi-unsteady movable-bed tests ............................................................................... 138

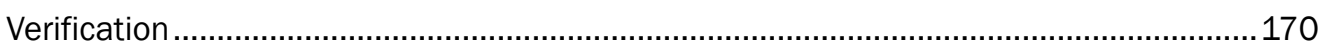

Deposition downstream from Old River ....................................................................... 170

Degradation at Smithland Crossing ............................................................................ 177

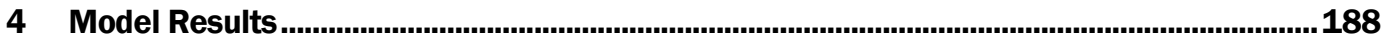

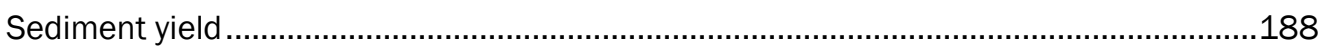

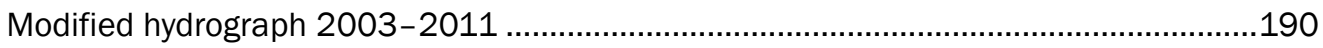

Sediment inflow for the Middle Mississippi River 2003-2012 .....................................191

Effect of declining sediment inflow at Thebes........................................................... 197

Effect of hard points on degradation .................................................................... 198

Effects of dike construction ....................................................................................200

5 Summary and Recommendations ..................................................................................... 202

References ....................................................................................................................................... 210

Unit Conversion Factors ...................................................................................................... 213

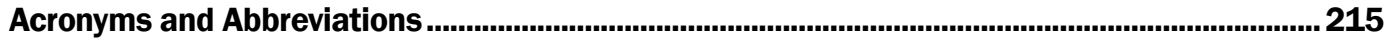

Report Documentation Page 


\section{Figures and Tables}

\section{Figures}

Figure 1. Schematic of HEC-6T Stream Network in New Orleans and Vicksburg Districts.................. 5

Figure 2. Schematic of HEC-6T stream network in Memphis and St. Louis Districts......................... 6

Figure 3. 1991-2002 hydrograph..........................................................................................22

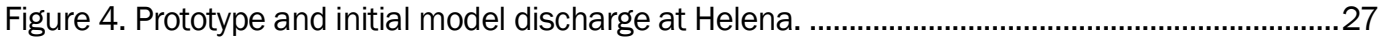

Figure 5. Prototype and initial model cumulative flow volume at Helena. ...........................................2

Figure 6. Flow decrease in downstream direction Memphis to Helena Reach..................................28

Figure 7. Measured Above Venice discharge in Pass a Loutre and South Pass.................................34

Figure 8. Measured Above Venice discharge in Cubits Gap.............................................................36

Figure 9. Measured Above Venice discharge in Grand Pass..............................................................37

Figure 10. Measured Above Venice discharge in Baptiste Collette...................................................38

Figure 11. Caernarvon tailwater rating curve, 2001-2006............................................................40

Figure 12. 2001 Stage-discharge rating curve Mississippi River at Caernarvon Inlet. ....................... 41

Figure 13. Percentage of upstream discharge diverted at Caernarvon. ............................................42

Figure 14. Tarbert Landing discharge diverted at Morganza and Bonnet Carré.................................43

Figure 15. Flow distribution at Old River, 1991-2002 and 2011 Flood...........................................44

Figure 16. Southwest Pass and Venice, 1991-1992, stage-discharge rating curves.......................46

Figure 17. Average monthly stages in Southwest Pass and at Grand Isle East..................................47

Figure 18. Venice rating curves, RM 10.7, 1991-2002 ...........................................................52

Figure 19. Empire rating curves, RM 29.5, 1991-2002. …….................................................52

Figure 20. West Pointe a la Hache rating curves, RM 48.7, 1991-2002 ......................................53

Figure 21. New Orleans rating curves, RM 102.8, 1991-2002 ...................................................53

Figure 22. Reserve rating curves, RM 138.7, 1991-2002.........................................................54

Figure 23. Donaldsonville rating curve, RM 175.4, 1991-2002 ……………………..................54

Figure 24. Baton Rouge rating curves, RM 228.4, 1991-2002....................................................55

Figure 25. Bayou Sara rating curves, RM 265.4, 1991-2002 ……………………...................55

Figure 26. Red River Landing rating curves, RM 302.4, 1991-2002. ...........................................56

Figure 27. Measured and calculated stages, RM -19 to RM 320 ..................................................56

Figure 28. Stage-discharge for St. Joseph (RM 396.4) and Natchez (RM 363.0).............................57

Figure 29. Stage-discharge for Lake Providence (RM 486.4) and Vicksburg (RM 437.4)................58

Figure 30. Stage-discharge for Arkansas City (RM 554.1) and Greenville (RM 531.5).....................58

Figure 31. Stage-discharge for Rosedale (RM 592).................................................................59

Figure 32. Stage-discharge for historical floods on the Mississippi River at Vicksburg. ....................60

Figure 33. Stage-discharge for Helena (RM 663.1). .....................................................................61

Figure 34. Stage-discharge for Memphis (RM 734.4) ................................................................61

Figure 35. Stage-discharge for Hickman (RM 922). ...................................................................62 
Figure 36. Stage-discharge for the Ohio River at Metropolis (RM 990 AHP), 1991-2002. ...............65

Figure 37. Stage-discharge for the Ohio River at Cairo (RM 955.8 AHP), 1991-2002......................66

Figure 38. Erosion rate characteristics. ..................................................................................69

Figure 39. Deposition rate characteristics..............................................................................

Figure 40. Total measured suspended sediment concentration at Thebes...................................... 74

Figure 41. Measured suspended sand concentration at Thebes. ..................................................... 74

Figure 42. Measured suspended total and sand concentrations at Thebes. ..................................75

Figure 43. Size class percentages for at Thebes, 1973-1991, and Chester, 1980-1991. ..............77

Figure 44. Total measured suspended sediment concentration at Dam 53..................................79

Figure 45. Measured suspended total and sand concentrations at Dam 53.................................80

Figure 46. Measured size class percentages, at Louisville............................................................81

Figure 47. Measured suspended total and sand concentrations Obion River near RM 62.............85

Figure 48. Measured suspended total and sand concentrations Hatchie River................................87

Figure 49. Combined measured suspended total and sand concentrations Hatchie River...............88

Figure 50. Measured suspended sediment concentrations, St. Francis River at Madison...............91

Figure 51. Measured suspended sediment concentrations at three gages, White River..................93

Figure 52. Measured suspended sand concentrations, White River................................................94

Figure 53. Measured suspended sediment concentrations, White River..........................................95

Figure 54. Measured sediment concentrations at two gages on the Arkansas River.......................97

Figure 55. Measured sediment concentrations on the Arkansas River. ..........................................97

Figure 56. Sediment inflow rating curves for Arkansas River. ..........................................................98

Figure 57. Sediment concentration Yazoo River at Redwood and Steel Bayou.............................. 100

Figure 58. Total sediment concentration trends Yazoo River............................................................ 100

Figure 59. Sediment inflow rating curves for Yazoo River. ............................................................. 101

Figure 60. Lateral variation in bed material gradation at RM 265, August 2005........................ 105

Figure 61. Historic change in Mississippi River median bed grain size.......................................... 106

Figure 62. Historic change in median bed grain size _ gravel samples removed.............................107

Figure 63. 1989 bed gradations downstream from RM 306 with polynomial trend lines..............107

Figure 64. 1989 bed gradations upstream from RM 306, with polynomial trend lines................. 108

Figure 65. Initial bed calculated starting with Nordin polynomials after 30 days............................ 108

Figure 66. 1980-1989 average bed-material gradation at Thebes. ............................................. 109

Figure 67. Ohio River bed-material gradations........................................................................ 110

Figure 68. Initial bed-material gradations used for the Obion and Hatchie Rivers........................ 111

Figure 69. USGS bed gradations for St. Francis River at Madison and Riverfront.......................... 112

Figure 70. White River bed-material gradations collected by ERDC at RM 4............................... 113

Figure 71. Arkansas River bed-material gradations at Emerson and Camp Bends........................ 114

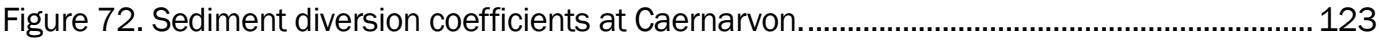

Figure 73. Sand concentration at Belle Chasse ....................................................................... 130

Figure 74. Sand concentration at Tarbert Landing.......................................................................... 130 
Figure 75. Sand concentration at Coochie (RM 317.3) and Union Point (326.6)......................... 131

Figure 76. Calculated channel velocity in the New Orleans District reach..................................... 132

Figure 77. Calculated channel velocity in the Vicksburg District reach......................................... 133

Figure 78. Calculated channel velocity in the Memphis District reach. ........................................ 133

Figure 79. Calculated bed change in the New Orleans District reach........................................... 135

Figure 80. Calculated bed change in the Vicksburg District. ......................................................... 136

Figure 81. Calculated bed change in the Memphis District. .......................................................... 136

Figure 82. Calculated bed change at five consecutive cross sections.......................................... 137

Figure 83. Calculated average bed change during the 1991-2002 hydrograph.......................... 138

Figure 84. Specific gage at Venice, RM 10.7.......................................................................... 140

Figure 85. Specific gage at West Pointe A La Hache, RM 48.7 ……............................................141

Figure 86. Specific gage at New Orleans, RM 102.8.................................................................141

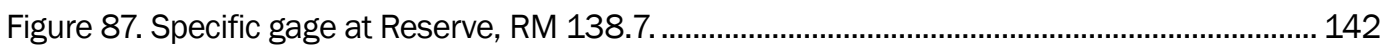

Figure 88. Specific gage at Donaldsonville, RM 175.4 ............................................................. 142

Figure 89. Specific gage at Baton Rouge, RM 228.0. ............................................................... 143

Figure 90. Specific gage at Bayou Sara, RM 265.4 ……....................................................... 143

Figure 91. Specific gage at Red River Landing, RM 302.4 ..................................................... 144

Figure 92. Specific gage at Natchez, RM 363.3................................................................... 144

Figure 93. Specific gage at Vicksburg, RM 435.7.................................................................. 145

Figure 94. Specific gage at Greenville, RM 531.1 ................................................................. 145

Figure 95. Specific gage at Arkansas City, RM 554.1............................................................... 146

Figure 96. Specific gage at Rosedale, RM 592.2 ……....................................................... 146

Figure 97. Specific gage at Helena, RM 663.1...........................................................................147

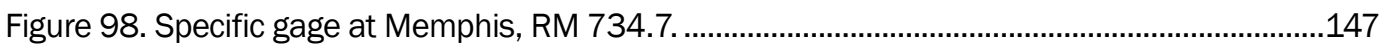

Figure 99. Specific gage at Hickman, RM 922 ................................................................... 148

Figure 100. Calculated average bed change, New Orleans District gages, 1991-2002.............. 149

Figure 101. Calculated average bed change, Vicksburg District gages, 1991-2002 ................... 150

Figure 102. Calculated average bed change, Memphis District gages, 1991-2002.................... 150

Figure 103. 1982-1985 and 2005 USGS bed-material gradations............................................ 151

Figure 104. USGS and Nordin and Queen bed-material gradations.............................................. 152

Figure 105. Calculated active layer gradation compared to 2005 USGS gradations....................... 153

Figure 106. Calculated active layer gradation - Head of Passes to Cairo. ...................................... 154

Figure 107. Sand and fine concentrations at Tarbert Landing 1991-2002. ................................. 155

Figure 108. Effect of model hydrographs on concentrations at Tarbert Landing. ......................... 157

Figure 109. Measured and calculated sediment concentrations at Belle Chasse......................... 158

Figure 110. Measured and calculated sediment concentrations at Union Point and

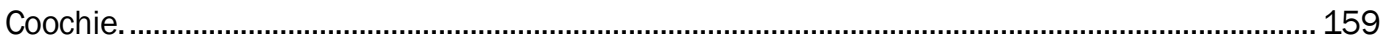

Figure 111. Calculated energy slope between Tarbert Landing and Natchez................................ 160

Figure 112. Measured fine sediment concentrations at Vicksburg (1984-2004)........................ 161

Figure 113. Measured fine sediment concentrations at Tarbert Landing (1984-2004).............. 161 
Figure 114. Measured sand concentrations at Vicksburg (1984-2004). .................................... 162

Figure 115. Measured and calculated sediment concentrations at Vicksburg. ............................ 162

Figure 116. Measured and calculated sediment concentrations at Memphis.............................. 163

Figure 117. Accumulated dredging in Southwest Pass, and from Head of Passes to RM 7.......... 169

Figure 118. 1999 Hydrographic survey at Old River Control Complex. .......................................... 172

Figure 119. 2008 Hydrographic survey at Old River Control Complex........................................... 173

Figure 120. Navigation map of Smithland Crossing before construction of contraction

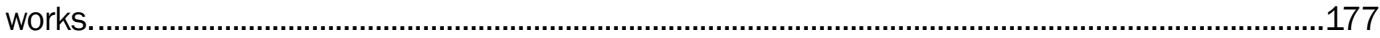

Figure 121. Navigation map of Smithland Crossing after construction. ....................................... 178

Figure 122. Looking upstream at Smithland Crossing after construction of dikes. The chute closure structure has not been completed, the river has not eroded to the trench fill revetment, and sediment has begun to deposit in the dike field.

Figure 123. Smithland Crossing after completion of chute closure structure. Looking downstream - the river has eroded back to the trench fill revetment, and sediment has deposited in dike field.

Figure 124. Calculated and measured degradation at Smithland Crossing, RM 300.3. ............... 182

Figure 125. Calculated and measured degradation at Smithland Crossing, RM 299.5. ............... 182

Figure 126. Calculated and measured degradation at Smithland Crossing, RM 298.9. ................ 183

Figure 127. Calculated and measured degradation at Smithland Crossing, RM 298.1 ................ 183

Figure 128. Calculated and measured degradation at Smithland Crossing, RM 297.45. ............ 184

Figure 129. Calculated bed changes at cross section 298.1 for 1991-2002 .............................. 186

Figure 130. Calculated accumulated sediment load for 1991-2002 …...................................... 187

Figure 131. Calculated cumulative sand delivery for 1 year and 12 years.................................... 189

Figure 132. Measured total suspended sediment concentration at Thebes................................ 193

Figure 133. Measured suspended sand concentration at Thebes. ............................................... 193

Figure 134. Mean daily measured total suspended sediment concentration at Thebes............... 194

Figure 135. Measured total suspended sediment concentration, at Hermann. ............................ 196

Figure 136. Measured suspended sand concentration for the Missouri River at Hermann. ........ 196

Figure 137. Calculated cumulative sand delivery 1991-2011 ..................................................... 197

Figure 138. Effect of hard points at Hickman on calculated cumulative sand delivery.................. 199

Figure 139. Calculated difference in average bed with hard points at Hickman removed. ........... 199

Figure 140. Effect of dike construction on calculated cumulative sand delivery............................ 201

Figure 141. Calculated difference in average bed change with dike construction......................... 201

\section{Tables}

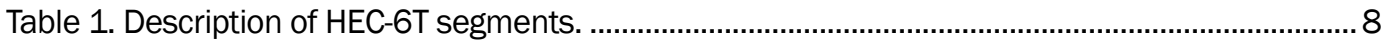

Table 2. Dikes in New Orleans District HEC-6T model, Pilots Station (RM -18.0) to Union

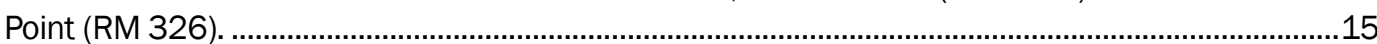

Table 3. Dikes in Vicksburg District HEC-6T Model, Union Point (RM 326) to Rosedale (RM 92).

Table 4. Dikes in Memphis District HEC-6T Model, Rosedale (RM 592) to Cairo (RM 954). 
Table 5. Reported water volume passing Mississippi River and Tributary gages, 19912002.

Table 6. Annual discrepancy in recorded discharges at gages........................................................24

Table 7. Calculated sediment delivery from the Ohio River. .................................................................29

Table 8. Outflow from Southwest Pass distributaries, percentage of discharge immediately upstream from Diversion. 32

Table 9. Distributary outflow between Above Venice and Head of Passes. ........................................33

Table 10. Calculated headwater upstream from Caemarvon Diversion Structure...........................42

Table 11. Outflow at Old River distributaries, percentage of Union Point discharge. .........................45

Table 12. Average monthly water temperatures, 1992-2002 ............................................................45

Table 13. Downstream water surface elevations at Pilots Station....................................................48

Table 14. Gages and datum used for water surface calibration. ..........................................................48

Table 15. HEC-6T roughness coefficients in New Orleans District..................................................63

Table 16. HEC-6T roughness coefficients in Vicksburg District. .........................................................63

Table 17. HEC-6T roughness coefficients in Memphis District............................................................64

Table 18. Silt and clay coefficients for Parthenaides and Krone equations......................................69

Table 19. Percentage of the annual Mississippi River discharge at Vicksburg, 19912002.

Table 20. Sediment inflow for Middle Mississippi River, Segment 25...............................................78

Table 21. Sediment inflow for Ohio River - Segment 24.................................................................82

Table 22. Sediment inflow for Obion River - Segment 16. ...............................................................86

Table 23. Sediment inflow for Hatchie River - Segment 14.................................................................89

Table 24. Sediment inflow for St. Francis River - Segment 12......................................................92

Table 25. Sediment inflow for White River - Segment 10..................................................................96

Table 26. Sediment inflow for Arkansas River - Segment 8.............................................................99

Table 27. Sediment inflow for Yazoo River - Segment 6.............................................................. 102

Table 28. Source of Mississippi River water and sediment loads. 1991-2002 by percentage - based on HEC 6 T input. 103

Table 29. Sediment diversion coefficients at Old River Control Complex from Catalyst-Old River Hydroelectric (1999). ...................................................................................................... 116

Table 30. Sediment diversion coefficients, Burrwood Bayou. ........................................................ 119

Table 31. Sediment diversion coefficients - outlet W-2 and overlfows.......................................... 119

Table 32. Sediment diversion coefficients - Joseph Bayou............................................................... 120

Table 33. Sediment diversion coefficients - Southwest Pass at Mile 3.0...................................... 120

Table 34. Sediment diversion coefficients - South Pass and Pass a Loutre................................... 120

Table 35. Sediment diversion coefficients - Cubits Gap. ............................................................... 121

Table 36. Sediment diversion coefficients - Baptiste Collette........................................................... 122

Table 37. Sediment diversion coefficients - Caenarvon. .................................................................. 123

Table 38. Sediment diversion coefficients - Bonnet Carré. .......................................................... 124

Table 39. Island sediment concentration ratios in secondary channel........................................... 125 
Table 40. Sand size class fractions. Measured versus calculated using different sediment transport function, 1991-2002.

Table 41. Measured and calculated size class distributions average percentages........................ 158

Table 42. 12-year calculated sand yield between 1991 and 2002 ….......................................... 164

Table 43. Reported and calculated* dredging 1991-2002. 167

Table 44. Bed and area changes downstream from Old River Control Complex, 19912002.

Table 45. Effects of sediment inflow and roughness on bed change. .176

Table 46. Roughness coefficients, falling limb of 2002 hydrograph, RM 267-306.3 ...................177

Table 47. Calculated and measured erosion at Smithland Crossing, 1991-2002. ....................... 185

Table 48. Calculated sediment loads from tributaries and distributaries, 1991-2002 ................. 189

Table 49. 2003-2011 calculated sediment delivery.................................................................... 198 


\section{Preface}

This study was conducted for the U.S. Army Corps of Engineers (USACE) as part of the Mississippi River Geomorphology and Potamology (MRG\&P) Program, under Project 127672; "Mississippi River Geomorphology and Potamology Program.” The MRG\&P Program is part of the Mississippi River and Tributaries Program (MR\&T) and is managed by the USACE, Mississippi Valley Division (MVD), and Districts. At the time of publication of this report, the MRG\&P Program Director was Dr. James W. Lewis. The MVD Commander was MG R. Mark Toy. The MVD Director of Programs was Mr. James A. Bodron.

This investigation was led by the U.S. Army Engineer Vicksburg District with support from the St. Louis District, Memphis District, and New Orleans District. 


\section{Introduction}

\section{Background}

This report incorporates findings from an unpublished interim report entitled Numerical Sedimentation Investigation - Mississippi River Vicksburg to Pilots Station dated 27 October 2009. The interim study was conducted first to help address pressing issues related to flow diversions and dredging in the New Orleans District. This interim model was subsequently used by other investigators as a starting point for numerical studies for the State of Louisiana and the U.S. Army Corps of Engineers (USACE). It was also used as the starting point for the numerical model described in this report and is referred to herein as the Regional Model.

The original scope of work for the Regional Model called for producing a numerical model of the entire Lower Mississippi River that was calibrated to the 1991-2002 time period. This work was completed in 2010. To demonstrate the applicability of the Regional Model, it was decided to expand the study to evaluate (1) effects of changing sediment inflow from the Middle Mississippi River, (2) construction of a dike field, and (3) removal of the hard point at Hickman. Then, the 2011 flood produced record stages up and down the Lower Mississippi River. As part of the extended study, data from this flood were used to re-calibrate roughness coefficients at flood flows in the Vicksburg District. Also, additional sediment data through 2012 were used to extend the sediment inflow data base. A draft report describing this work was prepared in 2014, and the Regional Model is frequently referred to as the 2014 Report. Before review of the Regional Model was completed, focus was diverted to completing a numerical sediment study for the USACE Flowline Study for the Mississippi River and Tributaries Project. The Flowline Model used the Regional Model as a starting point, incorporating enhancements from the State of Louisiana and USACE models and incorporating additional data obtained after completion of the Regional Model study. The Flowline Model Report (Copeland 2018) was actually reviewed and completed before the Regional Model Report. Hence, there is a somewhat confusing chronology when publication dates are compared. 
The Regional Model does not try to study specific areas in detail. The model is constructed so that more refinement can be added to study specific problem areas. The model can then be used to assess the systemwide effects of changes at the project site. The model extends from Chester, IL, on the Middle Mississippi River and Metropolis on the Ohio River to Pilots Station at the end of Southwest Pass - over 1000 miles.

\section{Objective}

The purpose of this study was to develop a numerical sedimentation model that can identify and predict the effects of planned Mississippi River and Tributaries Project features and dredging strategies on long-term sediment trends between Cairo, IL, and Pilots Station, LA. The New Orleans, Vicksburg, Memphis, and St. Louis Districts were responsible for developing the numerical model in their respective reaches of responsibility along the Mississippi River.

\section{Approach}

The study approach was to develop a one-dimensional (1D) computational model using the computer program HEC-6T. This program has been applied successfully to evaluate long-term sedimentation responses to various engineering projects along the Lower Mississippi River. These applications have included river response to dredging, river response to flow diversions through distributaries, stability of a low-flow sediment sill, and the effect of contraction works on navigation depth. It is recognized that river response to dikes, especially overtopping dikes, is more complex than a $1 \mathrm{D}$ steady-flow problem. Specific reaches will need multidimensional modeling, or perhaps physical modeling, to determine design details; however, $1 \mathrm{D}$ computations were one of the approaches used to link these specific reaches together during the planning and design of the Arkansas River Flood Control and Navigation project in the 1950s and 6os. That design included 450 miles of dikes and revetments that created an effective navigation channel. The project has performed exceptionally well in terms of evaluating maintenance requirements by dredging. The application of the computational model in the current study, by engineers who understand river behavior, will be equally successful in determining the appropriate length, height, and longitudinal extent for dike field construction, and it will give feedback on the long-term trends, due to sedimentation processes, that result from such projects. 


\section{Questions and metrics}

Dredging and sediment diversion significantly alter morphologic processes in the river system. The numerical model can be used to calculate the short-term and long-term effects of proposed dredging activities and the effectiveness of a dredging program. The model can calculate the increased deposition rates associated with dredging and the length of time required to refill the navigation channel back to a critical elevation. The model can be used to calculate the effectiveness of in-channel dredge disposal versus disposal outside of the channel. The timing of dredging activities with respect to annual flood peaks can be evaluated. Similarly, the short-term and long-term effects of sediment diversions can be calculated using the numerical model. Although the quantity of sediment diverted must be determined external to the numerical model, the morphologic changes induced by a specified quantity of sediment diversion can be determined. The most useful feature of the numerical model analysis is that systemwide effects of several diversions and dredging activities can be evaluated together so that the effect of each feature on the system can be determined. These effects can be evaluated using calculated bed elevation and corresponding water-surface elevation changes in the river channel, sediment yields past designated cross sections, sediment diversion quantities through designated diversions, and required dredging quantities to maintain project depths.

Dike fields are constructed to hold alignment and increase navigation depths. In addition to the intentional bed changes in the dike field, there will be additional morphological changes in the upstream and downstream river reaches. The numerical model can be used to calculate both the short-term and long-term bed and water-surface elevation changes in the dike field itself and in the river system as a whole. The model also calculates short-term and long-term changes in sediment yield upstream and downstream from proposed dike fields.

The effects of imposed hydrologic and sedimentation conditions on the river system can be evaluated using the numerical model. Changes in the sediment supply will affect the aggradation/degradation rates in the river system. The numerical model can be used to determine the calculated bed changes and the reach length affected. The effects of sea-level rise, temperature changes, and removal of riverbed hard points can also be calculated. The primary calculated metrics are bed elevation change and changes in sediment yield. 


\section{Numerical Model Description}

\section{HEC-6T description}

The HEC-6T 1D numerical sedimentation model was used in this study (MBH 2002). Mr. William A. Thomas initiated development of this computer program at the U.S. Army Engineer District, Little Rock, in 1967. Further development at the U.S. Army Engineer Hydrologic Engineering Center by Mr. Thomas produced the widely used HEC-6 generalized computer program for calculating scour and deposition in rivers and reservoirs. Additional modification and enhancement to the basic program by Mr. Thomas and his associates at the U.S. Army Engineer Research and Development Center (ERDC) led to the HEC-6W program. The HEC-6T program used in this study is the product of additional modification and enhancement conducted by Mr. Thomas at Mobile Boundary Hydraulics PLLC. Version nine of the HEC-6T code was used to make calculations in this study. The model is proprietary and can be obtained from Mobile Boundary Hydraulics.

The HEC-6T program produces a 1D model that simulates the response of the riverbed profile to sediment inflow, bed-material gradation, and hydraulic parameters. The model simulates a series of steady-state discharge events, their effects on the sediment transport capacity at cross sections and the resulting degradation or aggradation. The program calculates hydraulic parameters using a standard-step backwater method.

HEC-6T is a state-of-the-art program for use in mobile bed channels. The numerical model computations account for all the basic processes of sedimentation: erosion, entrainment, transportation, deposition, and compaction of the bed for the range of particle sizes found in the Mississippi River. The model calculates aggradation and degradation of the streambed profile over the course of a hydrologic event. It does not simulate bank erosion or natural adjustments in channel widths. When applied by experts using good engineering judgment, the HEC-6T program will provide good insight into the behavior of mobile bed rivers.

\section{Model network}

The New Orleans, Vicksburg, Memphis, and St. Louis Districts were responsible for developing the numerical model in their respective reaches of responsibility along the Mississippi River. 
The model network consists of 25 segments that are connected by control points. The network is shown in Figure 1 and Figure 2. In the figures, control points are designated with circles with a numerical designation, and segments are labeled inside of parentheses. For reference purposes, Figure 1 and Figure 2 also show tributaries, river miles, and loops. River miles are set using the 1962 Hydrographic Survey Index. River Mile (RM) o is at Head of Passes. Cross sections upstream from Head of Passes are positive values, and if there is any doubt, AHP (i.e., Above Head of Passes) is appended to the label. Cross sections along Southwest Pass are labeled as a negative values, and BHP (i.e., Below Head of Passes) is appended to those labels.

Figure 1. Schematic of HEC-6T Stream Network in New Orleans and Vicksburg Districts.

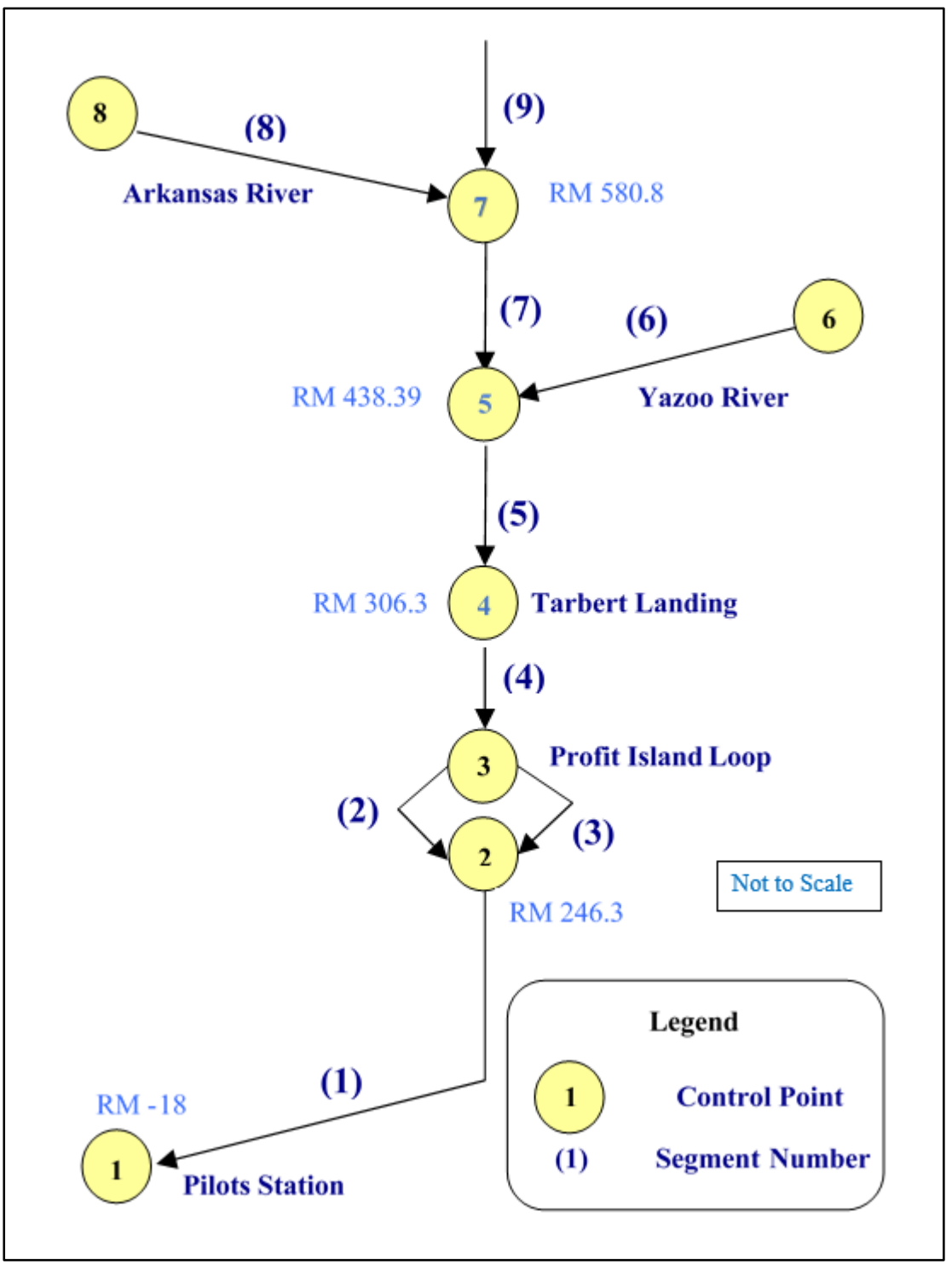


Figure 2. Schematic of HEC-6T stream network in Memphis and St. Louis Districts.

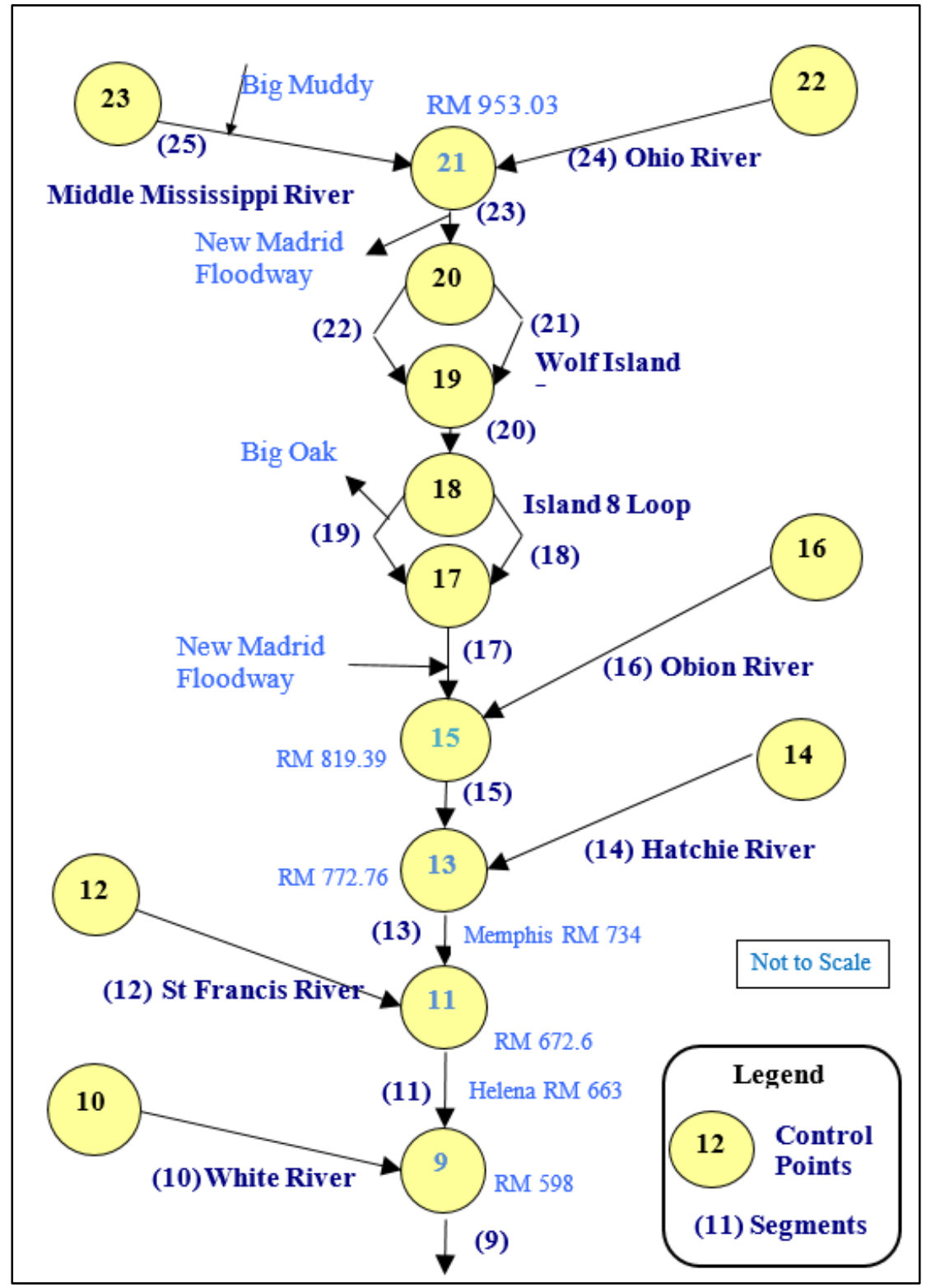

Segments 1 through 4 are in New Orleans District. The model begins at RM -18 (BHP), which is just inside the jetties of Southwest Pass at Pilots Station. The downstream boundary is designated as Control Point 1. Segment 1 extends from Pilots Station to Profit Island, which is designated as Control Point 2. Segments 2 and 3 model the loop at Profit Island. Segment 2 is the main channel side, and Segment 3 is the chute. Control Point 2 joins Segments 2 and 3 to the downstream segment (Segment 1), and Control Point 3 joins them to the upstream segment (Segment 4). Control Point 5, at the upstream end of Segment 4, is the gage at Tarbert 
Landing (RM 306.3). It is located just downstream from the Old River Control Complex.

Segments 5 through 9 are primarily located in the Vicksburg District. However, the Old River Diversion Complex, which is located between RM 311 and 316 AHP, is in the New Orleans District. Segment 5 begins at RM 306.3, and Segment 9 ends at RM 598. There are no loops in Vicksburg District, but the network schematic shows two major tributaries. They are the Yazoo River (Segment 6) at RM 438.39 AHP and the Arkansas River (Segment 8) at RM 580.8 AHP.

Segments 10 through 23 are primarily in the Memphis District with Control Points 9 and 21 representing the downstream and upstream boundaries, respectively. Tributaries in the Memphis District include the White River (Segment 10) at RM 672.6, the Hatchie River (Segment 14) at RM 772.76, and the Obion River (Segment 16) at RM 819.39. The model contains the Island 8 Loop (Segments 18 and 19) and the Wolf Island Loop (Segments 21 and 22).

The Middle Mississippi River (Segment 25) is in the St. Louis District. The downstream control point is at Cairo (Control Point 21), and the upstream control point is at Chester (Control Point 23), which is located 109.9 miles upstream.

Approximately 37 miles of the Ohio River are included in the model. The Ohio River is Segment 24. The downstream end of the segment is at Cairo, and the upstream end of the segment is located at Metropolis (Control Point 22.) Ohio River stationing starts at the confluence of the Allegheny and Monongahela Rivers in Pittsburgh, PA, and moves downstream to Cairo IL. However, in this report Ohio River stationing is sometimes referenced (for convenience) to River Miles Above Head of Passes (AHP).

The number of cross sections in each segment and the description of the segment boundaries are given in Table 1. 
Table 1. Description of HEC-6T segments.

\begin{tabular}{|c|c|c|c|}
\hline Segment & $\begin{array}{c}\text { Number of } \\
\text { Cross } \\
\text { Sections }\end{array}$ & Description & River Miles \\
\hline 1 & 133 & Mississippi River - Pilots Station to Profit Island & -18.0 to 246,3 \\
\hline 2 & 6 & $\begin{array}{l}\text { Mississippi River - Main Channel (West) Profit } \\
\text { Island }\end{array}$ & 246.9 to 251.8 \\
\hline 3 & 6 & $\begin{array}{l}\text { Mississippi River - Chute Channel (East) Profit } \\
\text { Island }\end{array}$ & 246.8 to 248.6 \\
\hline 4 & 27 & Mississippi River - Profit Island to Tarbert Landing & 253.0 to 306.3 \\
\hline 5 & 72 & Mississippi River - Tarbert Landing to Yazoo River & 306.3 to 437.3 \\
\hline 6 & 3 & Yazoo River & 1.5 to 16.7 \\
\hline 7 & 81 & Mississippi River - Yazoo River to Arkansas River & 438.4 to 580.8 \\
\hline 8 & 19 & Arkansas River & 0.6 to 29.0 \\
\hline 9 & 9 & Mississippi River - Arkansas River to White River & 580.8 to 598.0 \\
\hline 10 & 69 & White River & 0.0 to 100.0 \\
\hline 11 & 45 & Mississippi River - White River to St. Francis River & 600.1 to 672.6 \\
\hline 12 & 19 & St. Francis River & 0.5 to 17.7 \\
\hline 13 & 38 & Mississippi River - St. Francis River to Hatchie River & 674.7 to 772.8 \\
\hline 14 & 3 & Hatchie River & 0.1 to 2.0 \\
\hline 15 & 18 & Mississippi River - Hatchie River to Obion River & 774.0 to 819.4 \\
\hline 16 & 3 & Obion River & 0.1 to 2.0 \\
\hline 17 & 35 & Mississippi River - Obion River to Island 8 & 820.0 to 910.0 \\
\hline 18 & 5 & Mississippi River - East Loop Island 8 & 910.5 to 914.6 \\
\hline 19 & 5 & Mississippi River - West Loop Island 8 & 910.5 to 914.6 \\
\hline 20 & 9 & Mississippi River - Island 8 to Wolf Island & 915.6 to 930.8 \\
\hline 21 & 3 & Mississippi River - East Loop Wolf Island & 931.5 to 934.4 \\
\hline 22 & 3 & Mississippi River - West Loop Wolf Island & 931.5 to 934.4 \\
\hline 23 & 8 & Mississippi River - Wolf Island to Cairo & 934.4 to 953.0 \\
\hline 24 & 37 & Ohio River - Cairo to Metropolis & $\begin{array}{l}\text { 955.to } 0990.0 \\
\text { AHP }\end{array}$ \\
\hline 25 & 46 & Middle Mississippi River - Cairo to Chester & 0.8 to 109.90 \\
\hline
\end{tabular}

\section{Channel geometry}

The cross-section geometry in the HEC-6T model was developed from hydrographic survey data taken between 1987 and 1992 (USACE MVN 1993; USACE MVK 1990; USACE MVM 1990). The hydrographic surveys 
were conducted at different times in the different districts. There is a time discontinuity in the cross sections surveyed in individual districts as the hydrographic surveys in each district were conducted over a period of a year or more. One of the consequences of this anomaly is that direct comparisons between historical surveys at individual cross sections or even short reaches may be misleading. This factor makes model calibration to changes in surveyed bed volumes difficult and most likely unreliable.

Most of the cross sections in the 1987-1989 hydrographic survey for the Memphis District were obtained in 1988 and 1989. Gaps were filled by surveys obtained in 1985 through1987. Ten of the model cross sections came from these earlier dates. These were located at RMs 847.96, 792.1, 777.3, 748.94, 744.98, 632.6, 628.66, 627.1, 602.95, and 600.1.

Elevations from the hydrographic survey were related to mean sea level. Areas above the water line were obtained by photogrammetric methods from aerial photos taken between 1987 and 1988. River miles relate to distance AHP (1962).

The cross sections in the 1988-1989 hydrographic survey for the Vicksburg District were obtained between January 1988 and January 1989. Elevations from the hydrographic survey were related to National Geodetic Vertical Datum (NGVD) of 1929. Areas above the water line were obtained by photogrammetric methods from aerial photos taken between February and March 1988. River miles relate to distance AHP (1962).

The cross sections in the New Orleans District 1991-1992 hydrographic survey were obtained between October 1991 and September 1992. Elevations from the hydrographic survey were related to NGVD of 1929. Planimetry was from aerial photographs flown in November 1991. River miles relate to distance AHP (1962).

\section{New Orleans District channel geometry}

Two existing HEC-6T models of the Mississippi River through the New Orleans District were available. The first model extended from East Jetty to Tarbert Landing and was constructed by Kevin Fagot at the USACE, New Orleans District (Barbe et al. 2000). The second model extended from Donaldsonville, LA, to Vicksburg, MS, and was constructed by Dr. Ronald Copeland at the USACE, ERDC (Catalyst-Old River Hydroelectric 1999). Both of these models were constructed using the 1983 Mississippi River Hydrographic Survey. A new model was developed for this study using 
essentially the same cross-section locations but replacing the 1983 channel survey data with the 1991-92 hydrographic survey data. This was done to be consistent with the survey data dates used upstream through the Vicksburg, Memphis, and St. Louis Districts. Overbanks in the new model were taken from various sources such as Hydrographic Survey Contours, U.S. Geololgical Survey (USGS) Quad Maps, and Louisiana DOQQ ${ }^{1}$ and lidar. However, some overbanks were taken from the original 1983 models and were not changed with the 1992 channel conversion. At some cross sections, overbank elevations were artificially raised to the upstream or downstream natural levee elevation to restrict overbank conveyance.

\section{Vicksburg District channel geometry}

The initial Mississippi River channel geometry through the Vicksburg District was developed from 1988-89 hydrographic survey data. Most of the overbank elevations came from the hydrographic survey. For cross sections without overbank elevations, USGS quad maps were used to develop overbank geometry. The Vicksburg District channel and overbank cross sections came from a previously developed HEC-2 model. At some cross sections, overbank elevations were artificially raised to the upstream or downstream natural levee elevation to restrict overbank conveyance.

The Yazoo River Segment in the HEC-6T model was poorly defined due to lack of channel geometry data. This condition was deemed acceptable because the sole purpose of the Yazoo River Segment was to provide sediment inflow to the Mississippi River. Data were insufficient for calibration and determination of morphologic changes in the Yazoo River. Three cross sections were used to define the Yazoo River. Cross sections at Yazoo RMs 1.51 and 3.69 were taken from the 1988-1989 hydrographic survey of the Mississippi River. A cross section at RM 16.7 was developed from geometry data obtained from the USGS gage at Redwood.

The HEC-6T model includes 28.2 miles of the Arkansas River downstream from Dam No. 2 to the Mississippi River. Cross-section geometry was obtained from a HEC-RAS backwater model labeled ArkWhite_seed1.G13 provided by Little Rock District. Cross sections in the HEC-RAS model were surveyed in May 2003. The channel alignment reflects cutoffs in the Lower Arkansas River that took place in the mid-1990s. The Arkansas River confluence with the Mississippi River moved to RM 580.5 from 
RM 585 in 1989. This alignment and the location of the confluence are considerably different from that shown on the 1989 hydrographic survey.

Overbank geometry for Arkansas River cross sections where the overbank was shared with the Mississippi River was based on elevations from the 1989 and 1995 Hydrographic Surveys modified to account for the new Arkansas River channel. Farther upstream, overbank widths and elevations were based on USGS quad elevations. At some cross sections, overbank elevations were artificially raised to the upstream or downstream natural levee elevation to restrict overbank conveyance.

The purpose of the Arkansas River Segment in the HEC-6T model was to provide sediment inflow to the Mississippi River. Data are insufficient for calibration of the Arkansas River segment, and calculated morphologic changes should be treated with caution.

\section{Memphis District channel geometry}

The initial Mississippi River channel geometry for the Memphis District came from the 1988-89 hydrographic survey. USGS quads or lidar data were used to define overbank geometry. At some cross sections, overbank elevations were artificially raised to the upstream or downstream natural levee elevation to restrict overbank conveyance.

One hundred miles of the White River are included in the HEC-6T model. The channel cross sections were based on the 1997 hydrographic survey. Overbank elevations were taken from a 2000 survey and USGS quad maps. Data were insufficient for calibration and determination of morphologic changes in the White River.

Cross sections for the St. Francis River were taken from a previously developed HEC-6T model, which used 1997-1998 surveys for crosssection geometry. Overbank data came from 1997-1998 survey data and USGS quad maps. The Saint Francis River segment is 17.2 miles long.

There were no available survey data for the Obion and Hatchie Rivers, and therefore these segments were poorly defined. This condition was deemed acceptable because the sole purpose of these segments was to provide sediment inflow to the Mississippi River. Data were insufficient for calibration and determination of morphologic changes. Three cross sections were used to define 2 miles on the Obion and Hatchie River 
segments. The shape of the cross sections was determined from a discharge range at the Rialto gage on the Hatchie River. Elevations were determined by adjustments using the valley slope. Widths were adjusted using aerial photographs.

The 37-mile-long Ohio River segment was based on a Louisville District HEC-2 model. Cross sections in this model were surveyed in the mid-1960s. The Ohio River is relatively stable and has not experienced significant bed changes since 1960, which justifies use of the 1960 s survey data. However, it is recommended that more recent survey data be obtained for the Ohio River, especially, for any detailed study of reaches in the vicinity of the confluence of the Ohio and Mississippi Rivers. The purpose of the Ohio River segment in the HEC-6T model was to provide sediment inflow to the Mississippi River. Data are insufficient for calibration of the Ohio River Segment, and calculated morphologic changes should be treated with caution.

\section{St. Louis District channel geometry}

The St. Louis District channel cross sections came from the 1986-1988 hydrographic survey. The cross sections were obtained between March 1986 and June 1988. Elevations from the hydrographic survey were related to NGVD of 1929.

\section{Dike Fields}

\section{Southwest Pass}

The dike fields in Southwest Pass consist of pile dikes. The dimensions and stationing of these dikes were taken from drawings and information provided by the New Orleans District General Engineering Branch and Civil Branch Channel Stabilization Section. In addition, the pile dike locations and lengths were verified using the 1991-1992 Mississippi River Hydrographic Survey. All of the pile dikes were originally built to elevation of $+6.0 \mathrm{ft}$ (NGVD). The dikes were coded in the geometry to this elevation. Cross-section geometry was adjusted to account for the effects of the dikes. The dikes were coded into the model using a 1:1 contraction rate and a 1:4 expansion rate. These rates were taken from the 2001 HEC-RAS Reference Manual (HEC 2001) for general modeling guidelines for modeling bridges. The coefficients for contraction and expansion losses, 0.1 , and 0.3 , respectively, were also taken from the HEC-RAS Reference Manual. 


\section{Dikes in New Orleans District}

There are three crossings with dike fields in the New Orleans District. These dike fields are located in the Medora Crossing, Red Eye Crossing, and Smithland Crossing at Hog Point. The dimensions and stationing of the dikes in Medora, Red Eye, and Smithland crossings were taken from drawings and information provided by the New Orleans District Civil Branch Channel Stabilization Section. These dike locations were also verified using the 1991-1992 Mississippi River Hydrographic Survey. As with Southwest Pass, the dikes were coded into the model using a 1:1 contraction rate and a 1:4 expansion rate for the affected cross sections. The coefficients for contraction and expansion losses were 0.1 and 0.3 , respectively.

\section{Medora Crossing}

Medora Crossing is located between RMs 211 and 213. There are three dikes located within the crossing. The effects of these dikes are felt on cross sections 210.8 through 212.2. The dikes are coded from left to right beginning at the left descending bank.

The left top of bank begins at the end of the dikes as they extend into the channel. Points in the cross section from the 1992 Hydrographic Survey whose elevations were higher than those in the dikes' geometry were retained. Points whose elevations were lower than those for the dikes were raised to match the dikes' geometry.

Dike Number 3 is coded into the geometry for cross sections 210.8 and 211.6 to its crest elevation of +2 feet ( $\mathrm{ft}$ ) (NGVD). Cross section 212 is affected by both dikes Numbers 1 and 2 . The average length of $460 \mathrm{ft}$ and average crest elevation of $-7 \mathrm{ft}$ (NGVD) is coded into the geometry for this cross section. Dike Number 1 is coded into the geometry of cross section 212.6 to its crest elevation of $-10 \mathrm{ft}$ (NGVD).

Red Eye Crossing

Red Eye Crossing is located between RMs 223 and 225. There are six dikes located within the crossing. The effects of these dikes are felt on cross sections 223.0 through 224.4. 
The dikes are coded from left to right beginning at the left descending bank. The left top of bank begins at the end of the dikes as they extend into the channel. Points in the cross sections from the 1992 Hydrographic Survey whose elevations were higher than those in the dikes' geometry were retained. Points whose elevations were lower than those for the dikes were raised to match the dikes' geometry.

Dike Number 6 is coded into the geometry for cross section 223.0 to its crest elevation of zero $\mathrm{ft}$ (NGVD). Dike Number 3 is coded into the geometry for cross section 224.1 to its crest elevation of zero ft (NGVD). Dike Number 1 is coded into the geometry for cross section 224.4 to its crest elevation of $-4 \mathrm{ft}$ (NGVD). Dikes Numbers 2, 4, and 5 are not coded into the geometry because no cross sections in the model are affected by them.

\section{Smithland Crossing (Hog Point)}

Smithland Crossing is located between RMs 297 and 301. There are five dikes and one closure chute located within the crossing. The effects of the dikes and chute are felt on cross sections 297.45 through 300.3.

Initially, the cross sections in this reach were modeled using the geometry from the 1992 Hydrographic Survey. However, it was determined during the calibration phase of the study that changes due to the dikes had not occurred when the 1992 hydrographic survey was conducted. Therefore, this reach was used during the verification phase of the study to assess the numerical model's reliability for predicting degradation. The verification analyses are discussed in the section entitled "Degradation at Smithland Crossing" in this report. Following the verification phase of the study, the 2002 cross sections were used through Smithland Crossing.

The dikes are coded from left to right beginning at the left descending bank. The left top of bank begins at the end of the dikes as they extend into the channel. The chute is coded from right to left beginning at the right descending bank. The right top of bank begins at the end of the chute as it extends into the river. Points in the cross sections from the 2004 Hydrographic Survey whose elevations were higher than those in the dikes' and chutes' geometry were retained. Points whose elevations were lower than those for the dikes and chute were raised to match the dikes' and chutes' geometry. 
The locations of the dikes that are present in the New Orleans District reach of the HEC-6T model are listed in Table 2.

Table 2. Dikes in New Orleans District HEC-6T model, Pilots Station (RM -18.0) to Union Point (RM 326).

\begin{tabular}{|c|c|c|}
\hline Cross Section & Dike Field & Descending River Bank \\
\hline-18.0 & Southwest Pass & Left and Right \\
\hline-16.5 & Southwest Pass & Left and Right \\
\hline-14.7 & Southwest Pass & Left and Right \\
\hline-13.3 & Southwest Pass & Left and Right \\
\hline-11.9 & Southwest Pass & Left and Right \\
\hline-10.7 & Southwest Pass & Left and Right \\
\hline-9.3 & Southwest Pass & Right \\
\hline-7.7 & Southwest Pass & Right \\
\hline-5.8 & Southwest Pass & Right \\
\hline-1.9 & Southwest Pass & Right \\
\hline 211.6 & Medora Dikes & Left \\
\hline 212 & Medora Dikes & Left \\
\hline 212.2 & Medora Dike & Left \\
\hline 223.0 & Red Eye Dikes & Left \\
\hline 224.1 & Red Eye Dikes & Left \\
\hline 224.4 & Red Eye Dikes & Left \\
\hline 297.45 & Smithland Dikes & Left \\
\hline 298.1 & Smithland Dikes & Left \\
\hline 298.9 & Smithland Dikes & Left \\
\hline 299.5 & Smithland Dikes & Left \\
\hline 300.3 & Smithland Dikes & Left \\
\hline
\end{tabular}

\section{Dikes in Vicksburg and Memphis Districts}

There are numerous dike fields in the Vicksburg and Memphis Districts. The list of dikes that were implemented in the HEC-6T model are listed in Table 3 and Table 4. Due to the large number of dike fields, the level of detail in the Vicksburg and Memphis Districts was not as great as was applied in the New Orleans District reach. Cross sections where dikes were present in 1992 were modified to reflect the projections of both upstream and downstream dikes in the vicinity of the cross section. This is 
equivalent to assuming that cross sections in the dike field are filled to the top of dike elevations. At the time the HEC-6T model was constructed, it was not possible to change the geometry of cross sections to reflect changes to existing dikes or construction of new dikes as the simulation progressed. Therefore, changes to cross-section geometry due to construction in dike fields after 1992 is not simulated in the HEC-6T model. Recent enhancement of the HEC-6T model allows for changing cross-section geometry during the course of the historical simulation. Future studies should take advantage of this option.

Table 3. Dikes in Vicksburg District HEC-6T Model, Union Point (RM 326) to Rosedale (RM 592).

\begin{tabular}{|c|c|c|}
\hline Cross Section & Dike Field & $\begin{array}{l}\text { Descending } \\
\text { River Bank }\end{array}$ \\
\hline 330.61 & Jackson Point & Left \\
\hline 337.00 & Fritz Island & Right \\
\hline 346.81 & Esperance Point & Right \\
\hline 351.12 & Opposite Warnicott Landing & Left \\
\hline 352.98 & Opposite Warnicott Landing & Left \\
\hline 357.00 & Natchez Island & Right \\
\hline 358.63 & Natchez Island & Right \\
\hline 374.59 & Chute Restricted by Waterproof Bar Dikes & Right \\
\hline 377.00 & Chute Restricted by Waterproof Bar Dikes & Right \\
\hline 378.59 & Waterproof Bar & Right \\
\hline 385.01 & Spithead Towhead & Left \\
\hline 387.41 & Chute Restricted by Browns Field Dikes & Right \\
\hline 389.01 & Cottage Bed & Left \\
\hline 389.01 & Browns Field & Right \\
\hline 391.40 & Chute Restricted by Browns Field Dikes & Right \\
\hline 393.00 & Bondurant & Right \\
\hline 394.61 & Bondurant Towhead & Right \\
\hline 398.80 & Below Grand Gulf & Left \\
\hline 402.80 & Coffee Point & Right \\
\hline 405.18 & Upstream from Coffee Point & Right \\
\hline 407.62 & Yucatan Cutoff Restricted by Closure Dike & Right \\
\hline 409.03 & Yucatan Cutoff Restricted by Closure Dike & Right \\
\hline 415.00 & Togo Island & Left \\
\hline 429.20 & Below Racetrack & Left \\
\hline 431.00 & Below Racetrack & Left \\
\hline 438.39 & Chute Restricted by Upstream Dikes & Right \\
\hline 440.80 & False Point & Right \\
\hline
\end{tabular}




\begin{tabular}{|c|c|c|}
\hline Cross Section & Dike Field & $\begin{array}{l}\text { Descending } \\
\text { River Bank }\end{array}$ \\
\hline 447.20 & Marshall Point Cutoff & Right \\
\hline 448.79 & Forest Home Towhead & Left \\
\hline 451.20 & Forest Home Towhead & Left \\
\hline 460.80 & Willow Cutoff & Right \\
\hline 468.97 & Arcadia Point & Left \\
\hline 470.13 & Arcadia Point & Left \\
\hline 470.13 & Cottonwood & Right \\
\hline 471.40 & Arcadia Point & Left \\
\hline 477.20 & Point Lookout & Right \\
\hline 478.00 & Point Lookout & Right \\
\hline 481.06 & Ajax Bar & Left \\
\hline 483.00 & Ajax Bar & Left \\
\hline 484.80 & Ben Lomond & Left \\
\hline 486.40 & Ben Lomond & Left \\
\hline 487.80 & Ben Lomond & Left \\
\hline 489.00 & Ben Lomond & Left \\
\hline 490.80 & Baleshed Landing & Left \\
\hline 492.69 & Baleshed Landing & Left \\
\hline 494.59 & Baleshed Landing & Left \\
\hline 495.59 & Cutoff Restricted by Wilson Point Dike 3-R & Right \\
\hline 497.20 & Cutoff Restricted by Wilson Point Dike 3-R & Right \\
\hline 499.59 & Wilson Point & Right \\
\hline 502.80 & Corregidor & Left \\
\hline 504.66 & Corregidor & Left \\
\hline 507.29 & Chute Restricted by Cracraft Dike 3-R & Right \\
\hline 509.20 & Cracraft & Right \\
\hline 509.20 & Caroline & Left \\
\hline 510.00 & Cracraft & Right \\
\hline 512.80 & Leota & Left \\
\hline 512.80 & Cracraft & Right \\
\hline 515.03 & Leota & Left \\
\hline 515.03 & Chute Restricted by Island 86 Dikes & Right \\
\hline 516.60 & Chute Restricted by Island 86 Dikes & Right \\
\hline 518.21 & Chute Restricted by Island 86 Dikes & Right \\
\hline 518.21 & Island 86 & Right \\
\hline 521.19 & Chute Restricted by Island 86 Dikes & Right \\
\hline 522.76 & Seven Oaks & Right \\
\hline 524.40 & Seven Oaks & Right \\
\hline 524.40 & Walnut Point & Left \\
\hline
\end{tabular}




\begin{tabular}{|c|c|c|}
\hline Cross Section & Dike Field & $\begin{array}{l}\text { Descending } \\
\text { River Bank }\end{array}$ \\
\hline 526.00 & Cutoff Restricted by Refuge Dikes & Left \\
\hline 526.00 & Anconia Chute Dike & Right \\
\hline 527.80 & Cutoff Restricted by Refuge Dikes & Left \\
\hline 529.20 & Refuge & Left \\
\hline 532.20 & Island 84 & Left \\
\hline 533.13 & Island 84 & Left \\
\hline 535.17 & Longitudinal Dikes & Right \\
\hline 537.25 & Leland Bar & Right \\
\hline 538.56 & Leland Bar & Right \\
\hline 540.38 & Leland Neck & Left \\
\hline 540.38 & Tarpley Cutoff Dikes & Right \\
\hline 543.21 & Island 82 - Miller Bend & Right \\
\hline 544.72 & Island 82 - Miller Bend & Right/Left \\
\hline 546.83 & Ashbrook- Miller Bend & Right/Left \\
\hline 549.00 & Ashbrook Cutoff & Left \\
\hline 560.00 & Chute Restricted by Chicot Landing Dikes & Right \\
\hline 562.40 & Chute Restricted by Chicot Landing Dikes & Right \\
\hline 565.19 & Chute Restricted by Chicot Landing Dikes & Right \\
\hline 569.03 & Chute Restricted by Catfish Point Dikes & Left \\
\hline 576.21 & Chute Restricted by Below Prentiss Dikes & Left \\
\hline 578.80 & Below Prentiss & Left \\
\hline 584.86 & Malone Field & Right \\
\hline 589.07 & Terrene & Left \\
\hline 590.40 & Terrene & Left \\
\hline 591.99 & Montgomery Point Towhead & Right \\
\hline
\end{tabular}

Table 4. Dikes in Memphis District HEC-6T Model, Rosedale (RM 592) to Cairo (RM 954).

\begin{tabular}{|l|l|l|}
\hline Cross Section & Dike Field & $\begin{array}{l}\text { Descending } \\
\text { River Bank }\end{array}$ \\
\hline 600.10 & Smith Point & Left \\
\hline 602.95 & Henrico & Right \\
\hline 606.00 & Island 70 & Left \\
\hline 607.17 & Island 70 & Left \\
\hline 610.94 & Below Knowlton & Right \\
\hline 613.60 & Below Knowlton & Right \\
\hline 614.58 & Below Knowlton & Right \\
\hline 616.07 & Below Knowlton & Right \\
\hline
\end{tabular}




\begin{tabular}{|c|c|c|}
\hline Cross Section & Dike Field & $\begin{array}{l}\text { Descending } \\
\text { River Bank }\end{array}$ \\
\hline 621.03 & Island 67 & Left \\
\hline 623.12 & Below Ludlow & Left \\
\hline 627.10 & Sunflower & Left \\
\hline 637.91 & Island 62 & Right \\
\hline 637.91 & Chute Restricted by Closure Dike & Left \\
\hline 639.73 & Island 62 & Right \\
\hline 648.47 & Kangaroo Point & Right \\
\hline 649.00 & Kangaroo Point & Right \\
\hline 651.91 & Friars Point & Left \\
\hline 654.23 & Chute Restricted by Upstream Dike & Right \\
\hline 656.21 & Montezuma Towhead & Right \\
\hline 658.06 & Montezuma Bar & Left \\
\hline 666.01 & Chute Restricted by Closure Dike & Right \\
\hline 666.01 & Prairie Point & Right \\
\hline 667.00 & Chute Restricted by Closure Dike & Right \\
\hline 667.00 & Prairie Point & Right \\
\hline 668.22 & Prairie Point & Right \\
\hline 668.22 & Flower Lake & Left \\
\hline 670.00 & St. Francis Towhead & Left \\
\hline 676.20 & Below Walnut Bend & Right \\
\hline 681.00 & Bordeaux Point & Left \\
\hline 682.06 & Bordeaux Point & Left \\
\hline 691.40 & Chute Restricted by Commerce Dike & Left \\
\hline 692.43 & Commerce & Left \\
\hline 696.80 & Porter Lake & Right \\
\hline 700.28 & Porter Lake & Right \\
\hline 702.30 & Porter Lake & Right \\
\hline 704.08 & Pickett & Left \\
\hline 710.60 & Cat Island & Right \\
\hline 711.00 & Cat Island & Right \\
\hline 719.67 & Armstrong & Right \\
\hline 723.85 & Dismal Point & Right \\
\hline 735.90 & Hopefield Point & Right \\
\hline
\end{tabular}




\begin{tabular}{|c|c|c|}
\hline Cross Section & Dike Field & $\begin{array}{l}\text { Descending } \\
\text { River Bank }\end{array}$ \\
\hline 737.00 & Robinson Crusoe & Right \\
\hline 738.00 & Robinson Crusoe & Right \\
\hline 738.95 & Robinson Crusoe & Right \\
\hline 738.95 & Loosahatchie Bar & Right \\
\hline 740.00 & Robinson Crusoe & Right \\
\hline 741.00 & Above Loosahatchie & Left \\
\hline 744.98 & Randolph Point & Left \\
\hline 748.94 & Poker Point & Right \\
\hline 752.98 & Corona Bar & Right \\
\hline 756.97 & Densford & Left \\
\hline 766.90 & Below Richardson Landing & Left \\
\hline 770.60 & Lookout Bar & Right \\
\hline 772.76 & Lookout Bar & Right \\
\hline 783.50 & Plum Point & Left \\
\hline 784.00 & Plum Point & Left \\
\hline 788.13 & Keyes Point & Left \\
\hline 790.00 & Keyes Point & Left \\
\hline 792.10 & Keyes Point & Left \\
\hline 792.10 & Kat Aubrey & Right \\
\hline 796.01 & Ashport Goldust & Right \\
\hline 800.04 & Forked Deer & Left \\
\hline 803.84 & Island 25 & Right \\
\hline 807.79 & Nebraska Point & Left \\
\hline 812.44 & Below Tamm Bend & Left \\
\hline 818.00 & Wrights Point & Right \\
\hline 819.39 & Wrights Point & Right \\
\hline 820.80 & Wrights Point & Right \\
\hline 823.46 & Chute Restricted by Island 21 Dike & Left \\
\hline 828.24 & Head of Island 21 & Left \\
\hline 831.72 & Island 20 & Right \\
\hline 835.86 & Island 18 Towhead & Left \\
\hline 839.82 & Caruthersville - Linwood Bend & Right \\
\hline 841.50 & Tennemo & Left \\
\hline
\end{tabular}




\begin{tabular}{|c|c|c|}
\hline Cross Section & Dike Field & $\begin{array}{l}\text { Descending } \\
\text { River Bank }\end{array}$ \\
\hline 841.50 & Caruthersville - Linwood Bend & Right \\
\hline 844.20 & Caruthersville - Linwood Bend & Right \\
\hline 846.40 & Opposite Caruthersville & Left \\
\hline 847.96 & Sandy Hook Dike \#2 & Right \\
\hline 851.97 & Hathaway & Left \\
\hline 851.97 & Robinson Bayou & Right \\
\hline 864.70 & Below Cherokee & Left \\
\hline 869.08 & Steward Towhead & Right \\
\hline 872.40 & Steward Towhead & Right \\
\hline 873.04 & Ruddles Point Dikes & Right \\
\hline 874.20 & Ruddles Point Dikes & Right \\
\hline 880.00 & Island 11 & Right \\
\hline 881.89 & Island 11 & Right \\
\hline 885.40 & Kentucky Point & Left \\
\hline 886.40 & Kentucky Point & Left \\
\hline 887.20 & Kentucky Point & Left \\
\hline 888.20 & Chute Restricted by Dike & Left \\
\hline 895.00 & Hotchkiss Bend & Right \\
\hline 899.27 & Below Island 9 & Left \\
\hline 903.45 & Donaldson Point & Right \\
\hline 905.60 & Donaldson Point & Right \\
\hline 914.60 & Below Island 7 and 8 & Right \\
\hline 915.59 & Below Island 7 and 8 & Right \\
\hline 925.00 & Below Williams & Left \\
\hline 927.50 & Moore Island & Right \\
\hline 944.75 & Island No. 1 & Left \\
\hline 944.75 & Pritchard Dikes & Right \\
\hline 947.40 & Island No. 1 & Left \\
\hline 949.00 & Island No. 1 & Left \\
\hline
\end{tabular}

\section{Hydrographs}

Discharge hydrographs are simulated in the numerical model by a series of steady-state events. The duration of each event is chosen such that the 
changes in bed elevation, due to deposition or scour, do not significantly change the hydraulic parameters during that event. In this study, computational time-steps of one day were used. A one-day time-step is not necessary to meet the requirement of insignificant bed change but was chosen for convenience because available data were reported as mean daily flows.

The approach used in HEC-6T approximates unsteady flow by stepping through a time-sequence of steady discharges. This method does not take into consideration flow routing or backwater storage effects, introducing the potential for timing issues in flow propagation through the model. Thus, HEC-6T may not be appropriate for predicting flood hydrographs and stages, but experience has shown that it is successful in predicting long-term sedimentation processes.

Reported daily discharges are available at several gages within the study reach. The 12-year discharge hydrographs at Hickman, Vicksburg, and Tarbert Landing, between October 1990 and September 2002, are shown in Figure 3.

Figure 3. 1991-2002 hydrograph.

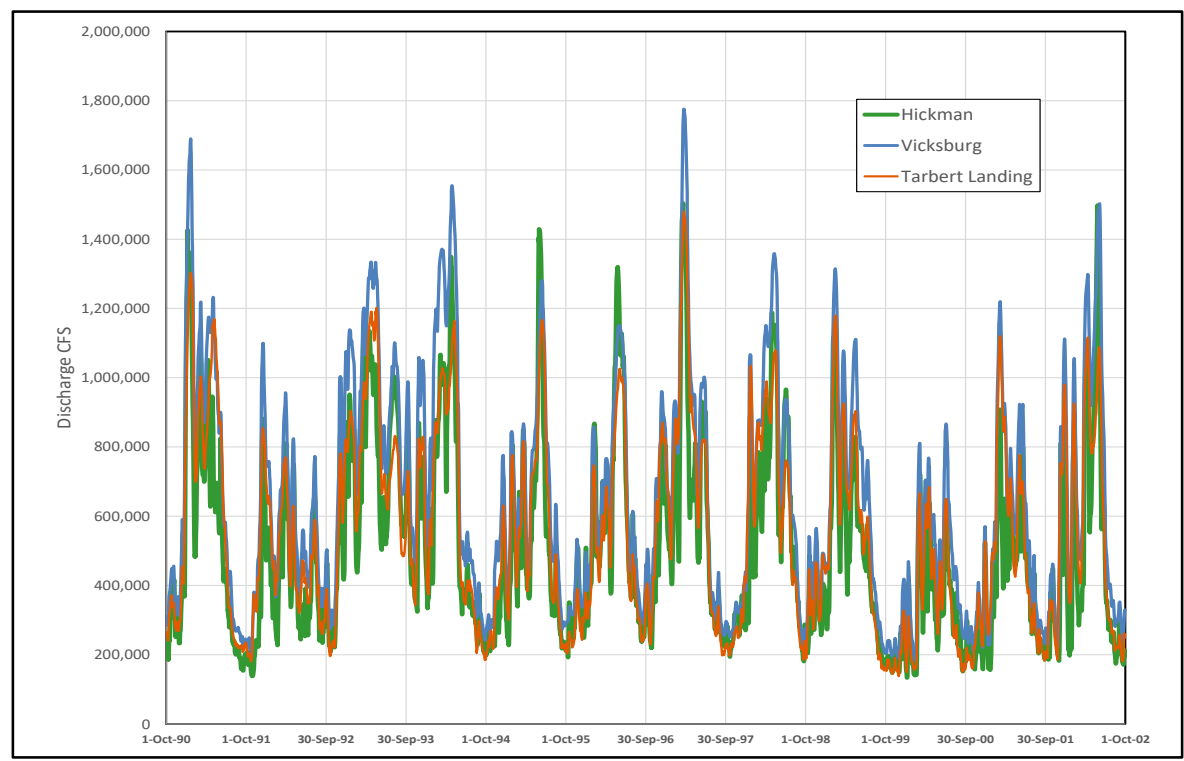

Uncertainty is associated with the choice of discharge data for the inflow hydrograph because there are discrepancies in the reported data. Continuity of the discharge record is inconsistent with both time and distance. Discrepancies in reported discharge volumes, between October 1990 and September 2002, at various points on the Mississippi River are listed in 
Table 5. The total volumes listed in Table 5 were calculated from USGS or USACE annual and mean daily discharge data. The 12-year volume of water flowing past Thebes on the Mississippi River above Cairo is approximately 2 percent greater than the combined volumes for the Mississippi River at Chester and from the Big Muddy River. Big Muddy discharges had to be estimated from upstream gages, and local inflow could account for some of the difference. The 12-year volume of water passing Memphis is consistent with the sum of the flow volumes from the Mississippi River at Thebes, the Ohio River at Metropolis, and the Obion and Hatchie Rivers. There is approximately a 4 percent loss in flow volume at Helena when compared to the sum of Memphis and St. Francis River flows. The 12-year volume of water passing Arkansas City is consistent with the sum of the flow volumes from the Mississippi River at Helena and the White and Arkansas Rivers. There is approximately a 2 percent increase in flow volume at Vicksburg when compared to the sum of Arkansas City and Yazoo River flows. This increase helps to balance out the decrease recorded at Helena. Flow past Vicksburg and Natchez is relatively consistent. The largest discrepancy is at the Old River Control Complex where the sum of reported discharges in the Old River Outflow Channel and in the Mississippi River at Tarbert Landing is approximately 8 percent higher than the reported discharge upstream at Natchez and Vicksburg.

Table 5. Reported water volume passing Mississippi River and Tributary gages, 1991-2002.

\begin{tabular}{|c|c|c|c|}
\hline & \multirow{2}{*}{$\begin{array}{l}\text { Total Volume } \\
\text { million acre-feet }\end{array}$} & \multicolumn{2}{|c|}{$\begin{array}{c}\text { Discrepancy } \\
\text { with Upstream Gage(s) }\end{array}$} \\
\hline & & million acre-feet & $\%$ \\
\hline Ohio River & 2559 & & \\
\hline Chester & 2122 & & \\
\hline Big Muddy River & 20 & & \\
\hline Thebes & 2188 & 46 & $2.15 \%$ \\
\hline Hickman (calculated) & 4747 & & \\
\hline Obion River & 22 & & \\
\hline Hatchie River & 33 & & \\
\hline Memphis & 4797 & -5 & $-0.10 \%$ \\
\hline St. Francis River & 69 & & \\
\hline Helena & 4679 & -187 & $-3.84 \%$ \\
\hline White River & 247 & & \\
\hline
\end{tabular}




\begin{tabular}{|c|c|c|c|}
\hline & \multirow{2}{*}{$\begin{array}{c}\text { Total Volume } \\
\text { million acre-feet }\end{array}$} & \multicolumn{2}{|c|}{$\begin{array}{c}\text { Discrepancy } \\
\text { with Upstream Gage(s) }\end{array}$} \\
\hline & & million acre-feet & $\%$ \\
\hline Arkansas River & 461 & & \\
\hline Arkansas City & 5387 & 0 & $0.00 \%$ \\
\hline Yazoo River & 179 & & \\
\hline Vicksburg & 5678 & 112 & $2.01 \%$ \\
\hline Natchez & 5671 & -7 & $-0.12 \%$ \\
\hline Old River Outflow & 1340 & & \\
\hline Tarbert Landing & 4770 & 439 & $7.74 \%$ \\
\hline Total & & 398 & \\
\hline
\end{tabular}

The discrepancies between reported discharges are not consistent annually. As shown in Table 6, there is an annual variation in the discrepancies between Natchez and Old River Control Complex and Vicksburg and Natchez. The differences between Vicksburg and Natchez are insignificant, but the differences between Natchez and Old River Control Complex are puzzling. These discrepancies at Old River Control Complex produce a conundrum with respect to determining a hydrograph for the HEC-6T model. Additional study, which should include evaluation of data at the Baton Rouge gage, is recommended to address these issues.

Table 6. Annual discrepancy in recorded discharges at gages.

\begin{tabular}{|c|c|c|c|c|c|}
\hline \multirow{2}{*}{$\begin{array}{c}\text { Water } \\
\text { Year }\end{array}$} & \multicolumn{2}{|c|}{ Mean Annual Flow, -cfs } & Discrepancy & $\begin{array}{c}\text { Mean Annual } \\
\text { Flow, cfs }\end{array}$ & Discrepancy \\
\cline { 2 - 6 } & Tarbert+C89* & Natchez & $\begin{array}{c}\text { Natchez/ } \\
\text { Tarbert+C89* }\end{array}$ & Vicksburg & $\begin{array}{c}\text { Vicksburg/ } \\
\text { Natchez }\end{array}$ \\
\hline 1991 & 775,973 & 710,782 & $8.4 \%$ & 720,087 & $-1.3 \%$ \\
\hline 1992 & 567,992 & 544,152 & $4.2 \%$ & 548,801 & $-0.9 \%$ \\
\hline 1993 & 950,403 & 872,373 & $8.2 \%$ & 886,602 & $-1.6 \%$ \\
\hline 1994 & 817,121 & 807,858 & $1.1 \%$ & 809,301 & $-0.2 \%$ \\
\hline 1995 & 672,033 & 629,302 & $6.4 \%$ & 612,695 & $2.6 \%$ \\
\hline 1996 & 673,667 & 585,902 & $13.0 \%$ & 587,385 & $-0.3 \%$ \\
\hline 1997 & 849,170 & 749,047 & $11.8 \%$ & 751,032 & $-0.3 \%$ \\
\hline 1998 & 752,027 & 679,636 & $9.6 \%$ & 679,671 & $0.0 \%$ \\
\hline 1999 & 700,016 & 638,434 & $8.8 \%$ & 638,328 & $0.0 \%$ \\
\hline
\end{tabular}




\begin{tabular}{|c|c|c|c|c|c|}
\hline \multirow{2}{*}{$\begin{array}{l}\text { Water } \\
\text { Year }\end{array}$} & \multicolumn{2}{|c|}{ Mean Annual Flow, -cfs } & \multirow{2}{*}{$\begin{array}{c}\text { Discrepancy } \\
\text { Natchez/ } \\
\text { Tarbert+C89* }\end{array}$} & \multirow{2}{*}{$\begin{array}{l}\text { Mean Annual } \\
\text { Flow, cfs } \\
\text { Vicksburg }\end{array}$} & \multirow{2}{*}{$\begin{array}{c}\text { Discrepancy } \\
\text { Vicksburg/ } \\
\text { Natchez }\end{array}$} \\
\hline & Tarbert+C89* & Natchez & & & \\
\hline 2000 & 426,175 & 427,524 & $-0.3 \%$ & 416,737 & $2.5 \%$ \\
\hline 2001 & 555,901 & 523,638 & $5.8 \%$ & 519,355 & $0.8 \%$ \\
\hline 2002 & 695,422 & 651,952 & $6.3 \%$ & 665,697 & $-2.1 \%$ \\
\hline 2003 & 649,492 & 605,962 & $6.7 \%$ & 616,508 & $-1.7 \%$ \\
\hline 2004 & 685,139 & 635,481 & $7.2 \%$ & 645,596 & $-1.6 \%$ \\
\hline 2005 & 701,797 & 676,948 & $3.5 \%$ & 682,081 & $-0.8 \%$ \\
\hline 2006 & 406,762 & 403,920 & $0.7 \%$ & 396,292 & $1.9 \%$ \\
\hline 2007 & 616,545 & 638,307 & $-3.5 \%$ & 630,790 & $1.2 \%$ \\
\hline 2008 & 846,169 & 804,268 & $5.0 \%$ & 799,308 & $0.6 \%$ \\
\hline 2009 & 695,614 & 696,099 & $-0.1 \%$ & 672,233 & $3.4 \%$ \\
\hline 2010 & 875,167 & 885,645 & $-1.2 \%$ & 878,661 & $0.8 \%$ \\
\hline 2011 & 799,482 & 795,681 & $0.5 \%$ & 801,581 & $-0.7 \%$ \\
\hline
\end{tabular}

*Old River Outflow Channel near Knox Landing

The hydrograph used in the 2009 interim study of the Mississippi River between Vicksburg and Pilots Station was based on the reported discharges at Vicksburg. The 12-year hydrograph extended between 1 October 1990 and 30 September 2002 (Water Years 1991-2002). Initially, this hydrograph was adjusted for use in the entire Regional Model study reach by setting tributary discharges upstream from Vicksburg as a constant percentage of the mean daily discharges at Vicksburg. The percentage was based on the percentage of the 12-year total volume of flow from the tributary with respect to the 12-year volume of flow at Vicksburg. One advantage of this approach is the relative simplicity associated with hydrograph development. One significant disadvantage is that the effects of high flows on the tributaries at low Mississippi River stages are not simulated. The effect of using this simplified hydrograph on sedimentation processes is evaluated in this report.

A second hydrograph used in the Regional Model was based on recorded mean daily inflows at the boundary gages, which are primarily in the Memphis District. Because tributary backwater effects extended as much as 100 miles from the Mississippi River, tributary flow could not easily be determined from existing tributary stream gages. Long reaches of some tributary streams were not included in the current modeling effort because 
survey data for tributary streams were limited or non-existent. The initial approach adopted for developing model boundary conditions was to limit the number of tributary inflow points to tributaries that are expected sources of geomorphic change. Here, sources of geomorphic change meant locations where observed geomorphic features in the main channel resulted from tributary sediment inflows. These features persisted for 10 or more miles in the Mississippi River. The numerical model included inflows for the Ohio, Obion, Hatchie, St. Francis, White, Arkansas, and Yazoo Rivers. The model network utilized a representative reach of the tributary channel as a boundary condition. Initial flow was estimated from historical stream discharge measurement stations located outside zones of backwater influence. The resulting inflow hydrograph provided the initial flows for model simulation.

After model assembly, annual water volumes and daily discharges were compared between model and prototype at measured discharge stations along the main-stem Mississippi River in the Memphis District. There was good agreement at the confluence of the Ohio and Middle Mississippi Rivers. However, downstream control points did not maintain the close agreement. Figure 4 highlights the discrepancies between measured and calculated daily discharge at Helena. Figure 5 shows the discrepancy between measured and calculated total cumulative volumes at Helena. These differences may be attributed to measurement error, unsteady flow effects and/or to assumptions related to the timing and magnitude of tributary inflows. Another possibility for the differences is that some reaches of the Mississippi River could lose flow between upstream and downstream measurement points. For example, the gage at Memphis, TN, shows more discharge than observed at the next downstream gage at Helena, AR, during some historical periods in the data record (Table 5). The reason for the decrease in discharge between these two stations is unknown. Several hypotheses exist including flow lost to the alluvial and deeper aquifers and extensive attenuation due to large backwater areas along the lower St. Francis basin. Nonetheless, the current model effort required an accurate representation of water in terms of flow rate and volume to calculate sediment transport over the simulation period. To achieve discharges and volumes that matched measured data along the Mississippi main-stem in the Memphis District, tributary flow magnitudes were adjusted to account for variances that resulted from using the quasisteady flow steps that were estimated using tributary stream gauges. The modified hydrologic data are shown in Figure 6. 
Figure 4. Prototype and initial model discharge at Helena.

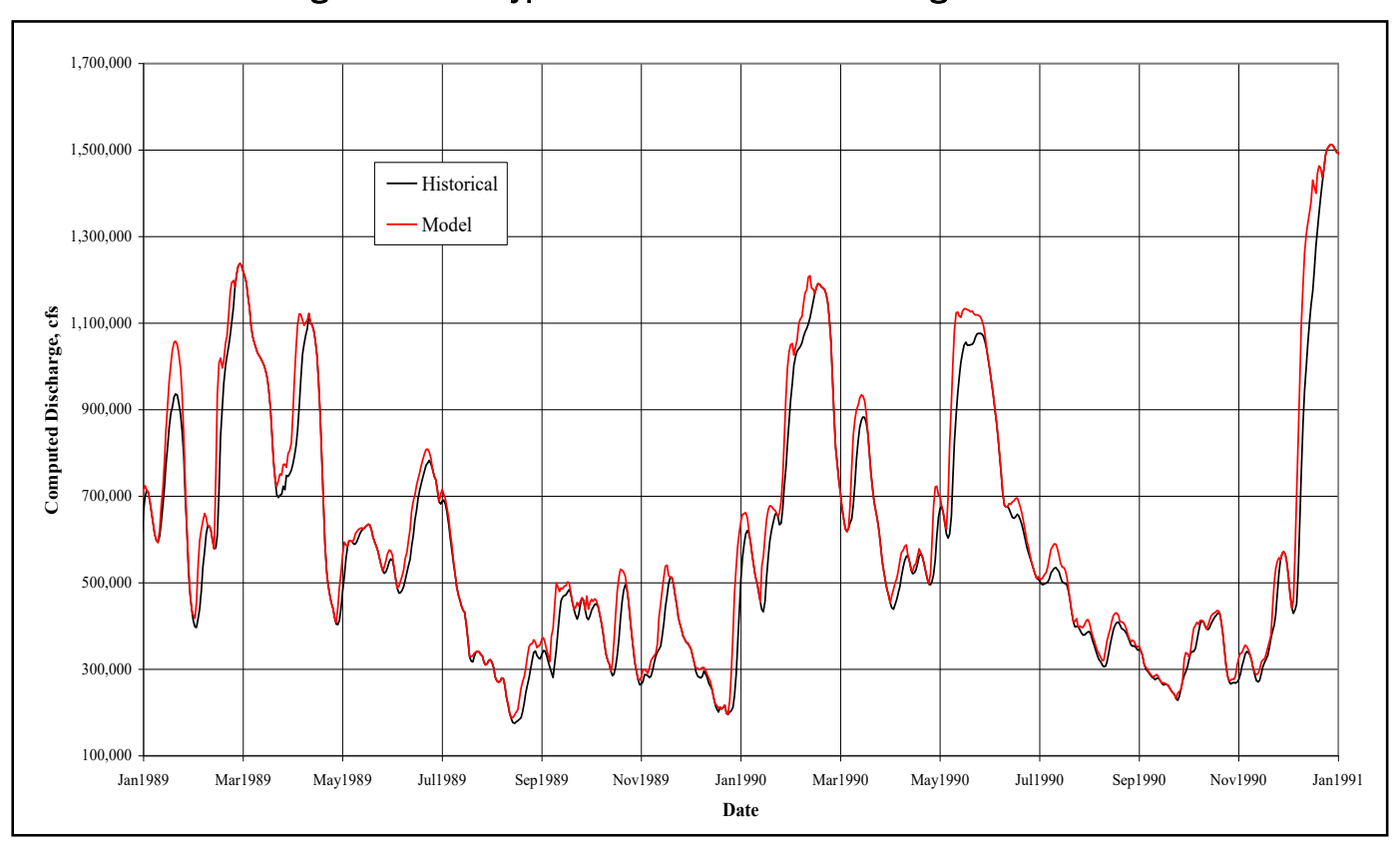

Figure 5. Prototype and initial model cumulative flow volume at Helena.

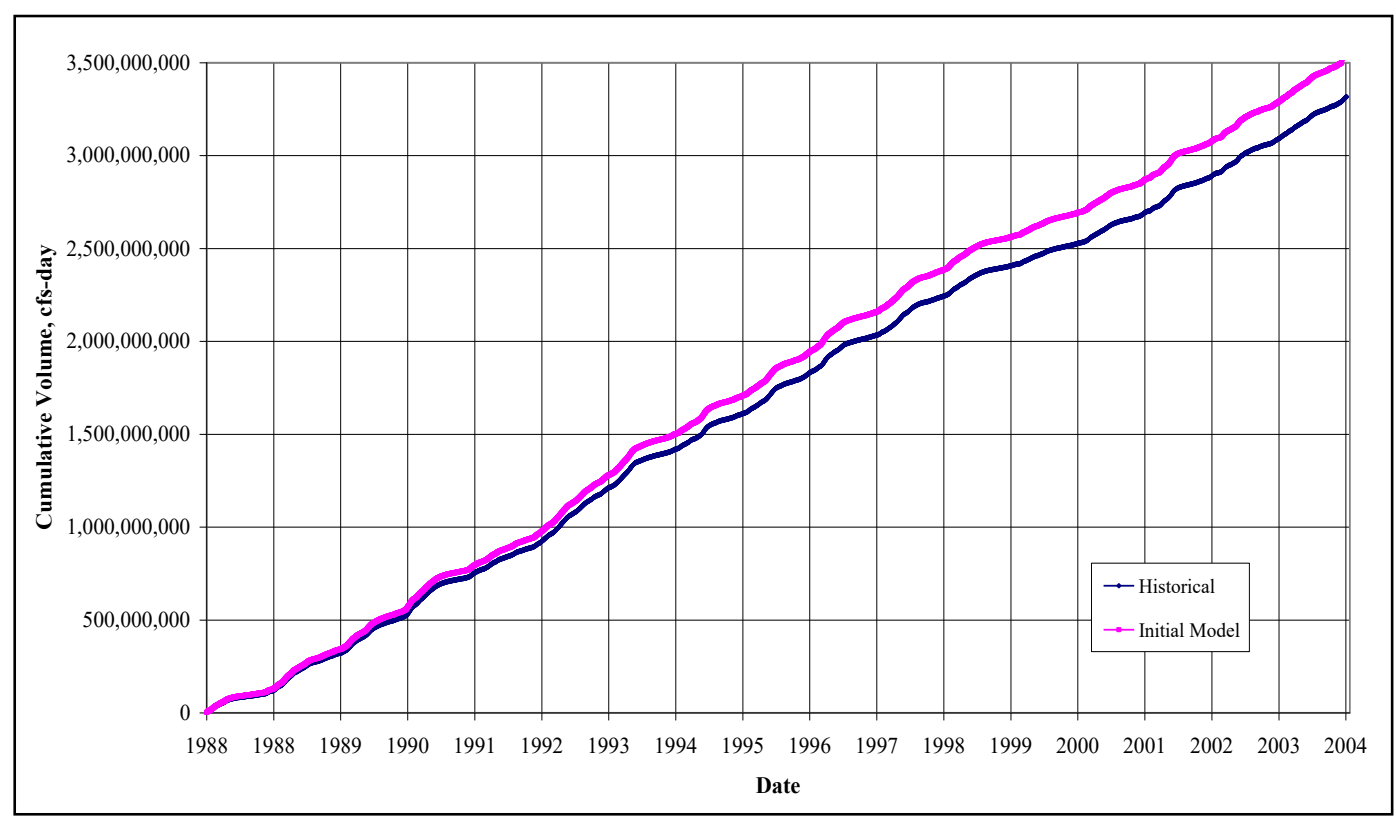


Figure 6. Flow decrease in downstream direction Memphis to Helena Reach.

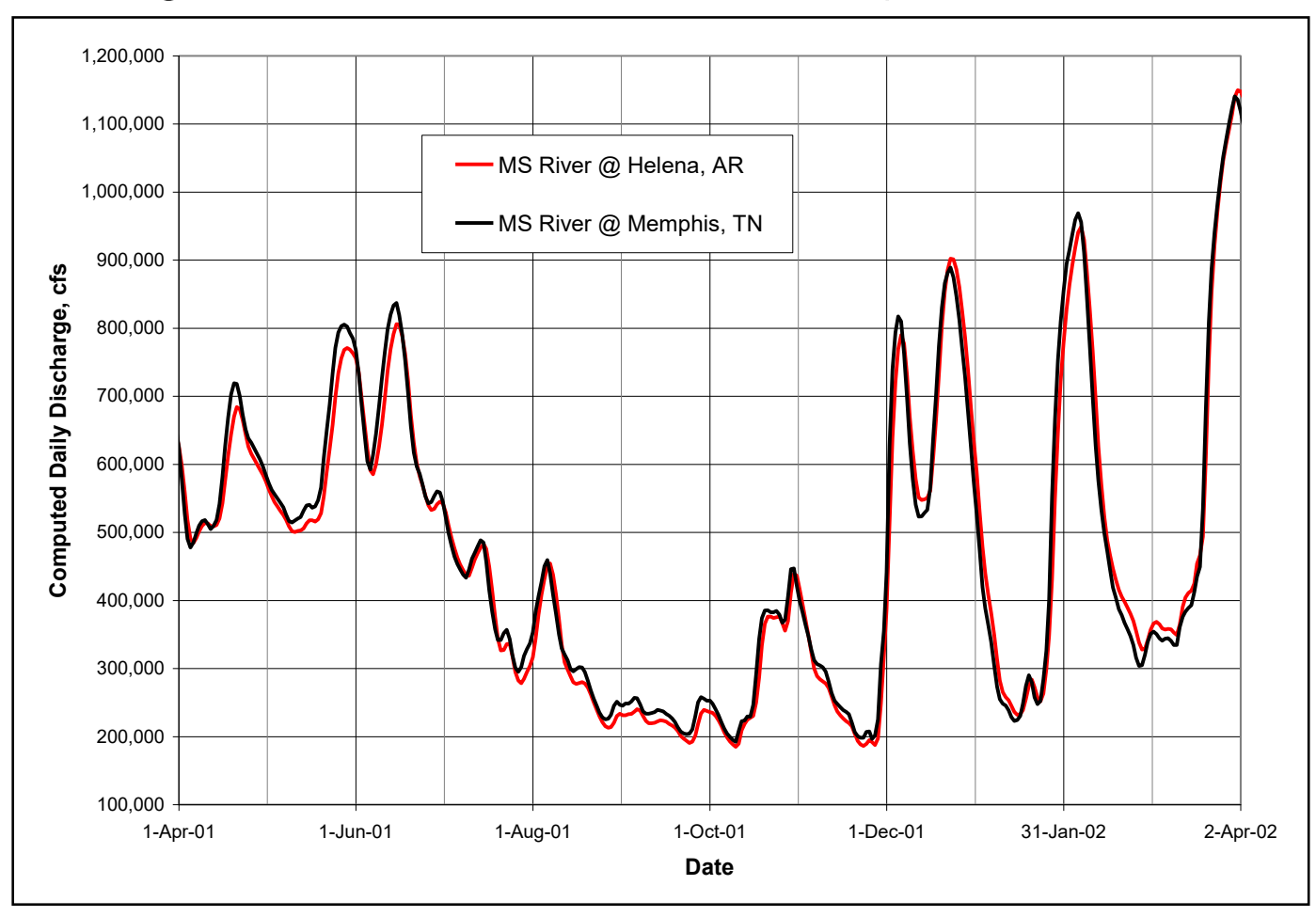

Adjusting the tributary discharges in an attempt to better simulate recorded Mississippi River discharges in the Memphis District did not necessarily provide accurate results at downstream gages. In future studies, this approach should be modified to focus on the particular reach of the river where project features are to be evaluated. The significant discrepancy in reported discharges downstream from the Old River Structure suggests that a different hydrograph based on Tarbert Landing discharges should be used in the New Orleans District.

Differences in calculated results using the two model hydrographs is not confined to just the differences in flow magnitudes. For example, the calculated sediment delivery from the Ohio River, during the 1991-2002 simulation period, is significantly affected by the choice of hydrograph. Table 7 shows the different results calculated for 12-years of sediment delivery to the Mississippi River from the Ohio River. The calculations used the same sediment discharge rating curves with the two model hydrographs. Even though the accumulated water inflows are essentially the same, the sediment delivery is significantly greater with the hydrograph developed from the recorded Ohio River discharges at Metropolis and Mississippi River discharges at Chester than with the hydrograph based on the average annual percentages of the Vicksburg 
discharge. It is concluded that studies in the Memphis District should use a hydrograph that accounts for the differences in tributary flood peaking.

Calculated results using both hydrographs are presented in this report. These results will be useful in selection of hydrographs for future studies.

Table 7. Calculated sediment delivery from the Ohio River.

\begin{tabular}{|c|c|c|c|}
\hline & $\begin{array}{c}\text { Tributary Flow Based on } \\
\text { Annual Percentage of } \\
\text { Vicksburg Discharges }\end{array}$ & $\begin{array}{c}\text { Tributary Flow Based on } \\
\text { Adjusted Measured } \\
\text { Discharges }\end{array}$ & $\begin{array}{c}\text { Percent of the Delivery } \\
\text { Lost using Annual } \\
\text { Percentage of Vicksburg } \\
\text { Discharges }\end{array}$ \\
\hline Clay & acre-feet & acre-feet & \\
\hline Silt & 214,000 & 277,000 & 23 \\
\hline Sand & 17,000 & 118,000 & 28 \\
\hline Water & $2,543,000,000$ & 30,000 & 43 \\
\hline
\end{tabular}

\section{Distributary flows and flows around islands}

Flows out the distributaries in the New Orleans District were calculated as a percentage of Mississippi River flow at a station upstream from the tributary. The location of this station was a function of the location of available data. Simple percentages were used rather than actual measured discharges to make model application easier for a wide range of projects located up and down the 1000-mile study reach. Future studies related to a specific diversion on the Mississippi River may require a more detailed treatment of the flow through the diversion or diversions of interest.

The reference cross section used to determine the distributary discharge in HEC-6T is specified on the PM record (PM is a label used within the software input properties) by sequence number in the HEC-6T version used for this study. Future users are cautioned that values on the PM record need to be changed if cross sections are added or deleted from this model. Newer versions of HEC-6T eliminate this issue for distributaries (but not return flows) by use of the PS record (PS is a label used within the software input properties) that directly identifies the reference cross section.

\section{Southwest Pass}

Four distributaries are included in the HEC-6T numerical model in Southwest Pass: Burrwood Bayou (RM -14.4), Outlet W - 2 (RM -9.8), 
Joseph Bayou (RM -4.5), and Southwest Pass at Mile 3.0 West (RM -3.0). In addition, flow is lost over the natural levees in Southwest Pass during flood events.

The water discharges diverted at each distributary were computed using a percentage of the water discharge in the Mississippi River approaching that distributary. The percentages were estimated from available measured data in Burrwood Bayou. Measurements were made between March 2003 and April 2005, so no analysis of variation with respect to time could be made. Measured data were not available for the other distributaries.

\section{Burrwood Bayou}

Nineteen pairs of flow measurements were made. One measurement was in the Burrwood Bayou diversion, and the other was in Southwest Pass just upstream of the diversion. The diverted discharge was expressed as a percentage of the approaching flow. These measurements were made between March 2003 and April 2005 in conjunction with repair of a stone closure dike constructed as a result of a blowout through the distributary. Only nine of the measurements were taken with the closure structure in place. These nine measurements showed no apparent trend between the percentage of flow diverted and upstream discharge. Therefore, the percentages were simply averaged giving a value of 12 percent. No other measurements are available, so 12 percent was used in the HEC-6T model.

\section{Outlet W-2 and overbank flows}

There were no available flow measurements in Outlet W-2. It was therefore assumed that the diverted flow percentages at Burrwood Bayou and Outlet W-2 could be directly related to the widths of the outlets. Using this assumption, 7 percent of the upstream flow in Southwest Pass is diverted through Outlet W-2.

No data were available for other time periods, so the 7 percent diversion percentage was used in the HEC-6T model.

During floods, water flows over the natural levees in Southwest Pass into East Bay and West Bay. There were no measurements available to estimate the magnitude of this overbank flow. However, a TABS-2 two-dimensional (2D) numerical model study was conducted at the USACE Waterways 
Experiment Station (Richards and Trawle 1988) in which overbank flow from Southwest Pass was calculated. Using results from that study, overbank flow percentages were estimated for flood conditions and assigned to Outlet W-2. This is the same approach employed in two previous numerical sedimentation studies in Southwest Pass (Copeland 1991; Copeland and Thomas 1992). In these studies, overflow discharges were determined to be 2 percent of the discharge Above Venice when the Above Venice discharge was 900,000 cubic feet per second (cfs) and 5 percent of the discharge Above Venice when the Above Venice discharge was 1,300,000 cfs. Converting these percentages to percentage of flow above Outlet W-2 and considering the changes in distributary flow distribution that occurred since 1992, the combined Outlet W-2 and Southwest Pass overbank flows were 7 percent of the upstream flow when the upstream flow was 300,000 cfs or less, 10 percent of the upstream flow when the upstream flow was $400,000 \mathrm{cfs}$, and 19 percent of the upstream flow when the upstream flow was 500,000 cfs or greater.

Joseph Bayou

There were no available flow measurements in Joseph Bayou. It was therefore assumed that the diverted flow percentages at Burrwood Bayou and Joseph Bayou could be directly related to the widths of the outlets. Using this assumption, 12 percent of the upstream flow in Southwest Pass is diverted through Joseph Bayou. No data are available for other time periods, so the 12 percent diversion percentage was used in the HEC-6T model.

\section{Southwest Pass at Mile 3.0 West}

There were no available flow measurements in this distributary. It was therefore assumed that the outflow that was measured at Burrwood Bayou could be directly related to the distributary at RM -3.o by using the width ratio of the two outlets. Using this assumption, 4 percent of the flow entering Southwest Pass is diverted through the distributary at RM -3.o. No data are available for other time periods, so the 4 percent diversion percentage was used for all time periods in the HEC-6T model.

The percentage of upstream flow diverted out of the four Southwest Pass distributaries in the HEC-6T model is listed in Table 8. 
Table 8. Outflow from Southwest Pass distributaries, percentage of discharge immediately upstream from Diversion.

\begin{tabular}{|l|c|c|c|c|c|}
\hline \multirow{2}{*}{ Distributary } & \multirow{2}{*}{ River Mile } & \multicolumn{3}{|c|}{ Discharge Upstream from Distributary, cfs } \\
\cline { 4 - 6 } & & 10,000 & 300,000 & 400,000 & 500,000 \\
\hline Burrwood Bayou & -14.4 & $12 \%$ & $12 \%$ & $12 \%$ & $12 \%$ \\
\hline Outlet W-2 and Overbank Flows & -9.8 & $7 \%$ & $7 \%$ & $10 \%$ & $19 \%$ \\
\hline Joseph Bayou & -4.5 & $12 \%$ & $12 \%$ & $12 \%$ & $12 \%$ \\
\hline Southwest Pass at Mile 3.0 West & -3.0 & $4 \%$ & $4 \%$ & $4 \%$ & $4 \%$ \\
\hline
\end{tabular}

Above Venice to Head of Passes

Four distributaries are included between the Above Venice discharge range at RM 12 and Head of Passes: combined South Pass and Pass a Loutre (RM 0.0), Cubits Gap (RM 3.0), Grand Pass (RM 10.5), and Baptiste Collette (RM 11.5). In addition, flow is lost over the natural levees in this reach. West Bay Diversion (RM 4.9) was not opened until 2004 and is not included in the 1992-2002 calibration simulations.

Flows that are diverted through the various distributaries in this reach were treated as a percentage of the Mississippi River discharge at the Above Venice discharge range. The diversion percentages at Cubits Gap and Head of Passes were calculated from measurements made between 1979 and 2004. Measurements made between 1979 and 2006 were used for Grand Pass and Baptiste Collette.

Between 1979 and 2004, there were 28 sets of measurements at two ranges in the Mississippi River: the Above Venice Discharge Range and the Pilottown Discharge Range at RM 2.0. Discharges in Baptiste Collette, Grand Pass, Cubits Gap, Pass a Loutre, South Pass, and Southwest Pass were also included in these measurements. Measurements at RM 2.0 were used to check flow continuity with respect to inflow at the Above Venice discharge range and outflow at Baptiste Collette, Grand Pass and Cubits Gap. If an error greater than 10 percent was found, then data from that set were not included in the analysis. This left 23 measurements that satisfied the continuity requirement.

Data collected between 2005 and 2006 at Grand Pass and Baptiste Collette were included in the analysis to increase the size of the data base 
and because these distributaries are upstream from West Bay Diversion, and the new diversion's effect on discharge percentages were deemed to be negligible. Inclusion of the 2005-2006 measurements added 16 data points to the Grand Pass and Baptiste Collette analysis.

The data were analyzed to determine trends with both time and discharge using linear regression curves in EXCEL to help define trends. The results are shown in Table 9 as a percentage of discharge at the Above Venice discharge range, and the analysis is discussed in the following paragraphs.

At the time the calibration study was conducted, diversion percentages could not be changed over time in the simulation hydrograph. Studies of different time periods might require modification of the average percentage values. If new diversions are added to this reach (e.g., West Bay Diversion), flow percentages will need to be modified so that the percentages reflect conditions immediately upstream from the distributary rather than in the Mississippi River at the Above Venice discharge range.

Table 9. Distributary outflow between Above Venice and Head of Passes.

\begin{tabular}{|l|c|c|c|c|c|c|}
\hline \multirow{2}{*}{} & \multirow{2}{*}{$\begin{array}{l}\text { River } \\
\text { Distributary }\end{array}$} & \multicolumn{5}{|c|}{ Discharge at Above Venice Discharge Range, cfs } \\
\cline { 3 - 7 } & Mile & 50,000 & 200,000 & 600,000 & $1,000,000$ & $1,300,000$ \\
\hline South Pass and Pass a Loutre & 0.0 & $30 \%$ & $30 \%$ & $26 \%$ & $23 \%$ & $23 \%$ \\
\hline $\begin{array}{l}\text { Cubits Gap and Overbank } \\
\text { Flows }\end{array}$ & 3.0 & $14 \%$ & $14 \%$ & $14 \%$ & $17.5 \%$ & $22 \%$ \\
\hline Grand Pass & 10.4 & $13 \%$ & $13 \%$ & $11 \%$ & $9 \%$ & $9 \%$ \\
\hline Baptiste Collette & 11.4 & $11 \%$ & $11 \%$ & $11 \%$ & $11 \%$ & $11 \%$ \\
\hline
\end{tabular}

South Pass and Pass a Loutre

Outflow through South Pass and Pass a Loutre was combined and treated as a single distributary in the HEC-6T numerical model. Figure 7 shows the variations in the flow percentage out combined South Pass and Pass a Loutre with time and discharge. Figure 7 suggests a significant decrease in distributary flow percentage with time. However, there were only four measurements between 1979 and 1990. There were only six measurements taken during the 1991-2002 calibration period. Thirteen measurements taken between 2003 and 2004 indicate a continuing decrease in the combined flow percentage out South Pass and Pass a Loutre. This continuing decrease may be due to the disposal of dredged material in 
Pass a Loutre, or a change in dredging practices in South Pass and Southwest Pass. The linear regression lines shown in Figure 7 also show a decrease in combined flow percentage out the distributaries with an increase in discharge at the Above Venice discharge range, although measured high flows do not appear to follow this trend.

The flow distribution percentages for the combined flows through South Pass and Pass a Loutre were varied with discharge in the HEC-6T model. The percentages are from the linear regression line labeled 1996-2002 in Figure 7.

Studies of different time periods may require modification of the flow distribution percentages. If new diversions are added to this reach (e.g., West Bay Diversion), flow percentages will need to be modified so that the percentages reflect conditions immediately upstream from the distributaries rather than in the Mississippi River Above Venice.

Figure 7. Measured Above Venice discharge in Pass a Loutre and South Pass.

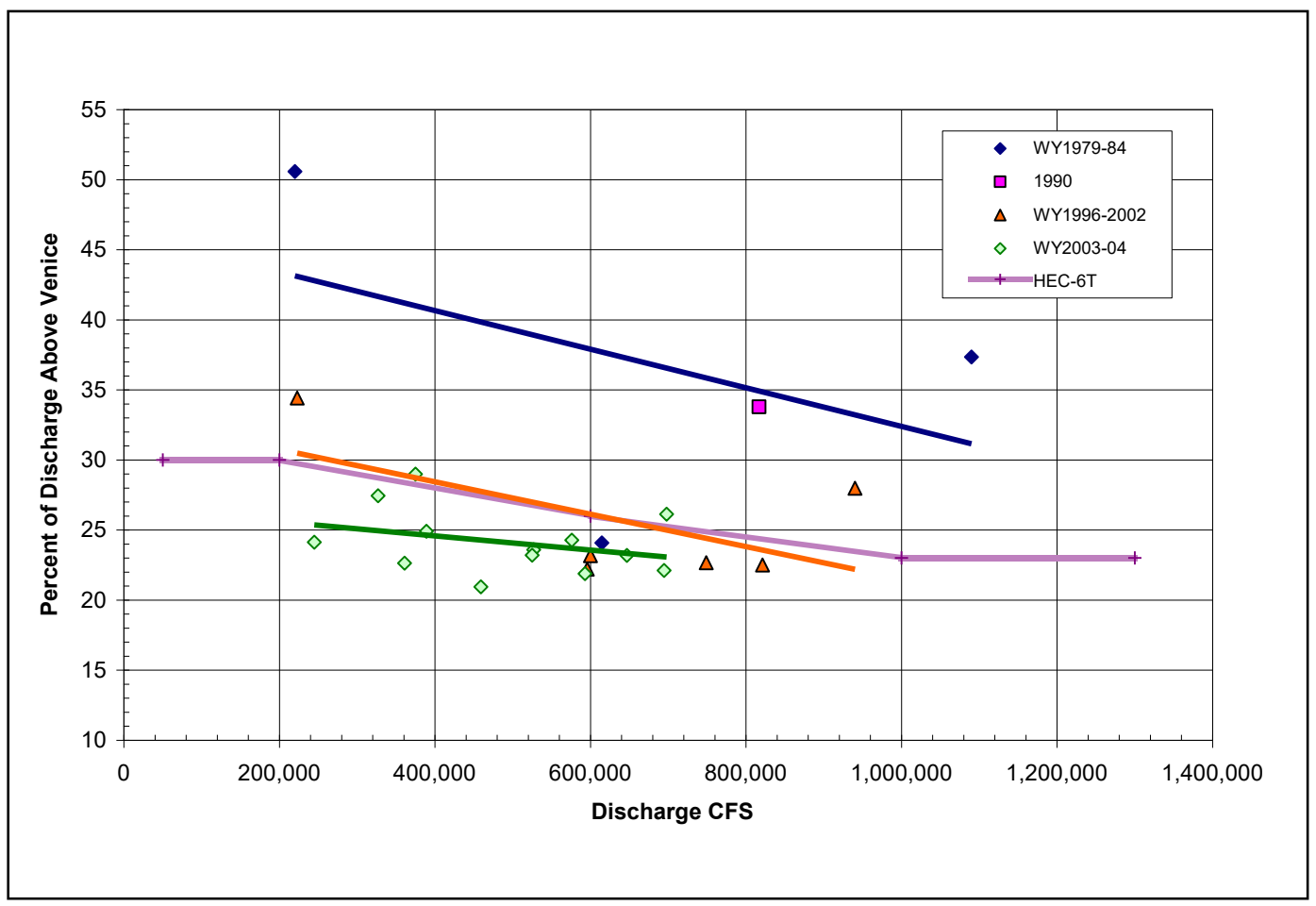

Cubits Gap and overbank flows

The measured data at Cubits Gap show a relatively constant relationship between the distributary discharge and time and Above Venice discharge. A constant distributary percentage of 14 percent of the Above Venice 
discharge was assigned for Cubits Gap. Figure 8 shows the variations in flow percentage out Cubits Gap with time and Above Venice discharge. If new diversions are added to this reach (e.g., West Bay Diversion), flow percentages will need to be modified so that the percentages reflect conditions immediately upstream from the distributary rather than in the Mississippi River Above Venice.

During floods, water flows over the natural levees between Venice and Head of Passes. There were no measurements available to estimate the magnitude of this overbank flow. However, a TABS-2 2D numerical model study was conducted at the USACE Waterways Experiment Station (Richards and Trawle 1988) in which overbank flow was calculated. Using results from that study, overbank flow percentages were estimated for flood conditions and assigned to Cubits Gap. This is the same approach employed in two previous numerical sedimentation studies in this reach of the Mississippi River (Copeland 1991; Copeland and Thomas 1992). In these studies, overflow discharges were determined to be 5 percent of the discharge Above Venice when the Above Venice discharge was 900,000 cfs and 12 percent of the discharge Above Venice when the Above Venice discharge was 1,300,000 cfs. Adjusting these percentages to account for the changes in distributary flow distribution upstream that has occurred since 1992, the combined Cubits Gap distributary and overbank flows were 16 percent of the discharge at Above Venice when the Above Venice flow was 900,000 cfs and 22 percent of the discharge at Above Venice when the Above Venice flow was 1,300,000 cfs. 
Figure 8. Measured Above Venice discharge in Cubits Gap.

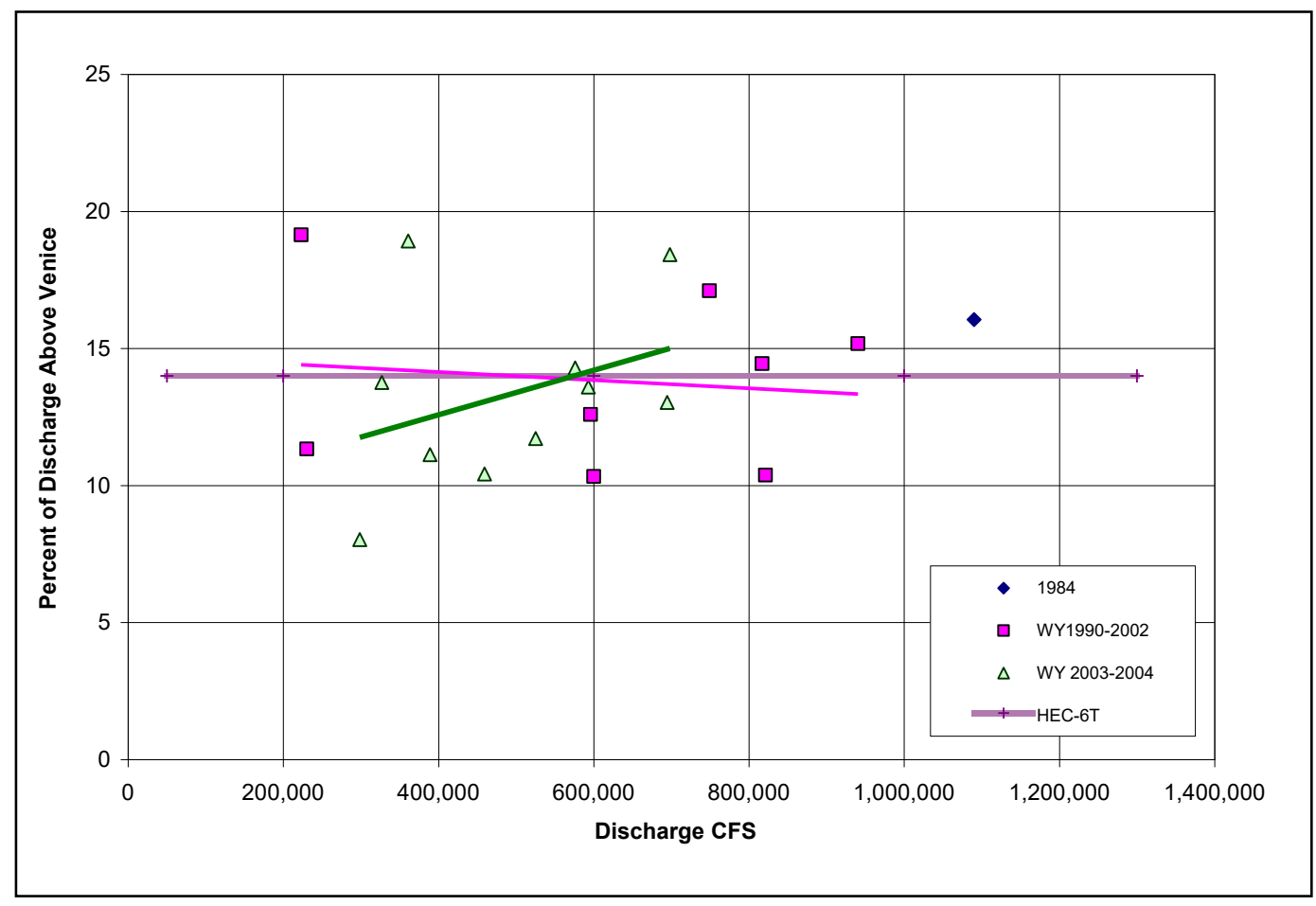

Grand Pass (The Jump)

Measurements taken between 2005 and 2006 were included in the analysis of flow distribution out Grand Pass because this distributary is upstream from West Bay, and West Bay's effect on diversion percentages was deemed to be negligible. However, subsequent AdH modeling (Sharp et al. 2013) indicated that the West Bay diversion has reduced flows into Grand Pass due to a reduction in head. The reduction was described but not quantified and may be small. Additional measurements should be taken to better estimate future diversion percentages at Grand Pass.

The measured data at Grand Pass show an increasing trend in the distributary discharge with time, expressed as a percentage of Above Venice discharge, between 1979 and 2006. The measured data also show a decreasing trend in the distributary discharge, expressed as a percentage of the Above Venice discharge, with increasing discharge Above Venice. Figure 9 shows the variations in flow percentage out Grand Pass with time and Above Venice discharge.

The average flow distribution percentages for Grand Pass were varied with discharge in the HEC-6T model. The percentages correspond to an average of all the data shown in Figure 8. 
Figure 9. Measured Above Venice discharge in Grand Pass.

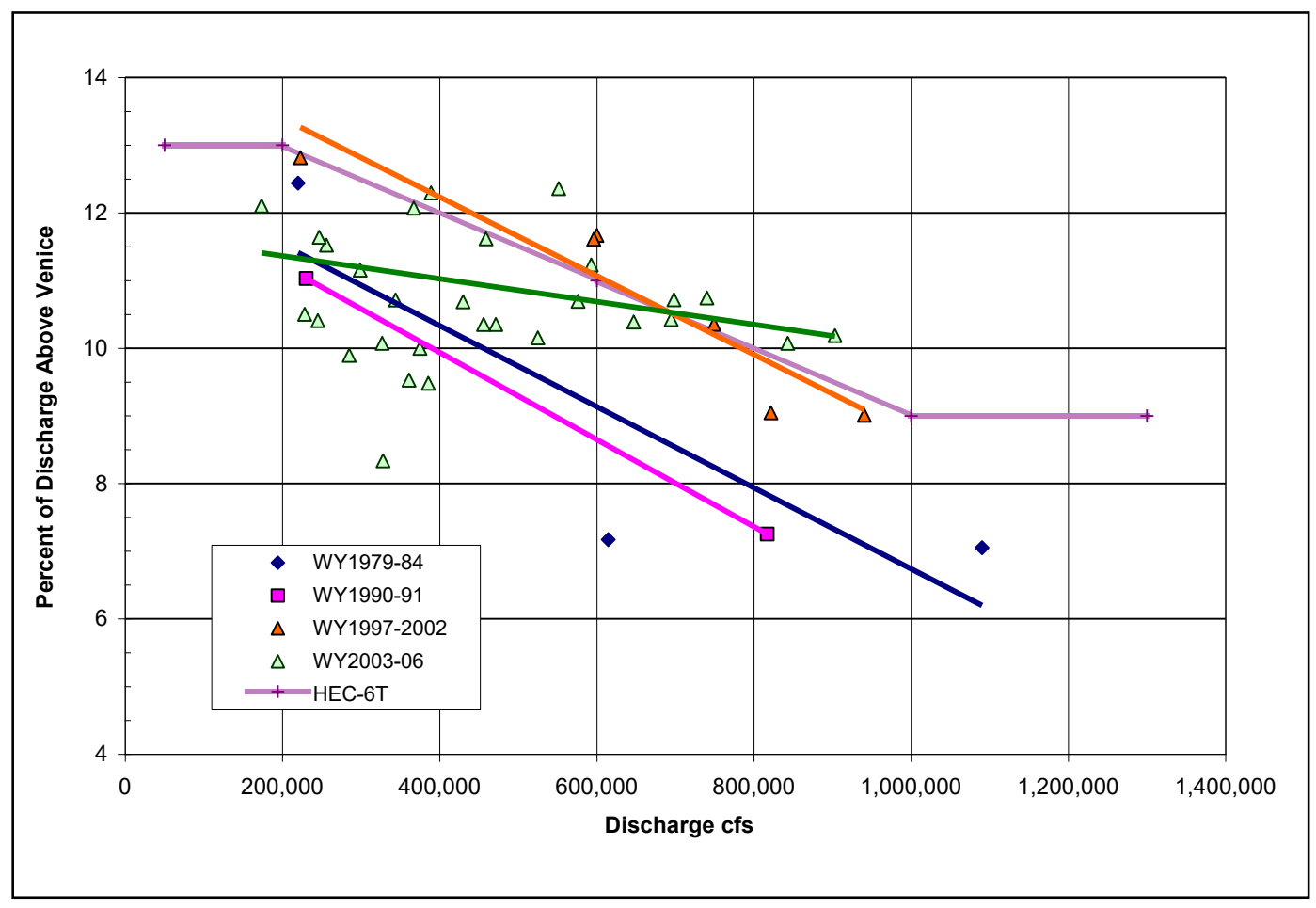

\section{Baptiste Collette}

Measurements taken between 2005 and 2006 were included in the analysis of flow distribution out Baptiste Collette because this distributary is upstream from West Bay, and West Bay's effect on diversion percentages was deemed to be negligible. This added significantly more data points to the analysis. The measured data at Baptiste Collette show an increase in the distributary discharge after 1997. However, the measured data also show a relatively constant relationship between the distributary discharge and the discharge at the Above Venice discharge range after 1997. The measured variations in flow percentage out Baptiste Collette with time and Above Venice discharge are shown in Figure 10.

A constant distributary percentage of 11 percent of the Above Venice discharge was assigned for Baptiste Collette in the HEC-6T model for the calibration study. Studies of different time periods will require modification of the flow distribution percentages in Baptiste Collette. 
Figure 10. Measured Above Venice discharge in Baptiste Collette.

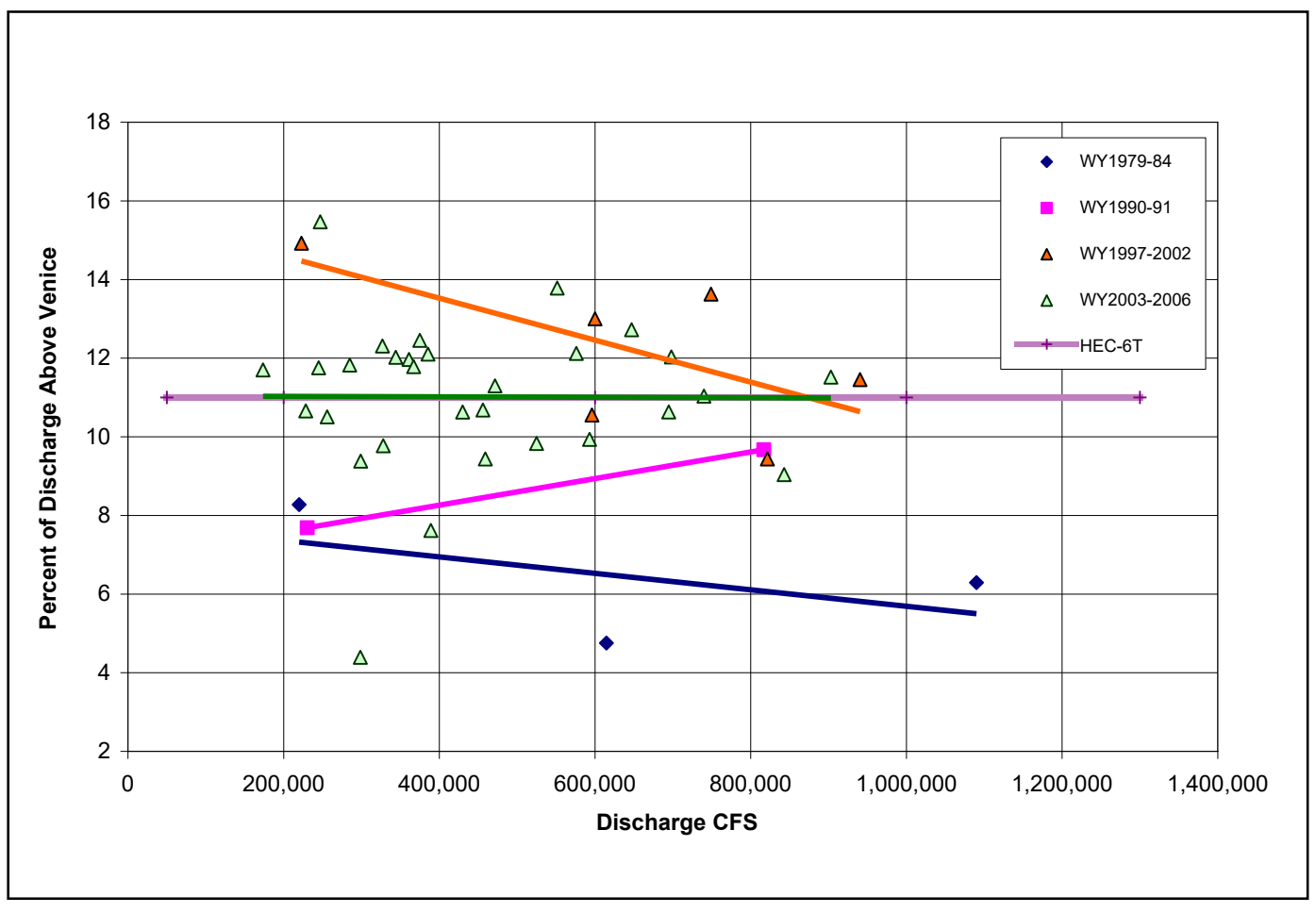

Tarbert Landing to Above Venice discharge range

Four distributaries are included between the Above Venice discharge range and Tarbert Landing: Bohemia Spillway (RMs 33 - 45), Caernarvon (RM 81.4), Bonnet Carré Diversion Structure (RMs 127-129) and the Morganza Spillway (RM 280). Davis Pond Diversion (RM 118.4) was not opened until March 2002 and is not included in the 1992-2002 calibration simulations.

Flow diversion discharges for the Bohemia Spillway and the Caernarvon diversion structure were determined as a percentage of the Mississippi River discharge immediately upstream from the diversions. Flow diversion discharges for the Bonnet Carré and Morganza Spillways were determined as a percentage of the flow at Tarbert Landing.

\section{Bohemia Spillway}

The Bohemia Spillway extends for 12 miles along the left descending bank of the Mississippi River between RMs 33 and 45. It is a constructed feature of the Mississippi River and Tributaries Project, but it has not been maintained. Flow presently occurs over the spillway during flood flows. It was determined from the analysis that flow over the spillway commenced 
when the Mississippi River flow exceeded 927,000 cfs. The maximum river flow approaching the Bohemia Spillway is 1,250,000 cfs. It is controlled by operations at the Old River Control Complex, Morganza Spillway, and Bonnet Carré Spillway. Therefore, the computation of outflows at the Bohemia Spillway was made for river flows between 937,000 cfs and 1,250,000 cfs.

Diversion percentages were calculated using the broad-crested weir equation. The weir heights in these calculations were determined by superimposing the left outer bank elevations over water surface profiles determined from stage gage records. The bank elevations were taken from the 1992 Hydrographic Survey. Water surface profiles were determined from recorded stages at West Pointe A La Hache, Port Sulphur, and Empire. The profiles were taken on dates that correspond to discharges of $800,000 \mathrm{cfs}, 1,000,000 \mathrm{cfs}$, and 1,250,000 cfs at Tarbert Landing. Discharges were calculated incrementally along the spillway using the equation $\mathrm{Q}=\mathrm{CLH} 3 / 2$, with $\mathrm{C}=3.0$. The calculated discharge for the project flood, 1,250,000 cfs, was approximately 50,000 cfs or 4 percent of the river discharge approaching RM 45.

There are four cross-sections in the model for the spillway. These cross sections extend from RM 33 to RM 45. The 50,000 cfs was divided into four 1.0 percent diversions - one increment for each of the four cross sections.

\section{Caernarvon}

The Caernarvon Diversion Structure is located at RM 81.4. Flow through the Caernarvon Diversion Structure is controlled and is not a unique function of Mississippi River discharge. For the calibration study, it was assumed that the gates would remain opened during the simulation. Flow through the diversion was calculated as a function of the Mississippi River stage, head loss through the structure with the gates open, and tailwater downstream from the structure. A maximum flow of 6,000 cfs was allowed.

Controlled conditions are not compatible with the HEC-6T option of assigning a percentage to determine the diversion discharge. However, for the systematic study purpose, the unique relationship is adequate. For studies relating to the operation of the Caernarvon Diversion Structure and its effect on downstream conditions and/or sediment delivery to the Gulf of Mexico, more detailed definition of diversion flows in the numerical model hydrograph is required. 
A tailwater rating curve for the structure was derived from stage-discharge gage data in the outflow channel from the period of record between January 2001 and December 2006 and is shown in Figure 11. Discharges ranged between 6,000 and $500 \mathrm{cfs}$. The stage data were converted from NAVD88 to NGVD29. Differential heads for 100 percent gate openings were determine from the discharge rating curve found in the Caernarvon Design Memorandum. The differential heads were added to values from a polynomial regression curve of the tailwater stage-discharge data to obtain a headwater stage-discharge rating curve through the structure.

Figure 11. Caernarvon tailwater rating curve, 2001-2006.

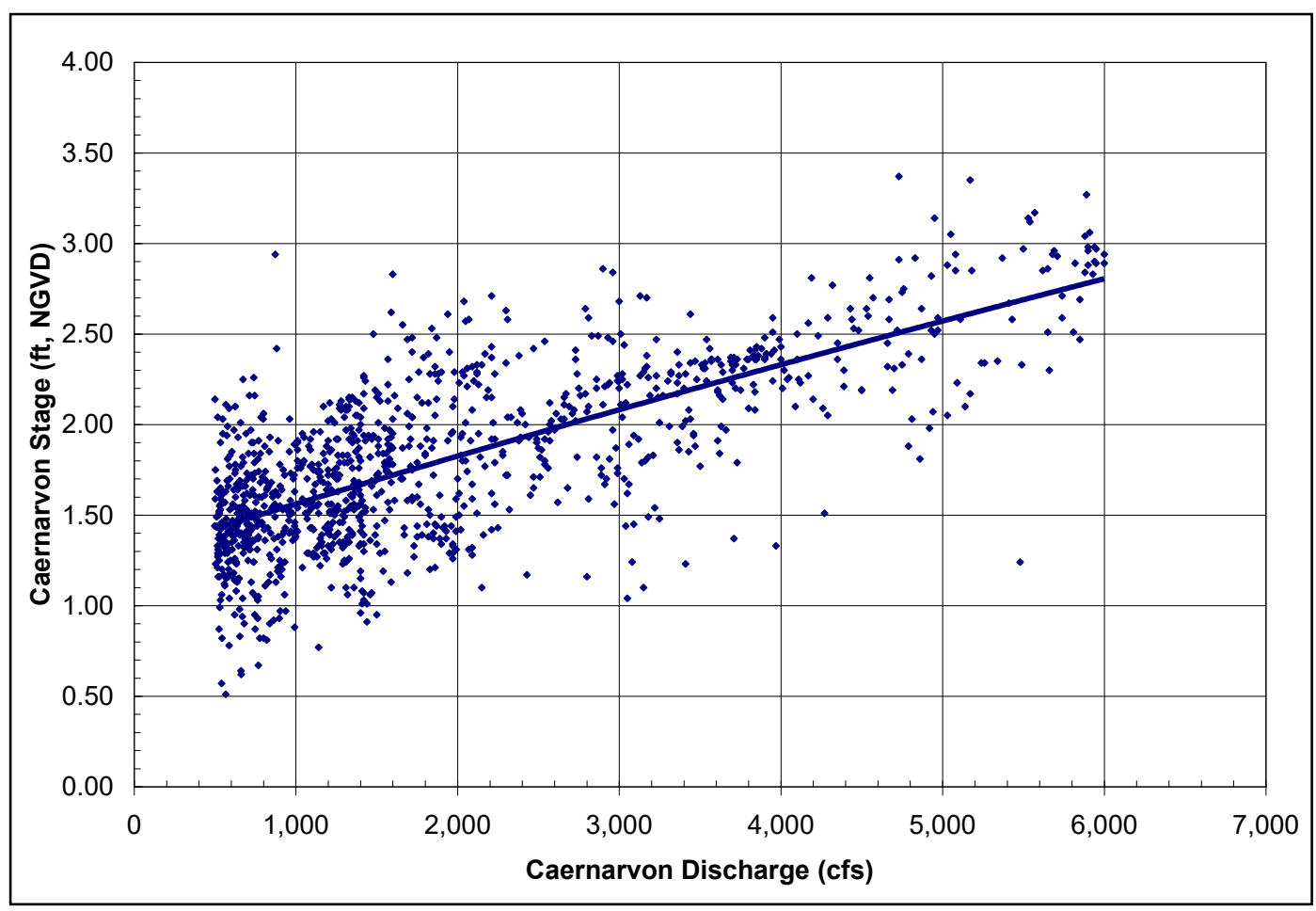

A stage-discharge curve in the Mississippi River at the Caernarvon Diversion Structure was developed from January-December 2001 stage data at Algiers Lock and Braithwaite and January-December 2001 discharge data at Tarbert Landing. Trend lines were computed through each data set. The stage for the riverside at Caernarvon was interpolated between those trend lines. The trend lines and the interpolated rating curve are shown in Figure 12. Maximum flow upstream from Caernarvon is 1,250,000 cfs and is controlled by operations at the Old River Control Complex, Morganza Spillway, and Bonnet Carré Spillway. 
Figure 12. 2001 Stage-discharge rating curve Mississippi River at Caernarvon Inlet.

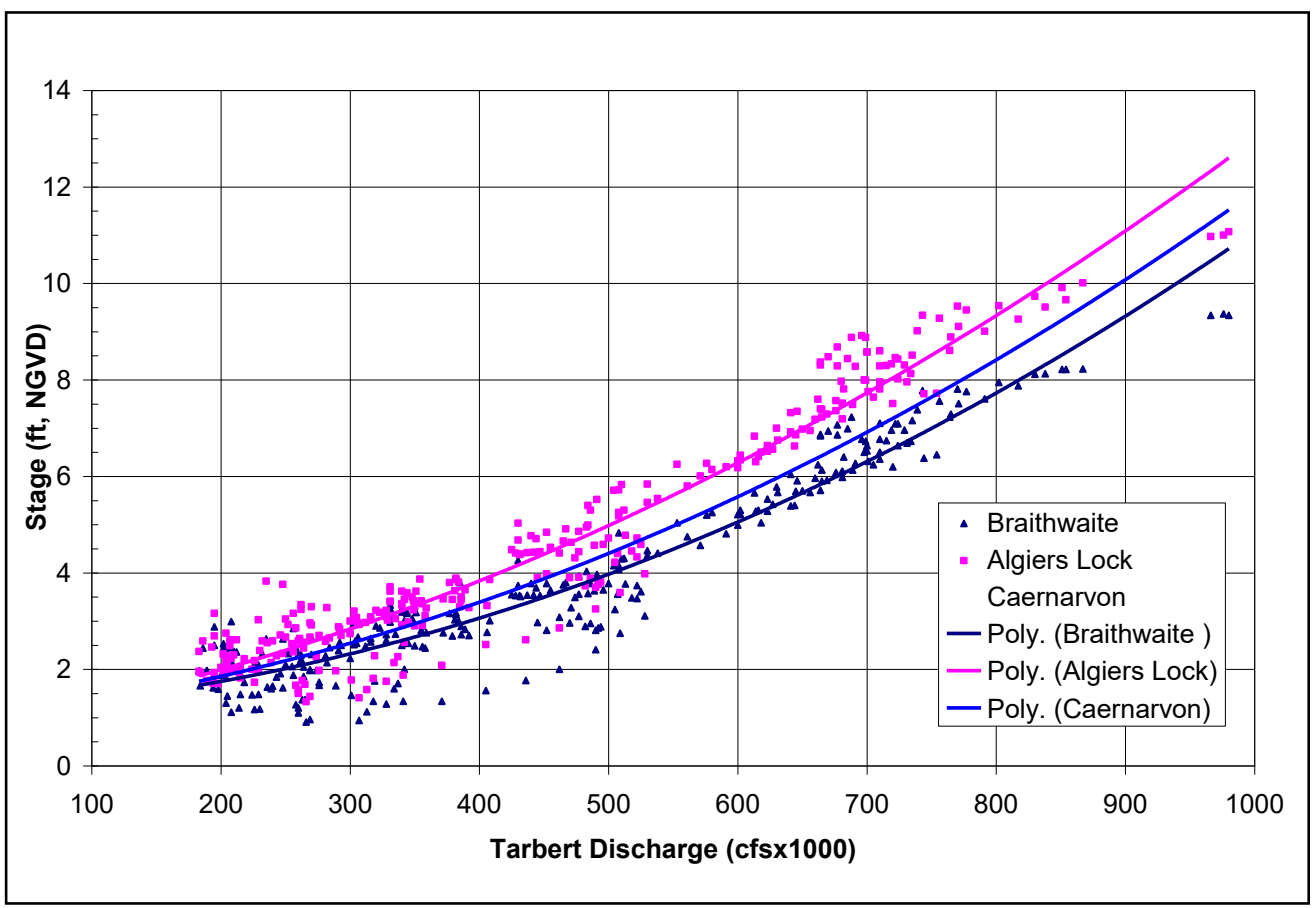

The Mississippi River discharges at Tarbert Landing that are required to achieve specified discharges through the Caernarvon Diversion Structure are shown in Table 10. Specified discharges through Caernarvon are in the first column. The headwater elevations required for those discharge are shown in the fourth column. The Mississippi River flows required to provide the headwater elevations were read from the interpolated rating curve in Figure 12 and recorded in the fifth column. For example, the headwater elevation required to provide a diversion flow of $1,000 \mathrm{cfs}$ is $1.8 \mathrm{ft}$. The Tarbert Landing discharge required to provide that head is $190,000 \mathrm{cfs}$. Expressing those discharges as a percent gives a diversion coefficient of 0.5 percent. When the Mississippi River discharge is 430,000 cfs, the head at Caernarvon is $3.7 \mathrm{ft}$. This will provide a diversion discharge of 6,000 cfs, and that is 1.4 percent of the Mississippi River flow. As the Mississippi River discharge increases above 430,000 cfs, the diverted percentage must decrease because the maximum discharge from Caernarvon is 6,000 cfs. The resulting diversion coefficients are shown in Figure 13. 
Table 10. Calculated headwater upstream from Caemarvon Diversion Structure.

\begin{tabular}{|c|c|c|c|c|}
\hline $\begin{array}{c}\text { Discharge through } \\
\text { Structure (cfs) }\end{array}$ & $\begin{array}{c}\text { Tailwater } \\
\text { NGVD (ft) }\end{array}$ & $\begin{array}{c}\text { Head Differential } \\
\text { (ft) }\end{array}$ & $\begin{array}{c}\text { Headwater } \\
\text { NGVD (ft) }\end{array}$ & $\begin{array}{c}\text { Discharge } \\
\text { Mississippi River } \\
\text { (cfs) }\end{array}$ \\
\hline 6,000 & 2.8 & 0.9 & 3.7 & 430,000 \\
\hline 5,000 & 2.55 & 0.7 & 3.25 & 385,000 \\
\hline 4,000 & 2.3 & 0.55 & 2.85 & 340,000 \\
\hline 3,000 & 2.05 & 0.4 & 2.45 & 290,000 \\
\hline 2,000 & 1.8 & 0.3 & 2.1 & 240,000 \\
\hline 1,000 & 1.6 & 0.2 & 1.8 & 190,000 \\
\hline 500 & 1.5 & 0.1 & 1.6 & $<190,000$ \\
\hline
\end{tabular}

Figure 13. Percentage of upstream discharge diverted at Caernarvon.

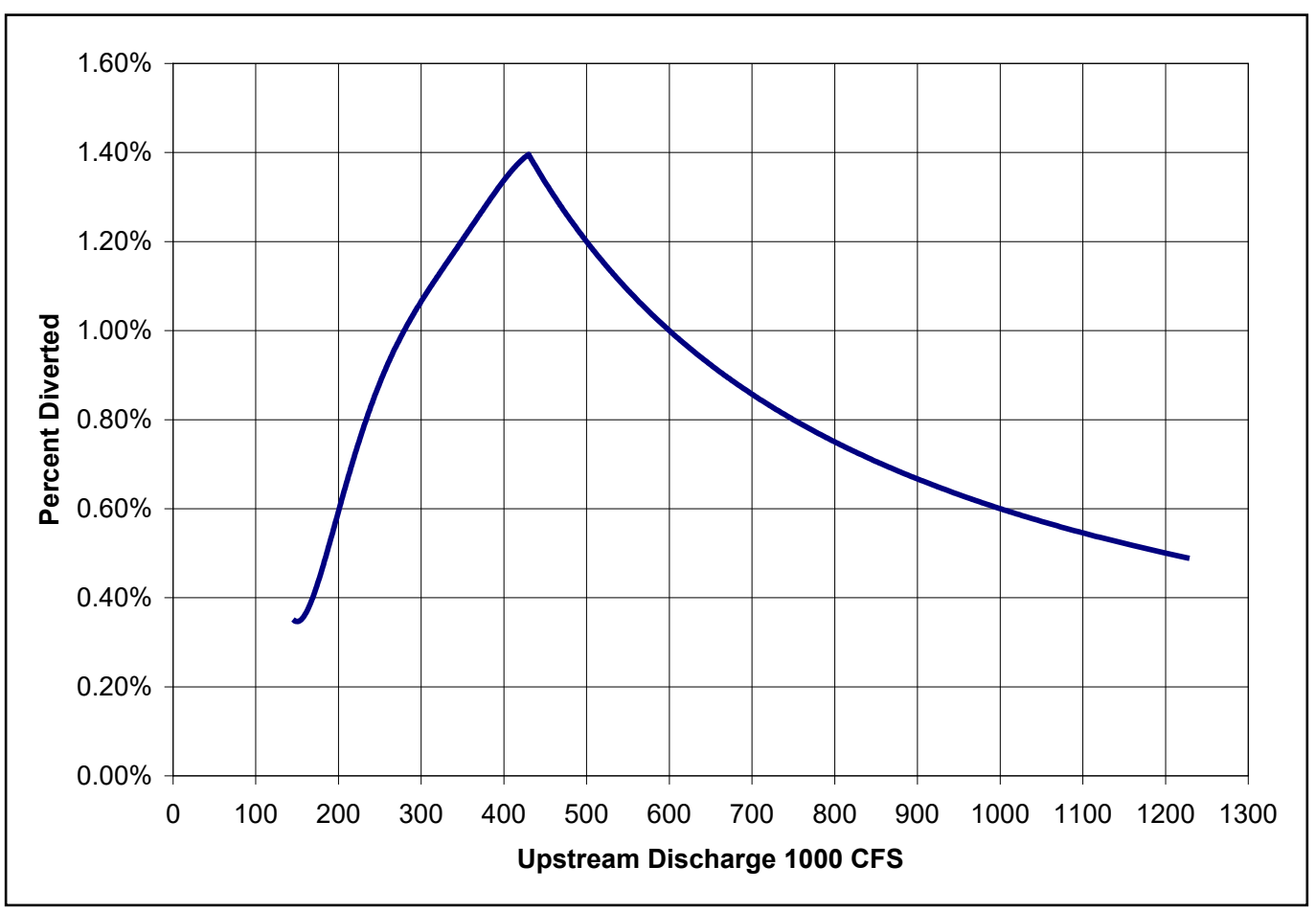

\section{Bonnet Carré and Morganza Spillways}

Flows over the Bonnet Carré and Morganza Spillways only occur when discharge upstream exceeds 1,250,000 cfs and 1,500,000 cfs, respectively. The Bonnet Carré structure is operated such that the downstream discharge does not exceed 1,250,000 cfs, and the Morganza Spillway is operated such that the downstream discharge does not exceed 1,500,000 cfs. Diversion percentages at Bonnet Carré and Morganza were assigned in the numerical model to match the operation schedule. The flow diversion percentages are 
calculated in the numerical model as a function of the Tarbert Landing discharge as shown in Figure 14. The Morganza Spillway was not operated during the 1992-2002 calibration simulation.

Figure 14. Tarbert Landing discharge diverted at Morganza and Bonnet Carré.

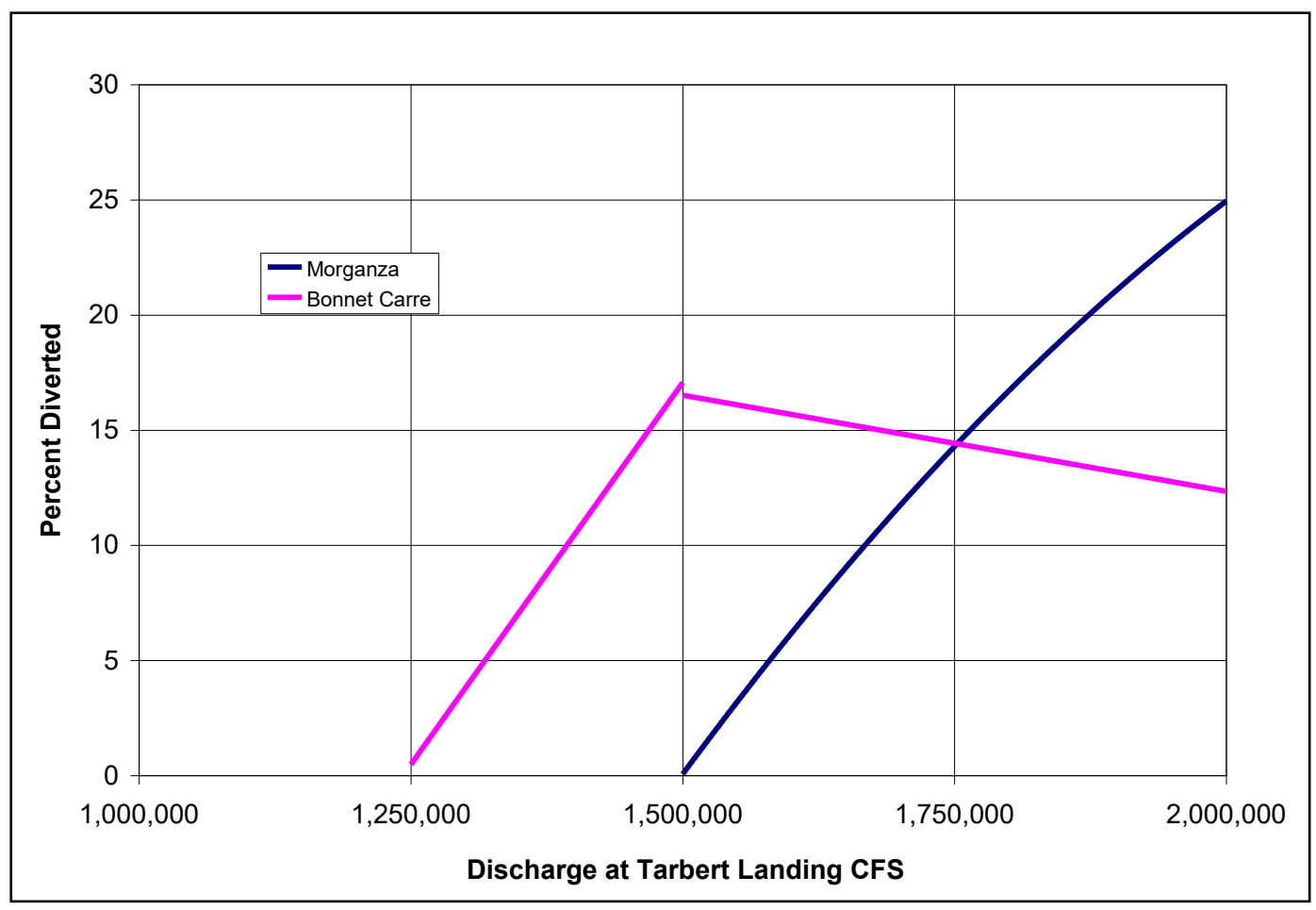

\section{Old River Complex}

The Old River Complex is operated to maintain a Congressionally mandated 30- to 70-percent split of both water and sediment between the Atchafalaya River at Simmesport and the Mississippi River at Tarbert Landing, respectively. The fraction of Mississippi River flow above Old River diverted through the complex is a function of several factors, including the discharges in the Red River and the Mississippi River, hydropower demand, the state of the river bed (e.g., bathymetry and bed material gradation), the shape of the hydrograph, and the distribution of the flow allocated to each diversion structure. There is no simple rule curve to predict the diversion percentage through the individual structures. The poor relationships between diversion percentages and Mississippi River discharge are shown in Figure 15. Historical diversion discharges are available and could have been used in the model calibration. However, future daily diversion percentages cannot be predicted. Model diversion percentages should be determined using the same methodology in both the calibration and predictive phase of the study. 
The study purpose was to provide a numerical model that could determine long-term sediment trends over the entire 1000-mile reach of the Mississippi River between the Gulf of Mexico and Cairo, IL, and to provide a model that can be used to evaluate the effect of particular project design modifications at a specific location on the entire Lower Mississippi River system. Detailed diversion percentages at the Old River Complex are not required to meet study objectives and are only necessary for specific studies relating to operation of the complex itself. For the general case, average historical diversion percentages are appropriate.

Average historical percentages for flow distribution through the Auxiliary Structure, Low Sill Structure, Old River Spillway, and Hydropower Structure were determined from reported daily discharges for 1991-2002 and for May-June 2011. There was no flow over the Old River Spillway during this period. Averages were determined for three distinct discharge ranges $-100,000$ to $800,000 \mathrm{cfs} ; 800,000$ to $1,600,000 \mathrm{cfs}$; and $1,600,000$ to 2,200,000 cfs. An average trend line was determined for the combined flow from the Auxiliary and Low Sill Structures, and then a straight average of the flow fraction within each data range was used to determine Auxiliary and Low Sill fractions. The daily data points and the average trend line are shown in Figure 15. Percentages used in the HEC-6T model are tabulated in Table 11.

Figure 15. Flow distribution at Old River, 1991-2002 and 2011 Flood.

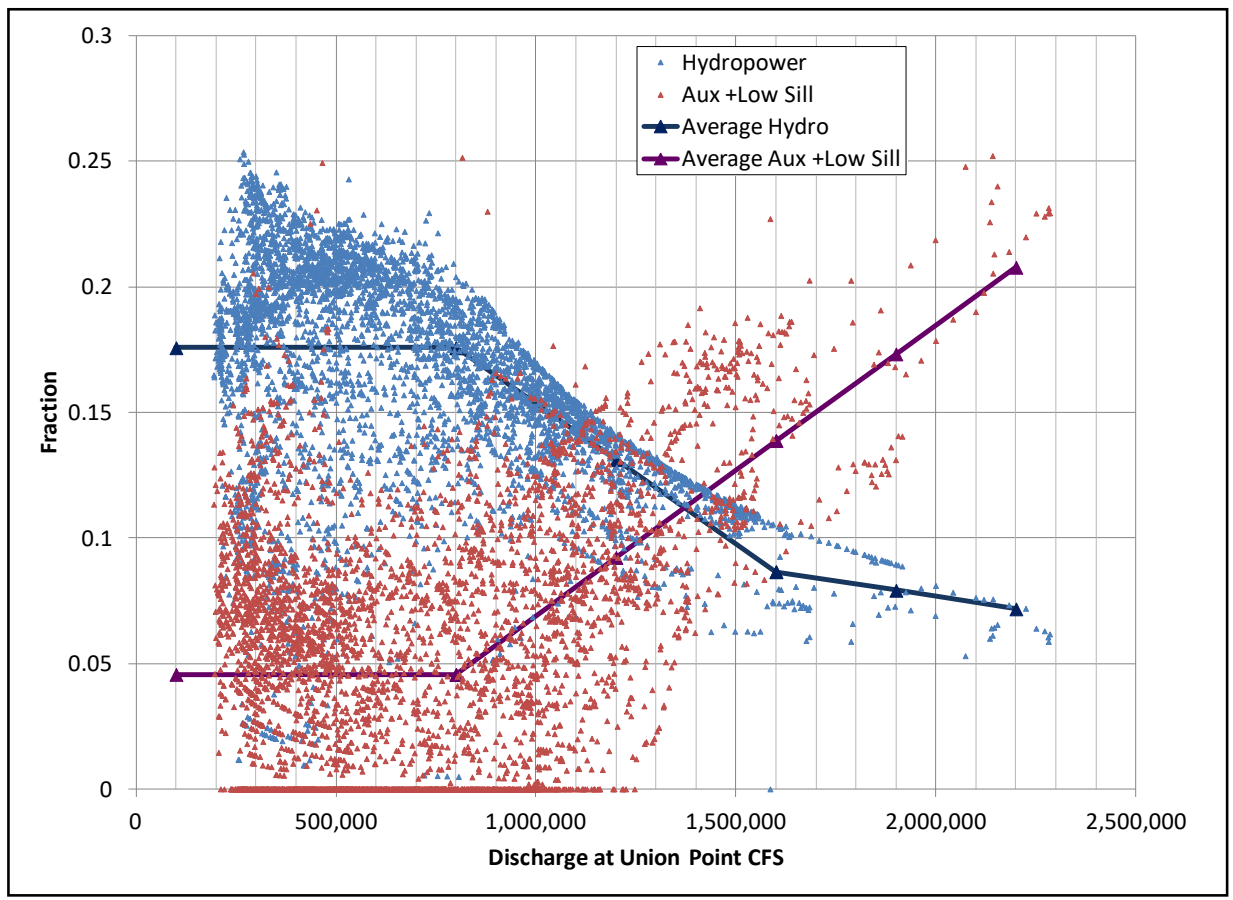


Table 11. Outflow at Old River distributaries, percentage of Union Point discharge.

\begin{tabular}{|l|c|c|c|c|c|}
\hline \multirow{2}{*}{ Distributary } & \multirow{2}{*}{ River Mile } & 100,000 & 800,000 & $1,600,000$ & $2,200,000$ \\
\cline { 3 - 6 } & 312 & $4.0 \%$ & $4.0 \%$ & $6.8 \%$ & $3.7 \%$ \\
\hline Auxiliary Structure & 314.6 & $0.6 \%$ & $0.6 \%$ & $3.9 \%$ & $17.0 \%$ \\
\hline Low Sill Structure & 315.2 & 0 & 0 & 0 & 0 \\
\hline Old River Spillway & 315.9 & $17.6 \%$ & $17.6 \%$ & $8.6 \%$ & $7.2 \%$ \\
\hline $\begin{array}{l}\text { Hydropower } \\
\text { Structure }\end{array}$ & & & & & \\
\hline
\end{tabular}

\section{Water temperature}

The assigned water temperatures in the numerical model were based on measurements reported by the USGS on its water quality web site. Temperature data were typically collected at the same time that sediment data were collected and are inadequate for determining daily values for water temperature. Average monthly values were determined from the available data at model inflow boundaries to account for seasonal variations in water temperature. Mean monthly temperatures for the Ohio River and the Mississippi River at Thebes are listed in Table 12. Also shown in Table 12 are the reported mean monthly temperatures at Tarbert Landing. This comparison demonstrates the seasonally and longitudinal variability in water temperature.

Table 12. Average monthly water temperatures, 1992-2002.

\begin{tabular}{|c|c|c|c|}
\hline Month & $\begin{array}{c}\text { Ohio River } \\
\text { at Dam 53 }\end{array}$ & $\begin{array}{c}\text { Mississippi } \\
\text { River } \\
\text { at Thebes }\end{array}$ & $\begin{array}{c}\text { Mississippi River } \\
\text { at Tarbert Landing }\end{array}$ \\
\hline January & 42.0 & 41.0 & 43.9 \\
\hline February & 42.3 & 38.8 & 44.5 \\
\hline March & 48.7 & 44.8 & 50.4 \\
\hline April & 55.5 & 54.3 & 59.6 \\
\hline May & 68.6 & 66.1 & 67.4 \\
\hline June & 76.4 & 73.5 & 76.0 \\
\hline July & 83.9 & 82.3 & 83.9 \\
\hline August & 83.6 & 81.6 & 84.4 \\
\hline September & 80.6 & 77.7 & 80.7 \\
\hline October & 65.8 & 64.0 & 67.8 \\
\hline November & 54.9 & 46.9 & 58.1 \\
\hline December & 47.4 & 39.2 & 50.2 \\
\hline
\end{tabular}




\section{Downstream water-surface elevations}

Stages at the end of Southwest Pass and routed discharges from Tarbert Landing show no stage-discharge correlation. Therefore, downstream water-surface elevations at Pilots Station in Southwest Pass (RM -18.0) were set based on average monthly stages. This is consistent with the approach taken in two previous studies (Copeland 1991; Copeland and Thomas 1992.) The simplifying assumption of an average monthly stage at the downstream boundary of the model is adequate for purposes of the generalized model developed in this study. However, studies of specific morphologic changes in the Mississippi River below Belle Chasse, especially in response to river diversions, may require a more detailed description of the downstream stages.

National Oceanic and Atmospheric Administration (NOAA) tide gage data were used to determine the average monthly stages at Pilots Station due to inconsistencies discovered in the USACE reported stage elevations in Southwest Pass. These inconsistencies are shown in Figure 16, which shows plots of reported daily stages versus routed discharges from Tarbert Landing for water years 1991 and 1992. A comparison of linear regression curves for the gages shows stages at East Jetty (RM -20.6) and Mile 9.2 (RM -9.2) to be higher than stages at Head of Passes (RM 0.0) and Venice (RM 10.7) for low discharges. The physically possible progression of stage elevations where water surface increases in an upstream direction does not occur until discharges at Tarbert Landing exceed 1,100,000 cfs. Therefore, the East Jetty and Head of Passes gage data were not used in this study.

Figure 16. Southwest Pass and Venice, 1991-1992, stage-discharge rating curves.

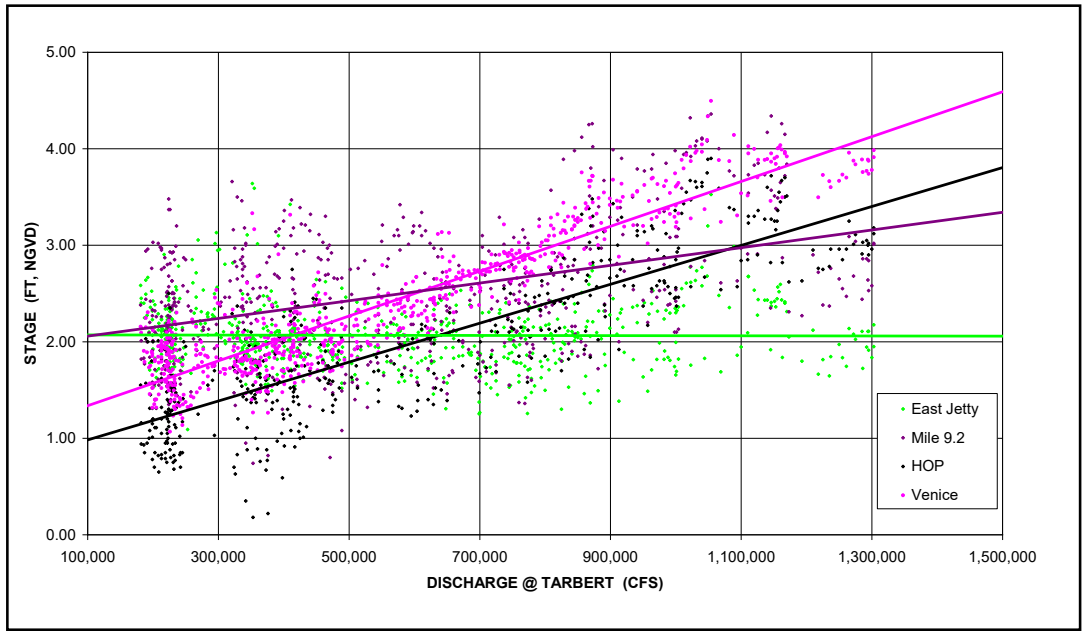


NOAA tide gage data were obtained from http://tidesandcurrents.noaa.gov. Data from Pilots Station East, Southwest Pass, LA (Station 8760922), which is located at the downstream boundary of the numerical model, were available for the months between September 2004 and September 2008. Data from Pilot Station, Southwest Pass, Louisiana (Station 8760943) were available the months between November 1996 and December 1998 and for the months between September 2002 and February 2004. The nearest station with a complete record between 1992 and 2008 was Grand Isle, East Point, LA (Station 876174). As shown in Figure 17, 2004 to 2008 average monthly stages at Pilots Station East correlated well to average monthly stages from Grand Isle East Point. The favorable correlation did not seem to be affected by the fact that mean sea level (MSL) at Pilots Station East was based on the 1983-2001 epoch and MSL at Grand Isle East Point was based on the 2002-2006 epoch. The 1997-1998 average monthly stages at Pilot Station did not correlate as well to average monthly stages at Grand Isle East Point. Therefore, the data from Pilot Station were dropped from further consideration. Due to the good correlation with the 2004-2008 average monthly stages at Pilots Station East, the 1992-2002 data at Grand Isle East Point were used to determine average monthly stages for the HEC-6T calibration runs. Data from Pilots Station East can be used for simulations starting in water year 2005 .

Figure 17. Average monthly stages in Southwest Pass and at Grand Isle East.

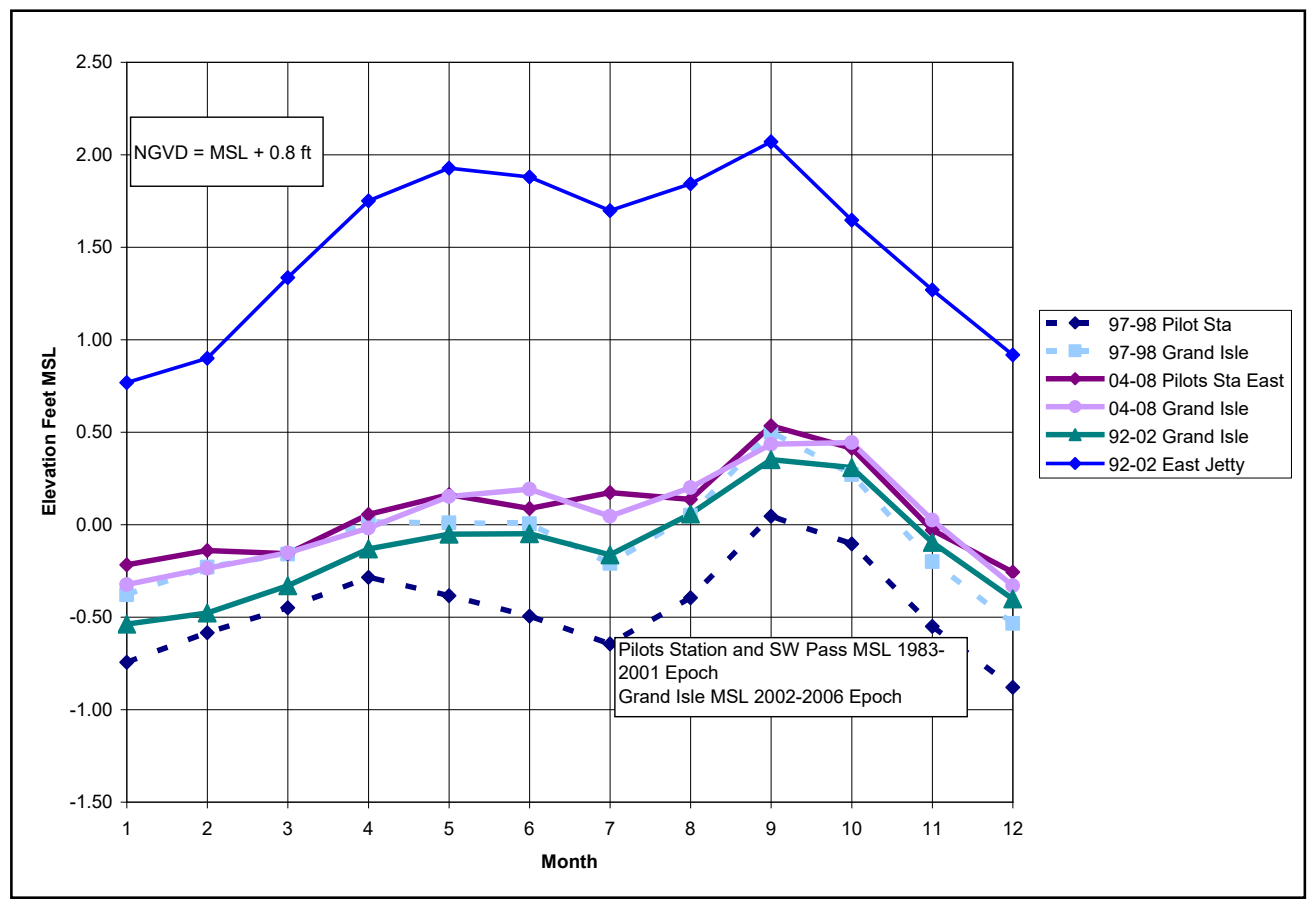


NOAA Stages are reported in MSL elevation. NGVD29 elevations are obtained by adding $0.8 \mathrm{ft}$ to the MSL values. Downstream water-surface elevations used in the numerical model are listed in Table 13.

Table 13. Downstream water surface elevations at Pilots Station.

\begin{tabular}{|c|c|c|c|}
\hline Month & $\begin{array}{c}\text { NGVD } \\
\text { feet }\end{array}$ & Month & $\begin{array}{c}\text { NGVD } \\
\text { feet }\end{array}$ \\
\hline January & 0.3 & July & 0.6 \\
\hline February & 0.3 & August & 0.9 \\
\hline March & 0.5 & September & 1.2 \\
\hline April & 0.7 & October & 1.1 \\
\hline May & 0.7 & November & 0.7 \\
\hline June & 0.8 & December & 0.4 \\
\hline
\end{tabular}

\section{Datum and gages}

The datum used in the model is NGVD29. This is the datum used for the 1991-92 hydrographic survey in the New Orleans District and for the stages reported on New Orleans District web site. This is also the datum used for the 1988-89 hydrographic survey in the Vicksburg District. Mean sea level was used at the datum for the 1988-1989 survey in the Memphis District. In Memphis District, mean sea level is theoretically equivalent to NGVD29. Stage elevations between 1991 and 2002 reported in Vicksburg District Annual Stages and Discharges reports are given in NGVD29. Stage elevations from the USACE website RiverGages.com, which includes stage gages in all three districts, are also given in NGVD29. Gages used to calibrate the model's roughness coefficients are listed in Table 14.

Table 14. Gages and datum used for water surface calibration.

\begin{tabular}{|l|c|c|}
\hline & $\begin{array}{c}\text { River Mile } \\
\text { AHP }\end{array}$ & $\begin{array}{c}\text { Gage Zero } \\
\text { feet, NGVD29 1 }\end{array}$ \\
\hline Venice & 10.7 & 0 \\
\hline Empire & 29.5 & 0 \\
\hline West Pointe a La Hache & 48.7 & 0 \\
\hline New Orleans & 102.8 & 0 \\
\hline Reserve & 138.7 & 0 \\
\hline Donaldsonville & 175.4 & 0 \\
\hline Baton Rouge & 228.0 & 0 \\
\hline
\end{tabular}




\begin{tabular}{|l|c|c|}
\hline & $\begin{array}{c}\text { River Mile } \\
\text { AHP }\end{array}$ & $\begin{array}{c}\text { Gage Zero } \\
\text { feet, NGVD29 } 1\end{array}$ \\
\hline Bayou Sara & 265.4 & 0 \\
\hline Red River Landing & 302.4 & 0 \\
\hline Natchez & 363.3 & 17.28 \\
\hline St. Joseph & 396.4 & 33.12 \\
\hline Vicksburg & 435.7 & 46.23 \\
\hline Lake Providence & 487.2 & 69.71 \\
\hline Greenville & 531.1 & 74.92 \\
\hline Arkansas City & 554.1 & 96.66 \\
\hline Rosedale & 595.2 & 108.73 \\
\hline Helena & 663.1 & 141.70 \\
\hline Memphis & 734.7 & 183.91 \\
\hline Hickman & 922.0 & 264.73 \\
\hline Cairo & $955.8\left(\right.$ AHP) ${ }^{2}$ & 270.47 \\
\hline Metropolis & $990.5\left(\right.$ AHP) ${ }^{3}$ & 300.00 \\
\hline Thebes & & 341.05 \\
\hline Chester & & \\
\hline
\end{tabular}

12014 from Rivergages.com

2Ohio RM 978.8 - 2 miles upstream from Mississippi River confluence

30hio RM 944.1 - 37 miles upstream from Mississippi River confluence

${ }^{4}$ River Miles upstream from Ohio River confluence

Daily stage data are available for most of the gages for the entire 1991-2002 simulation period. The gage at St. Joseph was discontinued in January 1996. When daily stages were missing from the record, linear interpolation was used to fill in the gaps.

The only discharge measurements in New Orleans District, for the calibration period, are at Tarbert Landing. They were used to develop the stage discharge rating curves at all gages in the New Orleans District

In Vicksburg District, discharge measurements were available at Natchez, Vicksburg, and Arkansas City during the calibration period. Daily discharge estimates, calculated from the measurements, were published in annual Stages and Discharges Reports until 1997. Subsequent daily discharge estimates are available from the Vicksburg District Water Control Branch. The stage-discharge curve at St. Joseph was developed 
using an average of the Vicksburg and Natchez calculated daily discharges. The stage-discharge curve at Lake Providence was developed using calculated daily discharges at Arkansas City that were lagged 1 day. The stage-discharge curve at Greenville was developed using calculated daily discharges at Arkansas City without any lag. The stage-discharge curve at Rosedale was developed using calculated daily discharges at Arkansas City and Dam No. 2 on the Arkansas River. The daily discharges on the Arkansas River were obtained from the USACE Little Rock District. The daily discharge at Rosedale was taken to be the difference between the Arkansas City and Dam No. 2 discharges. A 1-day lag was assumed between Arkansas City and Rosedale and between Dam No. 2 and Arkansas City.

Discharge measurements are taken at Helena, Memphis, and Hickman. Daily discharge estimates, calculated from the measurements, were provided by the Memphis District Water Control Office. Discharge data were not available at Hickman for 2001 and were not available at Helena for 2002. Daily stages are available from USACE website RiverGages.com.

\section{Roughness coefficients}

Model roughness coefficients were initially determined early in the calibration phase of the study using the initial cross-section geometry with a fixed-bed. The 1991-92 stage data were used to develop regression equations at each gage to which roughness coefficients were adjusted. At the end of the calibration phase of the study, the calculated water surface profiles at the end of the first year of simulation, 1991, and at the end of the 12-year simulation, 2002, were compared to average regression curves developed from the 12-year measured stage data reported between 1991 and 2002. These three regression curves were developed to determine if there were any obvious aggradation or degradation trends that could be identified from the gage data. Changes in the HEC-6T calculated rating curves between 1991 and 2002 would suggest aggradation or degradation trends in the reach associated with the gage. The annual scatter in the measured data makes it difficult to identify any geomorphic trends during the calibration period. However, results suggest that there was no significant change in the annual rating curves between 1991 and 2002. Specific gage analyses were conducted for each gage and are discussed later in this report. 
It is apparent from the measured data that there is significant variability about the regression line relating stage to discharge. In the coastal zone, some of this variability can be attributed to tidal effects. However, bed forms and unsteady flow effects account for most of the variability. There is an identifiable loop effect in the rating curves. The height and distribution of bed forms lag the rise and fall of hydrographs so that there is no distinct relationship between bed-form shape and discharge. In the steady-state $1 \mathrm{D}$ sediment model, the objective is to simulate average conditions to best replicate the movement of sediment over time. This is different from the approach taken to establish flow lines for maximum water surface elevations (e.g., for levee design). With the levee design approach, roughness coefficients would be chosen to match a regression curve through the maximum water surface elevation values.

The 1991-2002 measured data at nine gages in the New Orleans District and the computed regression curves for the 12-year period are shown in Figure 18 through Figure 26. Also shown on these figures are HEC-6T calculated rating curves at the end of the first and twelfth year of the movable-bed simulation. Figure 27 shows water surface profiles calculated by the movable-bed model for Tarbert Landing discharges of 150,000; 300,000; 500,000; 900,000; and 1,500,000 cfs at the end of the first and twelfth year. Also shown on Figure 27 are water surface elevations calculated from the 1991-2002 regression equations from Figure 18 through Figure 26. Roughness coefficients determined during the initial fixed-bed calibration were found to produce reasonable results during the movable bed simulation. At the end of the 12-year simulation, the rating curves suggest aggradation at high flows between Venice (RM10.7) and Reserve (RM 138.7). The calculated stages between Donaldsonville (RM 174.5) and Red River Landing (RM 302.4) show no significant difference between the 1992 and 2002 rating curves. Although the 2002 rating curves are well within the data scatter of the measured stages and discharges, the measured stage data do not support the aggradation trend shown in the calculated results downstream from Donaldsonville. One explanation for this inconsistency is that there was only 1 high-water year (1997) during the calibration period and the last 4 years of the calibration hydrograph (19982002) were relatively low-flow years. Another explanation is that the rating curves calculated by the model were developed by running an instantaneous discharge over the calculated bed conditions in September 2002. These are not necessarily the conditions that would be expected at peak flows where the ascending limb of the flood hydrograph would tend to change bed 
conditions. Nevertheless, this inconsistency must be considered with other calibration data from the river.

Figure 18. Venice rating curves, RM 10.7, 1991-2002.

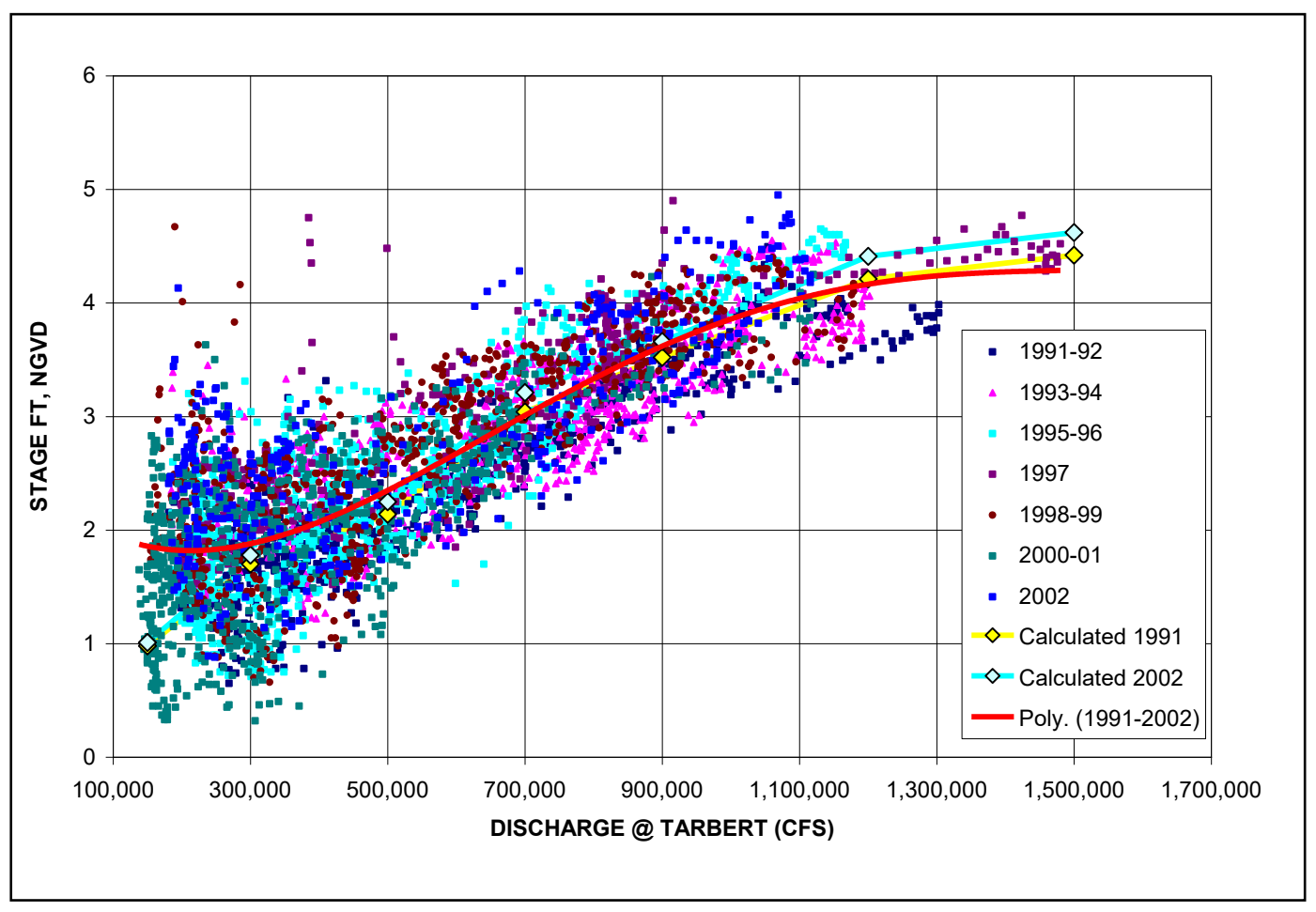

Figure 19. Empire rating curves, RM 29.5, 1991-2002.

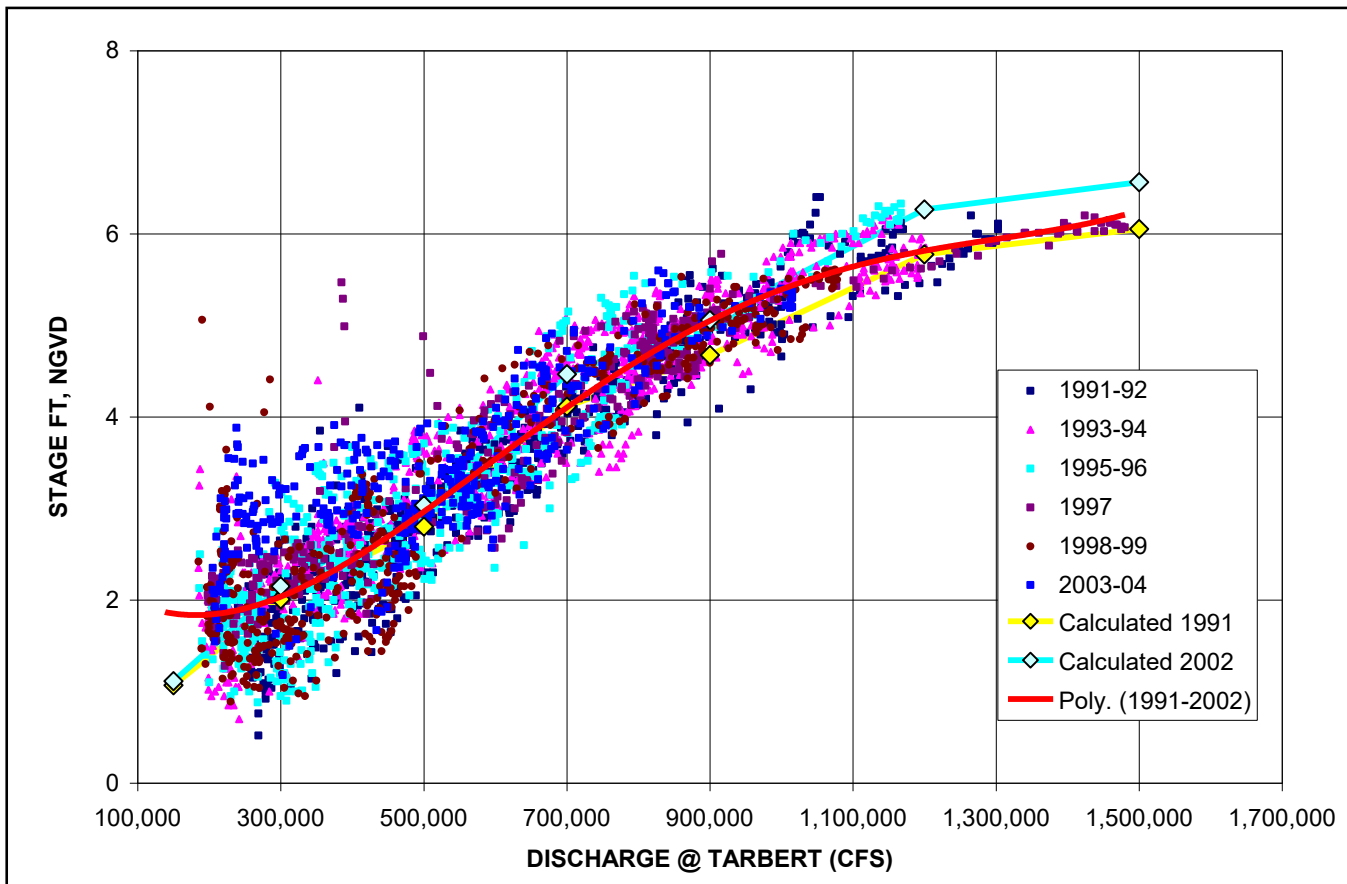


Figure 20. West Pointe a la Hache rating curves, RM 48.7, 1991-2002.

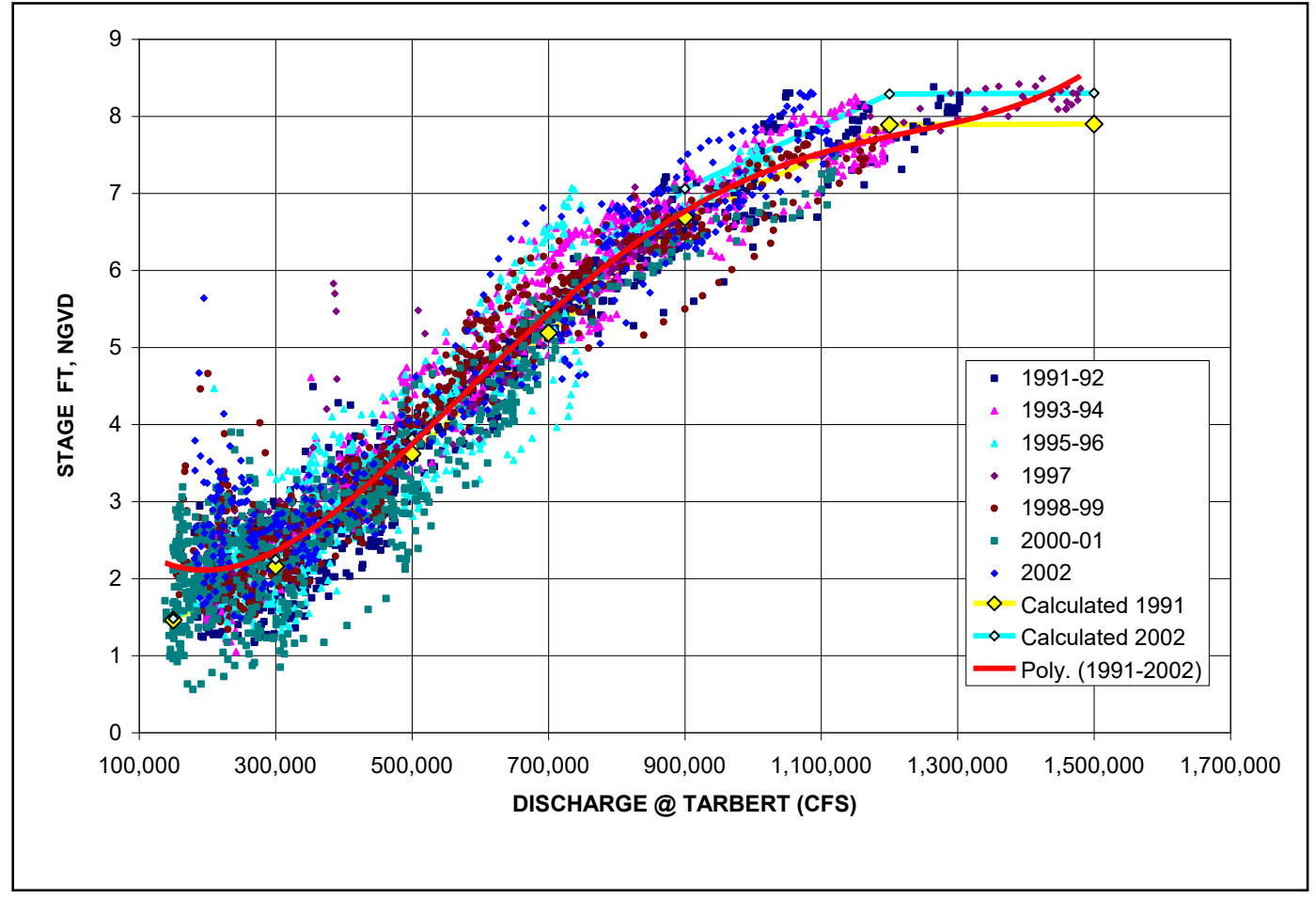

Figure 21. New Orleans rating curves, RM 102.8, 1991-2002.

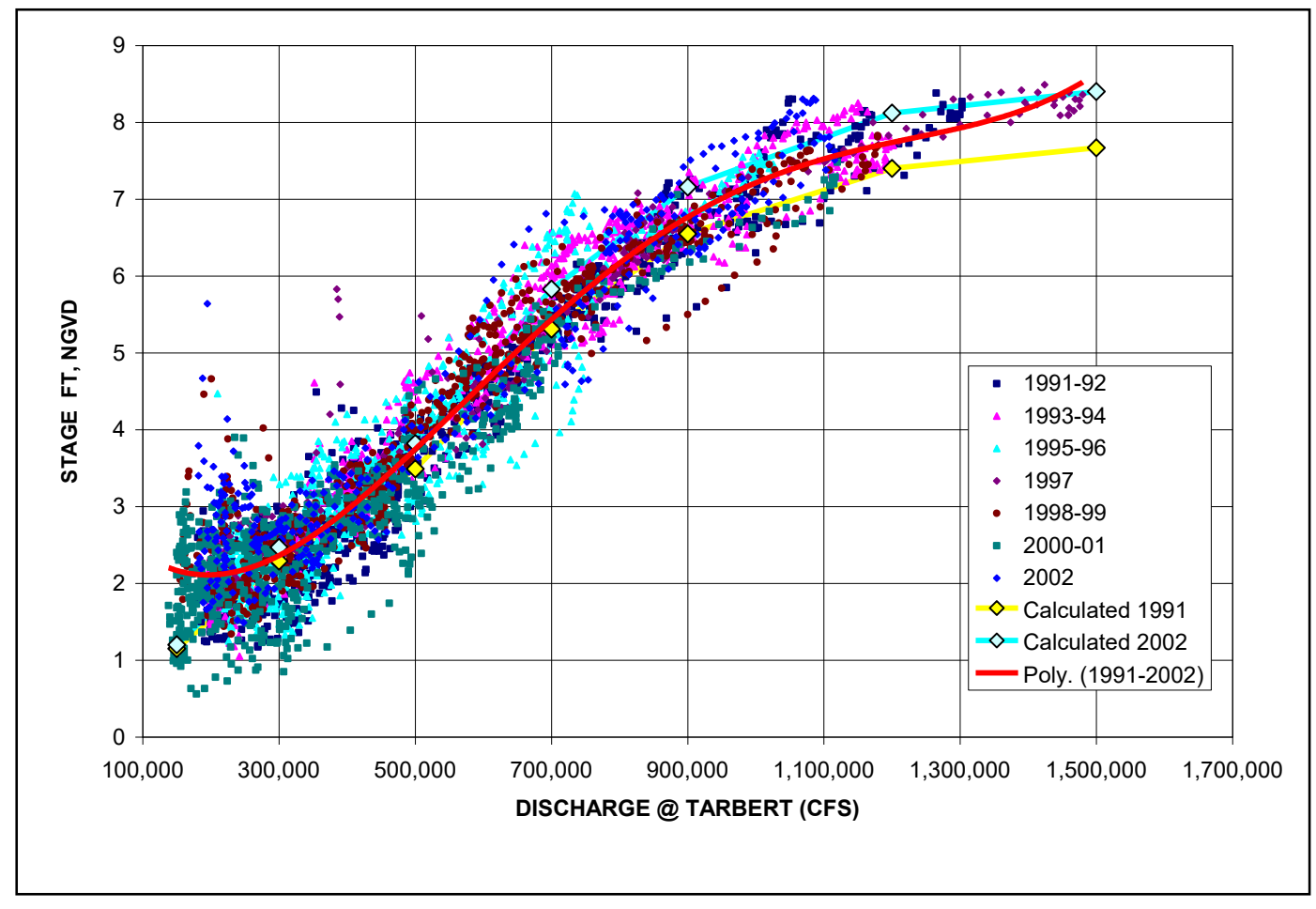


Figure 22. Reserve rating curves, RM 138.7, 1991-2002.

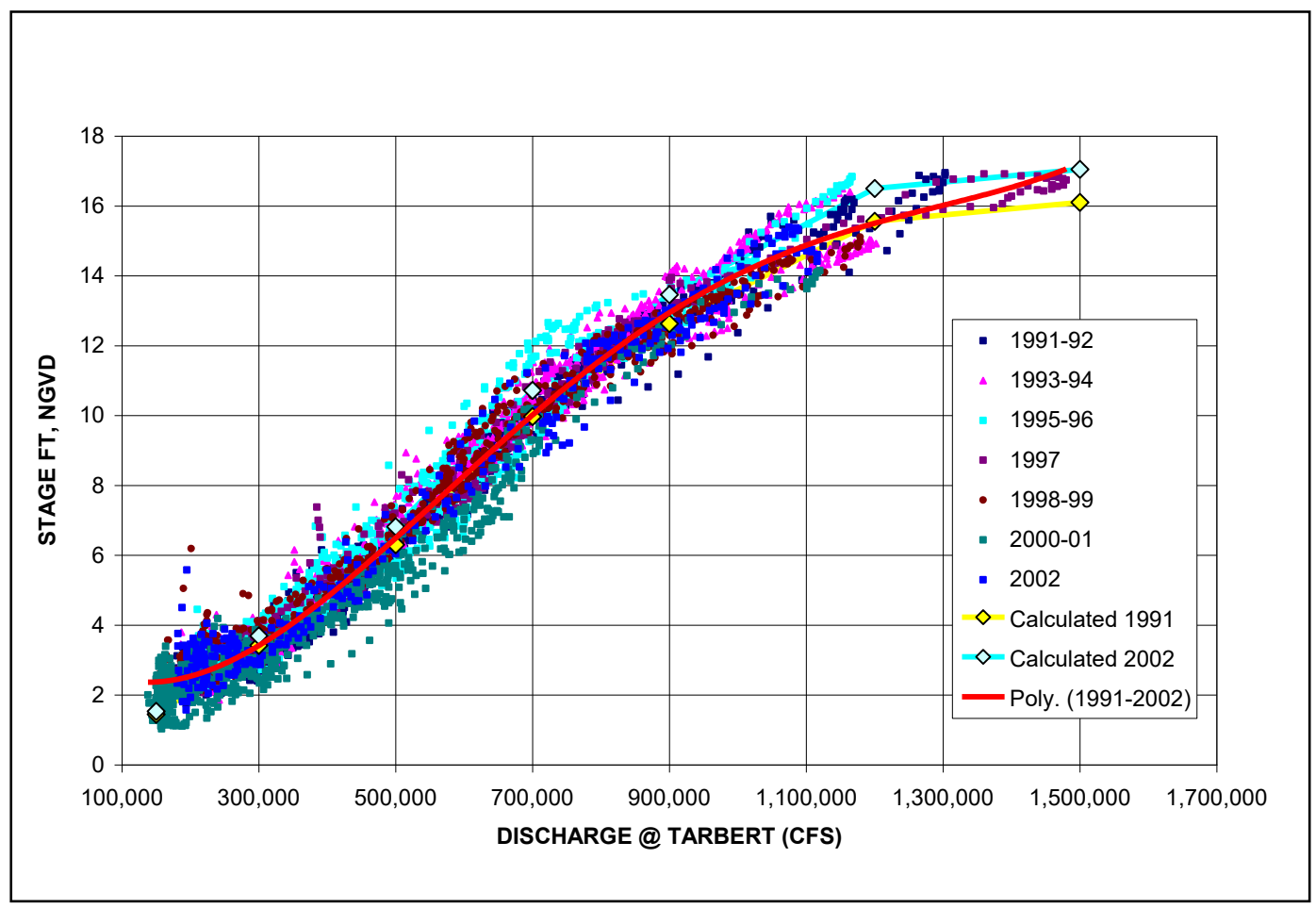

Figure 23. Donaldsonville rating curve, RM 175.4, 1991-2002.

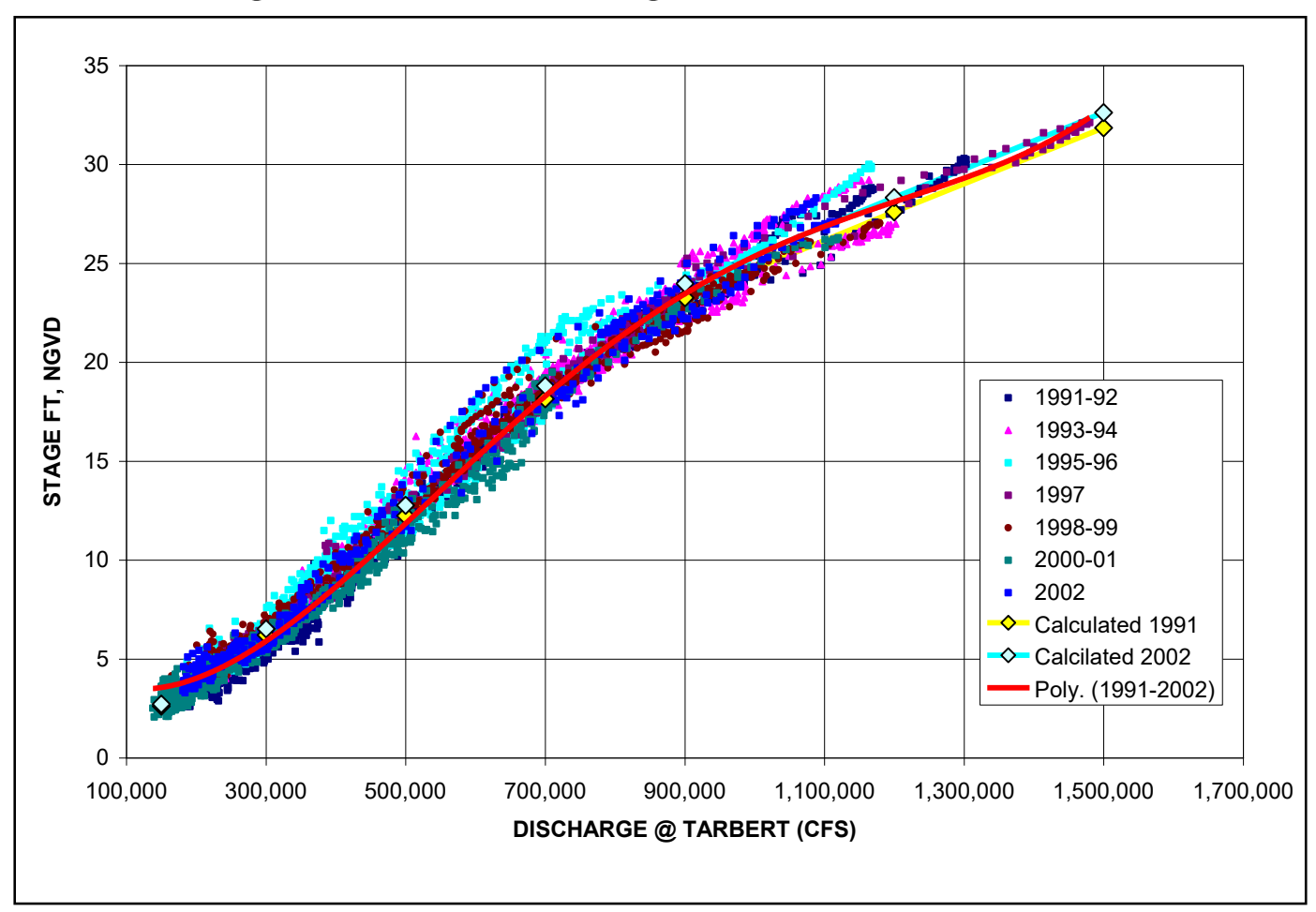


Figure 24. Baton Rouge rating curves, RM 228.4, 1991-2002.

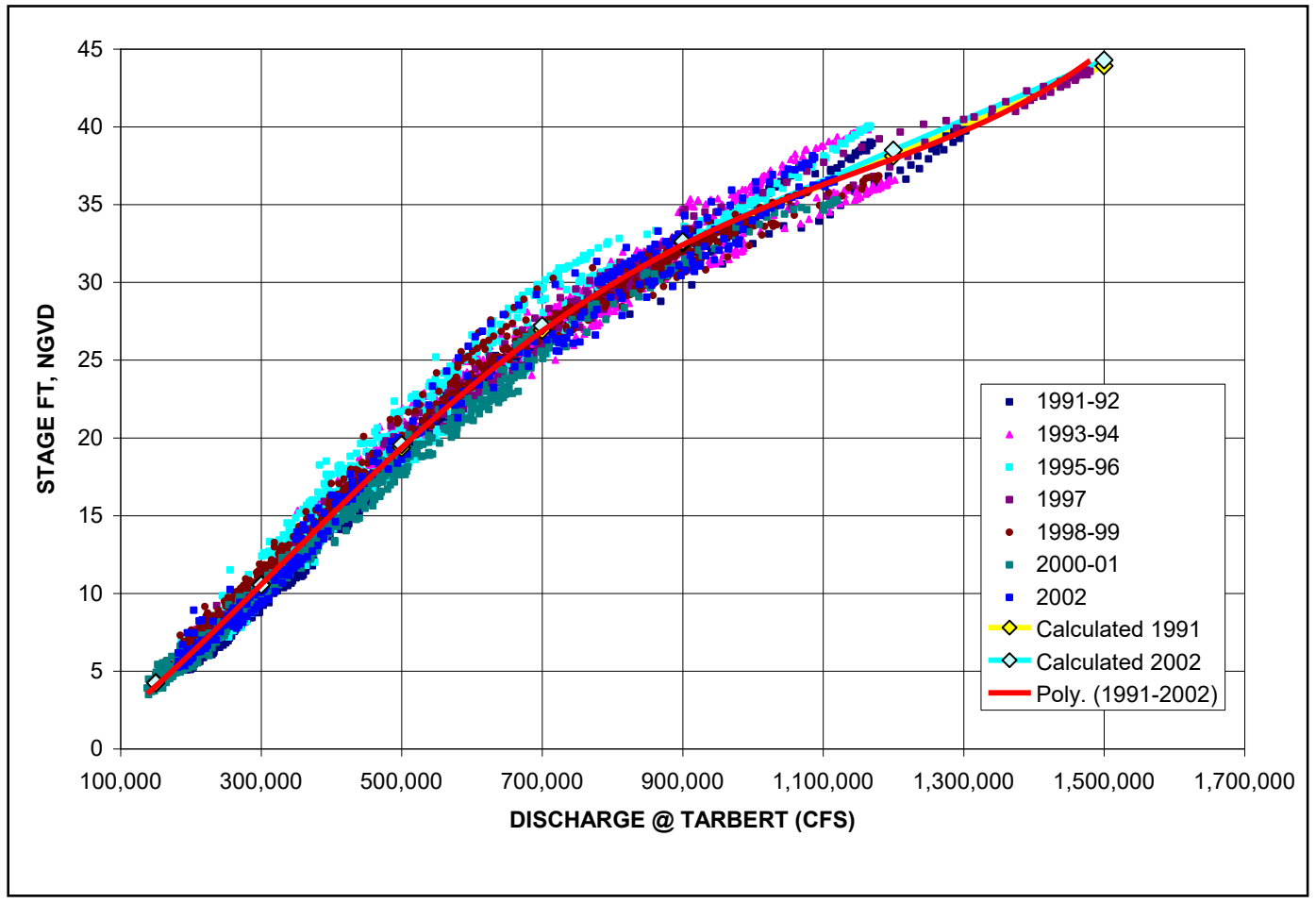

Figure 25. Bayou Sara rating curves, RM 265.4, 1991-2002.

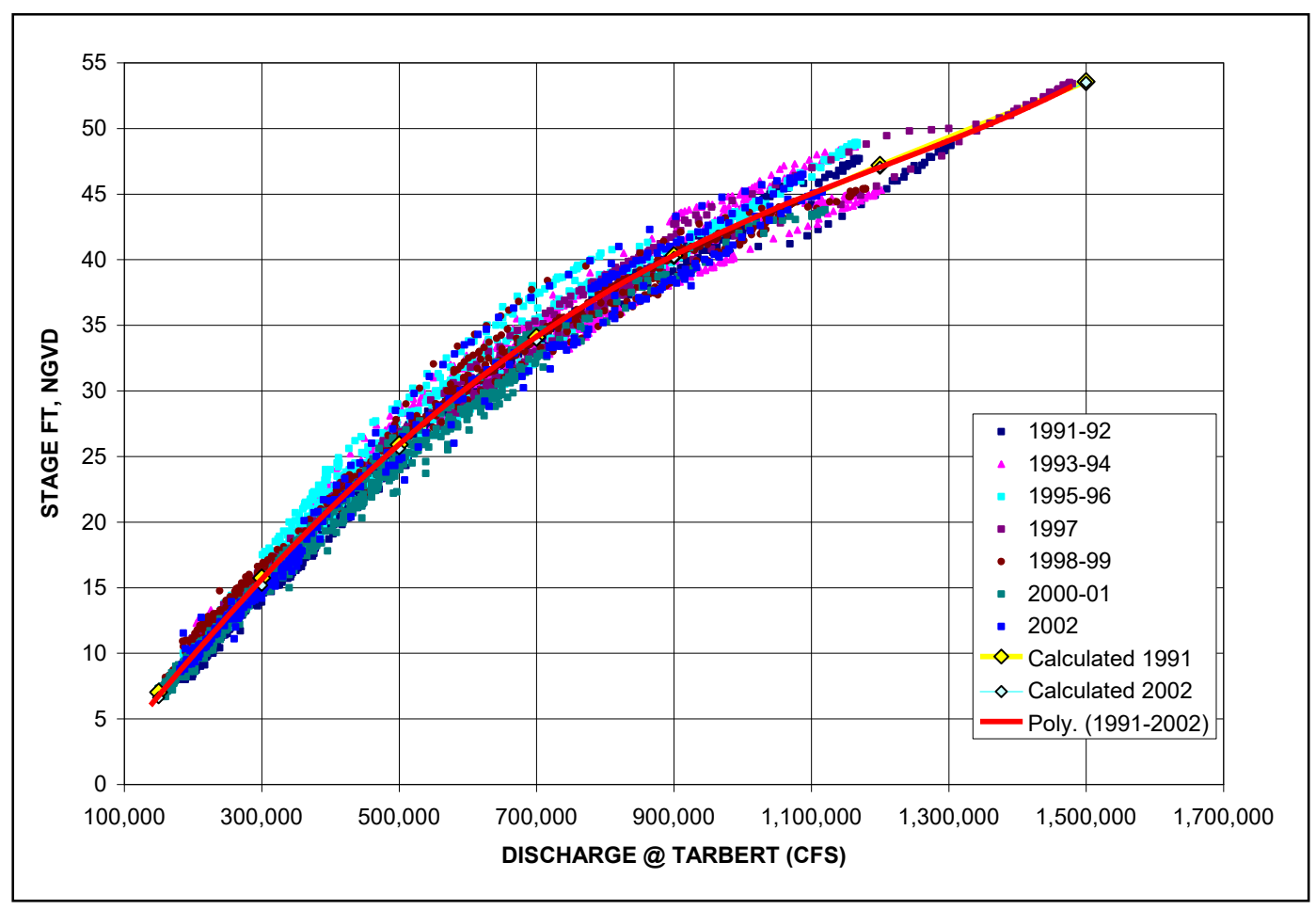


Figure 26. Red River Landing rating curves, RM 302.4, 1991-2002.

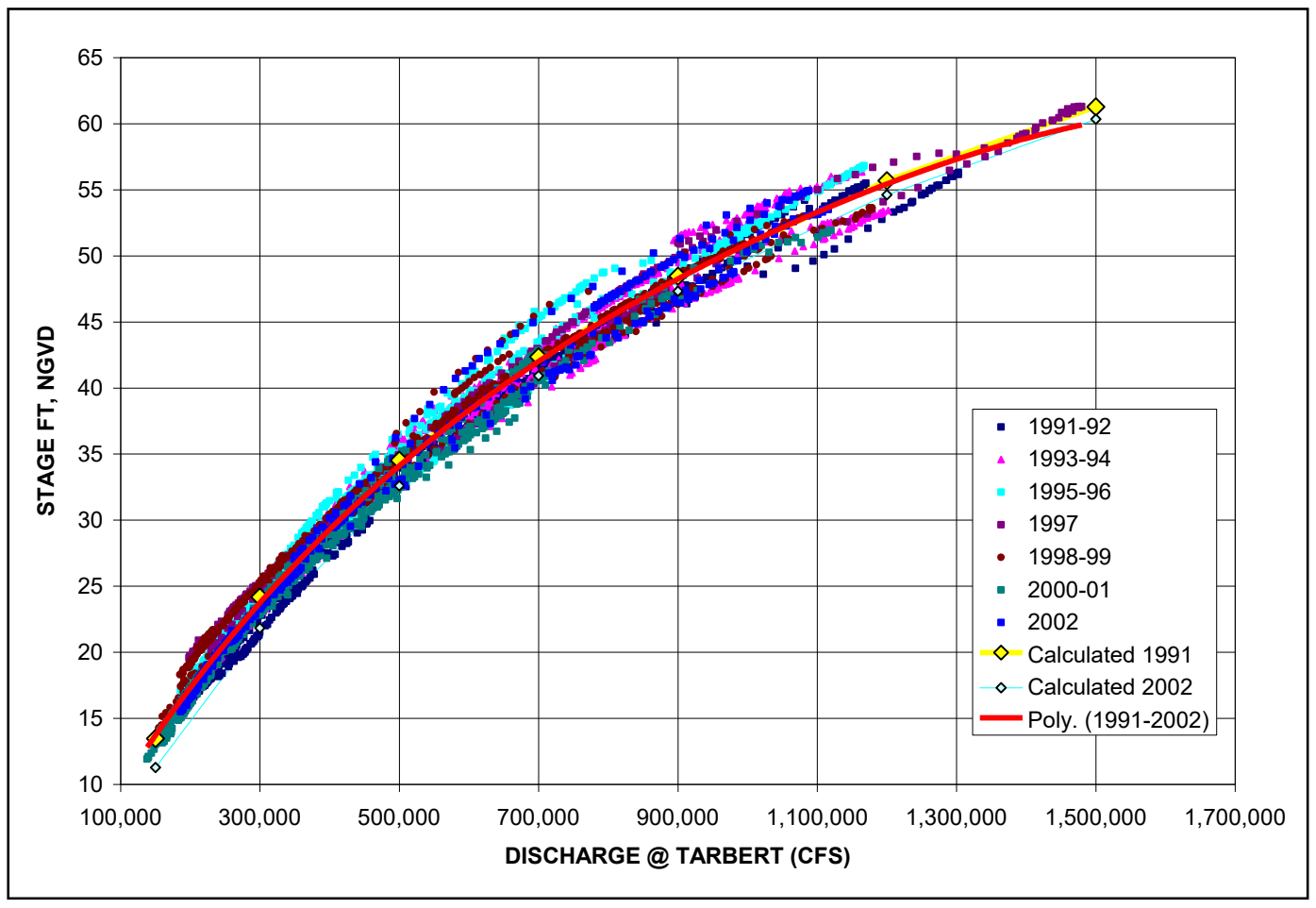

Figure 27. Measured and calculated stages, RM -19 to RM 320.

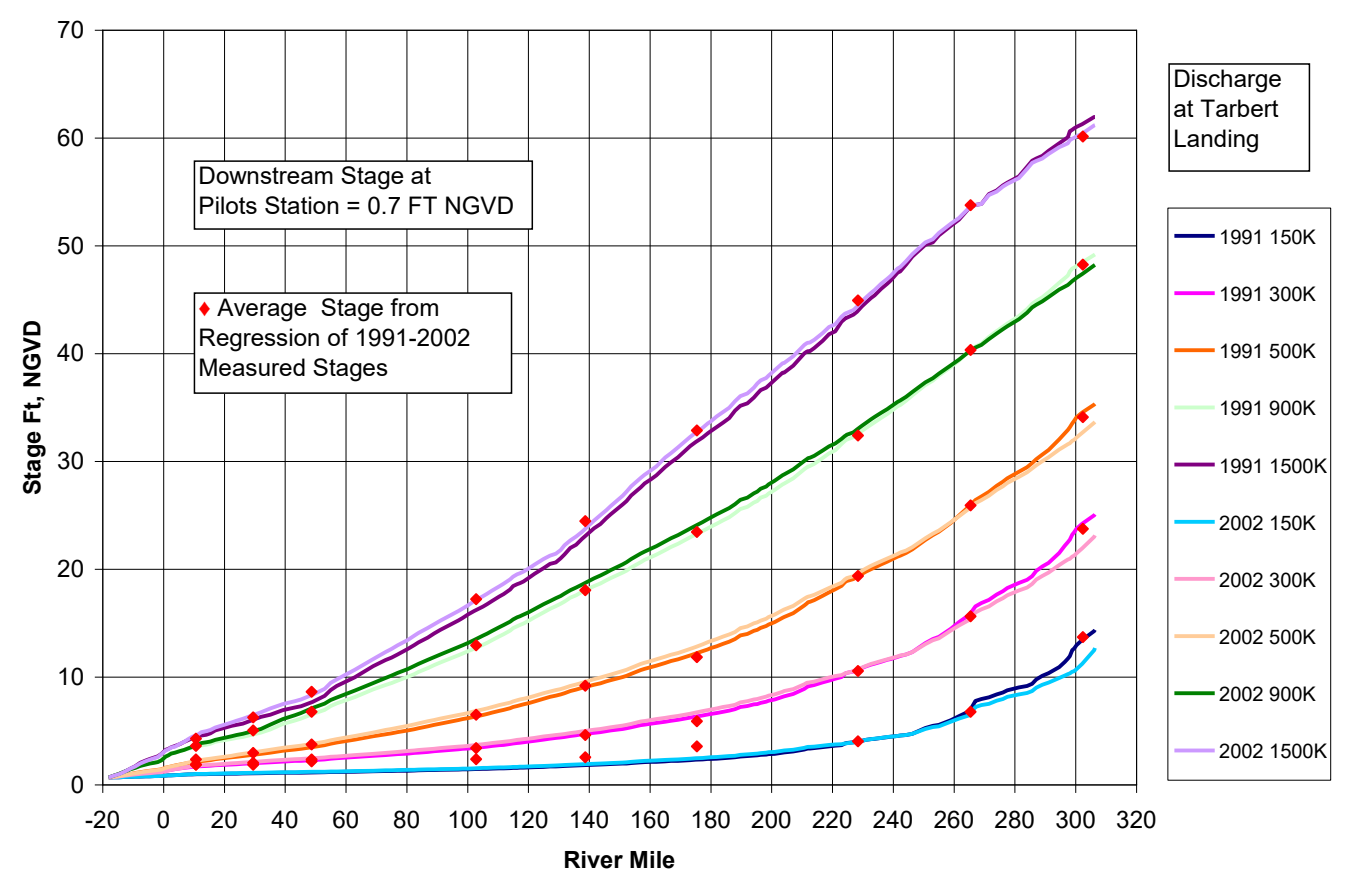


The 1991-2002 measured data for seven gages in Vicksburg District are shown in Figure 28 through Figure 31. Also shown on these figures are calculated rating curves at the end of the first year of the movable-bed simulation (1991) and at the end of the 12-year simulation (2002). Roughness coefficients determined during the initial fixed-bed calibration and after the 12-year simulation were found to produce reasonable results during the movable bed simulation. The significant variability about the regression lines relating stage to discharge in Vicksburg District is consistent with the measurements downstream in New Orleans District. This spread is attributed to bed forms and unsteady flow effects and demonstrates that stage is not a unique function of discharge. During flood events, there is an identifiable loop effect in the rating curves. In the steady-state 1D sediment model the objective is to simulate average conditions to best replicate the movement of sediment over time.

Figure 28. Stage-discharge for St. Joseph (RM 396.4) and Natchez (RM 363.0).

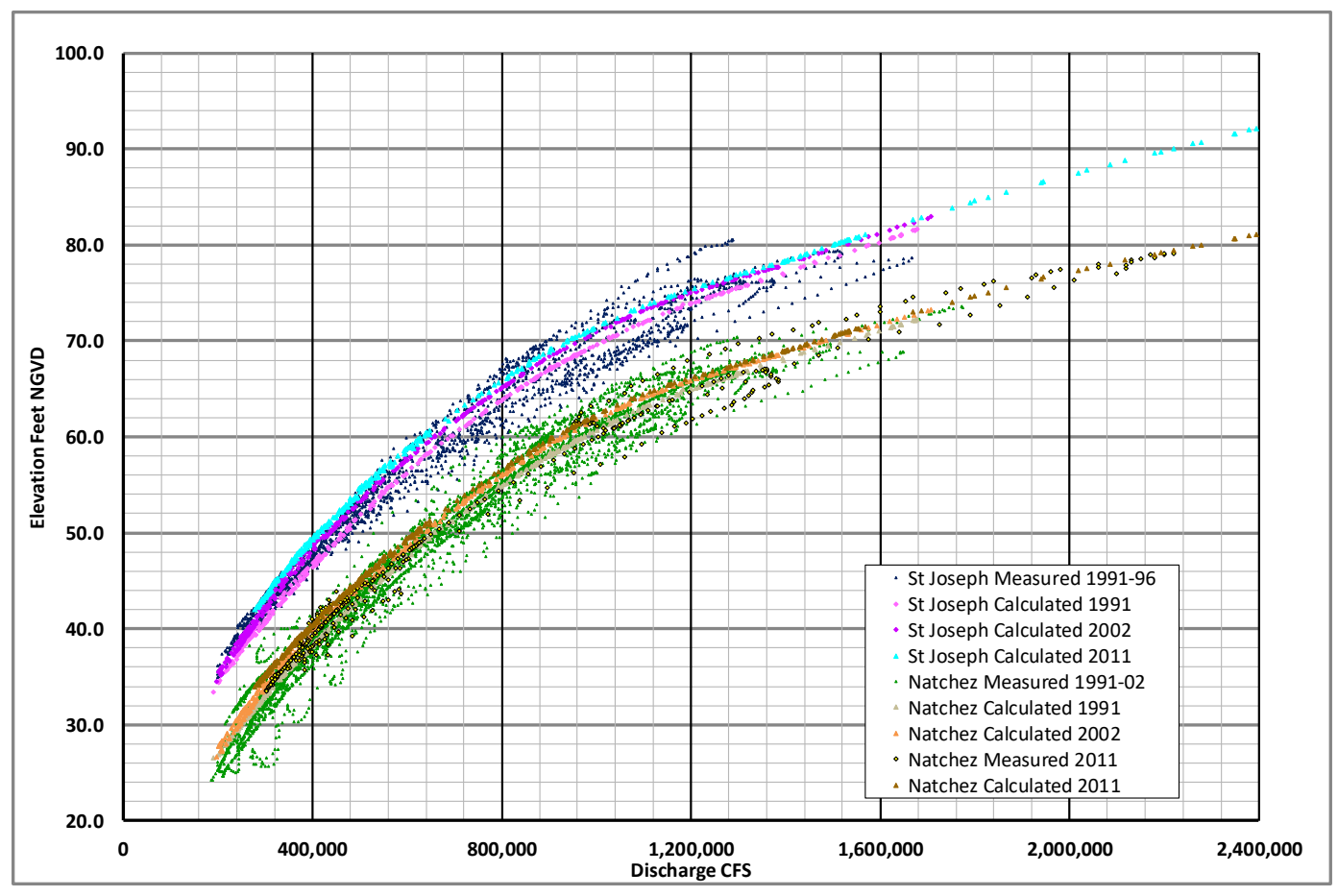


Figure 29. Stage-discharge for Lake Providence (RM 486.4) and Vicksburg (RM 437.4).

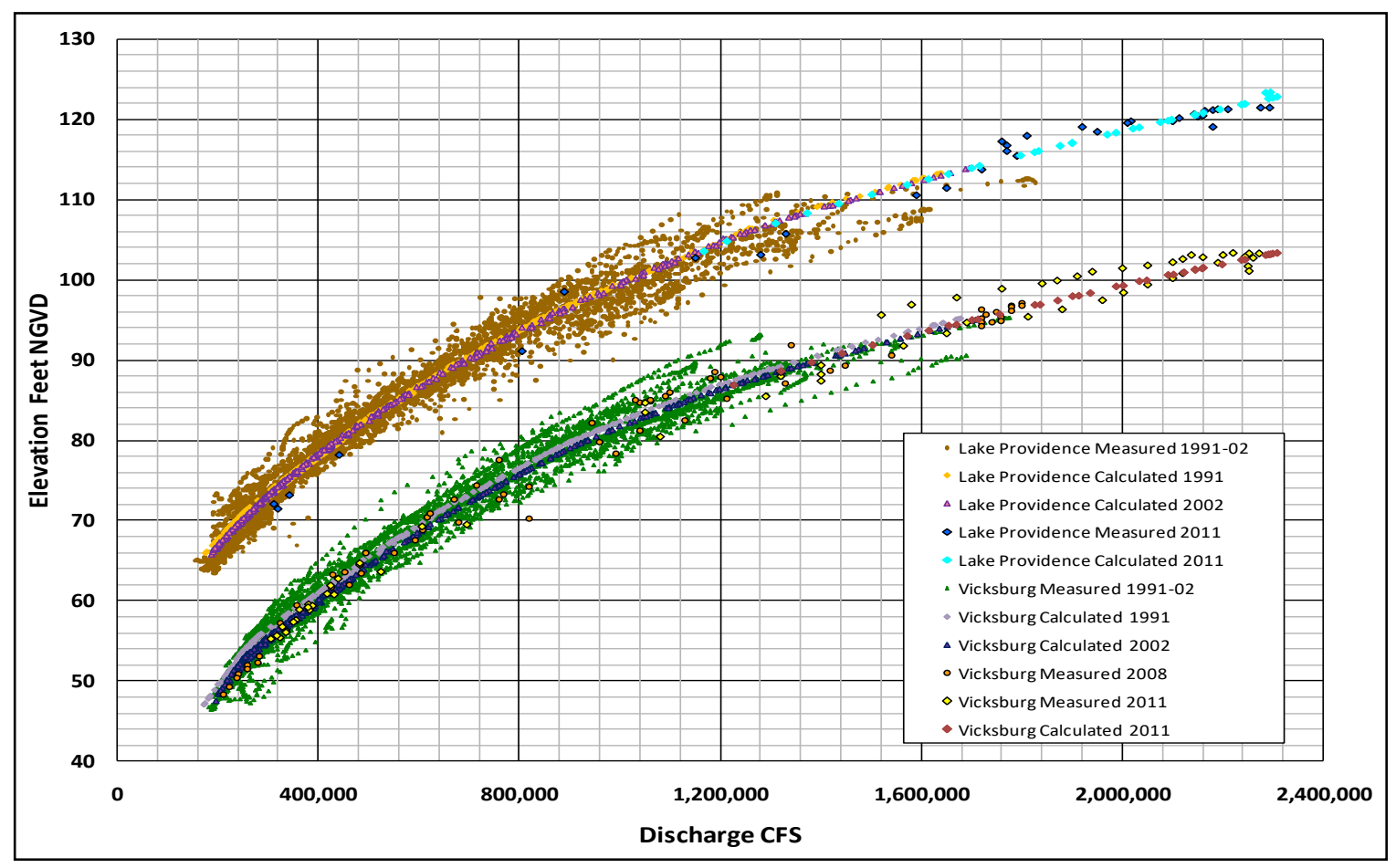

Figure 30. Stage-discharge for Arkansas City (RM 554.1) and Greenville (RM 531.5).

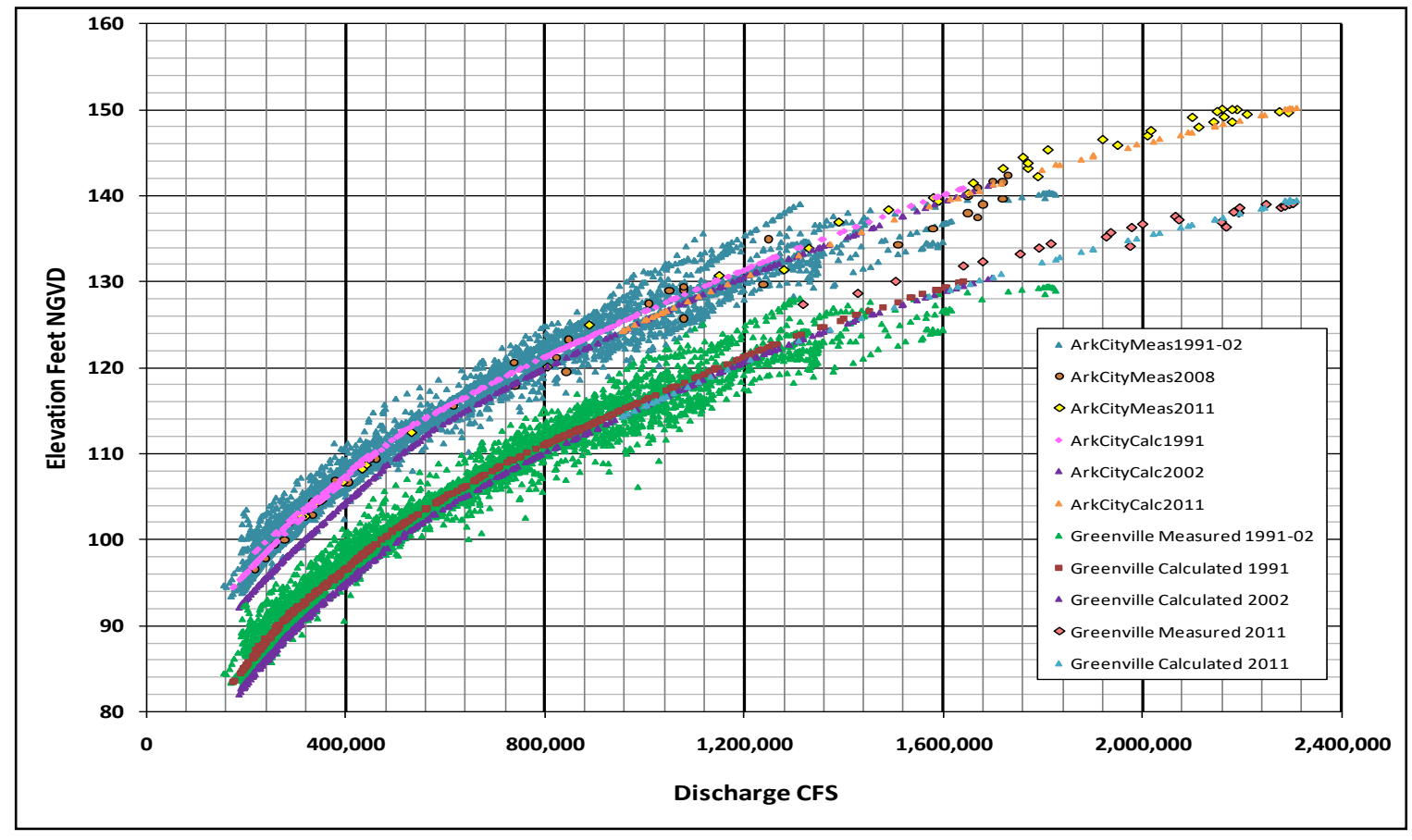


Figure 31. Stage-discharge for Rosedale (RM 592).

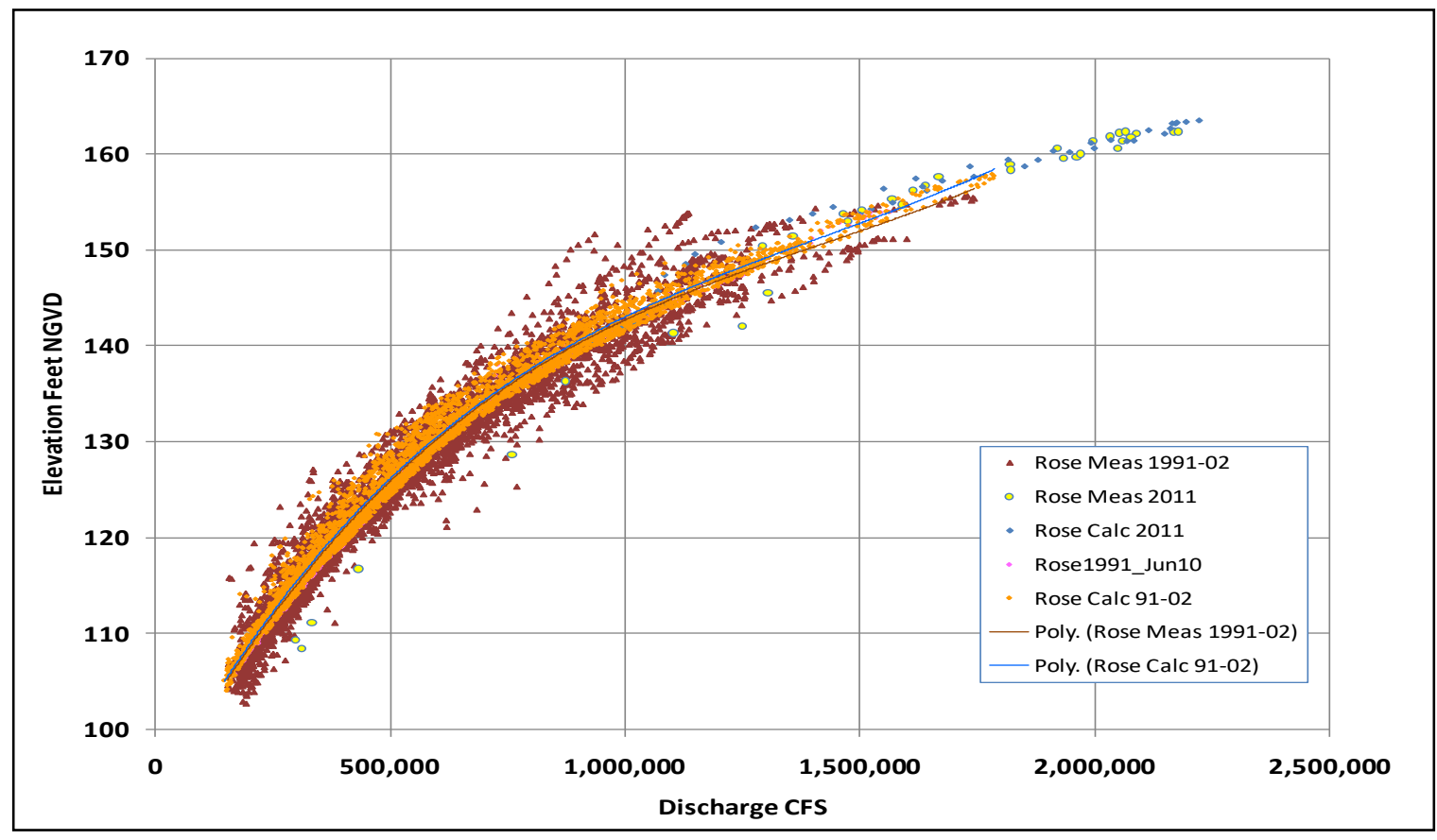

There were no significant flood events during the calibration period. Therefore, data from 1973 were initially used to estimate roughness coefficients in the Vicksburg District for large floods. Then, between completion of the modeling effort and this report documentation, the flood of record (in terms of stage) occurred at Vicksburg in 2011. Although this study was not intended to evaluate river response outside the 1991-2002 time frame, since 2011 flood data became available, it was deemed appropriate to use the more recent 2011 stage-discharge discharges to estimate roughness coefficients for high flows that will occur in future longterm studies. Stage-discharge relationships for floods in 1973, 1989, 1991, 2008 are compared to 2011 in Figure 32. Roughness coefficients calculated using the 2011 average rating curve were higher than originally used in the HEC-6T model, which had been calibrated using an extrapolation of the 1973 flood rating curves. This analysis is incomplete because the model was not used to simulate aggradation/degradation between 1973 and 2011, and the apparent increase in roughness could be due to a long-term loss in channel capacity, increase in vegetation on bars, or other factors. More study on these issues should be addressed in future studies. 
Figure 32. Stage-discharge for historical floods on the Mississippi River at Vicksburg.

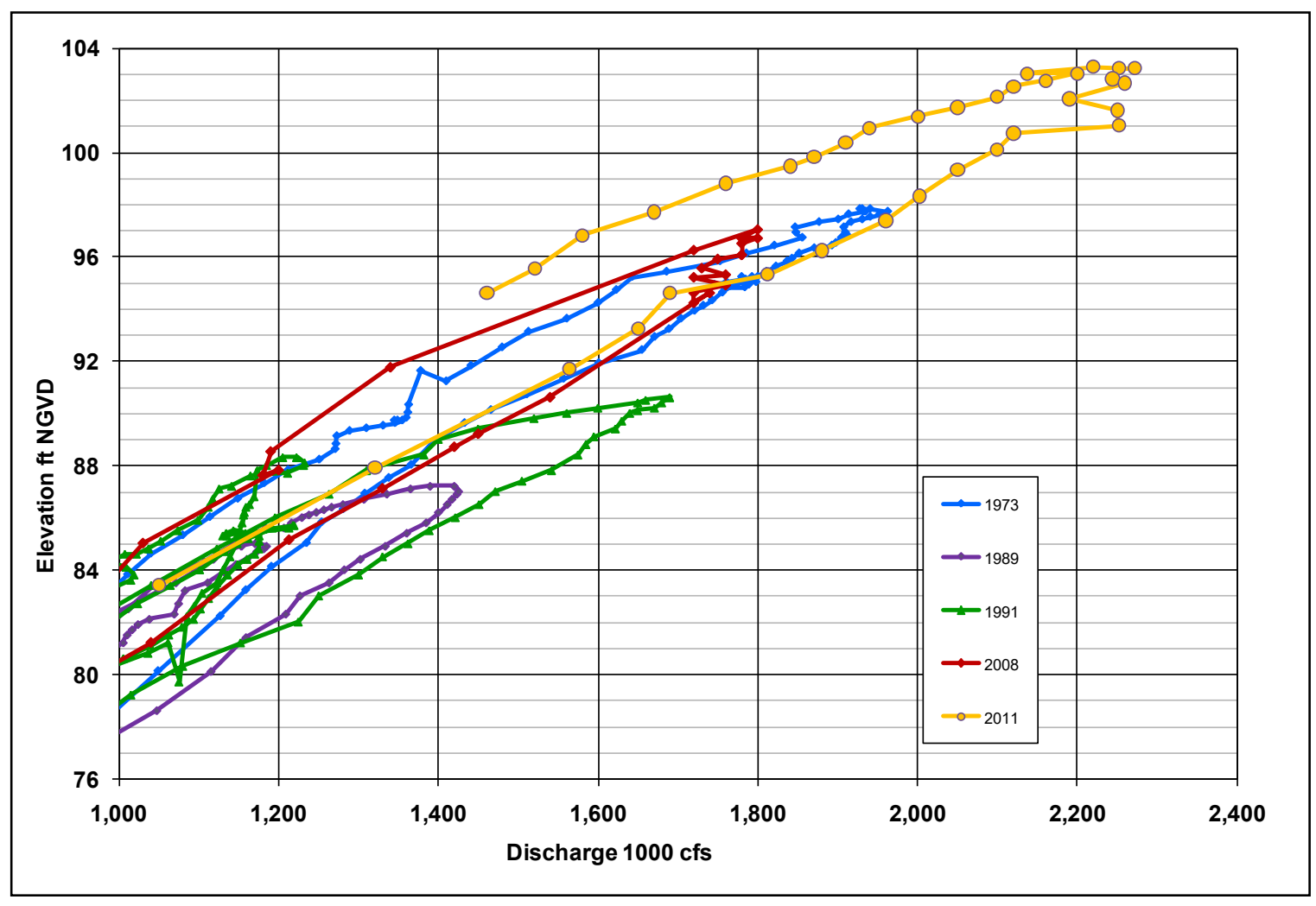

The 1991-2002 measured data for three gages in the Memphis District are shown in Figure 33 through Figure 35. The bottom row of points in Figure 35 is not an error; it represents stages during the rising limb of the hydrograph in December 1990. A similar row of low points can be identified in Figure 34 and represents the rising limb of the hydrograph in March 1993. Large variations in the stage discharge relationship is typical of the Mississippi River where the combination of unsteady flow effects and bed form changes significantly influence the energy slope and channel-bed roughness.

Also shown on these figures are calculated rating curves at the end of the first year of the movable-bed simulation (1991) and at the end of the 12-year simulation (2002). Roughness coefficients determined during the initial fixed-bed calibration were found to produce reasonable results during the movable bed simulation. 
Figure 33. Stage-discharge for Helena (RM 663.1).

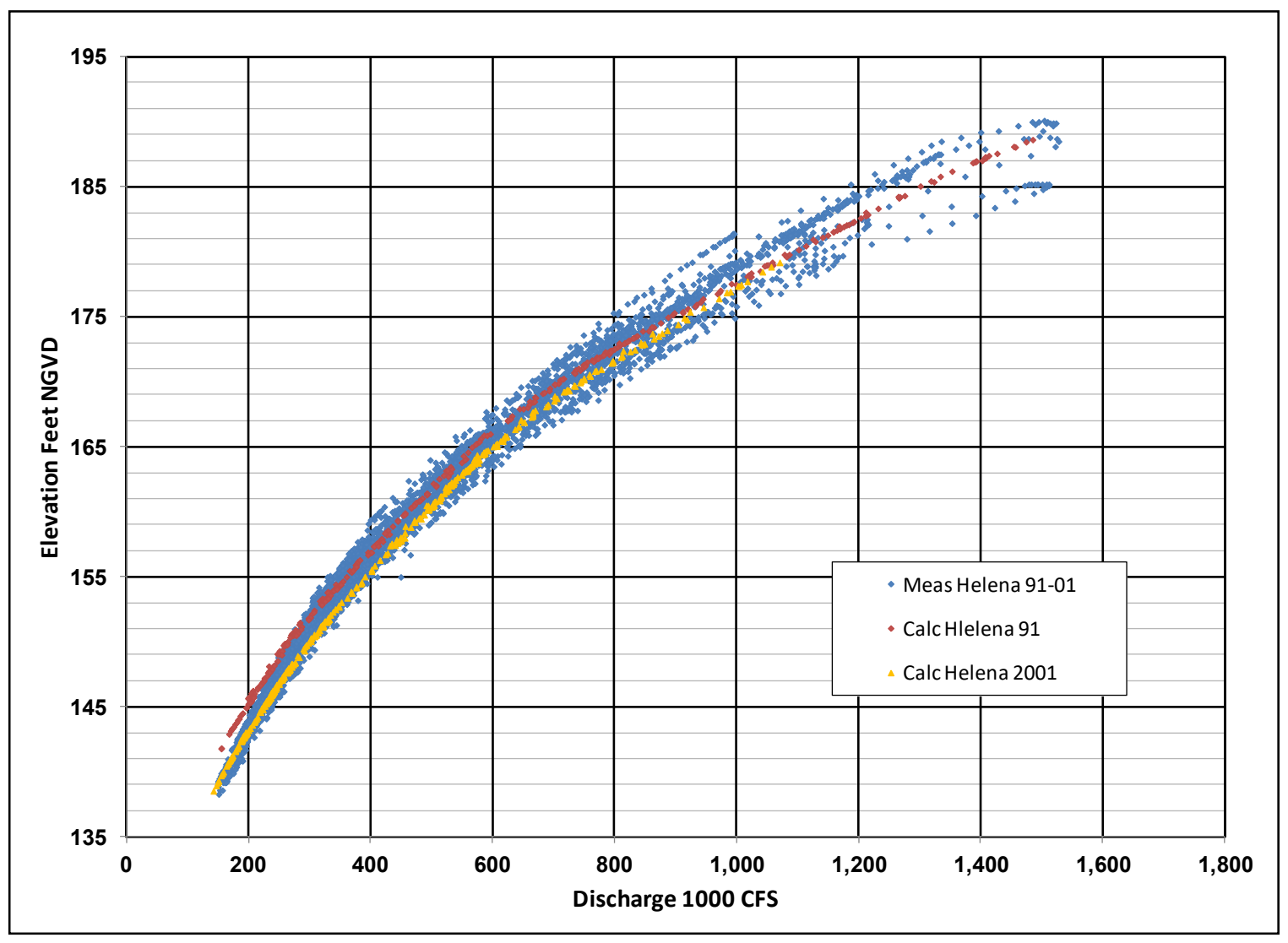

Figure 34. Stage-discharge for Memphis (RM 734.4).

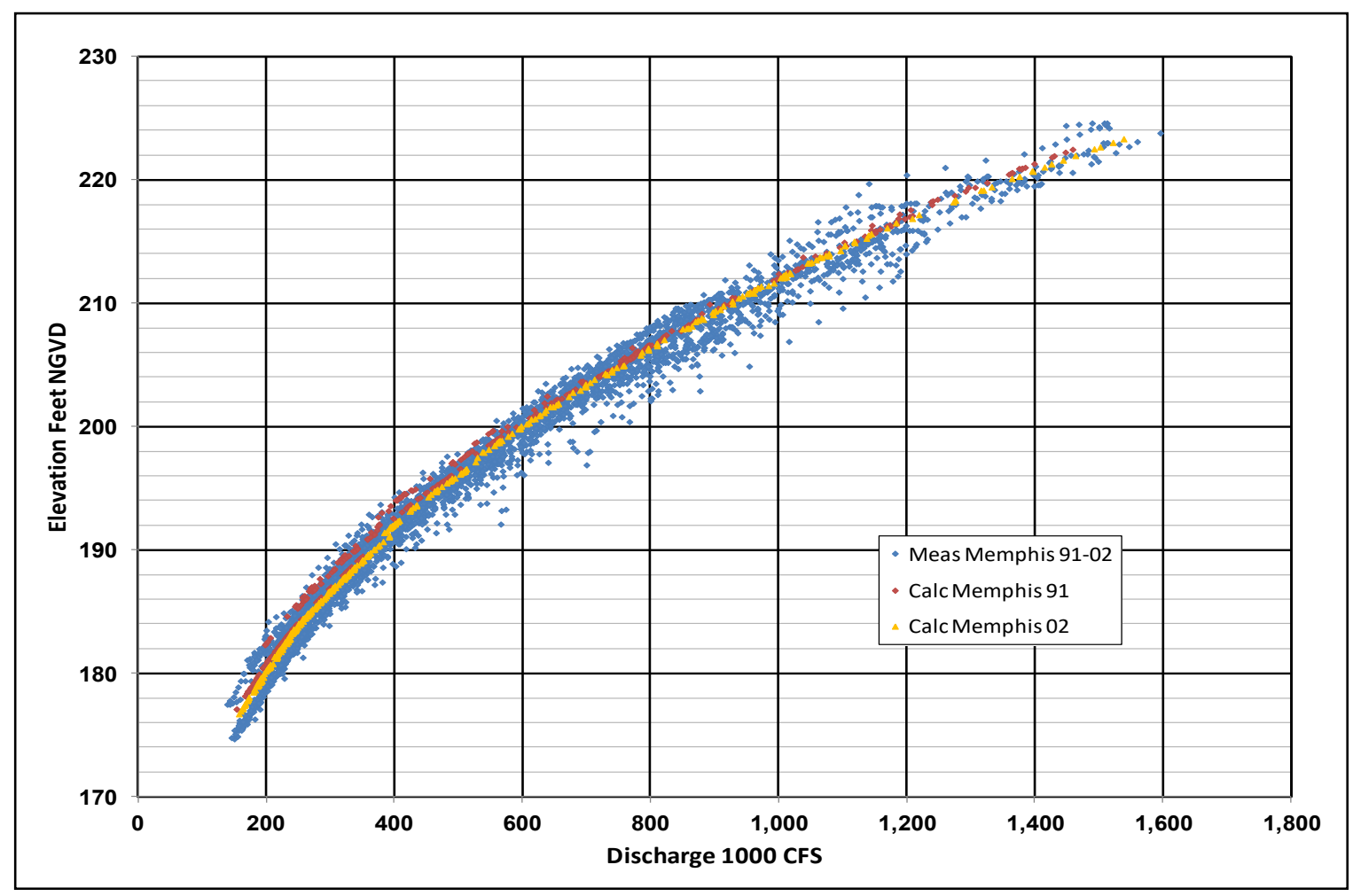


Figure 35. Stage-discharge for Hickman (RM 922).

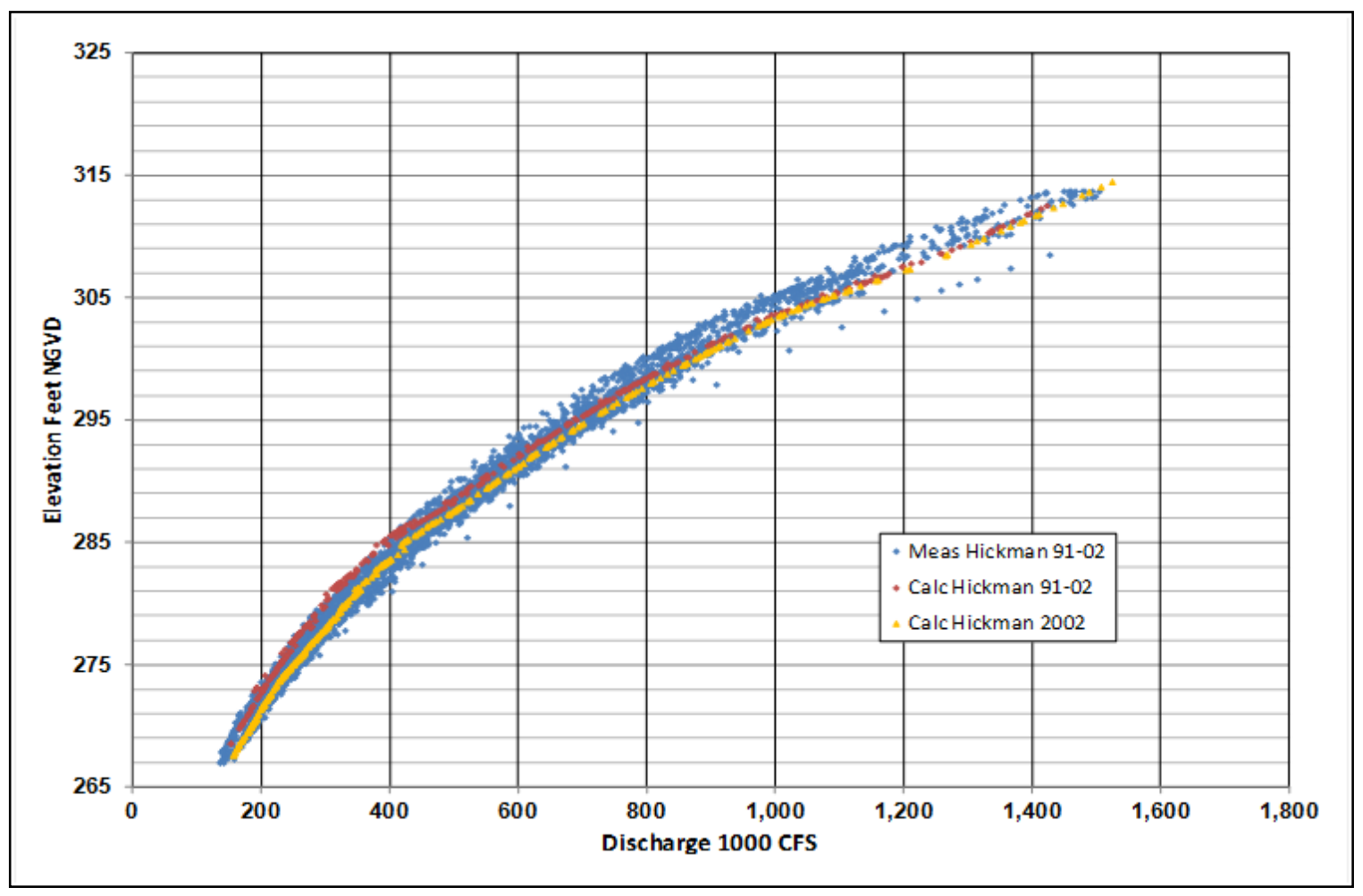

Roughness coefficients in the numerical model varied with both discharge and distance along the river. Overbank and channel roughness coefficients used in the HEC-6T model in the New Orleans District are shown in Table 15, in the Vicksburg District in Table 16, and in the Memphis District in Table 17. In the HEC-6T model, roughness values at a cross section are used at all subsequent upstream cross sections until changed. When the discharges are greater or less than those shown in the table, the last roughness coefficient shown in the table is used in the model. The discharges shown in the tables refer to the discharge at each specific river mile shown in column one of the table. The table discharges were chosen to account for any breaks in the regression of the measured stage data and do not relate to any specific frequency or event. Unreasonable coefficient magnitudes were not used for the sake of achieving a better fit to measured data. 
Table 15. HEC-6T roughness coefficients in New Orleans District.

\begin{tabular}{|c|c|c|c|c|c|c|}
\hline \multirow[b]{2}{*}{$\begin{array}{l}\text { River } \\
\text { Mile }\end{array}$} & \multirow[b]{2}{*}{ Overbanks } & \multicolumn{5}{|c|}{ Channel } \\
\hline & & $\begin{array}{l}250,000 \\
\text { cfs }\end{array}$ & $\begin{array}{c}550,000 \\
\text { cfs }\end{array}$ & $\begin{array}{c}850,000 \\
\text { cfs }\end{array}$ & $\begin{array}{c}950,000 \\
\text { cfs }\end{array}$ & $\begin{array}{c}1,500,000 \\
\mathrm{cfs}\end{array}$ \\
\hline-18.0 & 0.05 & 0.0165 & 0.0165 & 0.0165 & 0.0165 & 0.0165 \\
\hline 0.0 & 0.15 & 0.032 & 0.022 & 0.0165 & 0.0165 & 0.0165 \\
\hline 11.05 & 0.20 & 0.024 & 0.019 & 0.015 & 0.014 & 0.014 \\
\hline 35.1 & 0.20 & 0.024 & 0.023 & 0.022 & 0.022 & 0.015 \\
\hline 53.0 & 0.20 & 0.027 & 0.026 & 0.024 & 0.023 & 0.0205 \\
\hline 105.0 & 0.20 & 0.029 & 0.026 & 0.0253 & 0.025 & 0.021 \\
\hline 141.6 & 0.20 & 0.028 & 0.026 & 0.0245 & 0.024 & 0.022 \\
\hline 177.3 & 0.20 & 0.026 & 0.026 & .025 & 0.022 & 0.021 \\
\hline 195.3 & 0.20 & 0.026 & 0.026 & .025 & 0.022 & 0.021 \\
\hline 229.7 & 0.20 & 0.027 & 0.027 & .025 & 0.025 & 0.024 \\
\hline 267.0 & 0.20 & 0.029 & 0.027 & .024 & 0.0237 & 0.020 \\
\hline 306.3 & 0.15 & 0.034 & 0.031 & .031 & 0.0303 & 0.0275 \\
\hline
\end{tabular}

Table 16. HEC-6T roughness coefficients in Vicksburg District.

\begin{tabular}{|c|c|c|c|c|c|c|}
\hline \multirow{2}{*}{$\begin{array}{c}\text { River } \\
\text { Mile }\end{array}$} & Overbanks & $\begin{array}{c}\text { 200,000 } \\
\text { cfs }\end{array}$ & $\begin{array}{c}400,000 \\
\text { cfs }\end{array}$ & $\begin{array}{c}900,000 \\
\text { cfs }\end{array}$ & $\begin{array}{c}1,400,000 \\
\text { cfs }\end{array}$ & $\begin{array}{c}1,800,000 \\
\text { cfs }\end{array}$ \\
\hline 328.6 & 0.14 & 0.034 & 0.031 & 0.031 & 0.028 & 0.028 \\
\hline 365.0 & 0.14 & 0.034 & 0.029 & 0.028 & 0.028 & 0.028 \\
\hline 396.4 & 0.14 & 0.028 & 0.027 & 0.029 & 0.028 & 0.028 \\
\hline 438.4 & 0.14 & 0.029 & 0.028 & 0.027 & 0.028 & 0.028 \\
\hline 487.8 & 0.14 & 0.028 & 0.027 & 0.026 & 0.027 & 0.028 \\
\hline 531.7 & 0.14 & 0.028 & 0.027 & 0.026 & 0.027 & 0.029 \\
\hline 557.2 & 0.14 & 0.033 & 0.030 & 0.029 & 0.027 & 0.025 \\
\hline
\end{tabular}


Table 17. HEC-6T roughness coefficients in Memphis District.

\begin{tabular}{|c|c|c|c|c|c|c|}
\hline \multirow[b]{2}{*}{ River Mile } & \multirow[b]{2}{*}{ Overbanks } & \multicolumn{5}{|c|}{ Channel -1000 cfs } \\
\hline & & 200 & 400 & 600 & 1,400 & 1,800 \\
\hline 580.8 & 0.14 & 0.033 & 0.030 & 0.026 & 0.027 & 0.025 \\
\hline & & 100 & 500 & 750 & 1,000 & 2,000 \\
\hline 598 & $0.15-0.25$ & 0.033 & 0.029 & 0.029 & 0.029 & 0.028 \\
\hline 600.1 & $0.15-0.25$ & 0.033 & 0.031 & 0.031 & 0.030 & 0.029 \\
\hline 666.01 & $0.15-0.25$ & 0.035 & 0.031 & 0.030 & 0.030 & 0.029 \\
\hline & & 100 & 500 & 1,000 & 1,250 & 2,000 \\
\hline 738 & $0.10-0.19$ & 0.034 & 0.033 & 0.033 & 0.033 & 0.028 \\
\hline 741 & $0.10-0.25$ & 0.036 & 0.033 & 0.033 & 0.033 & 0.028 \\
\hline 752.98 & $0.15-0.25$ & 0.036 & 0.029 & 0.028 & 0.028 & 0.029 \\
\hline 784 & $0.15-0.25$ & 0.036 & 0.030 & 0.030 & 0.030 & 0.031 \\
\hline 796.01 & $0.15-0.25$ & 0.036 & 0.030 & 0.029 & 0.029 & 0.032 \\
\hline 803.84 & $0.10-0.25$ & 0.036 & 0.027 & 0.029 & 0.029 & 0.032 \\
\hline 828.24 & $0.15-0.25$ & 0.036 & 0.027 & 0.029 & 0.029 & 0.034 \\
\hline 846.4 & 0.10 & 0.036 & 0.032 & 0.031 & 0.031 & 0.034 \\
\hline 864.7 & 0.10 & 0.036 & 0.027 & 0.029 & 0.029 & 0.034 \\
\hline 873.04 & 0.10 & 0.036 & 0.027 & 0.029 & 0.029 & 0.036 \\
\hline 880 & 0.20 & 0.036 & 0.028 & 0.029 & 0.029 & 0.036 \\
\hline 881.89 & 0.20 & 0.036 & 0.028 & 0.033 & 0.033 & 0.040 \\
\hline 882.6 & $0.15-0.25$ & 0.036 & 0.030 & 0.033 & 0.033 & 0.040 \\
\hline 910.54 & $0.15-0.25$ & 0.036 & 0.036 & 0.036 & 0.036 & 0.036 \\
\hline 915.59 & 0.15 & 0.036 & 0.030 & 0.033 & 0.033 & 0.040 \\
\hline 923.46 & 0.15 & 0.033 & 0.025 & 0.028 & 0.028 & 0.034 \\
\hline 927.5 & 0.15 & 0.031 & 0.025 & 0.024 & 0.024 & 0.031 \\
\hline 934.41 & $0.15-0.25$ & 0.031 & 0.025 & 0.024 & 0.024 & 0.031 \\
\hline 949 & 0.12 & 0.031 & 0.025 & 0.023 & 0.023 & 0.029 \\
\hline 953.03 & 0.12 & 0.031 & 0.025 & 0.023 & 0.023 & 0.027 \\
\hline
\end{tabular}

\section{Roughness coefficients for Ohio and Arkansas Rivers}

Roughness coefficients for the Arkansas River were transferred from the Little Rock District HEC-RAS model. A roughness coefficient of 0.031 was used in the channel. Overbank roughness coefficients ranged between 0.08 and 0.14 .

Roughness coefficients for the Ohio River were adjusted until the computed water surface elevations reproduced average measured data from the USGS gage Ohio River at Metropolis, Illinois (0361150), which is located at RM 944.1 below Pittsburgh (The Point), which is equivalent to 
RM 990.5 (AHP) and is 37 miles upstream from the Mississippi River confluence. A roughness coefficient of 0.026 was used for the channel. Overbanks were assigned a roughness coefficient of 0.230. Daily stages and discharges were obtained from the USGS website http://nwis.waterdata.usgs.gov/nwis. Using discharges from Metropolis, a stagedischarge plot was also developed at Cairo (RM 955.8 AHP).

Daily stages reported at Metropolis for 1991-2002 are compared to daily stages calculated by HEC-6T in Figure 36. Based on scatter in plotted points in Figure 36, Metropolis appears to be in the backwater from the Mississippi River. As such, the rating curve is not strictly friction controlled. However, the selected roughness coefficients for the Ohio River reproduced both the scatter and the average regression documented by the measured data and is considered appropriate for use in the numerical model. Using a single event to calibrate roughness coefficients is not desirable when it is known that individual events produce significantly different looped rating curves. In the sediment analysis, it is average conditions that are appropriate.

Daily stage data at Cairo, shown in Figure 37, were obtained from the USACE website Rivergages.com.

Figure 36. Stage-discharge for the Ohio River at Metropolis (RM 990 AHP), 1991-2002.

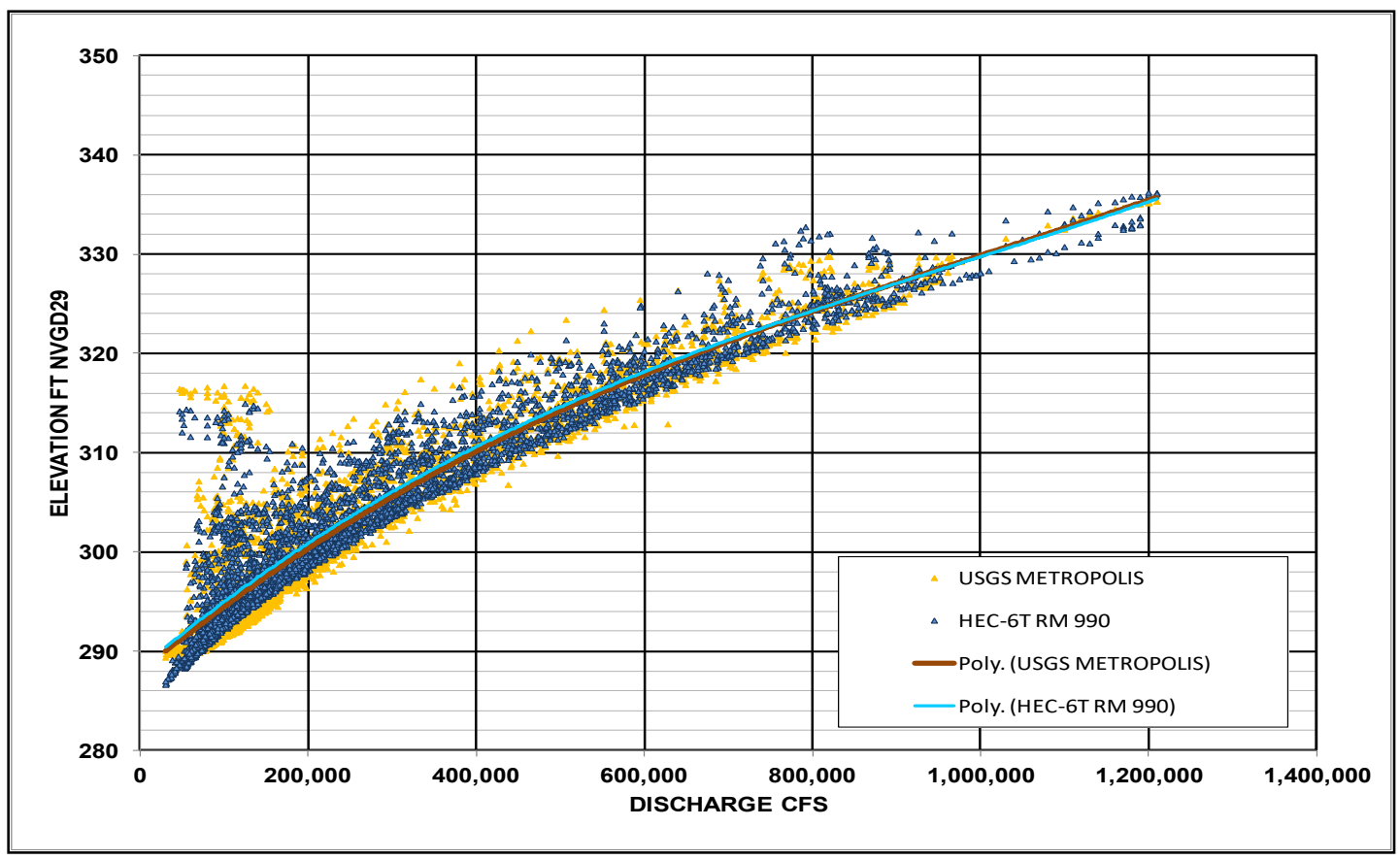


Figure 37. Stage-discharge for the Ohio River at Cairo (RM 955.8 AHP), 1991-2002.

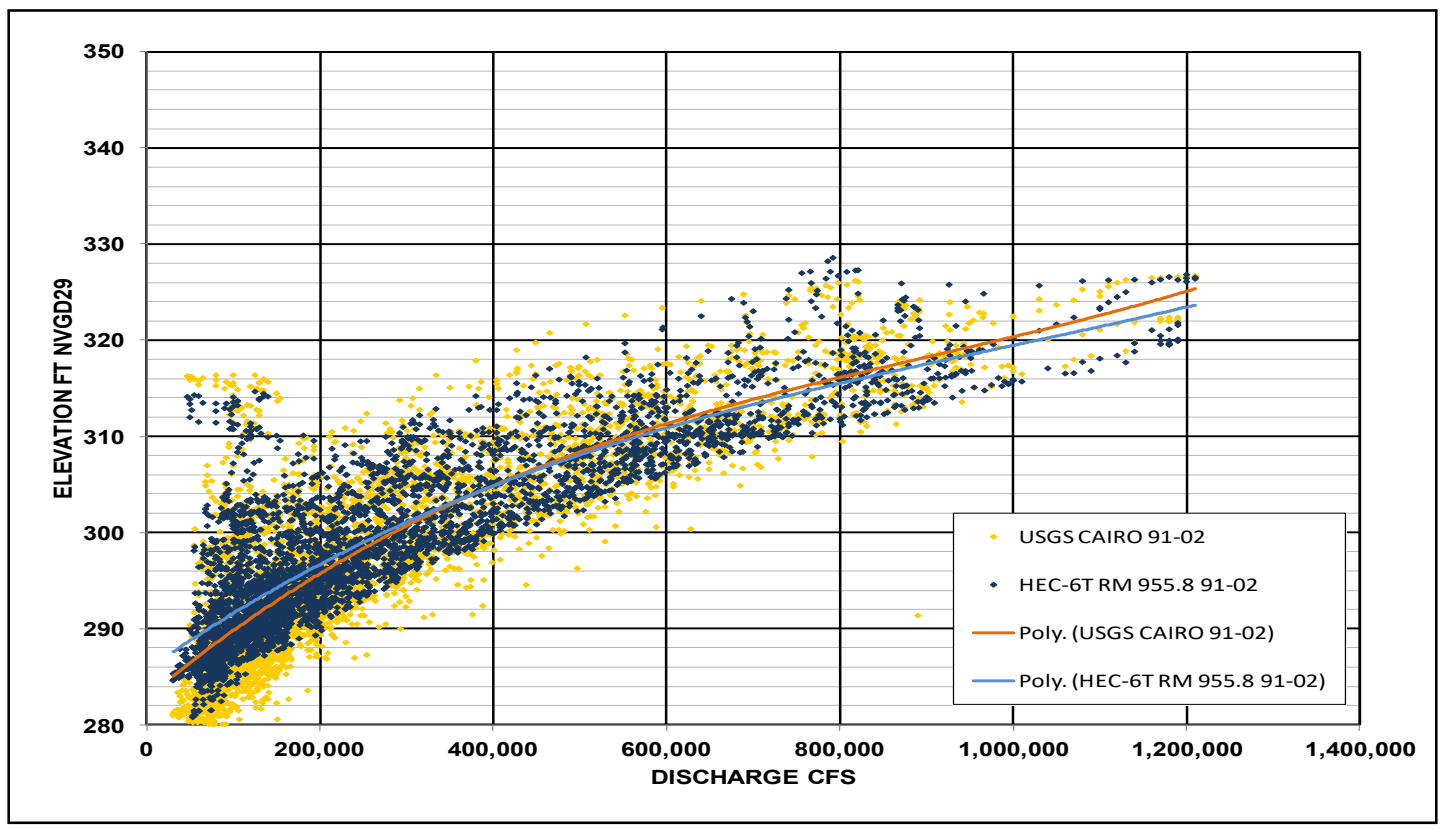

\section{Sediment transport}

The grain sizes of sediment particles transported by the Mississippi River range over several orders of magnitude. The small sizes behave much differently from the large sizes. Therefore, it is necessary to classify sediment material into groups for application of different sediment transport functions. The four basic classes considered in this study are clay, silt, sand, and gravel. The groups are identified and subdivided based on the American Geophysical Union classification scale (Lane 1947). Sediments smaller than 0.004 millimeter $(\mathrm{mm})$ are classified as clay. Sediments between 0.004 and $0.0625 \mathrm{~mm}$ are classified as silt. Sediments between 0.0625 and $2.0 \mathrm{~mm}$ are classified as sand. Sediments between 2 and $64 \mathrm{~mm}$ are classified as gravel. This study included one clay, four silt, five sand, and five gravel size classes.

\section{Sand and gravel transport function}

The sand sediment transport function in the HEC-6T numerical model calculates transport of the total sand and gravel sediment loads. This includes the sand and gravel bed-material load and the sand wash load. The bed-material load includes size classes found in substantial quantities in the bed and moves as bed load and suspended load. The armoring and sorting algorithm in the numerical model also allows for transport of sand sizes, not found in the bed, as suspended wash load. 
The sediment transport function for sand and gravel chosen for this study was the Toffaleti-Meyer-Peter Muller function. With this function, bed load is calculated using the Toffaleti (1968) and Meyer-Peter Muller (1948) methods, and the larger of the two is used. Suspended bed-material load is then calculated using the Toffaleti method. The Toffaleti-Meyer-Peter Muller function is capable of calculating sand and gravel transport rates by size class. The Toffaleti equation was developed for large rivers like the Mississippi River. The Meyer-Peter Muller equation was used to facilitate the transport of gravel size classes known to be in the river bed in the Memphis District reach.

\section{Silt and clay transport functions}

The equation for silt and clay deposition used in HEC-6T is the Krone (1962) equation. The required calibration coefficient is the critical bed shear stress below which deposition occurs. In HEC-6T, this coefficient has a variable name $D T C L$ for clay and $D T S L$ for silt.

$$
\begin{gathered}
\frac{C}{C_{o}}=e^{-k^{\prime} t} \\
k^{\prime}=\frac{\omega\left(1-\tau_{b} / \tau_{d}\right)}{2.3 D}
\end{gathered}
$$

where:

$$
\begin{aligned}
C & =\text { concentration at end of time step } \\
C_{o} & =\text { concentration at beginning of time step } \\
t & =\text { time }=\text { reach length/flow velocity } \\
\omega & =\text { settling velocity of sediment particle } \\
\tau_{b} & =\text { bed shear stress } \\
\tau_{d} & =\text { critical bed shear stress for deposition }(D T C L \text { and } D T S L) \\
D & =\text { water depth. }
\end{aligned}
$$

Erosion in HEC-6T is calculated using the Parthenaides (1965) equation as adapted by Ariathurai and Krone (1976). Initial erosion coefficients for the equation were taken from previous numerical model work by Thomas et al. (1989). These were modified during model calibration. It is the cohesive properties of the clay that determine the erosion thresholds. For this 
reason, the same erosion coefficients are used for silt and clay in HEC-6T. Particle erosion is determined by the following:

$$
C=\frac{M_{1} S_{a}}{Q \gamma}\left[\frac{\tau_{b}}{\tau_{s}}-1\right]+C_{o}
$$

where:

$$
\begin{aligned}
M_{1}= & \text { erosion rate for particle scour }\left[\tau_{b}{ }^{*} E R M E /(S T M E-S T C D)\right] \\
& \left(S T C D<\tau_{b}<S T M E\right) \\
S_{a}= & \text { surface area exposed to scour } \\
Q= & \text { water discharge } \\
\tau_{s}= & \text { critical bed shear stress for particle scour }(S T C D) \\
\gamma= & \text { specific weight of water. }
\end{aligned}
$$

As the bed shear stress increases, particle erosion gives way to mass erosion, and the erosion rate increases. Because the mass erosion can theoretically be infinite, a characteristic time, $T_{c}$, is used. With a computation time interval of $\Delta t$, the mass erosion becomes the following:

$$
C=\frac{M_{2} S_{a}}{Q \gamma} \frac{T_{c}}{\Delta t}+C_{o}
$$

where:

$$
\begin{aligned}
M_{2}= & \text { erosion rate for mass erosion }\left(E R M E+E R 2\left\{\tau_{b}-S T M E\right\}\right) \Delta t / \\
& T_{c} \\
T_{c}= & \text { characteristic time of erosion } \\
\Delta t= & \text { duration of time-step. }
\end{aligned}
$$

Silt and clay deposition coefficients were varied in the model. One set of coefficients was used in Southwest Pass, another in the reach between Head of Passes and RM 11.0, and another upstream from RM 11.0. Varying these coefficients was deemed reasonable to account for the effects of salinity on sediment deposition. Silt and clay coefficients used in the numerical model were determined during model calibration and are shown in Table 18. The erosion coefficients for Southwest Pass and upstream from RM 11.0 are the same as those used in two previous numerical sedimentation studies of the Lower Mississippi River (Copeland 
1991; Copeland and Thomas 1992).The relationships of erosion and deposition coefficients are shown in Figure 38 and Figure 39.

Table 18. Silt and clay coefficients for Parthenaides and Krone equations.

\begin{tabular}{|l|c|c|c|c|c|}
\hline Coefficient & $\begin{array}{c}\text { Variable Name } \\
\text { in HEC-6T }\end{array}$ & $\begin{array}{c}\text { Southwest } \\
\text { Pass }\end{array}$ & $\begin{array}{c}\text { River Miles } \\
0.0 \text { to } 11.05\end{array}$ & Fresh Water & Units \\
\hline $\begin{array}{l}\text { Shear threshold for clay } \\
\text { deposition }\end{array}$ & DTCL & .005 & .003 & .001 & $\mathrm{Ibs/ft2}$ \\
\hline $\begin{array}{l}\text { Shear threshold for silt } \\
\text { deposition }\end{array}$ & DTSL & .014 & .014 & .002 & $\mathrm{Ibs/ft2}$ \\
\hline $\begin{array}{l}\text { Shear threshold for erosion of } \\
\text { silt and clay particles }\end{array}$ & STCD & .025 & .020 & .020 & $\mathrm{lbs} / \mathrm{ft} 2$ \\
\hline $\begin{array}{l}\text { Shear threshold for mass } \\
\text { erosion }\end{array}$ & STME & .04 & .04 & .04 & $\mathrm{lbs} / \mathrm{ft} 2$ \\
\hline Erosion rate at STME & ERME & .001 & .001 & .001 & $\mathrm{lbs} / \mathrm{ft} 2 / \mathrm{hr}$ \\
\hline $\begin{array}{l}\text { Slope of the erosion rate curve } \\
\text { for mass erosion }\end{array}$ & ER2 & .03 & .03 & .03 & $1 / \mathrm{hr}$ \\
\hline
\end{tabular}

Figure 38. Erosion rate characteristics.

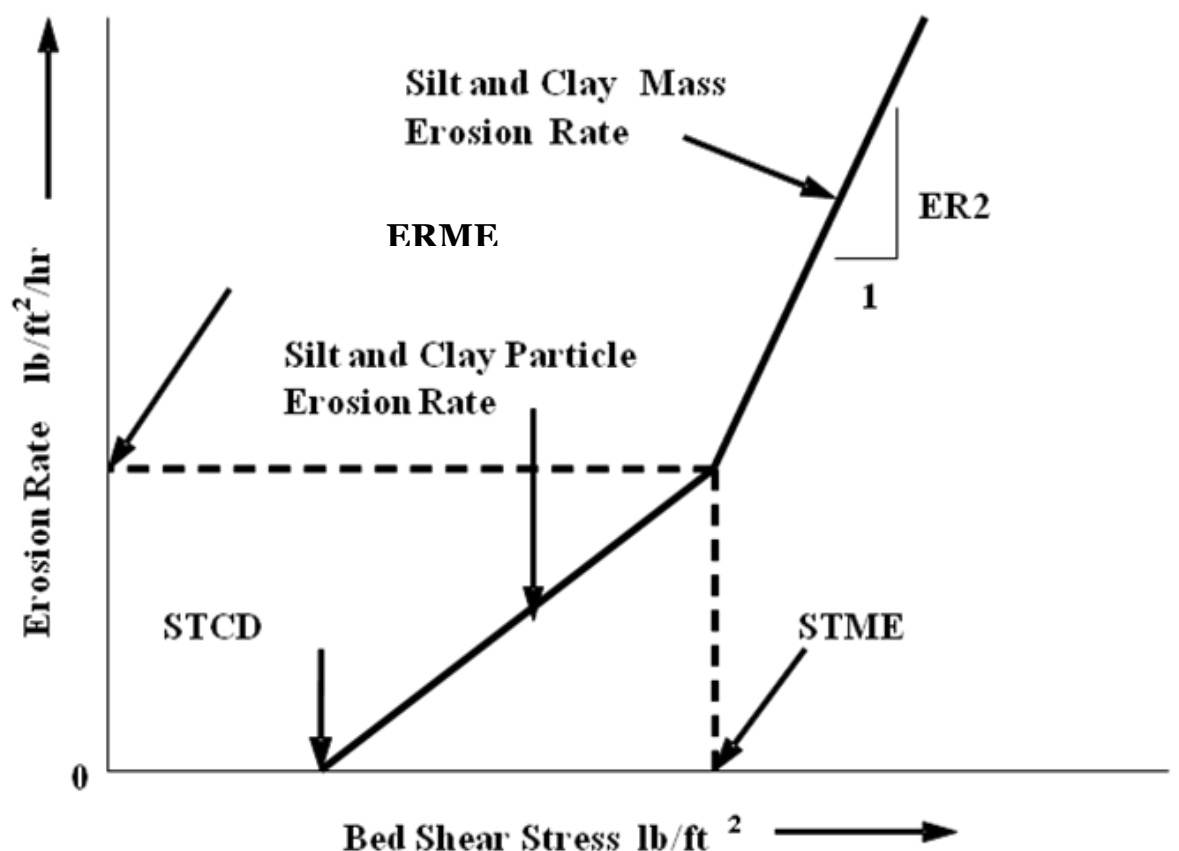

Bed Shear Stress $\mathbf{l b} / \mathrm{ft}^{2}$ 
Figure 39. Deposition rate characteristics.

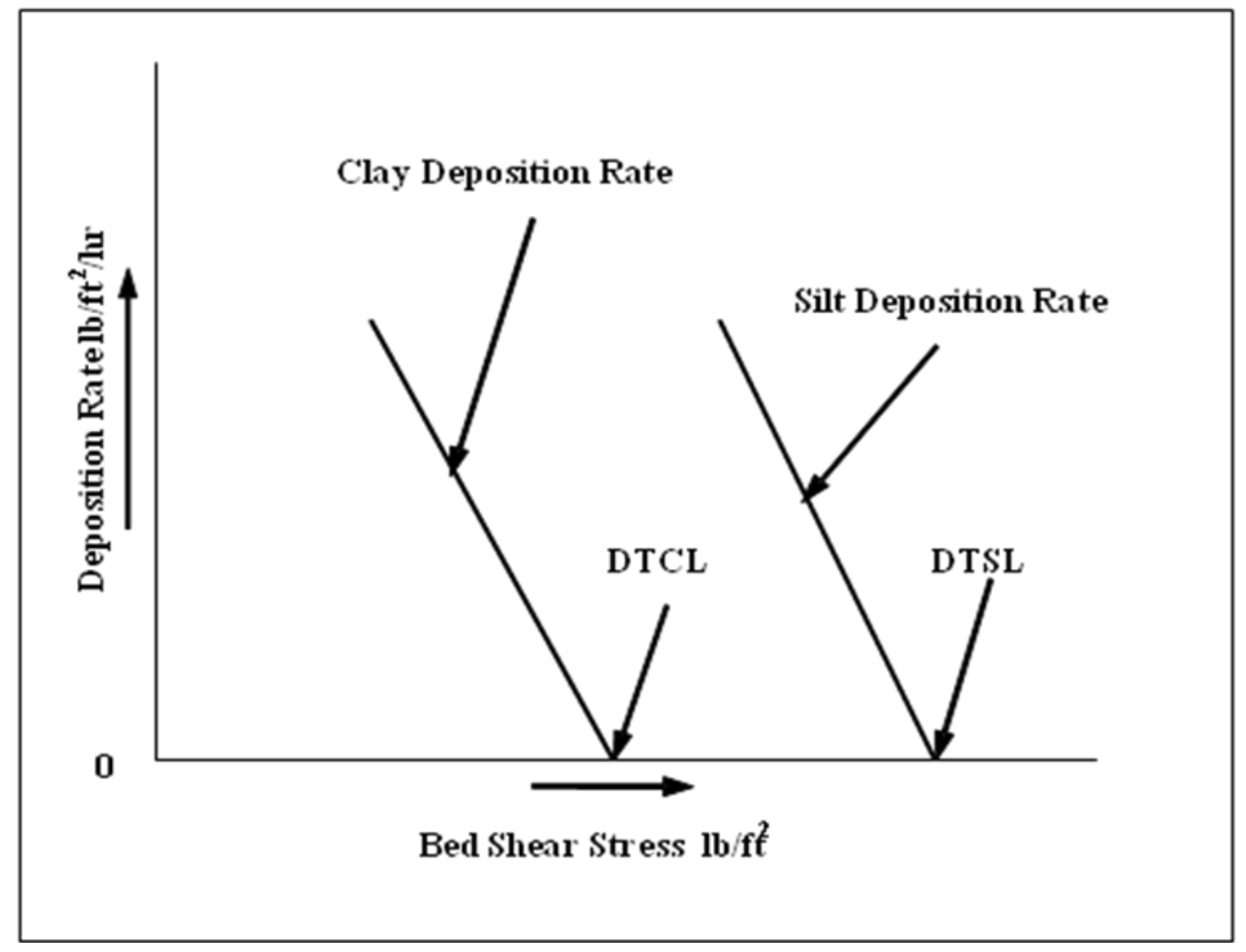

\section{Sediment inflow}

A combination of measured and calculated data was used to establish sediment inflow boundary conditions. To model sedimentation trends in the Mississippi River, it is necessary to account for movement and storage of each sediment size class. HEC-6T allows for this accounting; however, the required input data are generally lacking. Long-term size class sediment data are available in the study reach, on the Middle Mississippi River at Thebes, located 44 miles upstream from the Ohio River, and Chester, located 110 miles upstream from the Ohio River. Long-term size class data are also available at Union Point (RM 326.6 AHP) and Coochie (RM 317.3 AHP), which are located upstream from the Old River Control Complex and at Tarbert Landing (RM 306.3 AHP), which is located downstream from the Old River Control Complex. A shorter record is available at Belle Chasse, located 76 miles AHP. Data for the major tributaries, including the Ohio River, are generally limited to the sediment concentrations greater and less than $0.062 \mathrm{~mm}$. The lack of boundary condition data required that size class percentages be estimated by calculation and/or judgment. A continuing sediment data collection program is essential to verify and enhance future sediment inflow predictions. 
Sediment concentration is typically measured by mechanical samplers so that only a very small fraction of the actual load is physically measured. However, convention defines the measured suspended load as the sediment load that can be approximated from measured samples. The accuracy of the sediment measurement depends on the sampling collection method, the laboratory analysis of the samples and the protocol used to calculate average sediment concentration from the sample concentrations. The unmeasured load typically refers to the bed load plus the suspended load between the bed surface and the lowest sampled depth of the sampler's intake nozzle.

In this study, sediment transport rating curves at model boundaries and at gages within the study reach were based on the measured (reported) sediment data. Near the upstream boundary of the numerical model, at Thebes, sediment samples are collected using a depth-integrated sampler at five verticals using the equal-discharge increment (EDI) method. The unsampled zone is approximately 4 inches (in.). At this boundary, the unmeasured load includes the bed load and the suspended load in the first 4 in. above the bed. At Tarbert Landing, downstream from the Old River Control Complex, and at Coochie and Union Point, upstream from the Old River Control Complex, sediment samples are collected using a point sampler. Over the years, the number of verticals and the number of sampling points along each vertical has varied. Theoretically, the entire suspended load is considered to be measured. Practically, this is doubtful for the coarser sediment particles because the concentration profile for coarser particles increases exponentially near the bed, and the lowest point samples were taken between 70 and 95 percent of the depth. Nevertheless, only the bed load is considered unmeasured at the three gages near the Old River Control Complex. At Belle Chasse, samples are collected approximately 16 times a year with depth-integrated samplers and approximately 18 times a year with a point sampler. The depth integrated samplers have an unmeasured zone of approximately 4 in., and samples are collected at three fixed verticals. The point samples have been collected at four fixed verticals (changed to four EDI in April 2017) with points at $0.1,0.3,0.5,0.7$, and 0.9 of total depth at each vertical.

The unmeasured load has been historically estimated to be 15 percent of the total measured load. This approximation was first suggested by Dr. Hans Einstein in a personal communication in the 1960s. Based on subsequent studies and investigations, the New Orleans District concluded 
that the 15 percent estimate was appropriate (USACE MVN 1980, page 15). Numerical sediment studies conducted on the Lower Mississippi River increased the measured bed material load by 10 to 15 percent to account for unmeasured load at upstream model boundary (Copeland 1991; Copeland and Thomas 1992; Catalyst-Old River Hydroelectric 1999; Thomas 2012, page 124; Sharp et al. 2013). Uncertainty related to the unmeasured load decreases as the distance between the area of interest and the upstream boundary increases. This occurs because the numerical model calculates the total bed-material load. As the sediment calculations move in a downstream direction, the sediment continuity equation is solved, extracting material from the streambed as required to meet the total bed-material load transport capacity. However, the uncertainty increases as the simulation time increases.

Recent development of the ISSDOTv2 methodology (Abraham et al. 2011) has made it possible to physically measure the bed-form component of bed load by mapping the movement of dunes using sonar equipment. Measurements taken in the Mississippi River in the vicinity of the Old River Control Complex (Heath et al. 2015) demonstrated that the bed load percentage of the bed-material load varied with discharge. The bed load percentage of the bed-material load varied from highs near 45 percent to low vales of approximately 10 percent.

The relative importance of boundary condition precision at each model boundary is related to the contribution of water and sediment from that tributary. The percent of the annual Mississippi River discharge at Vicksburg for the years 1989-2003 is shown in Table 19. Over 8o percent of the annual discharge at Vicksburg comes from the Ohio and Middle Mississippi Rivers. Boundary conditions for these two rivers are by far the most important in the model study. 
Table 19. Percentage of the annual Mississippi River discharge at Vicksburg, 1991-2002.

\begin{tabular}{|l|l|}
\hline Ohio River & 45.1 \\
\hline $\begin{array}{l}\text { Middle Mississippi } \\
\text { River }\end{array}$ & 37.4 \\
\hline Arkansas River & 8.2 \\
\hline White River & 4.4 \\
\hline Yazoo River & 3.0 \\
\hline St. Francis River & 0.8 \\
\hline Hatchie River & 0.6 \\
\hline Obion River & 0.5 \\
\hline
\end{tabular}

\section{Sediment inflow Middle Mississippi River at Thebes and Chester}

Sediment data are available for the Mississippi River at Thebes, IL (o702200O), located 44 miles upstream from the Ohio River, and at Chester, IL (O702050O), which is located 110 miles upstream from the Ohio River. The number of measurements at Chester is much smaller than at Thebes. Total measured suspended sediment and measured suspended sand data were collected at Thebes between 1973 and 2010 and at Chester between 1982 and 1985. Size class data were collected at Thebes between 1973 and 1991 and at Chester between 1980 and 1991.

During the 37 years between 1973 and 2010, 396 measurements of the total sediment load and 366 measurements of the sand load were available from the Thebes gage. Only 17 concentration measurements were available at Chester for this period and were omitted from the analysis of concentrations. Average daily sediment concentrations were determined for days when multiple samples were reported. Power regression curves that were developed from the Thebes data are plotted by decade in Figure 40 and Figure 41. The curves suggest that the total load and the sand load have declined over the 37-year period. However, considering the data scatter, there is considerable uncertainty associated with this conclusion. Data were insufficient to evaluate measured sediment concentration trends for individual size classes including silt and clay. 
Figure 40. Total measured suspended sediment concentration at Thebes.

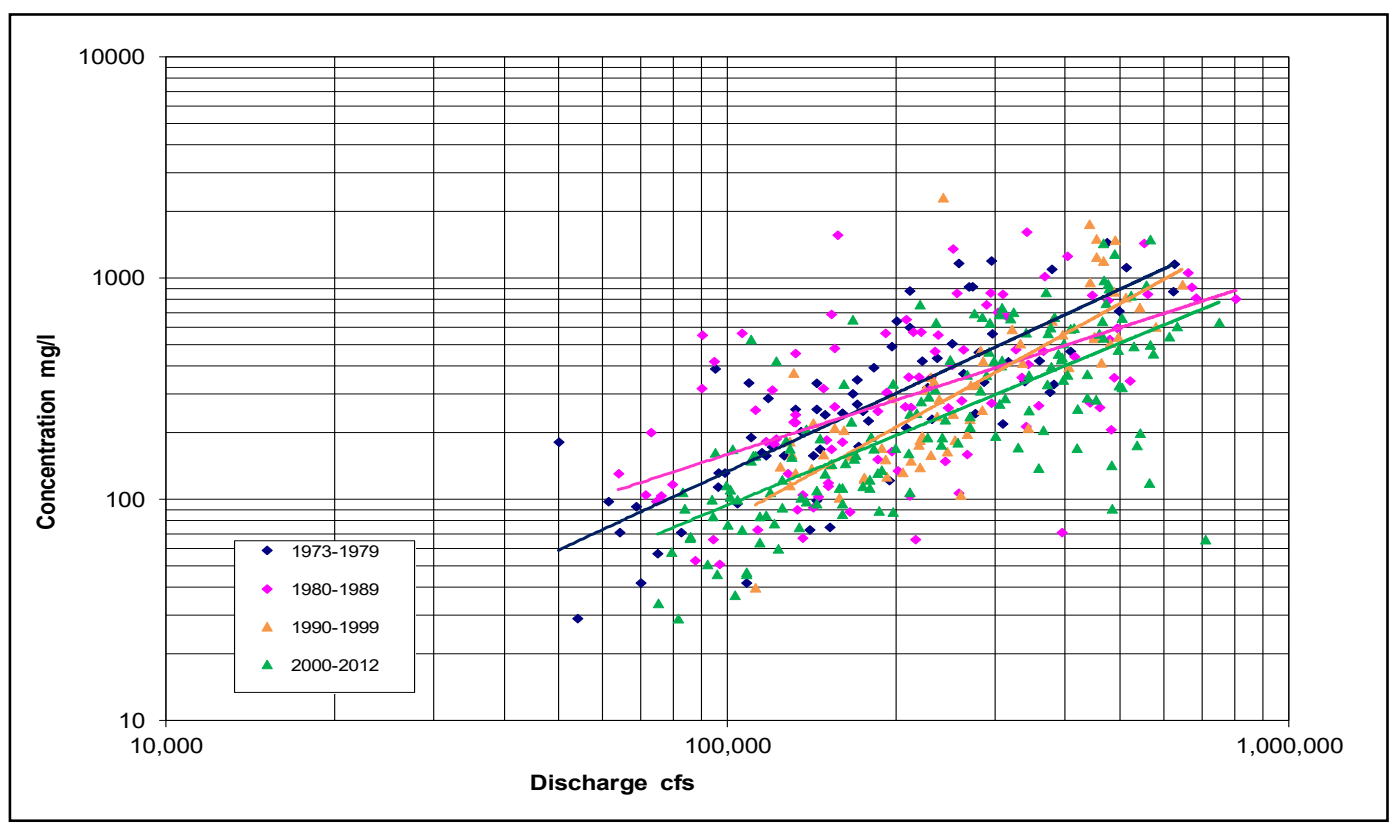

Figure 41. Measured suspended sand concentration at Thebes.

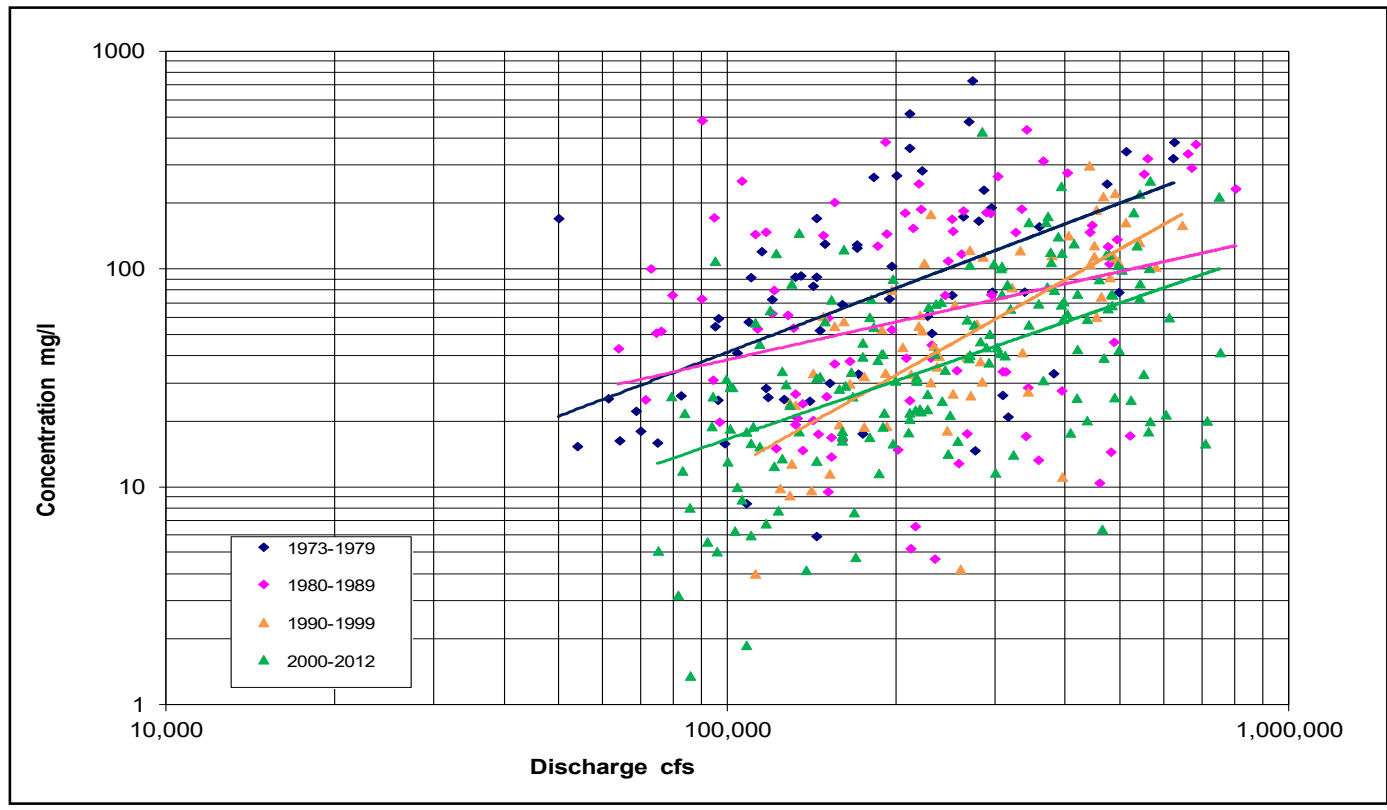

Measured total suspended sediment load and measured suspended sand load data collected at Thebes between 1991 and 2002 were used to calculate power regression curves for the HEC-6T sediment inflow rating table. These years correspond to the calibration time period. Later in the study, during sensitivity evaluations, a sediment inflow curve based on 2003-2012 data was employed. Average daily sediment concentrations were determined for days when multiple samples were reported. There 
were 106 measurements in this data set. The data are plotted in Figure 42. When the sediment concentrations are plotted against discharge, there is considerable scatter, indicating that concentration is a function of more variables than just the discharge. A simple power regression fit of the data produced the following equations, with an $\mathrm{R}^{2}$ value of 0.65 for the total load and 0.54 for the sand load:

$$
\begin{aligned}
& C_{\text {total }}=0.00002992 Q^{1.292} \\
& C_{\text {sand }}=0.000003533 Q^{1.334}
\end{aligned}
$$

where:

$$
\begin{aligned}
& C=\text { concentration }, \mathrm{mg} / \mathrm{l} \\
& Q=\text { discharge }, \text { cfs } .
\end{aligned}
$$

Figure 42. Measured suspended total and sand concentrations at Thebes.

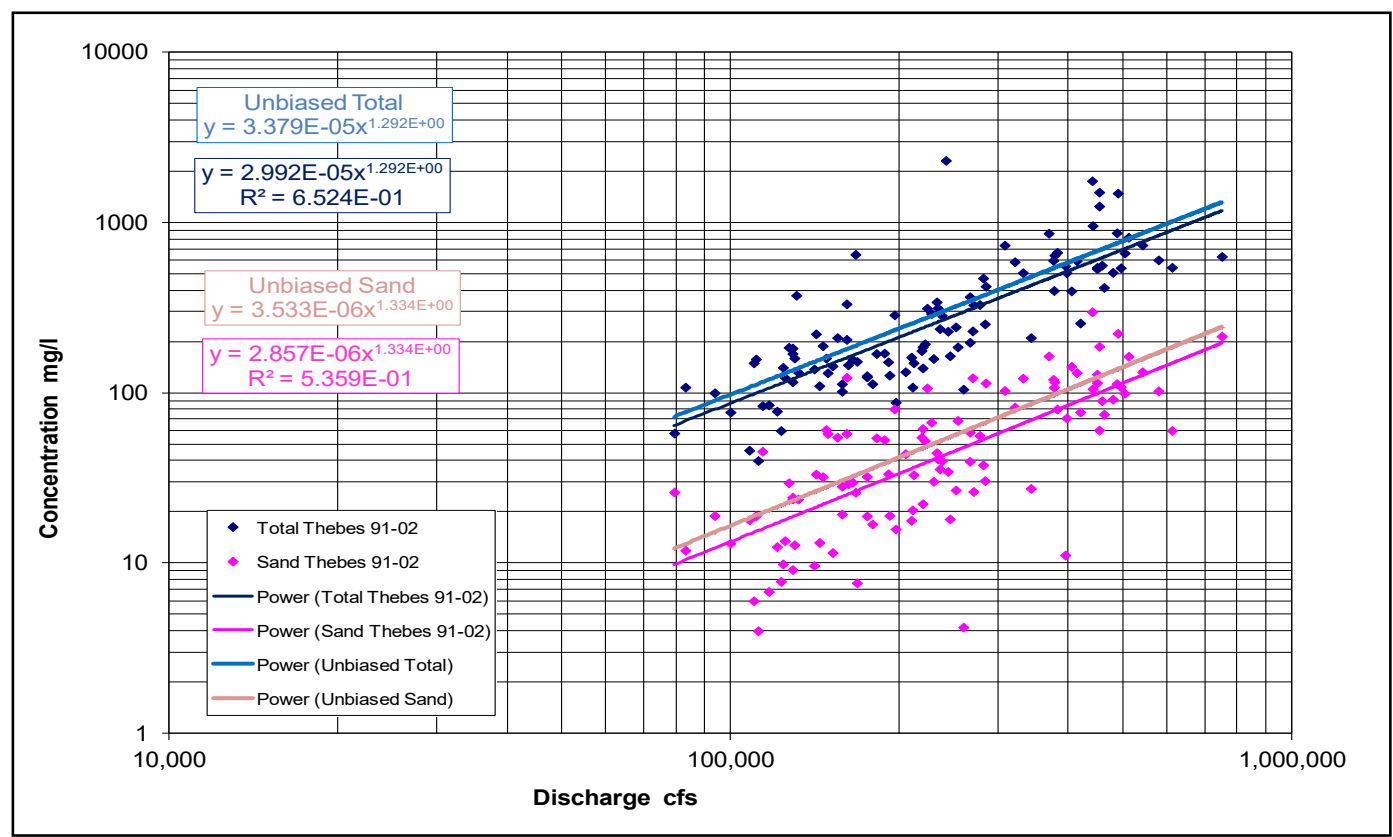

A statistical correction factor was applied to the power regression equations to account for bias created by using a least-squares regression for the logarithm of concentration. This bias occurs because the power regression produces a geometric mean instead of an arithmetic mean. The geometric mean is necessarily lower than the arithmetic mean, so concentrations are underestimated using the biased equation. The bias increases with the degree of scatter about the regression. A correction 
factor proposed by Ferguson (1986) was used to produce an unbiased estimator for both the total measured load and the sand load. The correction factor is given in the following equation:

$$
\begin{gathered}
\bar{C}_{i}=\hat{C}_{i} \exp \left(2.651 s^{2}\right) \\
s^{2}=\frac{\sum_{i=1}^{n}\left(\log C_{i}-\log \hat{C}_{i}\right)^{2}}{n-2}
\end{gathered}
$$

where:

$$
\begin{aligned}
\overline{C_{i}} & =\text { unbiased concentration at discharge event } i \\
\hat{C}_{i} & =\text { concentration from biased regression curve } \\
C_{i} & =\text { measured concentration } \\
N & =\text { number of measurements. }
\end{aligned}
$$

The unbiased estimators for the measured total and sand concentrations are given by the following equations. Note that the exponent is the same in the biased and unbiased equations so that the regression curves on log-log plots are parallel.

$$
\begin{aligned}
C_{\text {total }} & =0.00003379 Q^{1.292} \\
C_{\text {sand }} & =0.000003533 Q^{1.334}
\end{aligned}
$$

Size class percentages for each size class were determined using the measured suspended data at Thebes and Chester. Linear regression equations were calculated in EXCEL from 35 samples from Thebes, collected between 1973 and 1991, and 36 samples from Chester, collected between 1980 and 1991. Multiple samples collected at the two stations on the same day in June 1984 were not included in the analysis to avoid bias. There were no size class data available for the 1991-2002 time period simulated in the HEC-6T calibration study. Plots of the regression curves are shown in Figure 43. Although there was considerable scatter for individual measurements, the regression analysis showed little variation in the size class percentage with discharge. 
Figure 43. Size class percentages for at Thebes, 1973-1991, and Chester, 1980-1991.

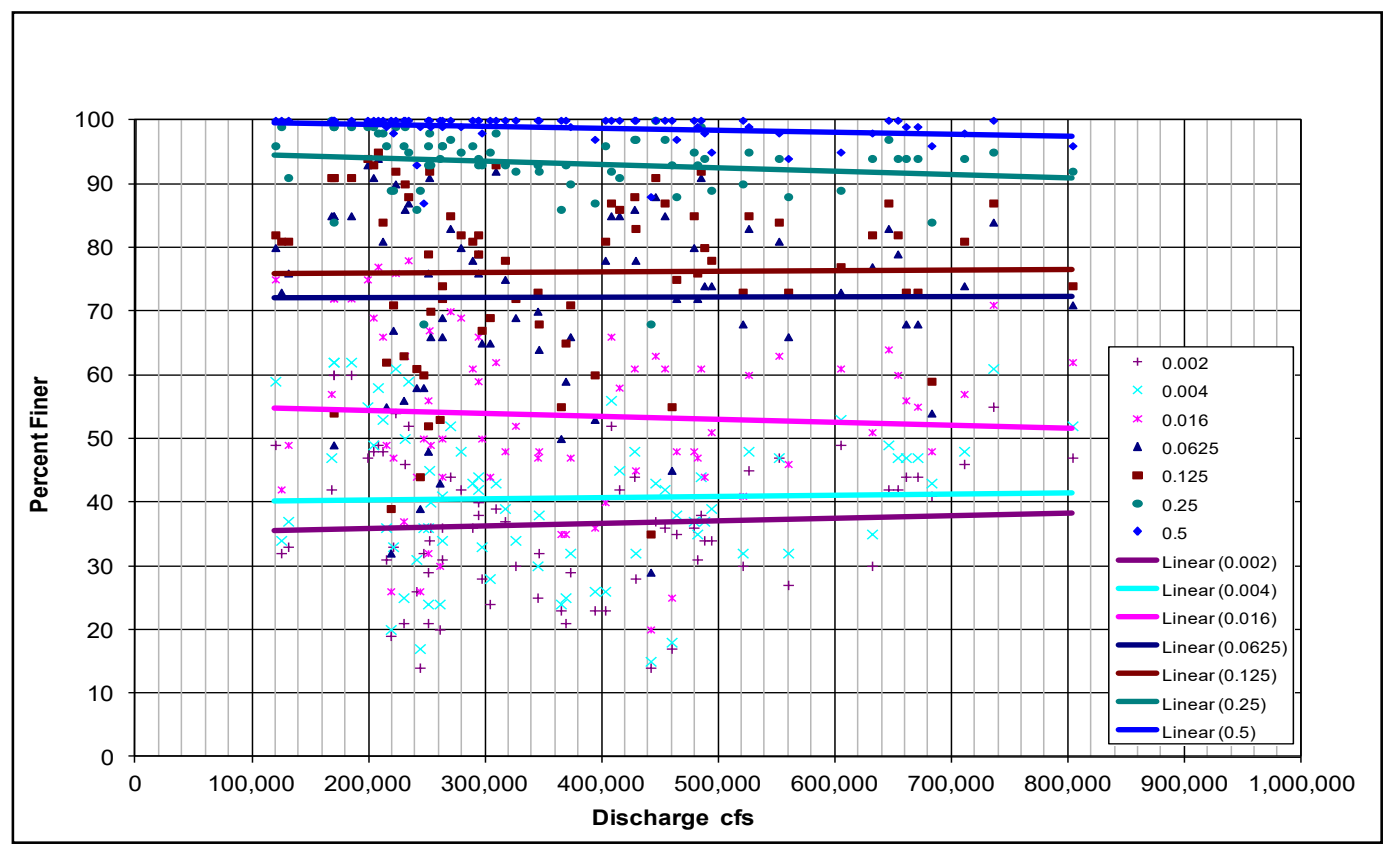

The sediment inflow rating curves for the Middle Mississippi River are shown in Table 20. The discharge range used to develop the sediment inflow regression curves was between 100,000 and $800,000 \mathrm{cfs}$. In Table 20, the calculated concentration at $800,000 \mathrm{cfs}$ was used for higher discharges. Assuming a flat concentration curve at higher discharges is generally closer to prototype behavior than an extrapolation of the regression curve. Size class percentages calculated from the regression curves at the 100,000 and 800,000 cfs were held constant for discharges beyond the data limits. In the HEC-6T sediment inflow table, fine sand through very coarse sand size class percentages were increased by 15 percent to account for unmeasured load. The very-coarse sand to veryfine gravel size classes were adjusted during the calibration process so that transport of these size classes into and out of the segment were equal. 
Table 20. Sediment inflow for Middle Mississippi River, Segment 25.

\begin{tabular}{|c|c|c|c|c|c|c|c|}
\hline Discharge, cfs & 10,000 & 50,000 & 100,000 & 300,000 & 500,000 & 800,000 & $1,200,000$ \\
\hline $\begin{array}{c}\text { Concentration } \\
\mathrm{mg} / \mathrm{l}\end{array}$ & 4.97 & 39.80 & 97.45 & 402.9 & 779.6 & 1431 & 1431 \\
\hline \multicolumn{8}{|c|}{ Fractions } \\
\hline Clay & 0.4011 & 0.4011 & 0.4011 & 0.0451 & 0.4090 & 0.4150 & 0.4150 \\
\hline Very Fine Silt & 0.0733 & 0.0733 & 0.0733 & 0.0669 & 0.0605 & 0.0510 & 0.0510 \\
\hline Fine Silt & 0.0733 & 0.0733 & 0.0733 & 0.0669 & 0.0605 & 0.0510 & 0.0510 \\
\hline Medium Silt & 0.0861 & 0.0861 & 0.0861 & 0.0911 & 0.0961 & 0.1035 & 0.1035 \\
\hline Coarse Silt & 0.0861 & 0.0861 & 0.0861 & 0.0911 & 0.0961 & 0.1035 & 0.1035 \\
\hline Very Fine Sand & 0.0397 & 0.0397 & 0.0397 & 0.0403 & 0.0410 & 0.0419 & 0.0419 \\
\hline Fine Sand & .02155 & 0.2155 & 0.2155 & 0.2011 & 0.1868 & 0.1653 & 0.1653 \\
\hline Medium Sand & 0.0578 & 0.0578 & 0.0578 & 0.0626 & 0.0674 & 0.0746 & 0.0746 \\
\hline Coarse Sand & 0.0031 & 0.0031 & 0.0031 & 0.0106 & 0.0180 & 0.0292 & 0.0292 \\
\hline Very Coarse Sand & 0.0000 & 0.0000 & 0.0008 & 0.0016 & 0.0025 & 0.0039 & 0.0039 \\
\hline Very Fine Gravel & 0.0000 & 0.0000 & 0.0003 & 0.0006 & 0.0010 & 0.0015 & 0.0015 \\
\hline Fine Gravel & 0.0000 & 0.0000 & 0.0001 & 0.0002 & 0.0003 & 0.0005 & 0.0005 \\
\hline Medium Gravel & 0.0000 & 0.0000 & 0.0000 & 0.0001 & 0.0001 & 0.0002 & 0.0002 \\
\hline Coarse Gravel & 0.0000 & 0.0000 & 0.0000 & 0.0000 & 0.0000 & 0.0000 & 0.0000 \\
\hline $\begin{array}{c}\text { Very Coarse } \\
\text { Gravel }\end{array}$ & 0.0000 & 0.0000 & 0.0000 & 0.0000 & 0.0000 & 0.0000 & 0.0000 \\
\hline
\end{tabular}

\section{Sediment inflow Ohio River}

Sediment inflow from the Ohio River was determined from measured suspended sediment data collected at two USGS gages. The gage closest to the upstream model boundary is at Dam 53 near Grand Chain, IL, (o361250o), which is 17 miles upstream from Cairo (Ohio River RM 962.6). The second gage is considerably upstream from the model boundary at Louisville, KY (03294500), which is approximately 372 miles upstream from Cairo (Ohio River RM 607.3). Total measured suspended sediment concentration and sand percentages were collected at Dam 53, between 1973 and 2010. Size class percentage data for clay through medium sand were collected at Louisville, between 1979 and 1982. The Louisville gage is located a considerable distance upstream from the Mississippi River confluence at Cairo, and the available data were collected 10 years prior to the calibration simulation period. However, the Louisville data are the only suspended size class data available. The Ohio River in the 
study reach essentially has a rigid boundary where most of the boundary materials do not actively exchange with the suspended load. Although, sand frequently moves as bed load throughput over a primarily gravel bed, calculation of suspended bed material load from available bed material gradations is not reliable.

During the 37 years between 1973 and 2010, 366 measurements of the total sediment load and 264 measurements of the sand load were available from the Dam 53 gage. Power regression curves were determined from the Dam 53 data for 4 decades covering the span of the measured data. When the sediment concentrations are plotted against discharge in Figure 44 it is apparent that there is considerable scatter, indicating that concentration is a function of more variables than just the discharge. The most obvious external variable is the backwater effect from the Mississippi River. In this model, there was no attempt at data segregation to exclude backwater effects because the study objective was to obtain long-term average values of sediment inflow. The data plotted in Figure 44 also suggest no longterm trend in the total concentration over the 37-year period. However, the data indicate that the 1990 s had a slightly lower average sediment inflow than the preceding and following decades. Considering the data scatter, this conclusion is accompanied with considerable uncertainty.

Figure 44. Total measured suspended sediment concentration at Dam 53.

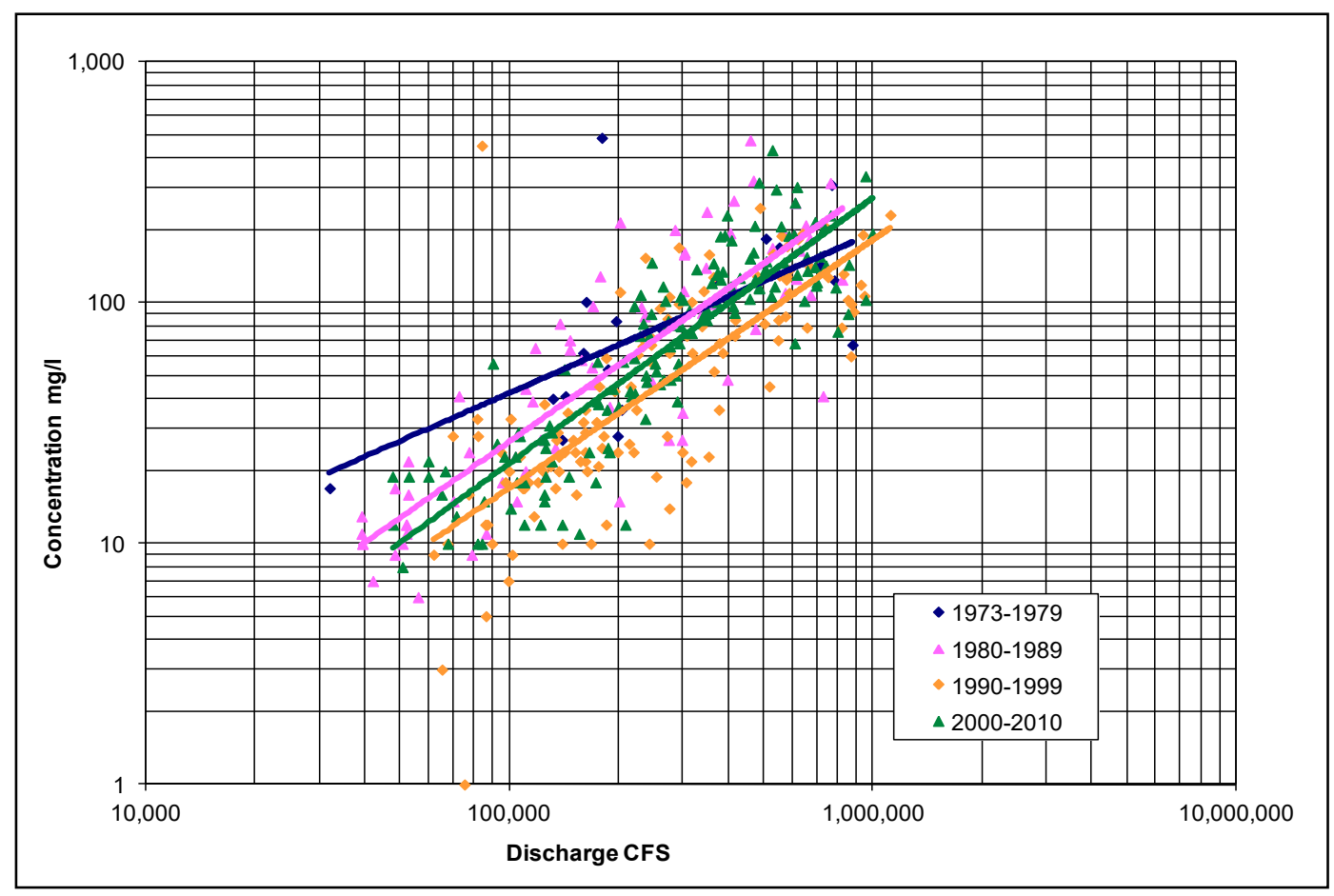


Measured total suspended sediment load and measured suspended sand load data collected at Dam 53 between 1991 and 2002 were used to calculate power regression curves for the HEC-6Tsediment inflow rating table. There were 158 measurements for the total suspended concentration and 108 measurements for the sand concentration. The data are plotted in Figure 45. A simple power regression fit of the data produced the following equations, with a $\mathrm{R}^{2}$ value of 0.59 for the total suspended concentration and 0.50 for the sand concentration:

$$
\begin{gathered}
C_{\text {total }}=0.0001008 Q^{1.0505} \\
C_{\text {sand }}=0.00000003744 Q^{1.4368}
\end{gathered}
$$

The unbiased power regression curves are the following:

$$
\begin{gathered}
C_{\text {total }}=0.00012437 Q^{1.0505} \\
C_{\text {sand }}=0.000000065424 Q^{1.4368}
\end{gathered}
$$

Figure 45. Measured suspended total and sand concentrations at Dam 53.

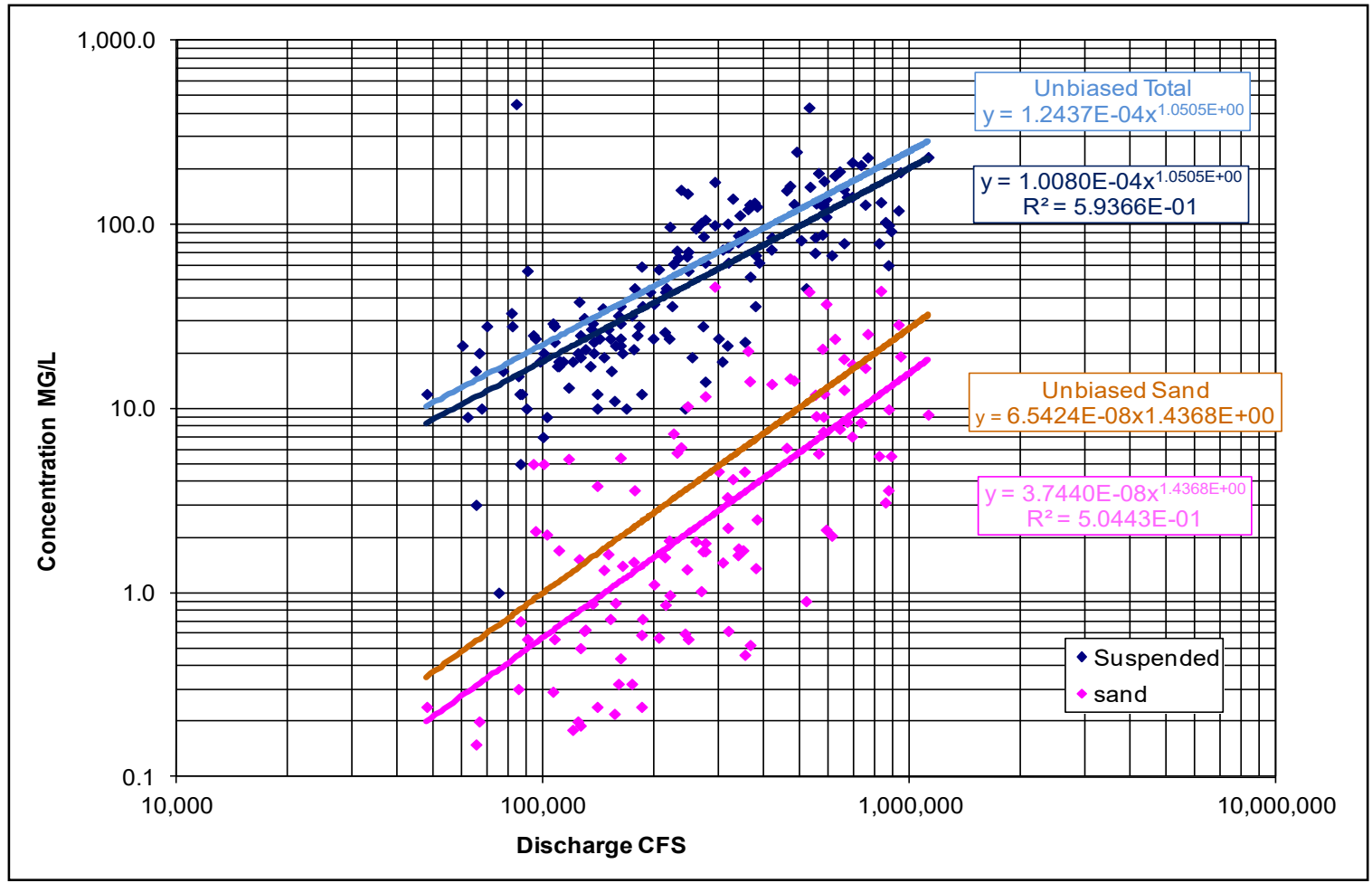


There were no suspended sediment size class data available for the 19912002 calibration period. In the HEC-6T model, size class percentages for each size class were estimated using the measured suspended data at Louisville collected between 1979 and 1982. Samples were collected on 11 days during these 4 years, with a discharge range between 200,000 and 450,000 cfs. Multiple samples collected on the same day were averaged to avoid bias. Linear regression equations were calculated in EXCEL to obtain percentages at specific discharges in the sediment input table. Plots of the regression curves are shown in Figure 46.

Figure 46. Measured size class percentages, at Louisville.

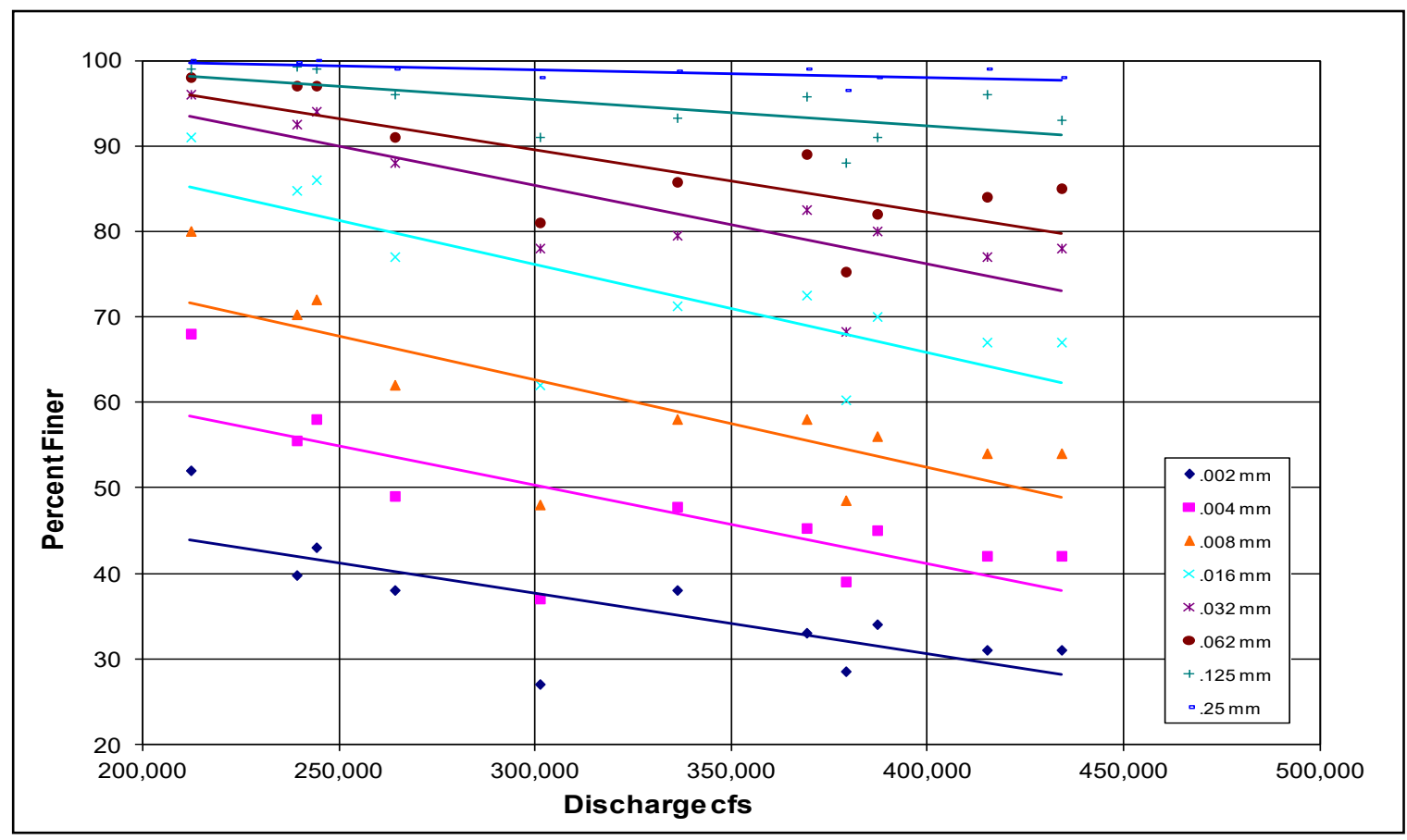

The sediment inflow rating curves used in the HEC-6T model, for the Ohio River, are shown in Table 21. Sand loads for very-fine, fine, and medium sand were determined from the sand regression curve, and fine load was determined from the difference between the total and sand load regression curves. The range of discharges used to develop the sediment inflow regression curves was between 50,000 and 1,200,000 cfs. In Table 21 the calculated concentration at 1,200,000 cfs was used for discharges greater than 1,200,000 cfs. Assuming a flat concentration curve at higher discharges is generally closer to prototype behavior than an extrapolation of the regression curve. 
Table 21. Sediment inflow for Ohio River - Segment 24.

\begin{tabular}{|c|c|c|c|c|c|c|c|c|c|c|}
\hline $\begin{array}{c}\text { Discharge } \\
1000 \text { cfs }\end{array}$ & 10 & 50 & 100 & 200 & 450 & 800 & 1000 & 1200 & 2000 \\
\hline $\begin{array}{c}\text { Concentration } \\
\text { mg/l }\end{array}$ & 1.98 & 10.74 & 22.24 & 46.07 & 108.0 & 197.7 & 249.9 & 302.6 & 302.6 \\
\hline \multicolumn{7}{|c|}{ Fractions } \\
\hline Clay & 0.6035 & 0.5938 & 0.5873 & 0.5788 & 0.4280 & 0.4187 & 0.4145 & 0.4108 & 0.4108 \\
\hline VF Silt & 0.1349 & 0.1327 & 0.1313 & 0.1294 & 0.1256 & 0.1229 & 0.1216 & 0.1205 & 0.1205 \\
\hline F Silt & 0.1377 & 0.1355 & 0.1340 & 0.1321 & 0.1557 & 0.1523 & 0.1508 & 0.1494 & 0.1494 \\
\hline M Silt & 0.0818 & 0.0805 & 0.0796 & 0.0785 & 0.1287 & 0.1259 & 0.1247 & 0.1235 & 0.1235 \\
\hline C Silt & 0.0235 & 0.0231 & 0.0229 & 0.0225 & 0.0817 & 0.0799 & 0.0791 & 0.0784 & 0.0784 \\
\hline VF Sand & 0.0112 & 0.0208 & 0.0272 & 0.0355 & 0.0527 & 0.0658 & 0.0718 & 0.0770 & 0.0770 \\
\hline F Sand & 0.0092 & 0.0171 & 0.0223 & 0.0292 & 0.0293 & 0.0366 & 0.0399 & 0.0428 & 0.0428 \\
\hline M Sand & 0.00090 & 0.00168 & 0.00347 & 0.0137 & 0.0174 & 0.0361 & 0.0326 & 0.0279 & 0.0279 \\
\hline C Sand & 0.0 & 0.0 & 0.00118 & 0.00621 & 0.0113 & 0.0137 & 0.0137 & 0.0120 & 0.0120 \\
\hline VC Sand & 0.0 & 0.0 & 0.0 & 0.00307 & 0.00667 & 0.00898 & 0.00867 & 0.00806 & 0.0806 \\
\hline VF Gravel & 0.0 & 0.0 & 0.0 & 0.0 & 0.00068 & 0.00230 & 0.00226 & 0.00209 & 0.00209 \\
\hline F Gravel & 0.0 & 0.0 & 0.0 & 0.0 & 0.0 & 0.00050 & 0.00101 & 0.00118 & 0.00118 \\
\hline M Gravel & 0.0 & 0.0 & 0.0 & 0.0 & 0.0 & 0.0 & 0.0 & 0.00015 & 0.00015 \\
\hline C Gravel & 0.0 & 0.0 & 0.0 & 0.0 & 0.0 & 0.0 & 0.0 & 0.0 & 0.0 \\
\hline VC Gravel & 0.0 & 0.0 & 0.0 & 0.0 & 0.0 & 0.0 & 0.0 & 0.0 & 0.0 \\
\hline
\end{tabular}

Size class percentages were calculated from the size class regression curves between 200,000 and 450,000 cfs. Percentages were held constant for discharges beyond the data limits. Sediment inflow for the sand size classes determined from regression curves was increased by 15 percent to account for unmeasured load. The coarse-sand to medium-gravel size classes were transported in the unmeasured zone, so inflow fractions for these sediment sizes was determined using the recirculation option in HEC-6T. With this option, a series of steady state discharges are run for a period of time (in this case 25 days) where the sediment load calculated at the downstream end of the segment is re-introduced at the upstream end of the segment for the next time-step until the calculated inflow and outflow of sediment is approximately equal during a time-step. This is equivalent to assuming that the reach is in equilibrium with respect to sediment continuity. 
Uncertainty exists with this approach because these calculations are directly dependent upon the designated bed gradation. In this case, the bed gradation came from an average of multiple samples collected at Olmstead Lock and Dam located at RM 970.5 (mileage calculated by adding to Mississippi River mileage at Cairo). Medium sand load was determined using the larger of the fractions calculated from the regression equations or the recirculation option.

\section{Sediment inflow Obion and Hatchie Rivers}

The purpose of the Obion and Hatchie River Segments in the HEC-6T model was to provide sediment inflow to the Mississippi River. Measured suspended sediment data from both rivers are available from USGS gages located considerable distances upstream from the HEC-6T model boundaries. Total suspended and sand inflow concentrations were available from these gages for a wide range of discharges. However, individual size class percentages of the suspended load were lacking. Bed material samples were collected for this study on the Hatchie River near Rialto (RM 34) and near Bogota on the Obion River (RM 36.7). Samples were collected at three transects at a crossing using a 6 in. clam-shell sampler in June 2005. There were no geometric data available between the Mississippi River and upstream sediment gages. A 2-mile study reach was included in the model based on estimated cross-section geometry. No calibration was attempted for these segments, and no conclusions can be made with respect to calculated morphologic changes in these segments.

In the HEC-6T model, the beds of the Obion and Hatchie Rivers were not allowed to scour below the initial cross-section elevations. Therefore, the river bed was not allowed to contribute any sediment to the Mississippi River. However, deposition was allowed in the model so that sediment inflow at the model boundary could be computationally reduced if hydraulic conditions were favorable.

Measured suspended sediment concentrations from two gages on the Obion River were used to determine sediment inflow concentrations for the HEC-6T model. The USGS reported sediment data at gage number o702600o, Obion River at Obion, Tennessee, from samples collected between 1975 and 1990, and from USGS gage number 07026040 , Obion River at Hwy 51 near Obion, Tennessee, from samples collected between 1990 and 1995. These gages are essentially at the same location at approximately RM 62, which is approximately 60 miles upstream from the 
HEC-6T model boundary. There were only 19 measurements at the Highway 51 near Obion gage. Considering the data scatter and the small number of samples collected during the 1991-2002 calibration period, it was deemed appropriate to use the measurements from the entire 19751995 record and from both gages to develop the best estimate of average sediment inflow rating curves.

Measured total suspended sediment concentrations and measured suspended sand concentrations collected at Hwy 51 near Obion and at Obion between 1975 and 1995 were used to calculate power regression curves for the HEC-6Tsediment inflow rating table. There were 149 measurements of the total suspended concentration and 122 measurements of the sand concentration. The data are plotted in Figure 47. A simple power regression fit of the data produced the following equations, with an $\mathrm{R}^{2}$ value of 0.2204 for the total suspended concentration and 0.1558 for the sand concentration:

$$
\begin{gathered}
C_{\text {total }}=1.890 Q^{0.6081} \\
C_{\text {sand }}=0.2244 Q^{0.5768}
\end{gathered}
$$

The unbiased power regression curves are the following:

$$
\begin{gathered}
C_{\text {total }}=3.381 Q^{0.6081} \\
C_{\text {sand }}=0.5520 Q^{0.5768}
\end{gathered}
$$


Figure 47. Measured suspended total and sand concentrations Obion River near RM 62.

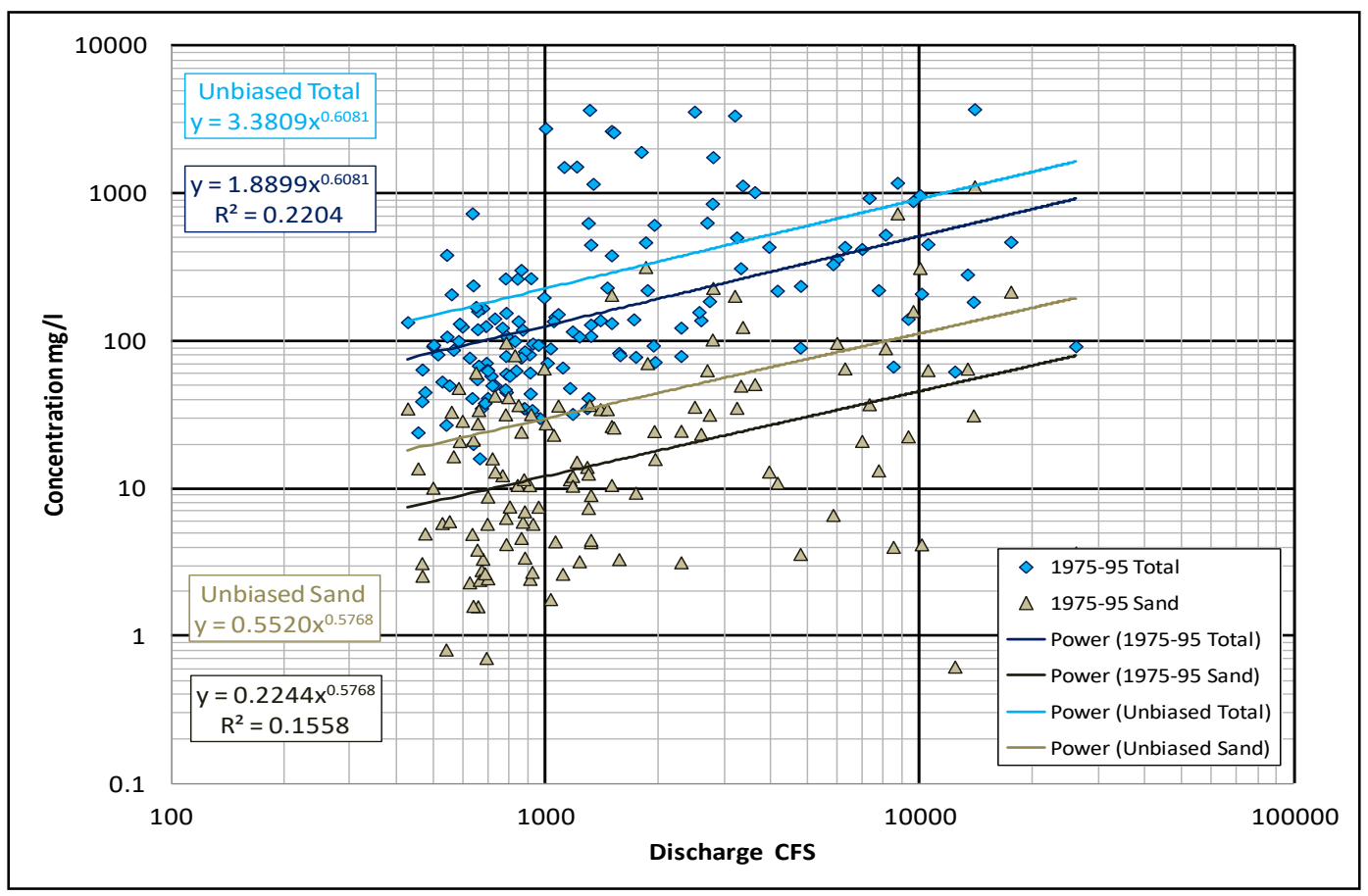

The measured Obion River data included a sand-silt break, and these data were used to determine the inflow concentrations for fines and sand. However, there were no additional size class percentage data available. The sand size class percentages were taken to be the same as the average sand size class percentages at Thebes and Chester. Likewise, the clay and silt size class percentages were taken to be the same as the average clay and silt size class percentages at Thebes and Chester. These were determined by summing the percent finer data from 71 Chester and Thebes samples collected between 1973 and 1991. These percentages are independent of discharge.

The sediment inflow rating curves used in the HEC-6T model, for the Obion River, are shown in Table 22. The discharge range used to develop the sediment inflow regression curves was between 400 and 30,000 cfs. In Table 22, the calculated concentration at 30,000 cfs was used for higher discharges. A flat concentration curve at higher discharges is generally closer to prototype behavior than an extrapolation of the regression curve. In the HEC-6T sediment inflow table, fine sand through coarse sand size class percentages were increased by 15 percent to account for unmeasured load. 
Table 22. Sediment inflow for Obion River - Segment 16.

\begin{tabular}{|c|c|c|c|c|c|c|c|}
\hline Discharge & 1 & 50 & 500 & 2,000 & 5,000 & 30,000 & 200,000 \\
\hline $\begin{array}{c}\text { Concentration } \\
\mathrm{mg} / \mathrm{I}\end{array}$ & 3.4 & 36.5 & 148.0 & 343.9 & 600.3 & 1784.7 & 1784.7 \\
\hline \multicolumn{7}{|c|}{ Fractions } \\
\hline Clay & 0.4735 & 0.4842 & 0.4898 & 0.4931 & 0.4951 & 0.4990 & 0.4990 \\
\hline VF Silt & 0.0733 & 0.0750 & 0.0758 & 0.0763 & 0.0767 & 0.0773 & 0.0773 \\
\hline F Silt & 0.0751 & 0.0768 & 0.0777 & 0.0782 & 0.0786 & 0.0792 & 0.0792 \\
\hline M Silt & 0.1074 & 0.1098 & 0.1111 & 0.1118 & 0.1123 & 0.1132 & 0.1132 \\
\hline C Silt & 0.1074 & 0.1098 & 0.1111 & 0.1118 & 0.1123 & 0.1132 & 0.1132 \\
\hline VF Sand & 0.0237 & 0.0209 & 0.0195 & 0.0187 & 0.0181 & 0.0171 & 0.0171 \\
\hline F Sand & 0.1150 & 0.1018 & 0.0947 & 0.0907 & 0.0881 & 0.0833 & 0.0833 \\
\hline M Sand & 0.0379 & 0.0335 & 0.0312 & 0.0299 & 0.0290 & 0.0274 & 0.0274 \\
\hline C Sand & 0.0072 & 0.0063 & 0.0059 & 0.0056 & 0.0055 & 0.0052 & 0.0052 \\
\hline VC Sand & 0.0000 & 0.0000 & 0.0000 & 0.0000 & 0.0000 & 0.0000 & 0.0000 \\
\hline VF Gravel & 0.0000 & 0.0000 & 0.0000 & 0.0000 & 0.0000 & 0.0000 & 0.0000 \\
\hline F Gravel & 0.0000 & 0.0000 & 0.0000 & 0.0000 & 0.0000 & 0.0000 & 0.0000 \\
\hline M Gravel & 0.0000 & 0.0000 & 0.0000 & 0.0000 & 0.0000 & 0.0000 & 0.0000 \\
\hline C Gravel & 0.0000 & 0.0000 & 0.0000 & 0.0000 & 0.0000 & 0.0000 & 0.0000 \\
\hline VC Gravel & 0.0000 & 0.0000 & 0.0000 & 0.0000 & 0.0000 & 0.0000 & 0.0000 \\
\hline
\end{tabular}

Measured suspended sediment concentrations from two gages on the Hatchie River were used to determine sediment inflow concentrations for the HEC-6T model. The USGS reported sediment data at gage number 07029500, Hatchie River at Bolivar, Tennessee, from samples collected between 1977 and 1995. This gage is at RM 135, considerably upstream from the model boundary. Downstream, at RM 34, a smaller data set was collected at USGS gage number 07030050, Hatchie River at Rialto, Tennessee. Data at this gage extend between 1977 and 1978 and between 2004 and 2008. Measured total sediment concentrations and measured sand concentrations from the two gages are compared in Figure 48. The figure shows considerable scatter for the total suspended concentrations and the sand concentrations. There were only 40 measurements at the Rialto gage, and 10 of these were collected during a 5-day period in September 1977. Only 17 measurements at Bolivar were collected during the 1991-2002 calibration period. Considering the data scatter, it was deemed appropriate to use the measurements from the entire 1977-2008 
record and from both gages to develop the best estimate of average sediment inflow rating curves. Future studies to assess downward trends in sand and fine sediment yields to downstream reaches of the Mississippi River will require the collection of additional sediment data on tributaries, such as the Obion and Hatchie Rivers.

Figure 48. Measured suspended total and sand concentrations Hatchie River.

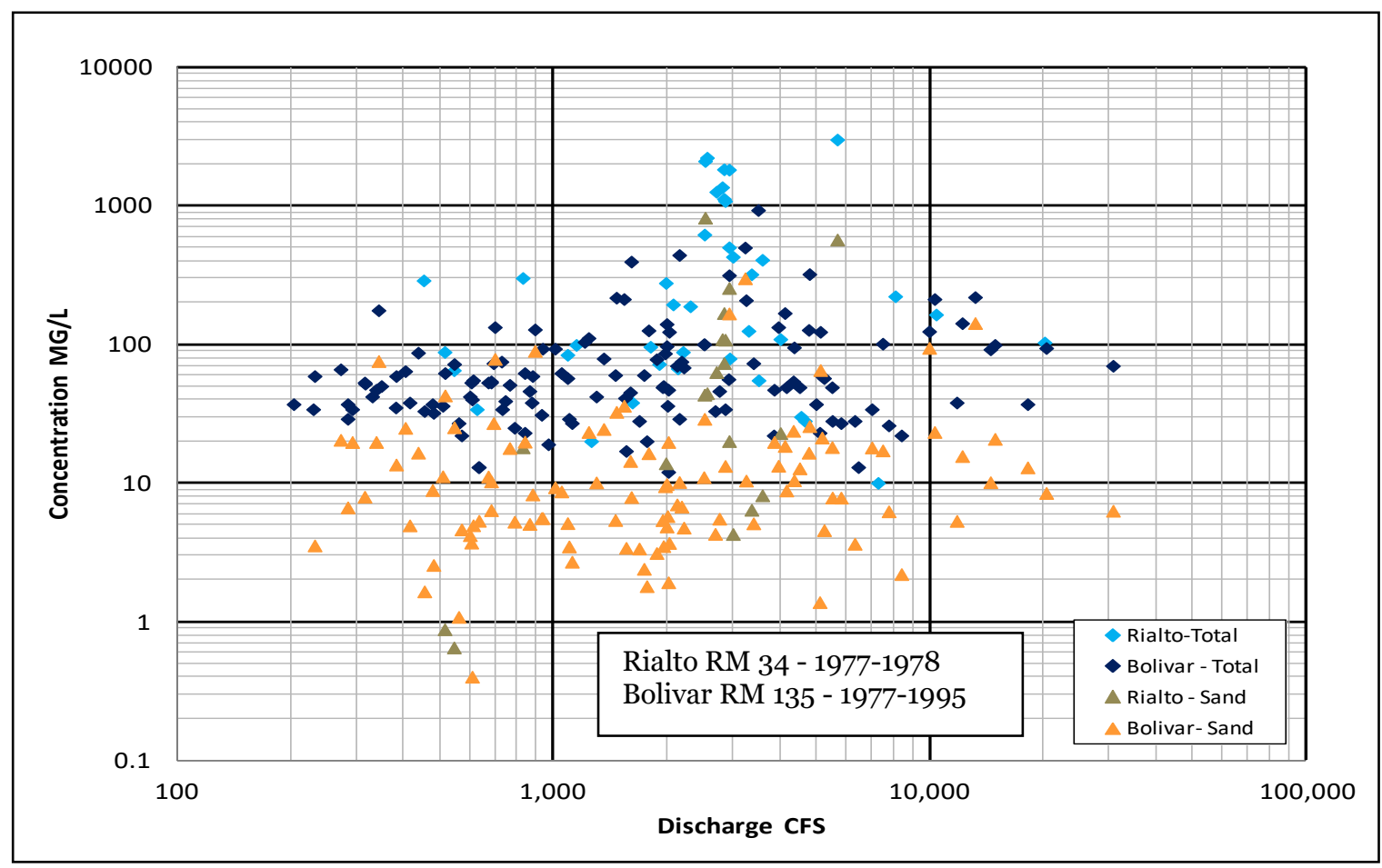

Measured total suspended sediment concentrations and measured suspended sand concentrations collected at Rialto and Bolivar between 1977 and 2008 were used to calculate power regression curves for the HEC-6Tsediment inflow rating table. There were 171 measurements of the total suspended concentration and 128 measurements of the sand concentration. The data are plotted in Figure 49. A simple power regression fit of the data produced the following equations, with an $\mathrm{R}^{2}$ value of 0.054 for the total suspended concentration and 0.045 for the sand concentration:

$$
\begin{aligned}
& C_{\text {total }}=13.09 Q^{0.2388} \\
& C_{\text {sand }}=1.659 Q^{0.2595}
\end{aligned}
$$


The unbiased power regression curves are the following:

$$
\begin{aligned}
& C_{\text {total }}=23.39 Q^{0.2388} \\
& C_{\text {sand }}=3.750 Q^{0.2595}
\end{aligned}
$$

Figure 49. Combined measured suspended total and sand concentrations Hatchie River.

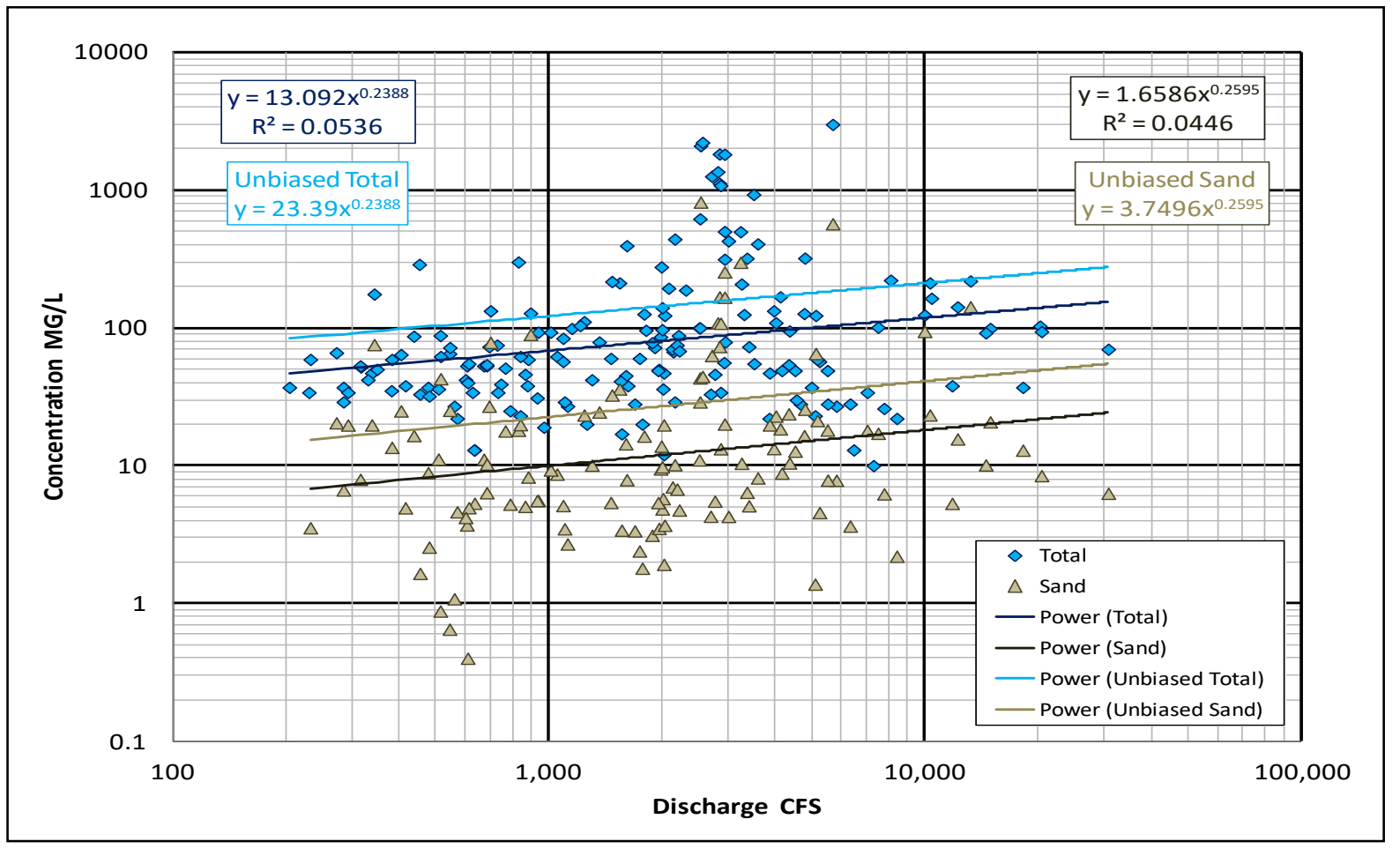

The measured Hatchie River data included a sand-silt break, and these data were used to determine the inflow concentrations for fines and sand. However, there were no additional size class percentage data available. The sand size class percentages were taken to be the same as the average sand size class percentages at Thebes and Chester. Likewise, the clay and silt size class percentages were taken to be the same as the average clay and silt size class percentages at Thebes and Chester. These were determined by summing the percent finer data from 71 Chester and Thebes samples collected between 1973 and 1991. These percentages are independent of discharge.

The sediment inflow rating curves used in the HEC-6T model, for the Hatchie River, are shown in Table 23. The discharge range used to develop the sediment inflow regression curves was between 200 and 30,000 cfs. In Table 23, the calculated concentration at 30,000 cfs was used for higher 
discharges. A flat concentration curve at higher discharges is generally closer to prototype behavior than an extrapolation of the regression curve. In the HEC-6T sediment inflow table, fine sand through coarse sand size class percentages were increased by 15 percent to account for unmeasured load.

Table 23. Sediment inflow for Hatchie River - Segment 14.

\begin{tabular}{|c|c|c|c|c|c|c|c|}
\hline Discharge & 1 & 50 & 200 & 1000 & 5000 & 30,000 & 200,000 \\
\hline Concentration $\mathrm{mg} / \mathrm{l}$ & 23.4 & 59.5 & 82.9 & 121.7 & 178.8 & 274.3 & 274.3 \\
\hline \multicolumn{8}{|c|}{ Fractions } \\
\hline Clay & 0.4752 & 0.4675 & 0.4647 & 0.4612 & 0.4577 & 0.4536 & 0.4536 \\
\hline VF Silt & 0.0736 & 0.0724 & 0.0719 & 0.0714 & 0.0709 & 0.0702 & 0.0702 \\
\hline F Silt & 0.0754 & 0.0742 & 0.0737 & 0.0732 & 0.0726 & 0.0720 & 0.0720 \\
\hline M Silt & 0.1078 & 0.1060 & 0.1054 & 0.1046 & 0.1038 & 0.1029 & 0.1029 \\
\hline C Silt & 0.1078 & 0.1060 & 0.1054 & 0.1046 & 0.1038 & 0.1029 & 0.1029 \\
\hline VF Sand & 0.0232 & 0.0252 & 0.0259 & 0.0268 & 0.0277 & 0.0288 & 0.0288 \\
\hline F Sand & 0.1130 & 0.1225 & 0.1261 & 0.1303 & 0.1347 & 0.1398 & 0.1398 \\
\hline M Sand & 0.0372 & 0.0403 & 0.0415 & 0.0429 & 0.0444 & 0.0460 & 0.0460 \\
\hline C Sand & 0.0070 & 0.0076 & 0.0078 & 0.0081 & 0.0084 & 0.0087 & 0.0087 \\
\hline VC Sand & 0.0000 & 0.0000 & 0.0000 & 0.0000 & 0.0000 & 0.0000 & 0.0000 \\
\hline VF Gravel & 0.0000 & 0.0000 & 0.0000 & 0.0000 & 0.0000 & 0.0000 & 0.0000 \\
\hline F Gravel & 0.0000 & 0.0000 & 0.0000 & 0.0000 & 0.0000 & 0.0000 & 0.0000 \\
\hline M Gravel & 0.0000 & 0.0000 & 0.0000 & 0.0000 & 0.0000 & 0.0000 & 0.0000 \\
\hline C Gravel & 0.0000 & 0.0000 & 0.0000 & 0.0000 & 0.0000 & 0.0000 & 0.0000 \\
\hline VC Gravel & 0.0000 & 0.0000 & 0.0000 & 0.0000 & 0.0000 & 0.0000 & 0.0000 \\
\hline
\end{tabular}

\section{Sediment inflow St. Francis River}

The purpose of the St. Francis River Segment in the HEC-6T model is to provide sediment inflow to the Mississippi River. Considerable sediment data are available for the St. Francis River and were used to calibrate a Memphis District HEC-6T study. Additional data were collected by the USGS subsequent to the 2000 study and were used to develop sediment inflow curves for this study. Total suspended sediment and suspended sand concentrations were available for a wide range of discharges. In almost all cases, bed material gradation data were also collected when the suspended samples were collected. Individual sand size class percentages were determined in the laboratory for almost all of the suspended samples 
Measured suspended sediment concentrations from the USGS gage number 07047907, St. Francis River at Madison, Arkansas, were used to determine sediment inflow concentrations for the HEC-6T model. The USGS reported sediment data at the Madison gage between 1977 and 2009. This gage is located at RM 37.9, which is approximately 20 miles upstream from the upstream model boundary.

Measured total suspended sediment concentrations and measured suspended sand concentrations collected at Madison between 1991 and 2002 were used to calculate power regression curves for the HEC6Tsediment inflow rating table. There were 139 measurements of the total suspended concentration and 127 measurements of the sand concentration. The data are plotted in Figure 50. A simple power regression fit of the data produced the following equations, with an $\mathrm{R}^{2}$ value of 0.112 for the total suspended concentration and 0.100 for the sand concentration:

$$
\begin{aligned}
& C_{\text {total }}=30.704 Q^{0.1765} \\
& C_{\text {sand }}=0.2688 Q^{0.3774}
\end{aligned}
$$

The unbiased power regression curves are the following:

$$
\begin{aligned}
& C_{\text {total }}=37.594 Q^{0.1765} \\
& C_{\text {sand }}=0.6344 Q^{0.3774}
\end{aligned}
$$


Figure 50. Measured suspended sediment concentrations, St. Francis River at Madison.

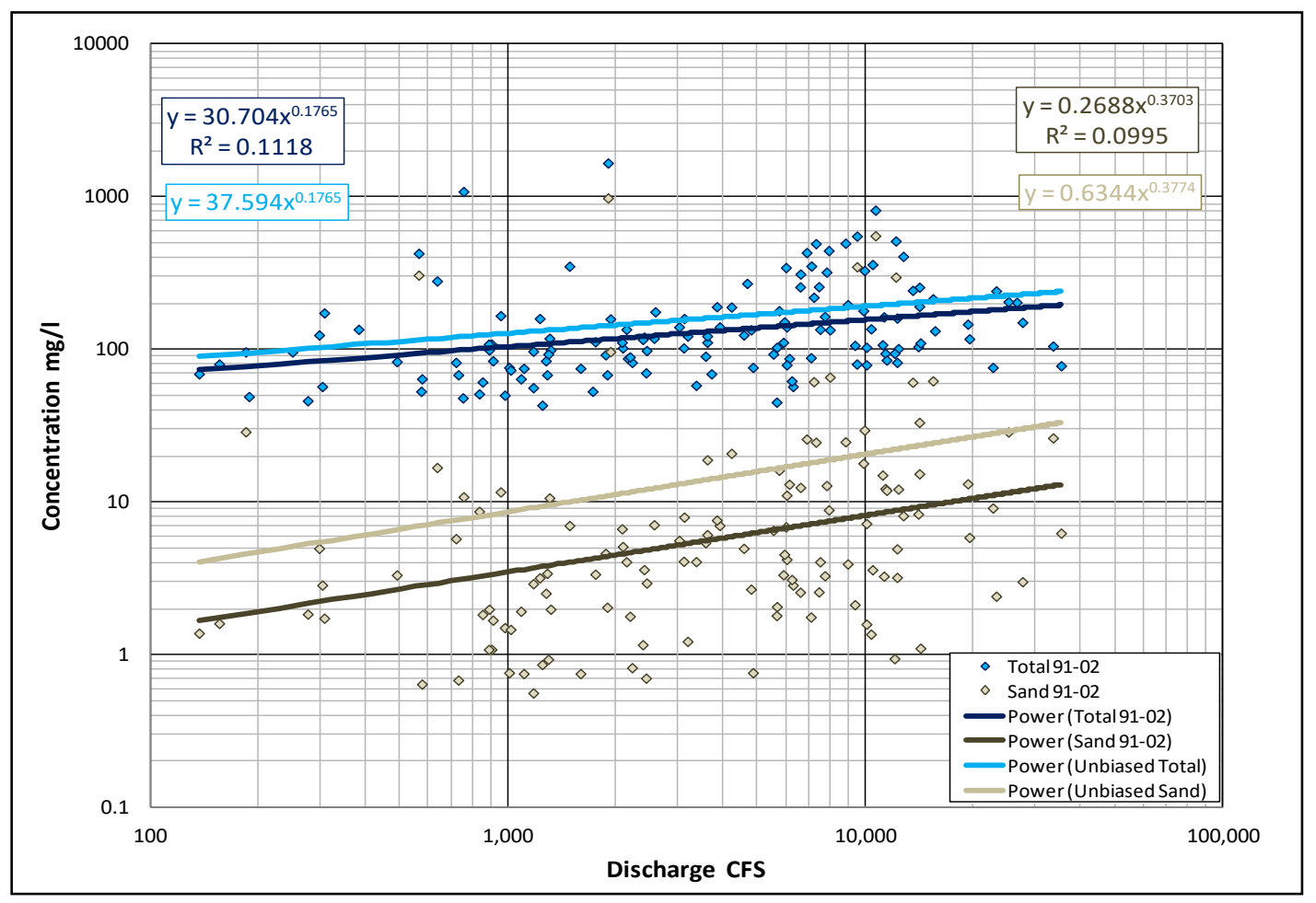

The measured St. Francis River data included a sand-silt break, and these data were used to determine the inflow concentrations for fines and sand. In addition, sand size class data were available for nearly all the sediment measurements. There was considerable scatter in the size class data, and no reliable relationship between size class and discharge was discernible. Due to the large data scatter, all the data between 1977 and 2009 were used to estimate the average percentage in each sand size class. There were no size class percentage data available for the silts and clays. The clay and silt size class percentages were taken to be the same as the average clay and silt size class percentages at Thebes and Chester. These were determined by summing the percent finer data from 71 Chester and Thebes samples collected between 1973 and 1991. These percentages are independent of discharge.

The sediment inflow rating curves used in the HEC-6T model, for the St. Francis River, are shown in Table 24. The discharge range used to develop the sediment inflow regression curves was between 100 and 40,000 cfs. In Table 24 the calculated concentration at 40,000 cfs was used for higher discharges. A flat concentration curve at higher discharges is generally closer to prototype behavior than an extrapolation of the regression curve. In the HEC-6T sediment inflow table, fine sand 
through coarse sand size class percentages were increased by 15 percent to account for unmeasured load.

Table 24. Sediment inflow for St. Francis River - Segment 12.

\begin{tabular}{|c|c|c|c|c|c|c|c|}
\hline Discharge & 1 & 50 & 500 & 2000 & 10000 & 40000 & 60000 \\
\hline $\begin{array}{c}\text { Concentration } \\
\mathrm{mg} / \mathrm{l}\end{array}$ & 37.6 & 75.0 & 112.6 & 143.8 & 191.0 & 244.0 & 244.0 \\
\hline \multicolumn{8}{|c|}{ Fractions } \\
\hline Clay & 0.5564 & 0.5449 & 0.5326 & 0.5219 & 0.5051 & 0.4856 & 0.4856 \\
\hline VF Silt & 0.0861 & 0.0844 & 0.0825 & 0.0808 & 0.0782 & 0.0752 & 0.0752 \\
\hline F Silt & 0.0883 & 0.0865 & 0.0845 & 0.0828 & 0.0801 & 0.0771 & 0.0771 \\
\hline M Silt & 0.1262 & 0.1236 & 0.1208 & 0.1184 & 0.1146 & 0.1101 & 0.1101 \\
\hline C Silt & 0.1262 & 0.1236 & 0.1208 & 0.1184 & 0.1146 & 0.1101 & 0.1101 \\
\hline VF Sand & 0.0055 & 0.0121 & 0.0193 & 0.0254 & 0.0351 & 0.0464 & 0.0464 \\
\hline F Sand & 0.0079 & 0.0174 & 0.0276 & 0.0364 & 0.0503 & 0.0665 & 0.0665 \\
\hline M Sand & 0.0047 & 0.0104 & 0.0165 & 0.0218 & 0.0302 & 0.0399 & 0.0399 \\
\hline C Sand & 0.0004 & 0.0008 & 0.0013 & 0.0018 & 0.0024 & 0.0032 & 0.0032 \\
\hline VC Sand & 0.0000 & 0.0000 & 0.0000 & 0.0000 & 0.0000 & 0.0000 & 0.0000 \\
\hline VF Gravel & 0.0000 & 0.0000 & 0.0000 & 0.0000 & 0.0000 & 0.0000 & 0.0000 \\
\hline F Gravel & 0.0000 & 0.0000 & 0.0000 & 0.0000 & 0.0000 & 0.0000 & 0.0000 \\
\hline M Gravel & 0.0000 & 0.0000 & 0.0000 & 0.0000 & 0.0000 & 0.0000 & 0.0000 \\
\hline C Gravel & 0.0000 & 0.0000 & 0.0000 & 0.0000 & 0.0000 & 0.0000 & 0.0000 \\
\hline VC Gravel & 0.0000 & 0.0000 & 0.0000 & 0.0000 & 0.0000 & 0.0000 & 0.0000 \\
\hline
\end{tabular}

\section{Sediment inflow White River}

The purpose of the White River Segment in the HEC-6T model is to provide sediment inflow to the Mississippi River. Sediment data for the White River were limited and are insufficient for calibration of the White River Segment. Total suspended and sand inflow concentrations were available for a wide range of discharges. However, bed material gradation data and individual size class percentages of the suspended load were lacking. In the HEC-6T model, the White River bed was not allowed to scour below the initial cross-section elevations. Therefore, the river bed was not allowed to contribute any sediment to the Mississippi River. However, deposition was allowed in the model so that sediment inflow at the model boundary could be computationally reduced if hydraulic 
conditions were favorable. Calculated morphologic changes in the White River are not reliable.

Measured suspended sediment concentrations from three gages on the White River were used to determine sediment inflow concentrations for the HEC-6T model. The USGS reported sediment data at gage number 07077800, White River at Clarendon, Arkansas, between 1974 and 1986. This gage is at the upstream boundary of the model at RM 99.1. A more recent record was reported by the USGS at gage number 07077000, White River at DeValls Bluff, Arkansas, which is located at RM 121.8. Data at this gage extend between 2001 and 2011. At RM 255.0 is USGS gage number 07074500, White River at Newport, Arkansas. Data were collected at this gage between 1978 and 1994. Measured total sediment concentrations and measured sand concentrations from the three gages are compared in Figure 51 and Figure 52, respectively. The figures show considerable scatter for the total and the sand concentrations. Power regression equations were included on the two figures to help identify data differences at the gages. There were only 12 measurements at DeValls Bluff and 23 measurements at Newport collected during the 1991-2002 calibration period. Considering the data scatter, it was deemed appropriate to use the measurements from the entire 1974-2001 time period and from all three gages to develop sediment inflow rating curves.

Figure 51. Measured suspended sediment concentrations at three gages, White River.

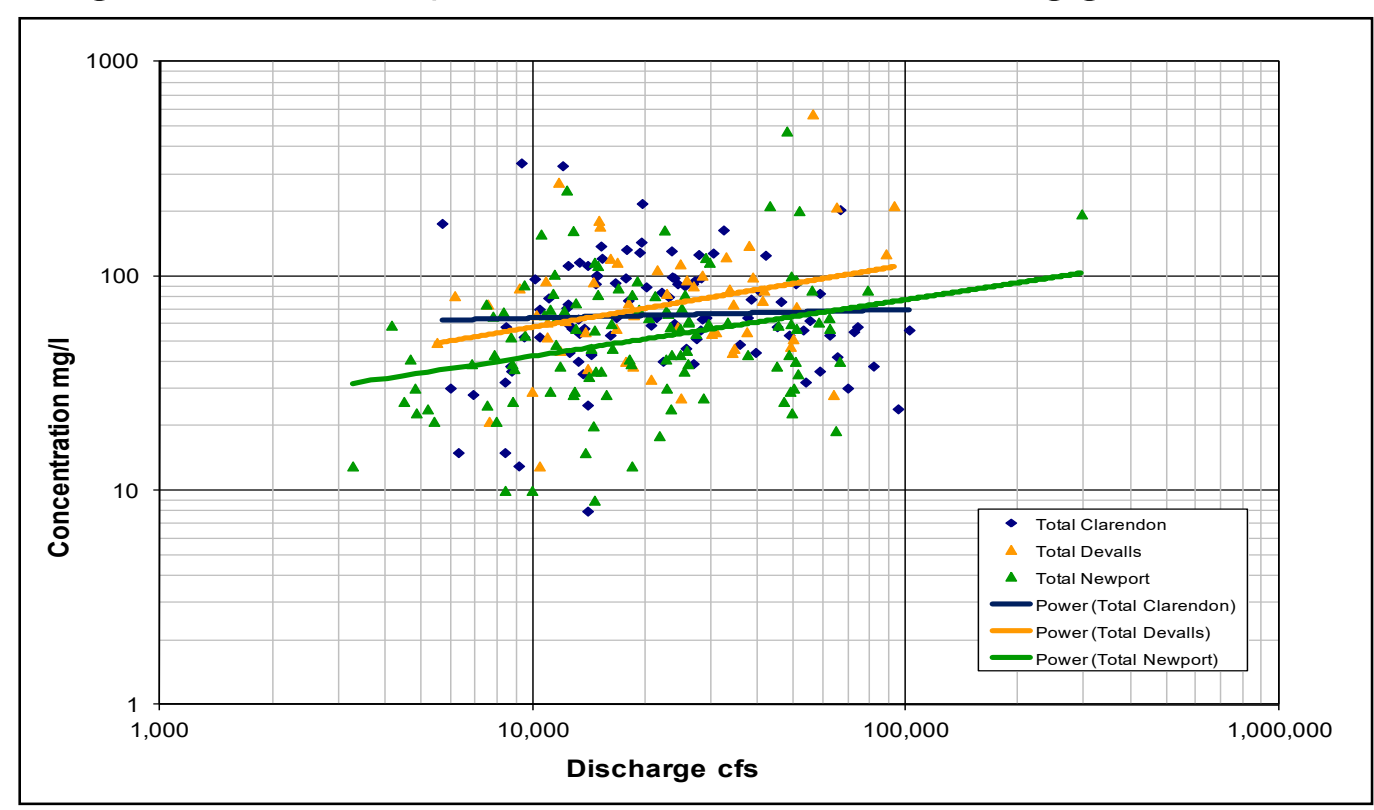


Figure 52. Measured suspended sand concentrations, White River.

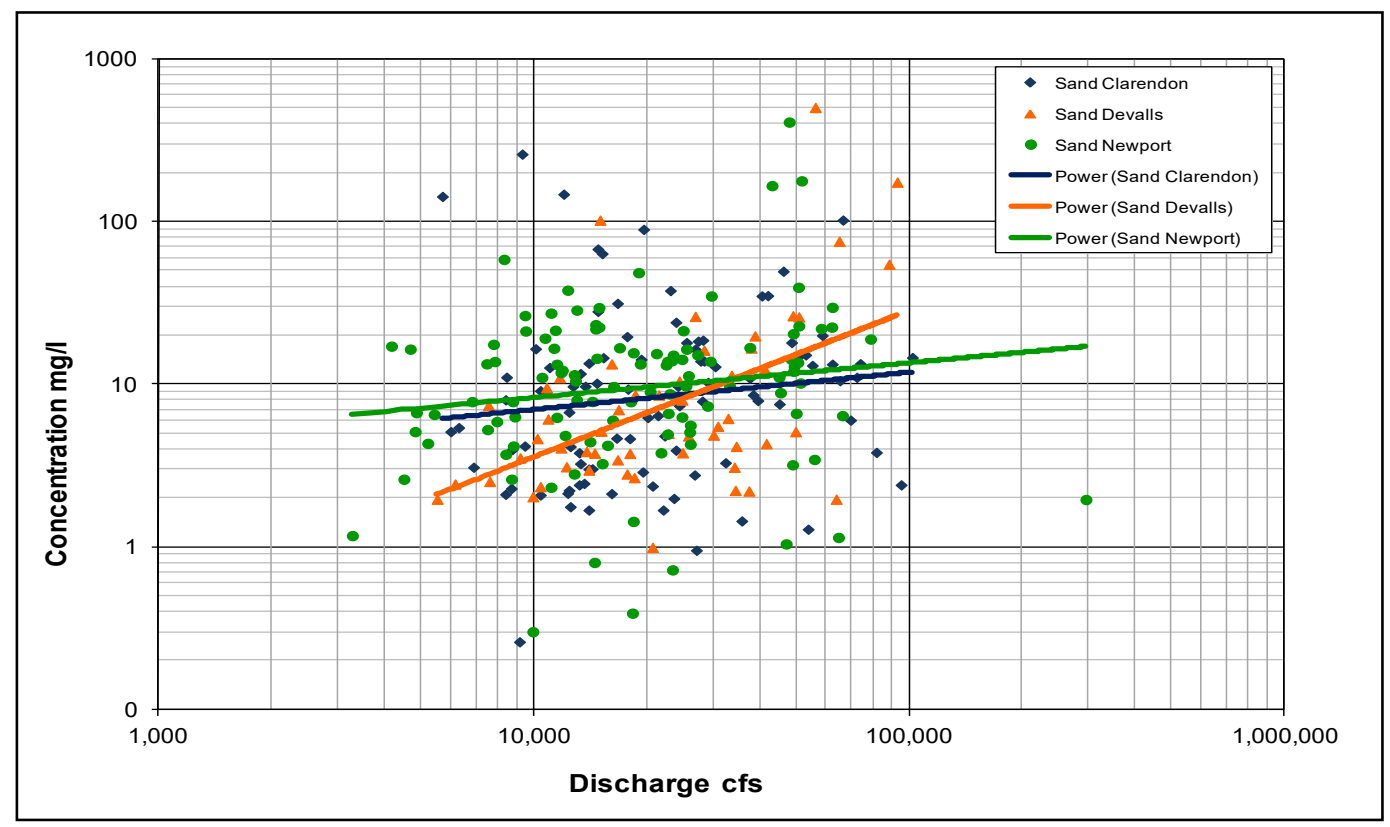

Measured total suspended sediment concentrations and measured suspended sand concentrations collected at Clarendon, DeValls Bluff, and Newport between 1974 and 2011 were used to calculate power regression curves for the HEC-6Tsediment inflow rating table. There were 264 measurements of the total suspended concentration and 258 measurements of the sand concentration. The data are plotted in Figure 53. A simple power regression fit of the data produced the following equations, with an $\mathrm{R}^{2}$ value of 0.052 for the total suspended concentration and 0.042 for the sand concentration:

$$
\begin{aligned}
& C_{\text {total }}=7.1875 Q^{0.2132} \\
& C_{\text {sand }}=0.3237 Q^{0.3294}
\end{aligned}
$$

The unbiased power regression curves are the following:

$$
\begin{aligned}
& C_{\text {total }}=8.9356 Q^{0.2132} \\
& C_{\text {sand }}=0.6232 Q^{0.3294}
\end{aligned}
$$


Figure 53. Measured suspended sediment concentrations, White River.

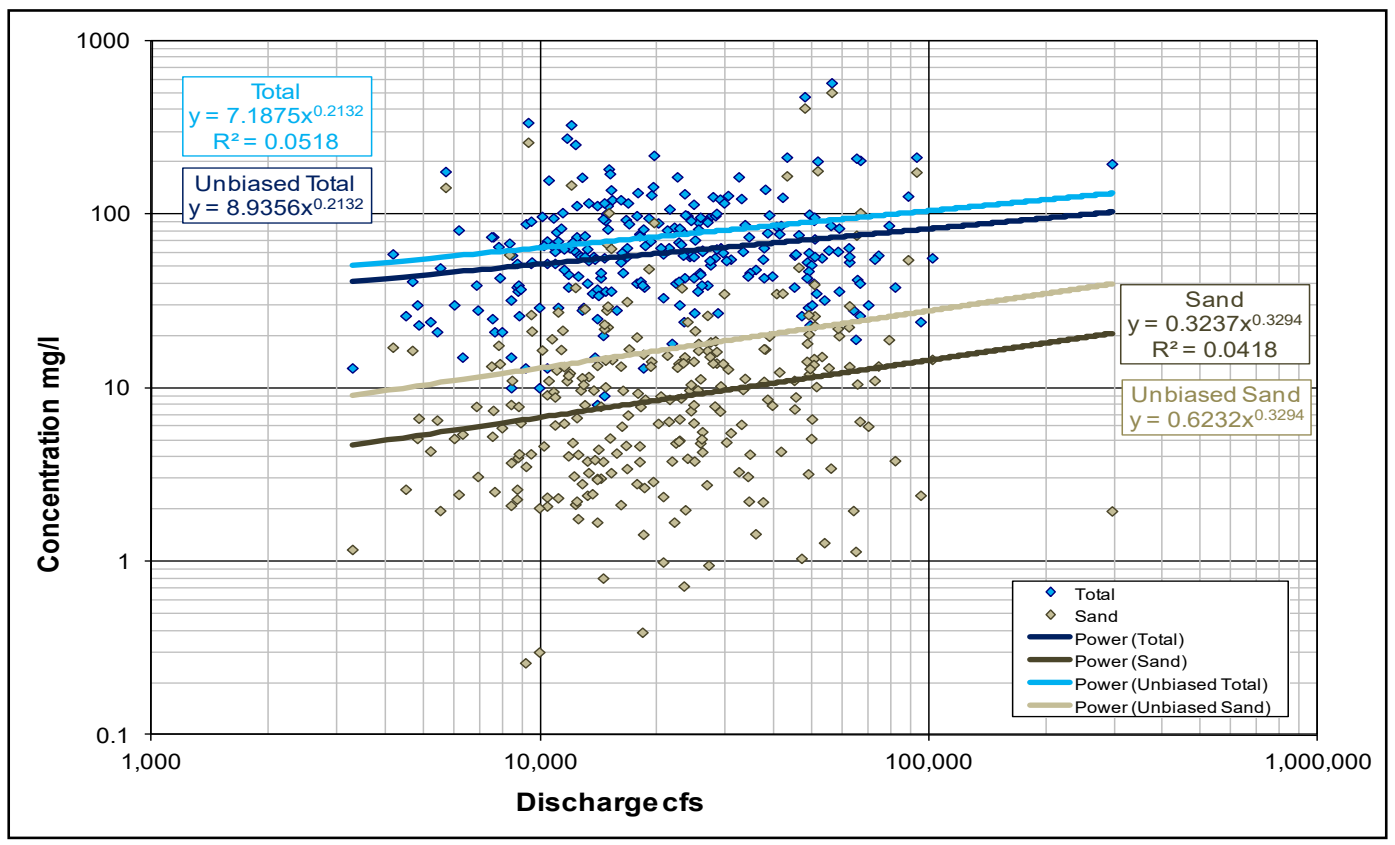

The measured White River data included a sand-silt break, and these data were used to determine the inflow concentrations for fines and sand. However, there were no additional size class percentage data available. The sand size class percentages were taken to be the same as the average sand size class percentages at Thebes and Chester. Likewise, the clay and silt size class percentages were taken to be the same as the average clay and silt size class percentages at Thebes and Chester. These were determined by summing the percent finer data from 71 Chester and Thebes samples collected between 1973 and 1991. These percentages are independent of discharge.

The sediment inflow rating curves used in the HEC-6T model, for the White River, are shown in Table 25. The discharge range used to develop the sediment inflow regression curves was between 3000 and $300,000 \mathrm{cfs}$. In Table 25 the calculated concentration at 300,000 cfs was used for higher discharges. A flat concentration curve at higher discharges is generally closer to prototype behavior than an extrapolation of the regression curve. In the HEC-6T sediment inflow table, fine sand through coarse sand size class percentages were increased by 15 percent to account for unmeasured load. 
Table 25. Sediment inflow for White River - Segment 10.

\begin{tabular}{|c|c|c|c|c|c|c|c|}
\hline Discharge & 1000 & 3000 & 10,000 & 50,000 & 100,000 & 300,000 & 800,000 \\
\hline $\begin{array}{c}\text { Concentration } \\
\mathrm{mg} / \mathrm{I}\end{array}$ & 39.0 & 49.3 & 63.7 & 89.7 & 104.0 & 131.5 & 131.5 \\
\hline \multicolumn{7}{|c|}{ Fractions } \\
\hline Clay & 0.4778 & 0.4658 & 0.4508 & 0.4271 & 0.4155 & 0.3950 & 0.3950 \\
\hline VF Silt & 0.0740 & 0.0721 & 0.0698 & 0.0661 & 0.0643 & 0.0612 & 0.0612 \\
\hline F Silt & 0.0758 & 0.0739 & 0.0715 & 0.0678 & 0.0659 & 0.0627 & 0.0627 \\
\hline M Silt & 0.1084 & 0.1057 & 0.1022 & 0.0969 & 0.0942 & 0.0896 & 0.0896 \\
\hline C Silt & 0.1084 & 0.1057 & 0.1022 & 0.0969 & 0.0942 & 0.0896 & 0.0896 \\
\hline VF Sand & 0.0226 & 0.0256 & 0.0295 & 0.0356 & 0.0385 & 0.0438 & 0.0438 \\
\hline F Sand & 0.1097 & 0.1246 & 0.1433 & 0.1728 & 0.1873 & 0.2128 & 0.2128 \\
\hline M Sand & 0.0361 & 0.0410 & 0.0472 & 0.0569 & 0.0617 & 0.0701 & 0.0701 \\
\hline C Sand & 0.0068 & 0.0077 & 0.0089 & 0.0107 & 0.0116 & 0.0132 & 0.0132 \\
\hline VC Sand & 0.0000 & 0.0000 & 0.0000 & 0.0000 & 0.0000 & 0.0000 & 0.0000 \\
\hline VF Gravel & 0.0000 & 0.0000 & 0.0000 & 0.0000 & 0.0000 & 0.0000 & 0.0000 \\
\hline F Gravel & 0.0000 & 0.0000 & 0.0000 & 0.0000 & 0.0000 & 0.0000 & 0.0000 \\
\hline M Gravel & 0.0000 & 0.0000 & 0.0000 & 0.0000 & 0.0000 & 0.0000 & 0.0000 \\
\hline C Gravel & 0.0000 & 0.0000 & 0.0000 & 0.0000 & 0.0000 & 0.0000 & 0.0000 \\
\hline VC Gravel & 0.0000 & 0.0000 & 0.0000 & 0.0000 & 0.0000 & 0.0000 & 0.0000 \\
\hline
\end{tabular}

\section{Sediment inflow Arkansas River}

The purpose of the Arkansas River Segment in the HEC-6T model is to provide sediment inflow to the Mississippi River. Data are insufficient for calibration of the Arkansas River Segment, and calculated morphologic changes should be treated with caution. Sediment data for the Arkansas River were limited. Sand and fine inflow concentrations were available for a wide range of discharges. However, bed material gradation data and individual size class percentages of the suspended load were lacking.

Measured suspended sediment measurements from two gages on the Arkansas River were used to determine sediment inflow. The USGS reported sediment data at gage number 0765283, Arkansas River at Dam No. 2, near Gillett, Arkansas, between 1979 and 1986. This gage is at the upstream end of the modeled reach. A much longer record was reported by the USGS, 95 miles upstream at gage number 07266283, Arkansas River at David D Terry Lock and Dam below Little Rock, Arkansas. Data at this 
gage extend between 1974 and 2010. Data from the two gages, for the years when both were operating, are compared in Figure 54. Regression equations for the total load and the sand load are similar. Because of this similarity, data from both gages were confidently used to develop sediment inflow rating curves for the HEC-6T model. Unbiased power regression curves were calculated for the total measured load and measured sand load and are shown in Figure 55.

Figure 54. Measured sediment concentrations at two gages on the Arkansas River.

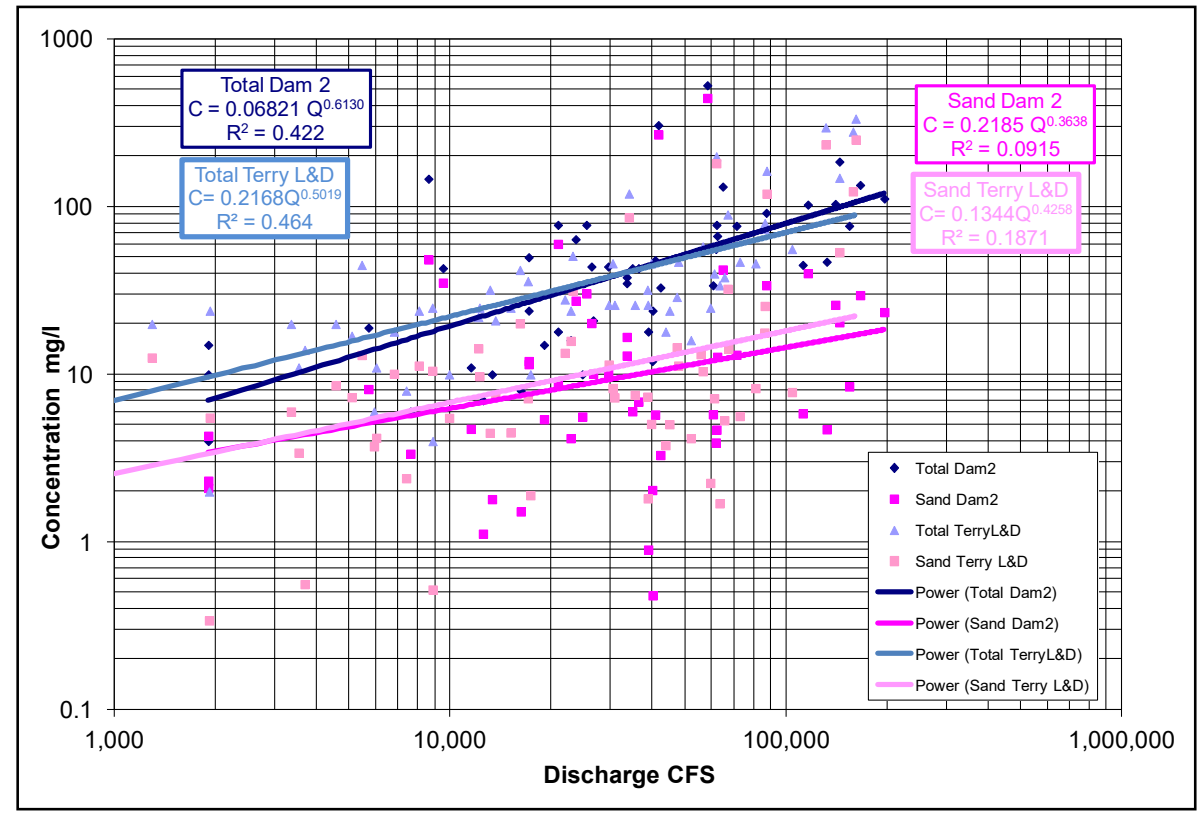

Figure 55. Measured sediment concentrations on the Arkansas River.

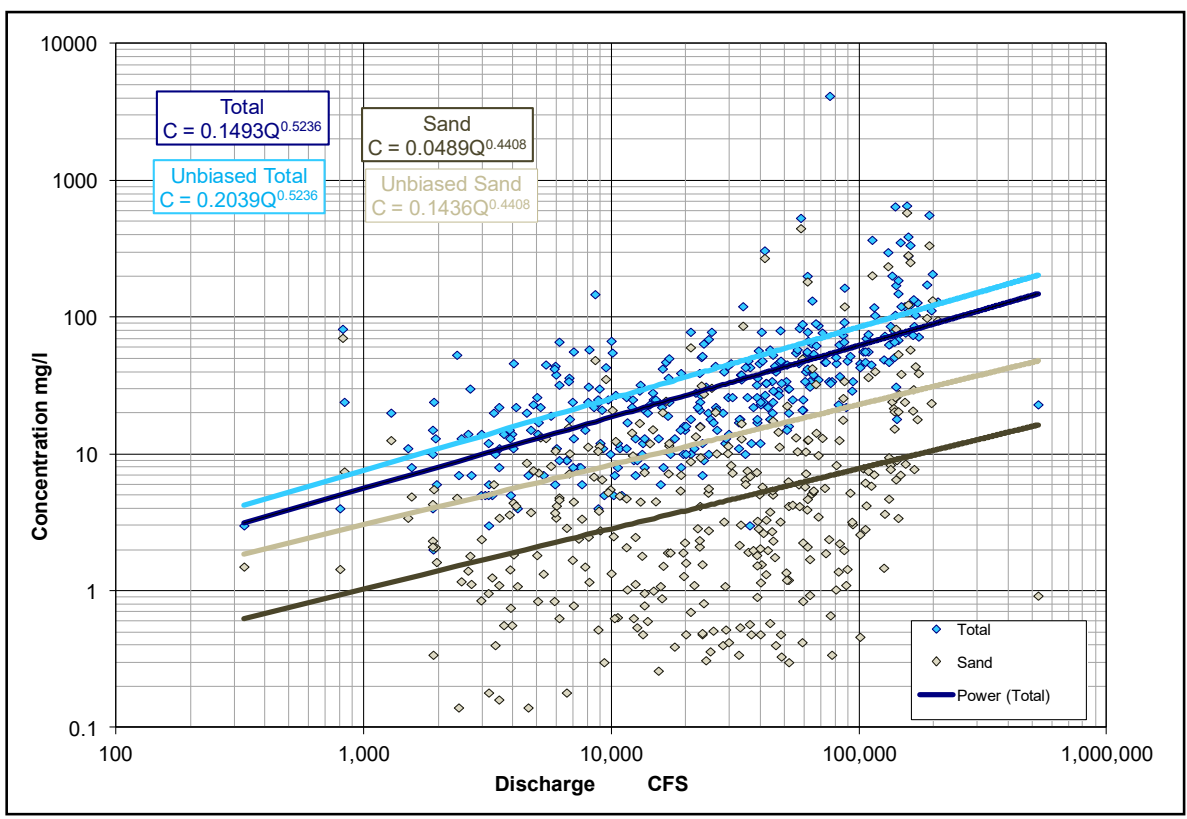


The measured Arkansas River data included a sand-silt break. These data were used to determine the inflow concentrations for fines and sand. However, there were no additional size class percentage data available. Measured percentages from Mississippi River gage data at Coochie and Union Point (Mississippi RMs 317 and 326, respectively) were assigned for clay and silt sizes on the Arkansas River.

Sediment transport for each sand size class was calculated for a series of steady state discharges at five upstream cross sections. Due to the small percentage of very fine sand in the bed, very fine sand was considered to be wash load. Very fine sand transport was assumed to be the difference between the measured sand transport from the unbiased sand regression curve and the calculated sand transport for the fine sand through very coarse sand size classes. Sand size class percentages were then determined from these calculated sand loads. The calculated percentages were then smoothed using regression analysis in EXCEL. Fine sand through very coarse sand size class percentages was increased by 15 percent to account for unmeasured load.

Arkansas River sediment inflow rating curves, for each size class, are shown in Figure 56. HEC-6T sediment inflow is shown in Table 26.

Figure 56. Sediment inflow rating curves for Arkansas River.

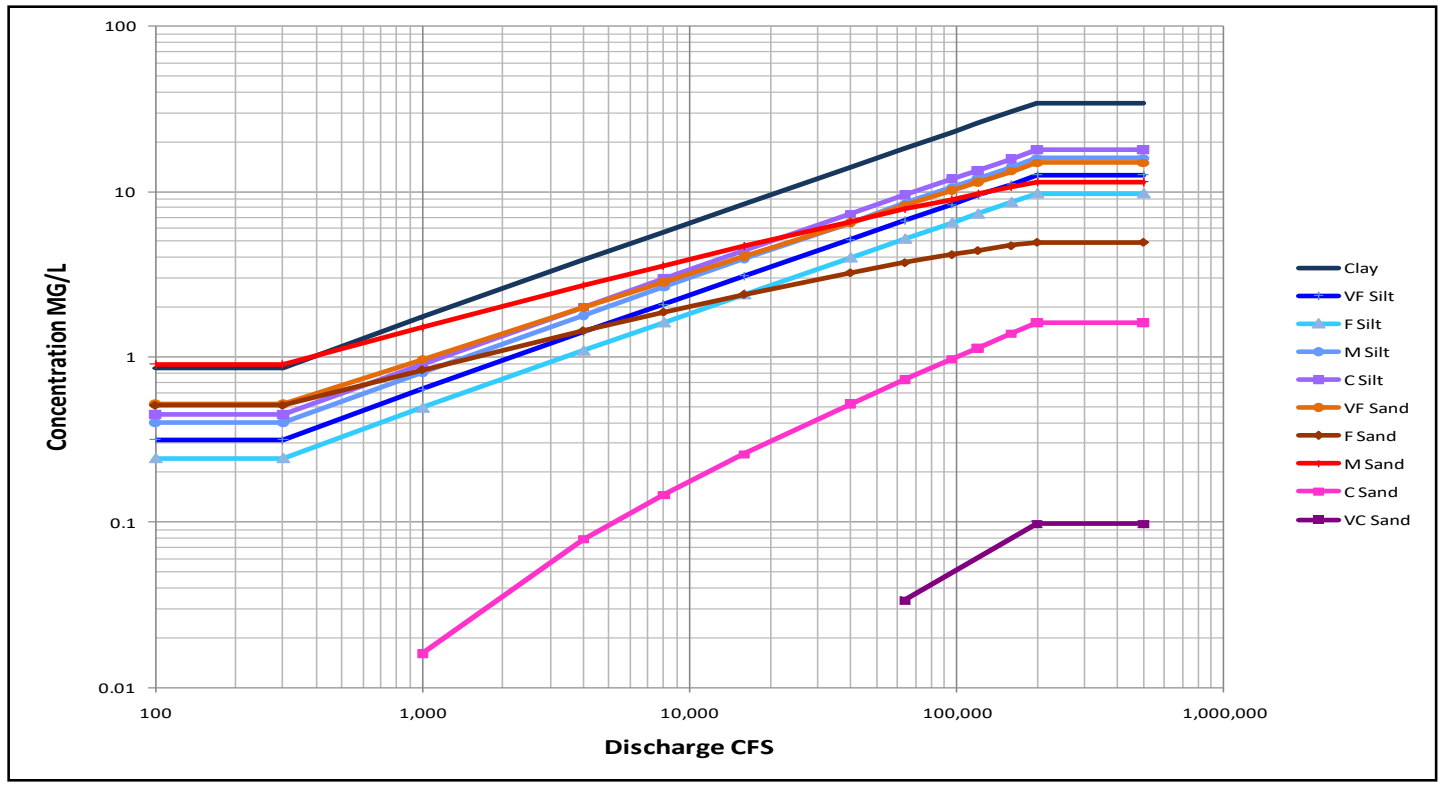


Table 26. Sediment inflow for Arkansas River - Segment 8.

\begin{tabular}{|c|c|c|c|c|c|c|c|c|}
\hline Discharge & 300 & 1000 & 4000 & 8,000 & 16,000 & 64,000 & 200,000 & $1,000,000$ \\
\hline Concentration mg/l & 4.0 & 7.6 & 15.7 & 22.5 & 32.4 & 67.0 & 121.6 & 121.6 \\
\hline \multicolumn{7}{|c|}{ Fractions } \\
\hline Clay & 0.2129 & 0.2287 & 0.2451 & 0.2526 & 0.2597 & 0.2727 & 0.2823 & 0.2823 \\
\hline VF Silt & 0.0779 & 0.0837 & 0.0897 & 0.0924 & 0.0950 & 0.0998 & 0.1033 & 0.1033 \\
\hline F Silt & 0.0604 & 0.0649 & 0.0696 & 0.0717 & 0.0762 & 0.0774 & 0.0802 & 0.0802 \\
\hline M Silt & 0.0987 & 0.1061 & 0.1137 & 0.1171 & 0.1245 & 0.1265 & 0.1309 & 0.1309 \\
\hline C Silt & 0.1108 & 0.1191 & 0.1276 & 0.1315 & 0.1352 & 0.1419 & 0.1470 & 0.1470 \\
\hline VF Sand & 0.1248 & 0.1273 & 0.1260 & 0.1254 & 0.1248 & 0.1236 & 0.1225 & 0.1225 \\
\hline F Sand & 0.1259 & 0.1101 & 0.0919 & 0.0829 & 0.0738 & 0.0556 & 0.0407 & 0.0407 \\
\hline M Sand & 0.2227 & 0.1988 & 0.1714 & 0.1577 & 0.1439 & 0.1165 & 0.0939 & 0.0939 \\
\hline C Sand & 0.0000 & 0.0021 & 0.0050 & 0.0065 & 0.0079 & 0.0108 & 0.0132 & 0.0132 \\
\hline VC Sand & 0.0000 & 0.0000 & 0.0000 & 0.0000 & 0.0000 & 0.0005 & 0.0008 & 0.0008 \\
\hline VF Gravel & 0.0000 & 0.0000 & 0.0000 & 0.0000 & 0.0000 & 0.0000 & 0.0000 & 0.0000 \\
\hline F Gravel & 0.0000 & 0.0000 & 0.0000 & 0.0000 & 0.0000 & 0.0000 & 0.0000 & 0.0000 \\
\hline M Gravel & 0.0000 & 0.0000 & 0.0000 & 0.0000 & 0.0000 & 0.0000 & 0.0000 & 0.0000 \\
\hline C Gravel & 0.0000 & 0.0000 & 0.0000 & 0.0000 & 0.0000 & 0.0000 & 0.0000 & 0.0000 \\
\hline VC Gravel & 0.0000 & 0.0000 & 0.0000 & 0.0000 & 0.0000 & 0.0000 & 0.0000 & 0.0000 \\
\hline
\end{tabular}

\section{Sediment inflow Yazoo River}

The purpose of the Yazoo River Segment in the HEC-6T model is to provide sediment inflow to the Mississippi River. Data are insufficient for calibration of the Yazoo River Segment, and calculated morphologic changes should be treated with caution. There are significant suspended sediment measurements of the total and sand load available for a wide range of discharges. However, only two bed samples were available, and there were no data defining the individual size class percentages in the suspended load.

The USGS has measured suspended sediment at Redwood (RM 16.7) and downstream from Steel Bayou (RM 9.5). Suspended sediment samples were collected at the Yazoo River at Redwood, Mississippi gage (USGS 07288800) between 1978 and 1993. Suspended sediment samples were collected at the Yazoo River below Steele Bayou near Long Lake, Mississippi gage (USGS 07288955) between 1995 and 2010. The data from both gages were plotted together to determine power regression 
equations for the total load and the sand load. Unbiased regression equations were calculated for both. The measured data and regression curves are shown in Figure 57.

Figure 57. Sediment concentration Yazoo River at Redwood and Steel Bayou.

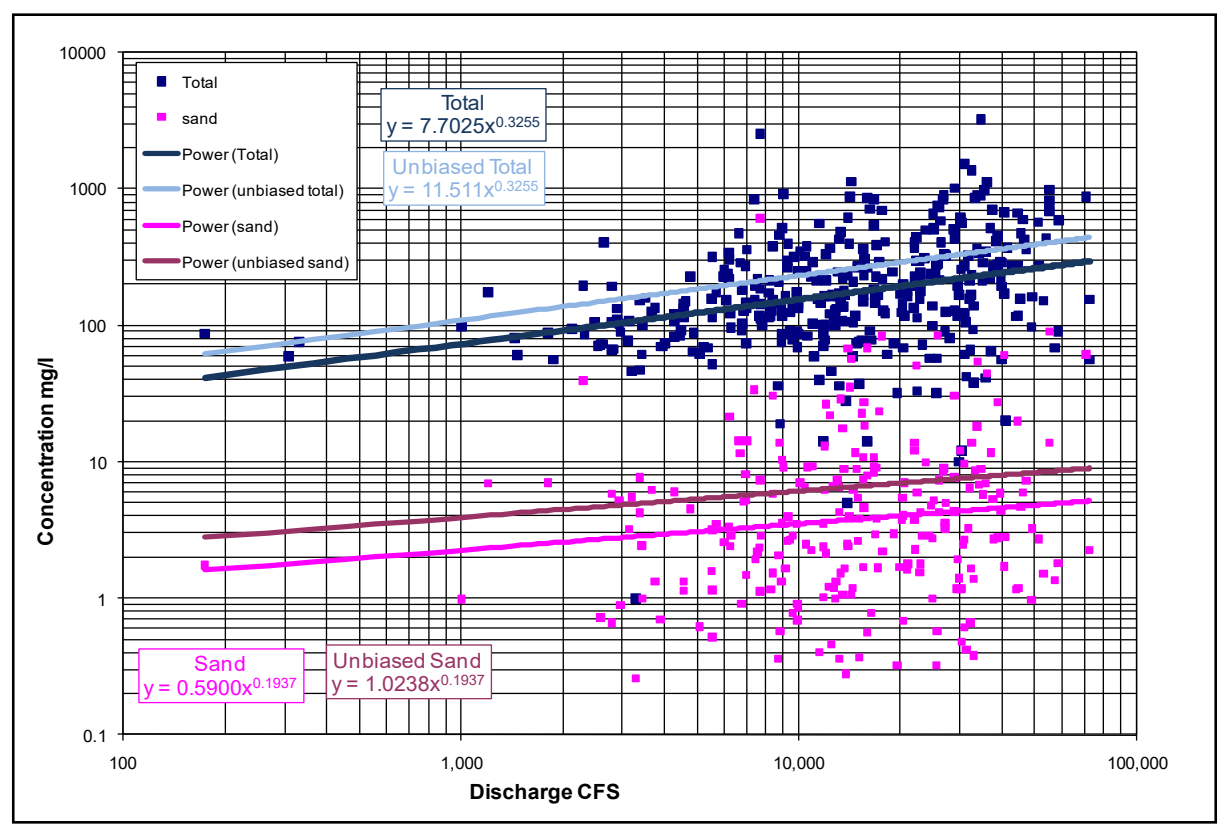

The total measured load data were used to evaluate the possibility of a declining or increasing trend in the sediment delivery to the Mississippi River. Power regression curves were calculated for the 1991-2002 and 2003-2010 time periods. These curves were found to be very close to the regression curve for the entire 1978-2010 period as shown in Figure 58.

Figure 58. Total sediment concentration trends Yazoo River.

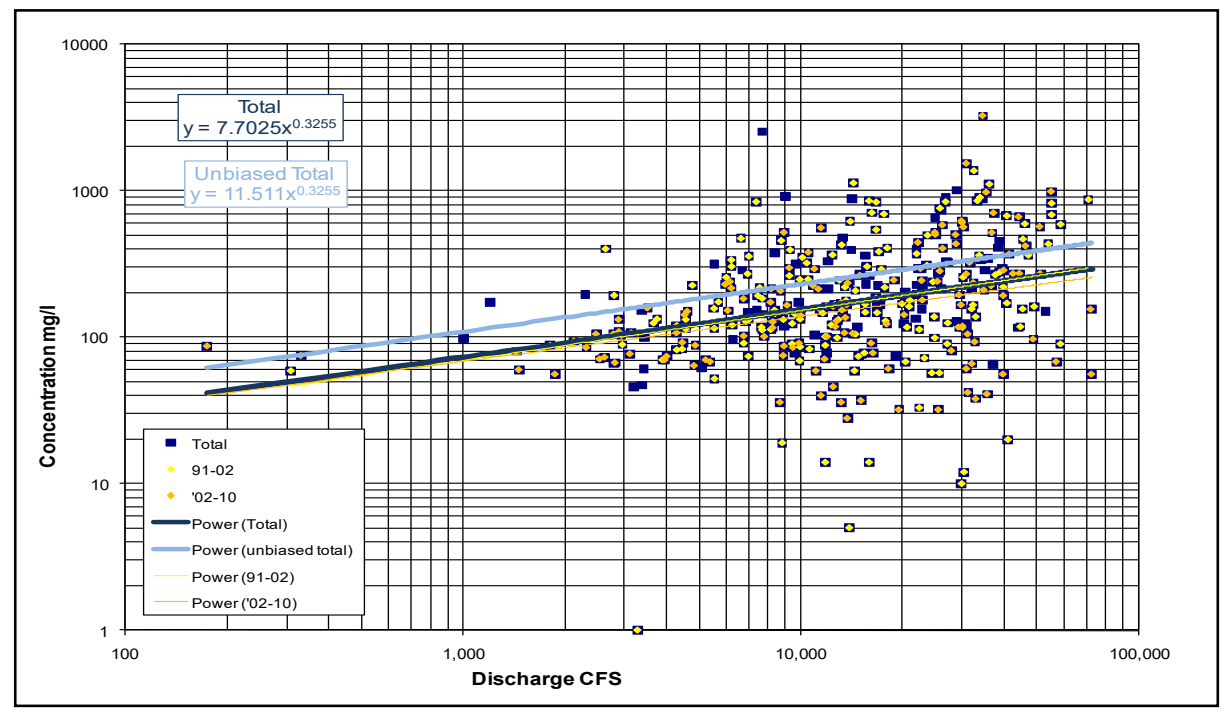


The inflowing sediment load size class percentages for fines and sands were assumed to be the same as the measured size class percentages from the 1991-2002 data at Coochie and Union Point. These sediment gages are located at Mississippi RMs 317 and 326, respectively, and are the closest gages with size class data. The total fine sediment concentration was determined from the measured Yazoo River data, and then the fine sediment size class distribution was taken from the Coochie and Union Point fine sediment size class distribution data. Similarly, the total sand concentration was determined from the measured Yazoo River data, and then the sand size class distribution was taken from the Coochie and Union Point data. This methodology results in a significant discontinuity between coarse silt and very fine sand concentrations in the inflowing sediment load rating curves. The sand concentrations were arbitrarily increased by 15 percent to account for the unmeasured load. The sediment inflow rating curves for the Yazoo River are shown in Figure 59 and Table 27.

Figure 59. Sediment inflow rating curves for Yazoo River.

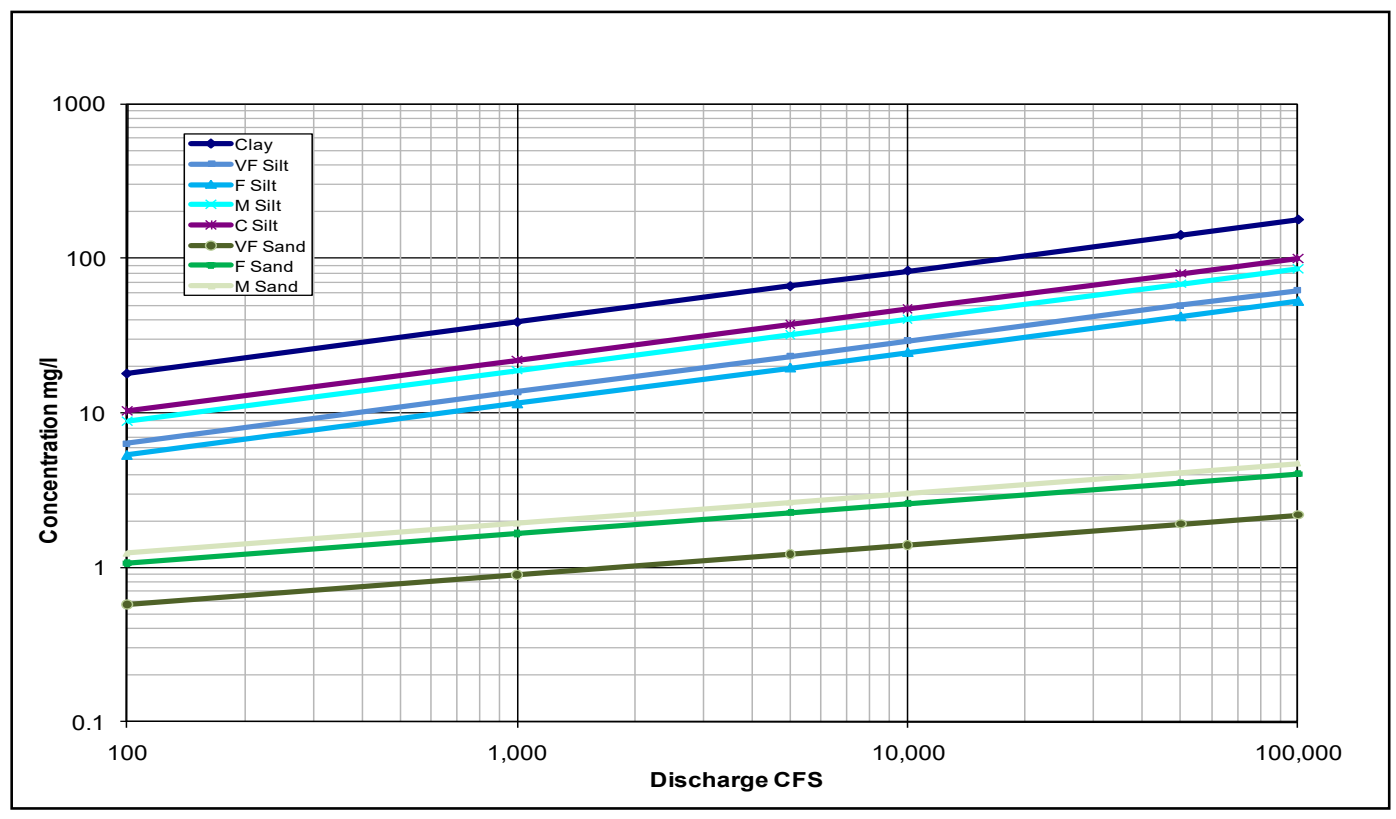

Only two bed material samples were available for the Yazoo River. The USGS collected these samples at the Steele Bayou Gage. Both samples were collected in August: one in 1995 that contained only 8 percent sand and one in 1997 that contained 5 percent sand. These data suggest that the bed of the Yazoo River is primarily cohesive. Therefore, the bed sediment reservoir in the HEC-6T model was set to zero. The initial bed gradation in the Yazoo River was determined based on the two measurements, 
normalizing them to 100 percent sand. Since the bed sediment reservoir has been given a zero depth, this bed gradation only serves as a starting point in the numerical solution of the sediment continuity equation.

Table 27. Sediment inflow for Yazoo River - Segment 6.

\begin{tabular}{|c|c|c|c|c|c|c|c|}
\hline Discharge & 10 & 100 & 1000 & 10,000 & 50,000 & 100,000 & 350,000 \\
\hline Concentration mg/l & 44.6 & 44.6 & 97.6 & 213.4 & 368.8 & 466.8 & 466.8 \\
\hline \multicolumn{7}{|c|}{ Fractions } \\
\hline Clay & 0.3482 & 0.3482 & 0.3522 & 0.3554 & 0.3573 & 0.3580 & 0.3580 \\
\hline VF Silt & 0.1224 & 0.1224 & 0.1237 & 0.1249 & 0.1255 & 0.1258 & 0.1258 \\
\hline F Silt & 0.1035 & 0.1035 & 0.1047 & 0.1057 & 0.1062 & 0.1064 & 0.1064 \\
\hline M Silt & 0.1694 & 0.1694 & 0.1713 & 0.1729 & 0.1738 & 0.1742 & 0.1742 \\
\hline C Silt & 0.1976 & 0.1976 & 0.1999 & 0.2017 & 0.2028 & 0.2032 & 0.2032 \\
\hline VF Sand & 0.0118 & 0.0118 & 0.0096 & 0.0079 & 0.0069 & 0.0065 & 0.0065 \\
\hline F Sand & 0.0218 & 0.0218 & 0.0178 & 0.0146 & 0.0127 & 0.0120 & 0.0120 \\
\hline M Sand & 0.0253 & 0.0253 & 0.0207 & 0.0170 & 0.0148 & 0.0139 & 0.0139 \\
\hline C Sand & 0.0000 & 0.0000 & 0.0000 & 0.0000 & 0.0000 & 0.0000 & 0.0000 \\
\hline VC Sand & 0.0000 & 0.0000 & 0.0000 & 0.0000 & 0.0000 & 0.0000 & 0.0000 \\
\hline VF Gravel & 0.0000 & 0.0000 & 0.0000 & 0.0000 & 0.0000 & 0.0000 & 0.0000 \\
\hline F Gravel & 0.0000 & 0.0000 & 0.0000 & 0.0000 & 0.0000 & 0.0000 & 0.0000 \\
\hline M Gravel & 0.0000 & 0.0000 & 0.0000 & 0.0000 & 0.0000 & 0.0000 & 0.0000 \\
\hline C Gravel & 0.0000 & 0.0000 & 0.0000 & 0.0000 & 0.0000 & 0.0000 & 0.0000 \\
\hline VC Gravel & 0.0000 & 0.0000 & 0.0000 & 0.0000 & 0.0000 & 0.0000 & 0.0000 \\
\hline
\end{tabular}

\section{Sediment inflow sources}

Cumulative sediment inflows to the Mississippi River from the tributaries were calculated for the 1991-2002 calibration period. Using the sediment inflow rating curves described in the preceding sections, the calculated sediment inflowing sediment load percentages from each tributary are tabulated in Table 28. The table shows the calculated inflow from the tributary, which includes any calculated supply or deposition in the tributary between the upstream boundary and the confluence. Calculations show that 69.0 percent of the total sediment and 80.4 percent of the sand are supplied by the Middle Mississippi River, even though most of the water is supplied by the Ohio River. 
Table 28. Source of Mississippi River water and sediment loads. 1991-2002 by percentage - based on HEC $6 \mathrm{~T}$ input.

\begin{tabular}{|c|c|c|c|c|c|}
\hline & Water & Total & Clay & Silt & Sand \\
\hline Ohio River & 45.1 & 21.0 & 21.7 & 26.6 & 11.5 \\
\hline Middle Mississippi River & 37.4 & 69.0 & 68.9 & 61.0 & 80.4 \\
\hline Arkansas River & 8.2 & 3.1 & 1.7 & 3.1 & 6.3 \\
\hline White River & 4.4 & 1.3 & 1.4 & 1.1 & 0.5 \\
\hline Yazoo River & 3.0 & 3.2 & 3.2 & 5.8 & 0.3 \\
\hline St. Francis River & 0.8 & 0.5 & 0.7 & 0.4 & 0.0 \\
\hline Hatchie River & 0.6 & 0.4 & 0.5 & 0.4 & 0.2 \\
\hline Obion River & 0.5 & 1.5 & 1.9 & 1.6 & 0.8 \\
\hline
\end{tabular}

\section{Depth of bed sediment reservoir}

The Exner 7 sorting and armoring algorithm used in this study assumes that the bed sediment reservoir provides an infinite supply unless a bottom elevation is prescribed. Sediment continuity is maintained in three separate bed layers during the computer simulation, and the bed sediment reservoir only comes into play during the initial time-step and when erosion of the three surface layers occurs. If the supply of bed sediment is limited in the prototype then that limit must be set in HEC-6T.

The bed sediment reservoir depth was limited at several locations in the Mississippi River where erosion is known to be limited by cohesive deposits, bedrock, gravel deposits, or constructed sills. A bed sediment reservoir depth of $1 \mathrm{ft}$ was assigned in the model between RMs 12.5 and 57. This reflects the presence of a cohesive layer underlying the Mississippi River over which sand is transported (Kolb 1962). A bed sediment reservoir of $0.01 \mathrm{ft}$ was specified in the Profit Island Chute (RMs 248.38 and 248.56) and the Wolf Island Chute (RM 934.4) to account for closure structures constructed in the chutes. The bed sediment reservoir was also limited to $1 \mathrm{ft}$ at RM 734.56 (I-55 Bridge at Memphis), $0.1 \mathrm{ft}$ at RM 911.2 (Island No. 8 main channel), $1.0 \mathrm{ft}$ at RM 917.6, and $0.01 \mathrm{ft}$ at RM 922.

The bed sediment reservoir was also limited in some of the tributaries. The bed of the Ohio River was limited to $1 \mathrm{ft}$ at the Metropolis Bridge, located approximately 41 miles upstream from Cairo. The Middle Mississippi River bed sediment reservoir was limited between RMs 32.84 and 44.29, and at 109.90 to account for exposed bed rock at these locations. The bed sediment reservoir in the St. Francis River was set at $20 \mathrm{ft}$ because that was used in a previous HEC-6T study conducted for that river. The entire 
White River and Yazoo River segments were assigned a bed sediment reservoir depth of only $0.01 \mathrm{ft}$. This was due to a lack of bed-material gradation data. These tributary segments are intended to provide a reasonable estimate of sediment inflow from the tributary. By setting a bed sediment reservoir depth of $0.01 \mathrm{ft}$, only deposition is allowed in the tributary so that there is no sediment contribution from the river bed. Data are insufficient for calibration of the White and Yazoo River segments, and calculated morphologic changes should be treated with caution. The cross sections on the Hatchie and Obion Rivers were assigned bed sediment reservoir depths of $0.01 \mathrm{ft}$.

The dredging algorithm in HEC-6T requires that a bed sediment reservoir depth be prescribed. At non-dredging sites, the bed sediment reservoir depth is calculated by the hydraulic sorting and armoring algorithm. A bed sediment reservoir depth of $20 \mathrm{ft}$ was assigned in the HEC-6T model in the New Orleans District between RMs -18.0 and 5.5 where dredging was calculated during the simulation. A bed sediment reservoir depth of $50 \mathrm{ft}$ was assigned in the HEC-6T model in the Memphis District at all of the dredging sites. However, in the calibration study there was no dredging calculated in the Memphis District reach. The sensitivity of the depth of bed sediment reservoir assumption should be tested in future studies where the model is being used to test project impacts at specific dredging sites. A bed sediment reservoir depth will need to be included in any future studies using this model if new dredging sites are specified.

\section{Mississippi River bed material gradations}

Bed material sampling programs of the Mississippi River have indicated significant longitudinal and lateral variability in the bed material gradations. An example of lateral variability is shown in Figure 60 where samples were taken from transects at quarter points at a river bend at Bayou Sara (RM 265). In Figure 60 the point bar is on the right side of the river. Longitudinal variability is primarily due to the differences in bed shear stresses associated with the natural bends and crossings along the course of the river. Variability over short distances of 1 or 2 miles can equal the average variability over the entire 950 miles between Head of Passes and Cairo. This variability makes it difficult to determine if there has been any long-term change in the bed material gradation. Nordin and Queen (1992) compared thalweg bed-material samples that they collected in 1989 to thalweg bed-material samples collected in 1932 (WES 1935) and concluded the following: 
1. The 1989 samples were more uniform than the 1932 samples, containing less coarse sand and gravel and less very fine sand than the 1932 samples. The significant decrease in gravel is shown in Figure 61 which plots the median grain diameters of both the 1932 and 1989 samples.

2. Between Cairo and Vicksburg, the median grain diameter was generally smaller in 1989 than it was in 1932. This small difference in shown in Figure 62 which plots the median grain diameters of only the sand samples. Without the linear regression lines it would be difficult to determine any difference in the median size between 1932 and 1989. The average difference is contained within the data scatter.

3. Downstream from Vicksburg, the median grain diameter of the bed material was essentially the same in 1989 and 1932.

Figure 60. Lateral variation in bed material gradation at RM 265, August 2005.

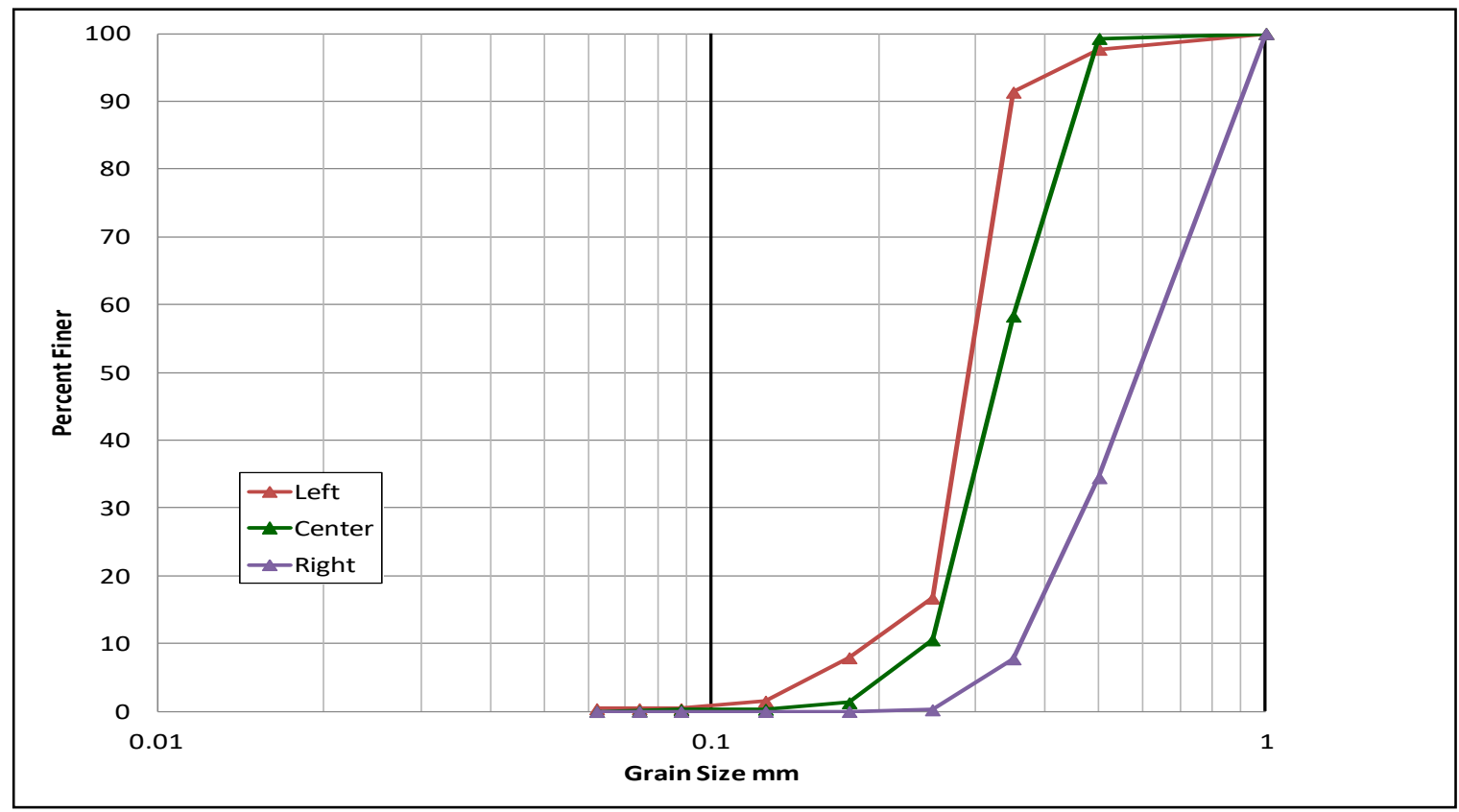


Figure 61. Historic change in Mississippi River median bed grain size.

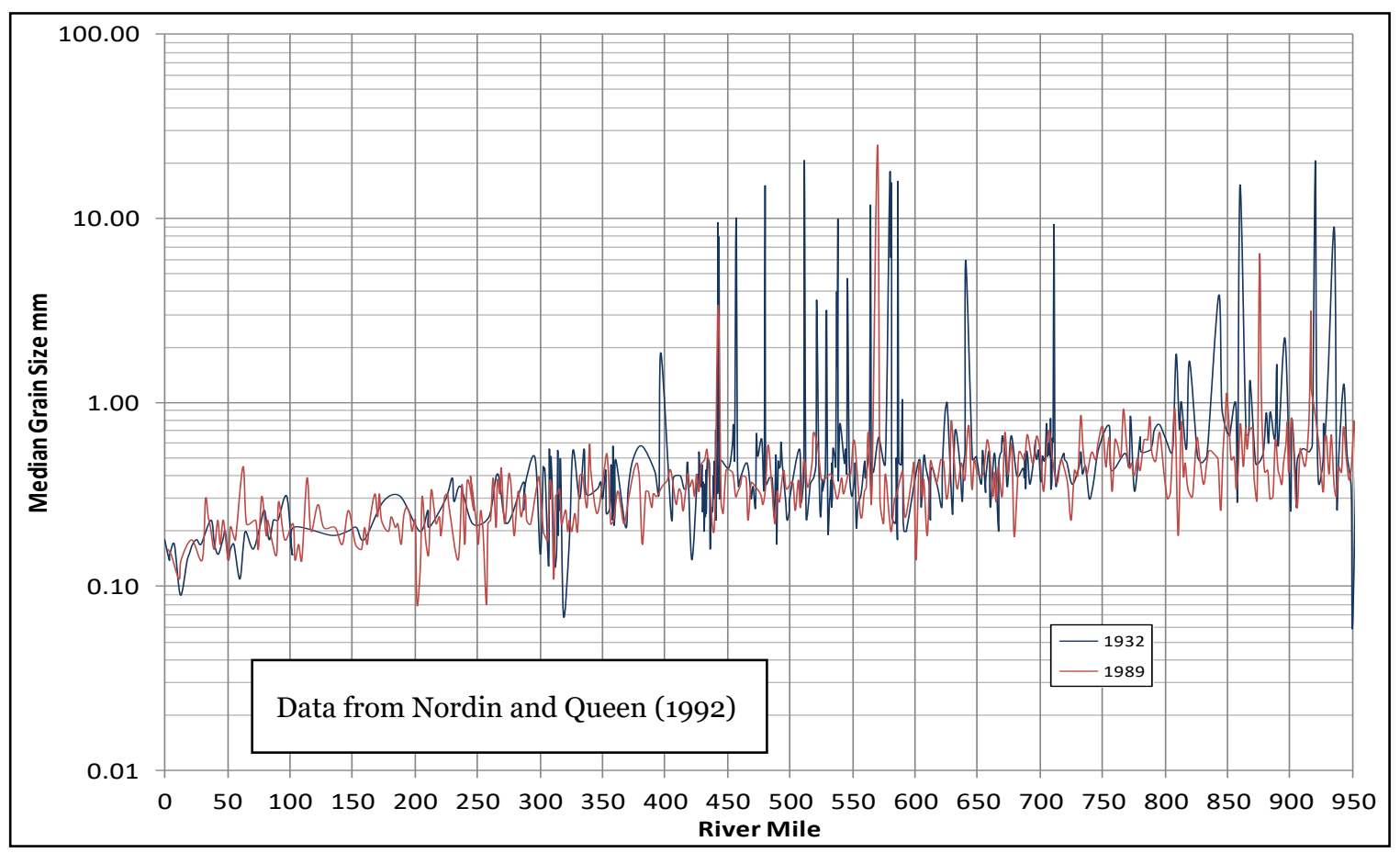

Initial bed-material gradations in the numerical model were adjusted to allow for variability associated with cross-section shape and velocity. The Nordin and Queen (1992) data were used to develop polynomial regression curves of the bed material gradations to determine an average longitudinal variability. These are shown in Figures 63 and 64. Initial bed gradations for each model cross section were calculated using a bankfull discharge of $1,436,000$ for 30 days at Vicksburg. The Vicksburg bankfull discharge was calculated from assigned bankfull discharges from tributaries in the Memphis District. These new calculated bed gradations were then set as initial conditions in the numerical model. The calculated initial bed gradations are shown in Figure 65. 
Figure 62. Historic change in median bed grain size -gravel samples removed.

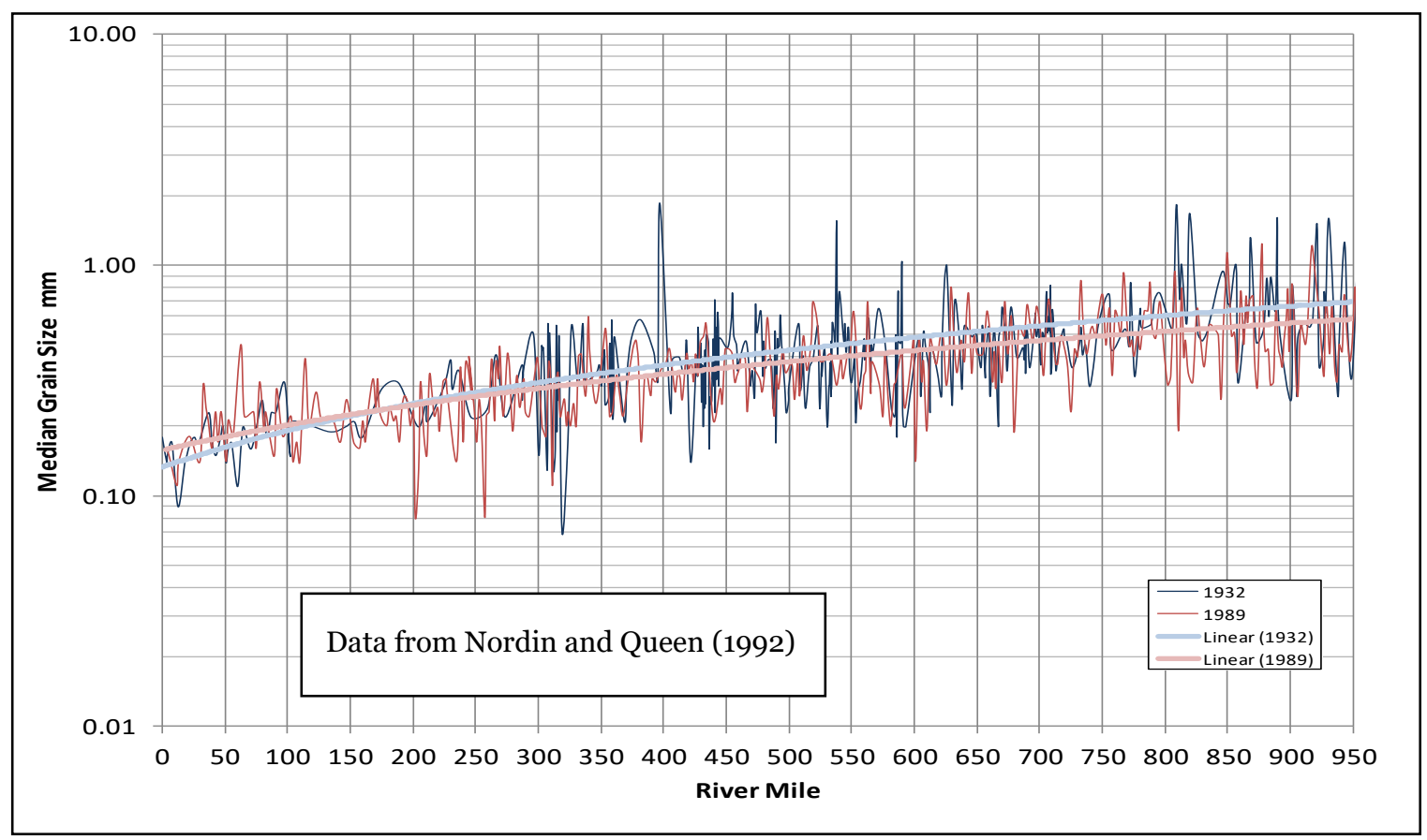

Figure 63. 1989 bed gradations downstream from RM 306 with polynomial trend lines.

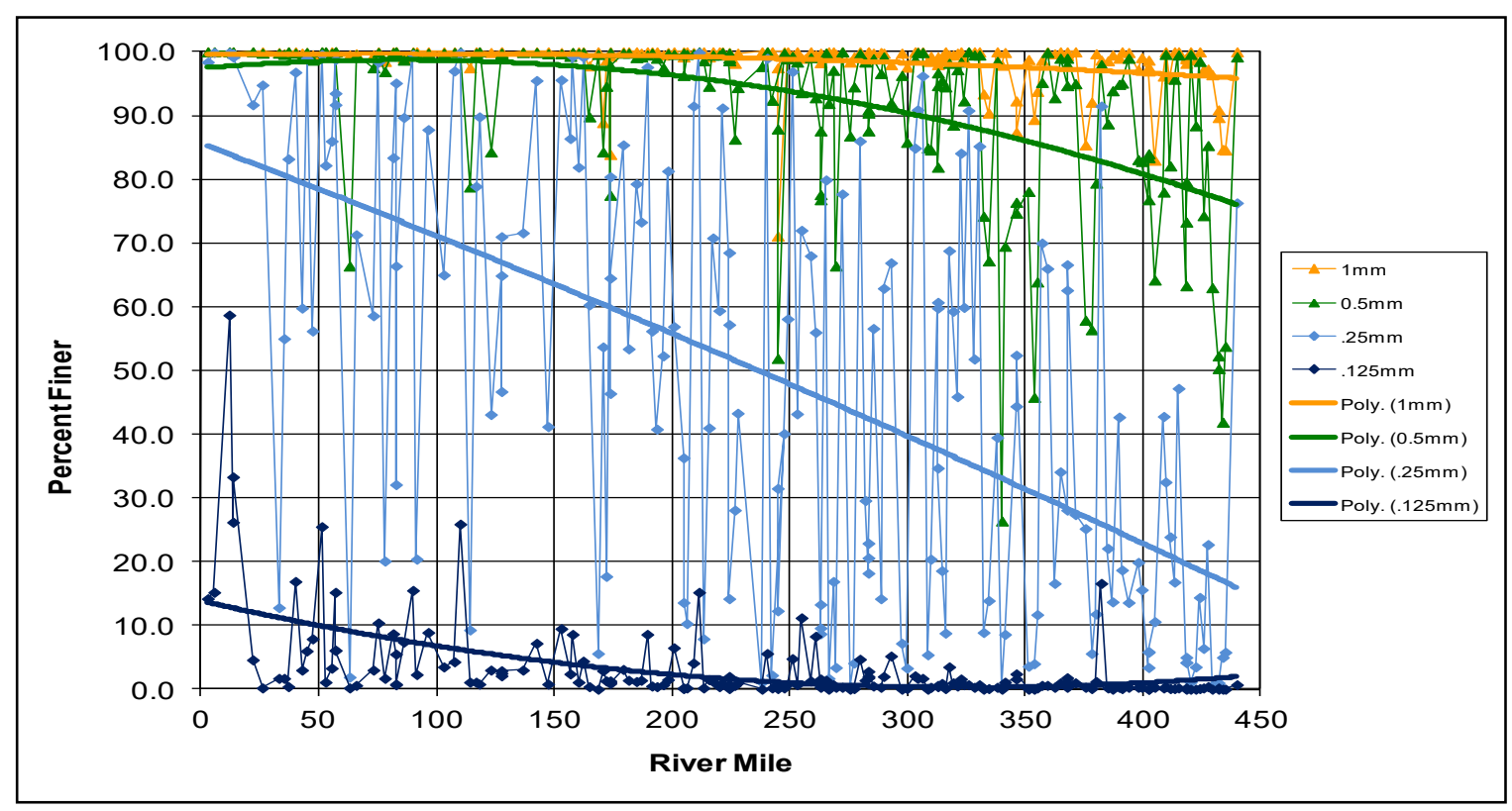


Figure 64. 1989 bed gradations upstream from RM 306, with polynomial trend lines.

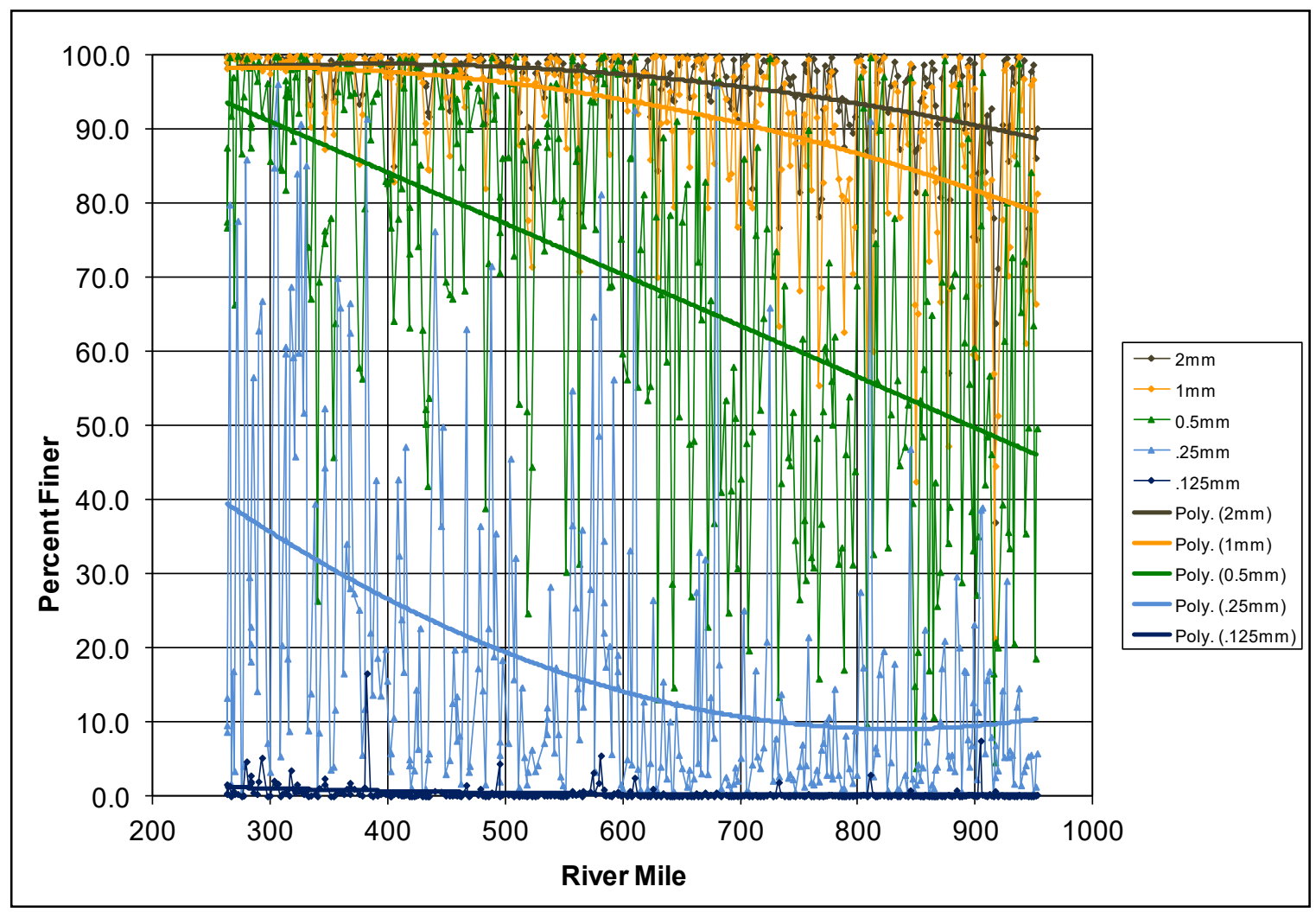

Figure 65. Initial bed calculated starting with Nordin polynomials after 30 days.

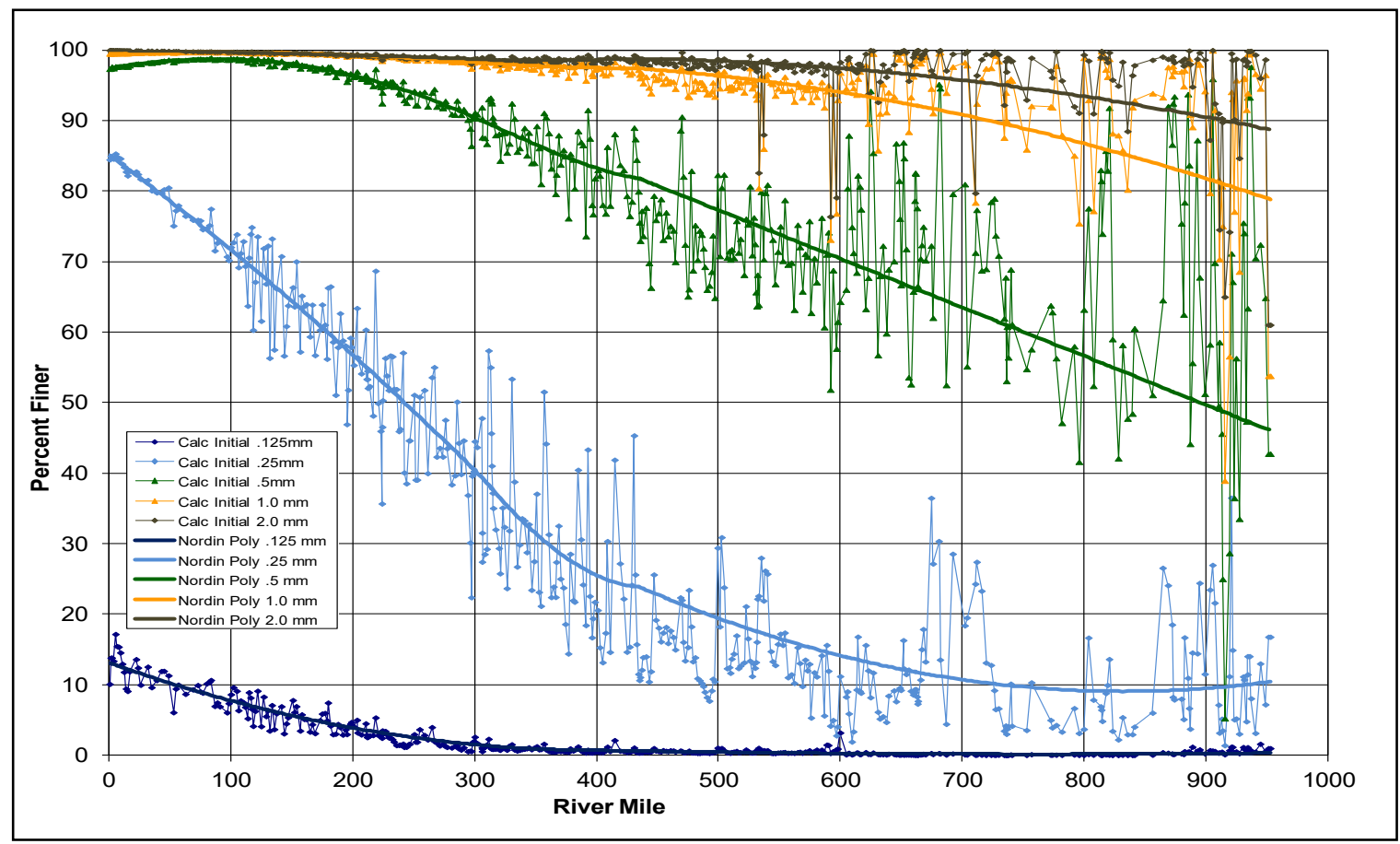




\section{Tributary bed gradations}

\section{Middle Mississippi River bed gradations}

The initial bed material gradations for the Middle Mississippi River segment between Cairo and Chester were developed from the USGS measured data at Thebes. Fourteen bed material gradations, taken between 1980 and 1989, were reported by the USGS on its water quality web site. The average of these gradations, and the maximum and minimum curves, are shown in Figure 66. The average Thebes bed gradation was assigned at all cross sections on the Middle Mississippi River segment. These initial bed-material gradations in the numerical model were then adjusted to allow for variability associated with crosssection shape and velocity by running a bankfull discharge of 413,000 cfs for 30 days.

Figure 66. 1980-1989 average bed-material gradation at Thebes.

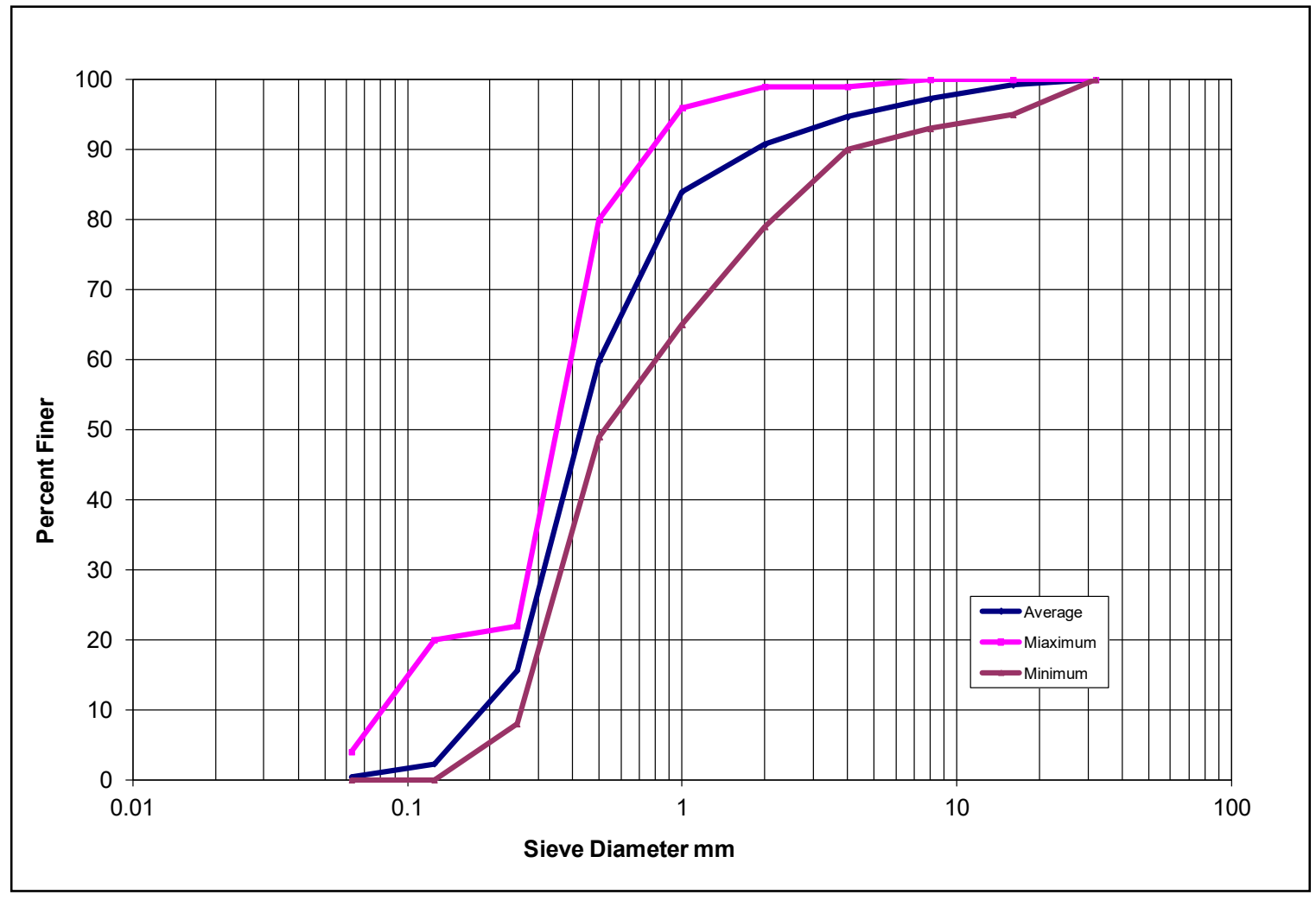

\section{Ohio River bed gradations}

The initial bed material gradations for the Ohio River segment between Cairo and Metropolis were developed from the average of multiple samples collected from three transects in the vicinity of Olmstead Lock 
and Dam (Ohio RM 964.6, RM 970.4 AHP). The bed sampling site is approximately 17 miles upstream from Cairo. These samples were normalized to eliminate fines. The average of these gradations is shown in Figure 67. The average Olmstead bed gradation was assigned at all of the cross sections in the Ohio River segment. A bankfull discharge of 552,000 cfs was run for 30 days to determine the initial bed-material gradations for the numerical model. The calculated initial gradations at the upstream end of the segment (Ohio RM 945, RM 990 AHP) and the downstream end of the segment (Ohio RM 981, RM 954 AHP) are shown in Figure 67. The calculated initial bed gradation for the Mississippi River at Cairo

(Mississippi RM 953) is also shown in the figure. The figure shows that the adjusted bed material gradations are coarser than the average gradation at Olmstead; however, the downstream Ohio River cross section has an adjusted bed gradation that is very close to the Olmstead gradation. Figure 67 also shows that the Ohio River bed is considerably coarser than the Mississippi River bed calculated at Cairo.

Figure 67. Ohio River bed-material gradations.

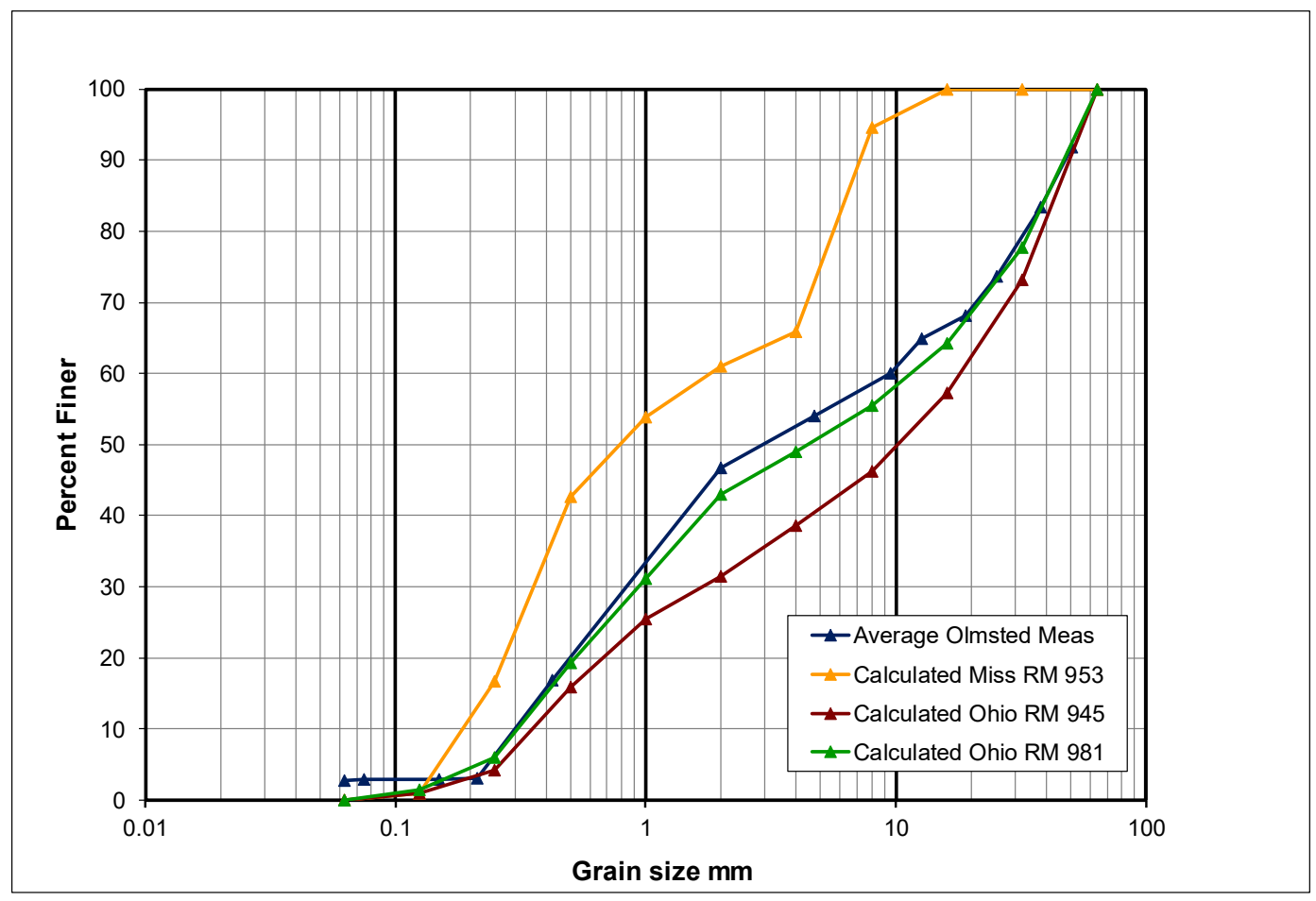




\section{Obion and Hatchie River bed gradations}

Bed material samples for the Hatchie and Obion Rivers were collected for this study at Highway 51 near Rialto, TN, on the Hatchie River (RM 34) and at Highway 78 near Bogota, TN, on the Obion River (RM 36.7). Samples were collected at three transects at a crossing using a 6 in. clamshell sampler in June 2005. The transects were near the right bank, in the center of the channel, and near the left bank. The sample collection sites were located well upstream of the model boundary to escape the influence of backwater effects from the Mississippi River. The assigned bed material gradations for the numerical model are shown in Figure 68.

Figure 68. Initial bed-material gradations used for the Obion and Hatchie Rivers.

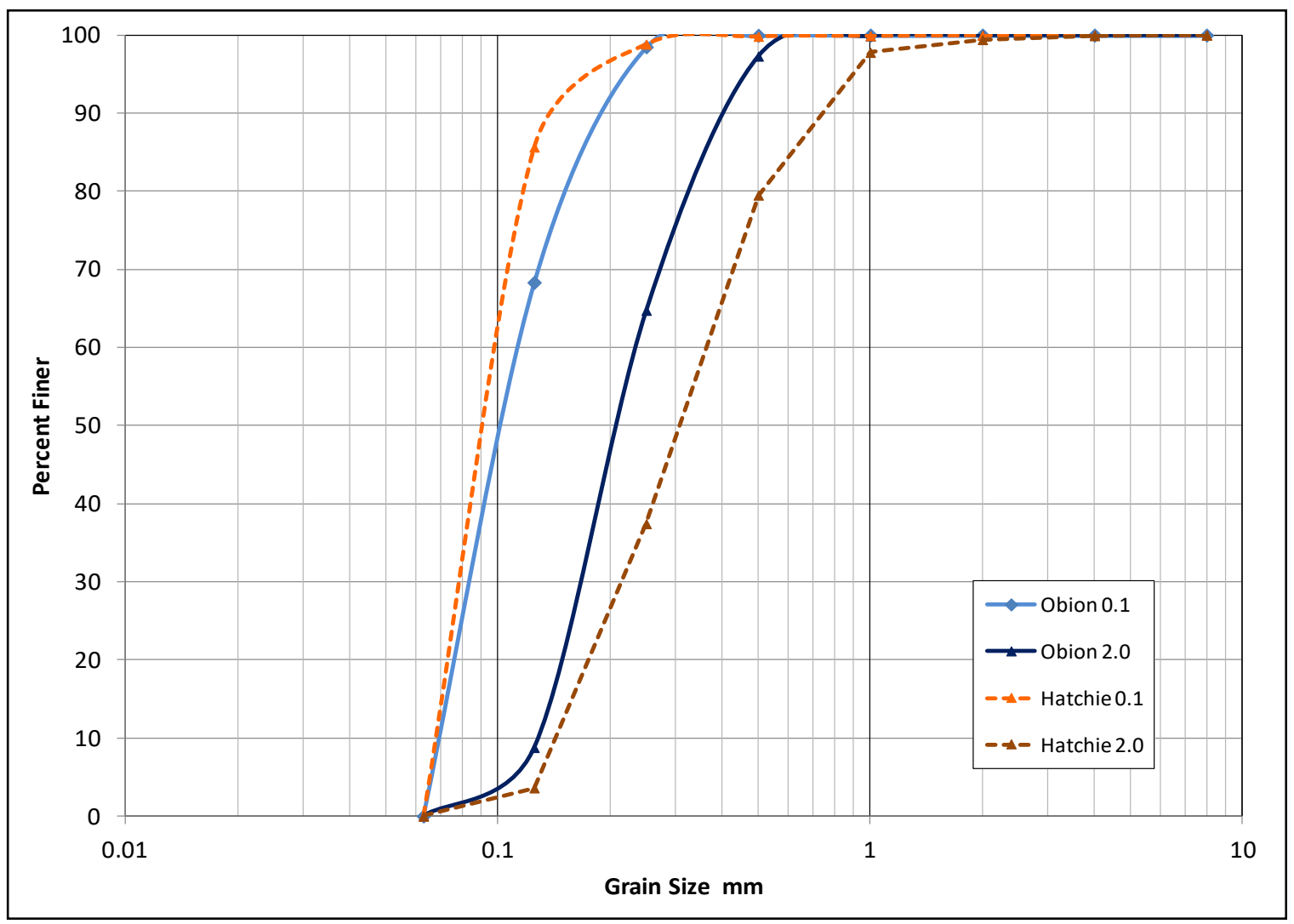

\section{St. Francis River bed gradations}

The USGS has collected an extensive set of bed material gradation data on the St. Francis River at Madison and Riverfront. Madison is at RM 37.4, approximately 20 miles upstream from the HEC-6T model boundary, and Riverfront is at RM 58.0. The initial HEC-6T bed material gradation used for the St. Francis River was taken from the average of 139 samples collected between 1991 and 2002 at Madison. The gradation was 
normalized to represent 100 percent sand. The average 1991 and 2002 gradation is compared to the 1977-2009 average gradation, which was determined from 377 samples, in Figure 69. Also shown are average gradations from the similar data set at Riverfront. The data suggest that there is no long-term variation in the bed gradation in the St. Francis River.

Figure 69. USGS bed gradations for St. Francis River at Madison and Riverfront.

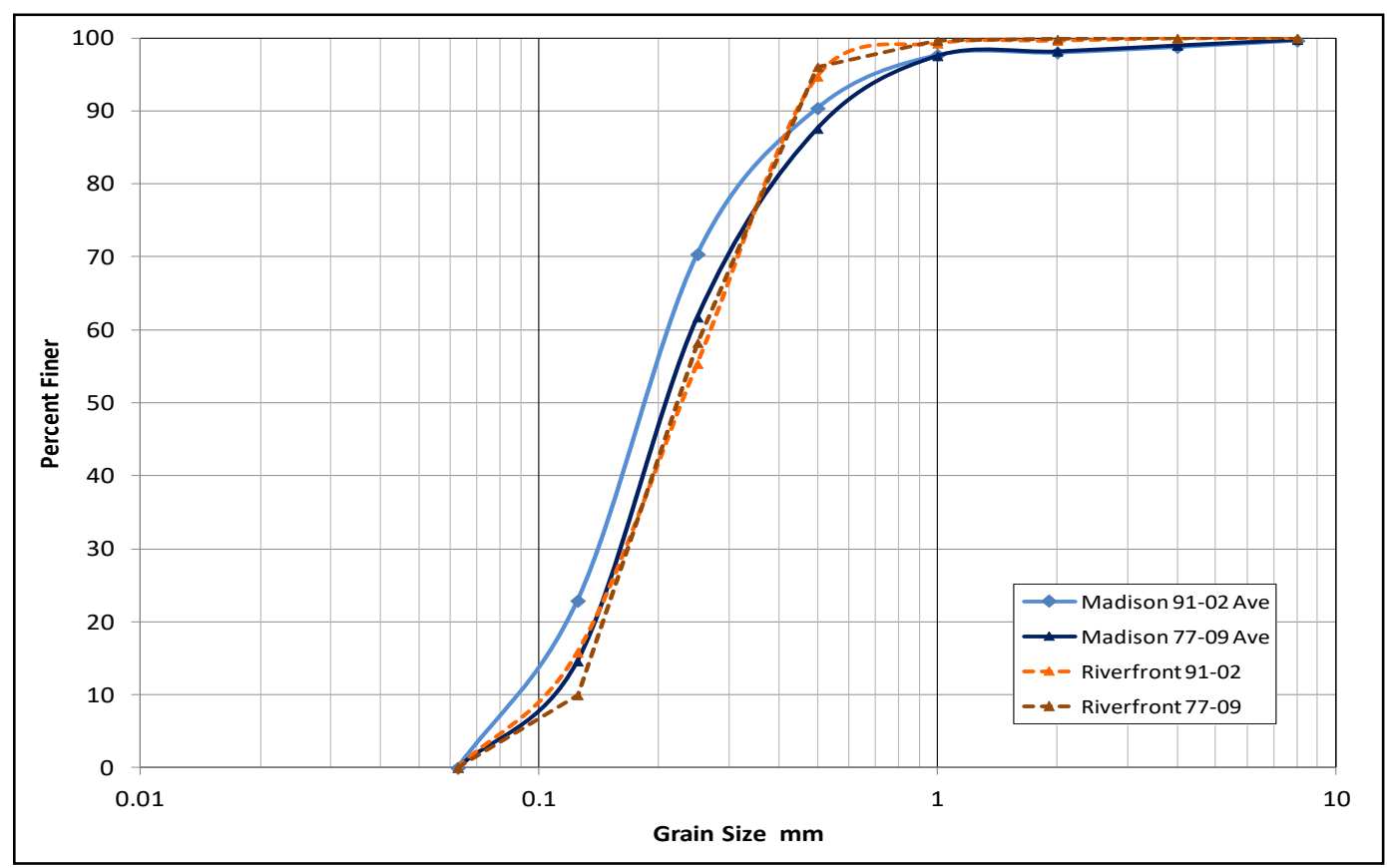

\section{White River bed gradations}

Bed material samples were available at one site on the White River in the reach between Clarendon and the Mississippi River. The samples were collected at RM 4 from the bed, the point bar, and the bank by ERDC in 2003 as part of a geomorphic assessment of the Arkansas and White Rivers. The median grain diameter of the bed was $0.18 \mathrm{~mm}$, and the median grain diameter of the point bar was $0.17 \mathrm{~mm}$. The bank was composed of entirely silts and clays. Bed gradations are shown in Figure 70. An average of the bed and point bar samples was used as an initial bed gradation for the White River in the HEC-6T model. However, early in the movable bed calibration it was determined that the calculated degradation was unreasonable with this initial bed gradation. To eliminate scour, the bed sediment reservoir was set at $0.01 \mathrm{ft}$, allowing the model to calculate a bed gradation based on the inflowing sediment load. With these constraints, HEC-6T could calculate deposition but not erosion below the initial bed elevation. 
Figure 70. White River bed-material gradations collected by ERDC at RM 4.

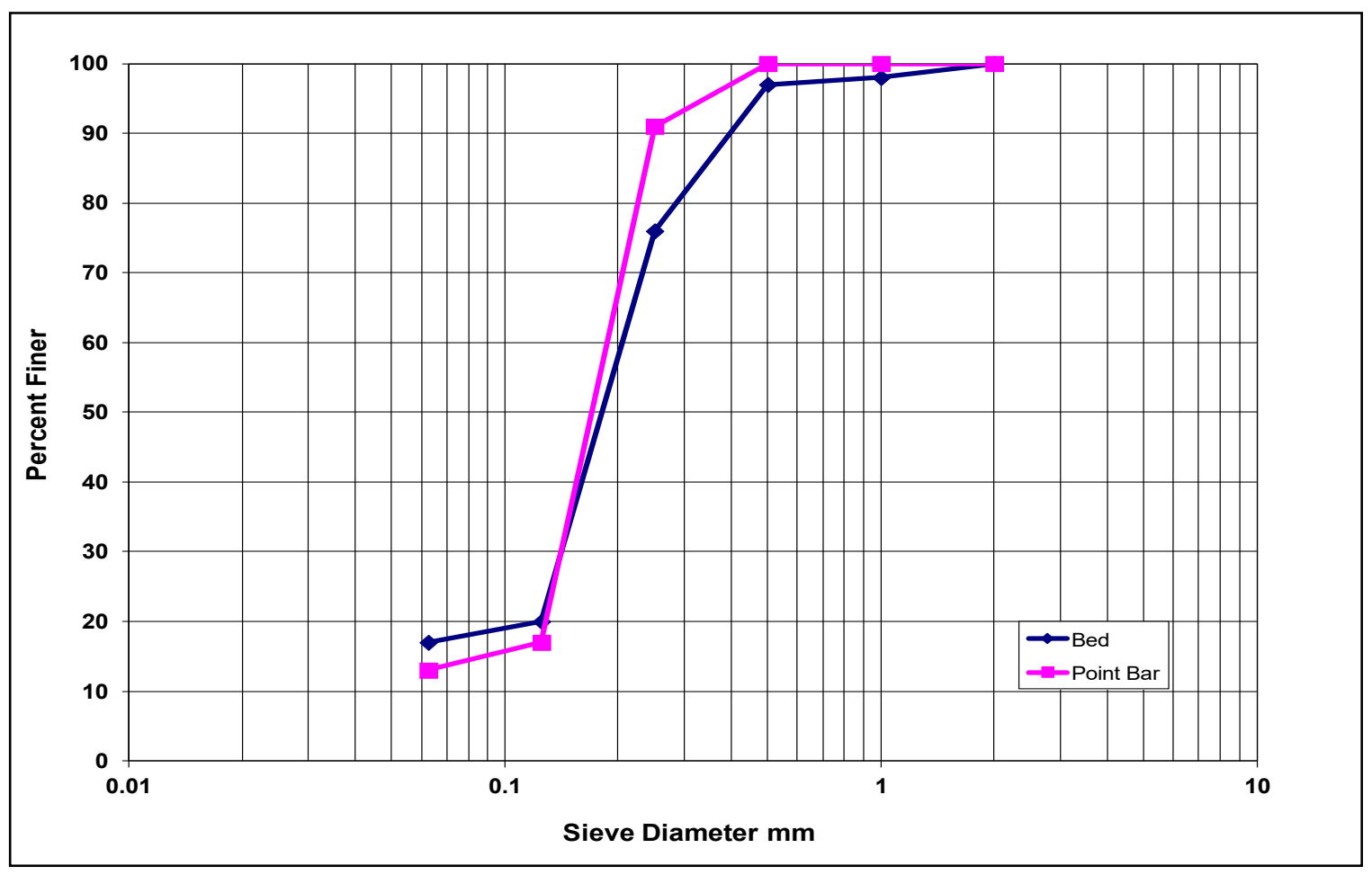

\section{Arkansas River bed gradations}

Only two Arkansas River bed material samples were available in the reach between Lock and Dam 2 and the Mississippi River. This reach of the Arkansas River does not have designated river miles, and the reach length varies with time due to lateral migration and cutoffs. The numerical model represents 2003 conditions when the approximate distance between Lock and Dam 2 and the Mississippi River was 29 miles. The bed samples were collected from point bars in 2003 as part of a geomorphic assessment of the Arkansas and White Rivers. The two samples were collected at Emerson Bend, which is located approximately 10 miles upstream from the mouth of the Arkansas River; and Camp Bend, which is located approximately 19 miles upstream from the mouth of the Arkansas River. Bed gradations are shown in Figure 71 . An average of these two samples was used to develop an initial bed gradation that was used for entire Arkansas River reach. The bed gradation was adjusted at each cross section using a 30-day bankfull simulation. The adjusted values were then used as the initial bed gradation for the calibration simulation. 
Figure 71. Arkansas River bed-material gradations at Emerson and Camp Bends.

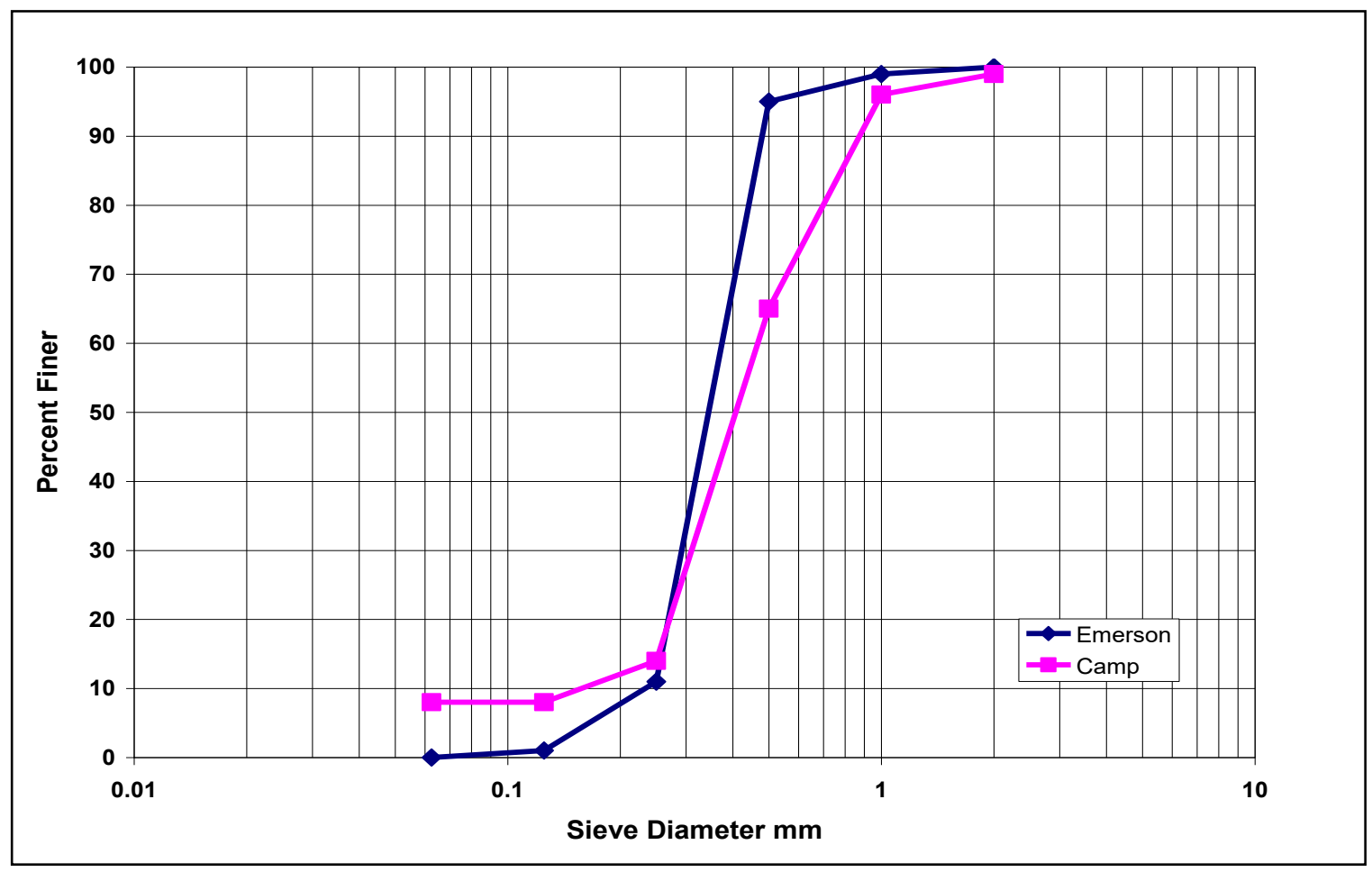

\section{Yazoo River bed gradations}

Two bed material samples were available from the USGS gage at Steele Bayou on the Yazoo River. The samples, which were collected during August 1995 and August 1997, contained only 3 and 4 percent sand, respectively. The gage is in the Mississippi River backwater area, and the data may not reflect the actual bed gradation during channel forming events. An average of the two samples was normalized to 100 percent sand and used as the initial bed gradation for the Yazoo River in the HEC-6T model. However, early in the movable bed calibration it was determined that the calculated degradation was unreasonable with this initial bed gradation. To eliminate scour, the depth of the bed sediment reservoir was set at $0.01 \mathrm{ft}$, which allowed the model to calculate a bed gradation based on the inflowing sediment load. With these constraints, HEC-6T could freely calculate deposition, but erosion was limited to $0.01 \mathrm{ft}$.

\section{Sediment concentrations in distributary flows}

The sediment concentrations that are diverted into distributaries are boundary conditions in a $1 \mathrm{D}$ model. The ratio of the sediment concentration in the distributary to the sediment concentration in the Mississippi River is called the sediment diversion coefficient and must be 
determined externally and coded as input data to the program. At the Old River Control Complex, sediment diversion coefficients for each size class were extracted from a previous study (Catalyst-Old River Hydroelectric, 1999). The sediment diversion coefficients from the 1999 study had been developed from available measured data and numerical model calibration. Due to the wide scatter in the measured data, no attempt was made to vary the sediment diversion coefficients with changes in discharge or with variations in operation schedules.

For the remaining distributaries, estimates of vertical sediment concentrations were computed using the Rouse (1937) equation. Sediment diversion coefficients were calculated for each size class by comparing the average Mississippi River bed elevation with the diversion sill or inlet channel elevation. This method accounts for the vertical variation in sediment concentrations, but it does not account for the lateral variation due to river meanders or for variable depths in a river cross section.

Sediment diversion coefficients for the Auxiliary Structure were determined from measured data in the 1999 study. Measurements from Tarbert Landing, taken between 1991 and 1998, were used to determine Mississippi River concentrations. The Tarbert Landing measurements were collected using standardized methods. Measurements at the Auxiliary Structure, taken between 1991 and 1997, were taken using nonstandard methods. That is, the suspended sediment samples were collected from three pumping samplers that were located on the downstream side of the gate piers. Additional measurements from the Auxiliary Structure inflow channel were made in 1998 using standardized methods. Sediment concentrations through the Auxiliary Structure were determined using measured averages. These concentrations were supplemented by hydrographic surveys of the inlet channel before and after flushing flows to include the sediment load passing the structure during flushing operations. When the measured data were combined with the survey data, the resulting ratio approximated the total sediment diverted through the structure.

Sediment diversion coefficients for the Low Sill Structure were determined from measured data in the 1999 study. Mississippi River measurements at both Tarbert Landing and Coochie/Union Point were collected between 1991 and1998 using standardized methods. Average concentrations calculated for these Mississippi River stations were compared to average 
concentrations calculated from pumping sampler data collected from the downstream side of the gate piers at the Low Sill Structure. The data from the pumping samplers were supplemented using inlet channel hydrographic survey data as described above for the Auxiliary Structure. Additional measurements were made, using standardized methods, in 1998 in the Low Sill Structure inflow channel and between 1989 and 1991 in the Low Sill Structure outflow channel. Data collected during the period from 1976 to 1979, at Tarbert Landing and at gage C-89, which is located in the Outlet Channel approximately 2 miles downstream from the diversion structures, were used to supplement the more recent data. Both of these data sets were collected using standardized methods.

In the 1999 study, sediment diversion coefficients for the Hydropower Plant were determined from the 1991-1998 average measured suspended loads at Coochie/Union Point and the 1991-1997 measured data from the Hydropower Plant. The measured suspended sediment loads at Coochie/Union Point were calculated from samples collected using standardized methods. The measured suspended loads at the Hydropower Structure were taken from pumping samplers located on the top of the power plant draft tubes. In 1998, measured suspended sediment data were collected from the Hydropower Structure inflow channel using standardized methods.

The final adopted sand sediment diversion coefficients from the 1999 study are tabulated in Table 29. These assignments were adopted in this study. Clay and silt sediment sizes and sediment larger than coarse sand were not considered in the 1999 study. In this study, fine sediments were assigned a sediment diversion coefficient of 1.0, and sediments coarser than coarse sand were assigned a sediment diversion coefficient of o.o.

Table 29. Sediment diversion coefficients at Old River Control Complex from Catalyst-Old River Hydroelectric (1999).

\begin{tabular}{|c|c|c|c|c|}
\hline & $\begin{array}{c}\text { Hydropower } \\
\text { RM 315.9 }\end{array}$ & $\begin{array}{c}\text { Spillway } \\
\text { RM 315.2 }\end{array}$ & $\begin{array}{c}\text { Low Sill } \\
\text { RM 314.6 }\end{array}$ & $\begin{array}{c}\text { Auxiliary } \\
\text { RM 312.0 }\end{array}$ \\
\hline Very-fine sand & 0.8 & 0.5 & 0.9 & 0.9 \\
\hline Fine sand & 0.4 & 0.2 & 0.8 & 0.8 \\
\hline Medium sand & 0.2 & 0.0 & 0.6 & 0.8 \\
\hline Coarse sand & 0.2 & 0.0 & 0.6 & 0.8 \\
\hline
\end{tabular}


As mentioned in the opening paragraph of this section, sediment diversion coefficients are specified as boundary conditions in the numerical model. A sediment diversion coefficient is specified for each sediment size class. Typically, inlet channels at diversions are at a higher elevation than the average bed of the river and draw flow from the upper portion of the water column in the river. Coarse sediment concentrations are higher at the bottom of the water column while fine sediment is more evenly distributed in the water column. Thus, the sediment diversion coefficients will be higher for finer sediment than for coarser sediment.

If the vertical velocity distribution and the vertical concentration distributions for each size class are known, then the sediment diversion coefficients for the sediment load can be calculated from the following equation:

$$
\text { Sediment Diversion Coefficient }{ }_{i}=\frac{\int_{y=h}^{y=D} C_{i y} u_{y} d y}{\int_{y=a}^{y=D} C_{i y} u_{y} d y}
$$

where:

$$
\begin{aligned}
C i= & \text { concentration of sediment size class } i . \\
D= & \text { depth of flow in the main channel } \\
h= & \text { height of diversion invert above average river bed } \\
a= & \text { reference height near the stream bed - taken to be zero for } \\
& \text { these calculations } \\
u_{y}= & \text { velocity at depth } \mathrm{y} .
\end{aligned}
$$

Using the Rouse (1937) equation for calculating sediment concentration, the following equation is derived by substitution.

$$
\text { Sediment Diversion Coefficient } t_{i}=\frac{\int_{y=h}^{y=D} C_{i a}\left[\frac{D-y}{y} \frac{a}{D-a}\right]^{Z} u_{y} d y}{\int_{y=a}^{y=D} C_{i a}\left[\frac{D-y}{y} \frac{a}{D-a}\right]^{Z} u_{y} d y}
$$


where:

$$
C_{i a}=\text { concentration at the reference elevation }
$$

and

$$
\begin{gathered}
z=\frac{\omega}{\beta k u_{*}} \\
u_{y}=u_{*} 5.75 \log \left(\frac{30.1}{k_{s} y}\right)
\end{gathered}
$$

where:

$$
\begin{aligned}
\omega= & \text { particle fall velocity } \\
\beta= & \text { ratio of sediment and momentum exchange coefficients }- \\
& \text { taken to be } 1.0 \\
k= & \text { Von Karman constant }- \text { taken to be } 0.4 \\
u^{*}= & \text { shear velocity } \\
k_{s}= & \text { roughness height. }
\end{aligned}
$$

Removing the constant terms and converting from sediment load to concentration leaves the following equation, which can be solved using numerical integration. Hydraulic terms for this equation were determined at upstream river cross sections from HEC-6T backwater calculations for a range of discharges. Other terms are known.

$$
\text { Sediment Diversion Coefficient } t_{i}=\frac{\frac{1}{D-h} \int_{y=h}^{y=D}\left[\frac{D-y}{y}\right]^{Z} u_{y} d y}{\frac{1}{D} \int_{y=a}^{y=D}\left[\frac{D-y}{y}\right]^{Z} u_{y} d y}
$$

The Rouse (1937) equation describes sediment concentration due to vertical diffusion. It does not account for convective sediment transport or for lateral diffusion. Thus, this analysis does not account for sediment that may ramp up into the diversion inflow channel. Ramping may not be a significant contributor of sediment for diversions located on the outside of meander bends, but ramping may be significant on the inside of bends or at bar locations. Actual measurements at diversions and in the upstream 
main channel are the most reliable means of determining existing sediment diversion coefficients. Establishing a sediment measurement program that includes use of standardized methods is recommended at significant distributary locations for use in future studies.

The invert elevation in the four Southwest Pass distributaries was estimated to be at elevation $-10 \mathrm{ft}$. The best available data to make this estimate were the 1992 and 2002 hydrographic surveys. Sills that may have been placed across these structures are accounted for only if they showed up in the hydrographic survey. At Outlet W-2, the sediment diversion coefficients represent a combination of flow over the levees at high flow and flow through the distributary channel. The elevation of the natural levee was estimated to be $1.2 \mathrm{ft}$ based on digital data used to develop the cross sections for HEC-6T. Sediment diversion coefficients used in Southwest Pass are tabulated in Table 30 through Table 33. Ratios for sediment coarser than fine sand were o.o.

Table 30. Sediment diversion coefficients, Burrwood Bayou.

\begin{tabular}{|c|c|c|c|c|c|c|}
\hline Discharge CFS & 24,000 & 18,000 & 10,600 & 7,500 & 3,000 & 1 \\
\hline Clay & 1.0 & 1.0 & 1.0 & 1.0 & 1.0 & 1.0 \\
\hline Very fine silt & 1.0 & 1.0 & 1.0 & 1.0 & 1.0 & 1.0 \\
\hline Fine Silt & 1.0 & 1.0 & 1.0 & 1.0 & 1.0 & 1.0 \\
\hline Medium silt & 1.0 & 1.0 & 0.98 & 0.92 & 0.64 & 0.30 \\
\hline Coarse silt & 0.90 & 0.85 & 0.65 & 0.50 & 0.09 & 0.0 \\
\hline Very fine sand & 0.49 & 0.38 & 0.12 & 0.03 & 0.0 & 0.0 \\
\hline Fine sand & 0.06 & 0.02 & 0.0 & 0.0 & 0.0 & 0.0 \\
\hline
\end{tabular}

Table 31. Sediment diversion coefficients - outlet W-2 and overlfows.

\begin{tabular}{|c|c|c|c|c|c|c|}
\hline Discharge CFS & 84,000 & 36,000 & 10,600 & 7,500 & 3,000 & 1 \\
\hline Clay & 1.0 & 1.0 & 1.0 & 1.0 & 1.0 & 1.0 \\
\hline Very fine silt & 1.0 & 1.0 & 1.0 & 1.0 & 1.0 & 1.0 \\
\hline Fine Silt & 1.0 & 1.0 & 1.0 & 1.0 & 1.0 & 1.0 \\
\hline Medium silt & 1.0 & 1.0 & 0.98 & 0.92 & 0.64 & 0.30 \\
\hline Coarse silt & 0.88 & 0.85 & 0.65 & 0.50 & 0.09 & 0.0 \\
\hline Very fine sand & 0.44 & 0.34 & 0.12 & 0.03 & 0.0 & 0.0 \\
\hline Fine sand & 0.05 & 0.03 & 0.0 & 0.0 & 0.0 & 0.0 \\
\hline
\end{tabular}


Table 32. Sediment diversion coefficients - Joseph Bayou.

\begin{tabular}{|c|c|c|c|c|c|c|}
\hline Discharge CFS & 24,000 & 18,000 & 10,600 & 7,500 & 3,000 & 1 \\
\hline Clay & 1.0 & 1.0 & 1.0 & 1.0 & 1.0 & 1.0 \\
\hline Very fine silt & 1.0 & 1.0 & 1.0 & 1.0 & 1.0 & 1.0 \\
\hline Fine Silt & 1.0 & 1.0 & 1.0 & 1.0 & 1.0 & 1.0 \\
\hline Medium silt & 1.0 & 1.0 & 0.98 & 0.92 & 0.64 & 0.30 \\
\hline Coarse silt & 0.90 & 0.85 & 0.65 & 0.50 & 0.09 & 0.0 \\
\hline Very fine sand & 0.49 & 0.38 & 0.12 & 0.03 & 0.0 & 0.0 \\
\hline Fine sand & 0.06 & 0.02 & 0.0 & 0.0 & 0.0 & 0.0 \\
\hline
\end{tabular}

Table 33. Sediment diversion coefficients - Southwest Pass at Mile 3.0.

\begin{tabular}{|c|c|c|c|c|c|c|}
\hline Discharge CFS & 12,000 & 9,000 & 5,300 & 3,800 & 1,500 & 1 \\
\hline Clay & 1.0 & 1.0 & 1.0 & 1.0 & 1.0 & 1.0 \\
\hline Very fine silt & 1.0 & 1.0 & 1.0 & 1.0 & 1.0 & 1.0 \\
\hline Fine Silt & 1.0 & 1.0 & 1.0 & 1.0 & 1.0 & 1.0 \\
\hline Medium silt & 1.0 & 1.0 & 0.98 & 0.92 & 0.64 & 0.30 \\
\hline Coarse silt & 0.90 & 0.85 & 0.65 & 0.50 & 0.09 & 0.0 \\
\hline Very fine sand & 0.49 & 0.38 & 0.12 & 0.03 & 0.0 & 0.0 \\
\hline Fine sand & 0.06 & 0.02 & 0.0 & 0.0 & 0.0 & 0.0 \\
\hline
\end{tabular}

The invert elevations in South Pass and Pass a Loutre were estimated to be at elevations $-31 \mathrm{ft}$ and $-17 \mathrm{ft}$, respectively. This estimate was based on the 2002 hydrographic survey. Sediment diversion coefficients were calculated separately for the two major diversions and combined for the HEC-6T model. The combined ratios are tabulated in Table 34. Ratios for sediment coarser than medium sand were o.o.

Table 34. Sediment diversion coefficients - South Pass and Pass a Loutre.

\begin{tabular}{|c|c|c|c|c|c|c|}
\hline Discharge CFS & 270,000 & 225,000 & 160,000 & 76,000 & 40,000 & 1 \\
\hline Clay & 1.0 & 1.0 & 1.0 & 1.0 & 1.0 & 1.0 \\
\hline Very fine silt & 1.0 & 1.0 & 1.0 & 1.0 & 1.0 & 1.0 \\
\hline Fine Silt & 1.0 & 1.0 & 1.0 & 1.0 & 1.0 & 1.0 \\
\hline Medium silt & 1.0 & 1.0 & 1.0 & 1.0 & 0.97 & .93 \\
\hline Coarse silt & 0.99 & 0.97 & 0.96 & 0.91 & 0.65 & .37 \\
\hline Very fine sand & 0.76 & 0.70 & 0.65 & 0.49 & 0.09 & 0.0 \\
\hline Fine sand & 0.29 & 0.22 & 0.16 & 0.05 & 0.0 & 0.0 \\
\hline Medium sand & 0.03 & 0.02 & 0.01 & 0.0 & 0.0 & 0.0 \\
\hline
\end{tabular}


The average inlet channel elevation in Cubits Gap was taken to be $-13 \mathrm{ft}$ based on 2009 surveyed cross sections. These surveys were conducted by ERDC. The 1992 hydrographic survey shows a sill across Cubits Gap. However, the existence of this sill was not confirmed by the recent surveys. The sill may be buried, or it may have washed out. Flow occurs over the natural levee between Head of Passes and Venice. Sediment diversion coefficients for the overbank flow were calculated using the minimum endof-cross-section elevation between Venice and Head of Passes. This elevation was $1.7 \mathrm{ft}$. The combined sediment diversion coefficients were calculated by discharge weighted averaging. The sediment diversion coefficients for Cubits Gap are tabulated in Table 35. Ratios for sediment coarser than fine sand were o.o.

Table 35. Sediment diversion coefficients - Cubits Gap.

\begin{tabular}{|c|c|c|c|c|c|c|c|}
\hline Discharge, cfs & 243,700 & 148,800 & 74,800 & 53,400 & 32,200 & 16,100 & 1 \\
\hline Clay & 1.0 & 1.0 & 1.0 & 1.0 & 1.0 & 1.0 & 1.0 \\
\hline Very fine silt & 1.0 & 1.0 & 1.0 & 1.0 & 1.0 & 1.0 & 1.0 \\
\hline Fine Silt & 1.0 & 1.0 & 1.0 & 1.0 & 1.0 & 1.0 & 1.0 \\
\hline Medium silt & 1.0 & 1.0 & 1.0 & 1.0 & 0.97 & 0.84 & 0.70 \\
\hline Coarse silt & 0.94 & 0.90 & 0.85 & 0.80 & 0.64 & 0.32 & 0.0 \\
\hline Very fine sand & 0.57 & 0.48 & 0.37 & 0.27 & 0.09 & 0.0 & 0.0 \\
\hline Fine sand & 0.12 & 0.05 & 0.02 & 0.0 & 0.0 & 0.0 & 0.0 \\
\hline
\end{tabular}

The invert elevations in Grand Pass were very close to the average bed elevations in the Mississippi River according to the 2002 hydrographic survey. Sediment diversion coefficients were set equal to 1.0 for clay and silt and 0.9 for sands for all discharges. Diversion coefficients for sediment coarser than medium sand were o.o.

The average invert elevation in Baptist Collette was taken from a 2009 survey conducted by New Orleans District. The invert elevation in Baptiste Collette was $-45 \mathrm{ft}$. The sediment diversion coefficients for Baptiste Collette are tabulated in Table 36. Diversion coefficients for sediment coarser than medium sand were o.o. 
Table 36. Sediment diversion coefficients - Baptiste Collette.

\begin{tabular}{|c|c|c|c|c|c|}
\hline Discharge CFS & 117,000 & 75,000 & 44,000 & 18,000 & 1 \\
\hline Clay & 1.0 & 1.0 & 1.0 & 1.0 & 1.0 \\
\hline Very fine silt & 1.0 & 1.0 & 1.0 & 1.0 & 1.0 \\
\hline Fine Silt & 1.0 & 1.0 & 1.0 & 1.0 & 1.0 \\
\hline Medium silt & 1.0 & 1.0 & 1.0 & 1.0 & 1.0 \\
\hline Coarse silt & 1.0 & 1.0 & 0.98 & 0.84 & 0.70 \\
\hline Very fine sand & 0.89 & 0.83 & 0.68 & 0.24 & 0.0 \\
\hline Fine sand & 0.49 & 0.34 & 0.12 & 0.0 & 0.0 \\
\hline Medium sand & 0.08 & 0.02 & 0.0 & 0.0 & 0.0 \\
\hline
\end{tabular}

The elevation of the natural levee along the Bohemia Spillway was determined by New Orleans District using 2004 Louisiana lidar data. Top of levee elevations were found to vary between 5.3 and $11.8 \mathrm{ft} \mathrm{NGVD29.}$ Sediment diversion coefficients for the maximum discharge of 1,250,000 cfs were calculated using the average of the calculated water-surface elevation and the minimum levee elevation in each of the four reaches along the spillway. The sediment diversion coefficient for clay through medium silt was 1.0. The coarse silt sediment diversion coefficient was 0.96. The very fine sand diversion coefficient was 0.6 , and the fine sand diversion coefficient was 0.14. The coefficient for sediment coarser than fine sand was 0.o.

The invert elevation in Caernarvon Diversion inlet channel is -12 ft. This elevation was obtained from the Operations and Maintenance Manual. Sediment diversion coefficients were calculated for a range of Mississippi River discharges up to 1,250,000 cfs. However, the maximum discharge through the Caernarvon structure was set at 6,000 cfs in the model simulations. This results in a non-unique relationship between discharge through the structure and the sediment diversion coefficient which is changing with depth in the Mississippi River. The calculated rating curve is shown in Figure 72. Average sediment diversion coefficients were used at Caernarvon and are tabulated in Table 37. Coefficients for sediment coarser than medium sand were o.o. 
Figure 72. Sediment diversion coefficients at Caernarvon.

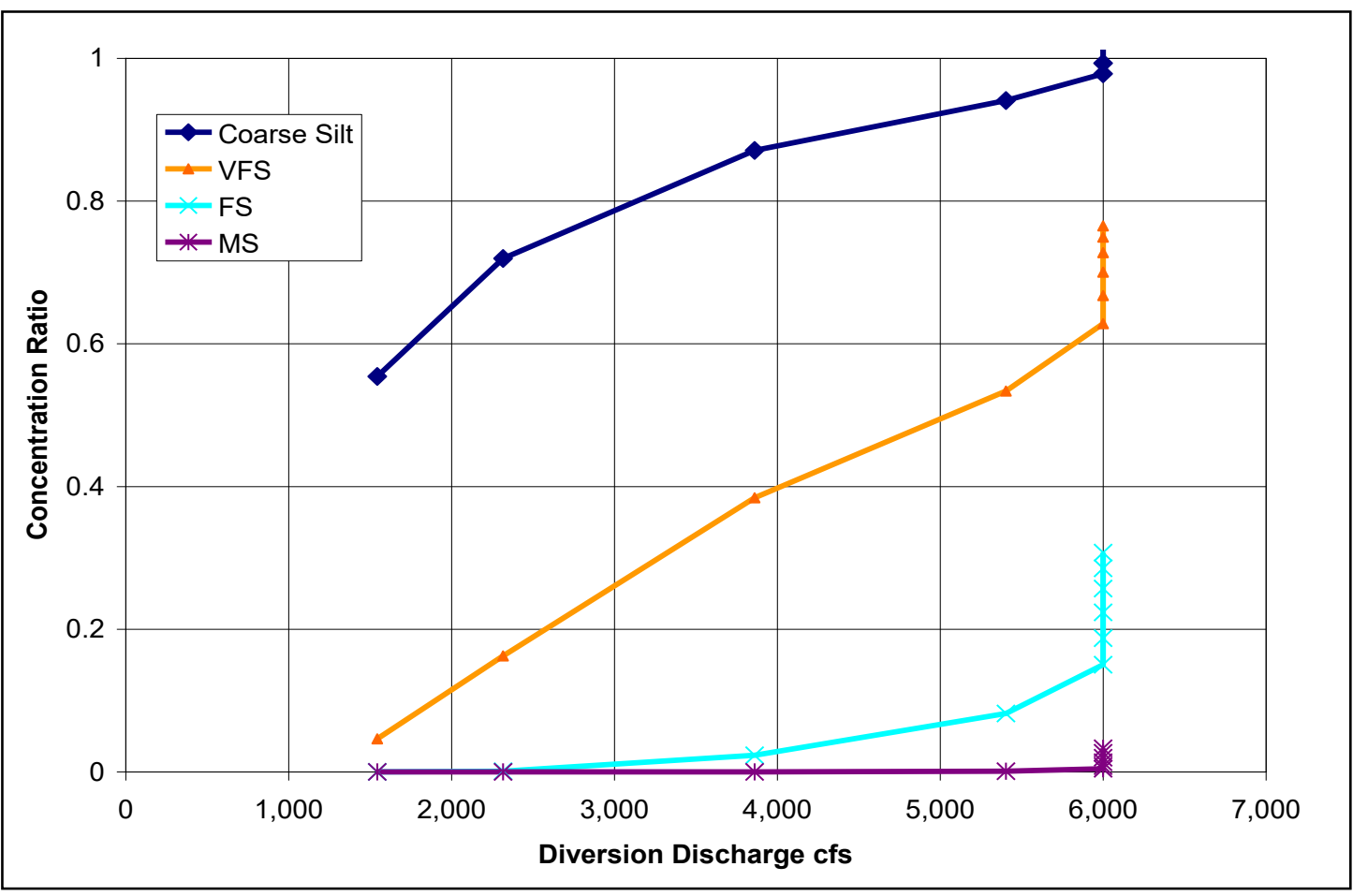

Table 37. Sediment diversion coefficients - Caenarvon.

\begin{tabular}{|c|c|c|c|c|c|c|c|}
\hline $\begin{array}{c}\text { Discharge, } \\
\text { cfs }\end{array}$ & 6000 & 5400 & 3900 & 2300 & 1500 & 1000 & 1 \\
\hline Clay & 1.0 & 1.0 & 1.0 & 1.0 & 1.0 & 1.0 & 1.0 \\
\hline Very fine silt & 1.0 & 1.0 & 1.0 & 1.0 & 1.0 & 1.0 & 1.0 \\
\hline Fine Silt & 1.0 & 1.0 & 1.0 & 1.0 & 1.0 & 1.0 & 1.0 \\
\hline Medium silt & 1.0 & 1.0 & 1.0 & 1.0 & 0.96 & 0.90 & 0.0 \\
\hline Coarse silt & 1.0 & 0.94 & 0.87 & 0.72 & 0.55 & 0.40 & 0.0 \\
\hline $\begin{array}{c}\text { Very fine } \\
\text { sand }\end{array}$ & 0.70 & 0.53 & 0.38 & 0.16 & 0.05 & 0.0 & 0.0 \\
\hline Fine sand & 0.22 & 0.08 & 0.02 & 0.0 & 0.0 & 0.0 & 0.0 \\
\hline Medium sand & 0.02 & 0.0 & 0.0 & 0.0 & 0.0 & 0.0 & 0.0 \\
\hline
\end{tabular}

The elevation of the Bonnet Carré inlet channel varies. Bank elevations along the Mississippi River at the spillway entrance channel were estimated from the 1992 hydrographic survey. The bank elevations were between $9.3 \mathrm{ft}$ and $12.9 \mathrm{ft}$. Calculations for the sediment diversion coefficients were based on average river channel depths and bank elevations. Clay and silt sediment diversion coefficients of 1.0 were 
calculated. Sand coefficients are listed in Table 38. Coefficients for sediment coarser than medium sand were o.o.

Table 38. Sediment diversion coefficients - Bonnet Carré.

\begin{tabular}{|c|c|c|c|c|}
\hline Discharge, cfs & 250,000 & 125,000 & 11,500 & 1 \\
\hline Clay & 1.0 & 1.0 & 1.0 & 1.0 \\
\hline Very fine silt & 1.0 & 1.0 & 1.0 & 1.0 \\
\hline Fine Silt & 1.0 & 1.0 & 1.0 & 1.0 \\
\hline Medium silt & 1.0 & 1.0 & 1.0 & 1.0 \\
\hline Coarse silt & 1.0 & 1.0 & 1.0 & 1.0 \\
\hline Very fine sand & 0.75 & 0.72 & 0.69 & 0.67 \\
\hline Fine sand & 0.30 & 0.27 & 0.23 & 0.20 \\
\hline Medium sand & 0.04 & 0.03 & 0.02 & 0.01 \\
\hline
\end{tabular}

\section{Sediment distribution around islands}

There are three islands in the numerical model. Wolf Island is located between RMs 930.8 and 934.4. Island 8 is located between RMs 910 and 915.59. Profit Island is located between RMs and 246.3 and 253. There are many more locations where divided flow occurs in the study reach, but only these three were included in the numerical model as separate looped segments. The other divided flow cross sections were assumed to have the same water surface elevation across the section. In some cases, geometry was adjusted to maintain appropriate flow distribution in the cross section. This treatment is deemed adequate for the general model. Detailed investigations of specific reaches may require the addition of additional looped segments.

Sediment distribution at the upstream end of looped segments is a model boundary condition. The model assumes equal sediment concentrations in both loops if no boundary condition is supplied. There were no measured suspended data available to calibrate the sediment distribution, so initially the model default was used in the calibration runs. The assignment of equal sediment concentrations in both loops produced deposition and erosion results inconsistent with known channel responses. Consequently, sediment inflow distributions were adjusted until reasonable channel responses were calculated. Without calibration data, the results remain questionable and are adequate for the general model but require more detailed investigation if the islands are part of a detailed reach investigation. 
The ratio of sediment concentration in the secondary loop to sediment concentration upstream from the island is specified for each sediment size class. The model then calculates the sediment concentration for the primary loop. The wash load, which constitutes all the sediment less than $0.125 \mathrm{~mm}$, was assumed to have the same concentration in both loops. The remaining size classes were assigned sediment distributions shown in Table 39.

Table 39. Island sediment concentration ratios in secondary channel.

\begin{tabular}{|c|c|c|c|}
\hline & Profit Island & Island 8 & Wolf Island \\
\hline Clay & 1.0 & 1.0 & 1.0 \\
\hline Very Fine Silt & 1.0 & 1.0 & 1.0 \\
\hline Fine Silt & 1.0 & 1.0 & 1.0 \\
\hline Medium Silt & 1.0 & 1.0 & 1.0 \\
\hline Coarse Silt & 1.0 & 1.0 & 1.0 \\
\hline Very Fine Sand & 1.0 & 1.0 & 1.0 \\
\hline Fine Sand & 0.8 & 0.75 & 0.9 \\
\hline Medium Sand & 0.6 & 0.5 & 0.7 \\
\hline Coarse Sand & 0.5 & 0.5 & 0.5 \\
\hline Very Coarse Sand & 0.5 & 0.5 & 0.5 \\
\hline Very Fine Gravel & 0.5 & 0.4 & 0.5 \\
\hline Fine Gravel & 0.5 & 0.4 & 0.5 \\
\hline Medium Gravel & 0.5 & 0.4 & 0.5 \\
\hline Coarse Gravel & 0.5 & 0.4 & 0.5 \\
\hline Very Coarse Gravel & 0.5 & 0.4 & 0.5 \\
\hline
\end{tabular}




\section{Model Calibration and Verification}

The calibration and verification procedure adopted for this study is the accepted USACE methodology described in Guidelines for Calibration and Application of HEC-6 (HEC 1982) and Chapter 14 of ASCE Manual 110 (ASCE 2006). Terminology for the study process of preparing a numerical model for predictive use is not consistent. Calibration, circumstantiation, validation, and verification are common terms used in practice.

Terminology from the above sources was adopted for use in this study. Calibration is defined herein to be the study process of arriving at roughness coefficients, a sediment transport function, model parameters, and representative data that will allow the model to calculate values that agree with values measured in the prototype. Verification is defined herein as the study process that demonstrates that the calibrated model will match the prototype when specified boundary conditions, such as time period or cross-section geometry, are changed.

This chapter presents the selection of model parameters and the determination of coefficients that allow the model to reconstitute measured stages, sediment concentrations, sediment yields, and trends in aggradation and degradation of the channel cross sections. Verification is demonstrated by the application of the calibrated model to compute channel changes resulting from the diversion at the Old River Control Complex and the newly constructed dike field at Smithland Crossing.

\section{Selection of model parameters}

Some of the input parameters to HEC-6T are considered "model parameters." These include the computational time-step, the sorting and armoring time interval (SPI), and the sediment transport function. These parameters should not be changed without conducting new calibration tests.

\section{Computational time-step}

The computational time-step needs to be short enough so that changes in bed elevation, due to deposition or aggradation, do not significantly change the hydraulic parameters during the event. Previous studies on the Lower Mississippi River with similar cross section spacing (Copeland 1991; and Copeland and Thomas 1992) varied the computational time-step as a 
function of discharge, using computational time-steps between 1 and 31 days. A more recent study on the Lower Mississippi River with similar cross section spacing (Catalyst-Old River Hydroelectric 1999) used a constant computational time-step of 1 day. The 1-day time-step is not necessary to meet the requirement of insignificant bed change but was chosen for convenience in this study because available data were reported as mean daily flow. If additional cross sections are added to this model, which significantly reduces the cross section spacing, then new calibration tests are required.

\section{Exchange increment}

The sorting and armoring time interval or exchange increment (SPI) is the parameter that determines how many times the Exner equation is solved during the computational time-step. If sediment transport capacity is greater than the sediment load entering the control volume defined by the upstream and downstream cross sections, available sediment is removed from the bed to satisfy continuity. Since sediment transport capacity for a given size class depends on the fraction of that size class on the bed, it is necessary to frequently recalculate fractions present as sediment is exchanged with the bed. The HEC-6T program will calculate SPI as a function of the computational time-step, $\Delta t$, average channel velocity, $V$, and the reach length, $\Delta L$.

$$
S P I=\frac{\Delta t \quad V}{\Delta L}
$$

Usually, the number of exchange increments can be less than calculated using this equation without inducing bed change and sediment yield oscillations from one time-step to the next. Fewer exchange increments relates to less computational intensity (i.e., shorter computer runs). In this study the computed exchange increment was 20. If the assigned SPI parameter is increased or decreased in future studies using this model, then new calibration tests are required.

\section{Sediment transport function}

The sediment transport function for sand and gravel chosen for this study was the Toffaleti-Meyer-Peter Muller function. With this function, bed load is calculated using the Toffaleti (1968) and the Meyer-Peter Muller 
(1948) methods, and the larger of the two is used. Suspended bed-material load is then calculated using the Toffaleti method.

The sediment transport function was selected by the project engineers from all four districts during the study scoping process. The ToffaletiMeyer-Peter Muller function was selected because it has the capability of transporting both sands and gravels and because the Toffaleti equation was developed for large sand-bed rivers and has been used successfully on previous Mississippi River studies. Gravel transport is not an issue in the New Orleans District portion of the model, but some reaches of the Mississippi River in the Memphis District are known to have significant quantities of gravel in the bed.

There are no size class suspended sediment measurement data between the Middle Mississippi River gages upstream from Cairo and the Lower Mississippi River gages in the New Orleans District. Therefore, size class comparisons between measured and calculated sand yield could only be made in the New Orleans District reach. Sand yield calculated using the Toffaleti-Meyer-Peter Muller equation was compared to measured sand yield at three stations in the New Orleans District. The calculated size class distributions of the total sand yield from the 1991-2002 simulation at Belle Chasse, Tarbert Landing, and Union Point are compared to measured sand size class distributions in Table 40 The measured data do not include bed load or sediment load in the unmeasured zone (the zone beneath the lowest elevation of the sediment sampler nozzle.) The base test used the Toffaleti-Meyer-Peter Muller sediment transport function. In the base test, the calculated very fine sand fractions were lower than the measured very fine sand fractions at all three gages, and the calculated medium sand fractions were higher than the measured medium sand fractions at all three gages. This result may partially be explained by the fact that the coarser sediment is transported closer to the bottom of the water column and is more likely to found in the unmeasured zone and thus more likely to be underestimated in the measured load.

Three additional sediment transport functions that have been used in large sand-bed rivers were tested in the numerical model. These were the Toffaleti, Laursen-Madden and Laursen-Copeland functions. Both the calculated percentages of base test sand yield during the 1991-2002 simulation and the sand fractions of the 1991-2002 sediment yield are tabulated in Table 40. Size class fractions calculated using the Toffaleti 
equation were very similar to those calculated in the base test. Three to seven percent less sand yield was calculated with the Toffaleti equation. Size class fractions calculated using the Laursen-Madden and LaursenCopeland functions were closer to the measured values at all three gages. Total sand yield with the two Laursen-based equations was between 9 and 30 percent less than calculated in the base test.

Table 40. Sand size class fractions. Measured versus calculated using different sediment transport function, 1991-2002.

\begin{tabular}{|c|c|c|c|c|c|}
\hline & Measured & $\begin{array}{c}\text { Base } \\
\text { Toffaleti and } \\
\text { Meyer-Peter } \\
\text { Muller }\end{array}$ & Toffaleti & $\begin{array}{l}\text { Laursen- } \\
\text { Madden }\end{array}$ & $\begin{array}{l}\text { Laursen- } \\
\text { Copeland }\end{array}$ \\
\hline \multicolumn{6}{|c|}{ Belle Chasse RM 76.0} \\
\hline VFS & .55 & .28 & .29 & .49 & .36 \\
\hline FS & .34 & .69 & .69 & .49 & .60 \\
\hline MS & .08 & .03 & .02 & .02 & .04 \\
\hline CS & .03 & .00 & .00 & .00 & .00 \\
\hline Sedim & eld as \% of & 100 & 97.0 & 69.6 & 71.4 \\
\hline \multicolumn{6}{|c|}{ Tarbert Landing RM 306.3} \\
\hline VFS & .29 & .25 & .26 & .35 & .32 \\
\hline FS & .60 & .56 & .59 & .56 & .51 \\
\hline MS & .10 & .18 & .14 & .09 & .16 \\
\hline CS & .01 & .01 & .01 & .00 & .01 \\
\hline Sedim & eld as \% of & 100 & 94.9 & 91.4 & 78.5 \\
\hline \multicolumn{6}{|c|}{ Union Point RM 326.6} \\
\hline VFS & .32 & .26 & .28 & .37 & .33 \\
\hline FS & .57 & .44 & .45 & .46 & .43 \\
\hline MS & .11 & .29 & .25 & .17 & .22 \\
\hline CS & .01 & .01 & .01 & .00 & .02 \\
\hline Sedime & eld as $\%$ of & 100 & 93.2 & 88.5 & 79.9 \\
\hline
\end{tabular}

The sediment transport function tests indicate that the Laursen-Madden or Laursen-Copeland functions may be more appropriate for the New Orleans District reach of the Mississippi River in terms of reproducing size class fractions. However, the improved size class distribution result must be weighed against the lower transport rate of fine and medium sand obtained when the Laursen based equations are used. Calculated sand transport at Union Point, Tarbert Landing, and Belle Chasse are compared 
to measured sand transport in Figure 73 through Figure 75. In these figures, the measured load does not include the bed load or the suspended load in the unmeasured zone.

Figure 73. Sand concentration at Belle Chasse.

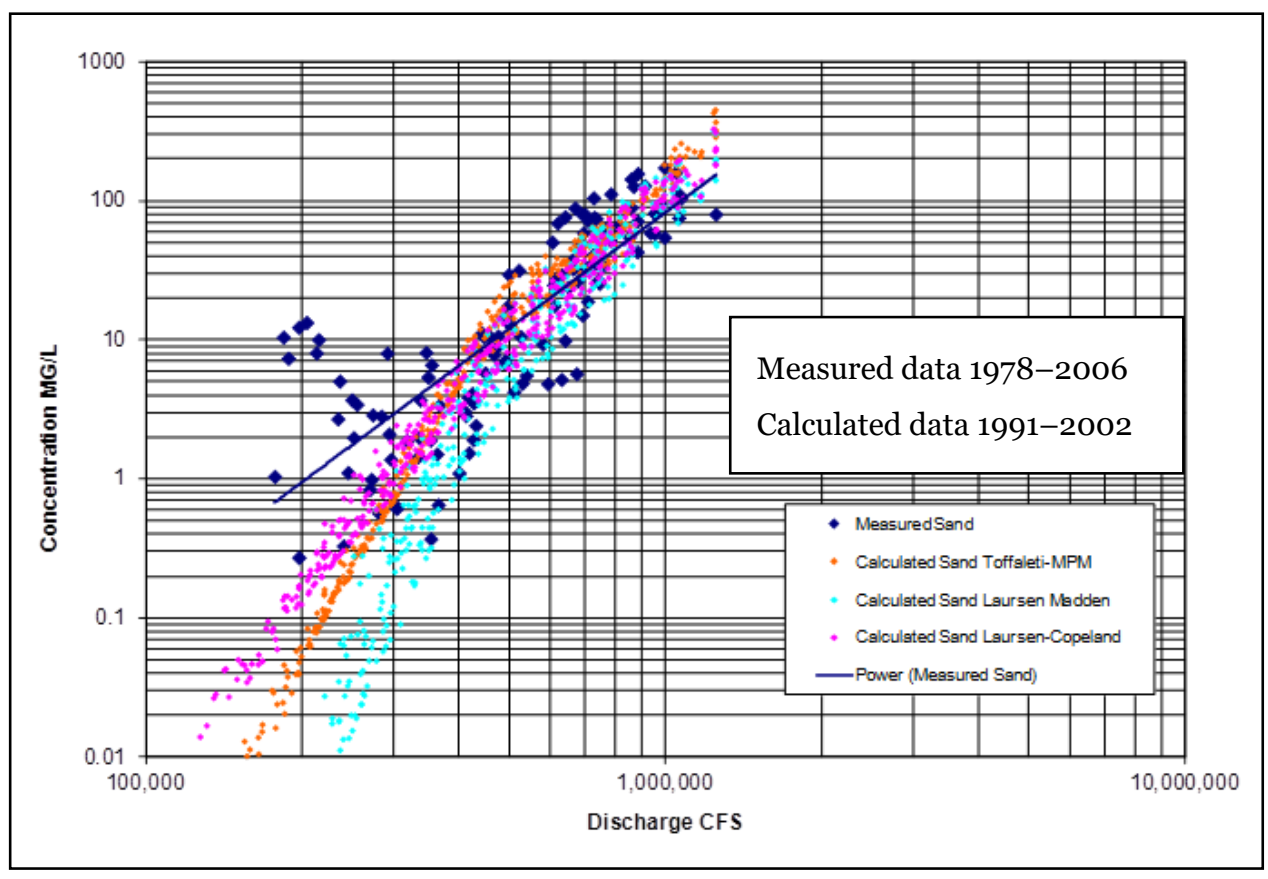

Figure 74. Sand concentration at Tarbert Landing.

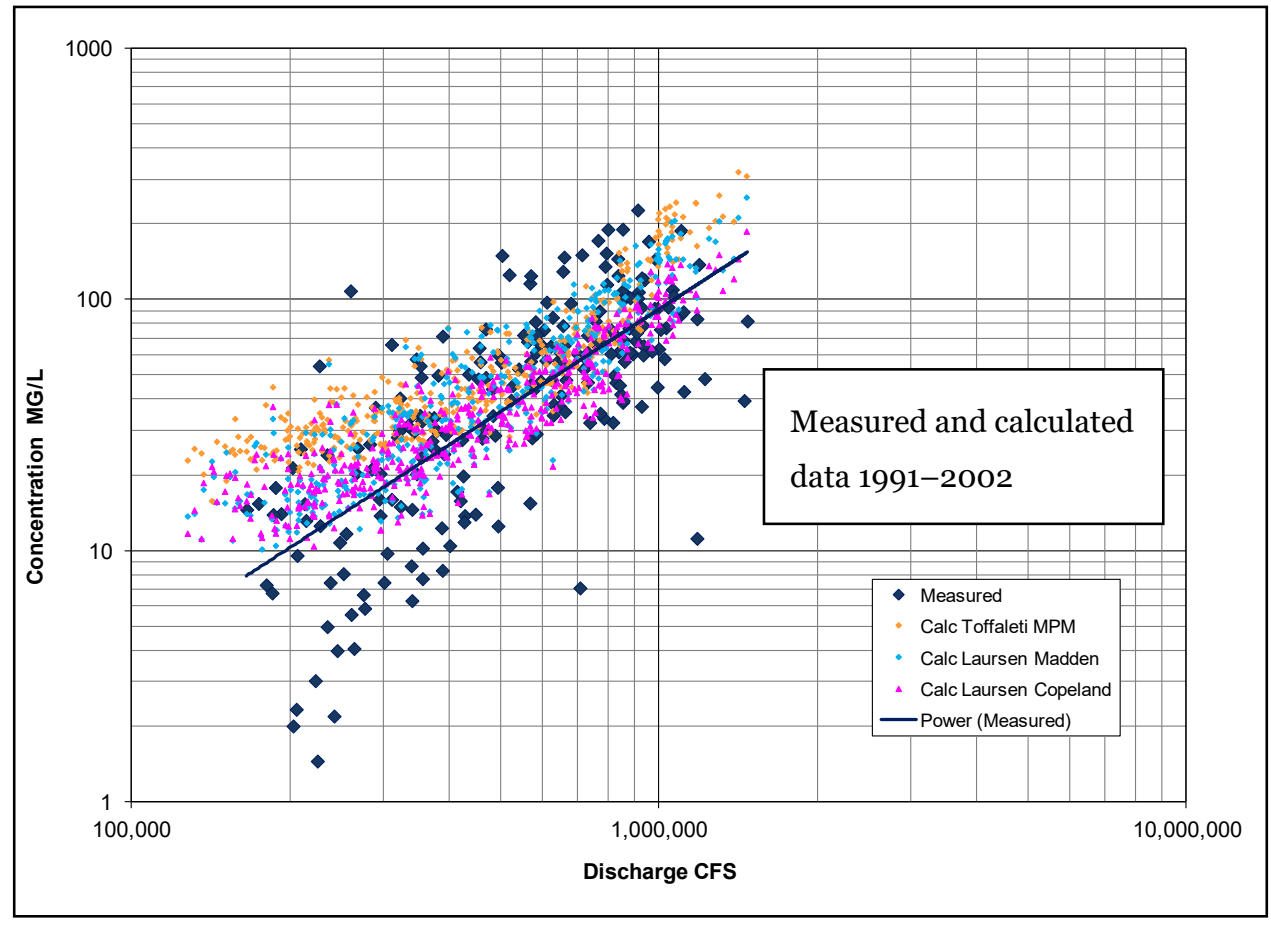


Figure 75. Sand concentration at Coochie (RM 317.3) and Union Point (326.6).

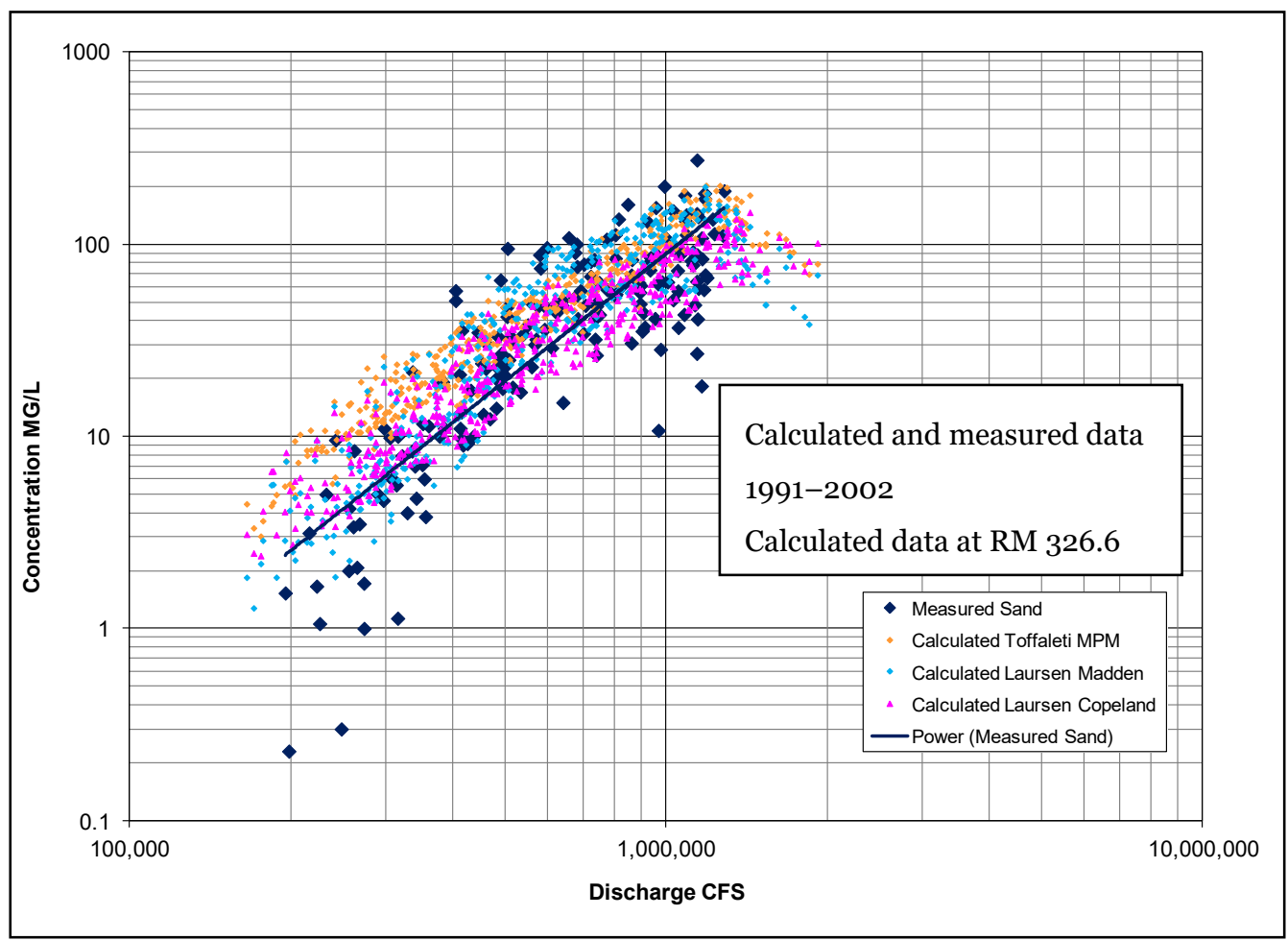

\section{Calibration tests}

The calibration procedure is organized into three steps: (1) steady-state fixed-bed tests, (2) steady-state, movable-bed tests, and (3) quasiunsteady movable-bed tests.

\section{Steady-state, fixed-bed tests}

As described in the section on channel roughness, water-surface profiles were calculated with the numerical model in a fixed-bed mode for a range of steady-state discharges. Model roughness coefficients were initially adjusted to 1991-92 stage data at several gages. Later in the quasiunsteady movable-bed tests, a final adjustment was made.

Channel velocity and channel discharge profiles were also plotted to ascertain if the model was reproducing acceptable hydraulic results. This test revealed a few cross sections with large spikes or valleys in channel velocity. Typically, this occurred where the 1992 channel geometry had not adjusted to superimposed dike fields or at deep-bend sections where the $1 \mathrm{D}$ assumption was invalid. At some locations, cross-section geometry was adjusted to reduce the spikes or the suspect cross section was removed from the numerical model. Calculated channel velocities for 
a range of steady state discharges at the end of 1 year are shown in Figure 76 through Figure 78.

The discharges shown in the legend on Figure 76 through Figure 78 are the discharges at Vicksburg. Discharges at inflow boundaries were set as a constant percentage of the discharge at Vicksburg. The percentage was based on the percentage of the 12-year total volume of flow from the tributary with respect to the 12-year volume of flow at Vicksburg.

Not all of the spikes were removed from the model as these occur naturally at some cross sections with variation in discharge. The large spike at RM 481.1 occurs at a narrow cross section constricted by the Ajax Bar Dike Field. The high calculated velocities at RM 637.9 and RM 645.9 occur at divided flow locations. The I-55 Bridge creates a high flow constriction at $\mathrm{RM} 734.6$ where the overbank is blocked by the raised roadway. At this cross section, the bed sediment reservoir was limited to a $1 \mathrm{ft}$ depth to avoid excessive scour calculations. The high velocity at RM 911.2 occurs at a constricted cross section in the main channel around the Island 8 loop and was assigned a bed sediment reservoir depth of $0.1 \mathrm{ft}$.

Figure 76. Calculated channel velocity in the New Orleans District reach.

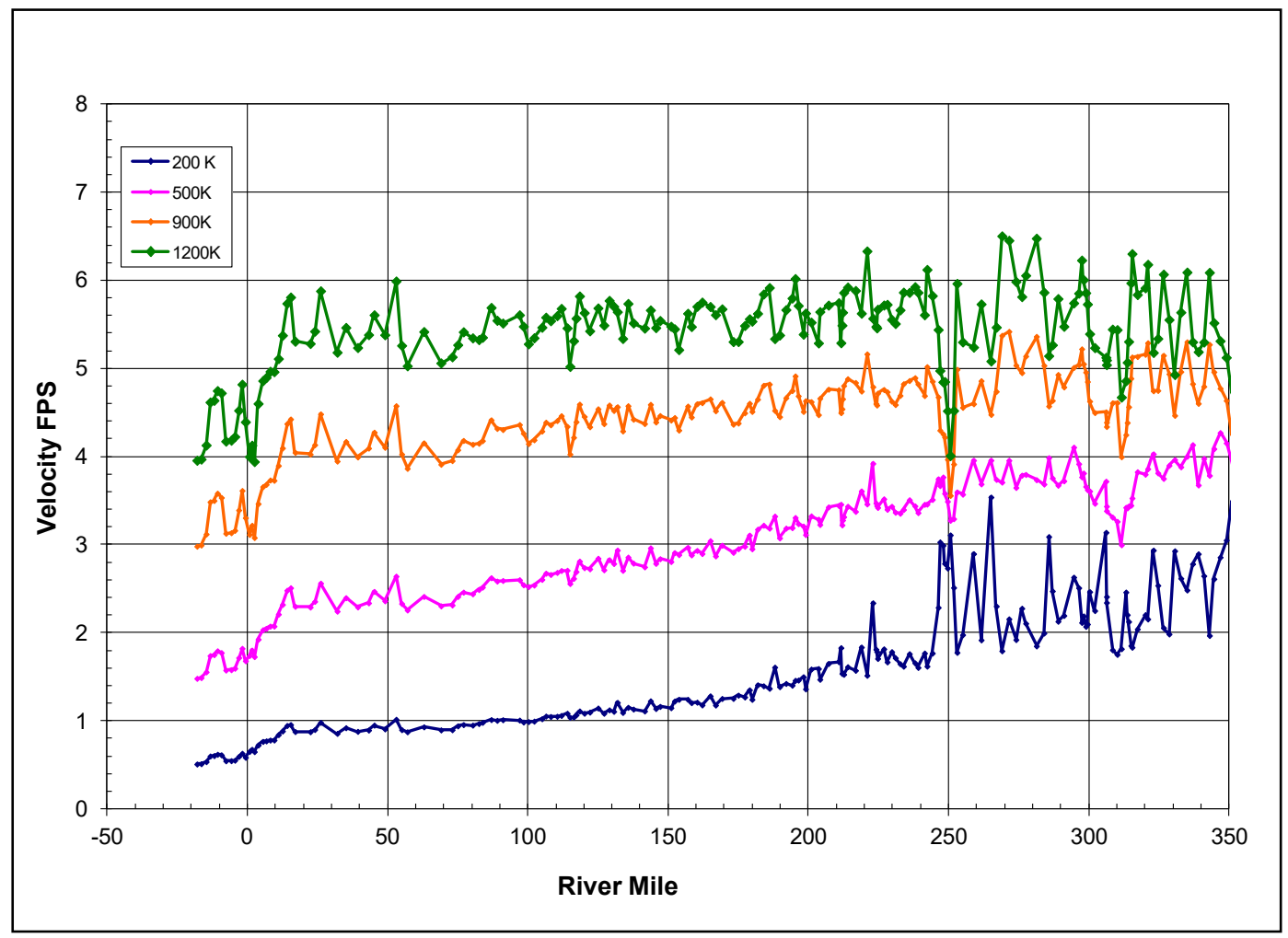


Figure 77. Calculated channel velocity in the Vicksburg District reach.

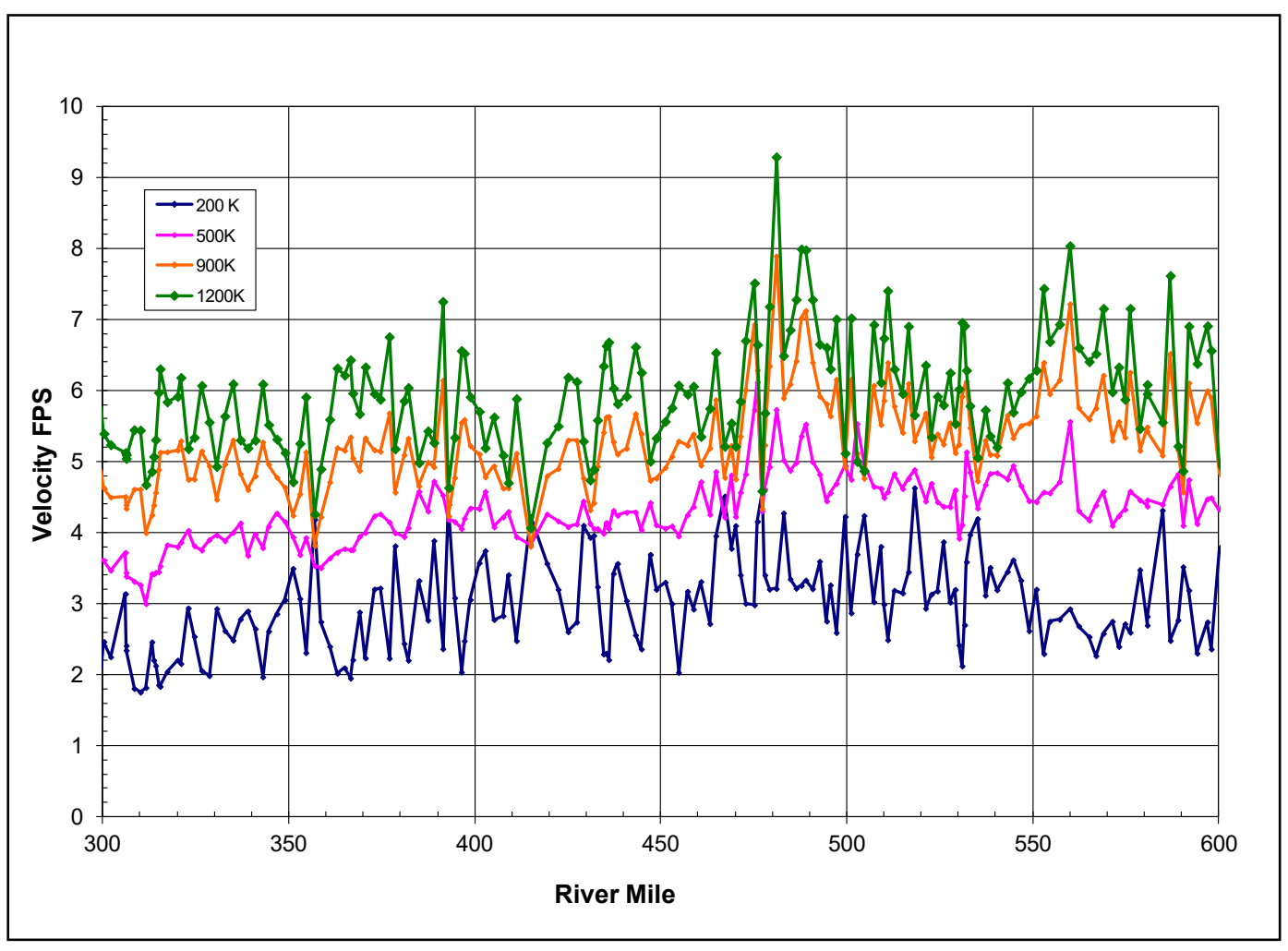

Figure 78. Calculated channel velocity in the Memphis District reach.

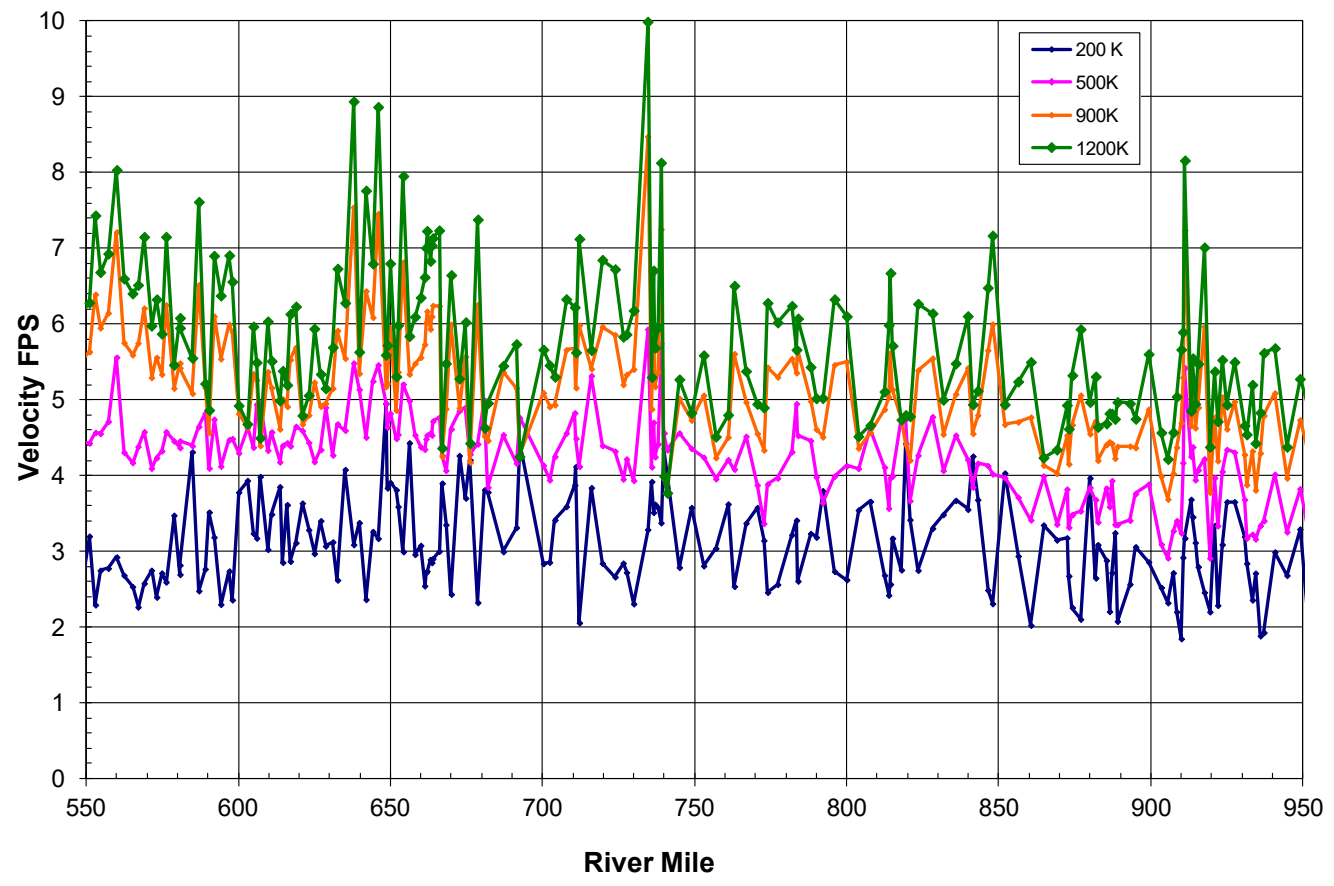




\section{Steady-state, movable-bed tests}

Model performance was evaluated for a channel-forming discharge and a movable bed. The movable-bed tests were conducted to adjust the initial bed material gradation to reflect reach-averaged conditions and to make sure that cross-section changes over time tend to stabilize with a channelforming discharge.

The initial bed reservoir in the numerical model has an infinite depth, and bed gradation is best determined using the channel-forming discharge. During the course of a simulation, the sorting and armoring algorithm in HEC-6T adjusts the composition of the bed as a function of the composition of each bed layer at the previous time-step, the incoming sediment load, and the hydraulic conditions during the computational time step. Hydraulic parameters and bed gradations in the HEC-6T model are representative of a reach. However, sampled bed gradations are representative of a point. Therefore, some adjustment of initial bed material gradation is typically required to prevent rapid bed changes and changes in sediment transport at the beginning of the numerical simulation. Results of bed material adjustments were described in the section on bed material gradation.

A constant discharge was simulated for 1,780 days in the numerical model to assess model stability. The constant discharge was 1,060,000 cfs at Vicksburg, which had been determined to be the channel-forming discharge by Biedenharn and Thorne (1994). Accumulated average bed changes over the 1,780 days for several cross sections are plotted in Figure 79 through Figure 81. These cross sections were chosen for display because they were cross sections that had significant bed elevation changes in the 1991-2002 simulation. The 1,780-day duration provides time for the model to transport a sediment load equivalent to 10 years of average annual sand discharge. Although some cross sections in Figure 79 through Figure 81 show considerable bed change, especially at the beginning of the simulation, the rate of change generally decreases as time passes. Rapid changes in average bed elevation at some cross sections, during the first 100 days, is related to the difficultly in choosing a representative cross section in a river reach where cross-section shapes are changing rapidly due to meanders or constrictions. At RMs 369 and 597 in Figure 80, an increasing trend begins after approximately 1,200 days. This can be attributed to problems with the equilibrium concept applied to a dynamic river system. Most important, there is not a numerical oscillation in the 
calculations, and therefore it can be concluded that the computations are stable for the water discharge tested and that the model is robust.

The results from the channel-forming discharge movable-bed test do not show changes that will occur in the river. They are only useful for demonstrating that the model may generally converge on an equilibrium condition in response to a constant discharge simulation hydrograph. Such a model is then ready to be applied to non-steady, discharge hydrographs to predict changes in the river. In this case, a divergence from equilibrium occurs at some of the cross sections shown in Figure 79 through Figure 81. This suggests that the equilibrium concept is simplistic and is more applicable to the uniform canal channels from which the concept developed and not to dynamic alluvial rivers.

Figure 79. Calculated bed change in the New Orleans District reach.

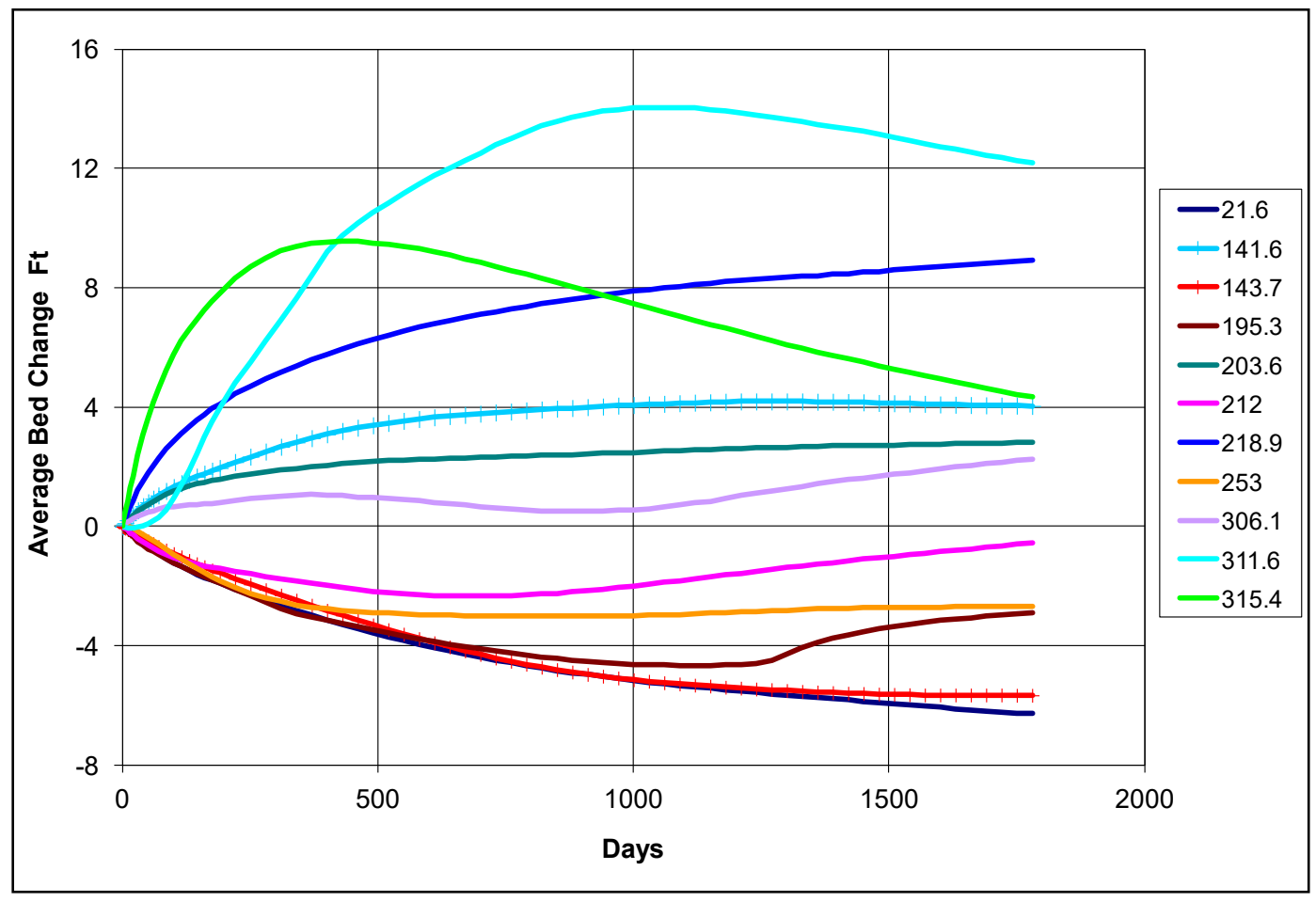


Figure 80. Calculated bed change in the Vicksburg District.

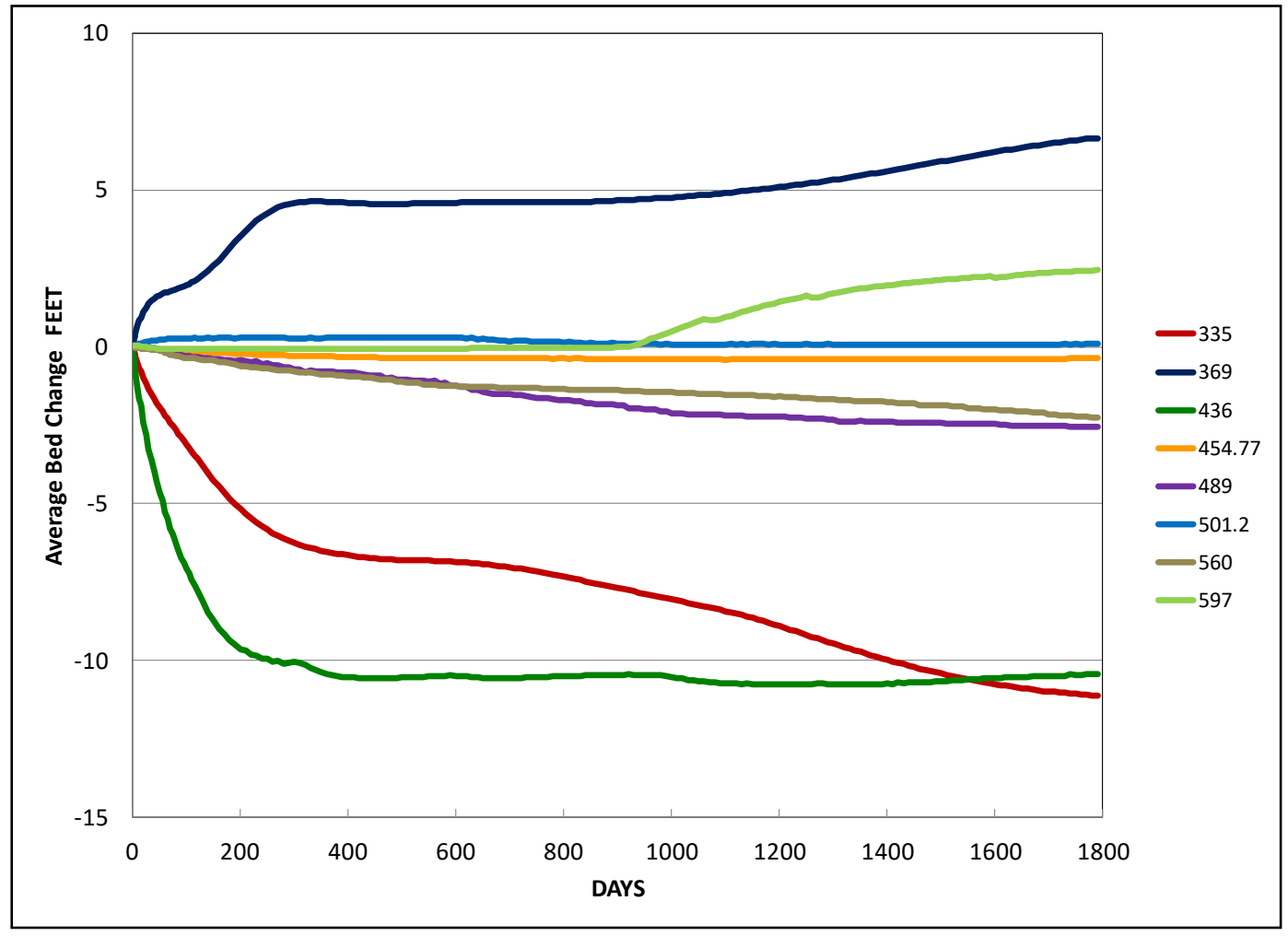

Figure 81. Calculated bed change in the Memphis District.

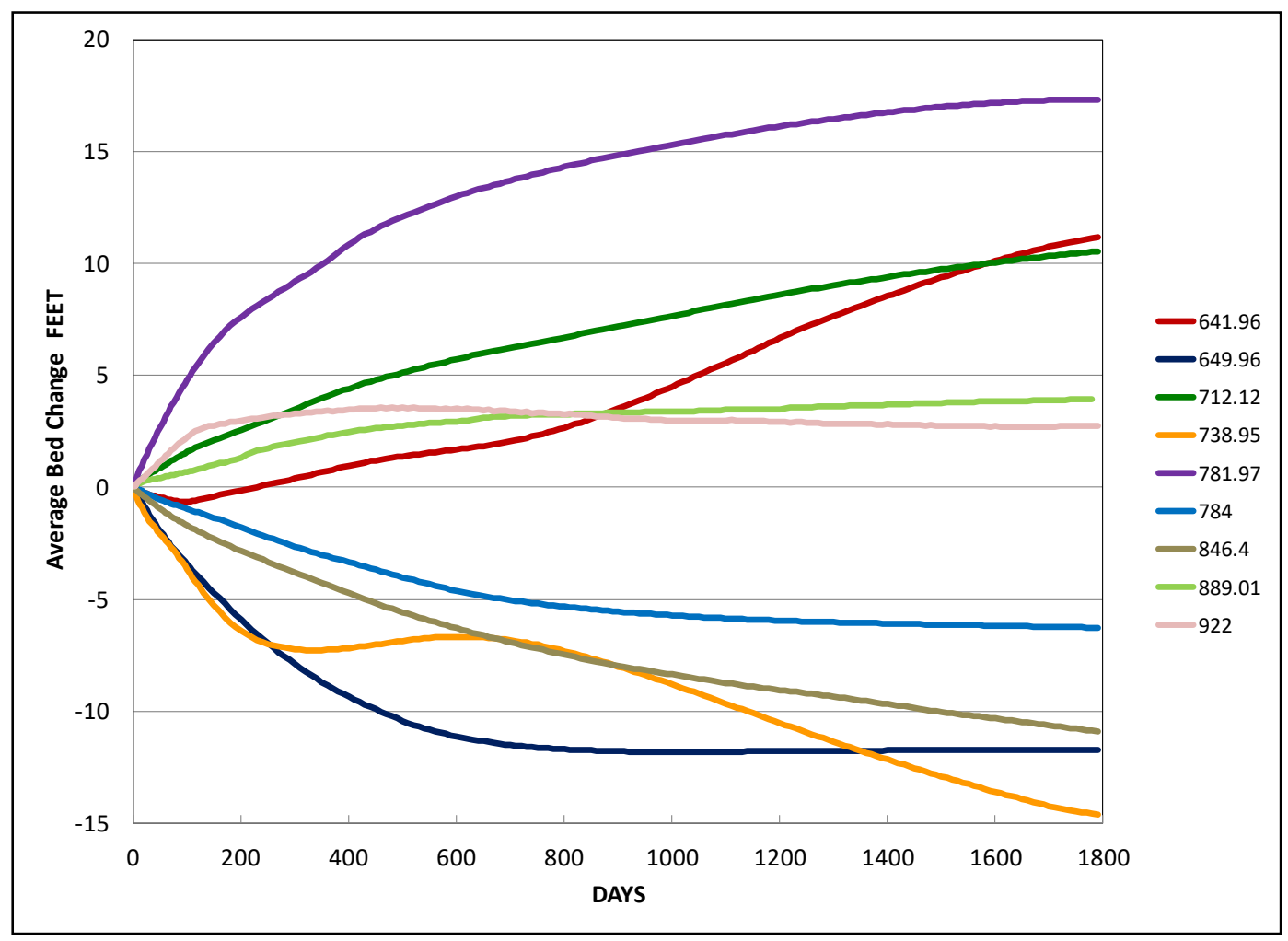


Problems with assuming a constant channel-forming discharge is demonstrated in Figure 82, which shows calculated average bed changes in five consecutive cross sections with a channel-forming discharge for 1,780 days. At the upstream cross section (578.8), the bed change trends toward equilibrium. However, at the next downstream cross section (576.21), there is a consistent degradation trend that accelerates after approximately 1,350 days of constant channel-forming discharge. This cross section is at a constriction, which tends to degrade at the channelforming discharge and may aggrade at other discharges. However, by simulating only a single discharge, the natural degradation and aggradation trend is masked. Average bed change at the next downstream cross section (574.8) is the reciprocal of bed change upstream. The sediment scoured from cross section 576.21 is deposited in cross section 574.8. The expected trend toward equilibrium is displayed at the next two downstream cross sections (573.15 and 571.4).

Figure 82. Calculated bed change at five consecutive cross sections.

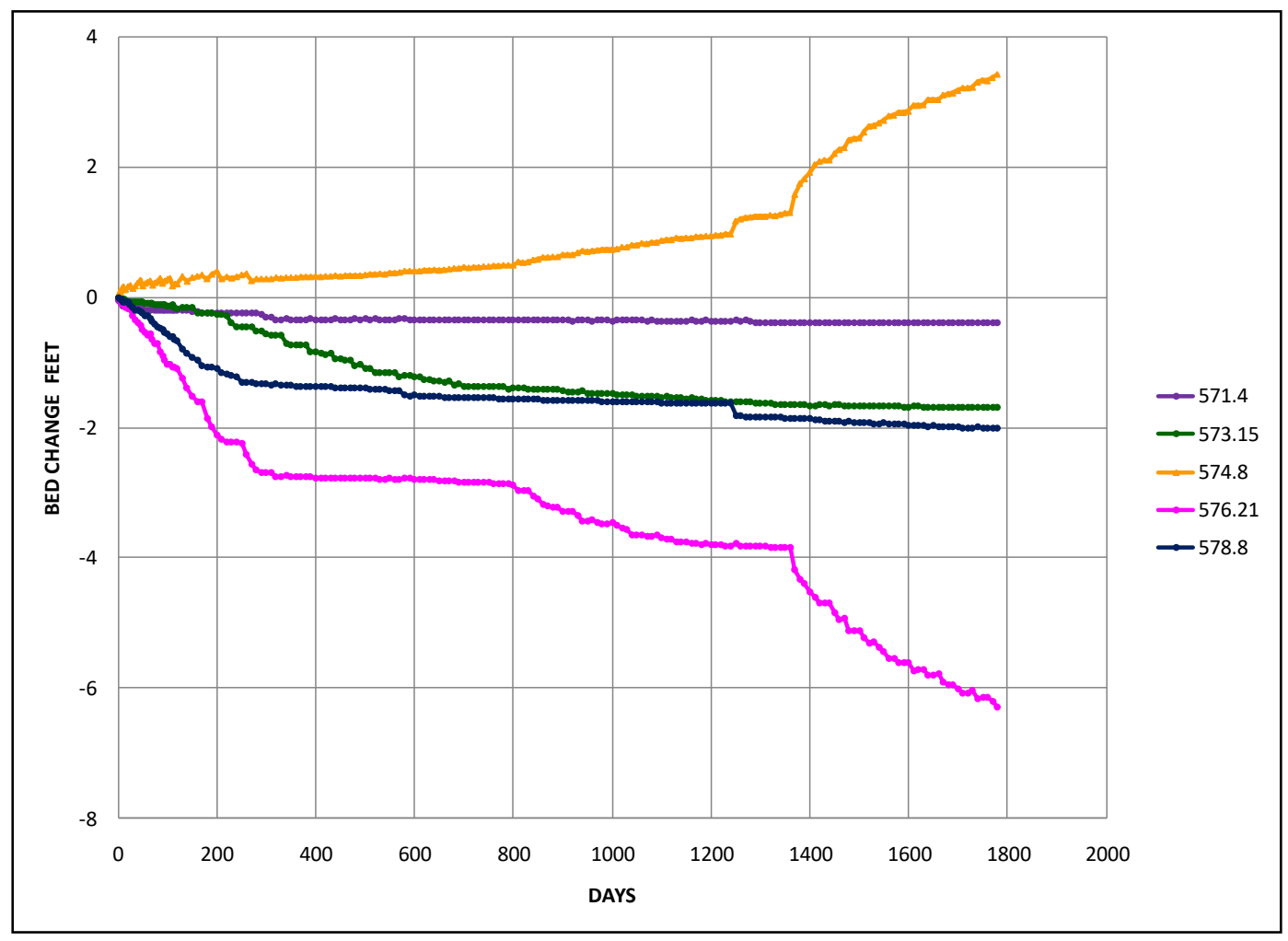

Calculated average bed changes at nine cross sections during the 19912002 simulation are plotted in Figure 83. This figure shows the true dynamic nature of the alluvial river. Cross-sections 369 and 574.8, show a variation with discharge and a general increasing trend over time with 
the actual annual hydrograph. Some cross sections (411.2) show significant variability in average bed change with discharge. Other cross sections (529.2 and 553) show little variation with the annual flood discharges.

Figure 83. Calculated average bed change during the 1991-2002 hydrograph.

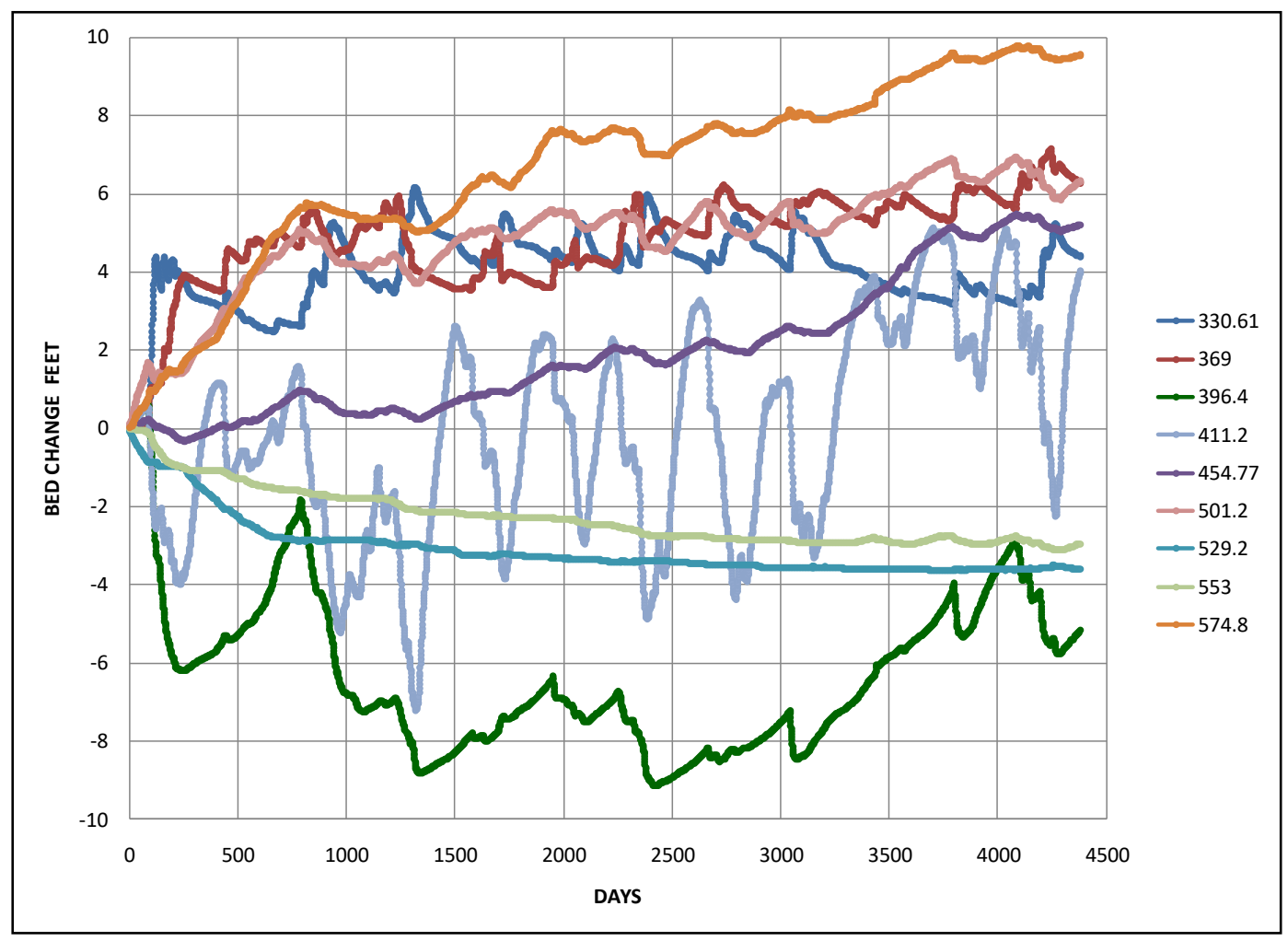

\section{Quasi-unsteady movable-bed tests}

Model performance was evaluated with a movable bed for the 1991-2002 hydrograph. The quasi-unsteady movable-bed tests were conducted to assess changes in calculated water-surface elevations and bed material gradations over time. Tests were also conducted to assess calculated sediment concentrations and size class distributions and total sediment yield for the 12-year hydrograph.

Stage variation with movable bed

As described in the section on channel roughness, water-surface profiles were calculated with the numerical model at the end of the 1991-2002 hydrograph for a range of steady-state discharges. The results of those calculations are shown in Figure 18 through Figure 37. The figures show that the calculated rating curves are slightly lower in 2002 than in 1991 in 
most of the New Orleans District. However, the differences are well within the annual variations of the measured data. In the Vicksburg and Memphis Districts, the figures show that the calculated rating curves are well within the scatter of data and essentially unchanged between 1991 and 2002.

\section{Specific gage analysis}

Specific gage analysis is sometimes used to assess the historical stability of a river system. A specific gage record is a graph of stage for a specific discharge at a particular gaging location plotted against time. A channel is considered to be in equilibrium if the specific gage record shows no consistent increasing or decreasing trends over time. An increasing or decreasing trend is indicative of aggradation or degradation, respectively. Annual variations in the specific gage record may obfuscate the true longterm trend, so care must be taken to ensure that a sufficient time record is evaluated. Specific gage records were used in this study to assess the numerical model's predictive ability with respect to matching trends, or lack of trends, during the 1991-2002 calibration period. The specific gage record evaluated in this study was of insufficient length to make any longterm conclusions relative to river geomorphology, which is outside the scope of this study.

In the New Orleans District reach, specific gage was calculated in HEC-6T by inserting a rating curve calculation at the end of each water year during the 1991-2002 simulation. In the Vicksburg and Memphis reaches, specific gage was calculated in HEC-6T during the 1991-2002 historical simulation using the specific gage option with a tolerance of $3,000 \mathrm{cfs}$. With this option, calculated water surface elevations for discharges within the tolerance range of specified discharges at specified cross sections are written to a Tape99 file. The specific gage option was an enhancement to the HEC-6T model that was unavailable when the New Orleans reach of the model was developed. Measured specific gage was calculated using statistical regression analyses in EXCEL. Third- or fourth-order polynomial regression curves were fit to the reported annual stage and discharge data at specific gages. Daily stage data are available for all the gages. In the New Orleans District, discharge measurements were not available at the gages, so the discharge from Tarbert Landing was used in the regression equations. The regression analysis produces questionable results for low discharges downstream from New Orleans because the stage is not a unique function of discharge and is influenced greatly by water surface elevations in the Gulf. Discharge measurements are taken at 
Natchez, Vicksburg, Arkansas City, Helena, Memphis, and Hickman. Discharge at Greenville was taken to be the discharge at Arkansas City without any lag. The stage-discharge curves at Rosedale were developed using calculated daily discharges at Arkansas City and Dam No. 2 on the Arkansas River. The daily discharges on the Arkansas River were obtained from the USACE Little Rock District. The daily discharge at Rosedale was taken to be the difference between the Arkansas City and Dam No. 2 discharges. A 1-day lag was assumed between Arkansas City and Rosedale and between Dam No. 2 and Arkansas City.

The HEC-6T calculated specific gages are compared to measured specific gages determined from the regression curves in Figure 84 through Figure 99. In the New Orleans District, upstream from New Orleans, the model results are consistent with the measured specific gage determined from the regression curves. Downstream from New Orleans, at lower discharges, the magnitude comparison between HEC-6 calculations and measured specific gage is not expected to be consistent due to the influence of the Gulf water-surface elevation. However, the trend comparison between HEC-6 calculations and measured specific gage may be useful. In the Vicksburg and Memphis Districts, calculated and measured specific gage is generally steady between 1991 and 2002, with no obvious aggradation or degradation trends displayed at any of the gages.

Figure 84. Specific gage at Venice, RM 10.7.

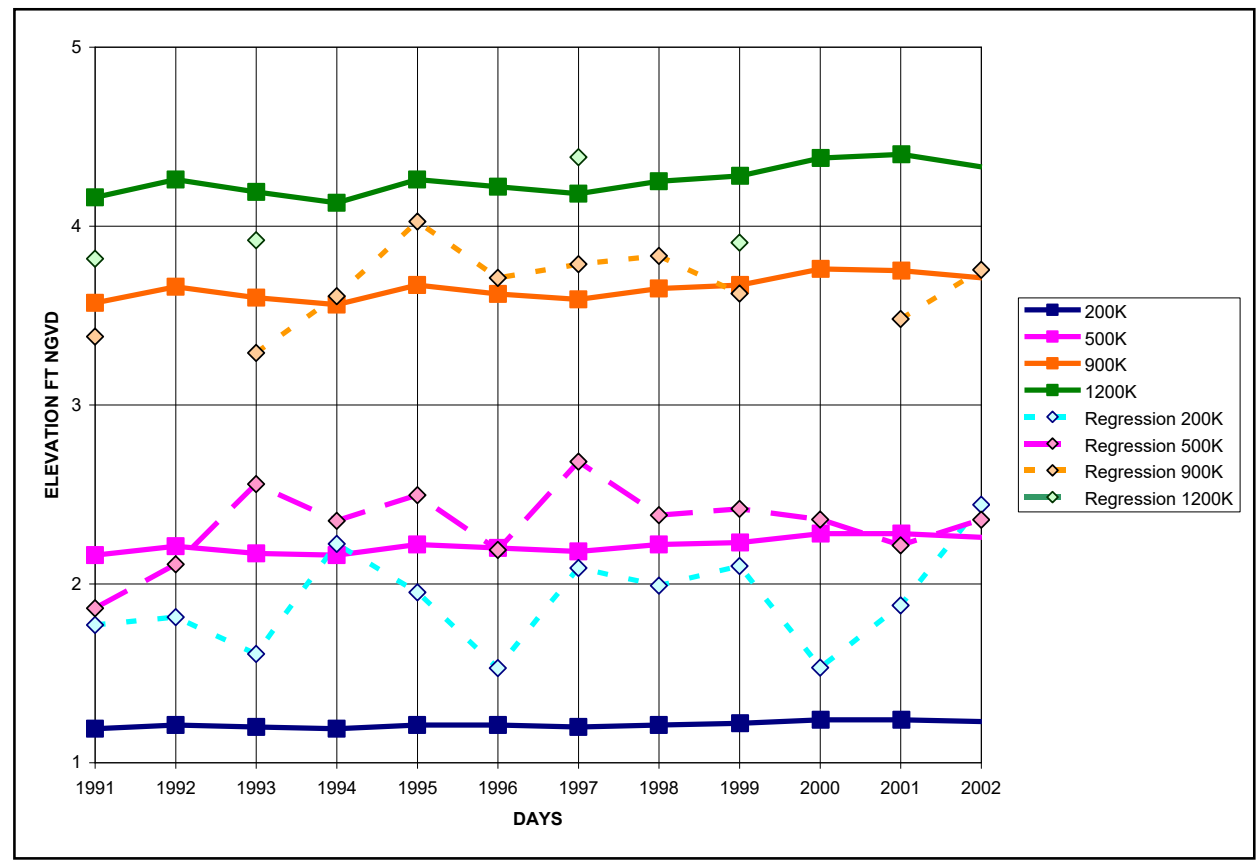


Figure 85. Specific gage at West Pointe A La Hache, RM 48.7.

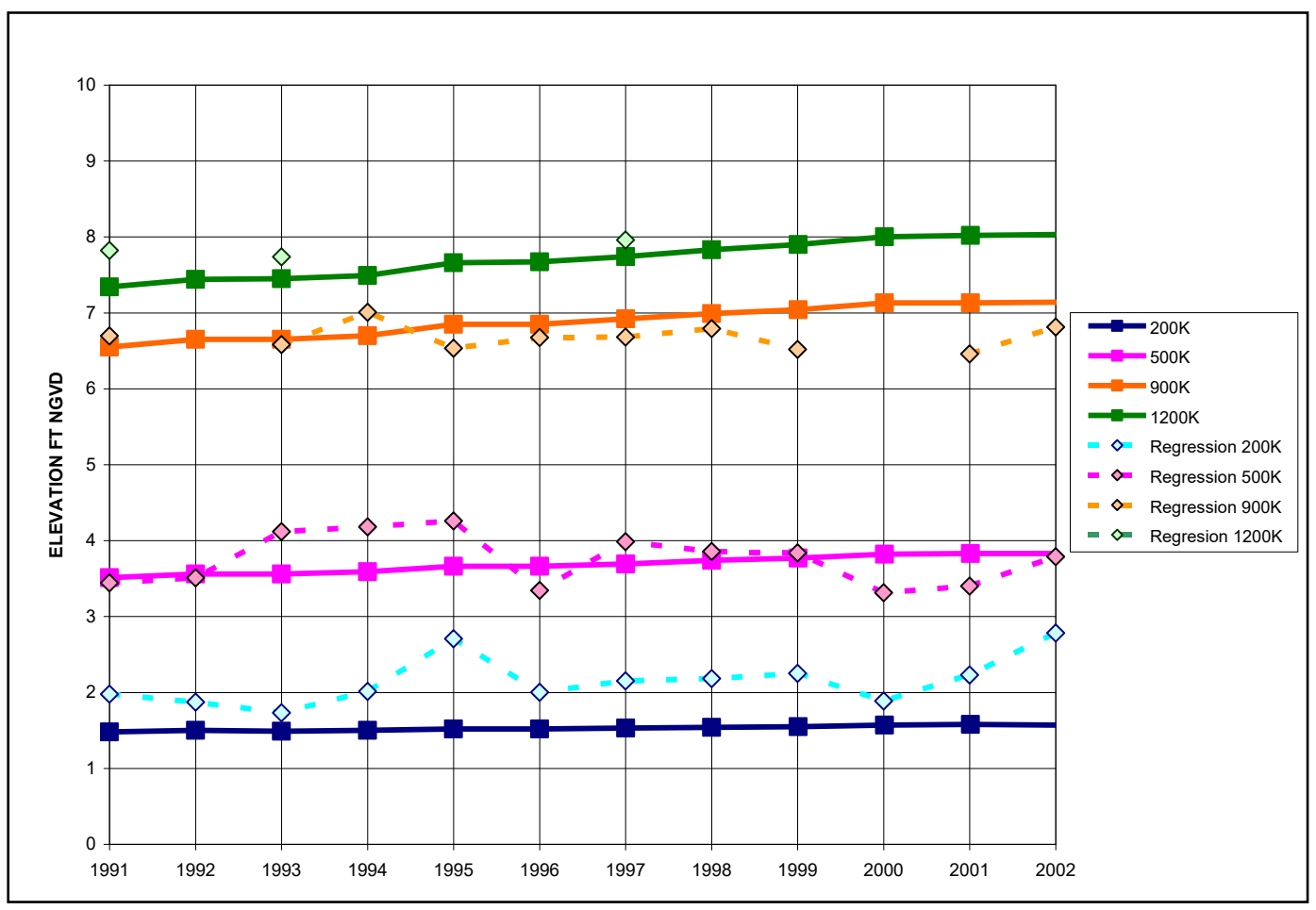

Figure 86. Specific gage at New Orleans, RM 102.8.

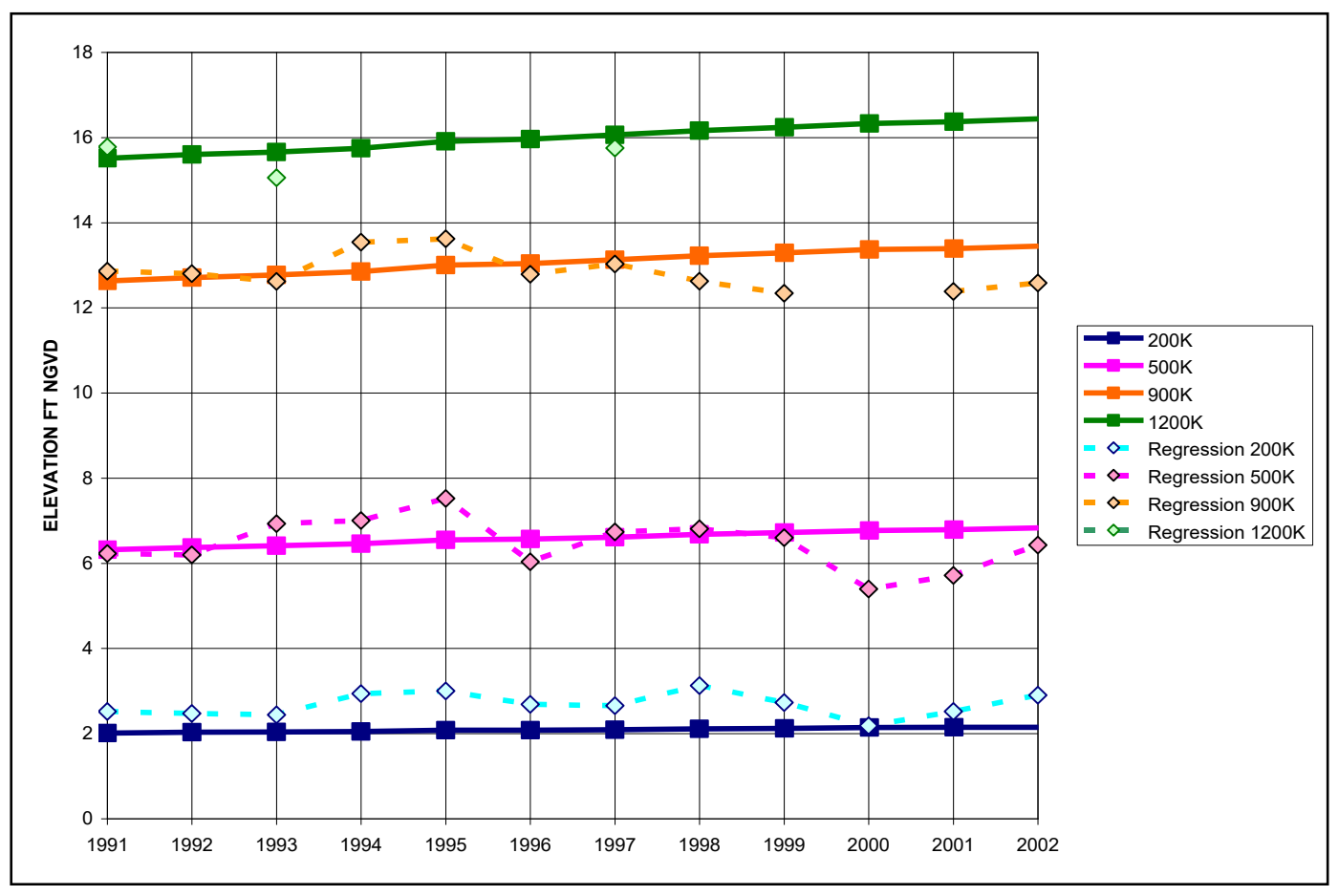


Figure 87. Specific gage at Reserve, RM 138.7.

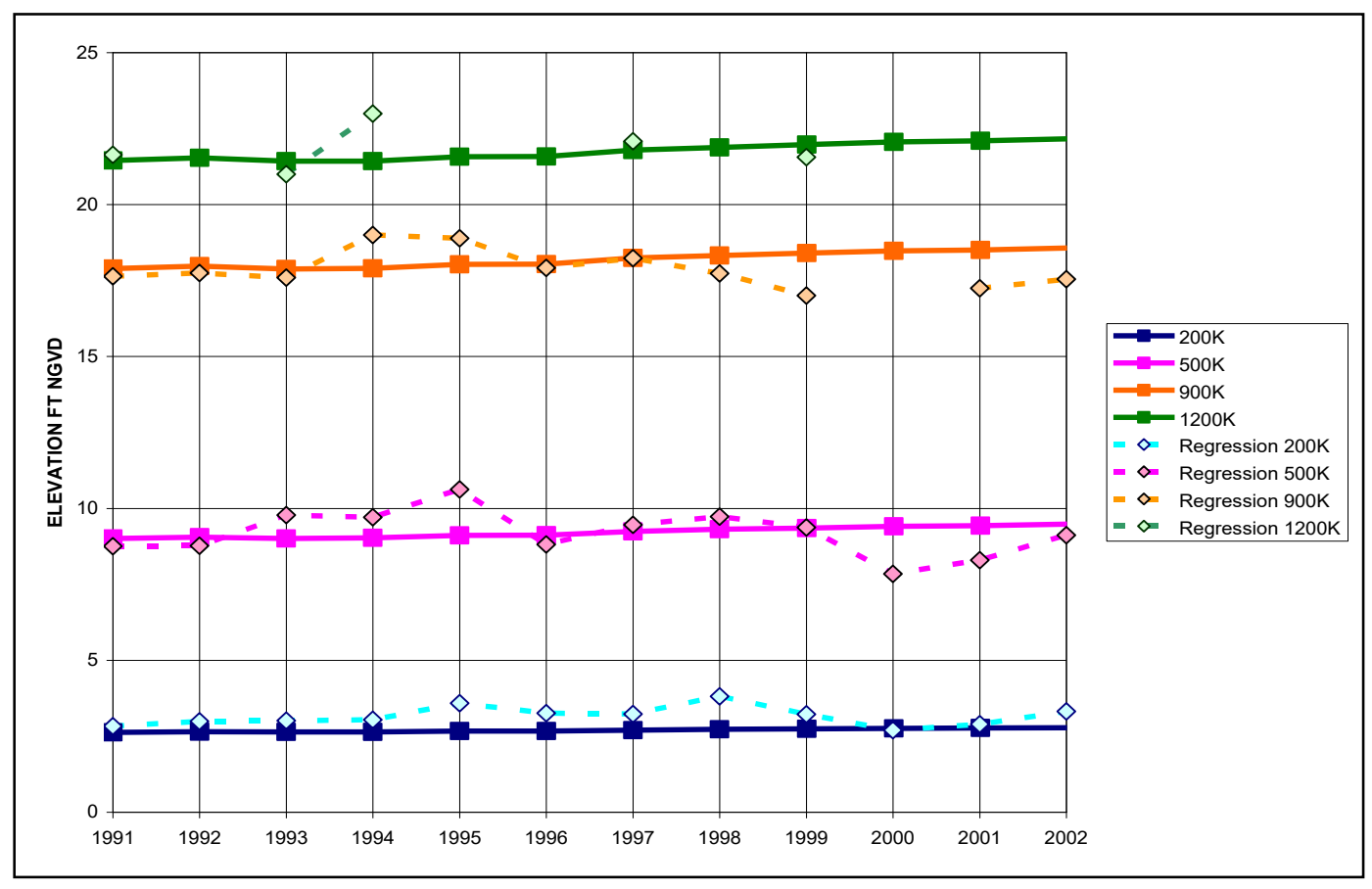

Figure 88. Specific gage at Donaldsonville, RM 175.4.

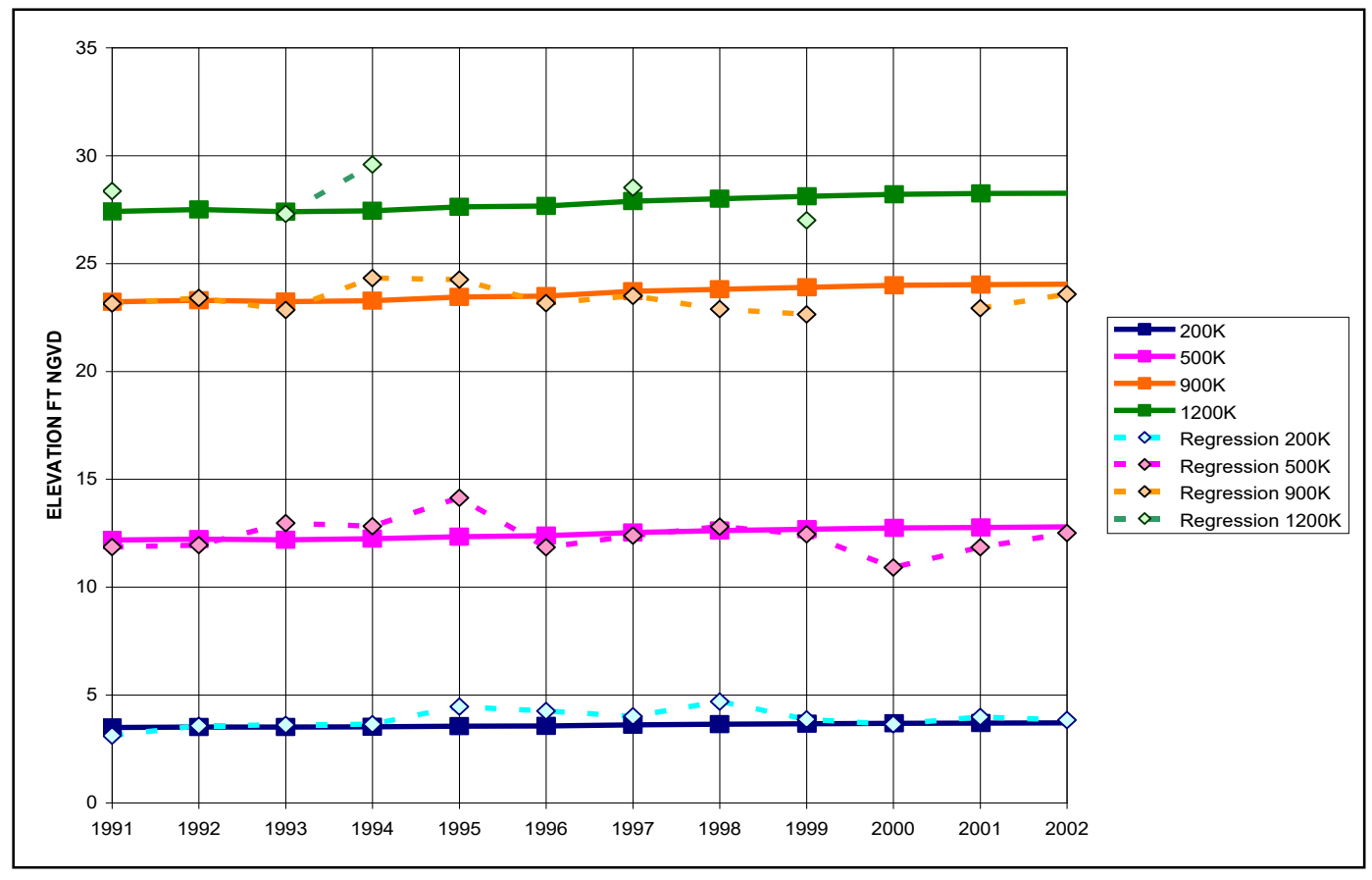


Figure 89. Specific gage at Baton Rouge, RM 228.0.

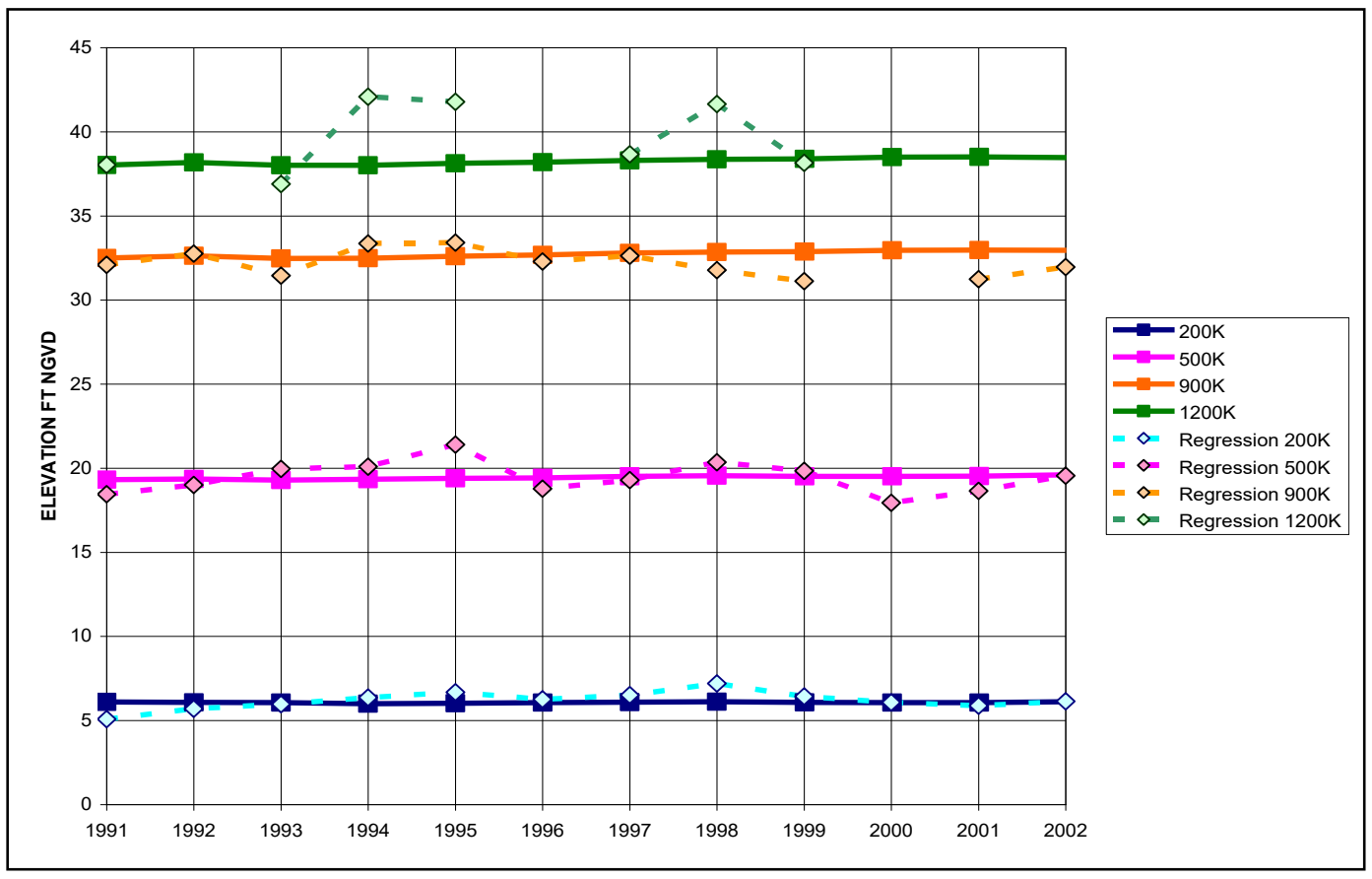

Figure 90. Specific gage at Bayou Sara, RM 265.4.

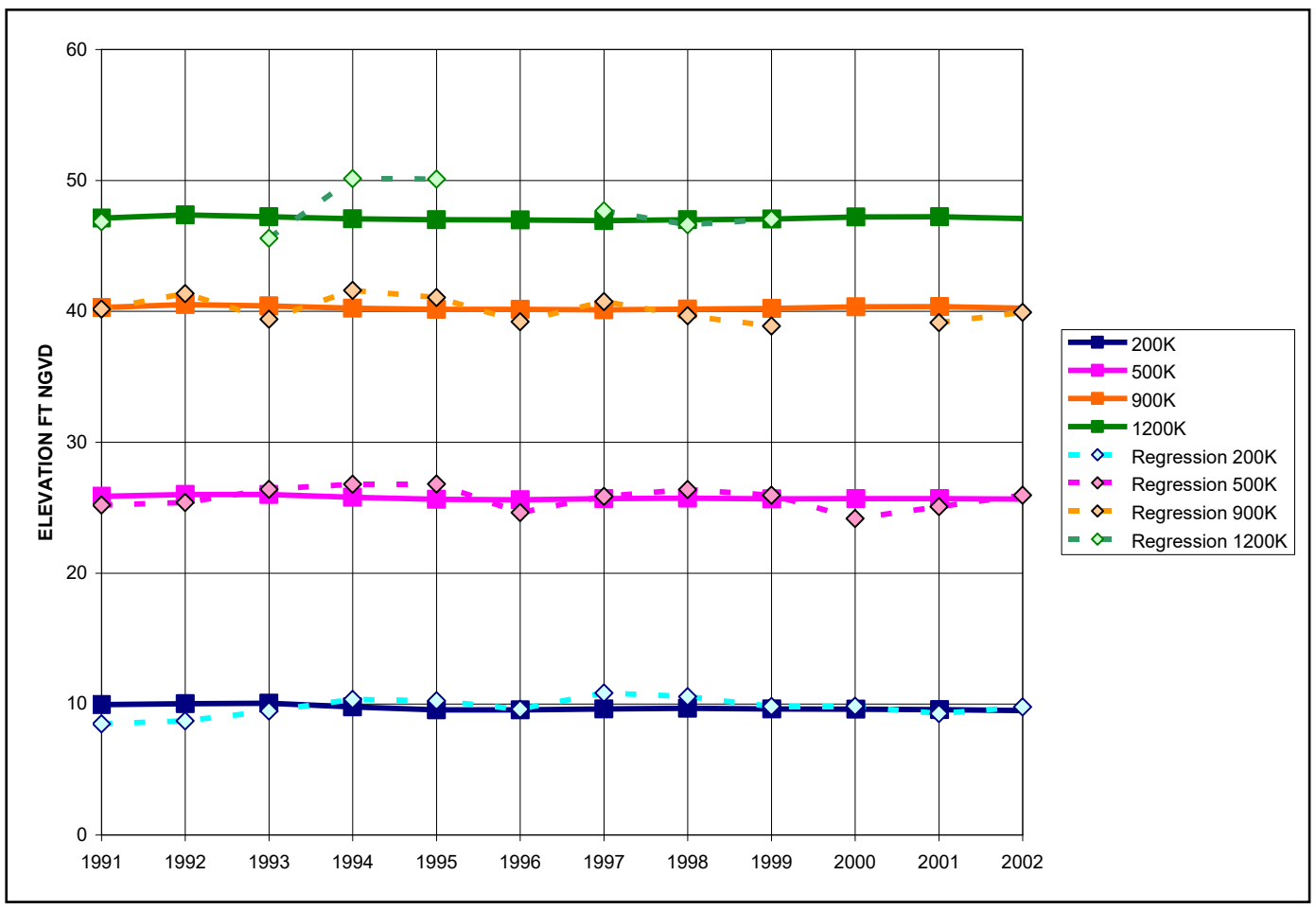


Figure 91. Specific gage at Red River Landing, RM 302.4.

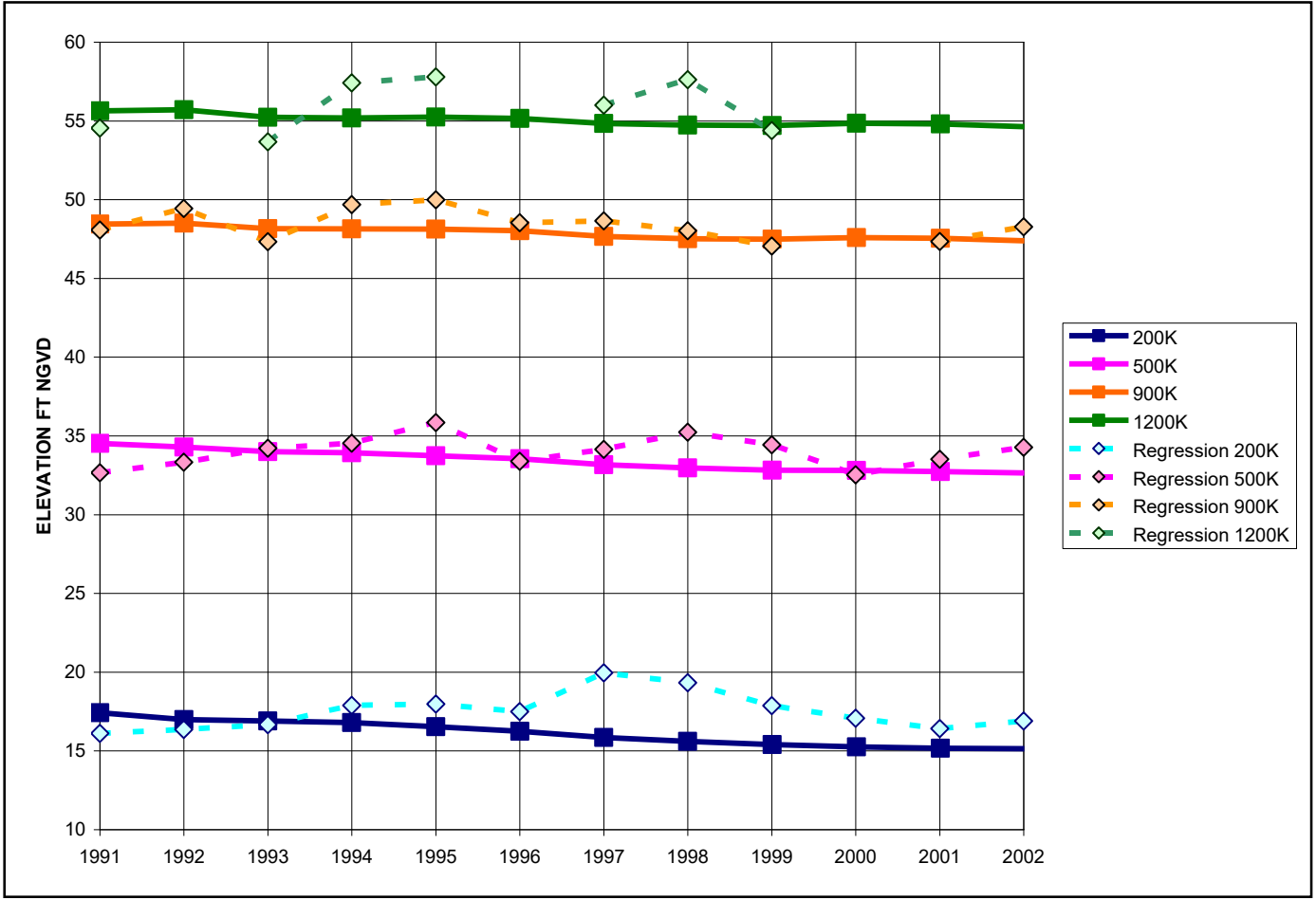

Figure 92. Specific gage at Natchez, RM 363.3.

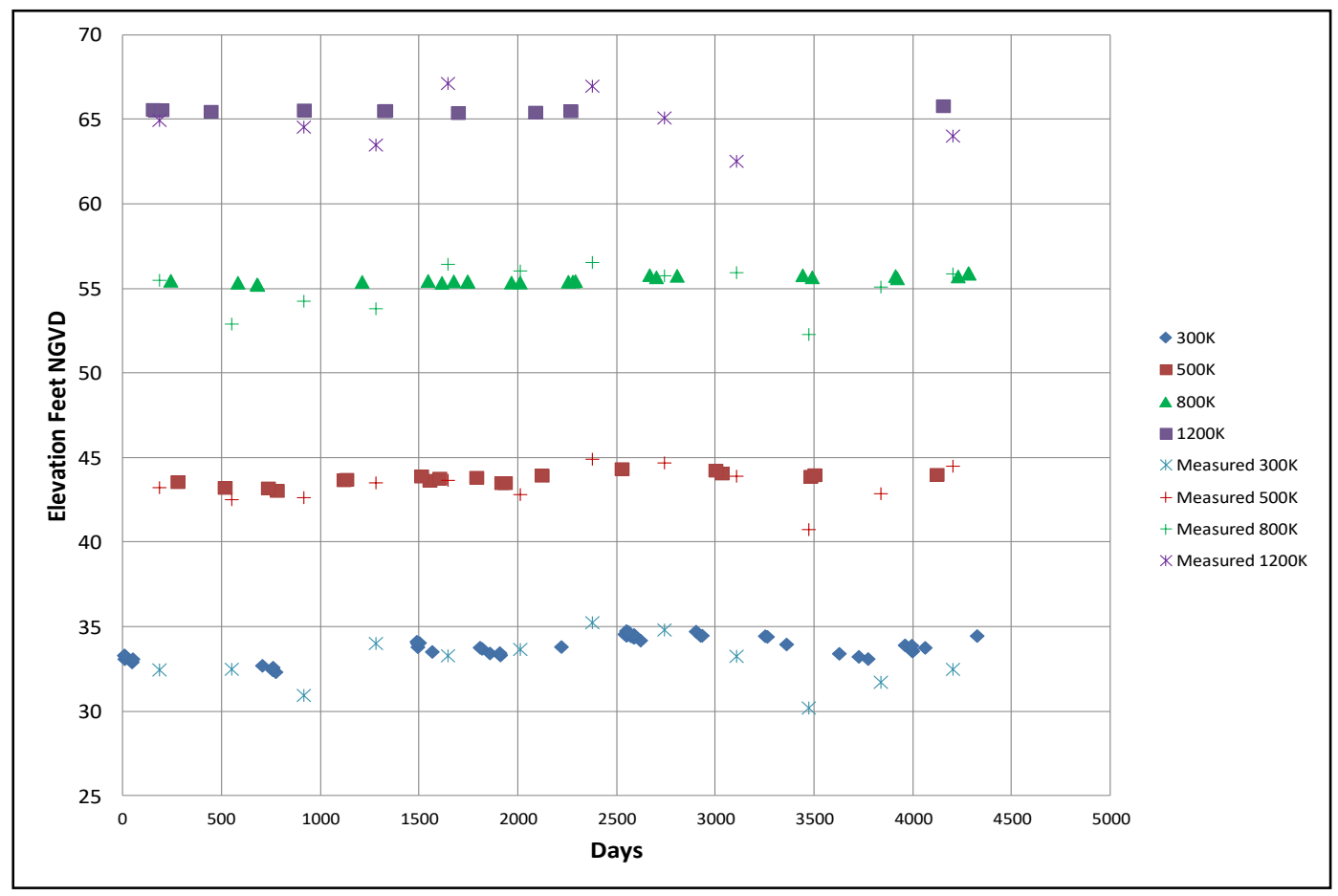


Figure 93. Specific gage at Vicksburg, RM 435.7.

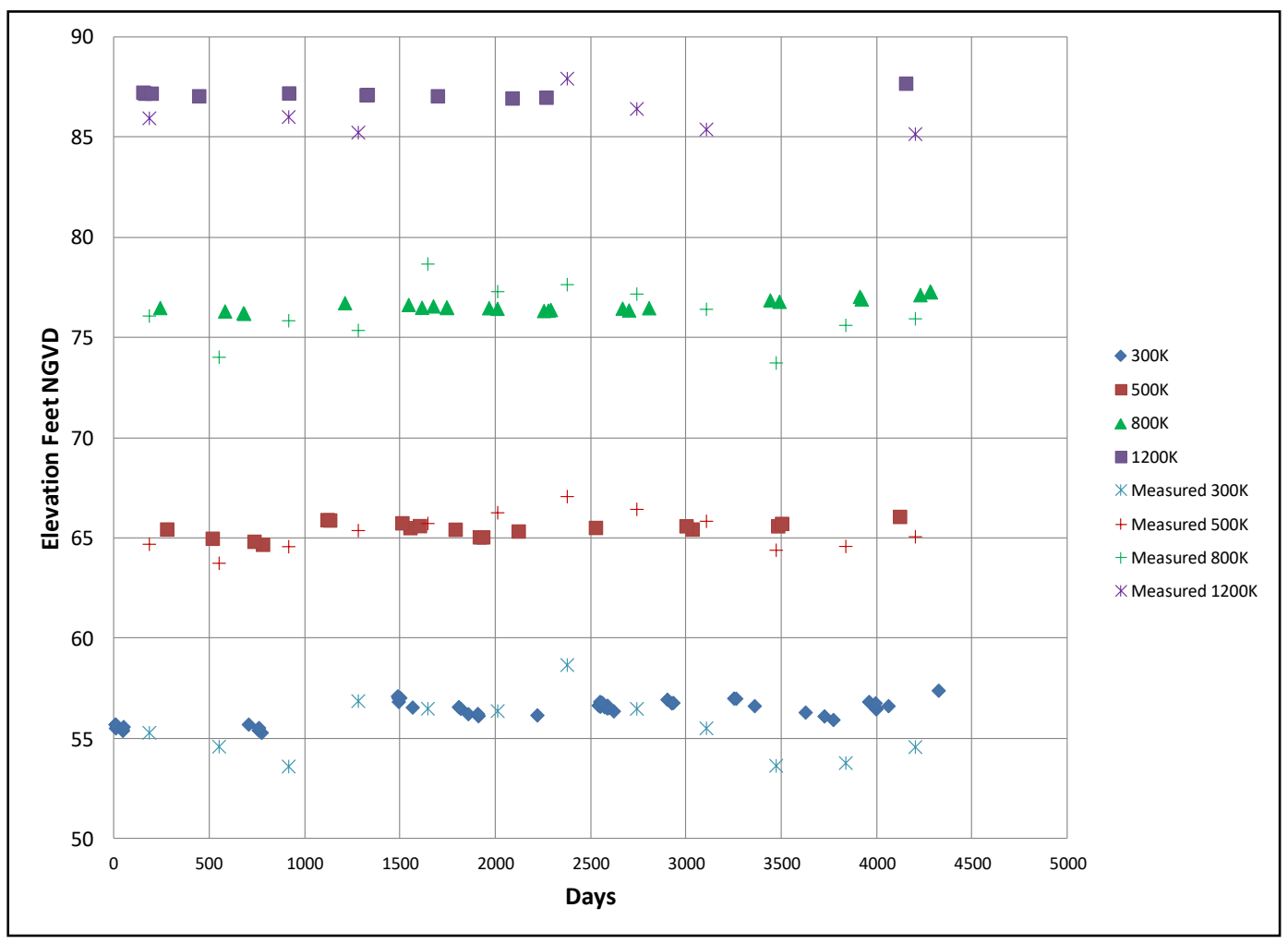

Figure 94. Specific gage at Greenville, RM 531.1.

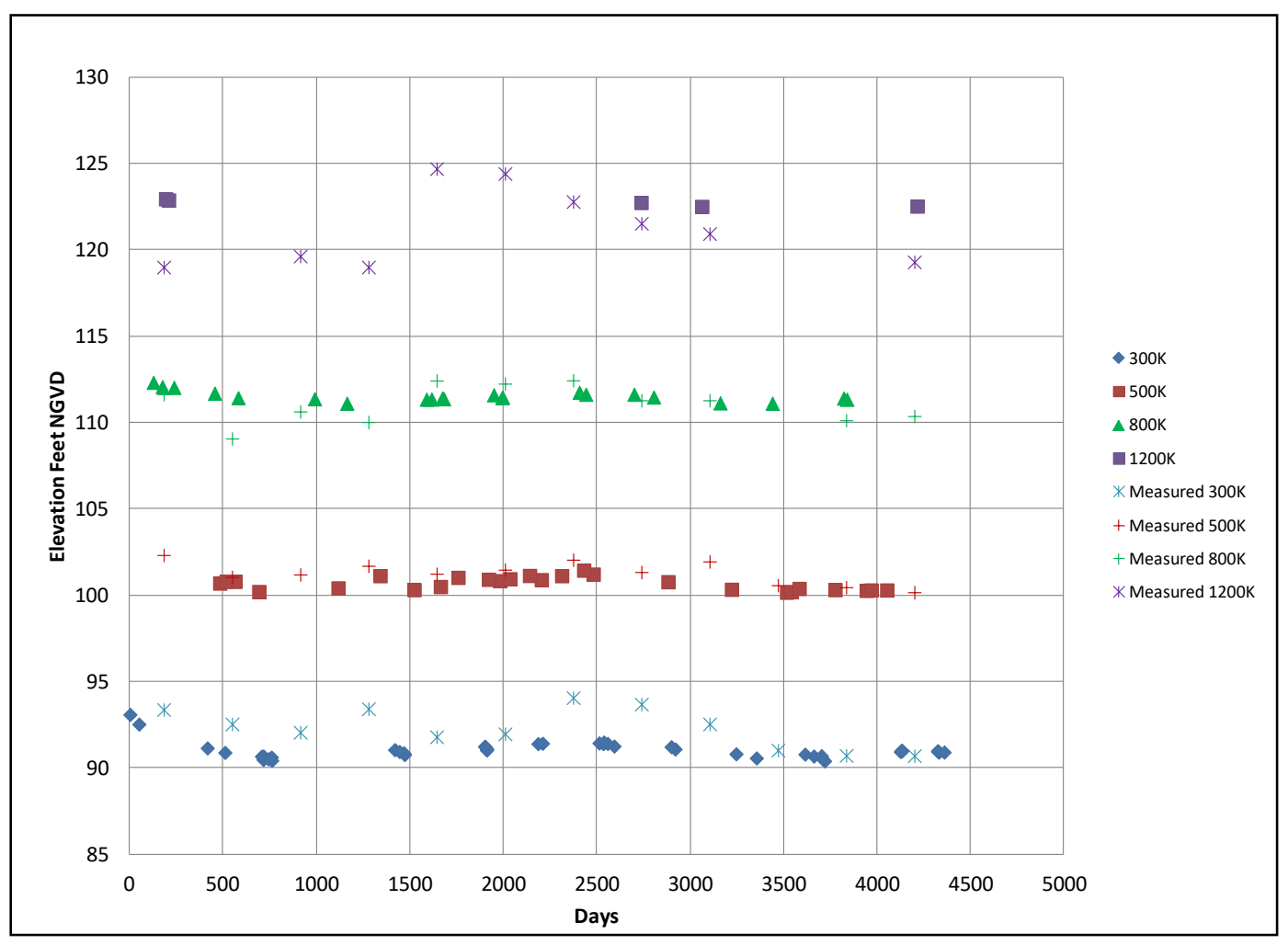


Figure 95. Specific gage at Arkansas City, RM 554.1.

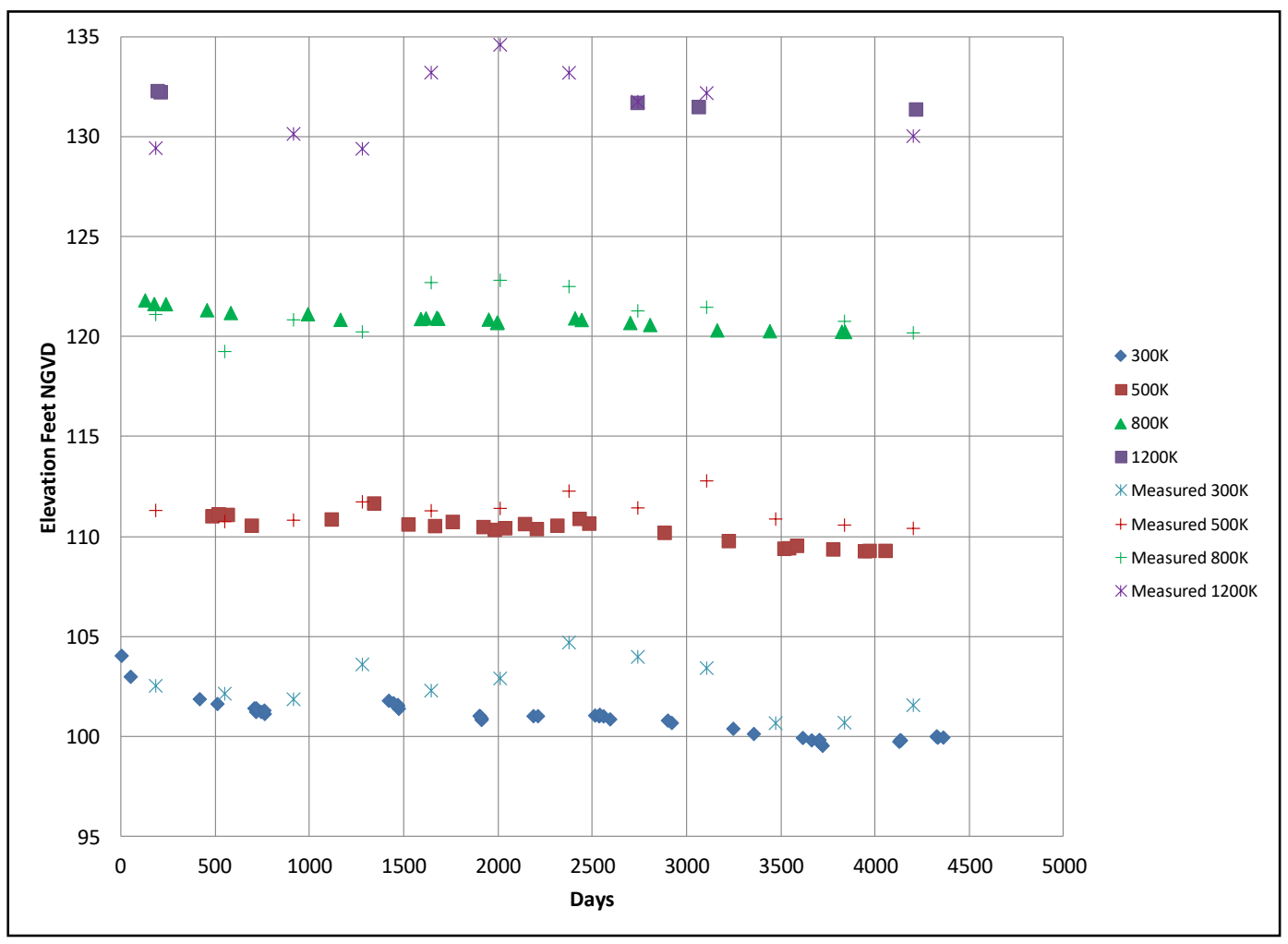

Figure 96. Specific gage at Rosedale, RM 592.2.

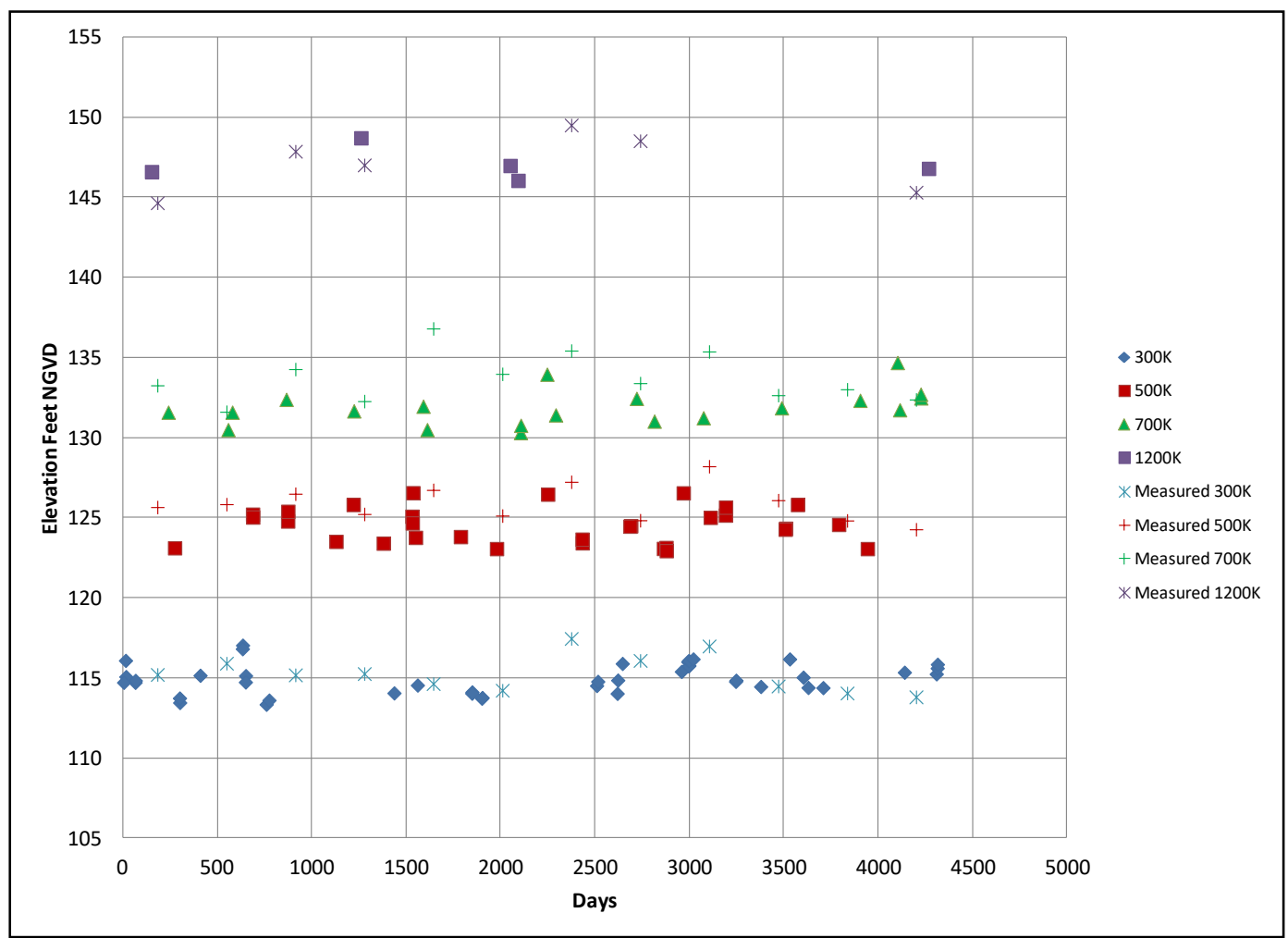


Figure 97. Specific gage at Helena, RM 663.1.

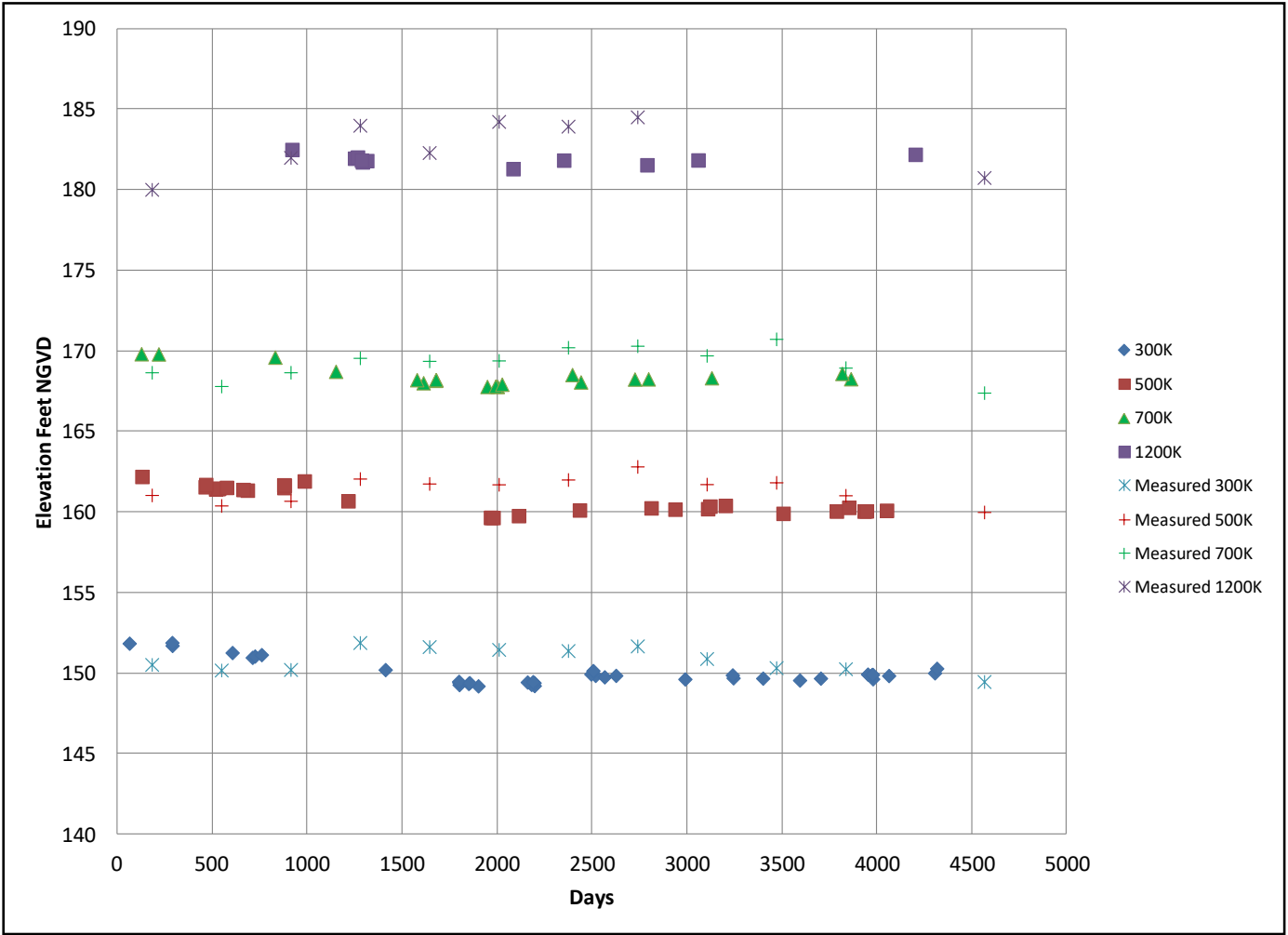

Figure 98. Specific gage at Memphis, RM 734.7.

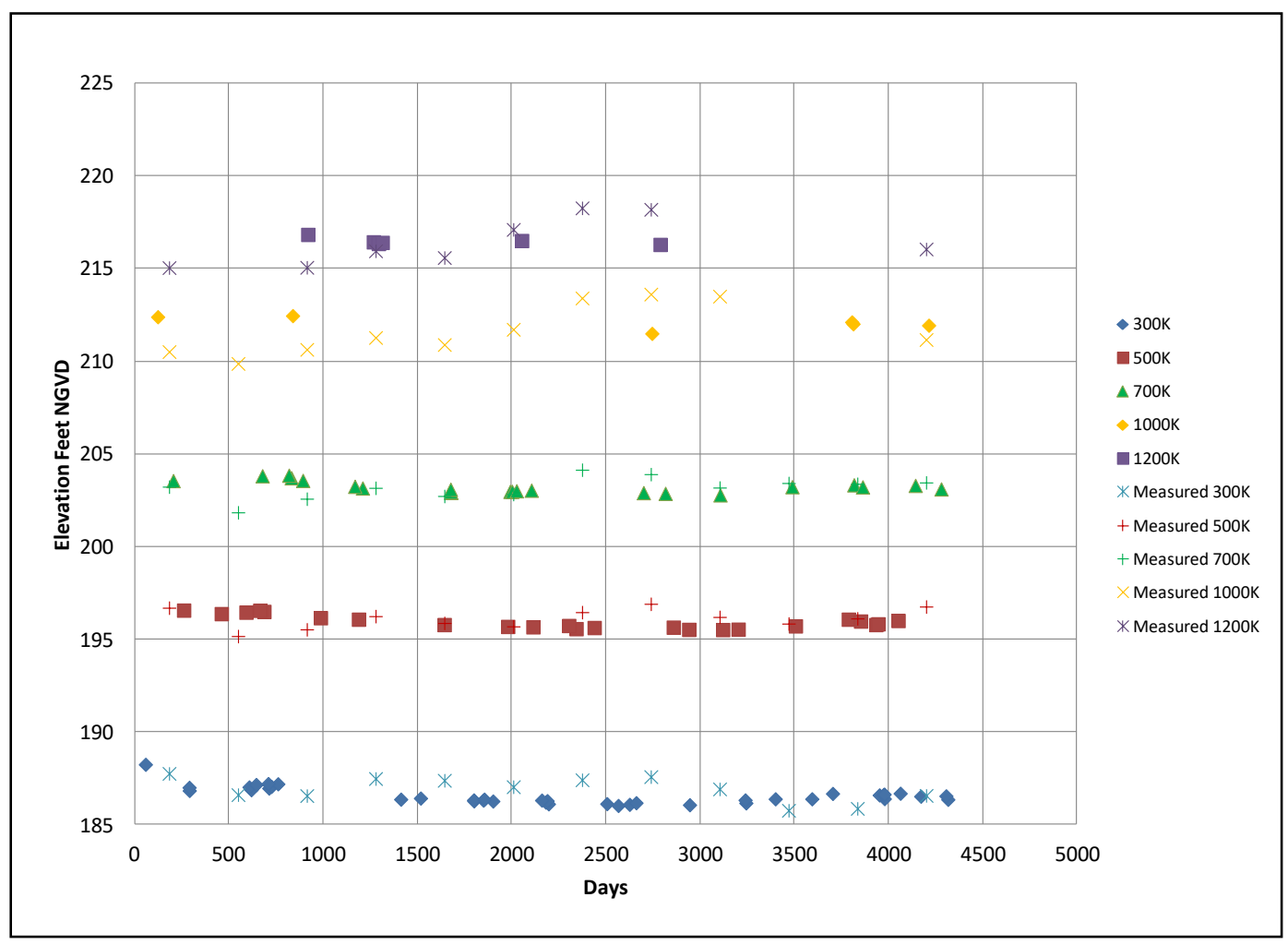


Figure 99. Specific gage at Hickman, RM 922.

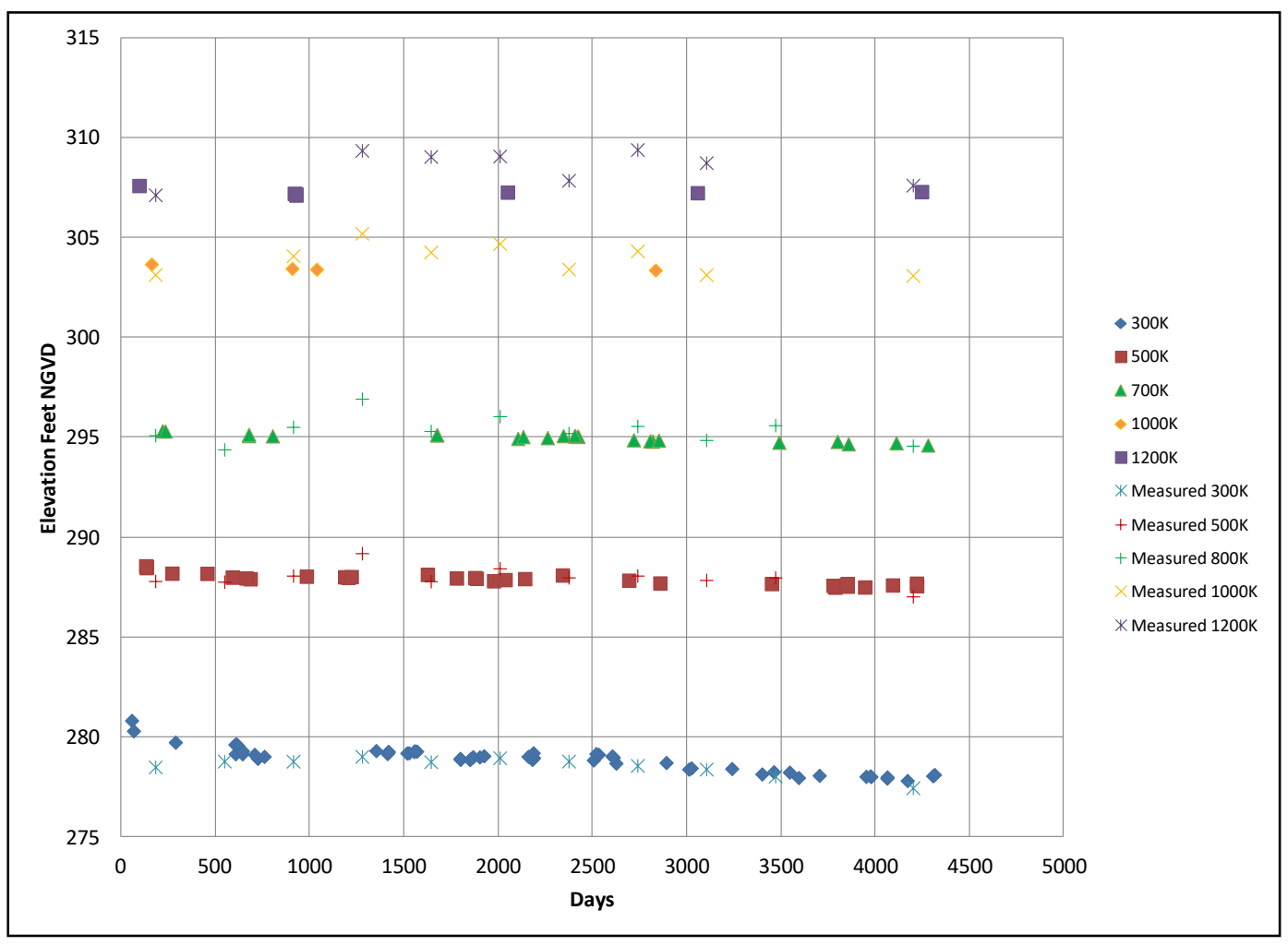

Average bed change

Calculated average bed changes at the gages during the 1991-2002 simulation are shown in Figure 100 through Figure 102. These plots show significant oscillation in the bed elevation at some gages, such as Bayou Sara and Greenville. General aggradation trends are calculated at Venice and Reserve. Some cross sections show significant change early in the simulation, such as New Orleans, Arkansas City, and Memphis. The rapid change in average bed elevation early in the simulation is most likely due to failure to select "reach-averaged" cross section for the numerical model. The calculated average bed changes at gages, and the results from the specific gage plots demonstrate the importance of looking at long reaches to access general aggradation and degradation and the danger of focusing on results from a single cross section in determining long-term or even short-term bed change.

The purpose of showing these calculations is to provide insight into how the model responds to changing hydrologic and hydraulic conditions. Given the available survey data and the fact that the cross-section surveys are not taken at the same time, prototype average bed change at specific 
cross sections was not determined. Comparing cross-section surveys at a specific location, taken 10 years apart, can lead to erroneous conclusions. For example, the crest of a bed form could be passing a specific cross section during one survey, and the trough of a bed form could be passing during the second survey. Comparing surveys at such a cross section could lead to the erroneous conclusion that aggradation/degradation is occurring, when in fact average conditions are unchanged. Proper analysis requires evaluating an entire reach of the river in the vicinity of the gage. This falls into the realm of a geomorphic study, which is beyond the scope of this study.

Figure 100. Calculated average bed change, New Orleans District gages, 1991-2002.

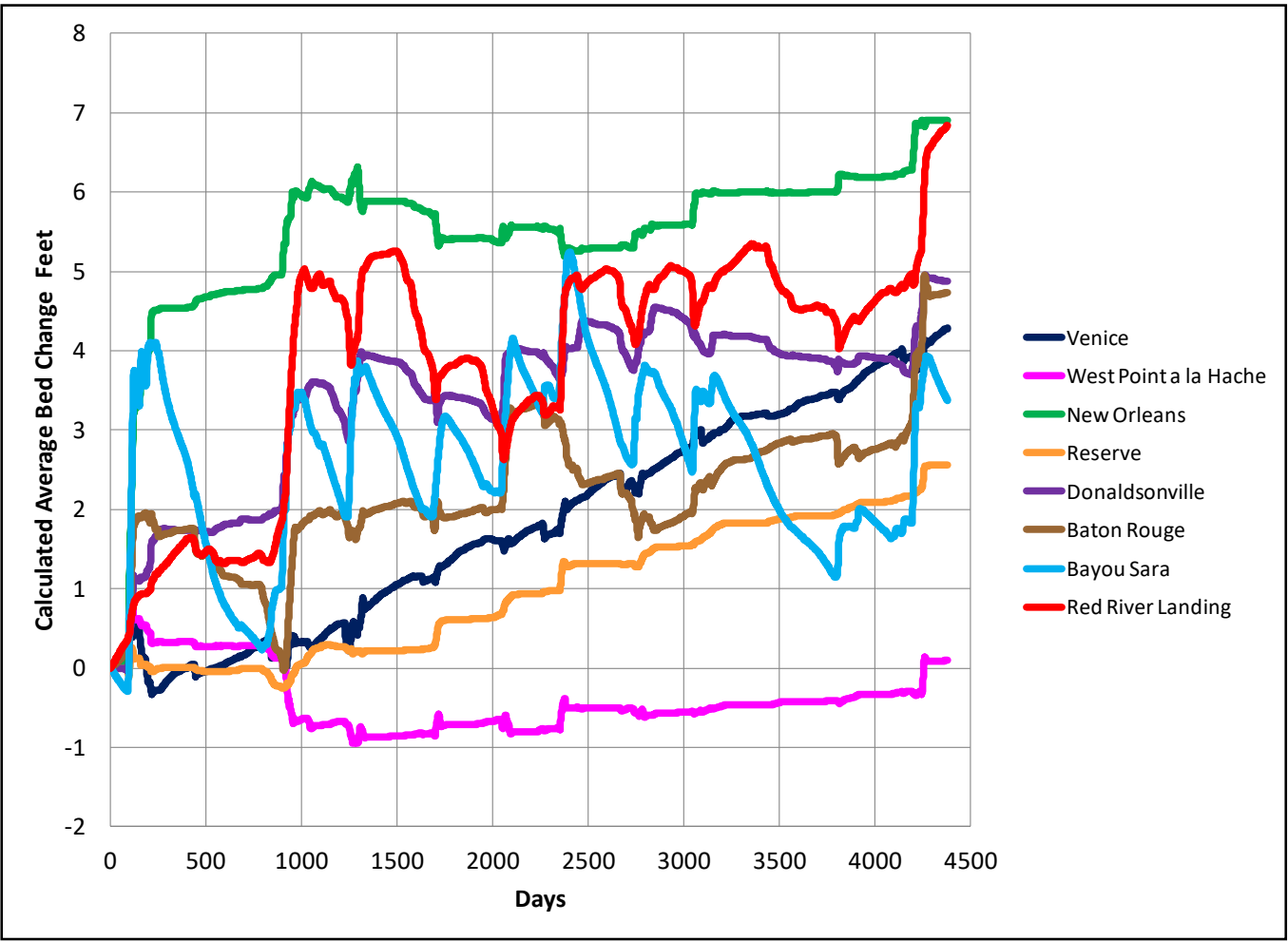


Figure 101. Calculated average bed change, Vicksburg District gages, 1991-2002.

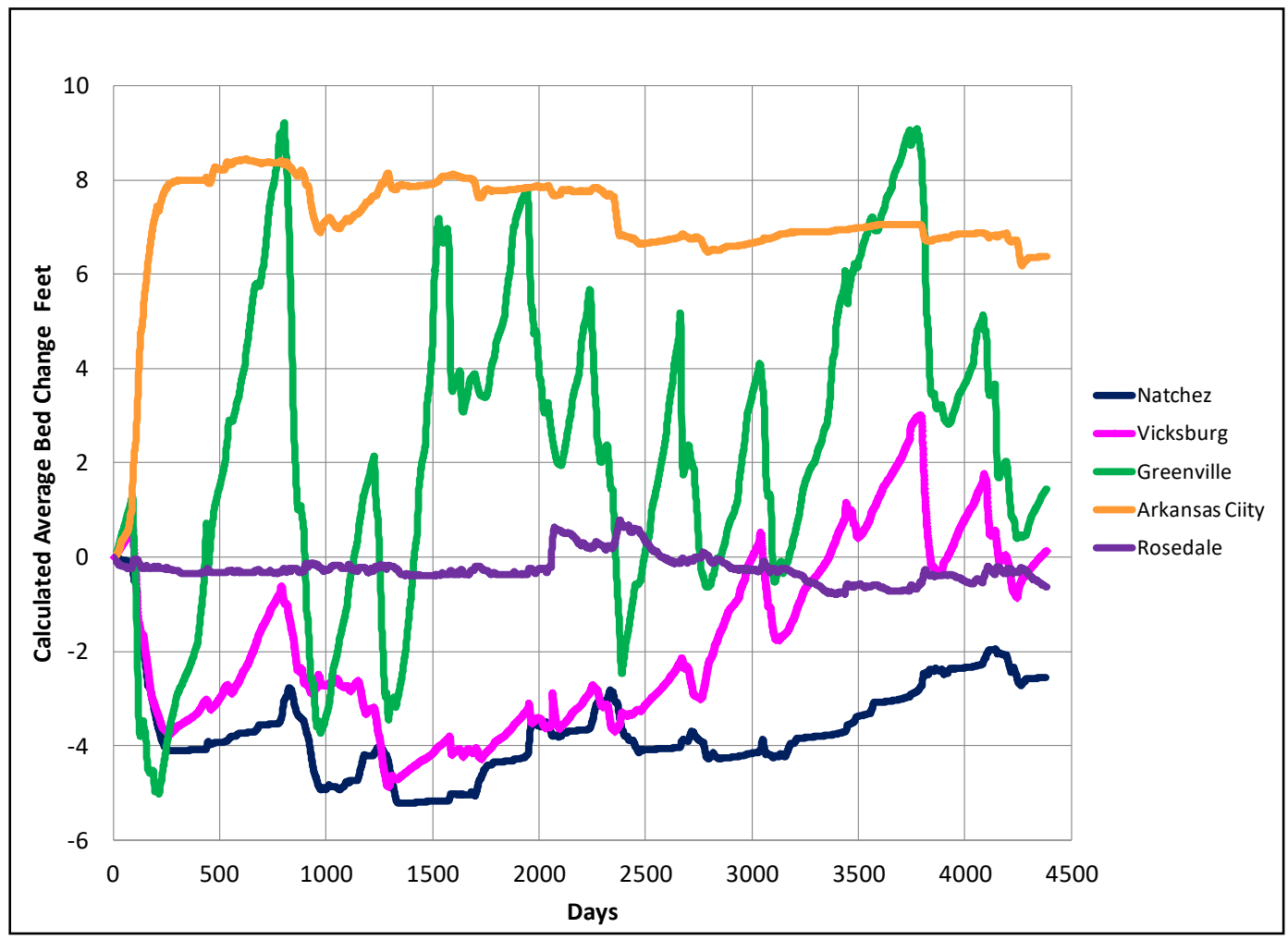

Figure 102. Calculated average bed change, Memphis District gages, 1991-2002.

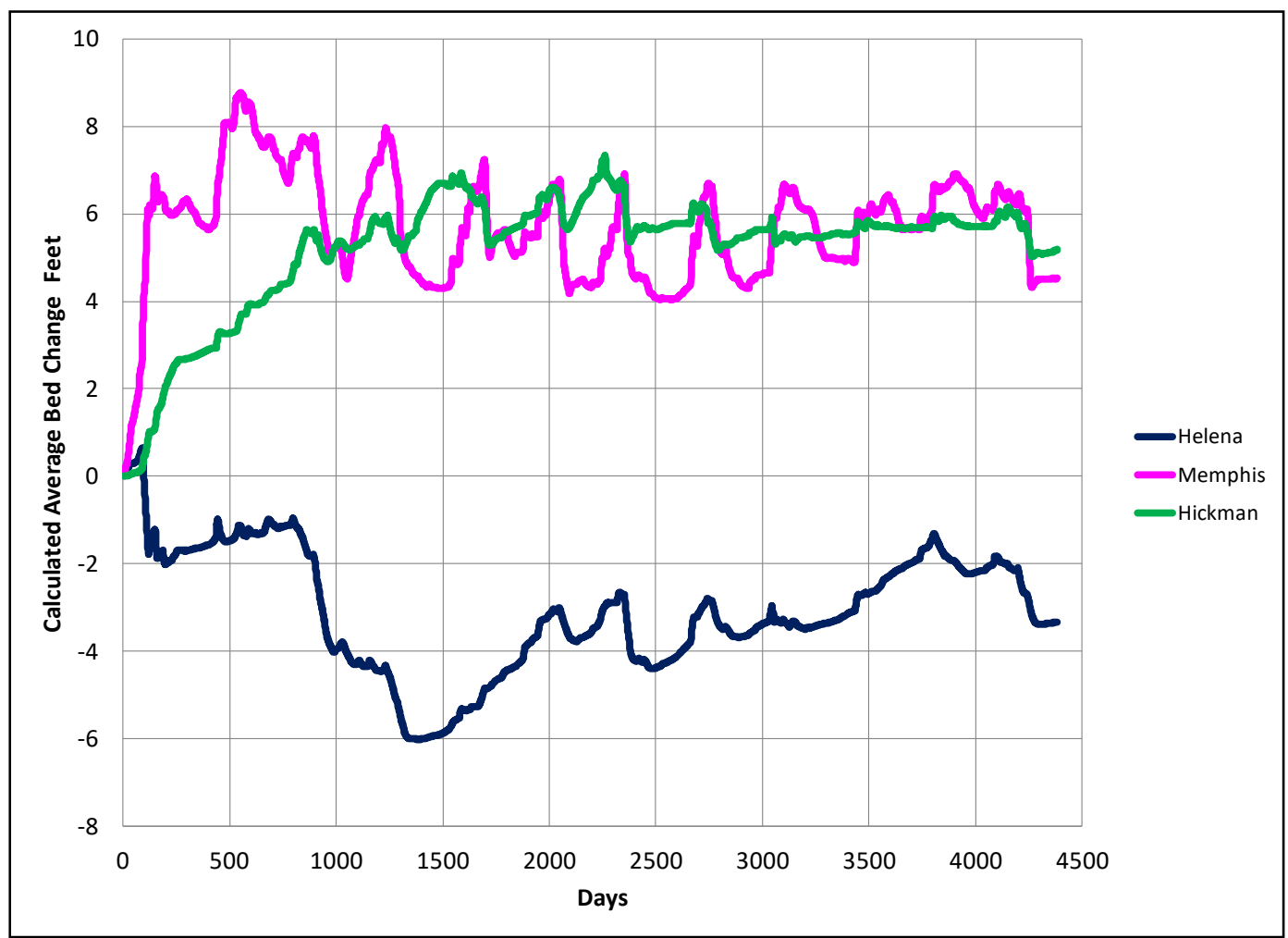


Bed gradation trends with movable bed

Changes in calculated bed material gradation trends between Head of Passes (RM 0.0) and Vicksburg (RM 435.7), during the 12-year calibration simulation, were compared to trends measured by the USGS between 1982 and 1985 (Demas and Curwick 1987) and in 2005. The 1982-85 data were collected at eight stations between Venice (RM 10.7) and Tarbert Landing (RM 306.3). At most stations, there were approximately 25 sets of data collected. Most sets consisted of three laterals, some sets had five laterals. In July 2005, the USGS collected bed material data at each of these eight stations at five laterals. In August 2005, the USGS collected samples at approximately 2-mile increments at three laterals between Head of Passes and Vicksburg. The data are shown in Figure 103. Samples that contained greater than 10 percent fines were excluded from the analysis.

Figure 103 shows the variability in the composition of the bed with distance along the river. When the $0.25 \mathrm{~mm}$ data collected at a few specific stations in 1982-1985 and 2005 are compared with the data collected at 2-mile increments in 2005, it is apparent that developing trend lines from a few stations can be problematic.

Figure 103. 1982-1985 and 2005 USGS bed-material gradations.

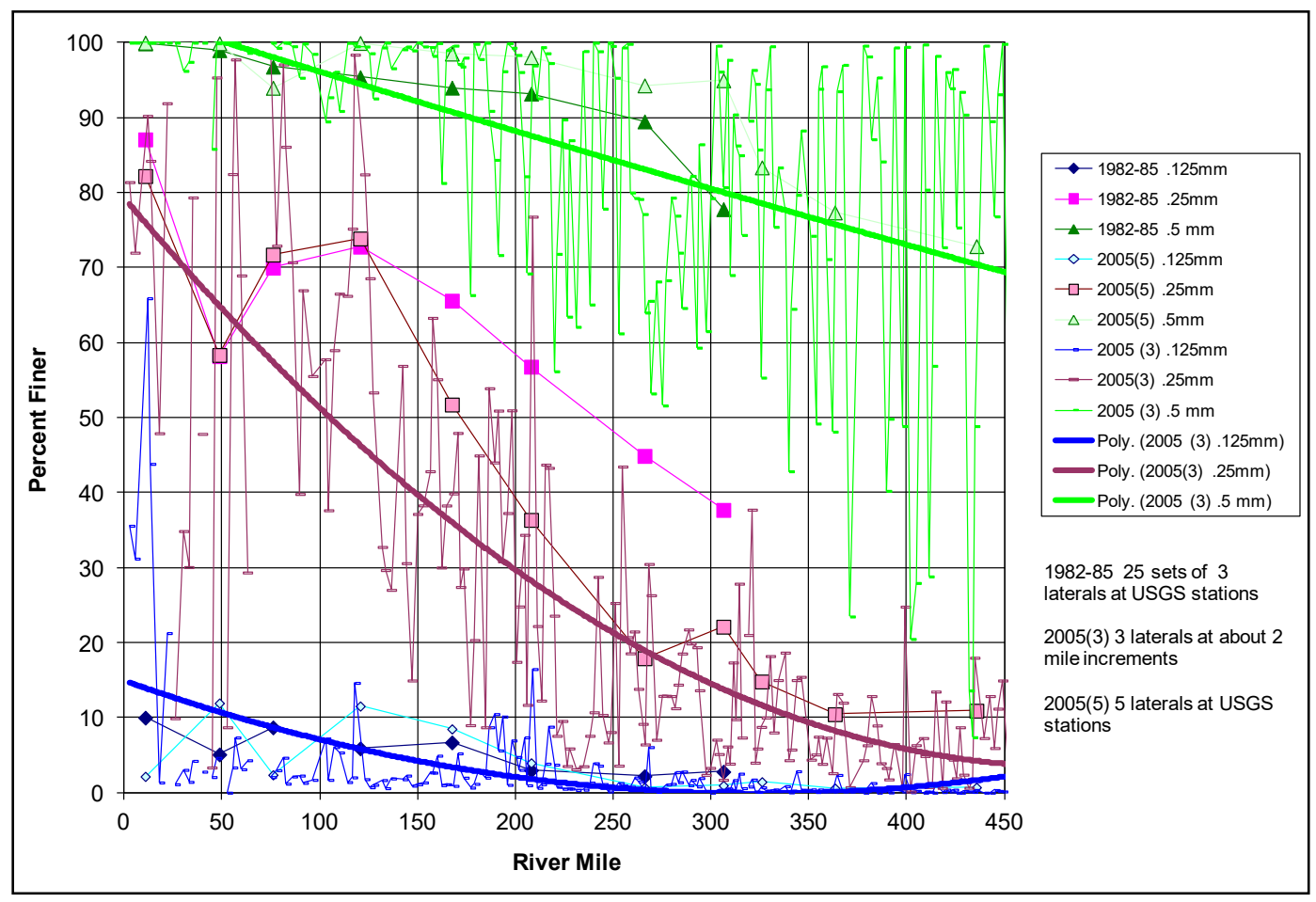


The USGS data are compared to polynomial regression curves of the Nordin and Queen (1989) data in Figure 104. The 1982-1985 USGS data and the Nordin and Queen data are similar, but the 2005 bed gradations appear to be slightly coarser.

Figure 104. USGS and Nordin and Queen bed-material gradations.

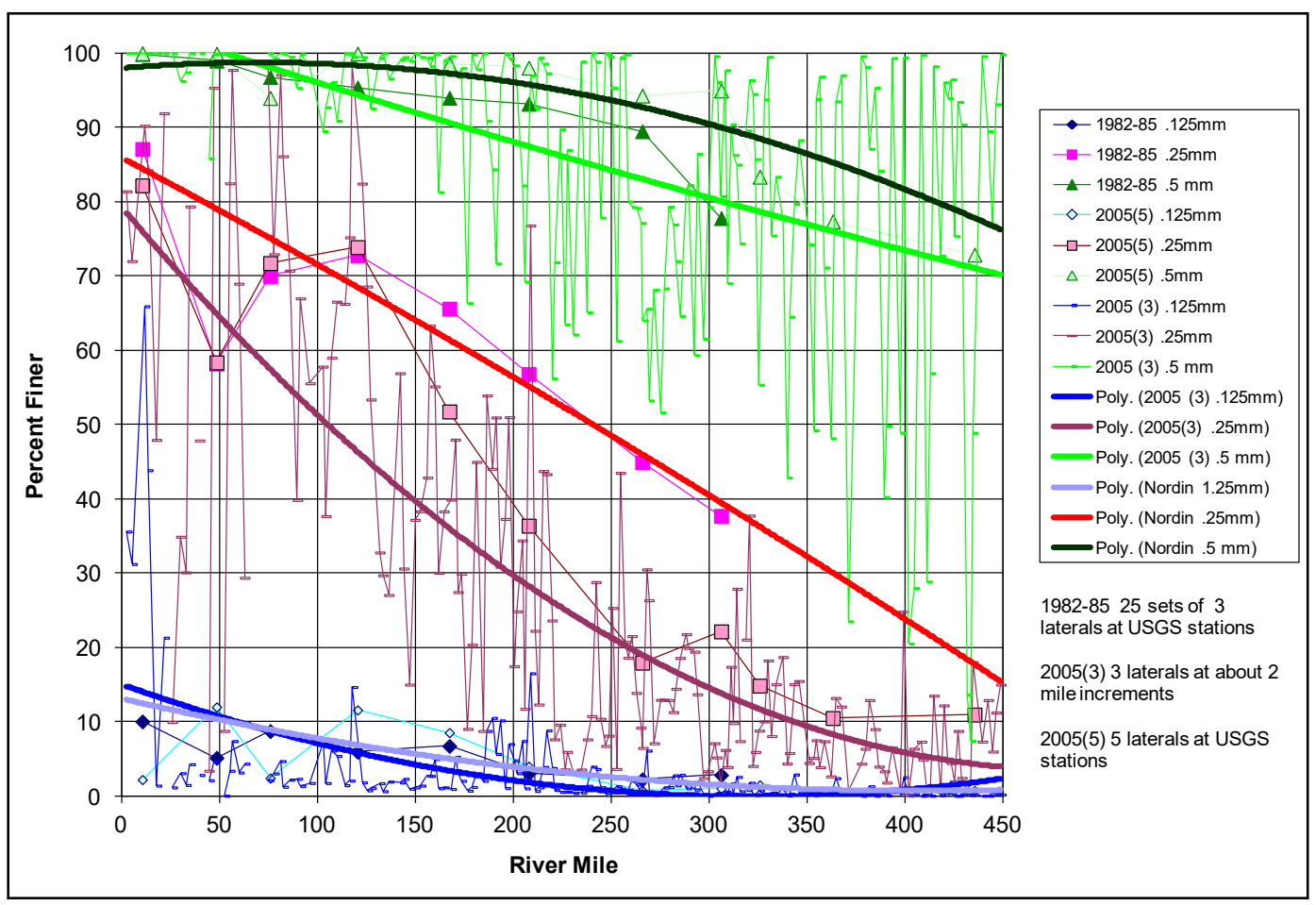

A comparison of the 1982-85 and 2005 USGS data suggests that the very fine and coarse sand percentages in the river bed between Venice and Tarbert Landing have remained approxiamtely the same. The comparison also suggests that the fine sand percentage has decreased and the medium sand percentage has increased so that the river bed is coarser. However, it must be remembered that the 1982-1985 data include approximately 25 sets of data that were collected over a 3 -year period and that the 2005 data is one set of data collected during the summer months.

The calculated active layer gradations at the end of the 12-year simulation are compared to the 1982-1985 and 2005 USGS bed gradations Figure 105. The calculated bed gradations indicate a slight coarsening of the bed over the 12-year period but not as much as suggested by comparing the 1982-1985 and 2005 USGS data. Calculations also indicate a reduction in the very fine sand component downstream from RM 250, making this lower reach of the river more consistent with upstream reaches. The 
numerical model does not include sediment contributions from bank erosion or construction activities. These sources could be responsible for additional very fine sand in the sediment inflow. Another explanation could be that the initial gradations reflect low flow conditions where the very fine sand is a remnant of receding flood flows. Note that the numerical model's active layer thickness can be quite small at lower discharges and that the gradation of underlying material can be finer. Upstream from RM 250, the calculated results show a slight increase in the medium sand percentage in the bed. It is noted that there were 20 years between the USGS data collection efforts and the HEC-6T simulation was only 12 years.

Figure 105. Calculated active layer gradation compared to 2005 USGS gradations.

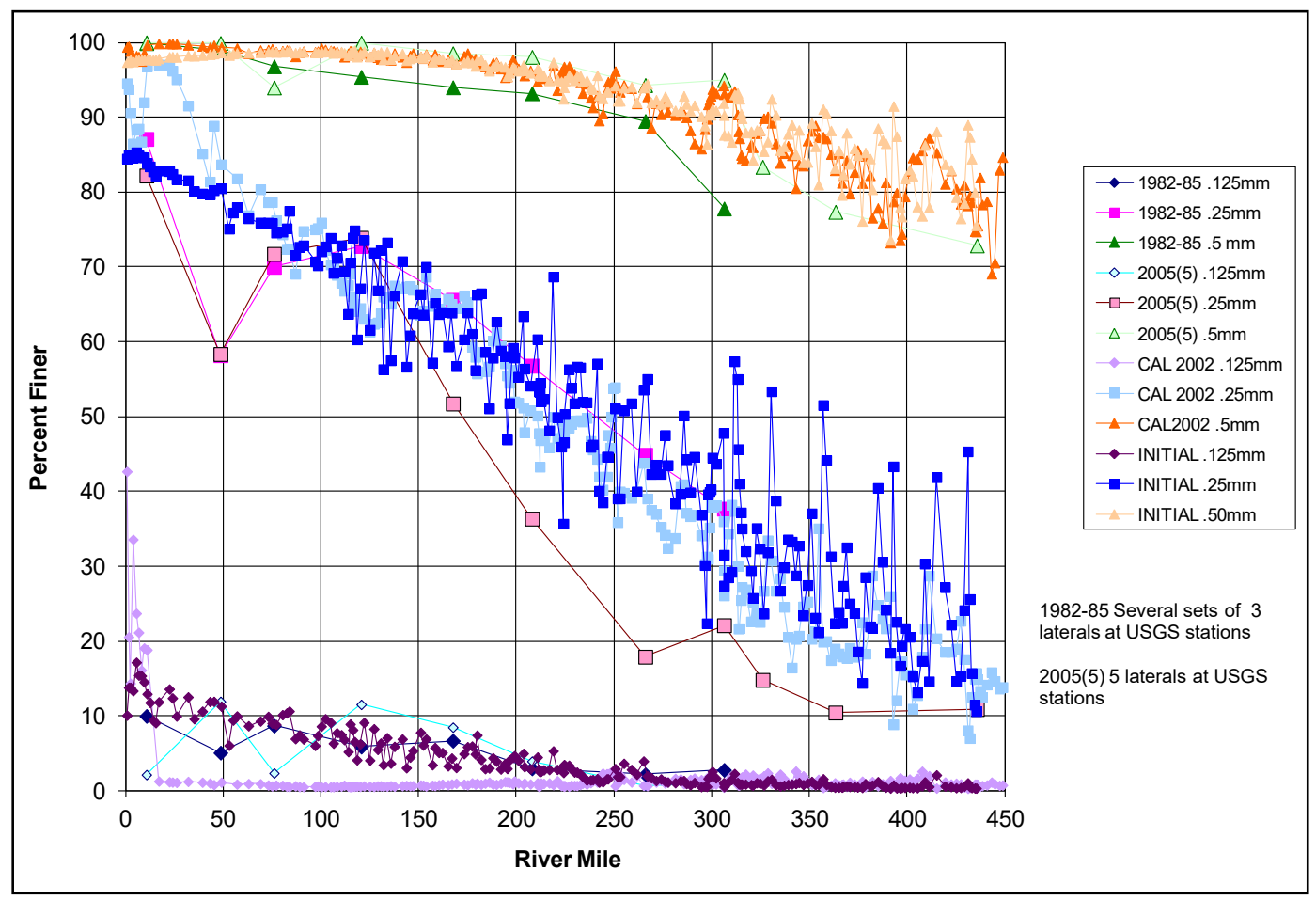

Calculated bed gradation changes between 1991 and 2002 for the entire Mississippi River reach between Head of Passes and Cairo are shown in Figure 106. The calculations do not show significant trends in the bed material gradations over the 12-year simulation. However, calculated bed gradations diffused some of the discontinuities in the initial bed gradations. The increase in the fine sand component upstream from $\mathrm{RM} 700$ is interesting in that it is not typical for a river bed to become finer in an upstream direction. Measured and calculated data appear to be consistent in this reach, so it is suggested that this trend is due to 
geomorphic discontinuities such as gravel bars or hard points. It could also be related to the differential sediment contributions from the Ohio and Middle Mississippi Rivers.

Figure 106. Calculated active layer gradation - Head of Passes to Cairo.

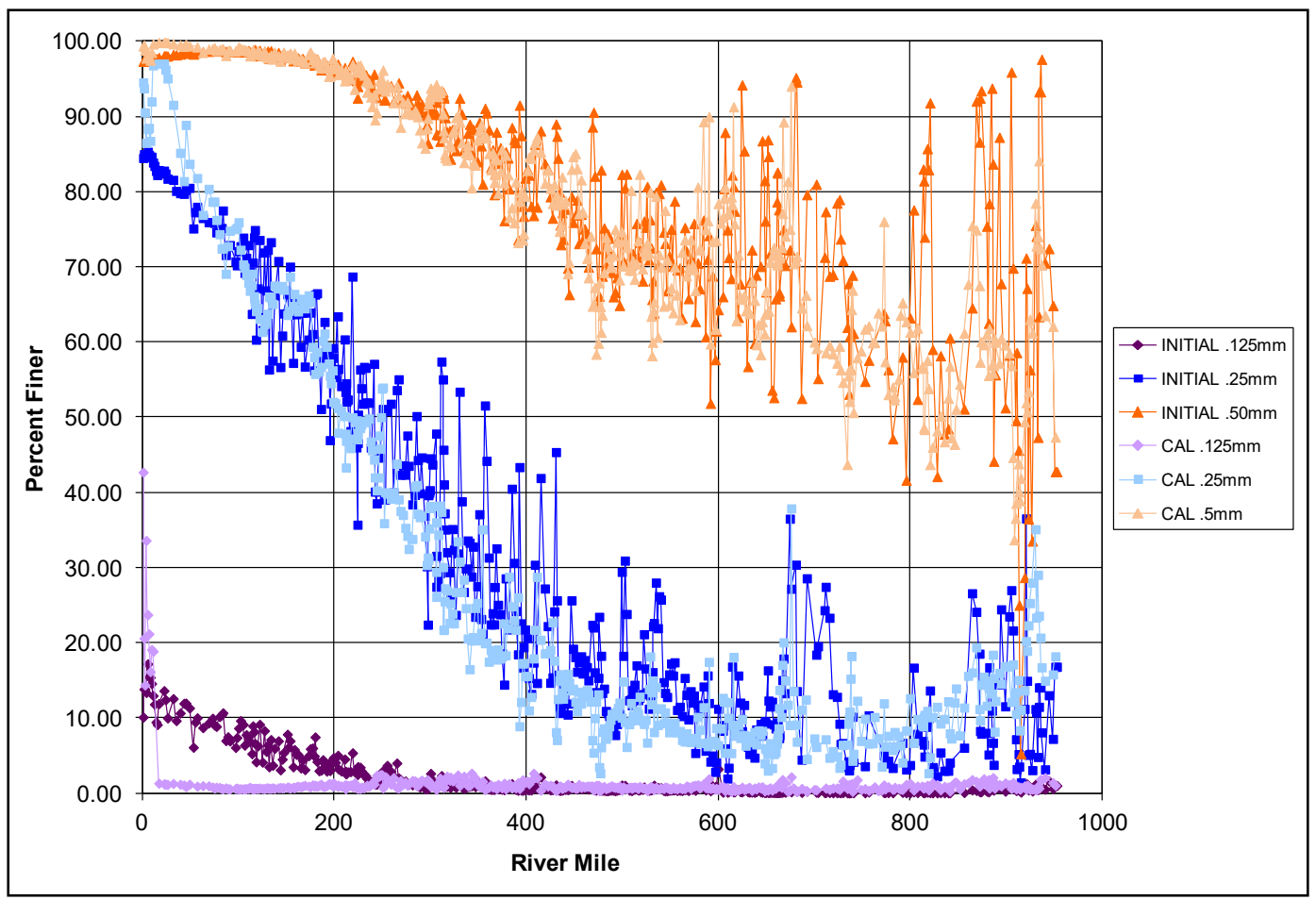

Available bed material data suggest a slight coarsening of the Mississippi River bed between RMs 100 and 400. Model results suggest a smaller coarsening trend. To increase the coarseness of calculated bed gradations, it would be necessary to significantly decrease the fine sediment contributions and increase the coarse sediment contributions at the upstream boundaries. The choice was made in this study to place more reliability on the sediment inflow measurements and to accept differences in the measured and calculated bed material changes as reasonable.

\section{Sediment concentrations at Tarbert Landing and Belle Chasse}

Calculated sediment concentrations were compared to measured sediment concentrations at two gages downstream from the Old River Control Complex. Tarbert Landing is located at RM 306.3, just downstream from the Old River Complex, and Belle Chasse is located at RM 76.o, upstream from most of the distributaries and typically upstream from the influence of salt water intrusion. Measured suspended data were available at Tarbert Landing for the entire 1991 to 2002 calibration period. Data at Belle Chasse 
were available between 1978 and 1997 and 2005 and 2007. Size class distribution data were available at Belle Chasse between 1982 and 1985 .

The calculated sediment concentrations at Tarbert Landing are compared to measured data in Figure 107. The calculated sand concentration at Tarbert Landing is consistent with the measured suspended sand load at discharges greater than $400,000 \mathrm{cfs}$. This is attributed to the greater concentration of sand in the unmeasured zone during low flow.

Approximately 100 percent of the clay and 99 percent of the silt that enters the model from the tributaries is transported to Tarbert Landing. Therefore, the comparison of calculated and measured fine load is more of a check on boundary conditions than a test of model performance.

Figure 107. Sand and fine concentrations at Tarbert Landing 1991-2002.

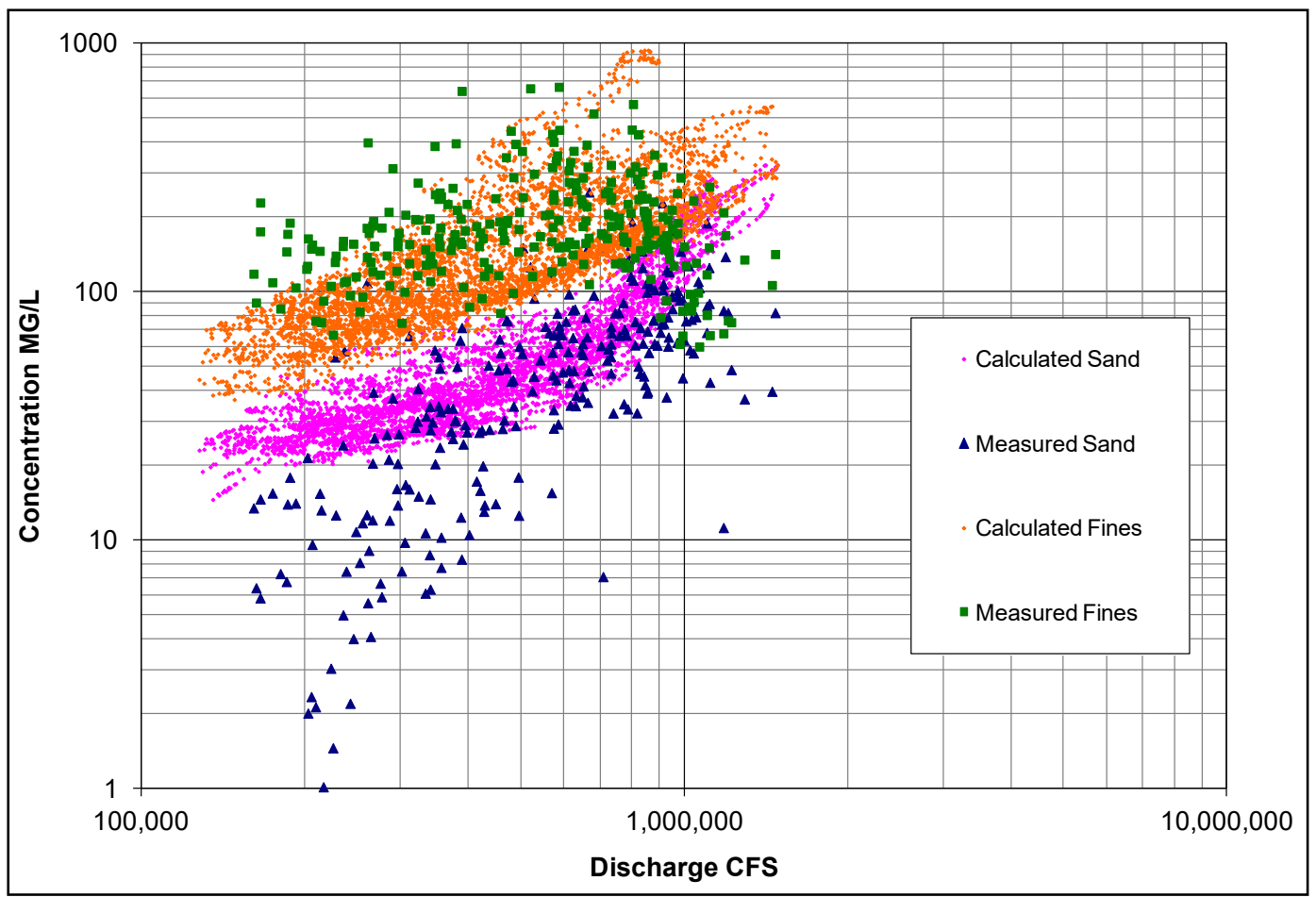

The hydrograph used to develop the calculated sediment concentrations in Figure 107 was the adjusted hydrograph discussed in the report section on hydrographs in the Numerical Model Description (MVMQ). This hydrograph was based on recorded mean daily inflows at the boundary gages. However, some of the measured tributary discharges where adjusted to achieve discharges and volumes that better matched measured data on the main-stem Mississippi River. The modified 
hydrologic data reproduced measured data within $1 \%$ at Hickman, KY, and within $3 \%$ at Helena, AR.

The hydrograph used in the 2009 interim study of the Vicksburg to Pilots Station reach was based on the reported discharges at Vicksburg. A simplified hydrograph, based on measured Vicksburg discharges (VickQ), was developed for the Regional Model by using a constant percentage of the Vicksburg discharge for each of the tributaries. The percentage was based on the percent of the total 1991-2002 volume of flow contributed by each tributary.

The calculated sediment concentrations at Tarbert Landing using the simplified hydrograph are compared to the calculated sediment concentration using the adjusted hydrograph in Figure 108. There are two significant observations made from Figure 108.

1. There is no scatter in the calculated fine concentration with the simplified hydrograph. This is because the discharge from each tributary is always the same percentage of the flow at Vicksburg (and Tarbert Landing) and there is essentially no deposition of silts and clays calculated between the boundaries and Tarbert Landing. Conversely, there is considerable scatter in the fine sediment concentrations using the adjusted hydrograph due to the irregularity in actual contribution from the tributaries - especially the Middle Mississippi and Ohio Rivers.

2. The relationship between calculated sand concentration and discharge is essentially the same with both hydrographs. This is because the sand concentration is more closely related to transport potential in the river reaches immediately upstream than to inflow boundary conditions.

These two observations are especially useful in determining which hydrograph to use for a specific study. If the primary objective is to evaluate sedimentation processes driven by sand transport, or by the longterm effects of fine sediment, then the simplified hydrograph is adequate. However, if determining the effects of fine sediment processes associated with a specific event or events is the objective, then an adjusted hydrograph would be more appropriate. 
Figure 108. Effect of model hydrographs on concentrations at Tarbert Landing.

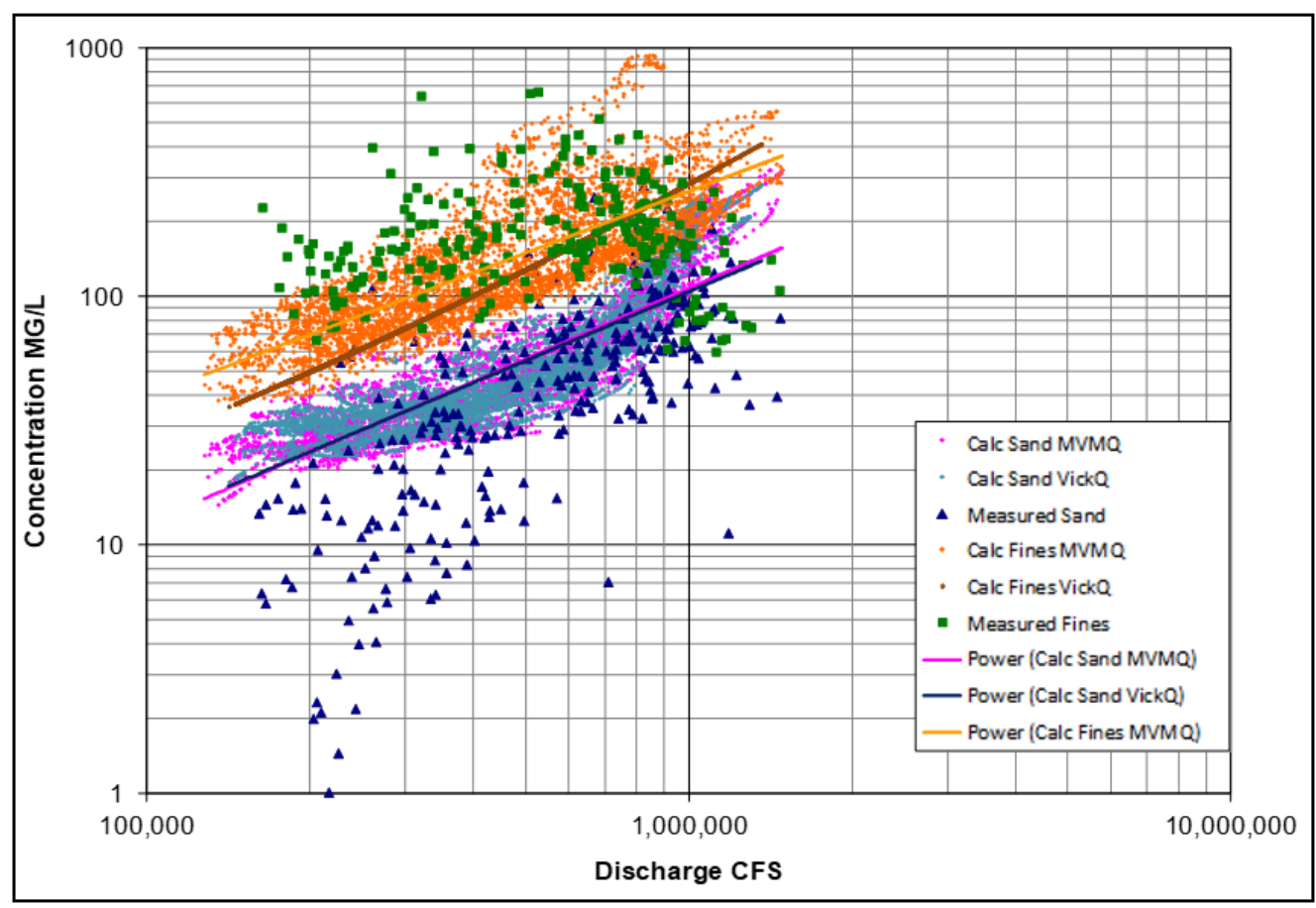

The calculated sediment concentrations at Belle Chasse are compared to measured data in Figure 109. All of the measured data (1978-1997 and 2005-2007) were used in the comparison because only 33 measurements were available from the 1991-2002 calibration period. The measured and calculated data are consistent for discharges greater than 400,000 cfs. Calculated fine sediment concentrations are higher than the measured fine concentrations at lower discharges. The measured sand concentrations at discharges below 400,000 cfs are characterized by significant scatter and are inconsistent with the calculated data. This inconsistency may be associated with the influence of salt water at low flow and/or difficulties in isokinetic sampling at low velocities.

Calculated size class percentages are compared to measured size class percentages in Table 41. The tabulated measured percentages were obtained by averaging all the available measurements - 1991-2002 at Tarbert Landing and 1982-1985 at Belle Chasse. The calculated percentages were obtained from the accumulated total transport of each size class past both gages during the 1991-2002 calibration simulation. Calculated percentages were calculated using the adjusted hydrograph (MVMQ) and the percentage of Vicksburg hydrograph (VickQ). The tabulated percentages indicate that appropriate quantities of each sediment size class are being transported through the study reach by the 
numerical model. The choice of hydrograph does not affect calculated percentages significantly.

Figure 109. Measured and calculated sediment concentrations at Belle Chasse.

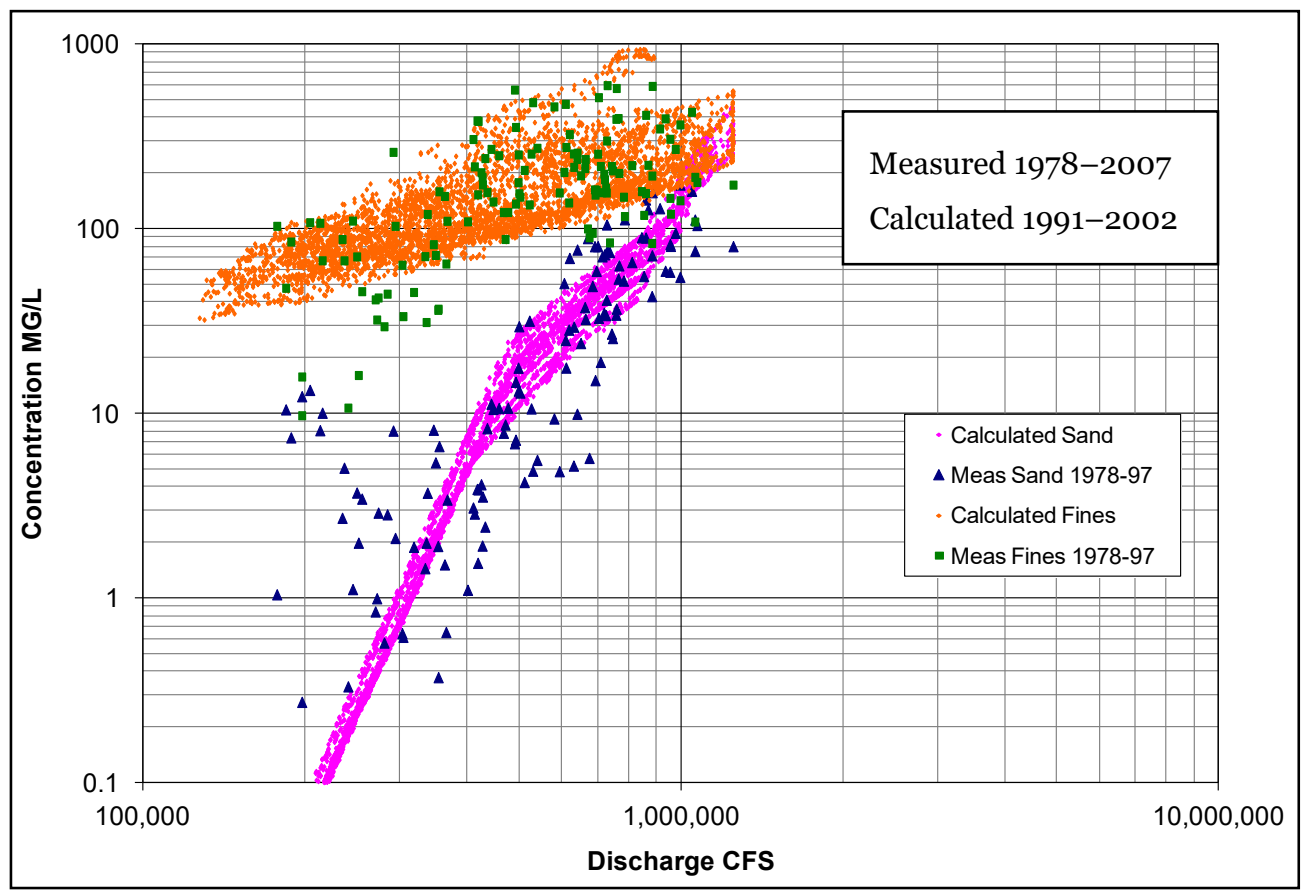

Table 41. Measured and calculated size class distributions average percentages.

\begin{tabular}{|c|c|c|c|c|c|c|}
\hline & \multicolumn{3}{|c|}{$\begin{array}{l}\text { Tarbert Landing } \\
\text { RM } 306.3\end{array}$} & \multicolumn{3}{|c|}{$\begin{array}{l}\text { Belle Chasse } \\
\text { RM } 76.0\end{array}$} \\
\hline & \multirow{2}{*}{$\begin{array}{l}\text { Measured } \\
\text { Suspended } \\
\text { Load } \\
\text { 1991-2002 }\end{array}$} & \multicolumn{2}{|c|}{$\begin{array}{l}\text { Calculated Total Load } \\
\text { 1991-2002 }\end{array}$} & \multirow{2}{*}{$\begin{array}{c}\text { Measured } \\
\text { Suspended } \\
\text { Load } \\
\text { 1982-1985 }\end{array}$} & \multicolumn{2}{|c|}{$\begin{array}{c}\text { Calculated Total Load } \\
\text { 1991-2002 }\end{array}$} \\
\hline & & MVMQ & VickQ & & MVMQ & VickQ \\
\hline Clay & 30 & 38 & 37 & 44 & 41 & 41 \\
\hline Very fine silt & 11 & 7 & 7 & 7 & 8 & 8 \\
\hline Fine silt & 9 & 8 & 7 & 9 & 8 & 8 \\
\hline Medium silt & 14 & 9 & 9 & 11 & 10 & 10 \\
\hline Coarse silt & 17 & 9 & 8 & 8 & 9 & 9 \\
\hline Very fine sand & 6 & 2 & 2 & 12 & 6 & 7 \\
\hline Fine sand & 11 & 22 & 24 & 7 & 17 & 16 \\
\hline Medium sand & 2 & 5 & 5 & 1 & 1 & 1 \\
\hline Coarse sand & 0 & 0 & 0 & 1 & 0 & 0 \\
\hline
\end{tabular}

MVMQ is adjusted hydrograph based on tributary gages.

VickQ is hydrograph based on constant percentage of Vicksburg discharge. 
Calculated sediment concentrations at Union Point were compared to measured sediment concentrations at Union Point and Coochie in Figure 110. Union Point is located at RM 326.6, which is upstream from the Old River Control Complex. Coochie, also located above the Old River Control Complex, is at RM 317.3. Sediment data were collected at Union Point between 1993 and 2002 and at Coochie between 1991 and 1996. The most interesting observation from Figure 110 is the decline in calculated sediment concentration at discharges greater than $1,200,000 \mathrm{cfs}$. Measured data are insufficient to confirm this trend. Calculations at RM 326.6 show increasing velocity, effective depth, and effective width with discharge. However, the slope decreases with discharge at this station as shown in Figure 111. The consequence of decreasing slope is decreasing sediment concentration in the calculations. Figure 111 shows that the decreasing slope with discharge trend is not typical. However, this result points to the importance of reach analysis rather than focusing on results from a single cross section.

Figure 110. Measured and calculated sediment concentrations at Union Point and Coochie.

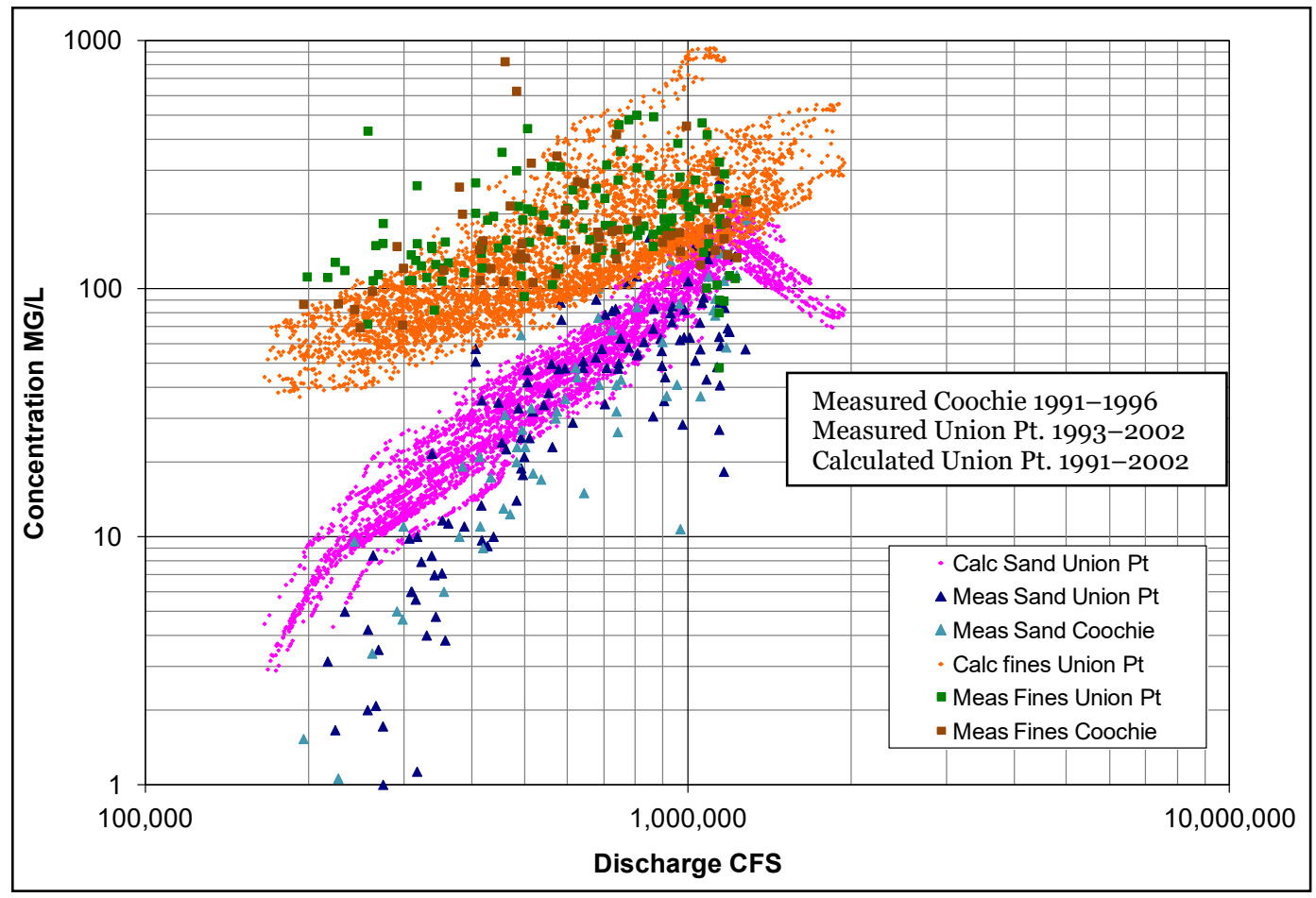


Figure 111. Calculated energy slope between Tarbert Landing and Natchez.

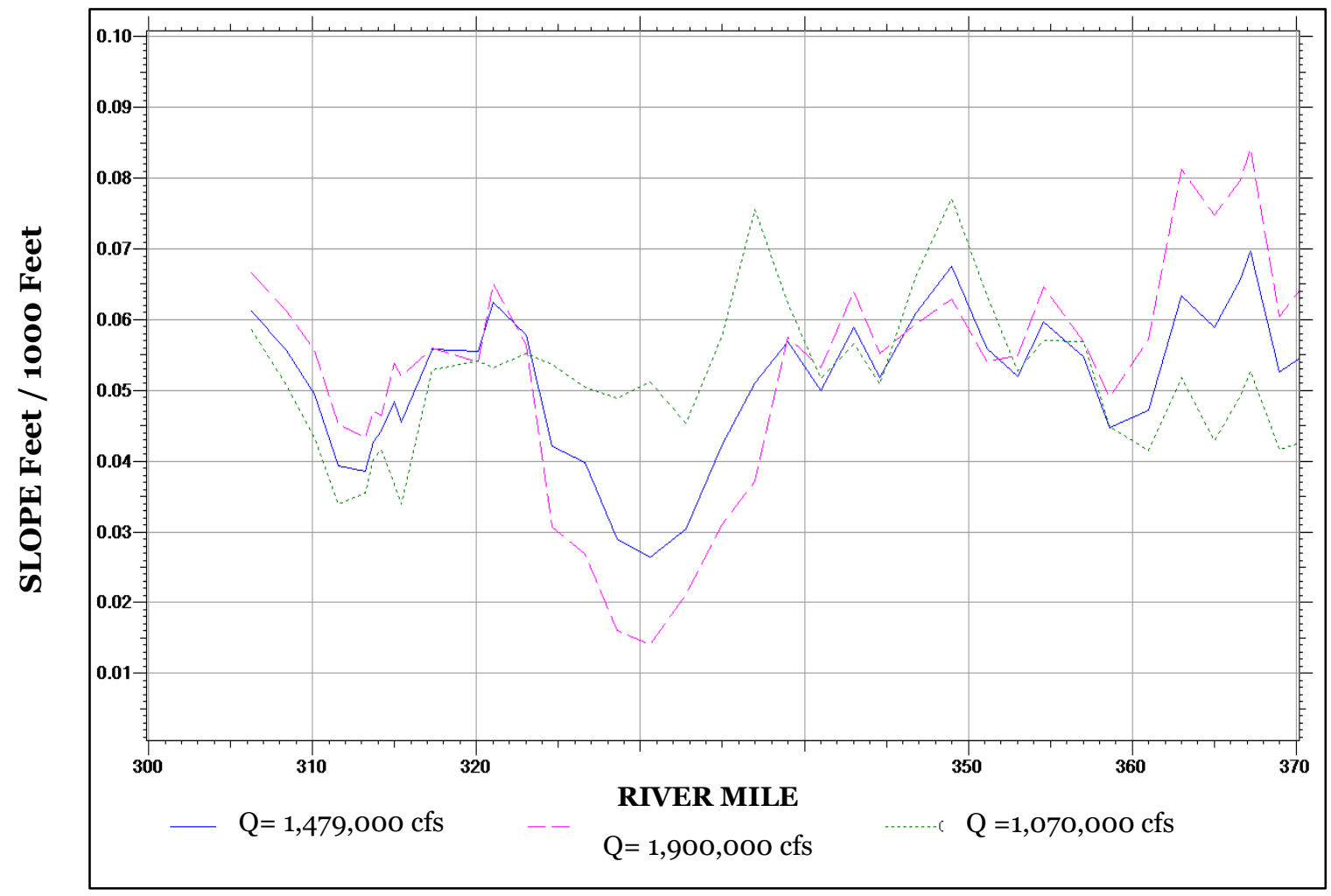

Sediment concentrations at Vicksburg

The reported 1992-2004 measured fine concentrations at Vicksburg and Natchez (RM 363.3) were found to be an order of magnitude less than the reported fine concentrations between 1984 and1989 at the same gages. This inconsistency, accompanied by a significant increase in 1992-2004 measured sand concentrations, leads one to suspect a laboratory error in determining the sand-silt break point. Comparative fine sediment concentrations between 1984 and 2002 at Vicksburg are shown in Figure 112. The Vicksburg and Natchez fine sediment concentrations between 1992 and 2004 were also inconsistent with downstream measurements for the same period at Tarbert Landing (RM 306.3) as shown in Figure 113. When the measured sand data are plotted as in Figure 114, it is more difficult, but not impossible, to detect the error. According to reported sediment data at Vicksburg, between 1984 and 1989, 24 percent of the measured sediment load was sand, but between 1992 and 2004, 75 percent of the measured sediment load was sand. For this reason only, the 19841989 data at Vicksburg were used to compare calculated and measured sediment load in Figure 115. 
Figure 112. Measured fine sediment concentrations at Vicksburg (1984-2004).

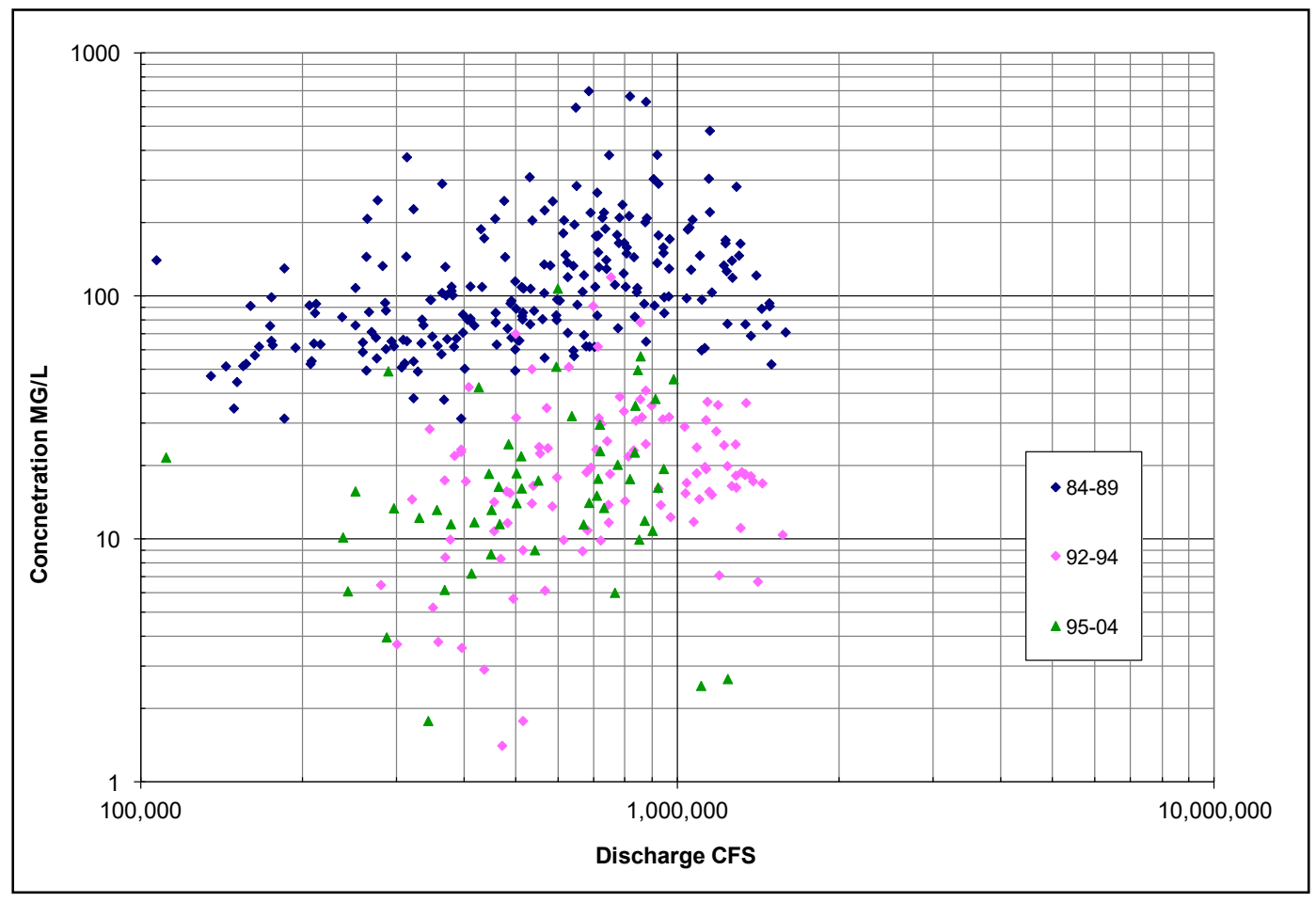

Figure 113. Measured fine sediment concentrations at Tarbert Landing (1984-2004).

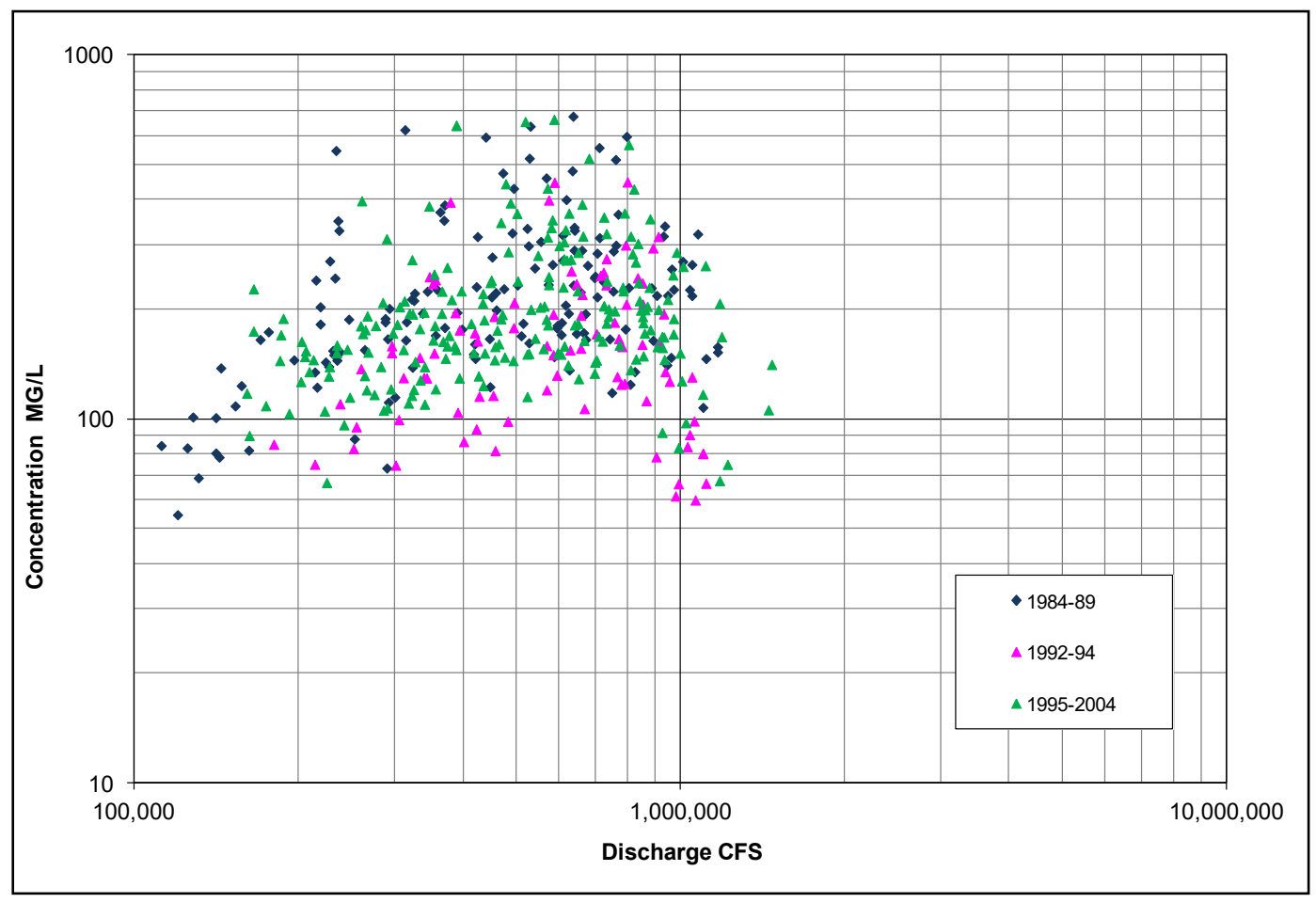


Figure 114. Measured sand concentrations at Vicksburg (1984-2004).

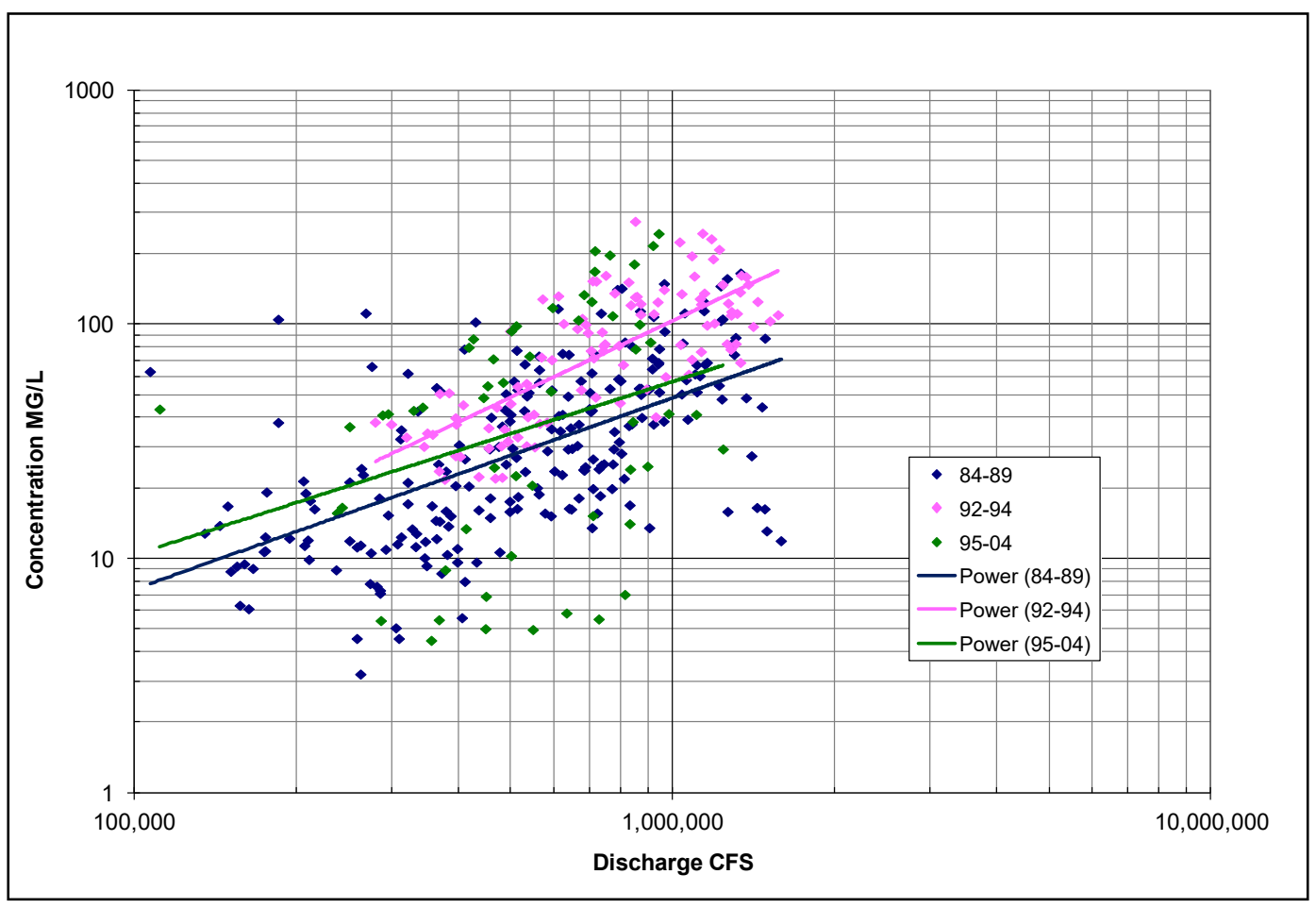

Figure 115. Measured and calculated sediment concentrations at Vicksburg.

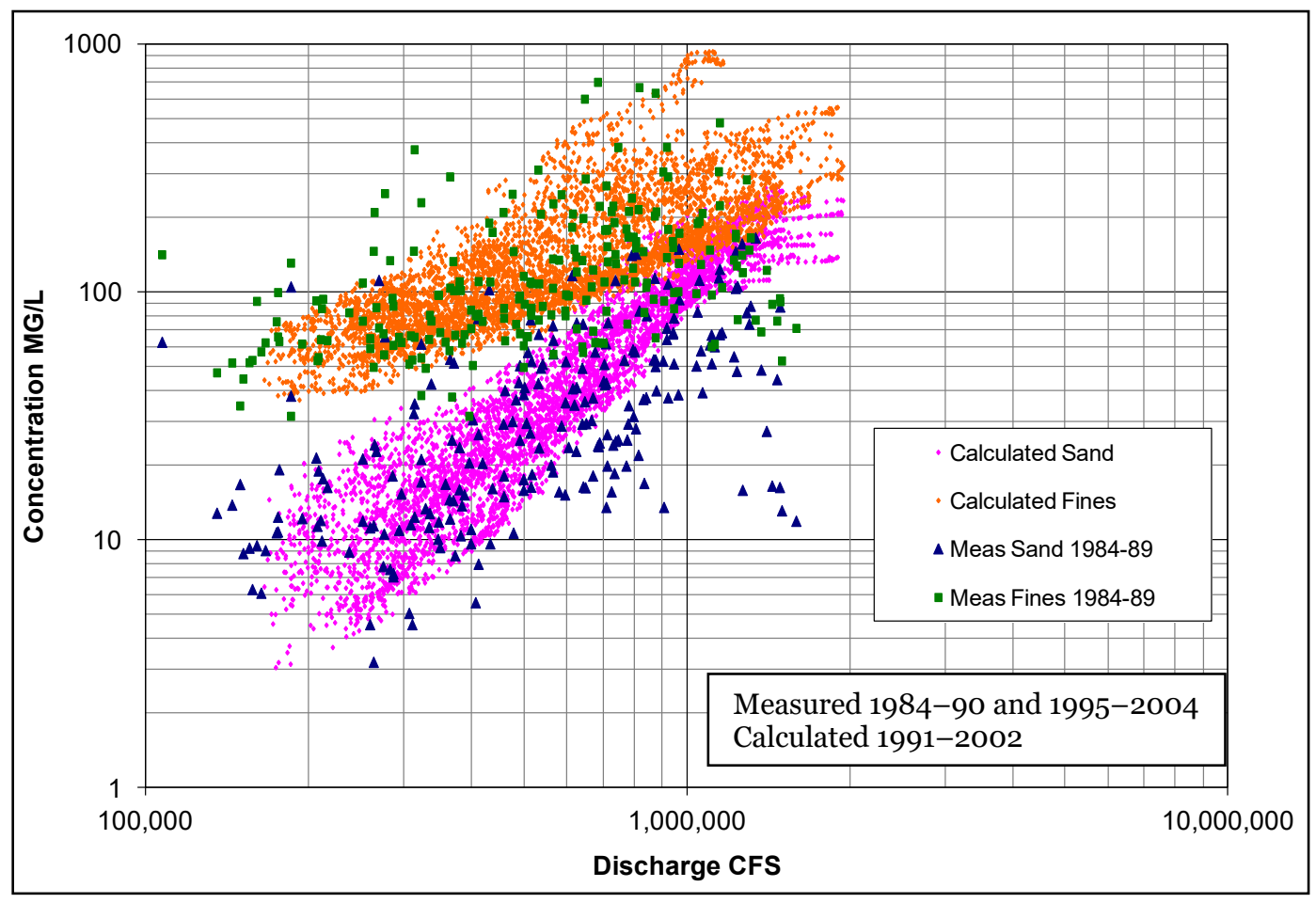


Sediment concentrations at Memphis

Calculated sediment concentrations were compared to measured sediment concentrations at the Memphis gage (USGS gage number 07032000), which is located at RM 734.4. Measured suspended data were collected by the USGS between 1974 and 1991. There were no available sediment data for the 1991-2002 calibration period. Calculated daily sediment concentrations of both the sands and fines at RM 734.4 are shown in Figure 116. There is good agreement in calculated and measured fine concentration, but the measured sand concentrations are considerably less than the calculated sand concentrations. The measured sand concentrations at Memphis are also considerably less than the measured sand concentrations at Vicksburg (Figure 115).

Figure 116. Measured and calculated sediment concentrations at Memphis.

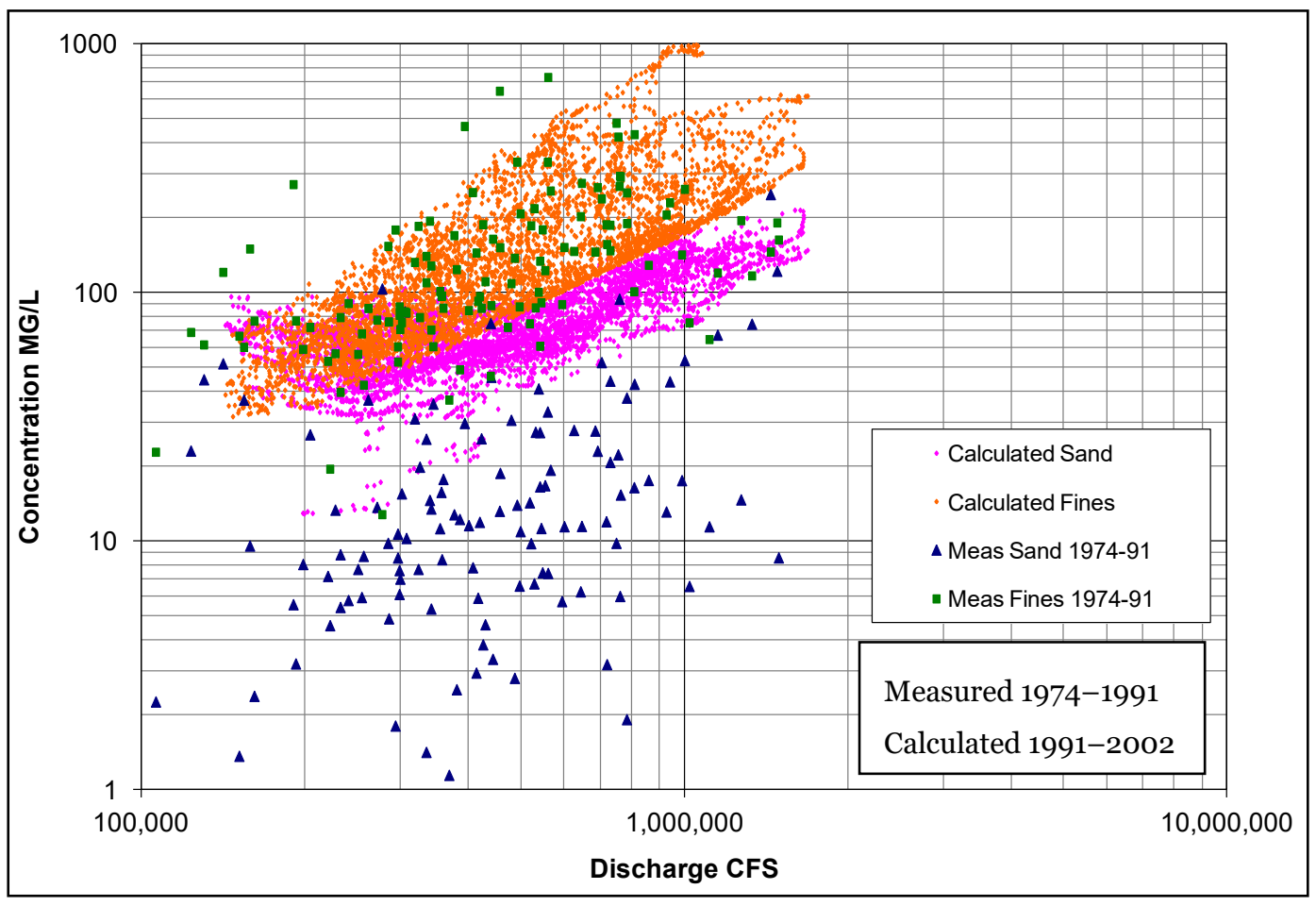

It is uncertain if the differences in measured and calculated sand concentrations are due to measurement errors or to problems with the numerical simulation. It is certain, however, that the reported sediment measurements represent an attempt to define sediment conditions at a single point on the river and do not require satisfaction of sediment continuity with upstream or downstream reaches. The numerical model, however, is governed by physical properties and requires that sediment continuity throughout the study reach be maintained. Sediment continuity 
is maintained by bed aggradation/degradation and sediment transport. The discrepancy in measured sand concentration at Memphis and Vicksburg highlights the need for coordinated sediment sampling programs for the entire Mississippi River reach. There should be consistency in collection methods and equipment. There should also be consistency in laboratory methodologies when the samples are analyzed. There is a need to compare sediment data collected at the various gages to ensure consistency and reasonableness in the reported data.

Comparison of calculated sand yields

Sand yields at Tarbert Landing, Union Point, and Belle Chasse were calculated using regression equations developed from measured data and results from the HEC-6T simulation. Both calculations are subject to uncertainty. The sand yield calculated using the regression curve analysis should not be considered to be the true or measured sand yield. However, it is useful to compare sand yields calculated using the measured data with that calculated using the numerical model. Calculated sand yields using both methods are listed in Table 42.

Table 42. 12-year calculated sand yield between 1991 and 2002.

\begin{tabular}{|c|c|c|c|}
\hline \multirow{2}{*}{} & \multirow{2}{*}{} & \multicolumn{2}{|c|}{ HEC-6T } \\
\cline { 3 - 4 } & Regression Analysis & MVM Hydrograph & $\begin{array}{c}\text { Vicksburg } \\
\text { Hydrograph }\end{array}$ \\
\hline & million tons & million tons & million tons \\
\hline Belle Chasse & 430 & 376 & 321 \\
\hline Tarbert Landing & 438 & 504 & 469 \\
\hline Union Point & 601 & 621 & 586 \\
\hline Vicksburg & 405 & 685 & 641 \\
\hline
\end{tabular}

Sand yield was calculated for each day between 1 October 1990 and 30 September 2002 using published mean daily discharges and an unbiased power regression curve developed from measured sand data at each gage (http://www.mvn.usace.army.mil/eng/edhd/wcontrol/discharge.asp).

At Belle Chasse, a sand power regression curve was developed from 35 measurements collected between October 1990 and June 1997. Data collection at Belle Chasse was discontinued after June 1997 and did not resume until 2005. The unbiased power regression curve for sand concentration is the following: 


$$
C=1.004 E-21 Q^{3.866}
$$

where:

$$
\begin{aligned}
& C=\text { concentration } \mathrm{mg} / \mathrm{l} \\
& Q=\text { discharge } \mathrm{cfs} .
\end{aligned}
$$

The discharges at Belle Chasse were assumed to be the same as the mean daily discharges at Tarbert Landing unless the Tarbert Landing discharge was greater than 1,250,000 cfs. To account for flows over the Bonnet Carré Spillway, the maximum discharge at Belle Chasse was set at 1,250,000 cfs. The maximum discharge for which data were collected at Belle Chasse was $1,060,000 \mathrm{cfs}$. The calculated concentration at this discharge was taken to be the maximum concentration for the sediment yield calculations (i.e., there was no extrapolation of the regression curve beyond the range of measured data).

The regression curves at Tarbert Landing were developed from 243 measurements taken between 1991 and 2002. Separate regression curves were developed for discharges greater than and less than 600,000 cfs. The maximum discharge for which data were collected at Tarbert Landing was 1,470,000 cfs. The maximum daily discharge recorded between 1991 and 2002 was $1,480,000 \mathrm{cfs}$, so there was no need to cap the regression curve at the highest discharges. The unbiased regression curves for sand concentration are the following:

For $Q<600,000$

$$
C=5.736 E-10 Q^{1.931}
$$

For $Q>600,000$

$$
C=1.694 Q^{0.2862}
$$

The regression curves at Union Point were developed from 223 measurements taken between 1991 to 1996 at Coochie and between 1993 to 2002 at Union Point. Discharge at Union Point was taken to be the sum of published discharges at Tarbert Landing and the Old River Outflow Channel. Separate regression curves were developed for discharges greater than and less than $600,000 \mathrm{cfs}$. The maximum discharge for which data 
were collected at Coochie/Union Point was 1,300,000 cfs. The calculated concentration at this discharge was taken to be the maximum concentration for the sediment yield calculations (i.e., there was no extrapolation of the regression curve beyond the range of measured data). The unbiased regression curves for sand concentration are the following:

For $\mathrm{Q}<600,000$

$$
C=3.306 E-19 Q^{3.515}
$$

For $\mathrm{Q}>600,000$

$$
C=2.962 E-5 Q^{1.078}
$$

The regression curves at Vicksburg were developed from 223 measurements taken between 1984 and 1989. Discharge measurements were available at Vicksburg for each day when sediment data were collected. The maximum discharge for which data were collected at Vicksburg was 1,590,000 cfs. The calculated concentration at this discharge was taken to be the maximum concentration for the sediment yield calculations (i.e., there was no extrapolation of the regression curve beyond the range of measured data). The unbiased regression curve for sand concentration is the following:

$$
C=7.8681 E-4 Q^{0.8167}
$$

HEC-6T sand yields were calculated using the MVM hydrograph and the Vicksburg hydrograph. The MVM hydrograph was based on actual gage data from the tributaries adjusted to match measured data at the Memphis District Mississippi River gages. The Vicksburg hydrograph was based on measured data at Vicksburg, with tributary inflows assigned a constant percentage of the Vicksburg discharge based on average annual runoff volumes. It is expected that the Vicksburg hydrograph would produce better results downstream from Vicksburg because the Vicksburg hydrograph better represents the actual hydrograph in this part of the Mississippi River. Unfortunately, measured sediment data are lacking to compare sediment yield in the Memphis District reaches. 
Adjustment to dredging volumes

The interim New Orleans District numerical model was calibrated to match reported dredging volumes in Southwest Pass and AHP between 1991 and 2002. Sediment inflow for the interim model was developed from measured sediment concentration data at Union Point and Tarbert Landing. The reported dredging volumes were taken from New Orleans District dredging logs. The logs provide approximate locations of daily dredging activities. Annual dredging volumes for Southwest Pass between Pilots Station (RM -18) and Head of Passes (RM o) and for the Mississippi River between Head of Passes and RM 7 were determined from the dredging logs. Estimated volumes of agitation dredging are not included in the reported volumes. Estimated volumes from operations where the dredged material was side cast out of the navigation channel onto a river bar are not included in the reported volumes. Annual reported dredging volumes in Southwest Pass and in the Mississippi River AHP are listed in Table 43.

Table 43. Reported and calculated* dredging 1991-2002.

\begin{tabular}{|c|c|c|c|c|c|c|}
\hline & \multicolumn{6}{|c|}{$\begin{array}{l}\text { Annual Dredging } \\
\text { (million cubic yards) }\end{array}$} \\
\hline & \multicolumn{3}{|c|}{ Southwest Pass RM -18 to 0} & \multicolumn{3}{|c|}{ AHP RM 0 to 7} \\
\hline & \multicolumn{2}{|c|}{ Calculated } & \multirow[b]{2}{*}{ Reported } & \multicolumn{2}{|c|}{ Calculated } & \multirow[b]{2}{*}{ Reported } \\
\hline & Interim Model & Final Model & & Interim Model & Final Model & \\
\hline 1991 & 13.19 & 13.71 & 3.33 & 4.66 & 4.99 & 8.47 \\
\hline 1992 & 3.66 & 4.84 & 8.23 & 0.91 & 1.21 & 1.31 \\
\hline 1993 & 14.60 & 10.26 & 9.95 & 5.11 & 2.53 & 8.04 \\
\hline 1994 & 13.15 & 11.66 & 7.68 & 9.30 & 5.13 & 6.97 \\
\hline 1995 & 6.23 & 5.57 & 9.15 & 3.78 & 4.10 & 6.38 \\
\hline 1996 & 6.51 & 6.17 & 8.09 & 7.78 & 4.07 & 4.32 \\
\hline 1997 & 8.06 & 7.28 & 10.24 & 8.41 & 6.68 & 6.42 \\
\hline 1998 & 4.85 & 6.22 & 7.50 & 4.68 & 2.18 & 6.01 \\
\hline 1999 & 6.10 & 6.27 & 8.55 & 2.63 & 2.04 & 0.97 \\
\hline 2000 & 4.66 & 3.41 & 2.32 & 0.59 & 1.25 & 0.60 \\
\hline 2001 & 3.81 & 4.55 & 6.82 & 1.76 & 1.76 & 2.58 \\
\hline 2002 & 5.45 & 6.54 & 8.37 & 8.22 & 6.44 & 5.43 \\
\hline Total & 90.28 & 86.46 & 90.24 & 57.82 & 42.38 & 57.51 \\
\hline
\end{tabular}

* Note: Annual calculated values include an equal distribution of the initial dredging that represents the difference between the 1992 and 2002 dredging templates. 
Typically, the input parameters with the greatest uncertainty are chosen as calibration parameters in the numerical model. The primary calibration parameters for adjusting the model to reported dredging volumes are the fine sediment deposition coefficients. These coefficients affect the deposition of the silts and clays but do not affect sand deposition. Varying these coefficients was deemed reasonable to account for the effects of salinity on sediment deposition. Dredging volumes are also sensitive to the sediment diversion coefficients and the quantity of flow in the distributaries. Sediment diversion coefficients can also be used as calibration parameters. However, in this study a systematic procedure was developed to assign the sediment diversion coefficients and, lacking measured data, the systematic procedure was used to assign the coefficients. Distributary flows in the numerical model are based on measured data when available. In cases where data are not available, such as for flood flows, adjustments to the flow distribution percentages were made during the calibration phase of the study.

Simulated dredging in the model was set arbitrarily and does not represent an historical operation. To evaluate operation alternatives, specific dredging times and rates would need to be entered into the model. In the Regional Model dredging was performed at the beginning of June and December each year at a dredging rate of 100,000 cubic yards per day.

The movable bed widths in the dredging reaches were set to be consistent with the dredging template in the navigation channel. This assignment in the numerical model allows for all deposited sediment to be subject to dredging. However, it does not allow for natural aggradation on bars outside the navigation channel.

The dredging template for the calibration phase of the study was developed from the 2002 hydrographic survey. The survey indicated that the navigation channel had been dredged well below the 1992 elevations at several locations. The consequence of assigning the 2002 channel as the dredging template is that a significant quantity of calculated dredging occurs during the initial dredging operation. In Southwest Pass, the initial dredging was 25.1 million cubic yards. In the Mississippi River AHP, the initial dredging was 0.3 million cubic yards. Rather than assign this 1992 and 2002 channel volume difference to a single year, the calculated initial dredging volumes were distributed equally among each of the 12 annual calculated volumes. Annual calculated dredging is shown in Table 43. 
Silt and clay deposition coefficients were adjusted in the numerical model to obtain a reasonable comparison between the total 12-year calculated and reported dredging volumes. A comparison of reported and calculated accumulated dredging volumes for the New Orleans District interim model is shown in Figure 117. Table 43 shows that the 12-year calculated dredging for the interim model is within 0.1 percent of the reported dredging in Southwest Pass and within 0.5 percent of the reported dredging AHP. Annual calculated and reported dredging volumes do not match as well as the overall volumes. This is to be expected because actual dredging operations are constrained by budgets, availability of dredges, weather, and other factors.

Figure 117. Accumulated dredging in Southwest Pass, and from Head of Passes to RM 7.

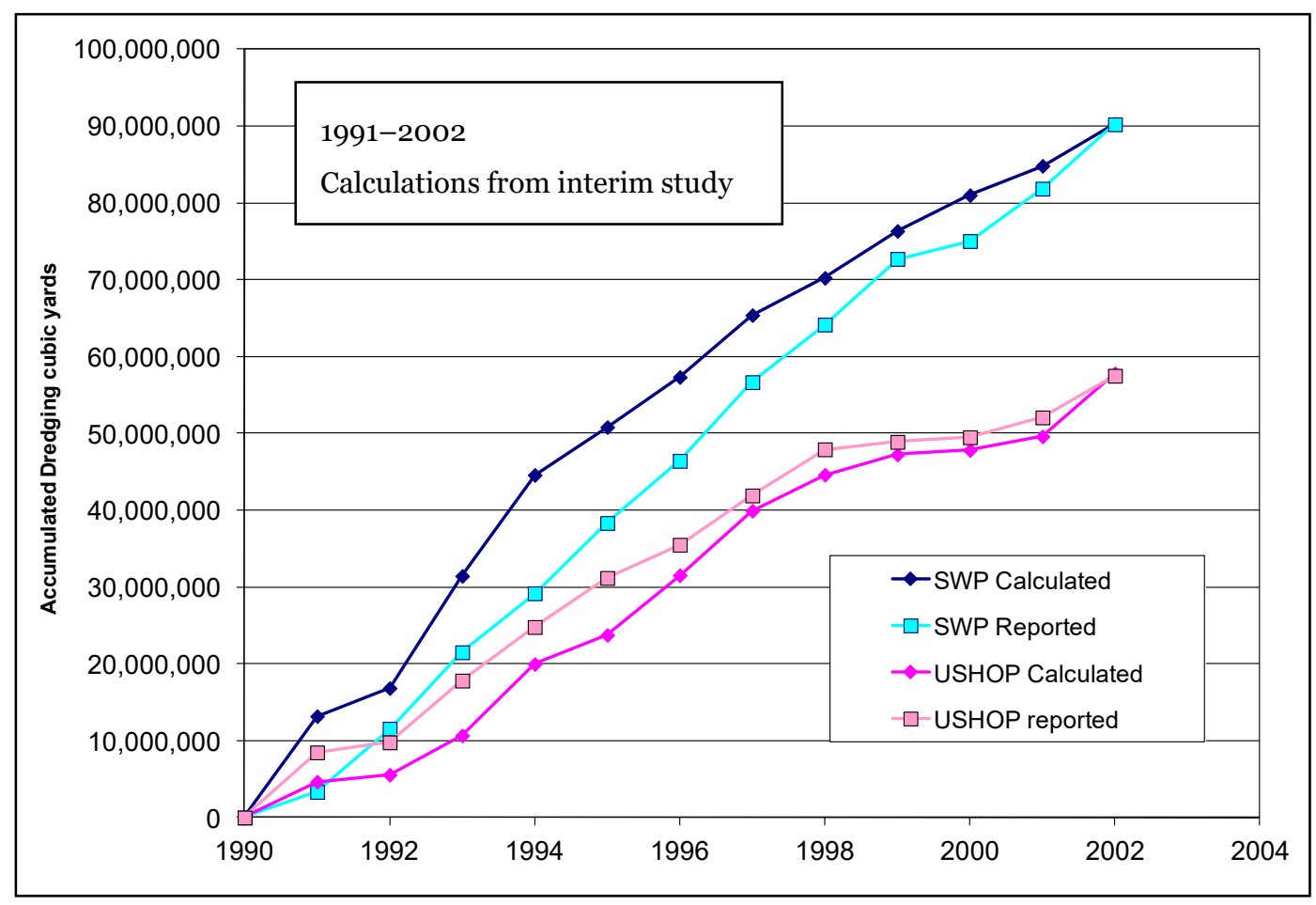

Calculated dredging AHP and in Southwest Pass did not match the reported data as well in the Regional Model. The difference is attributed to differences in the measured fine sediment data used to develop sediment inflow to the two models. The measured data indicates that fine sediment concentrations at Union Point and Tarbert Landing, which were used to develop sediment inflow for the interim New Orleans District model, are significantly greater at the lower discharges than reported at the upstream gages that were used to develop fine sediment inflow for the Regional Model. The consequence of this difference is that calculated dredging 
volumes are approximately $87 \%$ of reported volumes in the Regional Model. Table 43 shows that the 12-year calculated dredging is approximately 96 percent of the reported dredging in Southwest Pass and approximately 74 percent of the reported dredging AHP. Significant improvement in dredging volumes could not be achieved with additional adjustment of the cohesive sediment deposition coefficients. It was decided to use the cohesive deposition coefficients from the interim model.

Options for improving the dredging simulation in the Regional Model include decreasing the fine sediment concentrations in the diversions AHP and in Southwest Pass and/or arbitrarily increasing fine sediment inflow at the upstream boundary or along the reach between Vicksburg and Union Point. One could justify the latter by attributing the increase to bank erosion. However, these modifications are not systematic and are left to future modelers addressing specific issues and objectives in future studies.

The calibrated numerical model is reliable for assessing the relative effect of upstream projects, such as channel constriction works or flow diversions, on dredging in Southwest Pass and AHP. Careful attention to sediment inflow assignment is required in order to assess calculated dredging magnitudes. Recalibration of the model may be required to assess project changes within the calibration reach itself or if the project to be evaluated requires modifying numerical model assignments, such as movable bed width, essential to the calibration.

\section{Verification}

\section{Deposition downstream from Old River}

The numerical model was verified by simulating a deposition trend in the Mississippi River downstream from the Old River Control Complex. Measured deposition in the Mississippi River between RMs 310.1 and 315.4 was obtained from the 1992 and 2002 hydrographic surveys. The numerical model geometry came from the 1992 hydrographic survey, and the 11-year time period between the hydrographic surveys was simulated in the model to determine calculated deposition. Deposition trends can be identified by comparing surveys taken in 1999 and 2008, which are shown in Figure 118 and Figure 119.

The hydrograph simulated the 4,039 days between the 1992 and 2002 hydrographic surveys. The cross sections of interest were surveyed on 
2 November 1991 and on 20 November 2002. The comparison of measured and calculated deposition in the reach between RMs 310.1 and 315.4 is shown in Table 44. Calculated deposition in the reach was 26,461,00o cubic yards. Measured deposition was 29,360,000 cubic yards. The calculated deposition is 90 percent of the measured deposition. The comparison between calculated results and measured results are not as consistent when compared at individual cross sections. Calculated deposition was less than measured deposition at all cross sections except 315.4 and 311.6. Cross section 315.4 is located downstream from the Hydropower Structure, and Cross section 311.6 is located downstream from the Auxiliary Structure.

These results suggest that the numerical model is very successful in predicting deposition on a reach scale. If detailed information at a specific site is required then more detail in the vicinity of the site of interest needs to be added to the model geometry. 
Figure 118. 1999 Hydrographic survey at Old River Control Complex.

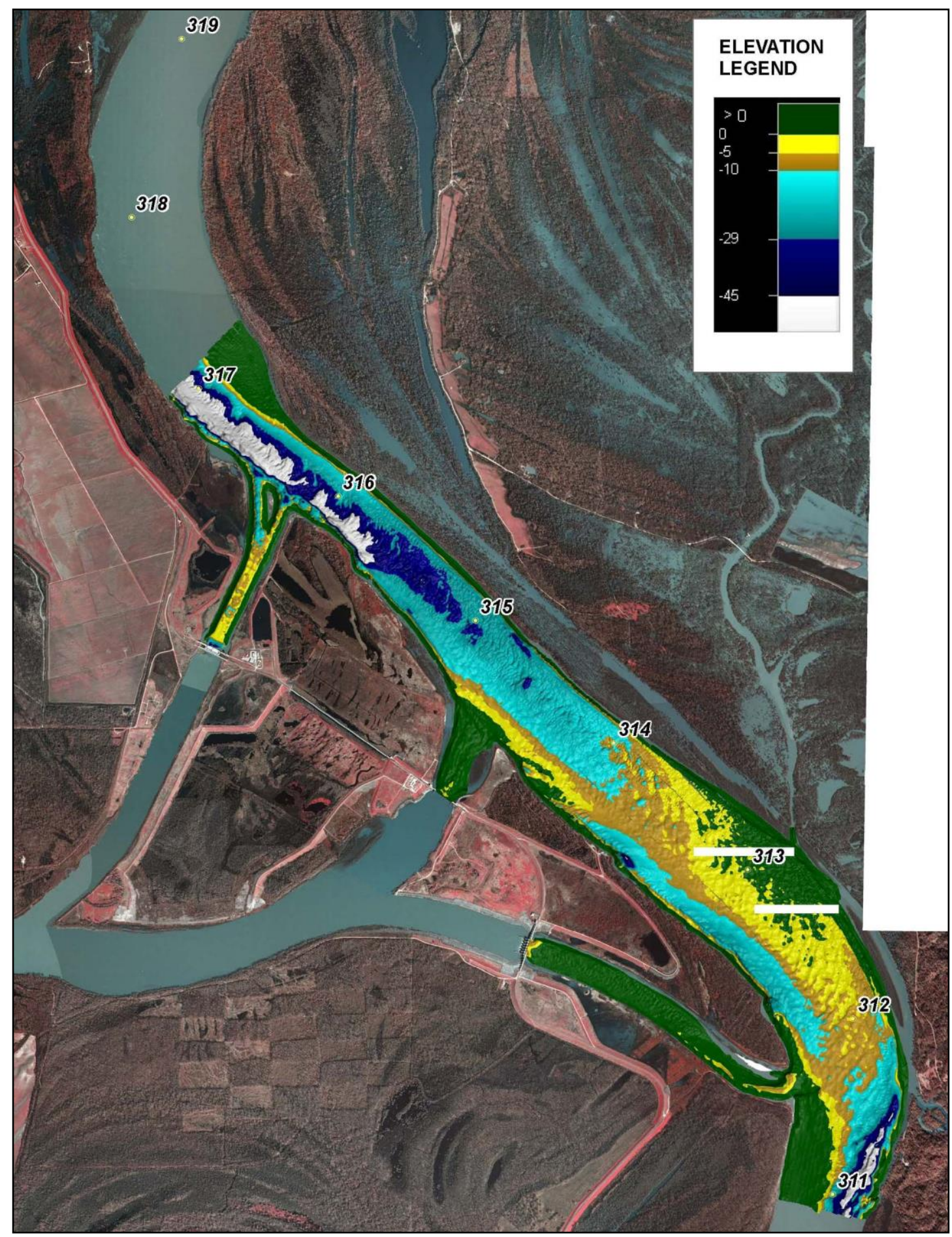


Figure 119. 2008 Hydrographic survey at Old River Control Complex.

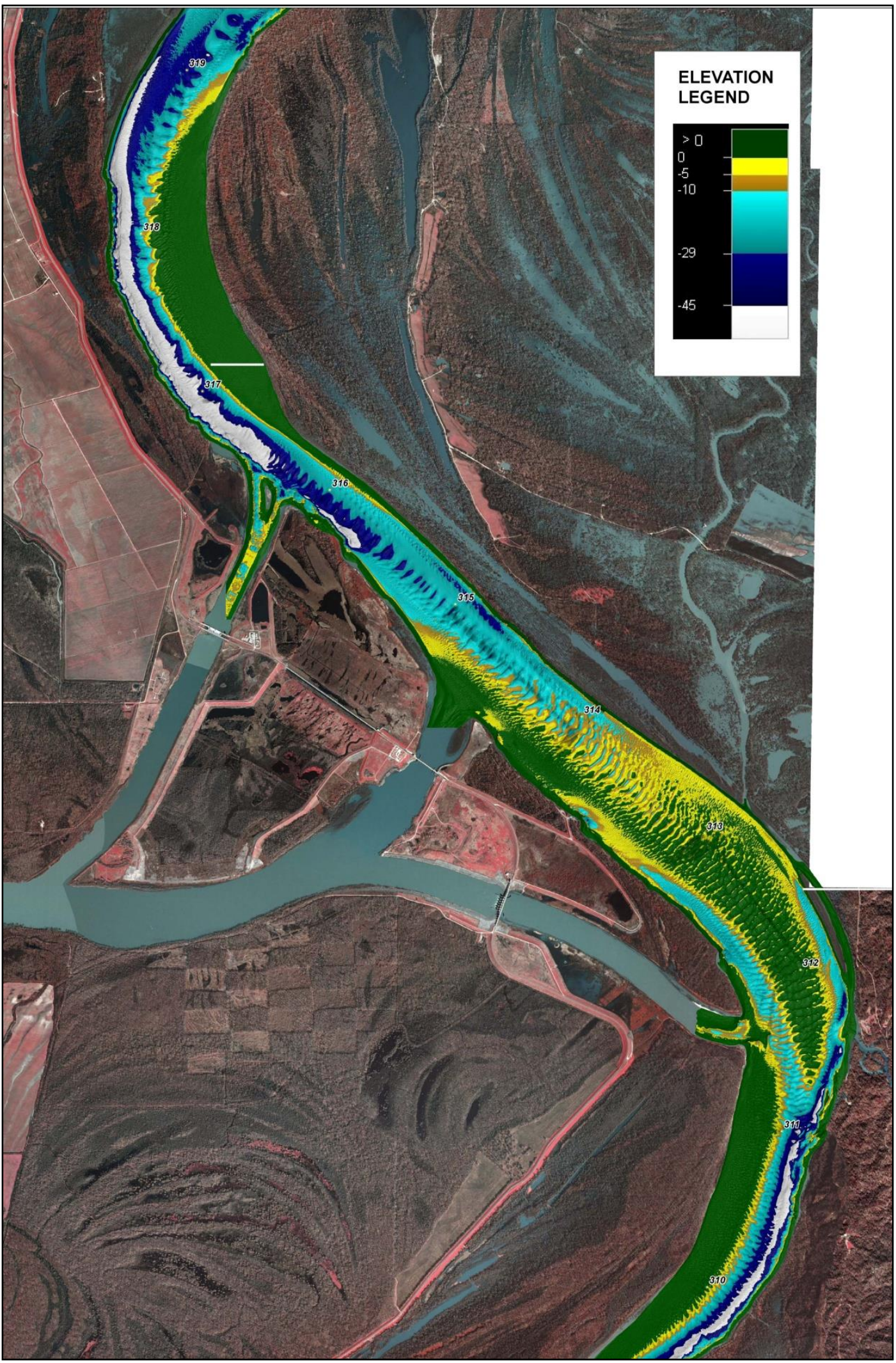


Table 44. Bed and area changes downstream from Old River Control Complex, 1991-2002.

\begin{tabular}{|c|c|c|c|}
\hline $\begin{array}{c}\text { Cross Section } \\
\text { RM }\end{array}$ & $\begin{array}{c}\text { Calculated Bed } \\
\text { Change, } \mathrm{ft}\end{array}$ & $\begin{array}{c}\text { Calculated Deposition } \\
\text { cubic yards }\end{array}$ & $\begin{array}{c}\text { Measured Deposition } \\
\text { cubic yards }\end{array}$ \\
\hline 315.4 & 7.85 & $4,956,000$ & $1,525,000$ \\
\hline 315.0 & 7.25 & $2,356,000$ & $3,954,000$ \\
\hline 314.2 & 4.88 & $1,851,000$ & $2,930,000$ \\
\hline 313.7 & 4.85 & $1,695,000$ & $2,231,000$ \\
\hline 313.2 & 3.38 & $2,996,000$ & $4,841,000$ \\
\hline 311.6 & 11.67 & $12,584,000$ & $10,132,000$ \\
\hline 310.1 & 0.07 & 3,000 & $3,747,000$ \\
\hline Total & & $26,461,000$ & $29,360,000$ \\
\hline
\end{tabular}

The sensitivity of the numerical model results to several input parameters was evaluated using the measured deposition downstream from the Old River Control Complex. This sensitivity assessment was conducted chronologically before the calibration evaluation reported on above. At the time of the sensitivity assessment, roughness coefficients in the numerical model had been set using 1991 stage rating curves. Roughness coefficients in the final numerical model were set using an average of the 1991-2002 stage rating curves. The sensitivity assessment was conducted using a 14-year hydrograph between October 1988 and November 2002. Fines had not been added to the model at the time the sensitivity assessment was conducted.

The effect of the sediment inflow rating curve on deposition downstream from the Old River Control Complex was evaluated. The sediment inflow rating curves for all the sand and gravel size classes at the upstream model boundary at Vicksburg was increased by a factor of 1.3. After a 14-year simulation, there was an insignificant change in deposition downstream from the Old River Control Complex as shown in Table 45. However, in this test, there was significant deposition downstream from the upstream boundary, which suggests that the inflow was too high. It was concluded that sediment inflow was not the primary factor influencing the increased deposition downstream from the Old River Control Complex.

A test was made to see if changes in bed roughness due to wash-out of dunes would affect sediment deposition in the reach downstream from the Old River Control Complex. This effect is accounted for somewhat in the numerical model by varying bed roughness with discharge and calibrating 
water-surface elevations to stages at gages. However, this approach ignores the loop effect as it assumes a unique roughness-discharge relationship. By using the Brownlie equations in HEC-6T, the bed roughness is calculated at each time-step as a function of the hydraulic conditions for that time-step. The Brownlie equations determine if dunes are present and account for increased roughness due to dunes. When the Brownlie equations were specified for the HEC-6T simulation for the falling limb of the 2002 hydrograph, there was an insignificant difference in calculated deposition downstream from Old River as shown in Table 46.

A test was made to see if manually increasing the roughness on the falling limb of the 2002 hydrograph would significantly increase the deposition downstream from the Old River Control Complex. Roughness was increased between RMs 267 and 306.3 only on the falling limb of the 2002 hydrograph. The increased roughness coefficients were determined by iteratively matching the falling limb of the stage-discharge rating curve at Red River Landing at RM 302.1. The revised roughness coefficients are shown in Table 46. Changes in bed elevation at the end of the 14-year simulation were insignificant as shown in Table 45. One reason is that the increased water surface elevations extend upstream and reduce sediment transport into the Old River Control Complex reach.

The effect of increasing the roughness downstream from the Old River Control Complex for the entire 14-year simulation was evaluated. Roughness coefficients were increased to match the average 1989-2002 stage data at Red River Landing. The roughness coefficients were higher for the long-term regression equations than for the 1991 rating curve used in the initial runs. Basically, this resulted in an insignificant increase in deposition during the 14-year simulation as shown in Table 45.

The effect of the sediment diversion ratios at the Hydropower Structure was evaluated by reducing the sand diversion concentrations by 50 percent. No diversion of very-coarse sand or larger grain sizes was allowed. This change resulted in a slight increase in deposition during the 14-year simulation as shown in Table 45.

The effect of the sediment diversion ratios at the Low Sill and Auxiliary Structures was evaluated by reducing the sand diversion concentrations by 50 percent. No diversion of very-coarse sand or larger grain sizes was allowed. This test was conducted to test the effect of reduced diversion of 
coarse material that may occur due to shifting bar locations in the vicinity of the Old River diversion structures. This change resulted in a slight increase in deposition similar to that calculated when the sand diversion concentrations at the Hydropower Structure were reduced by 50 percent. Calculated results are shown in Table 45.

The sensitivity assessment demonstrates that numerical model results related to reach aggradation in this reach of the Mississippi River are not significantly affected by sediment inflow, bed roughness, or even sediment diversion concentrations at the Hydropower Structure if these input parameters are within a reasonable range.

Table 45. Effects of sediment inflow and roughness on bed change.

\begin{tabular}{|c|c|c|c|c|c|c|c|}
\hline $\begin{array}{l}\text { HEC-6T } \\
\text { Section }\end{array}$ & $\begin{array}{l}\text { Base } \\
\text { Test }\end{array}$ & $\begin{array}{l}\text { Increase } \\
\text { Sediment } \\
\text { Inflow } x \\
1.3\end{array}$ & $\begin{array}{c}\text { Brownlie } \\
\text { Equations } \\
\text { on } 2002 \\
\text { Falling } \\
\text { Limb }\end{array}$ & $\begin{array}{l}\text { Increase } \\
\text { Roughness } \\
\text { on } 2002 \\
\text { Falling } \\
\text { Limb }\end{array}$ & $\begin{array}{c}\text { Increase } \\
\text { Roughness } \\
\text { for Entire } \\
\text { Simulation }\end{array}$ & $\begin{array}{l}\text { Reduce Hydropower } \\
\text { Diversion Ratio } 50 \%\end{array}$ & $\begin{array}{c}\text { Reduce Low } \\
\text { Sill and } \\
\text { Auxiliary } \\
\text { Diversion } \\
\text { Ratio 50\% }\end{array}$ \\
\hline 437.28 & -.02 & 2.65 & & & & & \\
\hline 436.0 & 2.53 & 6.40 & & & & & \\
\hline 435.37 & 4.82 & 10.09 & & & & & \\
\hline 434.60 & 1.98 & 7.52 & & & & & \\
\hline 433.00 & .82 & 3.60 & & & & & \\
\hline 326.6 & -1.65 & -1.20 & -2.26 & -2.19 & -1.37 & -1.69 & -1.65 \\
\hline 324.6 & 2.60 & 3.25 & 1.87 & 2.90 & 2.91 & 2.63 & 2.66 \\
\hline 323.0 & 0.36 & 0.77 & -1.85 & 0.53 & 0.64 & 0.38 & 0.43 \\
\hline 321.0 & -2.83 & -2.30 & -2.36 & -3.27 & -2.68 & -2.91 & -2.83 \\
\hline 320.1 & 2.76 & 3.25 & 5.15 & 2.39 & 2.88 & 2.71 & 2.77 \\
\hline 317.3 & -2.11 & -1.73 & -2.03 & -1.99 & -1.94 & -2.22 & -2.09 \\
\hline 315.4 & 11.13 & 11.58 & 10.92 & 10.53 & 11.20 & 11.28 & 11.10 \\
\hline 315 & 9.86 & 10.32 & 11.92 & 9.87 & 10.02 & 9.95 & 9.86 \\
\hline 314.2 & 6.42 & 6.75 & 6.51 & 6.72 & 6.47 & 6.53 & 6.64 \\
\hline 313.7 & 6.40 & 6.70 & 6.39 & 6.58 & 6.91 & 6.51 & 6.57 \\
\hline 313.2 & 5.47 & 5.85 & 5.08 & 5.46 & 5.47 & 5.59 & 5.60 \\
\hline 311.6 & 15.04 & 15.46 & 17.36 & 15.27 & 15.19 & 15.14 & 15.38 \\
\hline 310.1 & 4.98 & 4.99 & 5.93 & 4.54 & 4.65 & 4.60 & 4.84 \\
\hline 308.4 & 3.35 & 3.82 & 2.83 & 3.29 & 3.42 & 3.49 & 3.73 \\
\hline 306.3 & -0.89 & -0.58 & -2.81 & -0.86 & -0.83 & -0.87 & -0.69 \\
\hline
\end{tabular}


Table 46. Roughness coefficients, falling limb of 2002 hydrograph, RM 267-306.3.

\begin{tabular}{|c|c|c|c|}
\hline Discharge, cfs & 1991 Average, $\boldsymbol{n}$ & Falling Limb, $\boldsymbol{n}$ & 1992-2002 Average, $\boldsymbol{n}$ \\
\hline 250,000 & 0.029 & 0.030 & 0.030 \\
\hline 650,000 & 0.024 & 0.034 & 0.027 \\
\hline 850,000 & 0.022 & 0.033 & 0.025 \\
\hline $1,000,000$ & 0.021 & 0.026 & 0.023 \\
\hline $1,500,000$ & 0.020 & 0.025 & 0.020 \\
\hline
\end{tabular}

\section{Degradation at Smithland Crossing}

Channel constriction works were constructed in the Mississippi River at Smithland Crossing between September 1990 and June 1996. The constriction works are located between RMs 297.45 and 300.3 in the HEC6T model. A navigation map of Smithland Crossing prior to construction of the constriction works is shown in Figure 120. Note that the navigation channel is on the right side of the river and that an island separates the navigation channel from what is labeled Raccourci Cutoff, which is the new navigation channel.

Figure 120. Navigation map of Smithland Crossing before construction of contraction works.

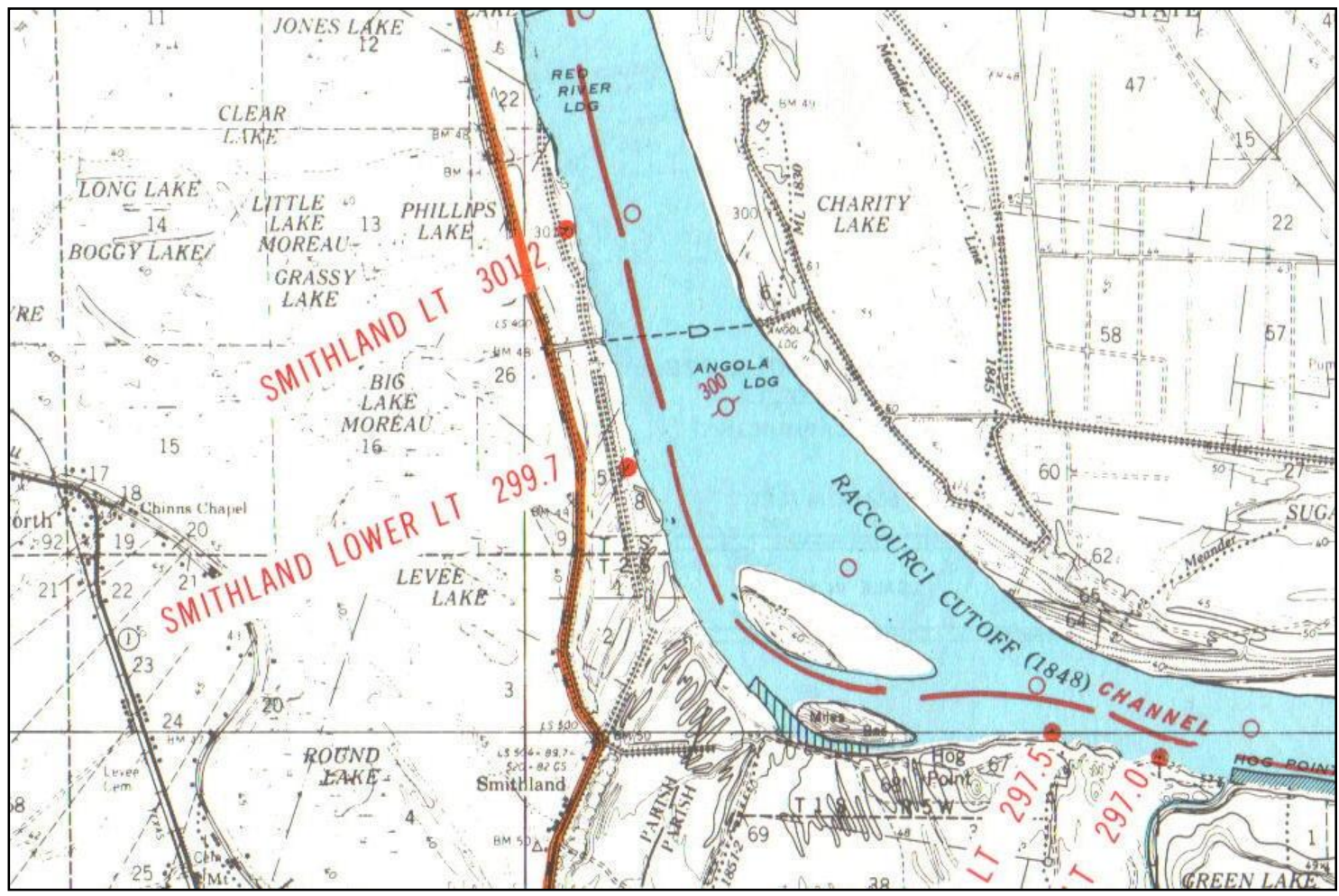


The construction sequence at Smithland Crossing started in September 1990 with a trench-fill revetment through the middle of the island. The trench-fill revetment was finished in July 1992. This revetment is the new right bank of the navigation channel. The constriction dikes were constructed on the left bank of the river between August 1991 and December 1991. The 1991-1992 hydrographic survey through this reach was surveyed between 26 November and 6 December 1991. A 1998 navigation map of Smithland Crossing is shown in Figure 121. A postconstruction photograph of Smithland Crossing looking upstream is shown in Figure 122. Note that in Figure 122, the navigation is still occurring in the old channel and that the trench fill revetment has not yet been reached. Sedimentation has begun in the dike field.

Figure 121. Navigation map of Smithland Crossing after construction.

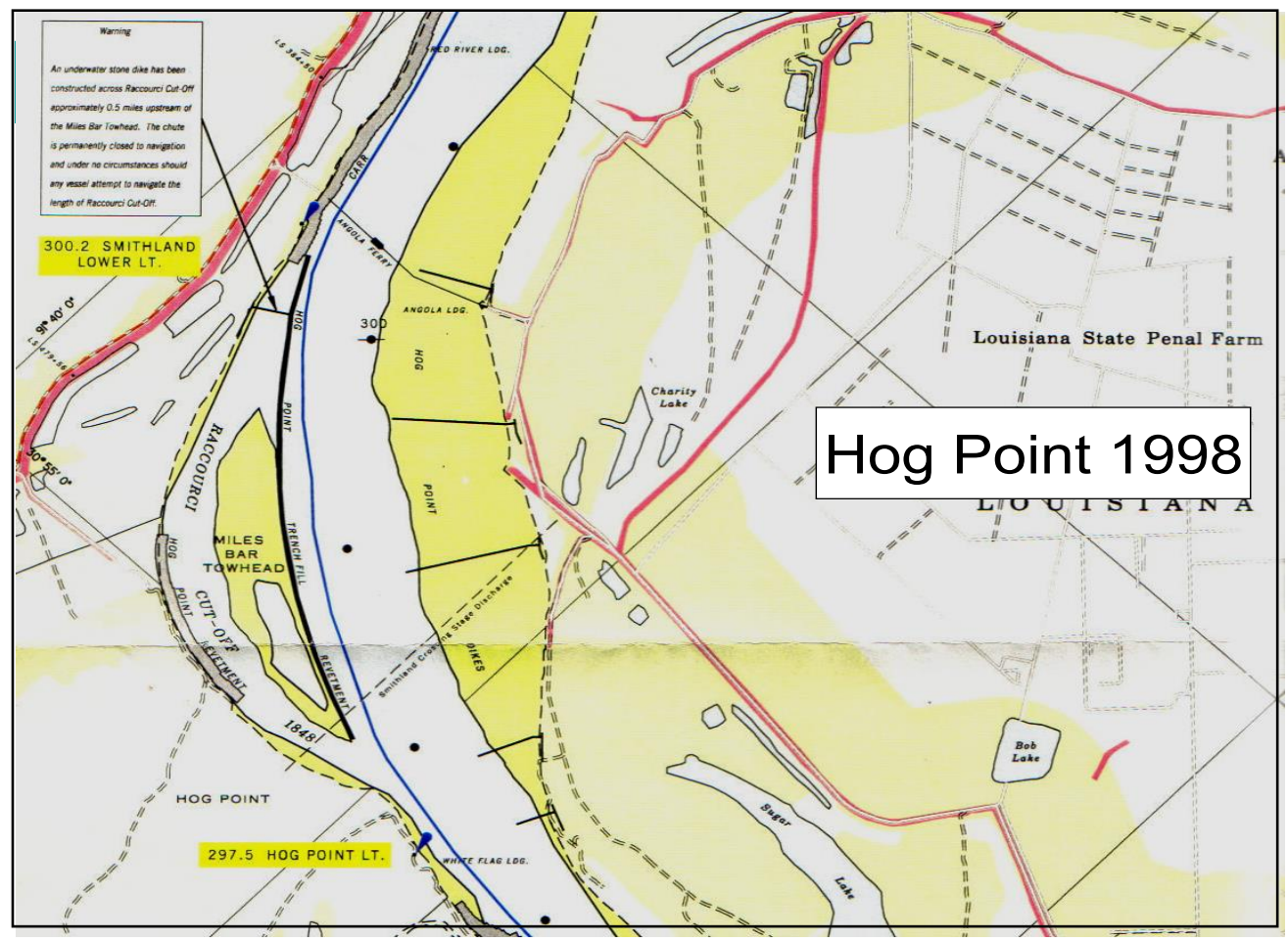


Figure 122. Looking upstream at Smithland Crossing after construction of dikes. The chute closure structure has not been completed, the river has not eroded to the trench fill revetment, and sediment has begun to deposit in the dike field.

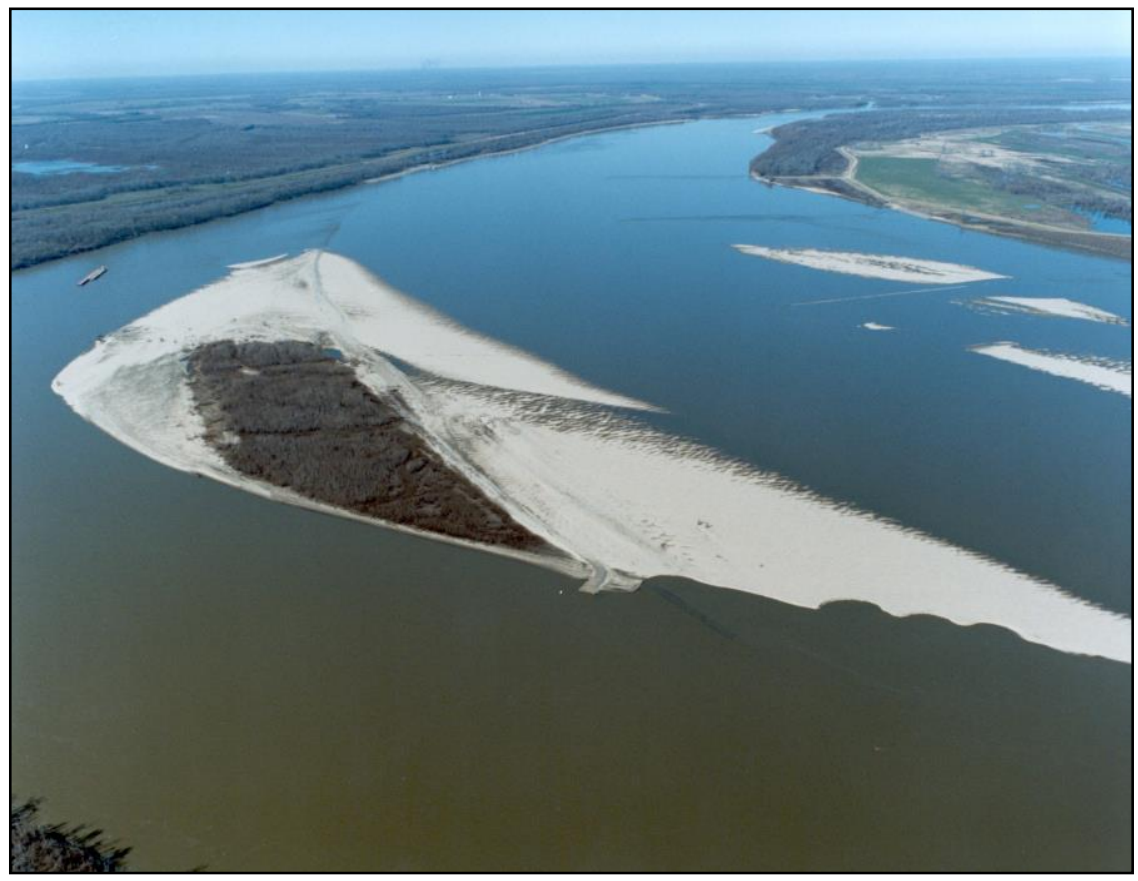

A recent photograph of Smithland Crossing (looking downstream) is shown in Figure 123. In this picture, the navigation channel has moved to the left side of the island, the river has eroded to the trench fill revetment, and significant sediment has deposited in the dike field.

Figure 123. Smithland Crossing after completion of chute closure structure. Looking downstream - the river has eroded back to the trench fill revetment, and sediment has deposited in dike field.

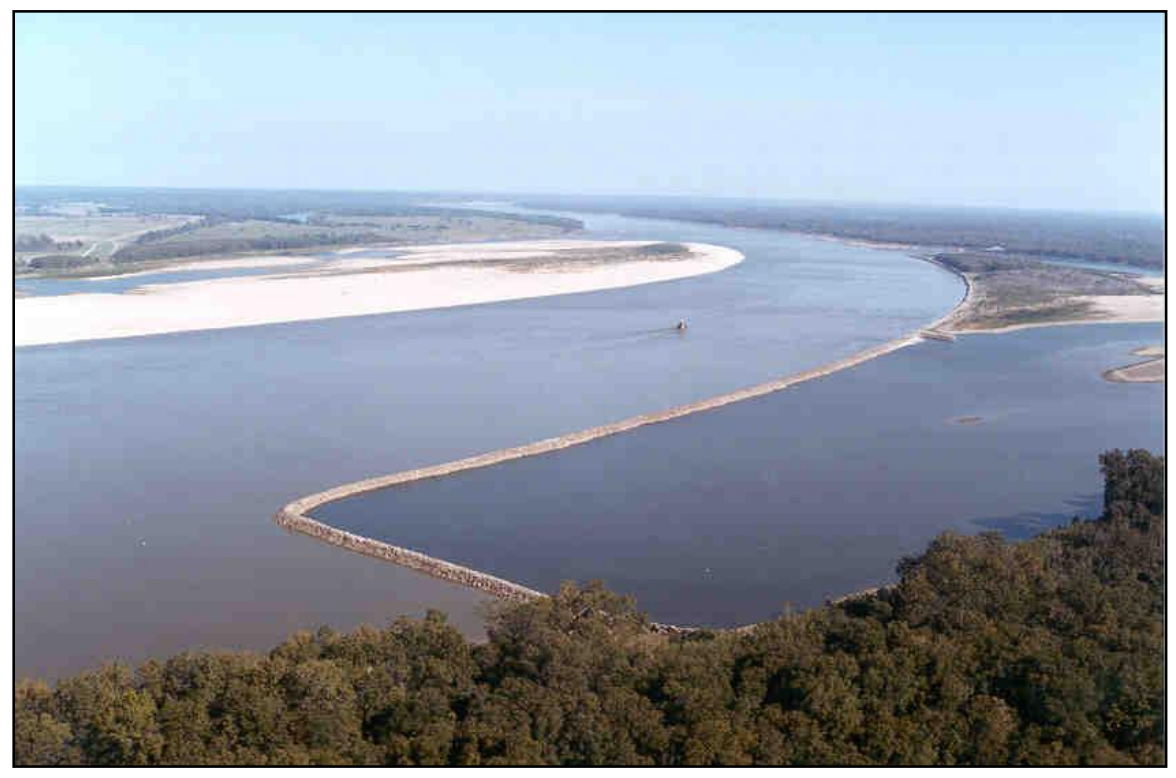


The HEC-6T numerical model was verified using data from Smithland Crossing. This verification study was conducted chronologically before the final calibration of initial bed material gradation and sediment inflow was completed. Therefore, the magnitude of calculated results may be different than those calculated with the final calibrated model. However, the calculated trends will be identical.

The initial geometry outside of the dike field came from the 1991-1992 hydrographic survey. The geometry at Smithland Crossing was modified to account for the closure structure and projection of dikes in the dike field. Bed elevations in the chute were raised to account for the closure structure so that conveyance in the chute was equal to the flow that occurs over the closure weir. Erosion limits in the model were set at the toe of the dikes and at the toe of the trench-fill revetment. Deposition limits were initially set at the right and left bank of the river. However, these limits were changed to match the erosion limits when excessive deposition was calculated in the dike field. This occurs in the numerical simulation when only deposition is allowed to occur in the dike field. Erosion cannot be allowed in the dike field because in the HEC-6T model all the bed elevation points within the erosion and deposition limits are moved an equal distance in the solution of the sediment continuity equation during each time-step. The 1D model does not allow for lateral variation of erosion rates, so it is an all-or-nothing choice. The consequence is that deposition in the dike field and on the island is not accounted for in the numerical model. The channel banks in the numerical model were set at the top of the trench fill revetment and at the end of the projection of the dikes. This designation is significant because it is the channel hydraulic parameters that are used in the sediment transport equations. Roughness coefficients in the dike field and in the chute were set at 0.035. Roughness coefficients in the channel were varied with discharge.

The HEC-6T cross sections through Smithland Crossing are shown in Figure 124 through Figure 128. The original cross sections from the 19911992 hydrographic survey are shown on these figures for reference, but they were not used in the HEC-6T simulations. The dike field was added to the 1991-1992 geometry and is indicated by the shaded green area in the figures. Blockage of the cross-sectional area in the chute for conveyance calculations is indicated by the shaded blue area in the figures. This modified geometry was then used as the initial conditions in the model. The cross sections labeled "2004" shown in the figures are from the 2004 hydrographic survey. Aggradation and degradation calculated by HEC-6T 
between 2 November 1991 and 10 December 2002 is shown on the figures. These are close to the actual dates of the hydrographic surveys at Smithland Crossing. The simulation covered 4,057 days, which is a little more than 11 years.

Calculated bed changes in the HEC-6T model occur equally at each crosssection point within the movable bed. Thus, the model is not able to reproduce the change in cross-section shape that occurred as a result of the construction of the constriction works. However, the model can be used to estimate the volume of erosion that occurs as a result of channel constriction.

Calculated and measured erosion at RM 300.3 are shown in Figure 124. This figure demonstrates that that the channel shape changed between 1992 and 2004. However, the change in measured and calculated cross-sectional area is similar. Figure 125 and Figure 126, which show the calculated and measured erosion at RMs 299.5 and 298.9, also demonstrate the differences between calculated and measured cross-section shapes, but a similarity in change in cross-sectional areas. The success of the model to produce a reasonable channel shape at RMs 299.5 and 298.9 is especially encouraging considering the extreme changes in the cross sections that were introduced by the dikes and the closure of the chute.

At RMs 299.5, 298.9, and 298.1 (Figure 125, Figure 126, and Figure 127), the 2004 hydrographic survey shows that deposition occurred above the top elevation of the dikes and at RM 298.9 on the island. This deposition was not simulated in the numerical model because cross-section changes were restricted to the channel. In one test with the numerical model, deposition was allowed in the dike field. Under these conditions, between 12 and $15 \mathrm{ft}$ of deposition above the dike crest elevation was calculated. This result highlights a dilemma with the modeling approach. To achieve appropriate conveyance in the main channel, it is necessary to assume that the dike field is filled to the top of the dikes for initial conditions. This means that the area between the dikes is available to accumulate sediment in the prototype but not in the model. Thus, if the model is allowed to deposit sediment in the dike field, the accumulation of sediment above the dike crest elevation begins at the start of the hydrograph simulation. Figure 123 shows that the area between the dikes has essentially been filled with sediment so that future projections based on the assumption of fill between the dikes will not have this problem. 
Figure 124. Calculated and measured degradation at Smithland Crossing, RM 300.3.

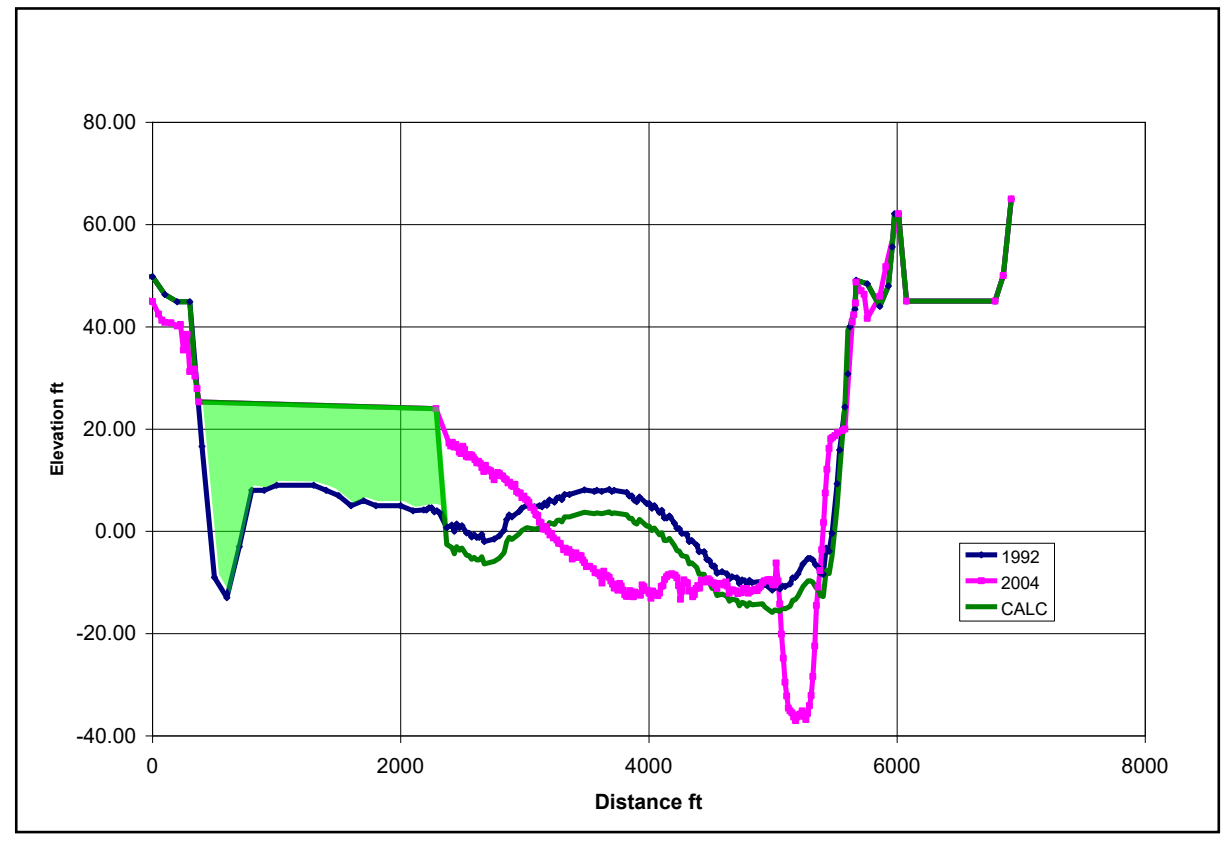

Figure 125. Calculated and measured degradation at Smithland Crossing, RM 299.5.

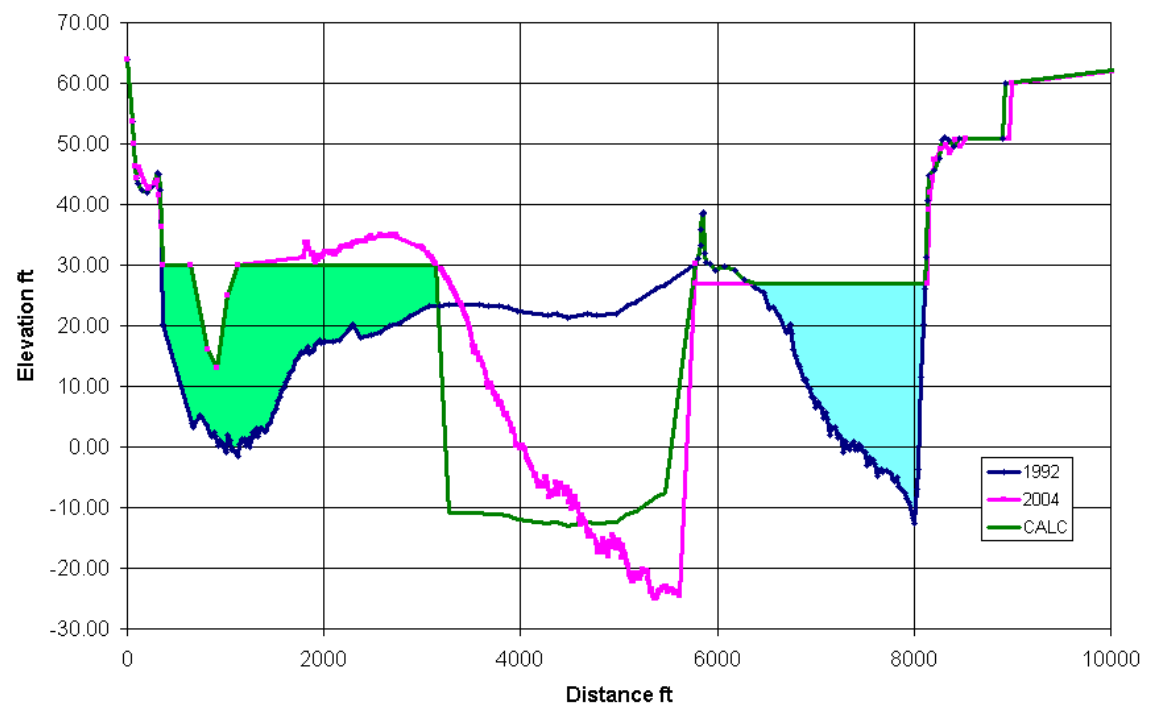


Figure 126. Calculated and measured degradation at Smithland Crossing, RM 298.9.

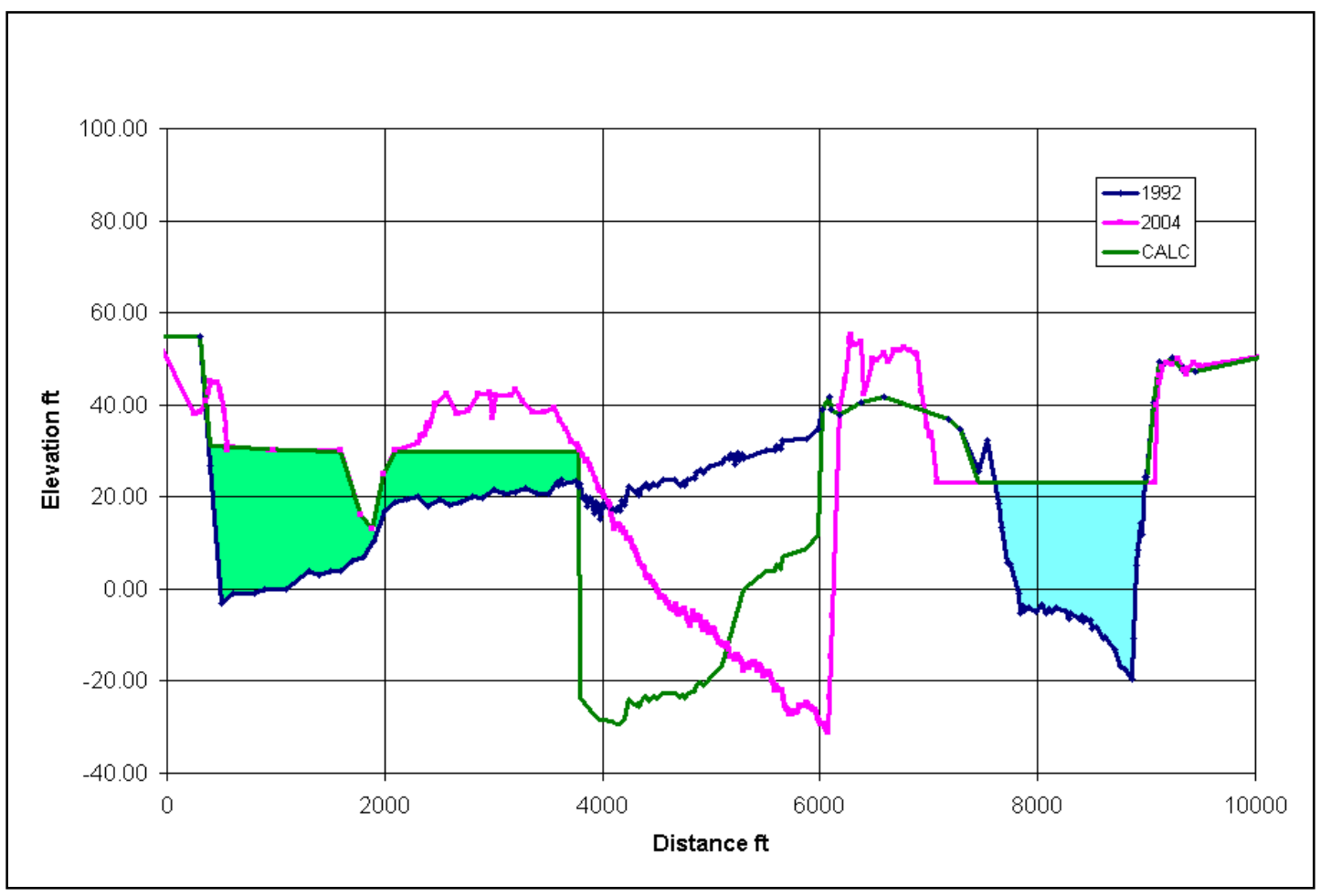

Figure 127. Calculated and measured degradation at Smithland Crossing, RM 298.1.

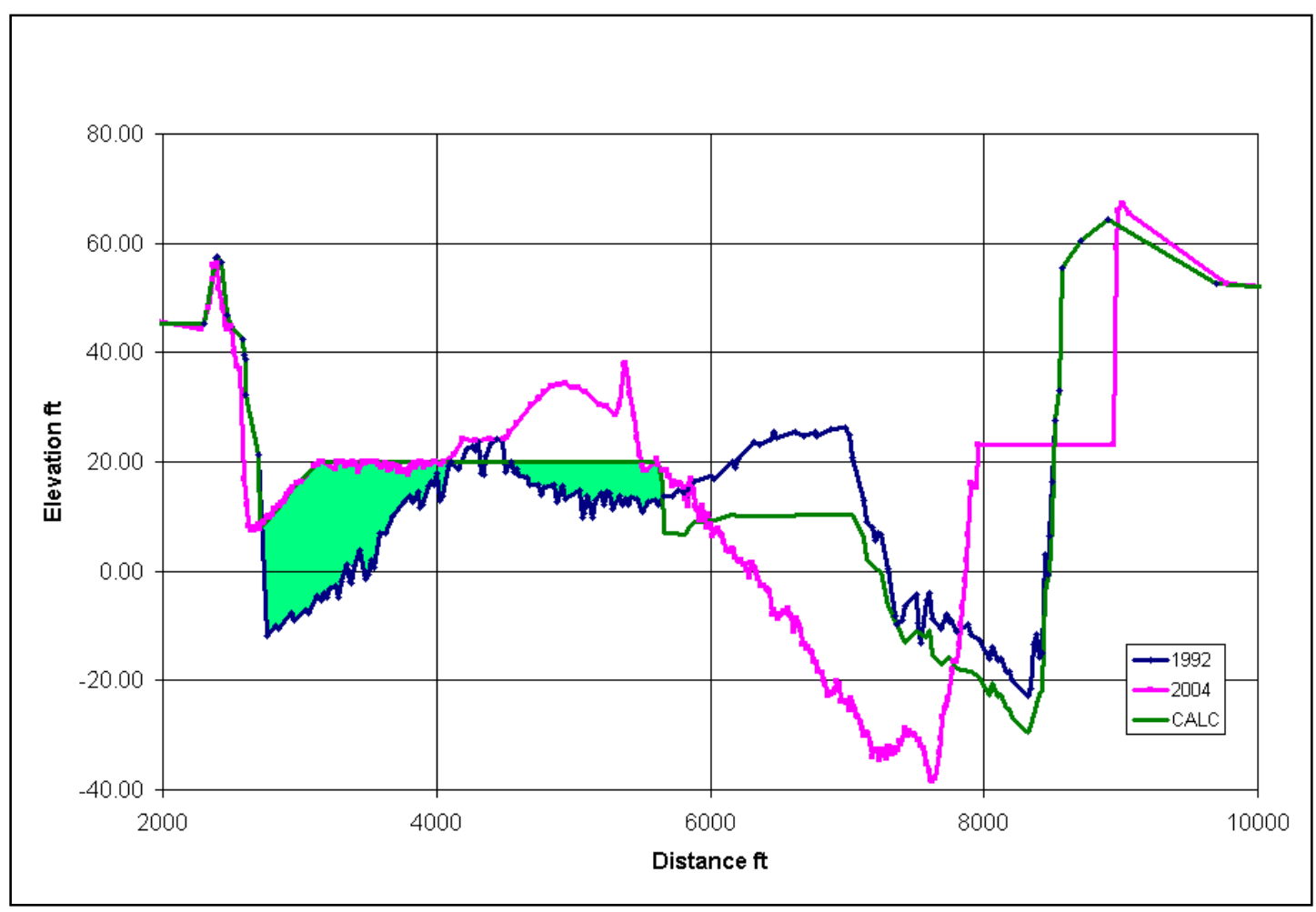


Figure 128. Calculated and measured degradation at Smithland Crossing, RM 297.45.

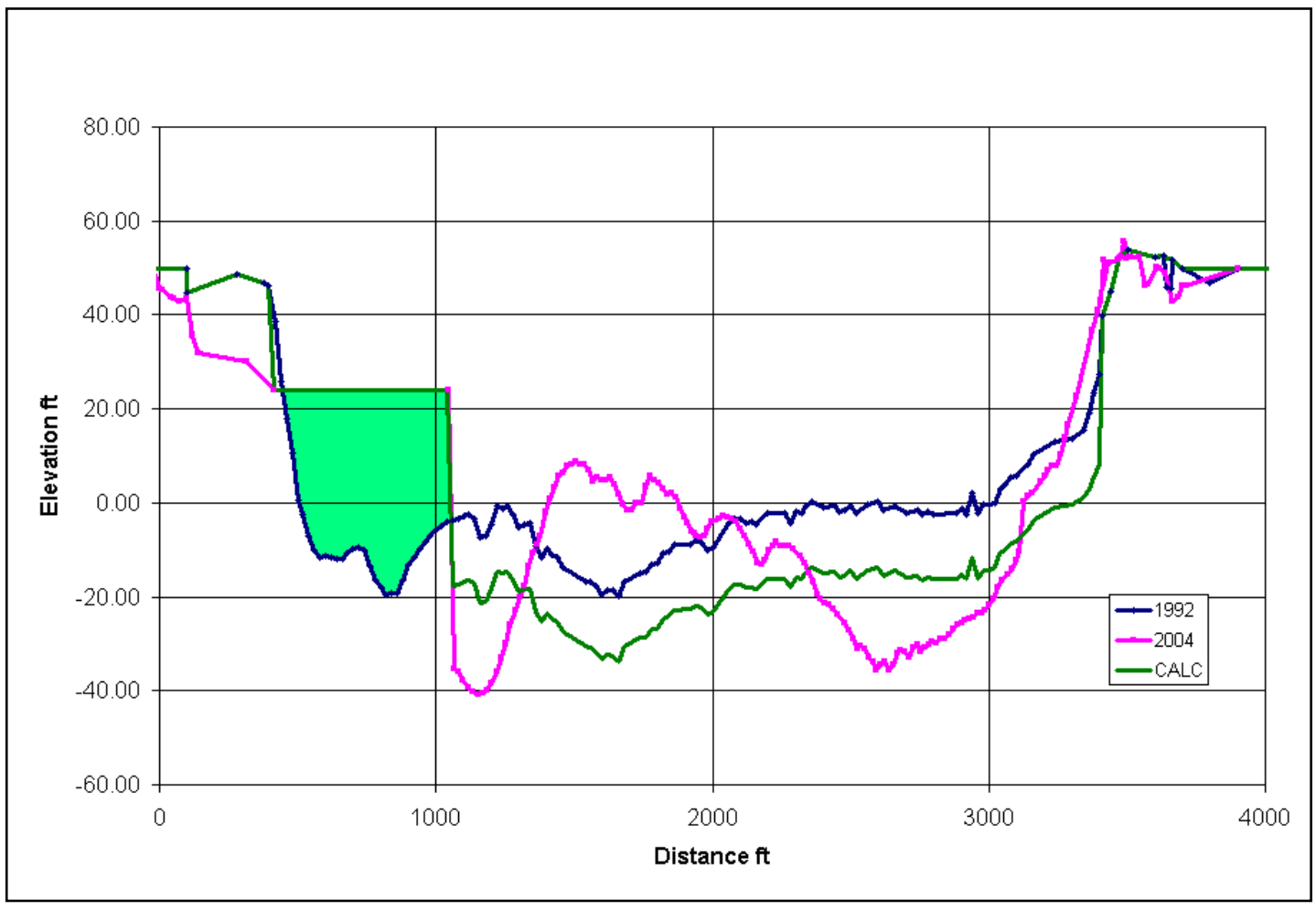

It is important to consider that calculated deposition in the dike field is a function of the sediment inflow and sediment transport capacity in the channel. The model deposits excess sediment uniformly across both the dike field and the channel if the movable bed includes the dike field. The flow parameters across the dike field are not considered in the model. Thus, at higher flows when erosion may actually occur across the dike field in the prototype, no erosion occurs in the model.

There are two options for modeling a dike field:

1. Allow sediment deposition in dike field. The Smithland Crossing results indicate that this approach will significantly overestimate the deposition in the dike field, at least for the first 11 years.

2. Restrict the movable bed to the main channel. The Smithland Crossing results indicate that this approach will not account for the deposition that occurs above the crest of the dikes. Over many years, the dike field may increase in elevation as the channel adjusts its shape to conform to upstream channel geometry.

The model verification results are based on the approach where channel erosion and deposition is limited to the channel. Calculated channel 
erosion in the Smithland Crossing reach is compared to measured erosion over the 11-year period between hydrographic surveys in Table 47. The tabulation does not include the deposition in the dike field or on the island. The calculated results are based on the assumption that the constriction works were in place at the beginning of the simulation in November 1991. This was true for the dikes, but the chute closure structure was not completed until June 1996. Therefore, modeled erosion is expected to be greater than prototype erosion. The calculated erosion in this reach was within 10 percent of the measured for the 11-year period.

Table 47. Calculated and measured erosion at Smithland Crossing, 1991-2002.

\begin{tabular}{|c|c|c|}
\hline Cross Section & $\begin{array}{c}\text { Calculated with HEC-6T } \\
\text { cubic yards }\end{array}$ & $\begin{array}{c}\text { Measured } \\
\text { cubic yards }\end{array}$ \\
\hline 297.45 & & \\
\hline & $4,370,000$ & $4,176,000$ \\
\hline 298.1 & & \\
\hline & $12,778,000$ & $12,692,000$ \\
\hline 298.9 & & \\
\hline & $8,695,000$ & $7,300,000$ \\
\hline 299.5 & & $7,854,000$ \\
\hline & $9,309,000$ & \\
\hline 300.3 & & $32,022,000$ \\
\hline & &
\end{tabular}

The designation of the movable bed limits will not only affect the shape of the cross sections in the dike field itself, it will also affect the sediment load downstream. A test was made to compare cross-section shape and downstream sediment transport load with the 1991-2002 hydrograph for the case where deposition was allowed in the Smithland Crossing dike field and for the case where it was not.

Calculated cross-section shape changes at Cross Section 298.1, for the case where deposition was allowed in the dike field and for the case where it was not, are shown in Figure 129. Note that there is less scour in the main channel for the case where deposition was not allowed in the dike field. Allowing deposition in the dike field resulted in less cross-sectional area at all Smithland Crossing cross sections. 
Figure 129. Calculated bed changes at cross section 298.1 for 1991-2002.

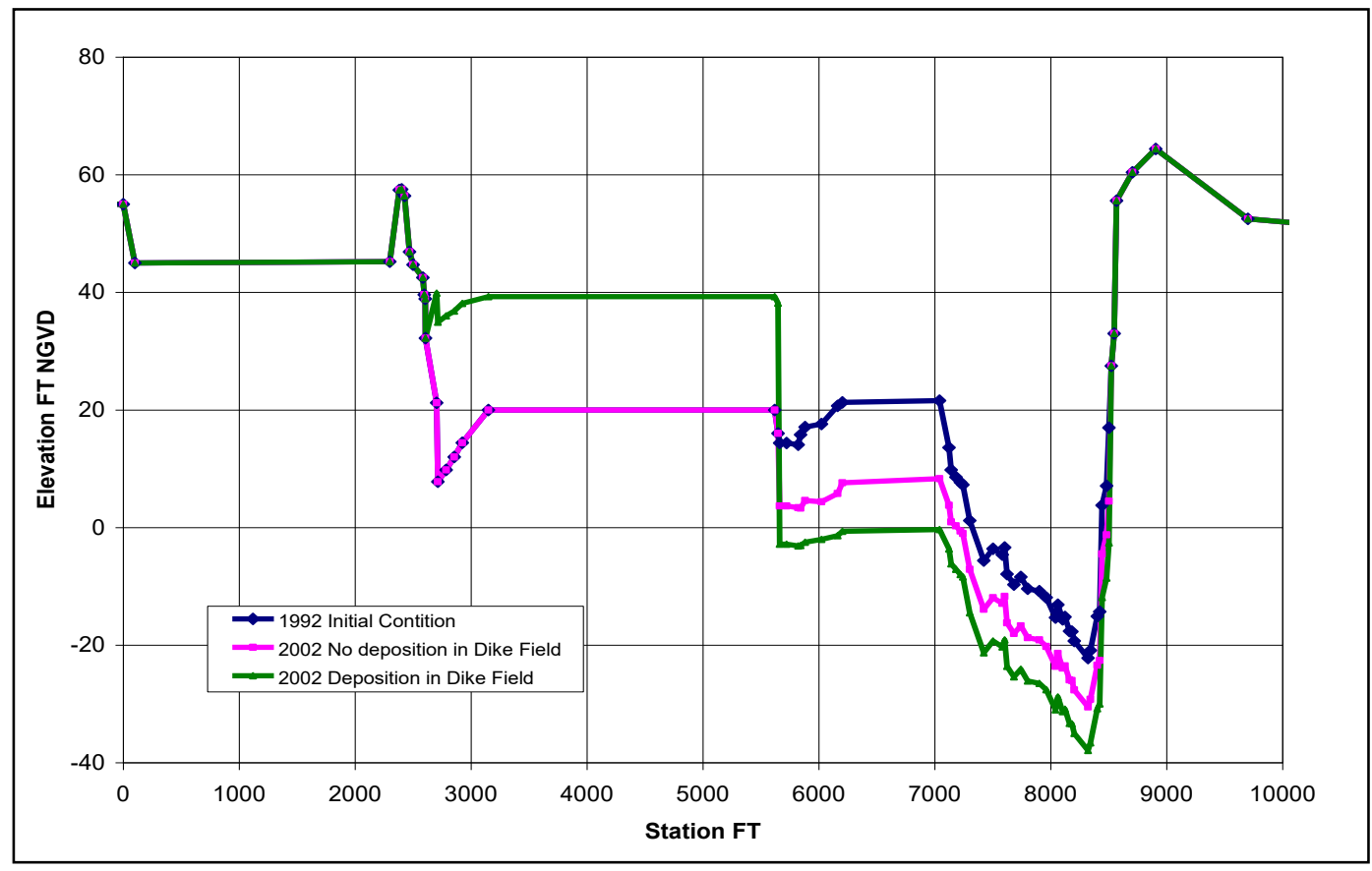

Calculated accumulated sediment transport downstream from Smithland Crossing, for the case where deposition was allowed in the dike field and for the case where it was not, is shown in Figure 130. Note that the dike field increased the sediment load downstream for both cases. The net effect of deposition in the dike field and more scour in the channel results in more sediment load downstream. The maximum increase in sediment load due to allowing deposition in the dike field is approximately 6 percent. The increased sediment load continues for approximately 100 miles downstream.

This appears to be a matter of approximating a $3 \mathrm{D}$ process with a $1 \mathrm{D}$ computation. It is possible that there may be long-term results in which the deposits exceed the height of the dikes if vegetation can get started. Two options that may allow the $1 \mathrm{D}$ model to approximate that condition are the following:

1. Include the dike field in the deposition zone for the best estimate of longterm future results and accept the fact that initial deposits build too quickly.

2. Put a loop through the dike field to determine if program will make a better estimate of the entire process. 
Figure 130. Calculated accumulated sediment load for 1991-2002.

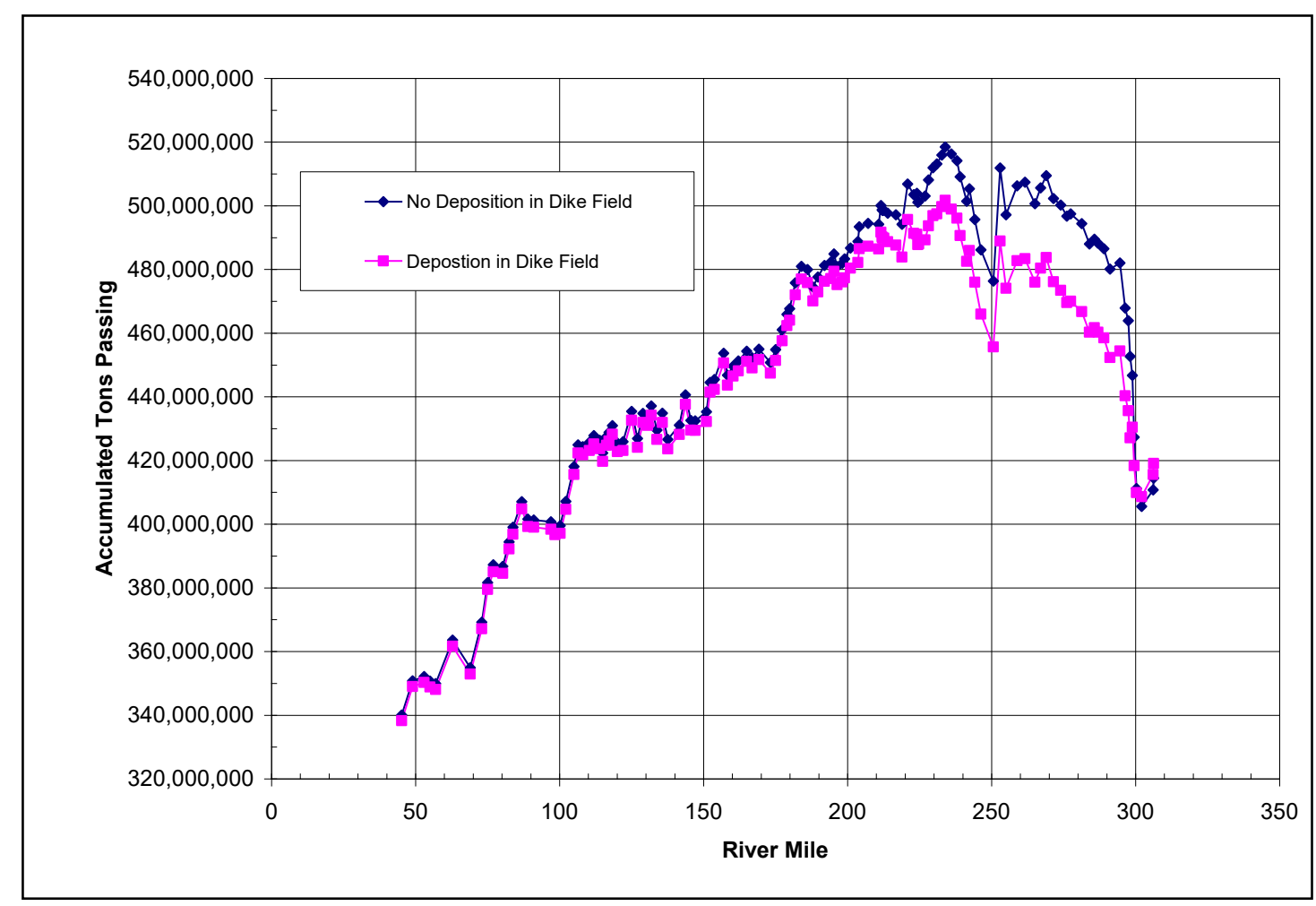




\section{Model Results}

\section{Sediment yield}

The accumulated sediment load at each model cross section is calculated by the HEC-6T numerical model. A profile of the total sediment delivery, the sand sediment delivery, and the sediment delivery for each size class can be displayed at any time during the numerical simulation. This profile provides insight into sedimentation trends along the river. Sand delivery profiles after 1 year of simulation and after 12 years (1991-2002) of simulation are shown in Figure 131. Moving downstream (right to left on the figure), an increase in sediment delivery along the profile indicates a degrading reach while a decreasing sediment delivery indicates an aggrading reach. For example, Figure 131 indicates significant degradation trends between RMs 900 and 840, 750 and 650, and 580 and 470. Aggradation trends are indicated between RMs 650 and 580, 470 and 410, and 230 and $\mathrm{o}$. The sharp decline in sediment delivery near RM 311 is due to diversions at the Old River Control Complex. Significant sediment diversion also occurs through several distributaries downstream from RM 15. A general conclusion is that the Lower Mississippi River is generally degrading upstream from RM 650 and aggrading downstream from RM 470. The degradation trend can be attributed to the low sediment concentrations being supplied by the Ohio River and the corresponding response of sediment entrainment from the bed of the Mississippi River to meet the increased sediment transport capacity. Downstream from RM 470, the aggradation trend can be attributed to the normal decrease in sediment transport capacity due to decreasing slope in the downstream reaches of natural rivers. 
Figure 131. Calculated cumulative sand delivery for 1 year and 12 years.

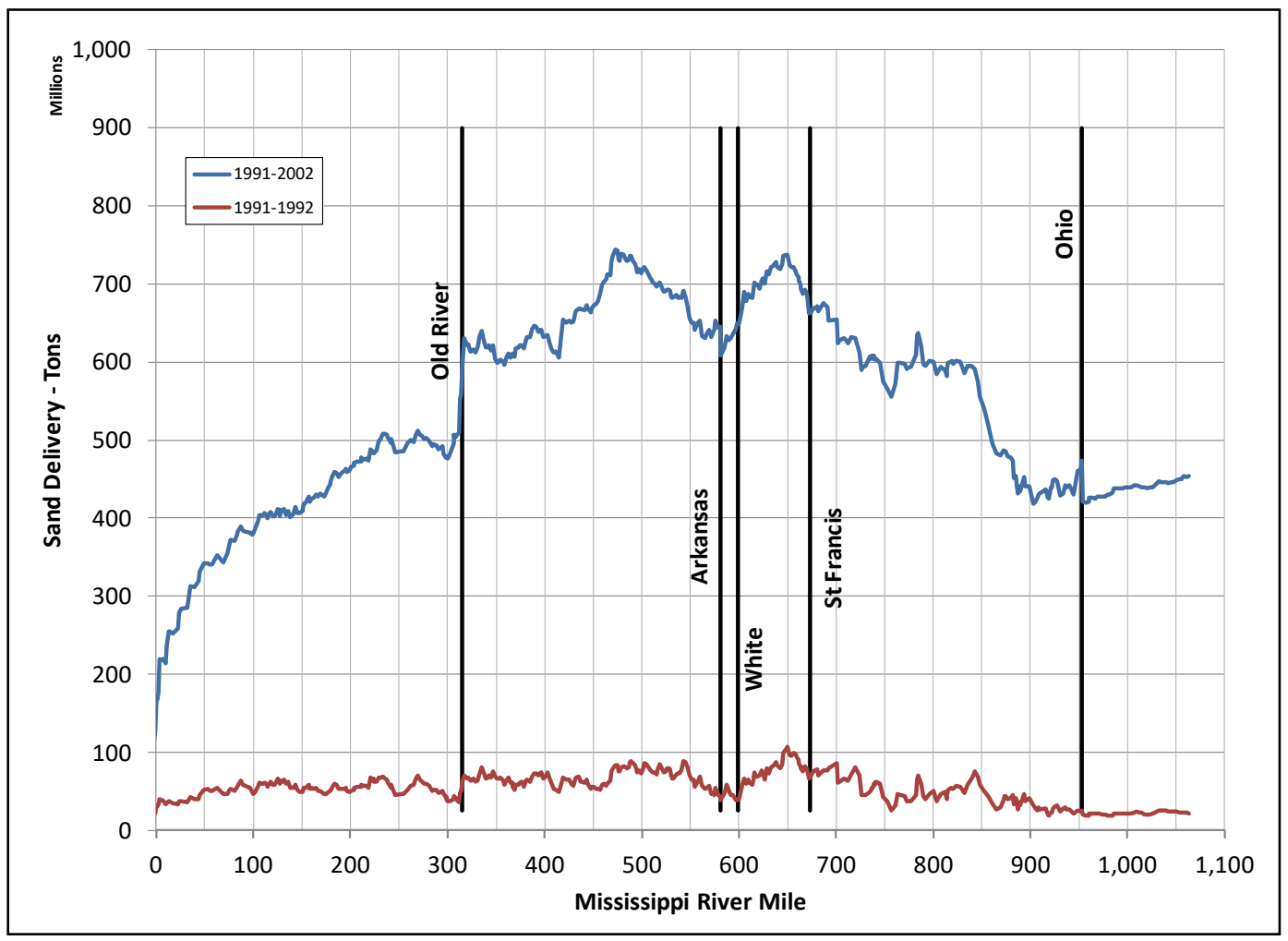

Accumulated sediment inflow/outflow at the model boundaries during the numerical simulation are calculated by the HEC-6T model. Calculated sediment loads from tributaries into the Lower Mississippi River between Cairo and the Old River Control Complex, between 1991and 2002, are shown in Table 48. Calculated outflow through distributaries between 1991 and 2002 are also shown in Table 48. The table includes calculated weights of both the total sediment load (clay, silt and sand) and the sand load. Only the sand load affects changes in river morphology.

Table 48. Calculated sediment loads from tributaries and distributaries, 1991-2002.

\begin{tabular}{|c|c|c|c|c|}
\hline & & River Mile & $\begin{array}{c}\text { Total } \\
\text { million tons }\end{array}$ & $\begin{array}{c}\text { Percentage of } \\
\text { Sand Load } \\
\text { Upstream of } \\
\text { Old River } \\
\text { Control } \\
\text { Complex }\end{array}$ \\
\hline Tributary & 953 & 1457.02 & 421.43 & 66.87 \\
\hline Middle Mississippi & 953 & 433.35 & 60.36 & 9.58 \\
\hline Obio & 819.2 & 31.21 & 3.97 & 0.63 \\
\hline Hatchie & 773 & 7.76 & 0.99 & 0.16 \\
\hline St. Francis & 672.4 & 8.53 & 0.16 & 0.04 \\
\hline
\end{tabular}




\begin{tabular}{|c|c|c|c|c|}
\hline Tributary & River Mile & $\begin{array}{l}\text { Total } \\
\text { million tons }\end{array}$ & $\begin{array}{l}\text { Sand } \\
\text { million tons }\end{array}$ & $\begin{array}{l}\text { Percentage of } \\
\text { Sand Load } \\
\text { Upstream of } \\
\text { Old River } \\
\text { Control } \\
\text { Complex }\end{array}$ \\
\hline White & 599 & 22.96 & 2.85 & 0.45 \\
\hline Arkansas & 580.8 & 74.05 & 37.16 & 5.90 \\
\hline Yazoo & 437 & 69.68 & 1.35 & 0.21 \\
\hline $\begin{array}{c}\text { Total Eroded between Cairo } \\
\text { and Old River Control } \\
\text { Complex }\end{array}$ & & & 103.28 & 16.37 \\
\hline \multicolumn{5}{|l|}{ Distributary } \\
\hline Old River Outflow Channel & $312-316$ & -447.70 & -84.65 & 13.43 \\
\hline Bonnet Carré & 129 & -8.28 & -1.94 & 0.31 \\
\hline Caernarvon & 81.4 & -10.61 & -0.70 & 0.11 \\
\hline Bohemia Spillway & $33-45$ & -7.31 & 0 & 0.00 \\
\hline Baptiste Collette & 11.5 & -147.63 & -16.96 & 2.70 \\
\hline Grand Pass & 10.5 & -146.18 & -22.81 & 3.62 \\
\hline Cubits Gap & 3.0 & -193.79 & -12.47 & 1.98 \\
\hline $\begin{array}{c}\text { South Pass and Pass a } \\
\text { Loutre }\end{array}$ & 0.0 & -326.98 & -30.29 & 4.81 \\
\hline SWP at Mile 3.0 & -3.0 & -18.36 & -1.27 & 0.20 \\
\hline Joseph Bayou & -4.5 & -53.14 & -3.79 & 0.60 \\
\hline Outlet W-2 & -9.8 & -26.48 & -0.82 & 0.13 \\
\hline Burrwood Bayou & -14.4 & -43.18 & -3.33 & 0.53 \\
\hline Pilots Station & -18.0 & -367.57 & -73.09 & 11.59 \\
\hline $\begin{array}{l}\text { Total Outflow downstream } \\
\text { from Coochie }\end{array}$ & & 1797.21 & -252.12 & 40.01 \\
\hline $\begin{array}{l}\text { Total Dredged/Deposited } \\
\text { downstream from Coochie }\end{array}$ & & 409.47 & 378.08 & 59.99 \\
\hline
\end{tabular}

Data From NODR_FINAL_ADJ_MODEL 1990-2011.T6

\section{Modified hydrograph 2003-2011}

The hydrographs used to evaluate conditions after the 30 September 2002 calibration period were based on data from upstream boundary gages and did not include adjustments to tributary inflows to match downstream gages. This approach maintains the beneficial effect of simulating the 
correct timing of tributary contributions but does not account for differences in measured discharges in upstream and downstream gages.

The inflow hydrograph for the Middle Mississippi River was developed from USGS gages on the Mississippi River at Chester (RM 110, USGS 07020500) and Thebes (RM 44, USGS 0702200) and from the USGS gage on the Big Muddy at Plumfield (RM 87, USGS 05597000). It is expected that the combined discharges at Chester and the Big Muddy should equal the discharge at Thebes. Since the Plumfield gage is located a considerable distance from the Big Muddy confluence with the Mississippi River, it is appropriate to take the difference between the Chester and Thebes measured data to be the contribution from the Big Muddy. However, there were several days when the measured discharge at Chester was greater than the measured discharge at Thebes. This apparent discrepancy could be due to measurement error or to floodplain/channel storage. The measured discharge at Plumfield was compared to the difference between the measured discharges at Chester and Thebes and the maximum of the two was used in the numerical model hydrograph. This assignment eliminates zero and negative flows from the Big Muddy. The measured daily discharge at Chester was compared to the sum of the measured daily data at Thebes minus the computed Big Muddy daily discharge. The maximum of these two values was used as the upstream boundary discharge on the Middle Mississippi River. The model hydrograph tends to maximize inflow from the measured data. However, the difference in total runoff volume between the maximized hydrograph and measured discharge at Thebes was calculated to be less than 1 percent.

The 2003-2011 hydrograph did not include changes to distributary outflow percentages that occurred after 2002. Changes in outflow percentages have been confirmed by recent measurements. Also excluded are new diversions constructed after 2002, including the Davis Pond (RM 118.4) and West Bay (RM 4.9) diversions. These updates have been incorporated into a separate HEC-6T numerical model developed by Mobile Boundary Hydraulics for the State of Louisiana (Thomas 2012) and were incorporated into the Flowline Sedimentation Model developed by the USACE (Copeland 2018).

\section{Sediment inflow for the Middle Mississippi River 2003-2012}

Measured sediment data at Thebes (USGS 07022000), which is located at RM 43.7 above the confluence of the Ohio River, suggest that sediment 
concentration is declining. The USGS Water Science Center in Rolla, MO, provided the following information about how sediment data are collected at Thebes:

Samples are collected at Thebes by both USGS personnel and contract observers. The contract observers collect a daily sediment sample at a single vertical using a D-74 depthintegrating sampler. The USGS collects sediment samples at 5 verticals using the equal-discharge-increment (EDI) method. The USGS also collects a sample at the contract observer transect. Both the contract observers and the USGS collected samples from the railroad bridge at Thebes until 1997, when both changed to collecting samples from a boat the USGS just upstream from the bridge and the contract observers under the bridge at the same location that was used from the bridge. The USGS used a P-61 sampler to obtain depth- integrated samples until 2009, when they switched to a D-96 depth-integrating bag sampler. The daily samples collected by contract observers are adjusted to account for lateral variability in concentration across the cross section. The adjustment coefficient is determined by the USGS, each year, using data from their EDI measurements and the measurement taken at the contract observer sampling transect. ${ }^{1}$

Data collected by the USGS were obtained from the USGS web site http://nwis.waterdata.usgs.gov/il/nwis/. The data are found in the Water Quality Field/Lab Samples data categories. Figure 132 shows plotted measured suspended sediment concentrations and power regression curves for the 1991-2002 and 2003-2012 time periods. Figure 133 shows the same for measured suspended sand concentrations. The figures suggest a decline in sediment concentrations for discharges greater than 150,000 cfs.

\footnotetext{
${ }^{1}$ Personal communication with Miya N. Barr, Hydrologist/QW DBA/ Sediment, Lab Chief USGS-Missouri Water Science Center, 10 Oct 2012.
} 
Figure 132. Measured total suspended sediment concentration at Thebes.

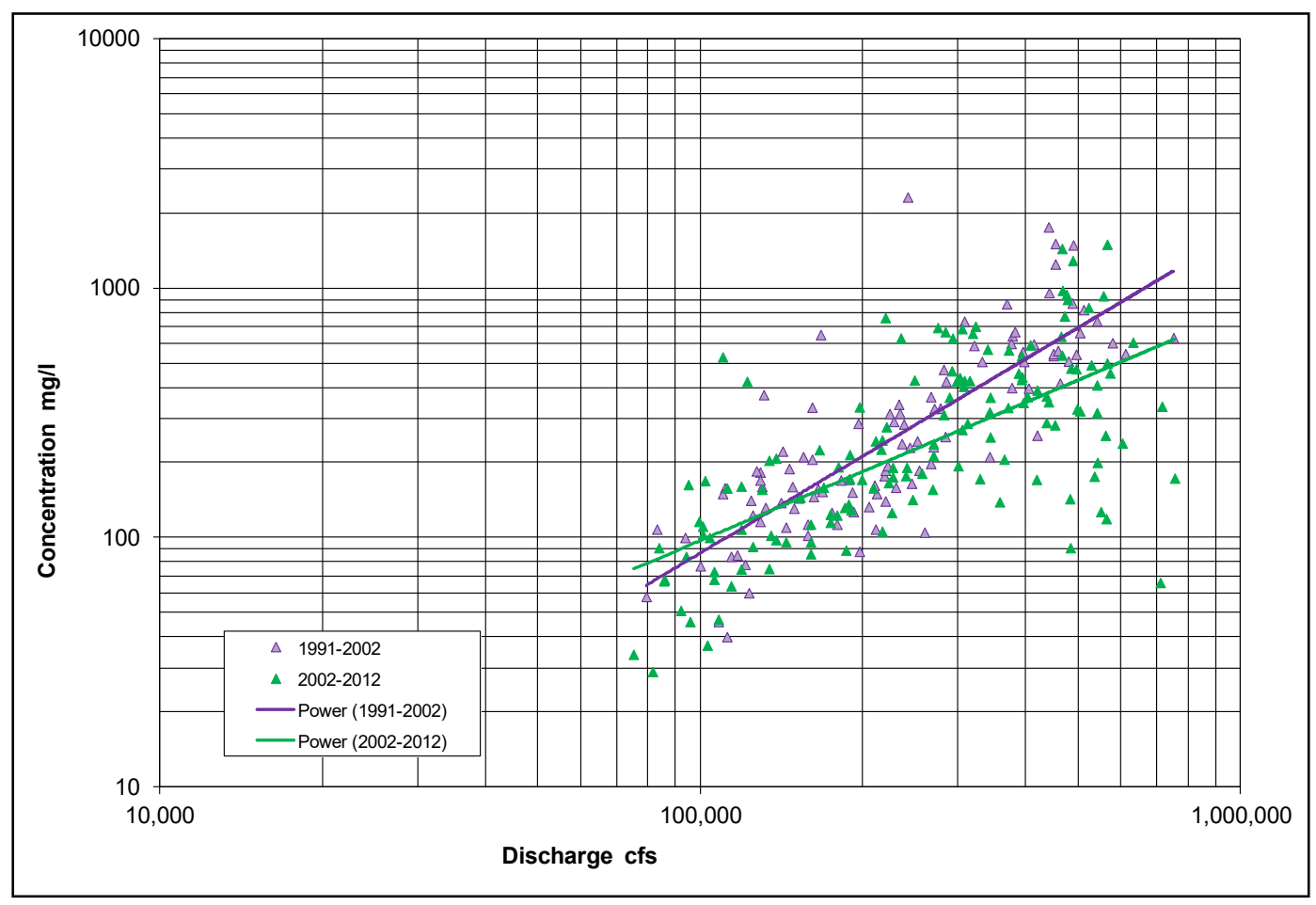

Figure 133. Measured suspended sand concentration at Thebes.

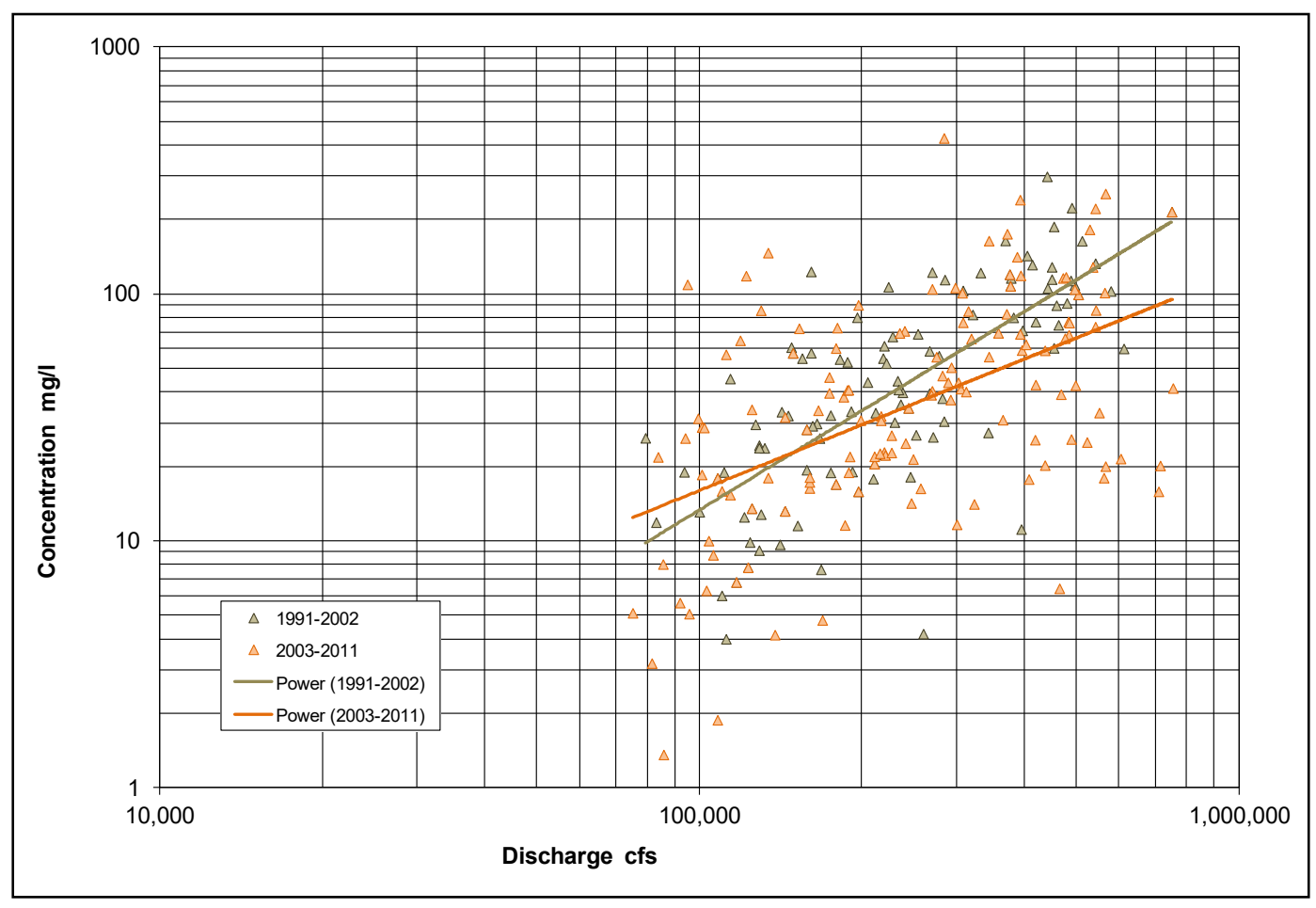


There is considerable uncertainty associated with approximations obtained from power regression curves at the extremes of the data range. A more accurate approximation of average sediment concentration at the upper and lower ends of the discharge range can be obtained if additional data points are used. Thebes is one of the few sediment gages where a long-term daily sediment record is available. The mean daily sediment measurements at Thebes provide additional data for the total suspended sediment load but not for the sand load. There are 7,670 adjusted mean daily sediment concentrations at Thebes, for water years 1991 through 2011, reported in the USGS web site at http://nwis.waterdata.usgs.gov/il/nwis/. The data are found in the Surface Water - Daily Data data categories. Figure 134 shows plotted mean daily suspended sediment concentrations and power regression curves for the entire 21-year period, between 1991 to 2011, and for the 19912002 and 2003-2011 time periods. The results suggest that the average sediment concentrations at all discharges were lower for 2003-2011 than for 1991-2002. The results also suggest that average sediment concentrations at discharges less than 100,000 cfs are essentially the same for 1991-2002 and 2003-2011. Figure 134 also highlights the considerable uncertainty at discharges greater than $400,000 \mathrm{cfs}$.

Figure 134. Mean daily measured total suspended sediment concentration at Thebes.

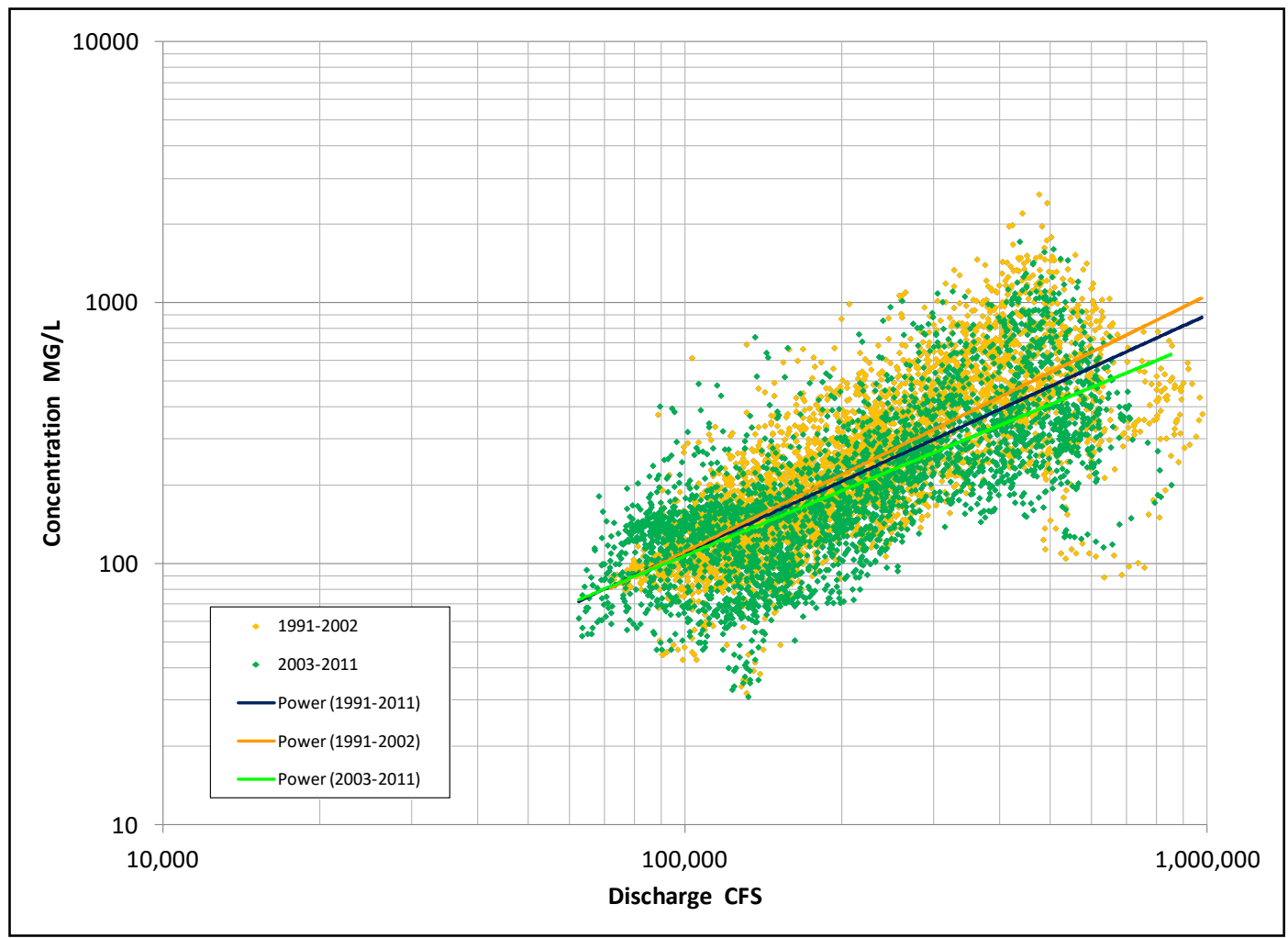


A significant portion of the sediment in the Middle Mississippi River at Chester and Thebes is provided by the Missouri River. Meade (1995) estimated that currently, nearly fifty percent of the sediment delivered to the Gulf of Mexico comes from the Missouri River. To check the conclusion that sediment concentrations at Thebes have declined since 2002, sediment data from the Missouri River were evaluated.

The first long-term sediment gage on the Missouri River, upstream from its confluence with the Mississippi River, is at Hermann (USGS 0693450). Hermann is located at RM 98. The USGS, in cooperation with the USACE Kansas City District, reported 220 sediment measurements at Hermann between 1991 and 2002 and 199 sediment measurements between 2003 and 2012. Sediment concentration data for the period 1991-2008 is available in Heimann et al. (2010). Data for 2009-2012 is available from the USGS web site http://nwis.waterdata.usgs.gov/mo/nwis/. According to Heimann et al. (2010), the sediment data were collected using either the equalwidth-increment method or the equal-discharge-increment method during the 1991-2008 study period. Between 1991 and 2004, depth-integrated and point samples were collected with either the US-P61 or US-P63 sampler. In 2005, the sampling equipment was changed to a US-D96, which collects only depth-integrated samples.

Measured suspended sediment and suspended sand concentrations between 1991 and 2002 at the Hermann gage were compared to measured sand concentrations between 2003 and 2012. As shown in Figure 135 and Figure 136, a comparison of power regression curves, through the measured data, indicates a decline in suspended sediment and suspended sand concentrations after 2002. This result supports the conclusion that the suspended sediment concentrations at Thebes have declined after 2002. 
Figure 135. Measured total suspended sediment concentration, at Hermann.

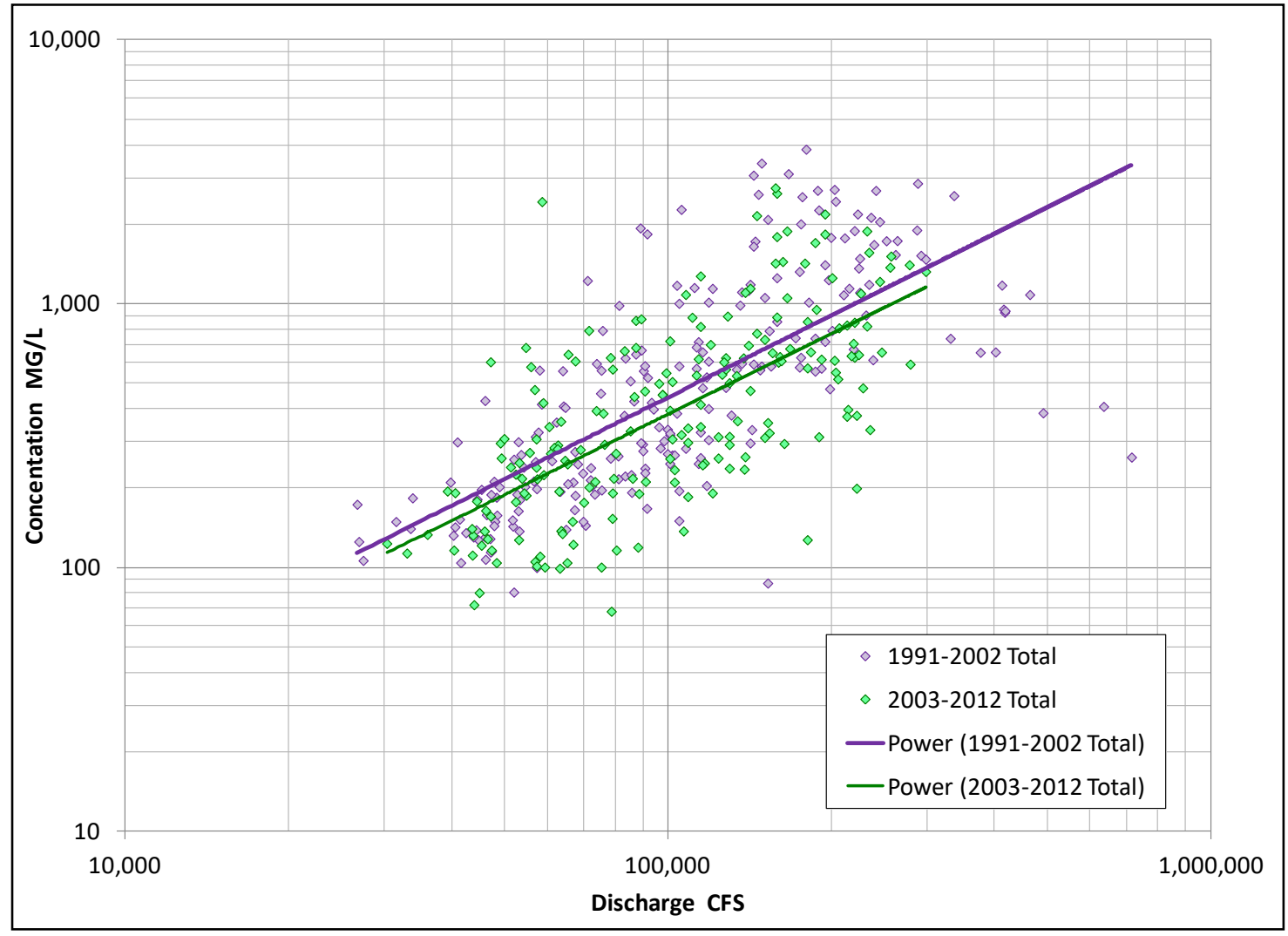

Figure 136. Measured suspended sand concentration for the Missouri River at Hermann.

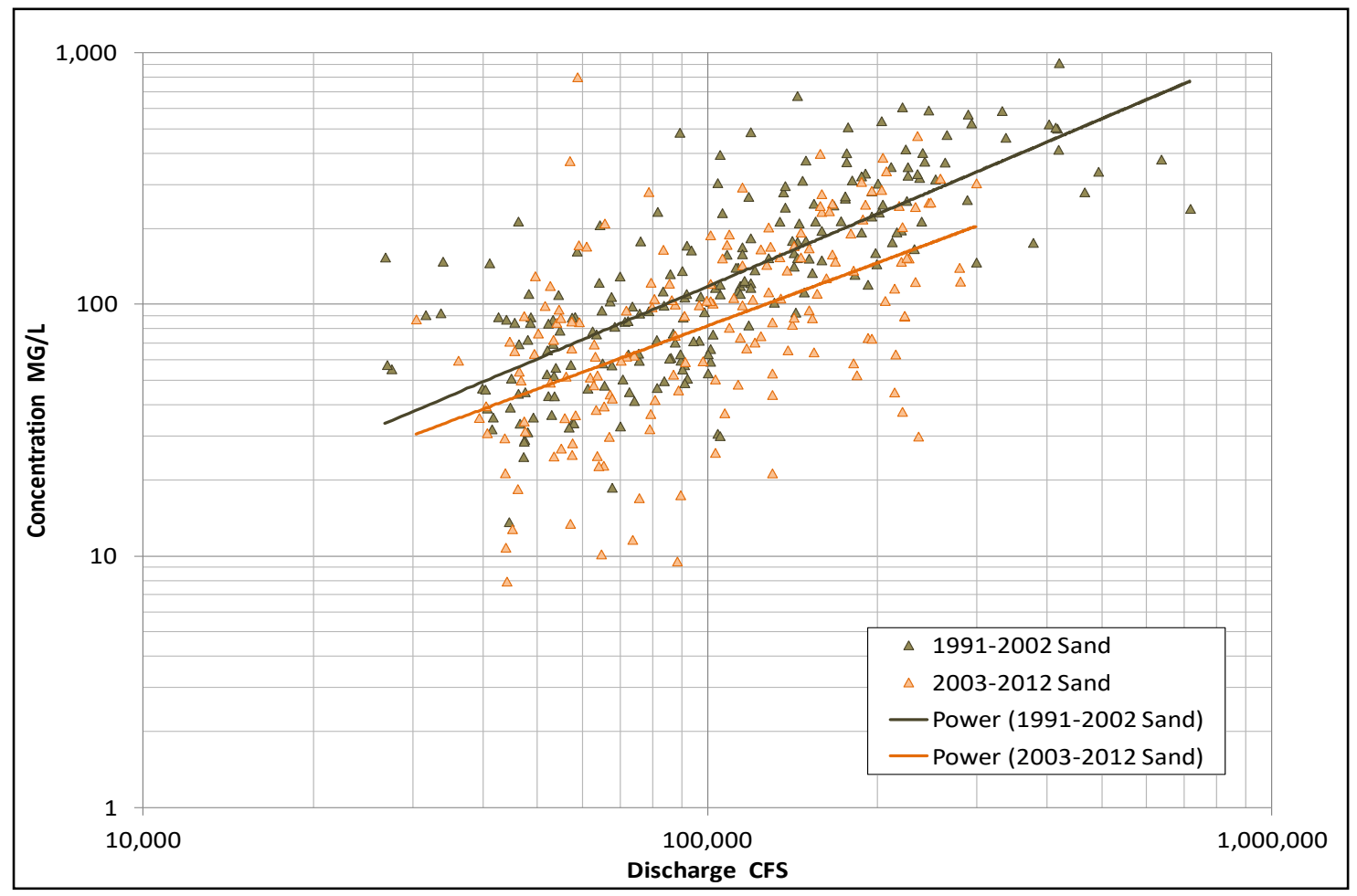




\section{Effect of declining sediment inflow at Thebes}

The numerical model was used to test the effect of a declining sediment inflow at Thebes on sediment delivery in the Mississippi River between Cairo and the Gulf of Mexico. The model hydrograph was extended to 30 September 2011. Sediment delivery for the 1991-2011 time period was then calculated using the same boundary conditions used for the 19912002 calibration period. Another calculation was made for the 1991-2011 time period with a reduced sediment inflow curve at Chester starting on 1 October 2002. All other boundary conditions were left unchanged. The calculated cumulative sand deliveries are shown in Figure 137. The numerical model results indicate that the change in sediment inflow from the Middle Mississippi River has a very small effect on sediment delivery after the first 50 miles.

Figure 137. Calculated cumulative sand delivery 1991-2011.

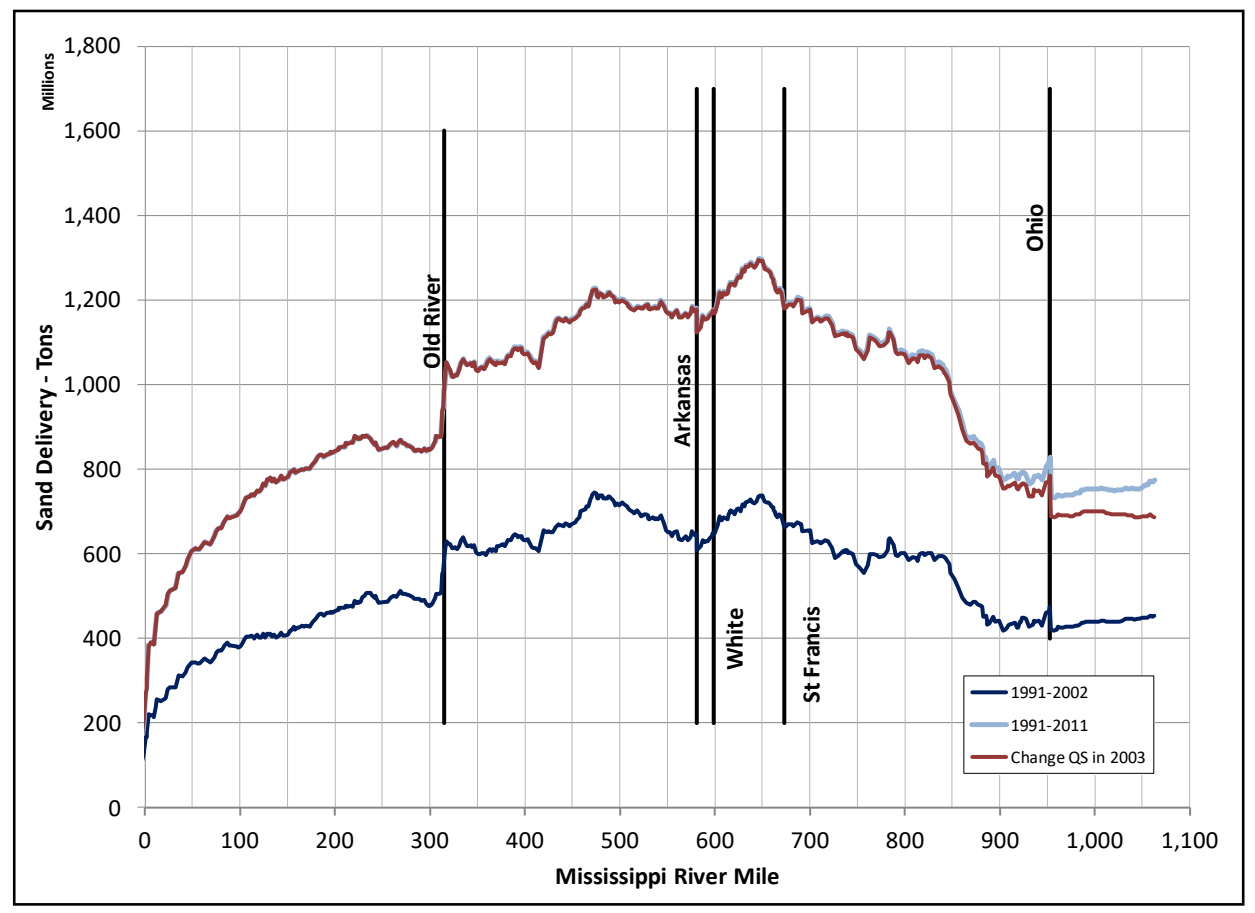

Calculated 2003-2011 sand delivery, at several Mississippi River gage locations, is shown in Table 49. The difference in sand transport for the 9-year period due to declining sediment inflow at Thebes is 43.8 million tons at Cairo, 42.7 million tons at Wickliffe, 25.9 million tons at Hickman, and 17.5 million tons at New Madrid. At Memphis, the decrease in sand delivery is 5.2 million tons, and the decrease in sand delivery is less at each downstream gage. 
Table 49. 2003-2011 calculated sediment delivery.

\begin{tabular}{|c|c|c|c|c|}
\hline \multirow{2}{*}{ Station } & \multirow{2}{*}{ River Mile } & 1991-2002 Inflow & 2003-2011 Inflow & Difference \\
\cline { 3 - 5 } & 317 & 422.0 & 421.8 & -0.2 \\
\hline Coochie & 363 & 451.4 & 449.0 & -2.4 \\
\hline Natchez & 435 & 489.6 & 486.6 & -3.0 \\
\hline Vicksburg & 431 & 498.6 & 496.4 & -2.3 \\
\hline Greenville & 531 Million Tons \\
\hline Rosedale & 592 & 475.9 & 473.0 & -3.0 \\
\hline Helena & 663 & 538.2 & 534.5 & -3.7 \\
\hline Memphis & 736 & 518.9 & 513.7 & -5.2 \\
\hline New Madrid & 889 & 370.0 & 352.5 & -17.5 \\
\hline Hickman & 922 & 347.9 & 322.1 & -25.9 \\
\hline Wickliffe & 952 & 352.5 & 309.8 & -42.7 \\
\hline Cairo & 953 & 361.1 & 317.2 & -43.8 \\
\hline
\end{tabular}

\section{Effect of hard points on degradation}

The river bed was assigned a fixed bed at RMs 917.6, 921, and 922 in the calibrated numerical model. This assignment reflects the existence of a known hard point in the Mississippi River bed at Hickman. Numerical model results indicate that this reach of the Mississippi River is degradational, which suggests that the Hickman hard point could have a significant influence on river morphology. The significance of this hard point was evaluated by removing the hard points at the three cross sections in the model and running the 1991-2012 simulated hydrograph. The 1991-2002 sediment inflow curves at Thebes were used in the comparison study. Figure 138 shows the 21-year difference in sand delivery, and Figure 139 shows the 21-year difference in calculated average bed change with the hard points removed.

Removing the hard points results in almost $10 \mathrm{ft}$ of degradation at Hickman over the 21-year period. Figure 138 shows that the increase in downstream cumulative sand delivery due to the degradation at Hickman and the subsequent increase in sediment transport potential upstream is relatively small. The calculations indicate that the eroded sediment at Hickman does not result in any significant increase in downstream aggradation until RM 600, and then the increase in average bed elevation is on the order of tenths of a foot. The reason for the 300-mile lag before 
the deposition pattern begins is that the 300-mile reach below Hickman is generally a degradation reach.

Figure 138. Effect of hard points at Hickman on calculated cumulative sand delivery.

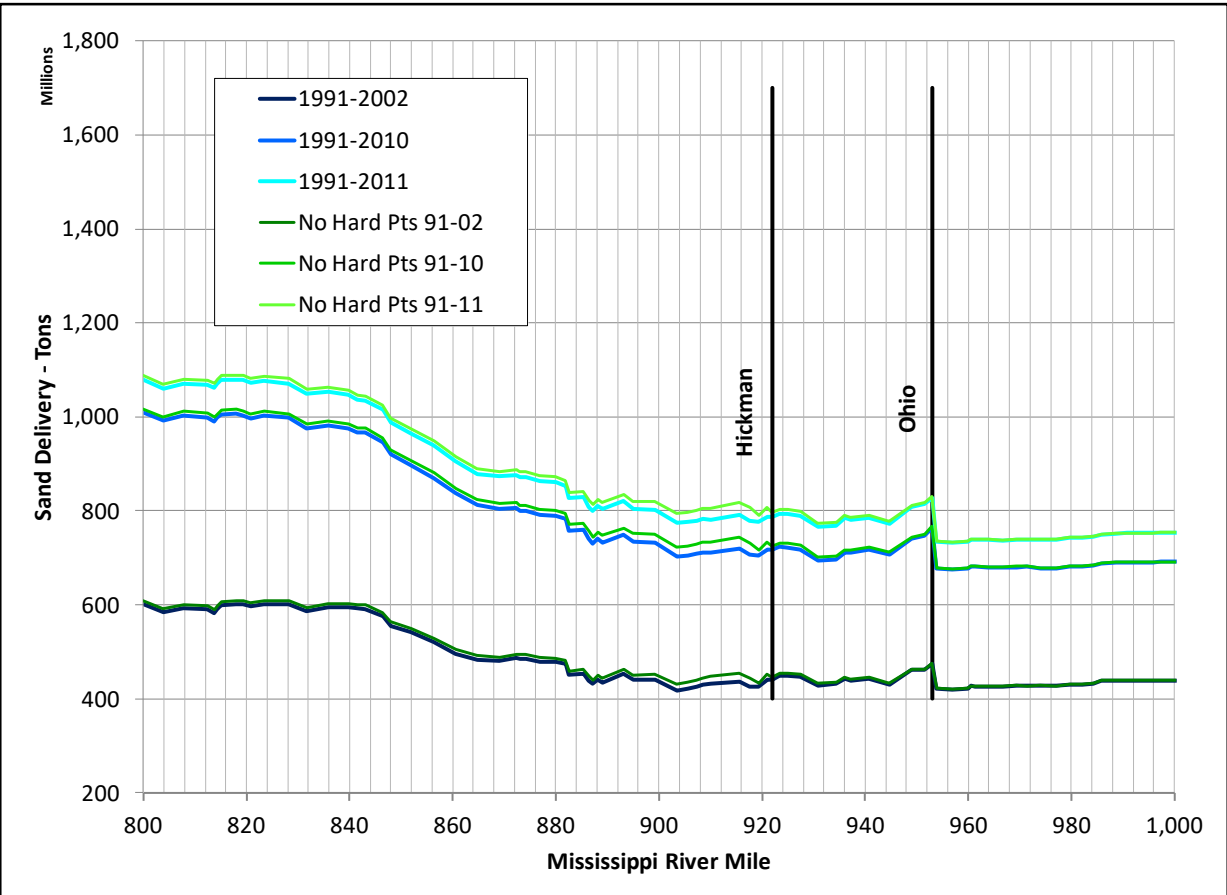

Figure 139. Calculated difference in average bed with hard points at Hickman removed.

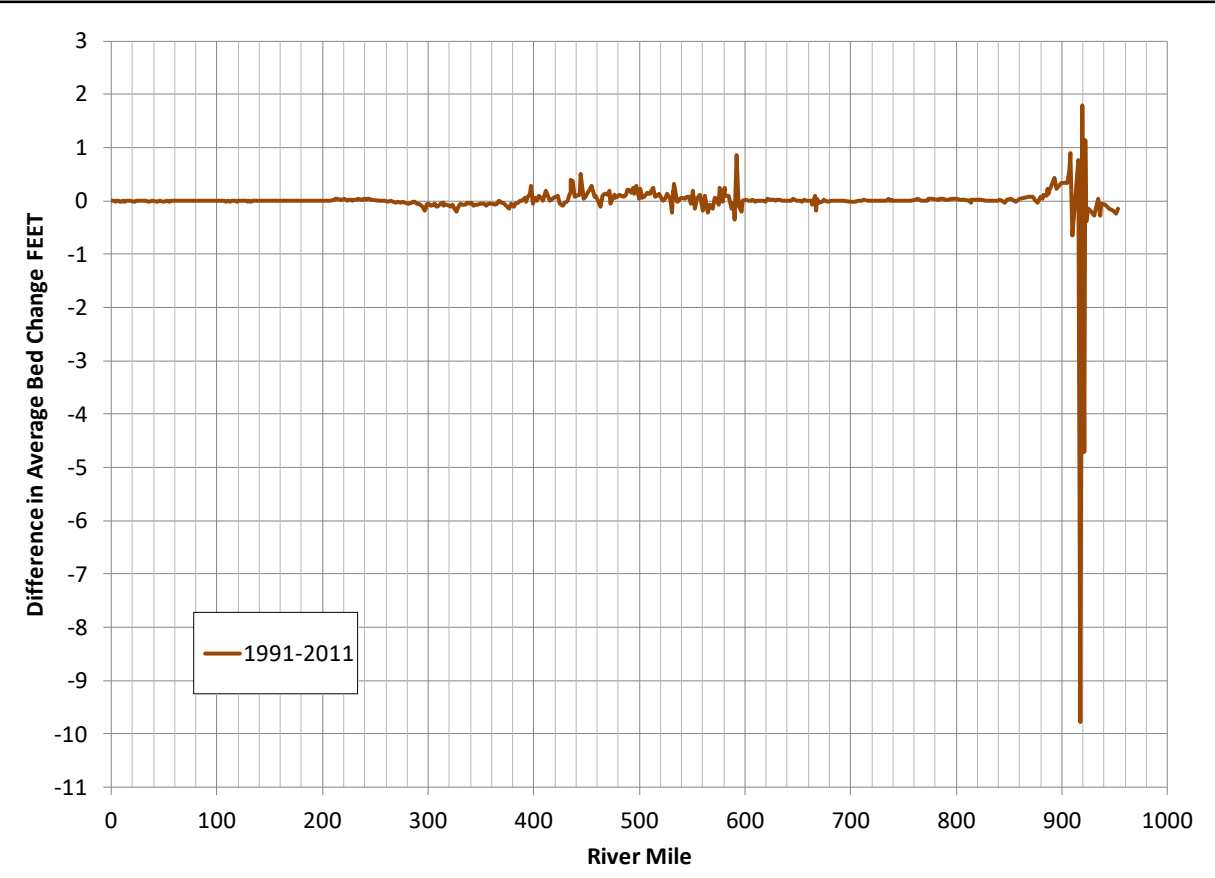




\section{Effects of dike construction}

The numerical model was used to determine the effect of dike construction on sediment delivery and average bed change. The 1991-2011 hydrograph was used for the evaluation. Dike construction between RMs 427.4 and 453 were added to the numerical model geometry at the time in the hydrograph that construction occurred. A new dike constructed in the Below Racetrack Dike field (RM 427.4) was added in August 1997. Increased dike heights in the Below Racetrack Dike Field (RM 429.2 and RM 431) were added in January 1996. New dikes in the Racetrack Towhead Dike Field (RM 432 and RM 433) were added in January 1995 and January 1996, respectively. Dike elevations in the Forest Home Towhead Dike Field (RM 448.8, RM 451.2 and RM 453) were raised in August 1997, September 1994, and July 1997, respectively. The 1991-2002 sediment inflow curves at Thebes were used in the comparison study.

As shown in Figure 140, the dike construction had only a small effect on the cumulative sediment delivery. Sediment delivery was increased upstream and downstream from the dike fields.

As expected, the dike construction resulted in significant degradation in the dike fields - approximately $4.5 \mathrm{ft}$ in the Racetrack Dike Fields and approximately $8.5 \mathrm{ft}$ in the Forest Home Dike Field (Figure 141). Average bed elevations increased by approximately $1 \mathrm{ft}$ immediately downstream from the Racetrack Dike Field, decreasing to zero in approximately 60 miles. Slight increases in average bed elevations (on the order of tenths of a foot) were calculated upstream from the Forest Home Dike Field for approximately 200 miles.

These tests demonstrate the numerical model's capability to determine the effective degradation induced in the vicinity of new dike construction and to determine the effect of the dike construction on river morphology upstream and downstream. 
Figure 140. Effect of dike construction on calculated cumulative sand delivery.

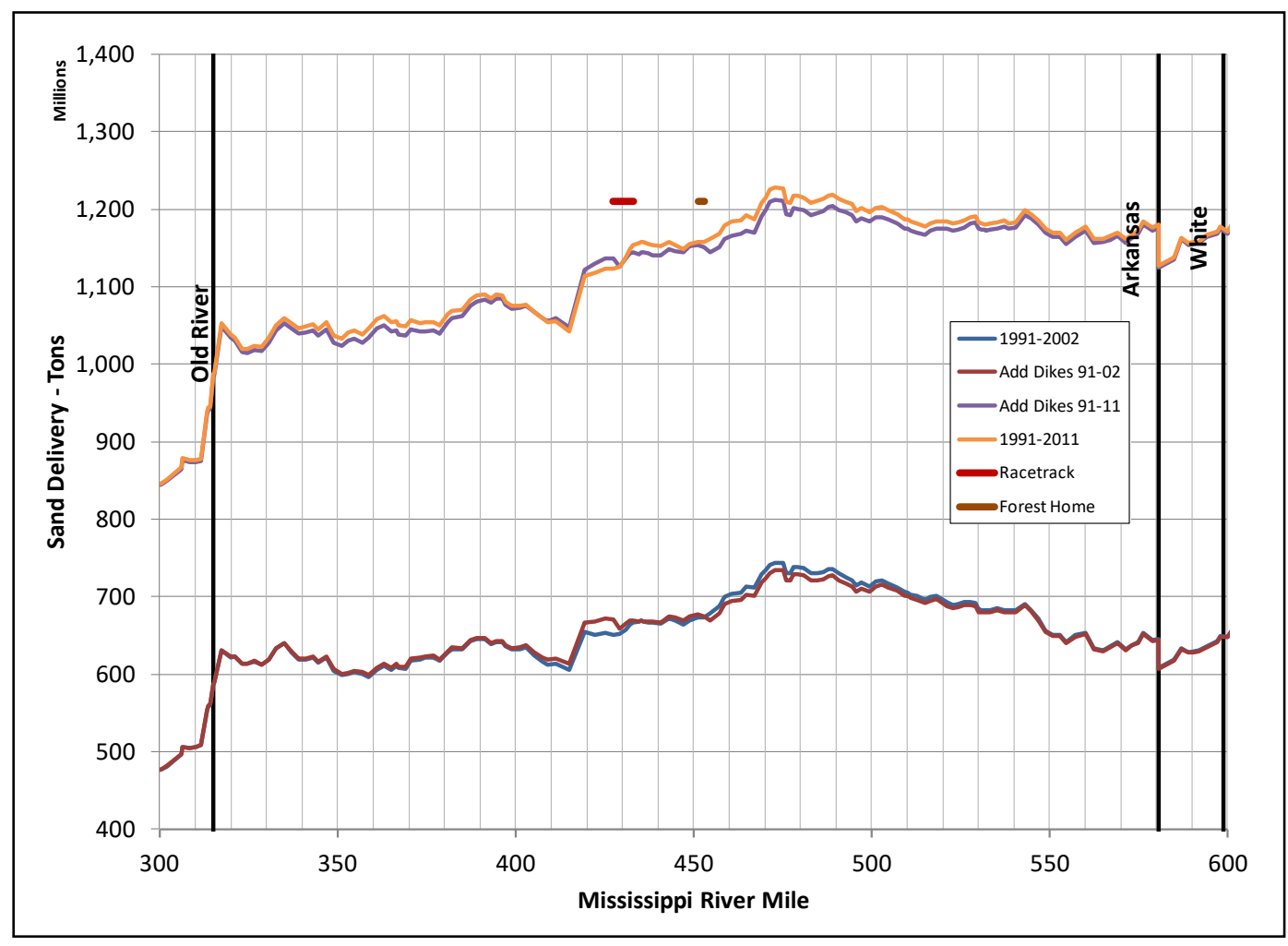

Figure 141. Calculated difference in average bed change with dike construction.

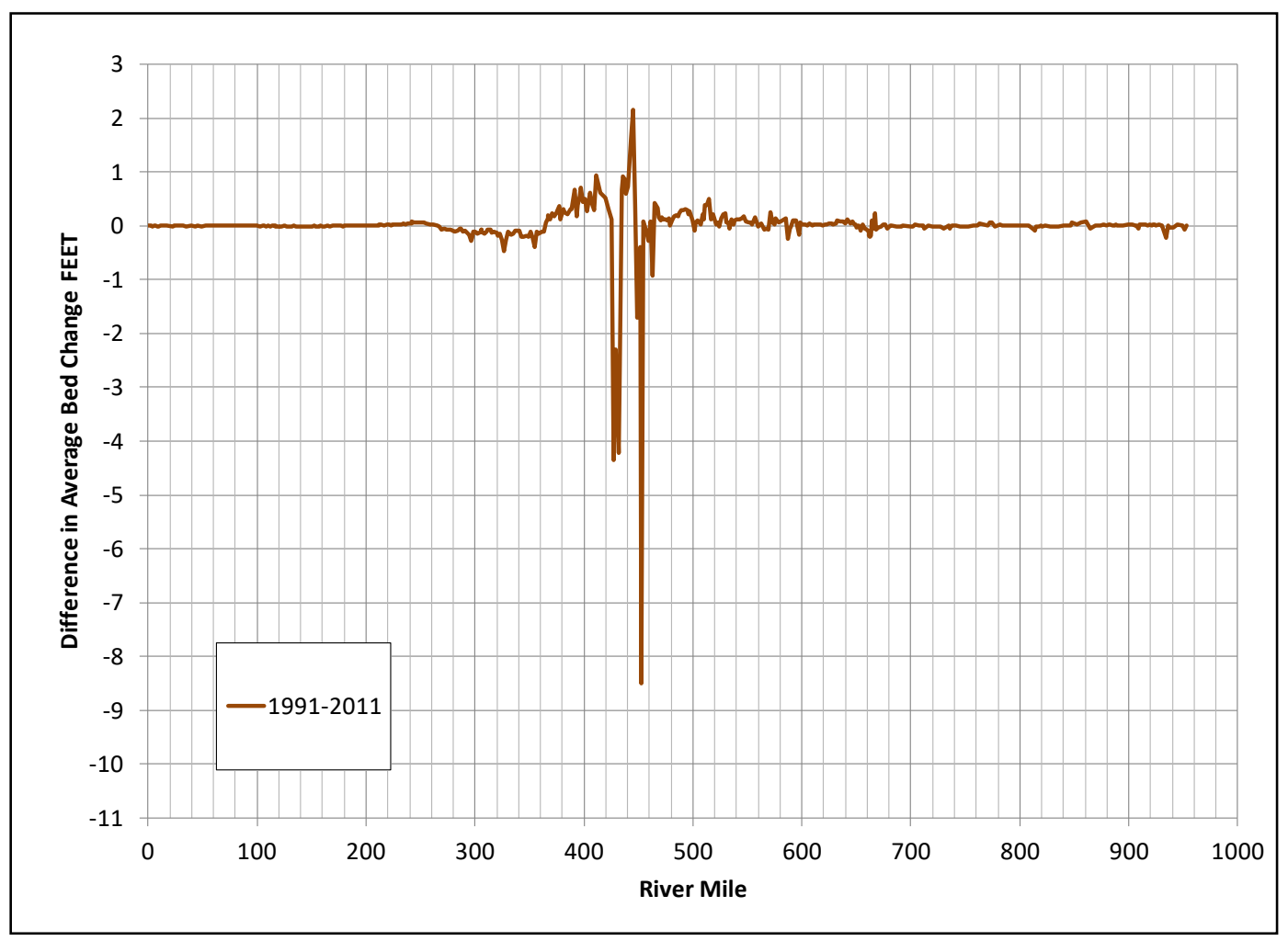




\section{Summary and Recommendations}

The purpose of this study was to develop a numerical sedimentation model that could identify and predict the effects of planned Mississippi River and Tributaries Project features and dredging strategies on long-term sediment trends in the Lower Mississippi River. The model is constructed so that specific design features can be evaluated by adding more refinement to the numerical model.

The study approach was to develop a 1D numerical model using the computer program HEC-6T. This program has been applied successfully to evaluate long-term sedimentation responses to various engineering projects along the Lower Mississippi River. These applications have included river response to dredging, river response to flow diversions through distributaries, stability of a low-flow sediment sill, and the effect of contraction works on navigation depth. Calculations in the HEC-6T numerical model are governed by physical properties that maintain sediment continuity throughout the study reach. Sediment continuity is maintained by bed aggradation/degradation and sediment transport. This characteristic of numerical modeling provides a distinct advantage over using reported sediment measurements at specific locations along the river to define sediment conditions where satisfaction of sediment continuity with upstream or downstream reaches is not required.

The New Orleans, Vicksburg, Memphis, and St. Louis Districts were responsible for developing the numerical model in their respective reaches of responsibility along the Mississippi River. The numerical model's downstream boundary was at Pilots Station, LA, which is just inside the jetties at the end of Southwest Pass (RM -18). The upstream boundaries were at Chester, IL, at Middle Mississippi RM 109.0, and Metropolis on the Ohio River, which is approximately 37 miles upstream from the confluence with the Mississippi River. The numerical model includes reaches along three major tributaries: the Arkansas River (28.2 miles), the White River (100 miles), and the St. Francis River (17.2 miles). Shorter reaches are included for minor tributaries. The numerical model simulates over 1000 miles of the Mississippi River.

The cross-section geometry in the HEC-6T model was developed from hydrographic survey data taken between 1987 and 1992. The hydrographic surveys were conducted at different times in the different districts. There 
is even a time discontinuity in the cross sections surveyed in individual districts as the hydrographic surveys in each district were conducted over a period of a year or more. One of the consequences of this anomaly is that direct comparisons between historical surveys at individual cross sections or even reaches may be misleading. This factor makes model calibration to changes in surveyed bed volumes difficult and most likely unreliable.

The model geometry includes dike fields that were present in 1992. Cross sections where dikes were present were modified to reflect the projections of upstream and downstream dikes in the vicinity of the cross section. This is equivalent to assuming that cross sections in the dike field are filled to the dike crest elevations. Recent enhancement of the HEC-6T model allows for changing cross-section geometry during the course of the historical simulation so that dikes can be added as they were constructed. Future studies should take advantage of this option.

HEC-6T approximates unsteady flow by stepping through a time-sequence of steady-state discharges. Mean daily flow data are entered at the upstream boundaries, and a backwater computation is made for the 1-day time step for the entire model length. This computational approach does not take into account flow routing or backwater storage effects, which introduces the potential for timing issues in flow propagation through the model. Thus, HEC-6T may not be appropriate for predicting flood hydrographs and stages, but experience has shown that it is successful in predicting long-term sedimentation processes. In this study, 1991-2002 historical mean-daily flows were used to define the hydrograph in the numerical model.

The calibration and verification procedure adopted for this study is the accepted USACE methodology described in Guidelines for Calibration and Application of HEC-6 (HEC 1982) and Chapter 14 of ASCE Manual 110 (ASCE 2006). It is recommended that future numerical sediment studies adopt these standardized guidelines for numerical model calibration and verification.

The study process reveled discrepancies associated with the reported discharge data. Continuity of the Lower Mississippi River discharge record is inconsistent in time and distance. During the 1991-2002 calibration period, there was approximately a 4 percent loss in annual flow volume at Helena when compared to the sum of Memphis and St. Francis River 
annual flows. The 12-year volume of water passing Arkansas City is consistent with the sum of the flow volumes from the Mississippi River at Helena and the White and Arkansas Rivers. There is approximately a 2 percent increase in annual flow volume at Vicksburg when compared to the sum of Arkansas City and Yazoo River annual flows. Annual flow past Vicksburg and Natchez is relatively consistent. The largest discrepancy is at the Old River Control Complex where the sum of reported discharges in the Old River Outflow Channel and in the Mississippi River at Tarbert Landing is approximately 8 percent higher than the reported discharge upstream at Natchez and Vicksburg. The discrepancies between reported discharges are not consistent annually. There is an annual variation in the discrepancies between Natchez and Old River and Vicksburg and Natchez. The differences between Vicksburg and Natchez are insignificant, but the differences between Natchez and the Old River Control Complex are puzzling. These discrepancies at the Old River Control Complex produce a conundrum with respect to determining a hydrograph for the HEC-6T model. Additional study, which should include evaluation of data at the Baton Rouge gage, is recommended to address these issues.

Distributary outflows in the New Orleans District were calculated from rating curves developed from limited measured data or as a percentage of Mississippi River flow at a station upstream from the distributary. The most significant distributary is the Old River Control Complex where simple average ratings curves were used rather than actual measured discharges to make model application easier for a wide range of projects located up and down the 1000-mile study reach. Future studies related to a specific diversions on the Mississippi River may require a more detailed treatment of the flow through the diversion or diversions of interest. It is also critical to continue flow measurement programs to better define the outflow from distributaries and possible changes in outflow magnitudes with time.

Stages at the downstream end of Southwest Pass showed no stage-discharge correlation. Therefore, downstream water-surface elevations at Pilots Station were set based on average monthly stages. The simplifying assumption of an average monthly stage at the downstream boundary of the model is adequate for purposes of the generalized model developed in this study. However, studies of specific morphologic changes in the Mississippi River below Belle Chasse, especially in response to river diversions, may require more a detailed description of the downstream stages. 
Roughness coefficients in the numerical model were adjusted so that 19912002 calculated stages replicated average reported stage-discharge data at several gages. There is significant variability about the average regression line of the measured data relating stage to discharge. In the coastal zone, some of this variability can be attributed to tidal effects. However, bed forms and unsteady flow effects account for most of the variability. Many years have an identifiable loop effect in the rating curves. The height and distribution of bed forms lag the rise and fall of hydrographs so that there is no distinct relationship between bed form shape and discharge. In the steady-state $1 \mathrm{D}$ sediment model, the objective is to simulate average conditions to best replicate the movement of sediment over time. This is different from the approach taken to establish flow lines for maximum water surface elevations (e.g., for levee design). With the levee design approach, roughness coefficients would be chosen to match a regression curve through the maximum water surface elevation values rather than the average regression curve used in the sediment study.

A combination of measured and calculated data were used to establish sediment inflow boundary conditions for the numerical model. To model sedimentation trends in the Mississippi River, it is necessary to account for movement and storage of each sediment size class. HEC-6T allows for this accounting; however, the required input data are generally lacking. Long-term size class sediment data are available in the study reach, at the upstream boundary on the Middle Mississippi River at Thebes, located 44 miles upstream from the Ohio River, and at Chester. Long-term size class data are also available at Union Point (RM 326.6) and Coochie (RM 317.3), which are located upstream from the Old River Control Complex and at Tarbert Landing (RM 306.3), which is located downstream from the Old River Control Complex. A shorter record is available at Belle Chasse, located 76 miles AHP. Data for the major tributaries, including the Ohio River, are generally limited to the sediment concentrations greater and less than $0.062 \mathrm{~mm}$. The lack of boundary condition data required that size class percentages be estimated by calculation and/or judgment. A continuing sediment data collection program is essential to verify and enhance future sediment transport predictions.

Cumulative sediment inflows to the Mississippi River from the Middle Mississippi and Ohio Rivers and from the tributaries were calculated for the 1991-2002 calibration period. These calculations, which were based on the historical record, show that the vast majority of the sediment is 
supplied by the Middle Mississippi River, even though most of the water is supplied by the Ohio River.

Study results highlight the significant discrepancies in the measured sediment data for the Mississippi River system. The physical laws that govern the numerical model require that sediment continuity be maintained throughout the system. However, it is apparent that sediment continuity is not maintained in analyses of the measured data at various gages in the system. The most probable explanation for the discrepancies in the measured data is related to the differences in the sediment collection and laboratory methodologies and in the analytical methods used to calculate sediment concentrations from the sampled data. It is recommended that a comprehensive investigation of the sediment data gathering methods be undertaken and that consistent methodologies be incorporated for sediment data collection in the Mississippi Valley Division.

Dredging volumes in Southwest Pass and AHP were simulated in the numerical model by adjusting the silt and clay deposition coefficients. Calculated dredging volumes were calibrated to match reported dredging volumes. The reported dredging volumes were taken from New Orleans District dredging logs. Estimated volumes of agitation dredging are not included in the reported volumes nor are estimated volumes from operations where the dredged material was side cast out of the navigation channel onto a river bar. In the interim New Orleans District study, the 1991-2002 calculated dredging was within 0.1 percent of the reported dredging in Southwest Pass and within 0.5 percent of the reported dredging AHP. Annual calculated and reported dredging volumes do not match as well as the overall volumes. This is to be expected because actual dredging operations are constrained by budgets, availability of dredges, weather, and other factors.

Calculated dredging AHP and in Southwest Pass did not match the reported data as well in the Regional model. The difference is attributed to differences in the measured fine sediment data used to develop sediment inflow to the two models. The measured data indicate that fine sediment concentrations at Union Point and Tarbert Landing, which were used to develop sediment inflow for the interim New Orleans District model, are significantly greater at the lower discharges than reported at the upstream gages that were used to develop fine sediment inflow for the Regional model. The consequence of this difference is that calculated dredging 
volumes are approximately $87 \%$ of reported volumes in the Regional Model. Significant improvement in dredging volumes could not be achieved with additional adjustment of the cohesive sediment deposition coefficients.

Options for improving the dredging simulation in the Regional model include decreasing the fine sediment concentrations in the diversions AHP and in Southwest Pass and/or arbitrarily increasing fine sediment inflow at the upstream boundary or along the reach between Vicksburg and Union Point. One could justify the latter by attributing the increase to bank erosion. However, these modifications are not systematic and are left to future modelers addressing specific issues and objectives in future studies.

Dredging and sediment diversion significantly alter morphologic processes in the river system. The numerical model can be used to calculate the short-term and long-term effects of proposed dredging activities and the effectiveness of a dredging program. The model can calculate the increased deposition rates associated with dredging and the length of time required to refill the navigation channel back to a critical elevation. The model can be used to calculate the effectiveness of in-channel dredge disposal versus disposal outside of the channel. The timing of dredging activities with respect to annual flood peaks can be evaluated. Similarly, the short-term and long-term effects of sediment diversions can be calculated using the numerical model. Although, the quantity of sediment diverted must be determined external to the numerical model, the morphologic changes induced by a specified quantity of sediment diversion can be determined. The most useful feature of the numerical model analysis is that systemwide effects of several diversions and dredging activities can be evaluated together, so that the effect of each individual feature on the system can be determined. These effects can be evaluated using calculated bed elevation and corresponding water-surface elevation changes in the river channel, sediment yields past designated cross sections, sediment diversion quantities through designated diversions, and required dredging quantities to maintain project depths.

Dike fields are constructed to hold alignment and increase navigation depths. In addition to the intentional bed changes in the dike field, there will be additional morphological changes in the upstream and downstream river reaches. The numerical model can be used to calculate the short-term and long-term bed and water-surface elevation changes in the dike field itself and in the river system as a whole. The model also calculates 
short-term and long-term changes in sediment yield upstream and downstream from proposed dike fields.

Construction of dikes fields between RMs 427.4 and 453 resulted in significant degradation in the dike fields as expected. However, the model demonstrated that the dike construction had only a small effect on the cumulative sediment delivery over a 21-year simulation period. These tests demonstrate the numerical model's capability to determine the effective degradation induced in the vicinity of new dike construction and to determine the effect of the dike construction on river morphology upstream and downstream.

The effects of imposed hydrologic and sedimentation conditions on the river system can be evaluated using the numerical model. Changes in the sediment supply will affect the aggradation/degradation rates in the river system. The numerical model can be used to determine the calculated bed changes and the reach lengths affected. The effects of sea-level rise, temperature changes, and removal of river-bed hard points can also be calculated. The primary calculated metrics are bed elevation change and changes in sediment yield.

Measured sediment data at Thebes suggest that sediment concentrations in the Middle Mississippi River are declining. The numerical model was used to determine the effect of the declining sediment inflow from the Middle Mississippi for a 9-year period between 2002 and 2011. The numerical model results indicated that the change in sediment inflow has a very small effect on sediment delivery after the first 50 miles.

Removing the hard point at Hickman resulted in almost $10 \mathrm{ft}$ of degradation in the immediate vicinity of Hickman over a 21-year period. However, significant bed degradation did not occur upstream, at least during the 21-year simulation period. The increase in downstream cumulative sand delivery due to the degradation at Hickman and the subsequent increase in sediment transport potential upstream is relatively small. The calculations indicate that the eroded sediment at Hickman does not result in any significant increase in downstream aggradation until RM 600 , and then the increase in average bed elevation is on the order of tenths of a foot. The reason for the 300-mile lag before the deposition pattern begins is that the 300-mile reach below Hickman is generally a degradation reach. 
The HEC-6T model was calibrated to reasonably match measured data between 1991 and 2002. Model applications related to the effects of sediment diversions and the effects of dredging in the New Orleans District were demonstrated. The model's ability to address the effects of new constrictive works on the long-term and short-term river morphology was demonstrated. The ability to test the effects of changes in upstream sediment inflow was also addressed. The model's ability to assess the effects of natural geomorphic changes, such as erosion of hard points, was demonstrated. Future application of this model to specific project sites should include the addition of more detailed geometry in the area of interest. The HEC-6T numerical sedimentation model developed for this study provides the general system-wide model that can be used to address the long-term and system effects of specific Mississippi River and Tributaries Project features. 


\section{References}

Abraham, D., R. A. Kuhnle, and A. J. Odgaard. 2011. "Validation of Bed-Load Transport Measurements with Time -Sequenced Bathymetric Data." Journal of Hydraulic Engineering 137(7): 723-728.

American Society of Civil Engineers (ASCE). 2006. Sedimentation Engineering. ASCE Manuals and Reports on Engineering Practice No. 110. Edited by M. H. Garcia Reston, VA.

Ariathurai, R., and R. B. Krone. 1976. "Finite Element Model for Cohesive Sediment Transport." Journal of the Hydraulics Division, ASCE 102(3): 323-338.

Barbe, D. E., K. Fagot, and J. A. McCorquodale. 2000. "Effects on Dredging Due to Diversions from the Lower Mississippi River." Journal of Waterway, Port, Coastal and Ocean Engineering, ASCE 126(3): 121-129.

Biendenharn, D. S., and C. R. Thorne. 1994. "Magnitude-Frequency Analysis of Sediment Transport in the Lower Mississippi River." Regulated Rivers: Research and Management 9: 237-251.

Catalyst-Old River Hydroelectric. 1999. Lower Mississippi River Sediment Study, Vo. 4 HEC-6W Mississippi River Numerical Sedimentation Model Investigation, Vicksburg to Donaldsonville. In association with U.S. Army Corps of Engineers Waterways Experiment Station, Coastal and Hydraulics Laboratory, Vicksburg Mississippi.

Copeland, R. R., and W. A. Thomas. 1992. Lower Mississippi River Tarbert Landing to East Jetty - Sedimentation Study, Numerical Model Investigation. Technical Report HL-92-6. Vicksburg, MS: USACE Waterways Experiment Station, Hydraulics Laboratory.

Copeland, R. R. 1991. Dredging Alternatives Study, Lower Mississippi River, Cubits Gap, Report 1, TABS-1 Numerical Model Investigation. Technical Report HL-9020. Vicksburg, MS: USACE Waterways Experiment Station, Hydraulics Laboratory.

Copeland, R.R. 2018. Mississippi River and Tributaries Flowline Assessment: Mississippi River Sedimentation Report. U.S. Army Engineer Mississippi Valley Division, Mississippi River Geomorphology and Potamology Program (MRG\&P) Report No. 24, Vol 4, Vicksburg, MS: U.S. Army Engineer Research and Development Center

Demas, C. R., and P. B. Curwick. 1987. Suspended-Sediment, Bottom-Material, and Associated Chemical Data from the Lower Mississippi River. Louisiana Water Resources Basic Records Report No. 14, U.S. Geological Survey. Baton Rouge, LA: Louisiana Department of Transportation and Development.

Ferguson, R. I. 1986. "River Loads Underestimated by Rating Curves." Water Resources Research 22(1): 74-76. 
Heath, R. E., G. L. Brown, C. D. Little, T. C. Pratt, J. J. Ratcliff, D. D. Abraham, D. W. Perkey, N. B. Ganesh, K. Martin, and D. P. May. 2015. Old River Control Complex Sedimentation Investigation. U.S. Army Engineer Mississippi Valley Division, Mississippi River Geomorphology and Potamology Program (MRG\&P) Report No. 6. Vicksburg, MS: U.S. Army Engineer Research and Development Center.

Heimann, D. C., P. P. Rasmussen, T. L. Cline, L. M. Pigue, and H. R. Wagner. 2010. Characteristics of Sediment Data and Annual Suspended-Sediment Loads and Yields for Selected Lower Missouri River Mainstem and Tributary Stations, 1976-2008. U.S. Geological Survey Data Series Report 530. Washington, DC: U.S. Geological Survey. http://pubs.usgs.gov/ds/530/

Hydrologic Engineering Center (HEC). 1982. Guidelines for the Calibration and Application of Computer Program HEC-6. Training Document No. 13. Davis, CA: USACE Hydrologic Engineering Center.

Hydrologic Engineering Center (HEC). 2001. HEC-RAS River Analysis System, Hydraulics Reference Manual. Davis, CA: USACE Hydrologic Engineering Center.

Kolb, C. R. 1962. Distribution of Soils bordering the Mississippi River From Donaldsonville to Head of Passes. TR No. 3-601. Vicksburg, MS: USACE Waterways Experiment Station.

Krone, R. B. 1962. Flume Studies of the Transport of Sediment in Estuarial Shoaling Processes. Berkeley, California: Hydraulic Engineering Laboratory, University of California.

Lane, E. W. 1947. "Report of the Subcommittee on Sediment Terminology." Transactions American Geophysical Union 28(6) 936-938.

Meade, R. H. 1995. Contaminants in the Mississippi River, 1987-92. U.S. Geological Survey Circular 1133. Washington, DC: U.S. Geological Survey.

Meyer-Peter, E., and R. Muller. 1948. "Formulas for Bed-Load Transport." Second Meeting of the International Association for Hydraulics Research. Appendix 2. Stockholm, Sweden, 39-64.

Mobile Boundary Hydraulics (MBH). 2002. Sedimentation in Stream Networks (HEC6T). Users Manual, Clinton, MS: Mobile Boundary Hydraulics.

Nordin, C. F., and B. S. Queen. 1992. Particle Size Distributions of Bed Sediments along the Thalweg of the Mississippi River, Cairo, Illinois to Head of Passes, September 1989. Potamology Program (P-1) Report 7. Vicksburg, MS: U.S. Army Corps of Engineers, Lower Mississippi Valley Division.

Parthenaides, E. 1965. "Erosion and Deposition of Cohesive Soils." Journal of the Hydraulics Division, ASCE 91(1): 755-771.

Richards, D. R., and M. J. Trawle. 1988. Numerical Model Analysis of Mississippi River Passes Navigation Channel Improvements, Report 2, 45-Foot Channel Tests and Flow Distribution Schemes. Miscellaneous Paper HL-87-2. Vicksburg, MS: USACE Waterways Experiment Station. 
Rouse, H. 1937. "Modern Conceptions of the Mechanics of Fluid Turbulence." Transactions, ASCE 102, Paper no. 1965, 463-505.

Sharp, J. A., C. D. Little, G. L. Brown, T. C. Pratt, R. E. Heath, L. C. Hubbard, C. F. Pinkard, K. Martin, N. D. Clifton, D. W. Perkey, and N. B. Ganesh. 2013. West Bay Sediment Diversion Effects. ERDC/CHL TR-13-15. Vicksburg, MS: U.S. Army Engineer Research and Development Center.

Thomas, W. A. 2012. Allocation of Water and Sediment Resources - Myrtle Grove Diversion for Land Building. Prepared for Coastal Protection and Restoration Authority, Office of Coastal Protection and Restoration, State of Louisiana, by Mobile Boundary Hydraulics PLLC. Clinton, MS: Mobile Boundary Hydraulics.

Thomas, W. A., R. E. Heath, J. P. Stewart, and D. G. Clark. 1989. The Atchafalaya River Delta, Report 5, The Atchafalaya River Delta Quasi-Two-Dimensional Model of Delta Growth and Impacts on River Stages. Technical Report HL-82-15, Report 5. Vicksburg, Mississippi: USACE Waterways Experiment Station.

Toffaleti, F. B. 1968. A Procedure for Computation of the Total River Sand Discharge and Detailed Distribution, Bed to Surface. Technical Report No. 5. Vicksburg, MS: Committee on Channel Stabilization, U.S. Army Corps of Engineers. http://hdl.handle.net/11681/1822

U.S. Army Corps of Engineers (USACE), Memphis District. 1990. Hydrographic Survey, Mississippi River, 1987-1989, Cairo, Illinois to Mouth of White River, Arkansas, Mile 595 to Mile 954.

U.S. Army Corps of Engineers (USACE), Vicksburg District. 1990. Mississippi River Hydrographic Survey 1988-1989, Mouth of White River, Ark. to Black Hawk, LA, Mile 320 to Mile 595 A.H.P.

U.S. Army Engineer District, New Orleans (USACE MVN). 1980. Mississippi River and Tributaries, Old River Control, LA, Auxiliary Structure, Design Memorandum No. 17, Hydraulic Design. TC2O2 M504 No.17.

U.S. Army Engineer District, New Orleans (USACE MVN). 1993. Mississippi River Hydrographic Survey 1991-1992, Black Hawk, LA to Head of Passes, LA, Mile o to Mile 324 (AHP) and South and Southwest Pass and Pass a Loutre.

Waterways Experiment Station (WES). 1935. Studies of River Bed Materials and Their Movement with Special Reference to the Lower Mississippi River. Paper No. 17. Vicksburg, MS: U.S. Army Waterways Experiment Station. 


\section{Unit Conversion Factors}

\begin{tabular}{|c|c|c|}
\hline Multiply & By & To Obtain \\
\hline acres & $4,046.873$ & square meters \\
\hline acre-feet & $1,233.5$ & cubic meters \\
\hline cubic feet & 0.02831685 & cubic meters \\
\hline cubic inches & $1.6387064 \mathrm{E}-05$ & cubic meters \\
\hline cubic yards & 0.7645549 & cubic meters \\
\hline degrees Fahrenheit & $(F-32) / 1.8$ & degrees Celsius \\
\hline feet & 0.3048 & meters \\
\hline foot-pounds force & 1.355818 & joules \\
\hline gallons (U.S. liquid) & $3.785412 \mathrm{E}-03$ & cubic meters \\
\hline hectares & $1.0 \mathrm{E}+04$ & square meters \\
\hline miles (nautical) & 1,852 & meters \\
\hline miles (U.S. statute) & $1,609.347$ & meters \\
\hline miles per hour & 0.44704 & meters per second \\
\hline pounds (force) & 4.448222 & newtons \\
\hline pounds (force) per foot & 14.59390 & newtons per meter \\
\hline pounds (force) per inch & 175.1268 & newtons per meter \\
\hline pounds (force) per square foot & 47.88026 & pascals \\
\hline pounds (force) per square inch & 6.894757 & kilopascals \\
\hline pounds (mass) & 0.45359237 & kilograms \\
\hline pounds (mass) per cubic foot & 16.01846 & kilograms per cubic meter \\
\hline pounds (mass) per cubic inch & $2.757990 \mathrm{E}+04$ & kilograms per cubic meter \\
\hline pounds (mass) per square foot & 4.882428 & $\begin{array}{l}\text { kilograms per square } \\
\text { meter }\end{array}$ \\
\hline pounds (mass) per square yard & 0.542492 & $\begin{array}{l}\text { kilograms per square } \\
\text { meter }\end{array}$ \\
\hline square miles & $2.589998 \mathrm{E}+06$ & square meters \\
\hline square yards & 0.8361274 & square meters \\
\hline tons (force) & $8,896.443$ & newtons \\
\hline tons (force) per square foot & 95.76052 & kilopascals \\
\hline tons (long) per cubic yard & $1,328.939$ & kilograms per cubic meter \\
\hline tons ( 2,000 pounds, mass $)$ & 907.1847 & kilograms \\
\hline
\end{tabular}




\begin{tabular}{|l|c|l|}
\hline Multiply & By & To Obtain \\
\hline tons (2,000 pounds, mass) per square foot & $9,764.856$ & $\begin{array}{l}\text { kilograms per square } \\
\text { meter }\end{array}$ \\
\hline yards & 0.9144 & meters \\
\hline
\end{tabular}




\section{Acronyms and Abbreviations}

1D one-dimensional

2D two-dimensional

3D three-dimensional

AHP Above Head of Passes

BHP Below Head of Passes

cfs cubic feet per second

EDI equal-discharge increment

ERDC U.S. Army Engineer Research and Development Center

$\mathrm{ft} \quad$ foot/feet

in. inch(es)

$\mathrm{mm} \quad$ millimeter(s)

MR\&T Mississippi River and Tributaries

MSL mean sea level

NGVD National Geodetic Vertical Datum

NOAA National Oceanic and Atmospheric Administration

$\mathrm{RM} \quad$ river mile

USACE U.S. Army Corps of Engineers

USGS U.S. Geological Survey 


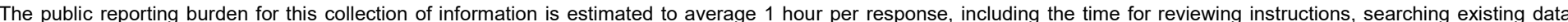

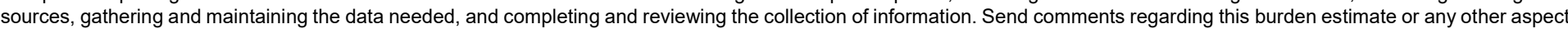

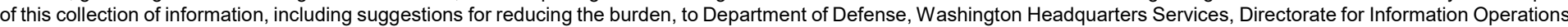

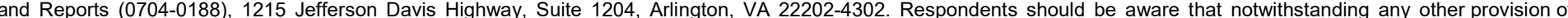
law, no person shall be subject to any penalty for failing to comply with a collection of information if it does not display a currently valid OMB control number. PLEASE DO NOT RETURN YOUR FORM TO THE ABOVE ADDRESS.

\begin{tabular}{l|l|l}
\hline 1. REPORT DATE & $\begin{array}{l}\text { 2. REPORT TYPE } \\
\text { February } 2020\end{array}$ & 3. DATES COVERED (From - To) \\
\hline
\end{tabular}

\section{TITLE AND SUBTITLE}

Numerical Sedimentation Investigation Mississippi River Cairo to Pilots Station

5a. CONTRACT NUMBER

5b. GRANT NUMBER

5c. PROGRAM ELEMENT NUMBER

6. AUTHOR(S)

Ronald R. Copeland, Leslie Lombard, Roger A. Gaines

5d. PROJECT NUMBER

127672

5e. TASK NUMBER

5f. WORK UNIT NUMBER

7. PERFORMING ORGANIZATION NAME(S) AND ADDRESS(ES) (see reverse)

8. PERFORMING ORGANIZATION REPORT NUMBER

MRG\&P Report No. 30

9. SPONSORING/MONITORING AGENCY NAME(S) AND ADDRESS(ES)

U.S. Army Corps of Engineers

10. SPONSOR/MONITOR'S ACRONYM(S)

Washington, DC 20314-1000

USACE

11. SPONSOR/MONITOR'S REPORT NUMBER(S)

\section{DISTRIBUTION/AVAILABILITY STATEMENT}

Approved for public release; distribution is unlimited.

\section{SUPPLEMENTARY NOTES}

\section{ABSTRACT}

A HEC-6T numerical model of the entire Lower Mississippi River between the end of Southwest Pass and the confluence of the Ohio River was developed. The model, which included over 1000 river miles, was calibrated to 1991-2002 measured data. The purpose of the numerical sedimentation model was to provide a tool to evaluate the long-term and system -wide effects of specific Mississippi River and Tributaries Project features. Model applications related to the effects of sediment diversions and the effects of dredging in the New Orleans District were demonstrated. The model demonstrated the effects of new constrictive works on the long-term and short-term river morphology. The model was used to test the effects of changes in upstream sediment inflow. The model's ability to assess the effects of natural geomorphic changes, such as erosion of hard points, was demonstrated. Future application of this model to specific project sites should include the addition of more detailed geometry in the area of interest.

\section{SUBJECT TERMS}

Diversion structures (Hydraulic engineering), Dredging, Mississippi River, Sedimentation and deposition-Numerical analysis, Sediment transport-Numerical analysis

16. SECURITY CLASSIFICATION OF:

a. REPORT

Unclassified

b. ABSTRACT

Unclassified c. THIS PAGE

Unclassified
17. LIMITATION OF ABSTRACT

SAR
18. NUMBER 19a. NAME OF RESPONSIBLE PERSON

OF PAGES

217 James. W. Lewis

19b. TELEPHONE NUMBER (Include area code) 601-634-5062 


\section{PERFORMING ORGANIZATION NAME(S) AND ADDRESS(ES) (continued)}

U.S. Army Corps of Engineers

Vicksburg District

4155 Clay Street

Vicksburg, Mississippi 39183

U.S. Army Corps of Engineers New Orleans District

7400 Leake Avenue

New Orleans, Louisiana 70118

U.S. Army Corps of Engineers Memphis District

167 N. Main St., Rm B-202

Memphis, Tennessee 38103-1894 